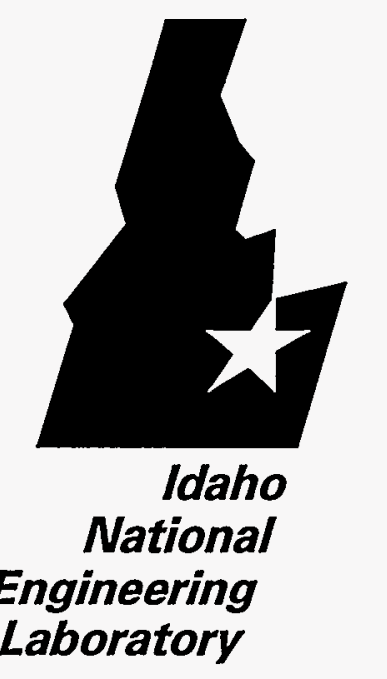

ustex
Site-Specific Probabilistic Seismic Hazard Analyses for the Idaho National Engineering Laboratory

\section{Volume 1 Final Report}

\author{
RECEIVED \\ JUL $2^{9} 1996$ \\ OSTI
}

The peak accelerations and acceleration response spectra presented in this report are not to be used for the seismic design of facilities. The intent of this study is to provide supporting documentation for development of design response spectra and peak accelerations for the INEL Architectural and Engineering Standards.

\title{
三人lockheed Idaho Technologies Company
}




\section{DISCLAIMER}

This report was prepared as an account of work sponsored by an agency of the United States Government. Neither the United States Government nor any agency thereof, nor any of their employees, makes any warranty, express or implied, or assumes any legal liability or responsibility for the accuracy, completeness, or usefuiness of any information, apparatus, product or process disclosed, or represents that its use would not infringe privately owned rights. References herein to any specific commercial product, process, or service by trade name, trademark, manufacturer, or othenwise, does not necessarily constitute or imply its endorsement, recommendation, or favoring by the United States Government or any agency thereof. The views and opinions of authors expressed herein do not necessarily state or reflect those of the United States Government or any agency thereof. 


\section{Site-Specific Probabilistic Seismic Hazard Analyses for the Idaho National Engineering Laboratory}

\section{Volume 1 Final Report}

Published May 1996

Woodward-Clyde Federal Services

Geomatrix Consultants

and

Pacific Engineering and Analysis

Prepared for Lockheed Martin Idaho Technologies

Under Subcontract C92120278 and for the

U.S. Department of Energy

Assistant Secretary for Environmental Management

Under DOE Idaho Operations Office

Contract DE-AC07-94ID13223 


\section{DISCLAIMER}

Portions of this document may be illegible in electronic image products. Images are produced from the best available original document. 
Section

Page

\section{VOLUME 1}

ACKNOWLEDGMENTS

EXECUTIVE SUMMARY

ES-1

1.0 INTRODUCTION $1-1$

1.1 Objectives 1-1

1.2 DOE Seismic Design Criteria $1-2$

1.3 Scope of Work $1-4$

1.4 Project Team and Review Panel $1-5$

2.0 SEISMIC HAZARD ANALYSIS METHODOLOGY 2-1

2.1 Hazard Formulation 2-1

2.2 Development of Seismic Hazard Model 2-3

3.0 SEISMIC SETTING AND SOURCES 3-1

3.1 Seismotectonic Setting 3-1

3.1.1 Snake River Plain 3-1

3.1.1.1 ESRP-Basin and Range Boundary 3-4

3.1.2 Intermountain Seismic Belt 3-5

3.1.3 Northern Basin and Range Province 3-7

3.2 Historical Seismicity $3-8$

3.2.1 Significant Earthquakes 3-9

3.2.2 Seismicity in the ESRP 3-11

3.2.2.1 1905 Earthquake 3-12

3.3 Potential Seismic Sources 3-13

3.3.1 Basin and Range Faults 3-14

3.3.2 ESRP Volcanic Zones 3-15

3.3.3 ESRP Random Earthquake 3-17 
4.1 Fault Sources

4.1.1 Source Parameters

4.1.1.1 Fault Dip

4-2

4.1.1.2 Seismogenic Depth

4-2

4.1.1.3 Earthquake Recurrence Model

4-3

4.1.1.4 Earthquake Recurrence

4-3

4.1.1.5

Fault Segmentation

4-4

4.1.1.6 Maximum Magnitude

4.1.2 Lost River Fault

4.1.2.1 Segmentation

4-7

4.1.2.2 Southern Termination

4.1.2.3 Displacements Per Event

4-9

4.1.2.4 Earthquake Recurrence

4.1.3 Lemhi Fault

4-11

4.1.3.1 Segmentation

4-11

4.1.3.2

Southern Termination

4-12

4.1.3.3 Displacements Per Event

4-13

4.1.3.4

Earthquake Recurrence

4-13

4.1 .4

Beaverhead Fault

4-16

4.1.4.1 Segmentation

4-16

4.1.4.2 Southern Termination

4-16

4.1.4.3 Earthquake Recurrence

4-17

4.1.5 Predicted Earthquake Frequency

4-18

4.2 ESRP Volcanic Rift Zones

4.2.1 Maximum Magnitude

4-20

4.2.2 Earthquake Recurrence

4-20

4.3 Regional Source Zones

4.3.1 Eastern Snake River Plain

4-24

4.3.2 Other Seismic Source Zones

4-25 
Section

Page

5.0 ATTENUATTON RELATIONSHIPS $\quad 5-1$

5.1 Empirical Ground Motion Relationships

5.2 Stochastic Ground Motion Relationships 5-3

5.2.1 Band-Limited-White-Noise Point Source Model 5-3

5.2.1.1 Random Vibration Theory 5-5

5.2.1.2 Stress Drop 5-5

5.2.1.3 Near-Surface Crustal Amplification 5-6

5.2.1.4 Near-Surface Crustal Damping 5-6

5.2.1.5 Path Attenuation 5-7

5.2.1.6 Layered Crustal and Site Structures 5-7

5.2.2 Input Parameters 5-7

5.2.2.1 Source Parameters 5-8

5.2.2.2 Path Parameters 5-8

5.2.2.3 Site Parameters $5-9$

5.2.3 Site-Specific Relationships $\quad 5-10$

5.3 Representation of Uncertainty in Ground Motion Modeling · $\quad$ 5-12

6.0 SEISMIC HAZARD ANALYSIS RESULTS 6-1

6.1 Analysis Procedure 6-1

6.2 Hazard Results and Sensitivity 6-2

6.2.1 Computed Hazard 6-2

6.2.2 Sources of Uncertainty and Sensitivity 6-5

6.3 Equal-Hazard Spectra $\quad 6-7$

6.4 Comparison with LLNL Hazard Results 6-8

$\begin{array}{ll}\text { REFERENCES } & \text { R-1 }\end{array}$ 


\section{LIST OF TABLES}

3-1 Significant Earthquakes in the Site Region

4-1 Rupture Lengths for Fault Sources

4-2 Estimated Volcanic Recurrence Intervals for Volcanic Zones

4-3 Seismic Source Zone Recurrence Parameters

5-1 Input Parameters and Weights for Stochastic Attenuation Relationships

5-2 Site-Specific Kappas

6-1 Equal Hazard Spectral Accelerations (5\% Damping)

\section{LIST OF FIGURES}

2-1 Seismic Hazard Model Logic Tree

2-2 Magnitude Distribution Models Used in Analysis

3-1 Historical Seismicity $(M \geq 2.5), 1884-1992$, and Quaternary Faults of the Snake River Plain and Surrounding Basin and Range Province

3-2 Collapse Shadow, Active Region and Peripheral Region Around ESRP

3-3 Late-Quaternary Faults and INEL Facility Sites

3-4 Generalized Map Showing Segments of the Lost River, Lemhi, and Beaverhead Faults in East-Central Idaho and Southwestern Montana

3-5 Locations of Volcanic Rift Zones

4-1 Seismic Sources and Spatial Distribution of Independent Earthquakes

4-2 Logic Tree for Lost River Fault

4-3 Logic Tree for Lemhi Fault

4-4 Logic Tree for Beaverhead Fault

4-5 Maximum Magnitude Distributions for Lost River Fault

4-6 Maximum Magnitude Distributions for Lemhi Fault

4-7 Maximum Magnitude Distributions for Beaverhead Fault

4-8 Southern Terminations and Rupture Scenarios for Faults

4-9 Predicted Recurrence Relationships for the Lost River, Lemhi, and Beaverhead Faults

4-10 Logic Tree for Volcanic Rit Zones

4-11 Predicted Recurrence Relationships for Volcanic Rift Zones

4-12 Logic Tree for Treatment of Northern Basin and Range and ISB Seismic Source Zones

4-13 Logic Tree for ESRP Seismic Source Zone

4-14a Recurrence Relationships for ESRP Source Zone Wwith the 1905 Earthquake

4-14b Recurrence Relationships for ESRP Source Zone Without the 1905 Earthquake

4-15 'Logic Tree for Northern Basin and Range Source Zone

4-16 Recurrence Relationships for Northern Basin and Range Source Zone 
4-17 Logic Tree for Northern and Central Intermountain Seismic Belt

4-18 Recurrence Relationships for Northern and Central Intermountain Seismic Belt

4-19 Recurrence Relationships for Central Intermountain Seismic Belt

4-20 Logic Tree for Yellowstone Source Zone

4-21 Recurrence Relationships for Yellowstone Source Zone

4-22 Logic Tree for Idaho Batholith Source Zone

4-23 Recurrence Relationships for Idaho Batholith Source Zone

4-24 Logic Tree for Central Basin and Range Source Zone

4-25a Recurrence Relationships for Central Basin and Range Source Zone With 1905 Earthquake

4-25b Recurrence Relationships for Central Basin and Range Source Zone without 1905 Earthquake

5-1 Median Empirical Peak Horizontal Acceleration Relationships

5-2a Median 5\% Damped Empirical Acceleration Response Spectra at a Distance of $15 \mathrm{~km}$

5-2b Median 5\% Damped Empirical Acceleration Response Spectra at a Distance of $50 \mathrm{~km}$

5-3 Standard Error of Peak Motion as a Function of Spectral Response Period for Empirical Attenuation Relationships

5-4 Schematic of Band-Limited-White-Noise Ground Motion Model

5-5 Computed Stochastic Peak Accelerations and Generalized Attenuation Relationship for $M_{w}$ 5,6 and 7 at $A N L$ for $Q_{0}=150$ and $k=0.012 \mathrm{sec}$.

5-6a Modeling Error and Total Standard Error for the Stochastic Attenuation Models for Distances of 0 to $10 \mathrm{~km}$.

5-6b Modeling Error and Total Standard Error for the Stochastic Attenuation Models for Distances Greater than $10 \mathrm{~km}$.

5-7a Comparison of Stochastic and Empirical Acceleration Response Spectra for ANL for a Distance of $15 \mathrm{~km}$.

5-7b Comparison of Stochastic and Empirical Acceleration Response Spectra for ANL for a Distance of $50 \mathrm{~km}$.

5-8a Comparison of Stochastic and Empirical Acceleration Response Spectra for ATR for a Distance of $15 \mathrm{~km}$.

5-8b Comparison of Stochastic and Empirical Acceleration Response Spectra for ATR for a Distance of $50 \mathrm{~km}$.

5-9a Comparison of Stochastic and Empirical Acceleration Response Spectra for CPP for a Distance of $15 \mathrm{~km}$.

5-9b Comparison of Stochastic and Empirical Acceleration Response Spectra for CPP for a Distance of $50 \mathrm{~km}$.

5-10a Comparison of Stochastic and Empirical Acceleration Response Spectra for NRF for a Distance of $15 \mathrm{~km}$. 


\section{TABLE OF CONTENTS (Continued)}

5-10b Comparison of Stochastic and Empirical Acceleration Response Spectra for NRF for a Distance of $50 \mathrm{~km}$.

5-11a Comparison of Stochastic and Empirical Acceleration Response Spectra for PBF for a Distance of $15 \mathrm{~km}$.

5-11b Comparison of Stochastic and Empirical Acceleration Response Spectra for PBF for a Distance of $50 \mathrm{~km}$.

5-12a Comparison of Stochastic and Empirical Acceleration Response Spectra for RWMC for a Distance of $15 \mathrm{~km}$.

5-12b Comparison of Stochastic and Empirical Acceleration Response Spectra for RWMC for a Distance of $50 \mathrm{~km}$.

5-13a Comparison of Stochastic and Empirical Acceleration Response Spectra for TAN for a Distance of $15 \mathrm{~km}$.

5-13b Comparison of Stochastic and Empirical Acceleration Response Spectra for TAN for a Distance of $50 \mathrm{~km}$.

6-1a Mean and 5th to 95th Percentile Seismic Hazard Curves for ANL

6-1b Mean and 5th to 95th Percentile Seismic Hazard Curves for ATR

6-1c Mean and 5th to 95th Percentile Seismic Hazard Curves for CPP

6-1d Mean and 5th to 95th Percentile Seismic Hazard Curves for NRF

6-1e Mean and 5th to 95th Percentile Seismic Hazard Curves for PBF

6-1f : Mean and 5th to 95th Percentile Seismic Hazard Curves for RWMC

6-1g Mean and 5th to 95th Percentile Seismic Hazard Curves for TAN

6-2a Contributions of the Seismic Sources to the Mean Seismic Hazard at ANL

6-2b Contributions of the Seismic Sources to the Mean Seismic Hazard at ATR

6-2c Contributions of the Seismic Sources to the Mean Seismic Hazard at CPP

6-2d Contributions of the Seismic Sources to the Mean Seismic Hazard at NRF

6-2e Contributions of the Seismic Sources to the Mean Seismic Hazard at PBF

6-2f Contributions of the Seismic Sources to the Mean Seismic Hazard at RWMC

6-2g Contributions of the Seismic Sources to the Mean Seismic Hazard at TAN

6-3a Contributions of the Fault Sources to the Mean Seismic Hazard at ANL

6-3b Contributions of the Fault Sources to the Mean Seismic Hazard at ATR

6-3c Contributions of the Fault Sources to the Mean Seismic Hazard at CPP

6-3d Contributions of the Fault Sources to the Mean Seismic Hazard at NRF

6-3e Contributions of the Fault Sources to the Mean Seismic Hazard at PBF

6-3f Contributions of the Fault Sources to the Mean Seismic Hazard at RWMC

6-3g Contributions of the Fault Sources to the Mean Seismic Hazard at TAN

6-4a Contributions of the Volcanic Sources to the Mean Seismic Hazard at ANL

6-4b Contributions of the Volcanic Sources to the Mean Seismic Hazard at ATR

6-4c Contributions of the Volcanic Sources to the Mean Seismic Hazard at CPP 
6-4d Contributions of the Volcanic Sources to the Mean Seismic Hazard at NRF

6-4e Contributions of the Volcanic Sources to the Mean Seismic Hazard at PBF

6-4f Contributions of the Volcanic Sources to the Mean Seismic Hazard at RWMC

6-4g Contributions of the Volcanic Sources to the Mean Seismic Hazard at TAN

6-5a Contributions of the Regional Source Zones to the Mean Seismic Hazard at ANL

6-5b Contributions of the Regional Source Zones to the Mean Seismic Hazard at ATR

6-5c Contributions of the Regional Source Zones to the Mean Seismic Hazard at CPP

6-5d Contributions of the Regional Source Zones to the Mean Seismic Hazard at NRF

6-5e Contributions of the Regional Source Zones to the Mean Seismic Hazard at PBF

6-5f Contributions of the Regional Source Zones to the Mean Seismic Hazard at RWMC

6-5g Contributions of the Regional Source Zones to the Mean Seismic Hazard at TAN

6-6a Magnitude and Distance Contributions to the Mean Seismic Hazard at ANL

6-6b Magnitude and Distance Contributions to the Mean Seismic Hazard at ATR

6-6c Magnitude and Distance Contributions to the Mean Seismic Hazard at CPP

6-6d Magnitude and Distance Contributions to the Mean Seismic Hazard at NRF

6-6e Magnitude and Distance Contributions to the Mean Seismic Hazard at PBF

6-6f Magnitude and Distance Contributions to the Mean Seismic Hazard at RWMC

6-6g Magnitude and Distance Contributions to the Mean Seismic Hazard at TAN

6-7a Comparison of Mean Hazard Computed Using the Empirical and Stochastic Attenuation Relationships at ANL

6-7b Comparison of Mean Hazard Computed Using the Empirical and Stochastic Attenuation Relationships at ATR

6-7c Comparison of Mean Hazard Computed Using the Empirical and Stochastic Attenuation Relationships at CPP

6-7d Comparison of Mean Hazard Computed Using the Empirical and Stochastic Attenuation Relationships at NRF

6-7e Comparison of Mean Hazard Computed Using the Empirical and Stochastic Attenuation Relationships at PBF

6-7f Comparison of Mean Hazard Computed Using the Empirical and Stochastic Attenuation Relationships at RWMC

6-7g Comparison of Mean Hazard Computed Using the Empirical and Stochastic Attenuation Relationships at TAN

6-8a Comparison of Hazard Computed Using the Individual Empirical Attenuation Relationships at ANL

6-8b Comparison of Hazard Computed Using the Individual Empirical Attenuation Relationships at ATR

6-8c Comparison of Hazard Computed Using the Individual Empirical Attenuation Relationships at CPP 
TABLE OF CONTENTS (Continued)

6-8d Comparison of Hazard Computed Using the Individual Empirical Attenuation Relationships at NRF

6-8e Comparison of Hazard Computed Using the Individual Empirical Attenuation Relationships at PBF

6-8f Comparison of Hazard Computed Using the Individual Empirical Attenuation Relationships at RWMC

6-8g Comparison of Hazard Computed Using the Individual Empirical Attenuation Relationships at TAN

6-9a Effect of $K$ on Stochastic-Based Mean Seismic Hazard Curve at ANL

6-9b Effect of $k$ on Stochastic-Based Mean Seismic Hazard Curve at ATR

6-9c Effect of $\kappa$ on Stochastic-Based Mean Seismic Hazard Curve at CPP

6-9d Effect of $k$ on Stochastic-Based Mean Seismic Hazard Curve at NRF

6-9e Effect of $K$ on Stochastic-Based Mean Seismic Hazard Curve at PBF

6-9f Effect of $k$ on Stochastic-Based Mean Seismic Hazard Curve at RWMC

6-9g Effect of $k$ on Stochastic-Based Mean Seismic Hazard Curve at TAN

6-10a Effect of $Q_{0}$ on Stochastic-Based Mean Seismic Hazard Curve at ANL

6-10b Effect of $Q_{0}$ on Stochastic-Based Mean Seismic Hazard Curve at ATR

6-10c Effect of $Q_{0}$ on Stochastic-Based Mean Seismic Hazard Curve at CPP

6-10d Effect of $Q_{0}$ on Stochastic-Based Mean Seismic Hazard Curve at NRF

6-10e Effect of $Q_{0}$ on Stochastic-Based Mean Seismic Hazard Curve at PBF

6-10f Effect of $Q_{0}$ on Stochastic-Based Mean Seismic Hazard Curve at RWMC

6-10g Effect of $Q_{0}$ on Stochastic-Based Mean Seismic Hazard Curve at TAN

6-11a Effect of Recurrence Calculation Method on Seismic Hazard from Fault Sources at ANL

6-11b Effect of Recurrence Calculation Method on Seismic Hazard from Fault Sources at ATR

6-11c Effect of Recurrence Calculation Method on Seismic Hazard from Fault Sources at CPP

6-11d Effect of Recurrence Calculation Method on Seismic Hazard from Fault Sources at NRF

6-11e Effect of Recurrence Calculation Method on Seismic Hazard from Fault Sources at PBF

6-11f Effect of Recurrence Calculation Method on Seismic Hazard from Fault Sources at RWMC

6-11g Effect of Recurrence Calculation Method on Seismic Hazard from Fault Sources at TAN

6-12a Effect of Fault Segmentation Model on Seismic Hazard at ANL

6-12b Effect of Fault Segmentation Model on Seismic Hazard at ATR

6-12c Effect of Fault Segmentation Model on Seismic Hazard at CPP

6-12d Effect of Fault Segmentation Model on Seismic Hazard at NRF

6-12e Effect of Fault Segmentation Model on Seismic Hazard at PBF

6-12f Effect of Fault Segmentation Model on Seismic Hazard at RWMC

6-12g Effect of Fault Segmentation Model on Seismic Hazard at TAN

6-13a Effect of Location of Southern Termination of Lost River Fault on Seismic Hazard at ANL 


\section{TABLE OF CONTENTS (Continued)}

6-13b Effect of Location of Southern Termination of Lost River Fault on Seismic Hazard at ATR

6-13c Effect of Location of Southern Termination of Lost River Fault on Seismic Hazard at CPP

6-13d Effect of Location of Southern Termination of Lost River Fault on Seismic Hazard at NRF

6-13e - Effect of Location of Southern Termination ofLost River Fault on Seismic Hazard at PBF

6-13f Effect of Location of Southern Termination of Lost River Fault on Seismic Hazard at RWMC

6-13g Effect of Location of Southern Termination of Lost River Fault on Seismic Hazard at TAN

6-14a Effect of Location of Southern Termination of Lemhi Fault on Seismic Hazard at ANL

6-14b Effect of Location of Southern Termination of Lemhi Fault on Seismic Hazard at ATR

6-14c Effect of Location of Southern Termination of Lemhi Fault on Seismic Hazard at CPP

6-14d Effect of Location of Southern Termination of Lemhi Fault on Seismic Hazard at NRF

6-14e Effect of Location of Southern Termination of Lemhi Fault on Seismic Hazard at PBF

6-14f Effect of Location of Southern Termination of Lemhi Fault on Seismic Hazard at RWMC

6-14g Effect of Location of Southern Termination of Lemhi Fault on Seismic Hazard at TAN

6-15a Effect of Location of Southern Termination of Beaverhead Fault on Seismic Hazard at ANL

6-15b Effect of Location of Southern Termination of Beaverhead Fault on Seismic Hazard at ATR

6-15c Effect of Location of Southern Termination of Beaverhead Fault on Seismic Hazard at CPP

6-15d Effect of Location of Southern Termination of Beaverhead Fault on Seismic Hazard at NRF

6-15e Effect of Location of Southern Termination of Beaverhead Fault on Seismic Hazard at PBF

6-15f Effect of Location of Southern Termination of Beaverhead Fault on Seismic Hazard at RWMC

6-15g Effect of Location of Southern Termination of Beaverhead Fault on Seismic Hazard at TAN

6-16a Effect of Regional Zonation Model on Seismic Hazard at ANL .

6-16b Effect of Regional Zonation Model on Seismic Hazard at ATR

6-16c Effect of Regional Zonation Model on Seismic Hazard at CPP

6-16d Effect of Regional Zonation Model on Seismic Hazard at NRF

6-16e Effect of Regional Zonation Model on Seismic Hazard at PBF

6-16f Effect of Regional Zonation Model on Seismic Hazard at RWMC

6-16g Effect of Regional Zonation Model on Seismic Hazard at TAN

6-17a Effect of 1905 Earthquake Location on Seismic Hazard at ANL

6-17b Effect of 1905 Earthquake Location on Seismic Hazard at ATR

6-17c Effect of 1905 Earthquake Location on Seismic Hazard at CPP 
6-17d Effect of 1905 Earthquake Location on Seismic Hazard at NRF

6-17e Effect of 1905 Earthquake Location on Seismic Hazard at PBF

6-17f Effect of 1905 Earthquake Location on Seismic Hazard at RWMC

6-17g Effect of 1905 Earthquake Location on Seismic Hazard at TAN

6-18a Mean Seismic Hazard Curves for Peak Acceleration and Spectral Acceleration at ANL

6-18b Mean Seismic Hazard Curves for Peak Acceleration and Spectral Acceleration at ATR

6-18c Mean Seismic Hazard Curves for Peak Acceleration and Spectral Acceleration at CPP

6-18d Mean Seismic Hazard Curves for Peak Acceleration and Spectral Acceleration at NRF

6-18e Mean Seismic Hazard Curves for Peak Acceleration and Spectral Acceleration at PBF

6-18f Mean Seismic Hazard Curves for Peak Acceleration and Spectral Acceleration at RWMC

6-18g Mean Seismic Hazard Curves for Peak Acceleration and Spectral Acceleration at TAN

6-19a Equal Hazard Spectra for Annual Exceedance Probability of $2 \times 10^{-3}$

6-19b Equal Hazard Spectra for Annual Exceedance Probability of $10^{-3}$

6-19c Equal Hazard Spectra for Annual Exceedance Probability of $5 \times 10^{-4}$

6-19d Equal Hazard Spectra for Annual Exceedance Probability of $10^{-4}$ 


\section{VOLUME 2}

\section{LIST OF APPENDIXES}
APPENDIXA -
HISTORICAL EARTHQUAKE CATALOGUE AND ANALYSES
APPENDIX B - INVERSION OF REGIONAL EARTHQUAKES AND BORAH PEAK AFTERSHOCKS
APPENDIXC - BASIN AND RANGE AND OTHER EXTENSIONAL EARTHQUAKE STRESS DROPS
APPENDIXD - $\quad$ BOREHOLE VELOCITY AND DAMPING MEASUREMENTS AT ANL WEST D BOREHOLE ANL-1
APPENDIXE - $\quad$ SITE-SPECIFIC GEOLOGIC PROFILES

\section{LIST OF TABLES FOR APPENDICES}

A-1 Earthquake Catalogue - Explanation and Abbreviations

B-1 Regional Earthquakes Used in Analysis

B-2 Borah Peak Aftershocks Used in Analysis

B-3 Source, Path, and Site Parameters from Inversion of Regional Earthquakes and Borah Peak Aftershocks

C-1 1935 Helena and 1962 Cache Valley Earthquake Stress Drops

C-2 1980 Mammoth Lakes Aftershocks Used in Analyses

C-3 Stress Drop Estimates for 1980 Mammoth Lakes Aftershocks

C-4 1975 Oroville Aftershocks Used in Analyses

C-5 Stress Drop Estimates for 1975 Oroville Aftershocks

C-6 Stress Drops from Basin and Range Earthquakes

C-7 Statistics on Stress Drop Estimates

\section{LIST OF FIGURES FOR APPENDICES}

A-1 Relationship Between $M_{L}$ and $M_{w}$ for Earthquakes Within the Study Region

A-2 Relationship Between $M_{s}$ and $M_{w}$ for Earthquakes Within the Study Region

A-3 Relationship Between $M_{D}$ and $M_{L}$ for Earthquakes Within the Study Region

A-4 Relationship Between $M_{u}$ and $M_{L}$ for Earthquakes Within the Study Region

A-5 Relationship Between $m_{b}$ and $M_{L}$ for Earthquakes Within the Study Region

A-6 Relationship Between $\mathrm{I}_{0}$ and $\mathrm{M}_{\mathrm{L}}$ for Earthquakes Within the Study Region

A-7 Empirical Spatial and Temporal Windows to Identify Dependent Events

A-8 Earthquake Frequencies of Independent Events as a Function of Magnitude Interval and Time Before the End of the Catalogue 
TABLE OF CONTENTS (continued)

A-9 Distributions of Seismograph Stations as a Function of Time and Specified Completeness Regions

A-10 Equivalent Periods of Completeness, TE, for the Two Completeness Regions and the Three Zonation Models

B-1 Results of Spectral Inversion of Regional Earthquakes and Borah Peak Aftershocks

C-1 Results of Spectral Inversion of 1935 Helena, MT Earthquakes

C-2 Results of Spectral Inversion of 1962 Cache Valley, UT Earthquakes

C-3 Results of Spectral Inversion of 1980 Mammoth Lake, CA Earthquakes

C-4 Results of Spectral Inversion of 1975 Oroville, CA Aftershocks

E-1. Shear-Wave Velocity Profile for ANL

E-2 Shear-Wave Velocity Profile for ATR

E-3 Shear-Wave Velocity Profile for CPP

E-4 Shear-Wave Velocity Profile for NRF

E-5 Shear-Wave Velocity Profile for PBF

E-6 Shear-Wave Velocity Profile for RWMC

E-7 Shear-Wave Velocity Profile for TAN 
This study was a joint effort by Woodward-Clyde Federal Services (WCFS) and its subcontractors, Geomatrix Consultants, Inc. and Pacific Engineering \& Analysis (PE\&A). We would like to acknowledge the contributions to this report of many individuals including Dick Smith and Suzette - Jackson of Lockheed Martin Idaho Technologies (LMIT); Bill Hackett of WRH Associates; Andy Gorton, Jackie Bott, Doug Wright, Sue Penn, Fumiko Goss, and Sadako McInerney of WCFS; Mark Hemphill-Haley and Tom Sawyer formerly of WCFS; Peter Knuepfer of Binghamton University; Steve Forman, The Ohio State University, and Ron Bruhn and Daning Wu of the University of Utah. We would also like to thank those who provided assistance, cooperation and information, including Sue Nava, University of Utah; Mike Stickney, Montana Bureau of Mines and Geology; and Bob Crowton of LMIT. This study was funded by LMIT Subcontract No. C92120278. Our sincere thanks to Suzette Jackson, Dick Smith, and Bob Secondo of DOE-ID for their enthusiastic support of our efforts. 



\section{EXECUTTVE SUMMARY}

This report describes and summarizes a probabilistic evaluation of ground motions for the Idaho National Engineering Laboratory (INEL). The purpose of this evaluation is to provide a basis for updating the seismic design criteria for the INEL. In this study, site-specific seismic hazard curves were developed for seven facility sites as prescribed by DOE Standards 1022-93 and 1023-96. These sites include the: Advanced Test Reactor (ATR); Argonne National Laboratory West (ANL); Idaho Chemical Processing Plant (ICPP or CPP); Power Burst Facility (PBF); Radioactive Waste Management Complex (RWMC); Naval Reactor Facility (NRF); and Test Area North (TAN). The results, probabilistic peak ground accelerations and uniform hazard spectra, contained in this report ARE NOT to be used for purposes of seismic design at INEL. A subsequent study will be performed to translate the results of this probabilistic seismic hazard analysis to site-specific seismic design values for the INEL as per the requirements of DOE Standard 1020-94. These sitespecific seismic design values will be incorporated into the INEL Architectural and Engineering Standards.

The probabilistic seismic hazard analysis methodology used in this study provides for the explicit inclusion of the range of possible interpretations in components of the model including seismic source characterization and ground motion estimation. Uncertainties in models and parameters are incorporated into the hazard analysis through the use of logic trees. Included in this report is the documentation of the choices of the parameter values on the logic trees, their relative credibilities, and the basis for the assessments in the available geologic, seismologic, geophysical and geotechnical data. The data resulting from the site characterization program for the once proposed New Production Reactor and GSG (geology, seismology, and geophysics) studies performed at the INEL and concluded in 1995 have been included in the seismic source characterization for this study.

Seismic sources that may contribute to the probabilistic seismic hazard at the INEL include active faults, volcanic zones, and areal source zones. The closest late-Quaternary Basin and Range fault zones, the Lemhi, Lost River, and Beaverhead faults, have been included in the analysis. Each fault is modeled by parameters that define its three-dimensional geometry, maximum earthquake magnitude, and earthquake recurrence rate. Recent studies of the Lemhi and Lost River faults 
were used to develop interpretations of the location of the southern termination of the fault, fault dip, timing and extent of prehistoric ruptures, fault segmentation, maximum earthquake magnitude, slip rate, earthquake recurrence intervals, and temporal clustering of earthquake activity. Information on the Beaverhead fault is sparse, although its impact on seismic hazard to the INEL is offset somewhat by its greater distance to most of the facility sites.

Volcanic zones are modeled for this analysis as source zones that incorporate the volcanic vents and deformational features related to dike emplacement within volcanic rift zones. Three volcanic rift zones, the Arco, Lava Ridge-Hell's Half Acre, and Great Rift, and the axial volcanic zone along the center of the eastern Snake River Plain (ESRP) were included as seismic sources. The HoweEast Butte zone was also included as another possible volcanic rift zone, although the probability that it is a volcanic rift zone is judged to be very low. The volcanic zones have been aseismic during the historical period. Earthquake recurrence rates are estimated based on the frequency of eruptive episodes within each of the volcanic zones. The geometries and maximum magnitude estimates for the volcanic zones (both volcanic rift zones and the axial volcanic zone) incorporate worldwide observations of volcanic ritts, as well as site-specific observations within the ESRP.

Several areal seismic source zones are modeled in the site region, the most important of which are the ESRP, in which the INEL is located, and the northern Basin and Range province immediately to the north. The historical earthquake catalogue, with dependent events removed and corrected for incompleteness, provides the basis for recurrence rates within these source zones. The ESRP has exhibited an extremely low level of seismicity during the historical period and hence, the size and location of the 1905 Shoshone, Idaho earthquake are important issues. The analysis specifically incorporates the uncertainties in this earthquake into estimates of the maximum size of the ESRP earthquake.

Four empirical ground motion attenuation relationships were used in this study to estimate ground motions. They were selected to represent the uncertainty in empirical modeling of earthquake ground motions. Site-specific relationships were also developed for each site based on a stochastic ground motion modeling approach. A comparison of the empirical and stochastic relationships shows that in general, the latter are lower at short-periods, 0.02 to $0.5 \mathrm{sec}$ and similar at periods $0.5 \mathrm{sec}$ and longer. The differences at high frequencies or short periods can be attributed to the 
interbedded volcanic stratigraphy beneath the INEL which has a lower velocity gradient and tends to damp out high frequency ground motions.

The probabilistic seismic hazard results are presented along with several sensitivity analyses to examine the important contributors to the total hazard and to the uncertainties in the hazard. At almost all return periods, the Lost River and Lemhi faults are the largest contributors to the total hazard at the INEL, with the former generally having the largest contribution at all sites except TAN. At high annual probabilities (short return periods of 100 to 300 years), the hazard is dominated by the northern Basin and Range areal source because of its proximity. Despite the location of the INEL in the ESRP, its extremely low level of seismicity contributes very little to the hazard at the INEL.

The following summarizes the peak horizontal accelerations on rock at the ground surface at the annual exceedance probabilities specified for the various Performance Categories (PC) as described in DOE Standard 1020-94. (For sites with soil atop bedrock such as TAN, ground motions have been computed by assuming no soil.)

\begin{tabular}{|c|c|c|c|c|}
\hline \multicolumn{5}{|c|}{ PROBABILISTIC PEAK HORIZONTAL ACCELERATIONS IN g'S ON ROCK } \\
\hline \multirow{3}{*}{ Site } & \multicolumn{4}{|c|}{ Annual Exceedance Probability (Return Period) } \\
\hline & A. & $T \pi(n)$ MRT & & \\
\hline & $\begin{array}{c}\text { PCl-2x10-3 } \\
(500 \mathrm{yrs})\end{array}$ & $\begin{array}{l}\text { PC2-1x10 } \\
(1,000 \mathrm{yrs})\end{array}$ & $\begin{array}{l}\text { PC3-5x } 10^{-4} \\
(2,000 \mathrm{yrs})\end{array}$ & $\begin{array}{l}\text { PC4-1x10 } 10^{-4} \\
(10,000 \mathrm{yrs})\end{array}$ \\
\hline $\mathrm{ANL}$ & $0.06 \sqcap \| S$ & $\left.\left.\Gamma m\right|^{0.08}=\sqrt{m}\right)$ & 0.10 & 0.16 \\
\hline ATR & 0.08 & 0.11 & 0.14 & 0.24 \\
\hline CPP & 0.08 & 0.10 & 0.13 & 0.22 \\
\hline NRF & $0.08 \bigcirc$ & $=[S 6 \mathrm{n} n \Theta$ & 0.15 & 0.26 \\
\hline PBF & 0.06 & 0.09 & 0.11 & 0.18 \\
\hline RWMC & 0.08 & 0.10 & 0.13 & 0.23 \\
\hline TAN & 0.09 & [20) 0.13$]$ & 0.18 & 0.33 \\
\hline
\end{tabular}


The primary source of uncertainty is the selection of the appropriate attenuation relationship and, to a lesser extent, the seismicity rates for both the faults and source zones and the value of kappa estimated for each site particularly at high frequencies of ground motions: The stochastic attenuation relationships differ significantly from the empirical relationships which accounts for some of this uncertainty. This is particularly true at high frequencies due to differences in the interbedded nature of the volcanic stratigraphy beneath the INEL and the somewhat lower kappa.

The hazard results at various spectral accelerations show that at high frequencies $(0.2 \mathrm{sec})$, the results are very similar to those at peak acceleration; at lower frequencies $(1.0 \mathrm{sec})$, the major contributor to the hazard becomes the fault zones. The reason for this change in the contributions to the hazard is a change in the relative contributions from earthquakes in various magnitude intervals. As the period of the ground motion increases, the larger magnitude events become increasingly important, dominating the hazard at a period of $1.0 \mathrm{sec}$. These larger magnitude events are associated with the Lemhi and Lost River faults. Equal-hazard spectra were developed for annual exceedance frequencies of $2 \times 10^{-3}, 10^{-3}, 5 \times 10^{-4}$, and $10^{-4}$. 
At the request of Lockheed Martin Idaho Technologies (LMIT) and the U.S. Department of Energy (DOE), the following report describes and summarizes a site-specific probabilistic evaluation of ground motions for the Idaho National Engineering Laboratory (INEL). This study was performed by Woodward-Clyde Federal Services (WCFS) and its principal subcontractors Geomatrix Consultants, Inc. and Pacific Engineering \& Analysis. Probabilistic ground motion estimates were computed for seven facility sites at the INEL: the Advanced Test Reactor (ATR); Argonne National Laboratory West (ANL); Chemical Processing Plant (CPP); Power Burst Facility (PBF); Radioactive Waste Management Complex (RWMC); Naval Reactor Facility (NRF); and Test Area North (TAN).

The bases for this analysis are the deterministic ground motion studies performed for the INEL (Woodward-Clyde Consultants, 1990) and the subsequent deterministic and probabilistic ground motion evaluations of the proposed New Production Reactor (NPR) (Woodward-Clyde Consultants, 1992a; 1992b). A significant aspect of this study is the incorporation of the recent results of paleoseismic studies performed by WCFS along the southern portions of the Lemhi and Lost River faults and of site-specific geologic and geotechnical data for each facility site when possible.

\subsection{OBJECTIVES}

The purpose of this study is to provide supporting documentation for revising the seismic design criteria presently being used at the INEL which is consistent with recently published DOE Standards for seismic hazards. The specific objectives of this study are:

1) To perform a site-specific probabilistic seismic hazard analysis for the INEL using stateof-the-art methodologies and incorporating the most up-to-date geological, geophysical, seismological, and geotechnical data available. The methods being used are aimed specifically at incorporating the uncertainties associated with seismic source characterization and ground motion assessment; 
2) To review, update and incorporate, where appropriate, the results of the NPR deterministic and probabilistic evaluations into this study, and

3) To perform sensitivity analyses to ascertain the dominant contributors to the seismic hazard and the most important elements of the model. These results can be instrumental in identifying the most important issues that should be addressed in future site characterization studies.

\subsection{DOE SEISMIC DESIGN CRITERIA}

In recent years, the DOE through their Natural Phenomena Hazards Project has focused on addressing the potential hazards that might affect their facilities due to earthquakes, wind, tornadoes and floods. DOE Order 5480.28 on "Natural Phenomena Hazards Mitigation" requires that all structures, systems and components at DOE facilities be designed and constructed to withstand the effects of natural hazards including earthquakes. The seismic effects include ground shaking, fault rupture, and ground failure such as liquefaction and landsliding. This study is consistent with the following $\mathrm{DOE}$ documents:

- DOE Standard 1020-94 Natural Phenomena Hazards Design and Evaluation Criteria for DOE Facilities (formerly UCRL-15910)

- DOE Standard 1022-94 Natural Phenomena Hazards Site Characterization Criteria

- DOE Standard 1023-95 Natural Phenomena Hazards Assessment Criteria (draft dated July 1995)

These Standards have been developed to aid in the definition of seismic design basis vibratory ground motion for DOE facilities. Appropriate methods and acceptance criteria for evaluating seismic hazards are described in these documents to insure a consistent approach for all DOE sites and that state-of-the-art techniques are being used to evaluate facility design. 
According to the DOE Standards:

1) For DOE sites with Category 3 (moderate hazard) and 4 (high hazard) facilities, a stateof-the-art site-specific probabilistic evaluation of seismic hazards should be performed;

2) An accurate site-specific geologic and seismic data base should be available when computing estimates of seismic hazard. The following activities need to be considered:

a) Characterization of Quaternary faults within $40 \mathrm{~km}$ ( 25 miles) of the site. Active Quaternary faults within $320 \mathrm{~km}$ ( 200 miles) of the site need to be identified and incorporated into the hazard analysis;

b)Detailed characterization of all faults that occur within $8 \mathrm{~km}$ ( 5 miles) of the site and determination if they have been active in the Quaternary. This factor is particularly important in terms of assessing the potential for fault displacement;

c) Evaluation of liquefaction potential of soils supporting facilities;

d)Assessment of potential slope instability and failure, soil compaction, ground subsidence and ground collapse; and

e) Evaluation of the potential for site-specific amplification of vibratory ground motion.

3) For vibratory ground motion, a Design/Evaluation Basis Earthquake (DBE) in terms of a design response spectrum shall be defined in order to perform seismic design and seismic safety evaluations.

DOE Standard 1020-94 provides guidelines to evaluate, modify or upgrade existing DOE facilities or to design new DOE facilities for the effects of natural phenomena hazards including those from earthquakes. UCRL-53582, as referenced by DOE Standard 1020-94, contains site-specific seismic hazard curves developed prior to 1984 by Tera Corporation (1984) under contract to Lawrence Livermore National Laboratory. The annual probabilities of exceedance for hazard and 
the peak horizontal ground surface accelerations (average soil/rock conditions) calculated in UCRL-53582 for the INEL are specified for four Performance Categories:

\begin{tabular}{||l|c|c||}
\hline \multicolumn{1}{|c|}{ Usage Category } & $\begin{array}{c}\text { Annual Hazard } \\
\text { Exceedance Probability }\end{array}$ & $\begin{array}{c}\text { Peak Horizontal Ground } \\
\text { Surface Acceleration (g) }\end{array}$ \\
\hline (1) General Use & $2 \times 10^{-3}(500 \mathrm{yrs})$ & 0.12 \\
(2) Important or Low Hazard & $1 \times 10^{-3}(1,000 \mathrm{yrs})$ & 0.14 \\
(3) Moderate Hazard & $1 \times 10^{-3}(1,000 \mathrm{yrs})$ & 0.14 \\
(4) High Hazard & $2 \times 10^{-4}(5,000 \mathrm{yrs})$ & 0.21 \\
\hline
\end{tabular}

DOE recognized that the Tera Corporation seismic hazard curves are outdated and that new sitespecific curves need to be developed using state-of-the-art techniques (DOE-STD-1024-92). It is with this recognition that the following study has been performed. It should be noted that during the performance of this study, the hazard exceedance probabilities for Performance Categories 3 and 4 were revised to $5 \times 10^{-4}$ (2,000 yrs) and $1 \times 10^{-4}$ (10,000 years), respectively, based on DOE Standard 1020-94. Thus the hazard was calculated at these new probabilities in this study.

\subsection{SCOPE OF WORK}

There are three primary components of probabilistic seismic hazard analysis: (1) seismic source characterization; (2) characterization of ground motions from the sources to the site; and (3) calculations of the seismic hazard at the site. All significant seismic sources in the INEL region were characterized in terms of capability, maximum magnitude, fault geometry, sense of slip, and slip rate and/or recurrence intervals. A logic tree approach was used to capture the range of interpretations for each fault parameter. This approach also enabled explicit quantification of uncertainty for each fault parameter and the performance of sensitivity analyses to evaluate which parameters are critical in terms of the seismic hazard to the INEL. Based on empirical data and observations, it is well known that near-surface geology can significantly influence, if not dominate, the level and spectral content of strong ground motions. Specifically, the interbedded volcanic stratigraphy beneath the INEL appears to be capable of strongly affecting ground motions. Based 
on geologic and velocity profiles developed for each of the seven INEL facility sites, stochastic attenuation relationships were developed and used to characterize the propagation of ground motions from the seismic sources to the site and up through the site geology. Empirical attenuation relationships were also used to incorporate the uncertainty in ground motion modeling.

In the implementation of UCRL-15910, DOE has used probabilistic seismic hazard analyses (UCRL-53582) as the basis for the seismic design of its facilities. The use of a probabilisticallybased hazard analysis is especially appropriate for tectonic regions such as the INEL region where the recurrence intervals of faults are on the order of several to many thousands of years. A stateof-the-art probabilistic seismic hazard analysis was thus performed to incorporate the results of recently completed GSG studies. Site-specific probabilistic hazard curves for peak horizontal acceleration and spectral accelerations at periods at $0.05,0.2$, and $1.0 \mathrm{sec}$ were calculated and equal hazard spectra were developed for all seven sites.

\subsection{PROJECT TEAM AND REVIEW PANEL}

DOE Standard 1023-95 recommends that the input into a probabilistic seismic hazard analysis be derived though either (1) the elicitation of multiple experts, or (2) peer review. The objective of both processes is to ensure that the diversity (or uncertainty) of opinion on how to model both earthquake occurrence and the propagation of seismic energy is properly incorporated into hazard analysis. In this study, the latter approach was used. A Project Team ("single analyst" as referred to in DOE Standard 1023-95) developed the probabilistic hazard analysis input which was then reviewed by multiple experts.

Several members of the Project Team and the reviewers are nationally or internationally known in their fields. In the seismic source characterization, which requires the more multi-disciplinary approach, both geologists, whose expertise were in paleoseismology and structural geology and seismologists participated. The members of the Project Team, the reviewers, and their affiliations and disciplines were as follows: 


\section{Seismic Source Characterization Participants}

Susan Olig
Mark Hemphill-Haley
Kevin Coppersmith
Thomas Sawyer
Peter Knuepfer
Andy Gorton
Ron Bruhn
Daning Wu
Ivan Wong
Suzette Jackson
Robert Youngs
Richard Smith
William Hackett

WCFS
WCFS
Geomatrix Consultants
WCFS
Binghamton University
WCFS
University of Utah
University of Utah
WCFS
LMIT
Geomatrix Consultants
LMIT
WRH Associates

$$
\begin{aligned}
& \text { Paleoseismology } \\
& \text { Paleoseismology } \\
& \text { Paleoseismology } \\
& \text { Paleoseismology } \\
& \text { Paleoseismology } \\
& \text { Paleoseismology } \\
& \text { Structural Geology } \\
& \text { Structural Geology } \\
& \text { Seismology } \\
& \text { Seismology } \\
& \text { Seismology } \\
& \text { Volcanology } \\
& \text { Volcanology }
\end{aligned}
$$

\section{Ground Motion Characterization Participants}

Walter Silva
Ivan Wong
Cathy Stark
Sylvia Li.
Robert Youngs

Jeffrey Kimball

Robert Smith

Don Bernreuter

C. Allin Cornell

Robin McGuire

James Zollweg
PE\&A

WCFS

PE\&A

PE\&A

Geomatrix Consultants

\section{$\underline{\text { Reviewers }}$}

DOE

University of Utah

DOE Consultant

DOE Consultant

Risk Engineering

Boise State University
Seismology

Seismology

Seismology

Seismology

Earthquake Engineering
Seismology

Seismology

Seismology

Seismic Hazard Analyses .

Seismic Hazard Analyses

Historical Seismicity Catalogue 
SEISMIC HAZARD ANALYSIS METHODOLOGY

For this study, probabilistic seismic hazard analysis is defined as an evaluation of the probability or likelihood that various levels of ground motion will be exceeded during a specified time period. The analysis procedure was originally proposed by Cornell (1968). Since that time there has been significant progress in our understanding of the earthquake process and in the techniques for evaluating relevant seismological, geological, and geophysical data. The methodology used in this study incorporates the significant advances that have been made in probabilistic seismic hazard analyses (e.g., Youngs and Coppersmith, 1990). The following section outlines the mathematical formulation used. The important considerations involved in selecting the analytical models and input parameters are also discussed.

\subsection{HAZARD FORMULATION}

In probabilistic terms, seismic hazard is defined as the likelihood that various levels of ground motion will be exceeded at a site during a specified time period. It is commonly assumed that the occurrence of individual mainshocks can be represented as a Poisson process. Following the approach developed by Cornell (1968), the probability that at a given site a ground motion parameter, $Z$, will exceed a specified level, $z$, during a specified time period, $t$, is given by the expression:

$$
P(Z>z \mid t)=1.0-e^{-\nu(z) \cdot t} \leq-\nu(z) \cdot t
$$

where $\nu(z)$ is the average frequency during time period $t$ at which the level of ground motion parameter $Z$ exceeds $z$ at the site resulting from earthquakes on all sources in the region. The inequality at the right of Equation 2-1 is valid regardless of the appropriate probability model for earthquake occurrence, and $\nu(z) \cdot t$ provides an accurate and slightly conservative estimate of the hazard for probabilities of 0.1 or less provided $\nu(z) \cdot t$ is the appropriate value for the time period of interest. 
The frequency of exceedance, $\nu(z)$, is a function of the uncertainty in the time, size and location of future earthquakes and uncertainty in the level of ground motions they may produce at the site. It is computed by the expression:

$$
\nu(z)=\sum_{N} \alpha_{n}\left(m^{0}\right) \int_{m^{0}}^{m^{\nu}} f(m)\left[\int_{0}^{\infty} f(r \mid m) \cdot P(Z>z \mid m, r) d r\right] d m
$$

where $\alpha_{n}\left(m^{\circ}\right)$ is the frequency of earthquakes on source $n$ above a minimum magnitude of engineering significance, $m^{\circ} ; f(m)$ is the probability density function for event size between $m^{\circ}$ and a maximum event size for the source, $m^{u} ; f(r)$ is the probability density function for distance to the earthquake rupture; and $P(Z>z \mid m, r)$ is the probability that, given a magnitude $m$ earthquake at a distance $r$ from the site, the ground motion exceeds level $z$.

The distance density function, $f(r)$, is developed by specifying the geometry of the seismic sources and allowing earthquake ruptures to occur randomly over the source volume. In this study, individual faults are modeled as segmented planar features with the earthquake rupture modeled as a rectangular area randomly located on the fault plane. Area sources are modeled by closely-spaced fault traces, each being an individual fault plane. The rate term $\alpha_{n}\left(m^{o}\right)$ and the density function $f(m)$ are specified by developing a recurrence relationship for the source. The function $f(m)$ is limited on the upper end by developing an estimate of the maximum magnitude for the source. The approaches used to develop these functions and parameters are described in the next section.

The probability functions contained in Equations 2-1 and 2-2 represent the uncertainties inherent in the natural phenomena of earthquake generation and seismic wave propagation. For the INEL region (as is usually the case in any region), considerable uncertainty is encountered in selecting appropriate models and model parameters required to apply Equation 2-2 arising from limited data and/or alternative interpretations of the available data. The approach used in this study explicitly incorporates these additional uncertainties into the analysis to assess their impact on the estimate of the expected level of seismic hazard as well as the uncertainty in that estimate. 
The uncertainty in modeling the natural phenomena is incorporated into the hazard analysis through the use of logic trees. The logic tree formulation for seismic hazard analysis (Kulkarni et al., 1984; Youngs et al., 1988; Coppersmith and Youngs, 1986) involves specifying discrete alternatives for states of nature or parameter values and specifying the relative likelihood that each discrete alternative is the correct value or state of the input parameter. The relative likelihoods of the different parameter values are typically based on subjective judgment, but may be specified by an objective statistical analysis if the available data warrant an assessment. The components of the logic trees developed for this study are described in the next section. The selection of the parameters and models for each source and the bases for parameter selection and relative weighting are discussed in Section 4.

\subsection{DEVELOPMENT OF SEISMIC HAZARD MODEL}

The seismic hazard at a site is a function of the location and geometry of potential sources of future earthquakes, the frequency of occurrence of various size earthquakes on these sources, and the characteristics of seismic wave propagation in the region. In the methodology used here, these elements are analyzed within a probabilistic framework that addresses both the randomness of the earthquake process and the uncertainty in modeling the process. The seismic hazard model consists of two basic components: a model of the sources of potential future earthquakes and a model of the effects at the site of future earthquakes. Each potential earthquake source is characterized by parameters that describe its location, geometry; maximum magnitude, and earthquake recurrence. The methods used in this study to characterize the seismic sources are state-of-the-art and provide for the specific inclusion of detailed aspects of fault behavior. Both published and unpublished data on specific seismic sources in the INEL region and in other portions of the Basin and Range province have been incorporated into the study.

Figure 2-1 displays the overall logic tree representing the seismic hazard model developed for this study. The logic tree is laid out to provide a logical progression from general aspects/hypotheses regarding the characteristics of seismicity and seismic wave propagation in the region to specific input parameters for individual faults and fault segments. The rationale for developing the various levels of the logic tree is discussed below. 
The first three nodes of the logic tree represent the uncertainty in selecting the appropriate strong ground motion attenuation relationship (Figure 2-1). Attenuation was placed first in the tree because it is felt that a single relationship (whichever relationship may be "best" at representing ground motion attenuation). is applicable to all earthquake sources in the region. The selection of attenuation relationships is discussed in Section 5 .

At this point, the logic tree is expanded into subtrees, one for each of the seismic sources included in the analysis to model the integrated hazard from multiple sources. To the right of this node of the logic tree, each source is considered to act independently, and the distribution in the total computed hazard is obtained by convolving the independent distributions obtained for each seismic source.

In the logic tree approach, discrete values of the source input parameters have been included along with our estimate of the likelihood that the discrete value represents the actual value. Generally all input parameters have been represented by three values: a central value, which represents our best estimate of the parameter, and lower and higher values to represent the distribution around the best estimate. The characterization of an input parameter and its uncertainties using a simple three-point approximation and specific weights for the median and selected percentiles were generally used in this study based on the studies of Keefer and Bodily (1983). They state that this approximation is more accurate than other approximations in characterizing continuous probability distributions "typical of those elicited via judgmental assessments." Two sets of weights were used: $0.185,0.63$, and 0.185 to approximate the $5^{\text {th }}, 50^{\text {th }}$ and $95^{\text {th }}$ percentile values, respectively, and $0.3,0.4$, and 0.3 for $10^{\text {th }}, 50^{\text {th }}$, and $90^{\text {th }}$ percentile values. The details of the selection of the parameter values and their probabilities are presented in the individual source characterizations in Section 4.

Two types of earthquake sources are characterized in this seismic hazard analysis: fault sources and areal source zones (Figure 2-1). Fault sources are modeled as three-dimensional fault surfaces and detäils of their behavior are incorporated into the source characterization. For this study, the fault sources are the nearby late-Quaternary Basin and Range faults located to the north of the ESRP. Source zones are areal source regions and earthquakes are assumed to occur randomly within them. Because more distant faults and tectonic provinces, such as the Intermountain seismic belt, Yellowstone region, and the southern Basin and Range south of the ESRP, are less significant to the seismic hazard at the INEL (due to 
greater distances), they are modeled simply as source zones rather than discrete faults. The volcanic zones are also modeled as source zones because seismicity is usually associated with magma intrusion.

The elements of the logic trees used to characterize fault sources are shown in Section 4. The first two elements of the logic tree describe the three-dimensional geometry of fault sources. The first element is the dip of the fault and the second element is the seismogenic thickness of the crust. The seismogenic crust is the part of the crust within which earthquakes occur. The combination of dip of the fault and the thickness of the seismogenic crust defines the downdip width of the fault within the seismogenic crust, which will be important to maximum magnitude and earthquake recurrence, as described later. The threedimensional geometry of the fault also defines the location of the fault rupture relative to each site. Because of the proximity of the late-Quaternary Basin and Range faults to the INEL, the uncertainty in the location of the southern end of the faults, and hence the closest distances to the site, is explicitly included in the logic tree. Ruptures are modeled threedimensionally as occurring randomly on the fault, and the size of the rupture is directly related to the magnitude of the earthquake using the empirical relationships of Wells and Coppersmith (1994).

The maximum magnitude earthquake, $m_{\max }$, is shown as a single node of the logic tree and is based on a consideration of the dimensions of the fault that might rupture in a maximum event and the associated displacement. The maximum magnitude is estimated based on assessments of the maximum surface rupture length, rupture area, and displacement per event using the relationships of Wells and Coppersmith (1994). Rupture lengths are evaluated considering the segmentation of the fault, and rupture areas are derived from multiplying the rupture length by the downdip width.

Several nodes of the logic tree relate to earthquake recurrence. For fault sources, the earthquake recurrence rate is estimated based on an assessment of either fault slip rate and a translation of the slip rate to seismic moment rate or recurrence intervals for the largest events. To develop an earthquake recurrence relationship from slip rate, the seismic moment rate must be partitioned into earthquakes of various magnitudes according to an earthquake recurrence model. Two recurrence models, which describe the distribution of earthquake magnitudes, are considered in this analysis: the characteristic earthquake model and the 
exponential model. Youngs and Coppersmith (1985) have shown that the characteristic earthquake model is more appropriate for fault sources, and areal source zones are typically modeled using the exponential recurrence model. For recurrence relationships developed on the basis of recurrence intervals for the largest events, the two models are used to define the recurrence for smaller earthquakes.

In applying Youngs and Coppersmith's (1985) characteristic magnitude distribution, the maximum magnitude assessed for the fault, $m_{\max }$, is taken to be the expected magnitude for the characteristic size event, with individual events uniformly distributed in the range of $m_{\max } \pm 1 / 4$ magnitude units. The cumulative frequency for earthquakes of magnitude $m_{\max }-1 / 4$ is then set equal to the annual frequency of maximum events assessed for the fault and the upper bound magnitude, $m^{u}$, in Equation $2-2$ is equal to $m_{\max }+1 / 4$. To provide a consistent interpretation for the exponential model, the standard truncated exponential distribution (Cornell and Van Marke, 1969) was modified to treat the upper-bound magnitude in the density function as uniformly distributed over the range of $m_{\max } \pm 1 / 4$ magnitude units. The effect is to smear out the upper boundary of the magnitude distribution without altering the general shape of the recurrence relationship. In this modified form, the distribution of events in the range $m_{\max } \pm 1 / 4$ remains nearly exponential.

Figure 2-2 compares the shape of the exponential, modified exponential, and characteristic magnitude distributions. Shown on the left are the three distributions developed for an assessed fault $m_{\max }$ of 7.25 with the frequency of events larger than $M 7$ (unspecified scale) held constant in all three models. Shown on the right in Figure 2-2 are the magnitude distributions developed on the basis of equal rate of seismic moment release. As can be seen, the modified exponential distribution is essentially equal to the exponential distribution except at the upper bound. The characteristic magnitude distribution results in a factor of about 10 reduction in the frequency of small magnitude events compared to the exponential model when the absolute level of the distribution is fixed by either the frequency of the largest events or by the rate of moment release.

For the Lemhi and Lost River faults, earthquake recurrence is estimated in two ways: from geologic estimates of average recurrence intervals and from fault slip rates. The recurrence interval estimates come from trenching studies, primarily along the southern parts of the Lemhi and Lost River faults (Section 4.2). The paleoseismic data for these parts of the 
faults suggest that the occurrence of large earthquakes may be clustered temporally. Therefore, the logic tree allows for recurrence interval estimates assuming average, intracluster, and inter-cluster behavior. Only fault slip rates were used to characterize earthquake recurrence for the Beaverhead fault due to a lack of recurrence interval data. Geologic studies of fault slip rates along all the faults suggest that the central segments have relatively higher long-term slip" rates than the segments on the northern and southern parts of the fault zone, and thus this variability in the logic tree is included.

The logic trees for the volcanic zones and the other areal source zones are simpler than those for the fault sources and consist primarily of assessments of the maximum magnitude and parameters related to earthquake recurrence. Recurrence rates have been estimated for the volcanic zones, which have been quiescent in the historical and instrumental seismicity period, based on the recurrence rates for volcanic eruptive episodes. For the other source zones, the observed historical seismicity provides the fundamental constraint on the recurrence rate. Note that the regional source zones, such as the Yellowstone region, are known to contain discrete faults. However, because of their distance to the INEL relative to the closer fault sources and their consequent insignificance to the seismic hazard at the sites, the individual faults within these source zones are not individually characterized for this assessment. The faults are considered, however, in terms of estimating maximum earthquake magnitude for the source region they are contained in. 



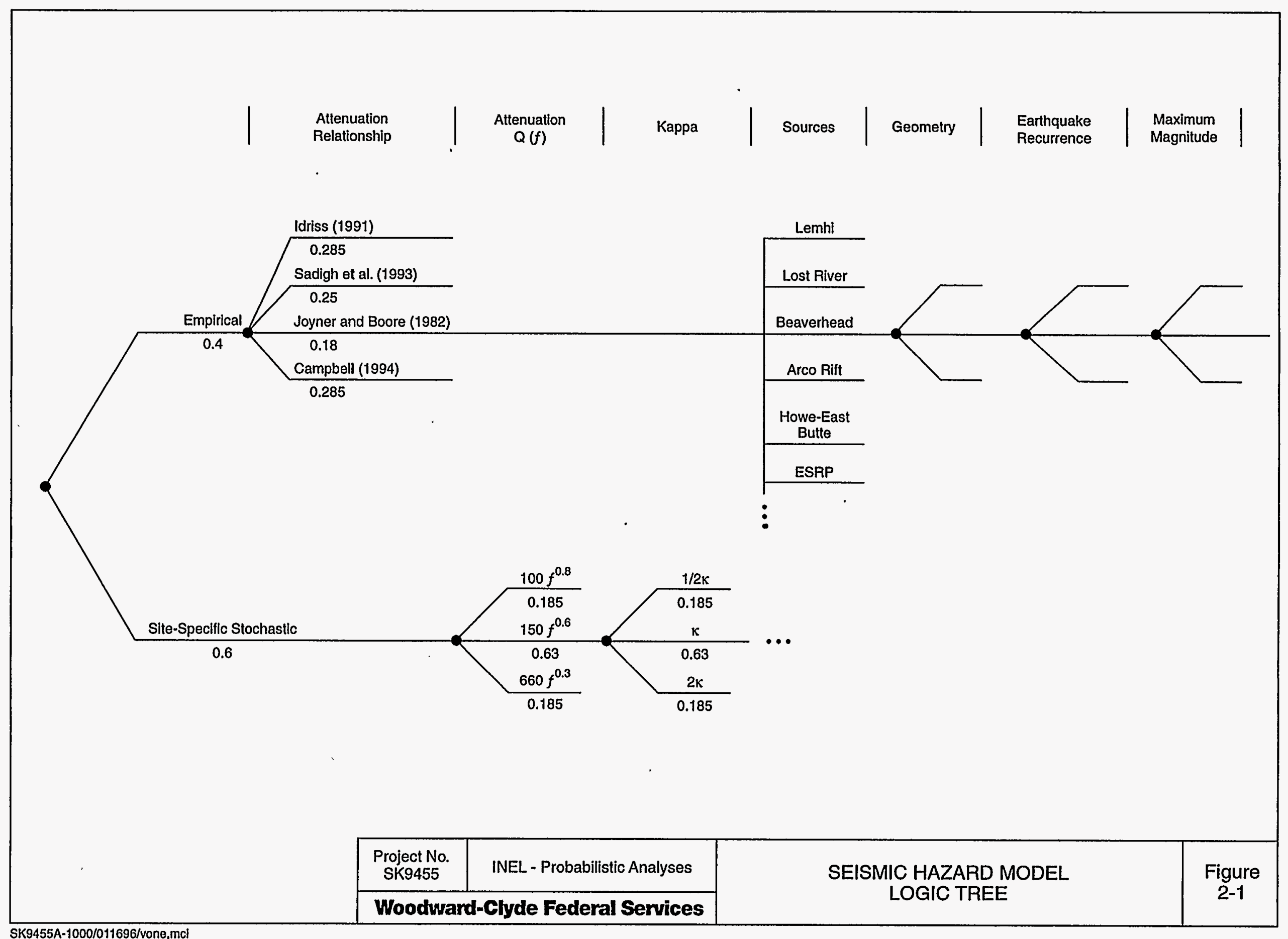



Cumulative Annual Frequency

$\overrightarrow{0}$

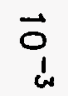

$\overrightarrow{0}$
1
$N$

$\overrightarrow{0}$

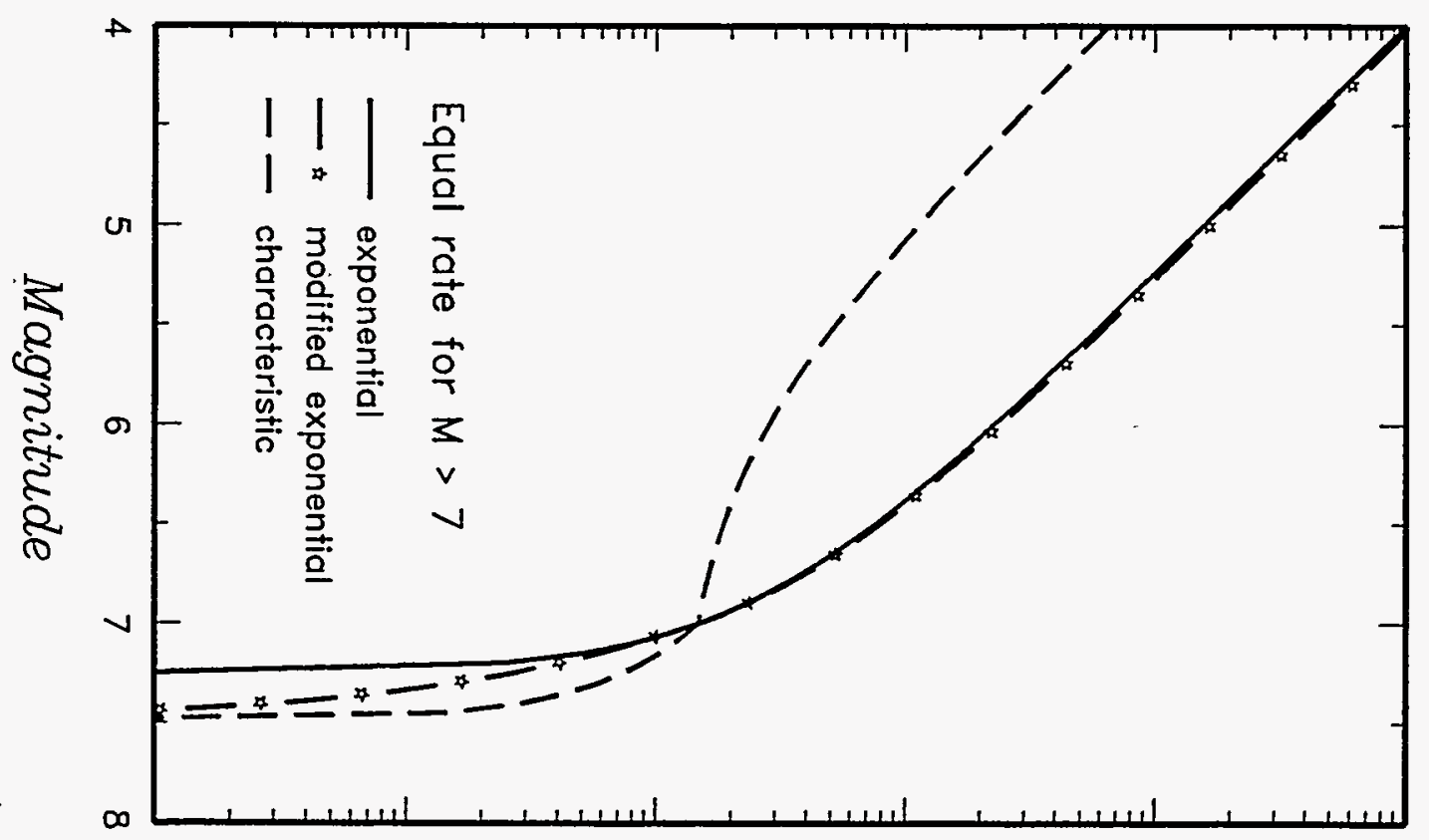

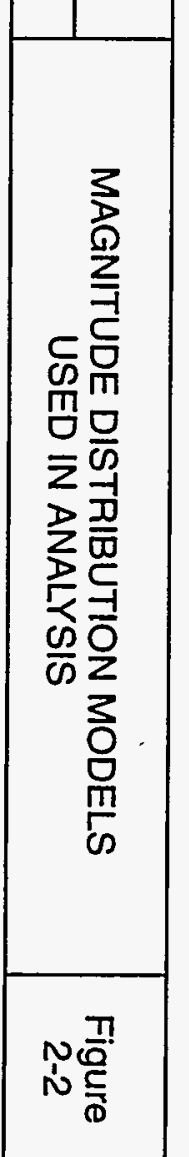

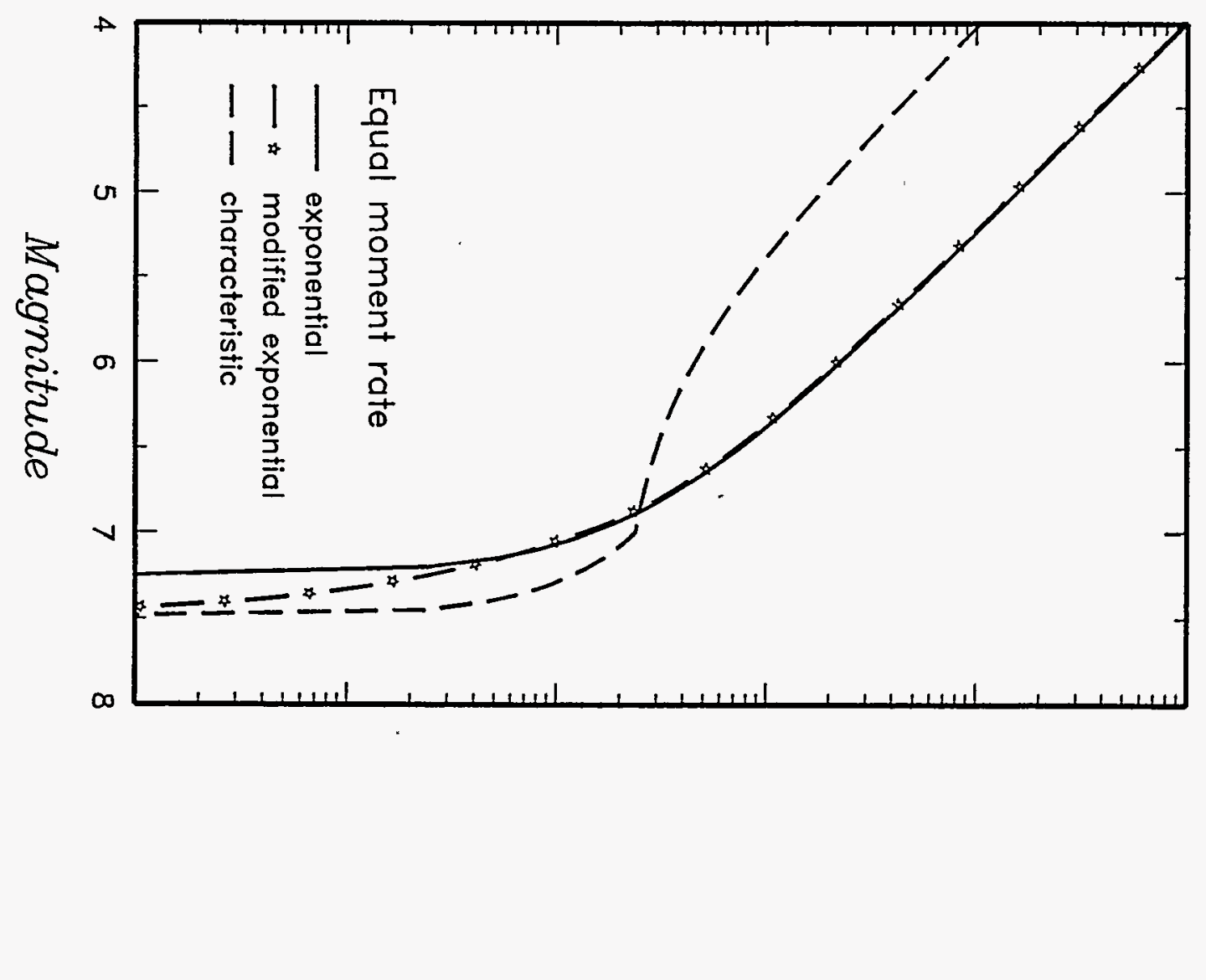


$\cdots$ 
SEISMIC SETTING AND SOURCES

This section describes the seismotectonic setting and historical seismicity of the INEL region. Potential seismic sources significant to the INEL are identified and discussed.

\subsection{SEISMOTECTONIC SETTING}

The INEL is located near the northwestern margin of the ESRP in southeastern Idaho (Figure 3-1). The ESRP is a northeast-trending, topographically-subdued physiographic province that is bordered on the northwest and southeast by the Basin and Range province and on the northeast by the Yellowstone Plateau. The northern and central Rocky Mountains lie to the north and southeast, respectively. The Intermountain seismic belt (ISB), a major zone of seismicity in the western United States, and the Centennial Tectonic Belt, an eastwest-trending seismic zone which may be part of the ISB, wrap around the southeastern, eastern, northern, and northwestern sides of the ESRP (Figure 3-1). Portions of the ISB exhibit repeated episodes of surface rupture associated with predominately normal-faulting earthquakes of M 7 and greater (Smith and Sbar, 1974; Smith and Arabasz, 1991). The largest historical earthquake within the ISB was the 1959 moment magnitude $\left(M_{w}\right) 7.3$ Hebgen Lake, Montana earthquake. The Centennial Tectonic Belt includes the epicentral area of the 1983 Borah Peak $M_{w} 6.8$ earthquake (Stickney and Bartholomew, 1987) (Figure 3-1).

\subsubsection{Snake River Plain}

Geologic and geophysical evidence support the interpretation that the Snake River Plain is the continental track of a mantle hotspot that now resides beneath the Yellowstone Plateau (Pierce and Morgan, 1992). The southwesterly movement of the North American plate over the hotspot during the past $17 \mathrm{Ma}$ has produced a $600 \mathrm{~km}$ by $100 \mathrm{~km}$ basalt-covered plain extending from north-central Nevada to the Yellowstone Plateau. The processes involved in producing the Snake River Plain are: 1) input of magma and heat into the continental lithosphere and crust from the hotspot produces uplift, crustal melting, and voluminous silicic volcanism from large calderas; 2) cooling of the crust, solidification of midcrustal mafic 
magmas and upper crustal silicic batholiths, and subsidence due to thermal contraction and densification of the crust in the wake of the hotspot as the plate moves to the southwest; and 3) filling of the subsiding elongate basin with basalt lava flows and terrigenous clastic sediments to depths as great as 1 to $2 \mathrm{~km}$ in the ESRP.

Seismic refraction profiles along and across the ESRP suggest that a lens-shaped zone of high-velocity, high-density material exists in the mid-crust at depths of 10 to $20 \mathrm{~km}$ (Sparlin et al., 1982). This probably represents the solidified mafic material introduced into the crust from the hotspot. It is not present in the Basin and Range province or the Rocky Mountains northwest or southeast of the ESRP. A systematic decrease in surface elevation southwestward from the Yellowstone Plateau to south-central Idaho is very similar to the decrease in elevation with distance from mid-ocean ridges, prompting the speculation by Brott et al. (1978) and Blackwell (1989) that the subsidence is due to thermal contraction in the wake of the hotspot. The basalt/sediment basin fill reaches a maximum of 1 to $2 \mathrm{~km}$ on the ESRP near INEL and thins to the northeast (Whitehead, 1986). Heat flow in the ESRP exceeds $100 \mathrm{mWm}^{-2}$ compared to about $85 \mathrm{mWm}^{-2}$ in the surrounding Basin and Range province (Blackwell, 1989).

Vents for basaltic volcanism in the ESRP are not random, but concentrated in volcanic rift zones and along the central axis of the Plain (Kuntz et al., 1992). The volcanic rift zones are characterized by alignments of basaltic vents (fissure eruptions and low shield volcanoes) and presence of numerous fissures, normal faults, and grabens produced by shallow dike injection processes. They are northwest-trending features, 2 to $20 \mathrm{~km}$ wide and 20 to $95 \mathrm{~km}$ long. Extensional features of the volcanic rift zones, such as fissures and grabens closely associated with volcanic vent areas, are likely produced by injection of shallow dikes (Smith et al., 1989), and are analogous to features observed to form during historical volcanism along active volcanic rift zones in Iceland and Hawaii (e.g., Rubin, 1992). Holocene and Pleistocene volcanic rift zones have similar strikes as the late-Quaternary Basin and Range faults northwest of the ESRP.

The axial volcanic zone is a northeast-trending, topographically high belt of volcanic vents including basaltic shield volcanoes, silicic (rhyolitic) domes and magma-induced uplifts. Although dike-induced extensional features are rare or absent along the axial volcanic zone, 
it is nonetheless a region of high vent density (of clustered volcanic vents) and is therefore considered a region of potential volcanic seismicity.

In order to explain perceived discontinuities of late Mesozoic structures in the IdahoWyoming thrust belt that may exist north of the ESRP, a northeast-trending, strike-slip fault has been postulated tô underlie the axis of the ESRP (Pratt, 1982; Woodward, 1988). This feature is hypothesized on the basis of indirect evidence, has no known surficial or geophysical expression in rocks of any age and if it exists at all, has been subsequently covered by Neogene and Quaternary volcanic rocks and sediment of the ESRP. The feature is both hypothetical and of pre-Quaternary age and therefore we have not considered it as a potential seismic source in this study (Section 3.1.1.1).

Very few stress data are available for the ESRP to characterize the contemporary state of tectonic stress (Zoback and Zoback, 1989). However, two focal mechanisms (Jackson et al., 1993) with northeast-striking T-axes and the northwest strikes of the volcanic rift zones in the ESRP suggest that the region is being subjected to the same northeast-trending extensional stresses that are affecting the northern Basin and Range province (Hackett et al., 1991). Absence of borehole breakouts in drillhole INEL-1 suggest low differential stresses at depths of 2 to $3 \mathrm{~km}$ (Moos et al., 1990).

The Snake River Plain has been recognized as a pronounced aseismic region even on the microearthquake level (Pennington et al., 1974; Smith and Sbar, 1974; Jackson et al., 1993) (Figure 3-1). Several investigators (Smith et al., 1985; Scott et al; 1985; Anders et al., 1989) have proposed that immediately adjacent to the ESRP exists a parabolic-shaped "collapse shadow" or region of inactive faults and seismic quiescence that is surrounded by an active region with an outwardly migrating pattern of increased fault activity (Figure 3-2). Anders et al. (1989) proposed that both regions result from correspondingly increased and decreased integrated lithospheric strength, respectively, due to thermal effects of the hotspot. Brott et al. (1981) suggested that deformation within the Plain is aseismic due to the high heat flow. Recently, Parsons and Thompson (1991) suggested magma overpressure and dike injection as a mechanism that may suppress normal faulting and seismicity within and near the ESRP. Smith and Arabasz (1991) suggest that the high-velocity crustal body beneath the ESRP, which may represent a solidified mafic remnant of the Yellowstone hotspot, may act to increase the strength and hence, reduce the seismic capability of the ESRP. 


\subsubsection{ESRP-Basin and Range Boundary}

The nature of the boundary between the ESRP and the Basin and Range province to the north has been a focus of research for the past.decade. Based on geophysical observations and borehole data, an abrupt geologic discontinuity exists at the edge of the Plain which separates Paleozoic limestones as exposed in the mountain ranges to the northwest and late Cenozoic volcanics or the ESRP to the southeast. Several geophysical approaches have been taken to characterize the nature of this discontinuity.

Mabey (1978) suggested that the boundary is a major fault with nearly north-south orientation, based on the interpretation of a steep gravity gradient in the Arco Hills area. Two-dimensional modeling of magnetotelluric data collected in a 1979 survey on the INEL also suggested a fault contact between the northern Basin and Range and the ESRP in the vicinity of the Arco Hills (Stanley, 1982).

Sparlin et al. (1982) developed a crustal model for the ESRP based on ray-trace travel-time modeling of seismic refraction date collected during the 1978 Yellowstone-ESRP Seismic Profiling Experiment. The northwest margin of the ESRP was interpreted as a fault structure with the Plain downthrown by more than $4 \mathrm{~km}$. In contrast, the southern margin of the ESRP appears to be a downwarp with minor faulting. Computed Bouguer gravity profiles were also consistent with this interpretation (Sparlin et al., 1982).

The results of a seismic-refraction survey indicate that a vertical, fault-like discontinuity with about $1 \mathrm{~km}$ of down-to-the-south displacement is located about $2 \mathrm{~km}$ from the southeast flank of the Arco Hills (Pankratz and Ackermann, 1982). The strike of this discontinuity is not resolvable on the basis of a single refraction line, but other geophysical data including gravity and aeromagnetic data suggest it is a northeast-trending feature in the subsurface. The data also suggest that Paleozoic rocks may extend beneath the Plain as far as $5.6 \mathrm{~km}$ eastward of the Arco'Hills (Pankratz and Ackermann, 1982). If so, they are present only at great depth, as shown by drillhole INEL-1 (Doherty et al., 1979) which was drilled only a few kilometers southeast of the Arco Hills and intersected only ESRP volcanic rocks to its total depth of about $3 \mathrm{~km}$. 
In addition to the obvious topographic contrast along the ESRP - Basin and Range boundary zone, northeast-trending faults have been identified parallel to the boundary (Rodgers and Zentner, 1988). Zentner (1989) mapped a set of east-northeast-striking normal faults near the southern end of the Beaverhead Mountains with steep dips of 65 to 75 degrees both to the northwest and southeast. Total vertical offset was estimated to be minor, less than 100 $\mathrm{m}$, and no evidence of strike-slip offset was apparent. Zentner (1989) stated that these faults do not offset Quaternary deposits and are therefore older than about 2 Ma. Such eastnortheast trending normal faults appear to be widespread along the flanks of the ESRP and within $30 \mathrm{~km}$ of its boundary zone. Zentner (1989) proposed that they are related to the passage of the Yellowstone mantle plume and subsequent downwarping of the ESRP. Such downward lithospheric flexure is probably due to the combined effects of thermal contraction, loading by volcanic rocks, and underplating of the lithosphere by magmatic material (Zentner, 1989).

Several lines of evidence indicate that the northeast-striking normal faults along the northern boundary of the ESRP are not significant seismogenic features: (1) they are oriented perpendicular to Basin and Range normal faults and are therefore not products of the presentday regional stress field; (2) they do not displace deposits younger than about $2 \mathrm{Ma}$; and (3) individual displacements and fault lengths are small suggesting that if the faults were reactivated, their maximum earthquakes would be $M_{w} 5$ or less. Such events are insignificant in a deterministic sense, compared to potential large earthquakes on the Basin and Range faults that extend to the edge of the Plain, such as the Lemhi fault.

The major subsurface boundary fault that has been inferred from geophysical data has no surficial expression, and no other evidence has been revealed to suggest it is seismogenic. One conceptual explanation of the subsurface boundary fault is that it represents a segment of a buried caldera, associated with Tertiary silicic volcanism on the ESRP. Based on the above evidence, the ESRP-Basin and Range boundary, whether it is composed of one or several faults of varying extent, is not considered in this study to be a seismic source.

\subsubsection{Intermountain Seismic Belt}

The ISB, as originally defined by Smith and Sbar (1974) on the basis of seismicity, extends 'from northern Arizona through Utah, along the Idaho-Wyoming border east and southeast 
of the ESRP and terminates in northwestern Montana (Figure 3-1). The southern portion of the ISB coincides with the transition zones between the Basin and Range province to the west and the Colorado Plateau and Middle Rocky Mountains to the east. At Yellowstone, the ISB turns northwestward into the Northern Rocky Mountains. The deformational processes occurring along the ISB are principally in response to ongoing tectonic extension as observed throughout the Basin and Range province. East of the ESRP, the ISB coincides with a portion of the Idaho-Wyoming Thrustbelt (Figure 3-1), a portion of the Middle Rocky Mountains physiographic province that has been subjected to Cenozoic extensional stresses similar to the Basin and Range province. Within the Thrustbelt, extension appears to be presently accommodated along (1) older faults that formed in the late Cretaceous and early Tertiary as imbricate, westward-dipping thrust faults and (2) younger normal planar faults. The late Cenozoic normal faults are thought to be listric faults based on seismic reflection data (Royse et al., 1975).

Presently, the role of the thrust faults in contemporary tectonics is controversial. Seismological evidence to date does not support seismogenesis along low-angle listric faults within the ISB (Smith and Bruhn, 1984; Arabasz et al., 1987a; Doser and Smith, 1989) or the Basin and Range province (Doser and Smith, 1989). In contrast, West (1992) suggests that seismogensis along moderate to steeply-dipping normal planar faults (e.g., 1983 Borah Peak earthquake) represents a late stage in the evolution of faulting from reactivated thrust faults. Also that in some regions, particularly at the edge of regional extension (e.g., southwestern Wyoming), seismogenic low angle and listric structures such as decollements and thrust faults, which represent an early to intermediate stage of extension, may exist.

The Grand Valley and Snake River faults, both within the Thrustbelt and the ISB, are the closest significant Basin and Range faults located to the east of the INEL (Figure 3-1; the latter is not shown because it is not considered to be a Quaternary fault). Based on extensive geologic studies, the U.S. Bureau of Reclamation (USBR) has concluded that the potential for surface faulting and hence the occurrence of large magnitude $\left(M_{w} \geq 61 / 2\right)$ earthquakes on the Grand Valley and Snake River faults is very low (Piety et al., 1986). Their investigation shows that the Snake River fault is an antithetic fault to the Grand Valley fault and has a very low Quaternary displacement rate compared to the Grand Valley fault (Piety et al., 1986). The USBR does not consider either fault to be a significant seismic source. Both faults lie within the collapse shadow of the ESRP (Anders et al., 1989) (Figure 3-2). 
The north-striking, 70-km-long Teton fault has experienced significant Holocene surface displacements (Gilbert et al., 1983; Byrd and Smith, 1990) (Figure 3-1). The average slip rate in the past 15,000 to 22,000 years is estimated to be between 0.8 to $1.8 \mathrm{~mm} / \mathrm{yr}$, the highest of any fault in the region (Byrd and Smith, 1990). The most recent event on the Teton fault appears to have occurred about 4,840 to 7,000 years ago, resulting in $1.3 \mathrm{~m}$ of displacement (Byrd et al., 1994).

The Centennial fault is another fairly active Quaternary fault within the northern ISB that lies north of the ESRP, roughly $60 \mathrm{~km}$ northeast of the INEL. This $68-\mathrm{km}$-long range-bounding, normal fault is somewhat unusual in that it strikes east-west. It displaces Holocene deposits and, based on fault scarp patterns, may be subdivided into three segments (Stickney and Bartholomew, 1987).

\subsubsection{Northern Basin and Range Province}

Immediately adjacent to the northwestern boundary of the ESRP is the northern Basin and Range province. The development of the Snake River Plain in the late Cenozoic by the migrating hotspot has essentially divided the Basin and Range province. As a result, the northern Basin and Range has experienced slightly different post-Laramide tectonism than the southern Basin and Range (Stickney and Bartholomew, 1987). Stickney and Bartholomew (1987) define the southern margin of the northern Basin and Range province as the Centennial Tectonic Belt (Figure 3-1). The belt is the most tectonically and seismically active portion of the northern Basin and Range province.

Similar to the Basin and Range province south of the ESRP, the northern Basin and Range is characterized by north-northwest-trending mountain ranges bounded on one or more sides by steeply-dipping normal faults and surrounded by broad alluvial valleys filled with late Cenozoic sediments (Ruppel, 1982). In addition to these relatively simple basins in the northern Basin and Range, some investigators recognize two other modes of extensional basin development that are probably more prevalent south of the ESRP: (1) asymmetric tilted basins displaced chiefly by a listric or planar low-angle normal fault and (2) complex basins, typically with sub-basins, associated with both planar and listric normal faults that sole into low-angle detachments (Smith and Arabasz, 1991). 
The Basin and Range province immediately north of the INEL includes three major rangefront normal faults, the Lost River (source of the 1983 Borah Peak earthquake), Lemhi, and Beaverhead faults which extend for a distance of 140 to $150 \mathrm{~km}$ from the northwest edge of the ESRP (Figure 3-1). These faults bound the west side of eastward-tilted Paleozoic fault blocks (Ruppel, 1982; Scott et al., 1985) and the east side of half-graben structures (Anders et al., 1989). The footwall of the faults consists of allochthonous Paleozoic and Precambrian rocks that were transported east to northeastward on gently dipping thrust faults, from as early as the early Cretaceous and continued into the early Eocene (Ross, 1947; Skipp and Hait, 1977; Ruppel, 1978). Thrust faulting was followed by Eocene and Oligocene volcanism and the development of northeast-striking late Cenozoic normal faults (Baldwin, 1951). Finally, late Cenozoic extension resulted in northwest-striking normal faults and the development of the modern basins and ranges (Reynolds, 1979). Much of the present topography of the region probably results from Quaternary displacement of the three faults, which all exhibit prominent evidence of late Pleistocene to Holocene activity (Scott et al., 1985; Crone and Haller, 1991). Quaternary displacement on the faults is dominantly normal slip, although a lateral component is recognized locally by en echelon patterns of faults (Scott et al., 1985) and by the 1983 rupture process along the Lost River fault (Crone and Machette, 1984; Doser and Smith, 1985; Crone et al., 1987).

Based on focal mechanism data such as the 1983 Borah Peak earthquake, the contemporary crustal extension in the portion of the Basin and Range province north of the ESRP appears to be northeast-trending (Smith et al., 1985; Stickney and Bartholomew, 1987). In the Hebgen Lake region, the minimum principal stress trends more north-south (Zoback and Zoback, 1989; Smith and Braile, 1993). The dominance of Quaternary normal faulting along the northwest-trending ranges and historic seismicity in the northern Basin and Range province suggest that rates of crustal extension of $2 \mathrm{~mm} / \mathrm{yr}$ observed south of the ESRP may also be characteristic of the region to the north (Smith et al., 1991).

\subsection{HISTORICAL SEISMICITY}

The historical earthquake record for the Snake River Plain and adjacent Basin and Range province (region defined in Figure 3-1; see Appendix A) extends back only to 10 November 1884, the date of the first documented earthquake, an event of estimated Richter magnitude $\left(\mathrm{M}_{\mathrm{L}}\right) 6.3$ which may have occurred near Paris, Idaho. Through 1992, more than 5,800 
earthquakes of approximate $M 2.5$ (generally $M_{L}$ ) and greater have been documented as occurring within the region (Figure 3-1). Appendix A describes the historical earthquake catalogue compiled for this study.

The majority of the known earthquakes in the region have been recorded by: (1) the regional seismographic network in Utah, eastern Idaho, and western Wyoming, operated by the University of Utah beginning in the mid-1960s; (2) the Yellowstone network that was operated from 1970 to 1981 by the U.S. Geological Survey and from late-1983 to present by the University of Utah; and (3) the INEL network which was installed in the mid-1970s. Prior to this time, seismographic coverage of the ESRP and surrounding region was relatively poor as only the larger earthquakes $\left(M_{L}>5\right)$ were capable of being recorded by seismographs worldwide and by the intermountain stations in the Worldwide Network of Standardized Seismograph Stations beginning in the early 1960s. The detection of most earthquakes prior to the mid-1960s essentially relied on felt reports. The locations of such felt earthquakes were generally based on the locations of the reported maximum intensity. Such epicentral locations may be in error by as much as $100 \mathrm{~km}$ or more. Because the ESRP and surrounding region was sparsely populated prior to modern times, poor location accuracy and incompleteness (except for the largest earthquakes) probably characterize the historical record until the establishment of seismographic stations.

\subsubsection{Significant Earthquakes}

Two earthquakes dominate the historical seismicity of the region: the 18 August 1959 $M_{w} 7.3$ (surface wave magnitude $\left.M_{s} 7.5\right)$ Hebgen Lake and 28 October $1983 M_{w} 6.8\left(M_{s}\right.$ 7.3) Borah Peak events (Figure 3-1). The rupture process and fault geometry of the latter earthquake is discussed in detail in later sections.

The 1959 Hebgen Lake earthquake represents the largest earthquake to have occurred in the intermountain region in historic times. The event occurred in an area of complex geology at the juncture of the ISB and the Yellowstone volcano-tectonic system (Doser, 1985). The 1959 earthquake affected an area of $600,000 \mathrm{~km}^{2}$ and had a reported maximum Modified Mercalli (MM) intensity of X (Coffman et al., 1982). Most of the 28 deaths in the earthquake were due to the Madison River Canyon landslide. Minor to moderate damage, consisting principally of cracked chimneys and plaster and broken windows, occurred 
throughout southern Montana, northeastern Idaho and northwestern Wyoming (Coffman et $a l .$, 1982). The mainshock appears to have consisted of two normal faulting subevents that reactivated pre-existing Laramide thrust faults (Doser, 1985a). Rupture was initiated at a focal depth of approximately $15 \mathrm{~km}$ and propagated unilaterally northwestward. Two faults appeared to have ruptured during the earthquake: the Red Canyon fault which had up to 6.7 $\mathrm{m}$ of vertical displacement and a surface rupture $23 \mathrm{~km}$ long; and the Hebgen fault, which exhibited $6.1 \mathrm{~m}$ of maximum vertical displacement and had a rupture length of $14.5 \mathrm{~km}$ (Doser, 1985a).

The 1983 Borah Peak earthquake ruptured a total fault length of $36 \mathrm{~km}$, which included all of the nearly $21-\mathrm{km}$-long Thousand Springs segment of the Lost River fault (Crone et al., 1987). The maximum intensity of MM IX was assigned to the area adjacent to the surface rupture where landslides, rockfalls, and water fountains due to liquefaction were observed (Stover, 1985). The earthquake occurred in an area characterized by seismic quiescence for at least two decades prior to the event (Dewey, 1987; King et al., 1987). The earthquake resulted in two deaths and one injury (Stover, 1985). The earthquake shook eight western states with minor building damage extending as far as Salt Lake City and Boise (Reaveley, 1985). Damage in the epicentral area was concentrated in the town of Mackay and, to a lesser degree, in Challis, where moderate to major damage (MM VII) was sustained by generally unreinforced masonry buildings (Stover, 1985).

In addition to these two $M \geq 7$ earthquakes, several $M \geq 6$ events have occurred in the site region (Figure 3-1) änd are listed on Table 3-1. Of particular significance to assessing seismic hazards in the intermountain U.S. is the 1975 Pocatello Valley earthquake. This event occurred on a "blind" fault which was not evident in the surface geology (Arabasz et al., 1981). The fault was also a cross-structure in that its strike was transverse to the structural trend of the region. The occurrence of the 1975 earthquake has suggested that similar events could occur elsewhere within the ISB without prior knowledge because of the absence of any surficial expression of the seismogenic fault (Arabasz et al., 1981). This earthquake helped form the concept of a "random" earthquake presently used in state-of-theart seismic hazards evaluations of the ISB (Section 3.3.3).

In summary, the $M \geq 6$ historical earthquakes in the region reflect the moderate to high level of tectonism that exists within the ISB and surrounding Basin and Range province. As 
exemplified by the seismic quiescence preceding the 1983 Borah Peak earthquake, however, the historical earthquake record is often not an accurate indicator of the future occurrence of large magnitude earthquakes within the ISB, because the recurrence times of such events can be on the order of several to tens of thousands of years or more. The absence of historical seismicity within areas of the ISB should not be assumed as an indicator that individual areas are totally aseismic.

\subsubsection{Seismicity in the ESRP}

Based on the historical record, the ESRP has been, to a large extent, seismically quiescent (Figure 3-1). Most of the reported events in the ESRP are based solely on a few felt reports and thus their location uncertainties are estimated to be quite large. Many of these earthquakes may not have occurred within the ESRP, including the 1905 event (Section 3.2.2.1). Two events of possible note are the 28 April 1934 earthquake east of Twin Falls, which was felt with a maximum intensity of MM IV, and a body-wave magnitude $\left(\mathrm{m}_{\mathrm{r}}\right) 4.1$ event on 18 August 1964 between Pocatello and Idaho Falls (Figure 3-1). Both events were probably smaller than $M_{L} 4$.

In modern times, during which seismographic coverage has been much improved, the seismicity of the ESRP appears to be characterized by very infrequent and small magnitude microearthquakes (Pennington et al., 1974; King et al., 1987; Pelton et al., 1990; Jackson et al., 1993). In December 1971, the INEL initiated the installation of a regional seismographic network which has grown from three stations to its present configuration of 26 stations. During the nearly 20-year operation of the regional network, only nineteen microearthquakes, coda magnitude, $M_{c}<1.5$, have been located within the ESRP (King et al., 1987; Jackson et al., 1993). However, undetected microearthquakes may have occurred due to their small size and the relatively wide station-spacing of the regional network (50 to $70 \mathrm{~km}$ ).

Based on two portable microearthquake surveys in 1988 and 1989, several small microearthquakes were located at depths less than $8 \mathrm{~km}$ (Jackson et al., 1993). These relatively shallow depths, although few in number, are consistent with the hypothesis that elevated crustal temperratures in the ESRP confine the brittle portion of the crust, and hence seismogenesis, to the upper 5 to $10 \mathrm{~km}$. Additionally, assuming a heat flow of about 
$100 \mathrm{mWm}^{-2}$ (Section 3.1.1) and using steady-state static geotherms for typical continental lithosphere, a temperature of $350^{\circ} \mathrm{C}$ (approximate maximum value for earthquake occurrence in the crust) corresponds to a depth of about $8 \mathrm{~km}$ (Wong and Chapman, 1990). A composite focal mechanism exhibited normal faulting on northwest-striking planes in response to northeast-southwest extension, similar to the minimum principal stress direction observed to the north in the Basin and Range province (Jackson et al., 1993).

\subsubsection{1905 Earthquake}

The only large earthquake $(M \geq 6)$ that has reportedly occurred within the ESRP was the 1905 Shoshone earthquake (Figure 3-1). Until recently, however, the location and size of the event have been controversial given the absence of seismographs in the region and assessment of a few felt reports. Reports of the earthquake have been extensively reviewed and additional observers' reports, newspaper accounts, and seismograms were obtained (Oaks, 1992; Oaks et al., 1992). One of the earliest and most complete accounts of the event was documented in the Townley and Allen (1939) earthquake catalog for Idaho:

November 11, 2:29 pm local time (22:29 GMT):

"South central Idaho. A shock was felt from Ogden, Utah, to Baker, Oregon, and seems to have centered in the general vicinity of Shoshone, Idaho, although the report from that city describing a shock of intensity VII gives the time as 7:45 p.m. The shock at 2:29 pm registered at seismographic stations as far as Europe, and was reported in a Salt Lake City dispatch as felt at Hailey and Glenn's Ferry, Idaho, and at Salt Lake City, in addition to the places mentioned above.

As stated above, the earthquake as reported in Shoshone had a time of 7:45 pm local time (03:45 GMT November 12):

"RF (Rossi-Forel) VII+? Shoshone, Idaho. Walls of courthouse and school cracked; plaster broken from ceilings of nearly all buildings. Two shocks in rapid succession. This did not record instrumentally. There is a possibility 
that this description should be for the shock which occurred at 2:29 pm Dispatch from Salt Lake City, November 11, 1905."

Based on a comprehensive examination of diaries, journals, weather observer's reports, newspapers and other historical sources, data on damage and distribution of felt effects were used to assign MM intensities to 25 towns located in Idaho, Utah, Oregon, and Nevada, and to establish isoseismals for MM intensities IV and V (Oaks, 1992; Oaks et al., 1992). The area for the $M M V$ isoseismal suggests that the epicenter may be located near the Idaho-Utah border. The 1905 isoseismals were also compared to those for the 12 March $1934 \mathrm{M}_{\mathrm{L}} 6.6$ Hansel Valley, Utah, 30 August $1962 \mathrm{M}_{\mathrm{L}} 5.7$ Cache Valley, Utah, and 28 March 1975 $M_{L} 6.0$ Pocatello Valley, Idaho earthquakes. A value of $M_{L} 6.0 \pm 1.0$ was approximated for the 1905 event using the areal size of the $M M V$ isoseismal and comparing it to the other earthquakes (Oaks, 1992).

A search for North American seismograms of the 1905 earthquake only revealed amplitude measurements made on two Milne seismographs which were operating in Victoria and Toronto, Canada (British Association for the Advancement of Science, 1904-1905). (The original seismograms were lost.) Assuming an epicenter within an uncertainty of $50 \mathrm{~km}$ near the Idaho-Utah border, the calculated magnitude for the earthquake based on the reported maximum amplitudes at Victoria and Toronto is $\mathrm{M}_{s} 4.9 \pm 0.4$ (Oaks et al., 1992). These values are derived from Abe's (1988) formula for computing $M_{s}$ on a Milne seismograph incorporating individual station corrections. Based on this analysis, the 11 November 1905 earthquake appears to have occurred within the Basin and Range province south of the ESRP, with an estimated magnitude of $\mathrm{M}_{\mathrm{L}} 5-1 / 2 \pm 1 / 2$ (Oaks et al., 1992).

\subsection{POTENTIAL SEISMIC SOURCES}

The following section discusses the three categories of seismic sources considered most significant to the INEL based on past and current studies: (1) the late-Quaternary Basin and Range faults immediately north to northwest of the INEL including the Lemhi, Lost River and Beaverhead faults; (2) the ESRP volcanic zones; and (3) seismic sources within the ESRP with no geologic surficial expression which would be associated with a random "floating" earthquake. 


\subsubsection{Basin and Range Faults}

Three major late-Quaternary Basin and Range normal faults approach the northwest margin of the ESRP adjacent to the INEL and are considered significant seismic sources (Figure 33). The Lost River fault extends for 130 to $140 \mathrm{~km}$ along the western front of the Lost River Range from Arco to Challis, Idaho. Crone and Machette (1984) used the present topography of the Lost River Range and the estimated thickness of the sediments in Thousand Springs Valley to arrive at a minimum amount of late Cenozoic displacement of 2500 . $\mathrm{m}$ on the fault. The fault has been divided into six segments by Scott et al. (1985) with an average length of about $24 \mathrm{~km}$ and a range in lengths from 18 to $29 \mathrm{~km}$ (Crone and Haller, 1991). Their segmentation of the fault was primarily based on fault-scarp and rangefront morphology and on the structural relief of the range. We modified southern segment boundaries slightly (Figure 3-4) based on similar data from more recent studies (Janecke, 1993; Wu and Bruhn, 1994; Woodward-Clyde Federal Services, 1995). The Thousand Springs and part of the Warm spring segments, in the central part of the fault zone, ruptured during the 1983 Borah Peak earthquake (Crone et al., 1985, 1987; Scott et al., 1985). These segments and the adjacent segments to the south (Mackay) all had major surface faulting events during the middle to early Holocene.

The Lemhi fault, the closest and probably most significant fault to the majority of facility sites at the INEL, is $150 \mathrm{~km}$ long and bounds the western front of the Lemhi Range (Figures 3-3 and 3-4). Haller (1988) and Crone and Haller (1991) divided the fault into six segments based on several characteristics including behavioral discontinuities along the fault zone. Turko and Knuepfer (1991) presented a somewhat different segmentation model for the northern one-half of the fault. Paleoseismic studies by Woodward-Clyde Consultants (1992c) and Gorton (1995) indicate that the existing segmentation model for the southern Lemhi fault also requires revision. The segmentation model of the Lemhi fault proposed in this study is based on results from paleoseismic trenching (Woodward-Clyde Consultants et $a l .$, 1992c) and detailed mapping (Gorton, 1995) (Figure 3-3).

The 150-km-long Beaverhead fault has been divided into six segments based on fault-scarp morphology and geometric discontinuities along strike of the fault (Haller, 1988; Crone and Haller, 1991) (Figure 3-4). The average segment length is $25 \mathrm{~km}$ and segments range from 
20 to $42 \mathrm{~km}$ in length (Crone and Haller, 1991). Only one segment, the Leadore along the central part of the fault, has ruptured during the Holocene based on scarp morphology and mapping studies (Haller, 1988).

The central segments of the Lost River, Lemhi, and Beaverhead faults appear to have been more active (e.g., higher long-term slip rates) relative to their distal segments during the Quaternary (Scott et al., 1985; Crone and Haller, 1991; Pierce and Morgan, 1992), similar to other Basin and Range normal faults (e.g., the Teton and Wasatch faults). In addition to higher slip rates, the central segments of these faults tend to show evidence of more recent surface faulting, as indicated from fault-scarp morphology and paleoseismic trenching.

\subsubsection{ESRP Volcanic Zones}

Portions of four volcanic zones containing a concentration of volcanic features are located within the boundaries of the INEL: the Arco volcanic rift zone and Lava Ridge-Hells Half Acre volcanic rift zones, the axial volcanic zone, and the Howe-East Butte volcanic rift zone (Figure 3-5). Because the two volcanic rift zones are approximately colinear with the surface traces of the Lost River and Lemhi faults to the northwest, respectively. Active volcanic rift zones worldwide have exhibited seismicity; thus the seismogenic potential of the ESRP volcanic rift zones need to be addressed.

Although no volcanic seismicity has ever been observed in the vicinity of the Arco and Lava Ridge-Hells Half Acre volcanic rift zones or the axial volcanic zone (Jackson et al., 1993), the potential exists for seismicity associated with potential future volcanism and dike injection within these zones based on worldwide observations of active volcanic rift zones (Klein et al., 1987; Bjornsson et al., 1977). Dike-induced seismicity can occur in the different geometric relationships to dikes within volcanic rift zones. According to Rubin and Pollard (1988), these are (1) the zone of dike-induced extension above the dike top and (2) the process zone ahead of the dike as it propagates laterally. For (1), normal faults, grabens and fissures are produced, and the extent of graben subsidence indicates that faults extend to or slightly beyond the dike top. The volcanic rift zone events are generated at shallow depths along faults above the intruding dike. This constraint on depth and the discontinuous extent of the faults naturally limits the potential rupture areas and hence the maximum size of any dike-induced earthquake. 
Although it is difficult to distinguish between different types of volcanic earthquakes, it is generally accepted that seismic events produced by volcanic explosions and migration of magma are relatively small and typically have magnitudes of M 5 or less (Hoblitt et al., 1987). Empirical data from dike-induced seismicity in volcanic rift zones suggest the maximum earthquake that is associated with dike injection is about $\mathrm{M}_{\mathrm{w}} 4$ (Woodward-Clyde Consultants, 1992b; Jackson, 1994; Smith et al., 1996; Hackett et al., 1995). A few dikeinduced earthquakes had magnitudes up to $\mathrm{M}_{\mathrm{w}} 5.5$, although this appears to be a rare occurrence (Jackson, 1994).

The Arco volcanic rift zone is about $20 \mathrm{~km}$ long and is characterized by a discontinuous series of ground deformation and constructional volcanic features (Kuntz, 1977; Smith et al., 1989) (Figure 3-5). The ground deformation features consist of fissures and smalldisplacement faults that offset the basaltic lava flows at the surface. Fissures comprise about $80 \%$ of the total length all such surficial features. The fissures are open vertical cracks; displacement is characterized by dilational opening only, with no vertical or strike-slip motion (Smith et al., 1989). The constructional volcanic features within the Arco volcanic rift zone consist of aligned vents, elongate vents, eruptive fissures, and small shield volcanos.

Faults are expressed at the surface as both vertical scarps and monoclinal flexures. The maximum fault length observed within the Arco volcanic rift zone is $5.3 \mathrm{~km}$ and is associated with the "Railroad" monocline (Figure 3-5). The Box Canyon graben could be interpreted to be as long as $8 \mathrm{~km}$ although the longest individual feature within the graben is only $1.5 \mathrm{~km}$ long. Both of these features are probably the result of several dike intrusion episodes. Fault displacements, which are predominately southwest-side-down, range up to $10 \mathrm{~m}$ although generally are less than $5 \mathrm{~m}$. Fissures and faults occur in a branching en echelon overlapping pattern that is up to $6 \mathrm{~km}$ wide.

Although the Lava Ridge-Hells Half Acre volcanic rift zone is not as well preserved or as well studied as the Arco rift, its surficial features appear to be quite similar (Smith et al., 1989). The longest fault or fault-related features within this zone are two sets of fissures associated with the vent area of Hell's Half Acre lava field (Figure 3-5). These fissure sets have a mapped extent of $3.8 \mathrm{~km}$ but a large part of their length is covered by the lava field; they may be interpreted to be as long as $15 \mathrm{~km}$. 
Evidence for the Howe-East Butte volcanic rift zone is meager. It consists of four volcanic vents and two isolated fissures in a broad area south and southeast of Howe (Kuntz, 1978; Golder Associates, 1992), and the tenuous association of these with vents in the axial volcanic zone near East and Middle Buttes and with a positive northwest-trending aeromagnetic anomaly that may reflect the presence of subsurface basaltic dikes (Josten $e t$ al., 1993).

In contrast to the northwest-trending volcanic rift zones, the axial volcanic zone (Figure 3-5) trends northeast parallel to the axis of the ESRP and includes few surface deformation features. Nonetheless, it is a zone of enhanced volcanic activity, as shown by its constructional volcanic topography and its numerous volcanic vents. The vent density is comparable to that of the Arco volcanic rift zone. Geochronometry indicates that the axial volcanic zone has been an area of basaltic and rhyolitic volcanism for at least the past 1.2 million years, and it is the site of several Holocene lava fields. Because small-magnitude seismicity invariably accompanies dike injection and volcanism, even in the case where surface-deformation features are rapidly covered by associated lava flows, the axial volcanic zone is considered as a seismic source in this study.

\subsubsection{ESRP Random Earthquake}

Based on the historical earthquake record for the Intermountain seismic belt, Doser (1985b) stated that the possibility exists for "blind" earthquakes of $M 6$ to $63 / 4$ to occur with very little or no evidence for surface faulting. As previously stated, the 1975 Pocatello valley earthquake was one such example. A more recent example is the 3 February $1994 M_{w} 5.9$ Draney Peak, Idaho earthquake which occurred east of the INEL near the Idaho-Wyoming border. Other examples cited as having no reported surface rupture include the $1925 \mathrm{M}_{\mathrm{w}} 6.6$ Clarkston and $1944 \mathrm{M}_{\mathrm{L}} 6.1$ and 6.0 Seafoam earthquakes (Table 3-1). Thus, within the Basin and Range province and the Intermountain seismic belt, a random earthquake is often assigned a maximum magnitude of about $\mathrm{M}_{\mathrm{L}}$ 6.5. The random earthquake is defined as an event that can occur without an apparent association with a known or identified tectonic feature. For instance, the USBR in their seismotectonic evaluations of dams uses a random earthquake of $\mathrm{M}_{\mathrm{L}} 6 \frac{1 / 2}{2}$; this was the case for the Palisades Dam located about $100 \mathrm{~km}$ eastsoutheast of the INEL within the central ISB (Piety et al., 1986). Both Youngs et al. (1987) 
and Arabasz et al. (1987b) selected a random earthquake of $M_{s} 61 / 2$ in their probabilistic seismic hazard analysis for the Salt Lake Valley region.

In this study, we need to consider a random earthquake for the ESRP. There appear to be clear differences between the ESRP and the more tectonically- and seismically-active Basin and Range province, and hence, a smaller MCE is considered to be more appropriate for the ESRP.

Despite the observation that the historical seismicity of an area often does not reflect the level of potential seismic hazard, the historical quiescence of the ESRP in addition to its recent volcanic history (e.g., high heat flow) and the lack of mapped faults suggests that significant tectonic earthquake sources are absent and low differential stresses occur within the Plain (Jackson et al., 1993). Several tectonic/volcanic hypotheses, generally related to the thermal effects of the advancing Yellowstone hotspot and mechanisms for volcanism within the ESRP, may explain this seismic quiescence (Section 3.1.1). Consistent with regulatory precedent, however, a ESRP random earthquake with some specified maximum magnitude must still be considered for seismic hazard evaluations.

The maximum historical earthquake that has been previously associated with the ESRP is the 1905 estimated $M_{\mathrm{L}}$ 5-1/2 earthquake reported near Shoshone. As previously discussed, this earthquake likely occurred outside the ESRP.

Given the possibility of a relatively thin ESRP seismogenic crust, on the order of 5 to $10 \mathrm{~km}$, it is also likely that shallow earthquakes larger than $M_{w} 5.5$ to 6.0 would have been accompanied by surface rupture, and repeated events of this size would have produced recognizable geologic structures at the earth's surface. Thus, a maximum magnitude of $\mathrm{M}_{\mathrm{w}}$ $5.5 \pm 0.5$ appears reasonable for a random earthquake in the ESRP because of: (1) the apparent absence of significant geological structures within the ESRP (other than dikeinduced structures within volcanic rift zones); (2) evidence that the ESRP extends in a different manner than the surrounding Basin and Range province (i.e., dike-injection versus normal faulting; see Section 3.1.1); (3) evidence suggesting low differential stresses at 2 to $3 \mathrm{~km}$ depth; and (4) aside from the 1905 earthquake, which probably had its source outside the ESRP, the largest events to have reportedly. occurred within the Plain were probably smaller than $M_{L} 4$ in size. 
TABLE 3-1

SIGNIFICANT EARTHQUAKES IN THE SITE REGION

\begin{tabular}{|c|c|c|c|}
\hline Date & Magnitude & Location & $\begin{array}{l}\text { Notes or Additional } \\
\text { References }\end{array}$ \\
\hline 10 Nov 1884 & $\mathrm{M} \mathrm{61/4}$ & Bear Lake, Utah & \\
\hline 4 Nov 1897 & $\mathrm{M}_{\mathrm{L}} 6.4$ & Dillon, Montana & \\
\hline 11 Nov 1905 & $M_{L} 5^{1 / 2}$ & Shoshone, Idaho & $\begin{array}{l}\text { Location uncertain; } \\
\text { assigned magnitude as high } \\
\text { as M } 6.3 \text { (see Section } \\
\text { 3.2.2.1) }\end{array}$ \\
\hline 6 Oct 1909 & $M_{L} 6.3$ & Hansel Valley, Utah & \\
\hline \multirow[t]{2}{*}{28 Jun 1925} & $M_{w} 6.6$ & Clarkston, Montana & $\begin{array}{l}\text { Associated with Lewis and } \\
\text { Clark zone (Stickney and } \\
\text { Bartholomew, 1987); Doser } \\
\text { (1989a) }\end{array}$ \\
\hline & $M_{L} 6$ & Clarkston, Montana & Aftershock \\
\hline \multirow[t]{2}{*}{$12 \operatorname{Mar} 1934$} & $M_{L} 6.6$ & Hansel Valley, Utah & $\begin{array}{l}\text { Produced surface faulting } \\
\text { (Doser, 1989b) }\end{array}$ \\
\hline & $M_{L} 6.1$ & Hansel Valley, Utah & Aftershock 3 hours later \\
\hline 12 Jul 1944 & M 6.1 & Seafoam, Idaho & $\begin{array}{l}\text { Centennial Tectonic Belt; } \\
\text { Stickney and Bartholomew } \\
\text { (1987) and Dewey (1987) }\end{array}$ \\
\hline 14 Feb 1945 & M 6.0 & Seafoam, Idaho & Aftershock \\
\hline \multirow[t]{4}{*}{18 Aug 1959} & $M_{w} 7.3$ & Hebgen Lake, Montana & See Section 3.2.1 \\
\hline & M 6.5 & Hebgen Lake, Montana & $\begin{array}{l}756 \text { GMT Aftershock; } \\
\text { Doser and Smith (1989) }\end{array}$ \\
\hline & M 6.0 & Hebgen Lake, Montana & $\begin{array}{l}0841 \text { GMT Aftershock; } \\
\text { Doser and Smith (1989) }\end{array}$ \\
\hline & $M_{L} 6.7$ & Hebgen Lake, Montana & $\begin{array}{l}1526 \text { GMT Aftershock; } \\
\text { Doser (1985a) }\end{array}$ \\
\hline 19 Aug 1959 & $\dot{M}_{L} 6.1$ & Hebgen Lake, Montana & $\begin{array}{l}\text { 0404 GMT Aftershock; } \\
\text { Doser (1985a) }\end{array}$ \\
\hline $28 \operatorname{Mar} 1975$ & $M_{L} 6.0$ & Pocatello Valley, Idaho & See Section 3.2.1 \\
\hline 30 Jun 1975 & $M_{L} 6.4$ & Yellowstone, Montana & Pitt et al. (1979) \\
\hline 28 Oct 1983 & $M_{w} 6.8$ & Borah Peak, Idaho & See Section 3.2.1 \\
\hline
\end{tabular}





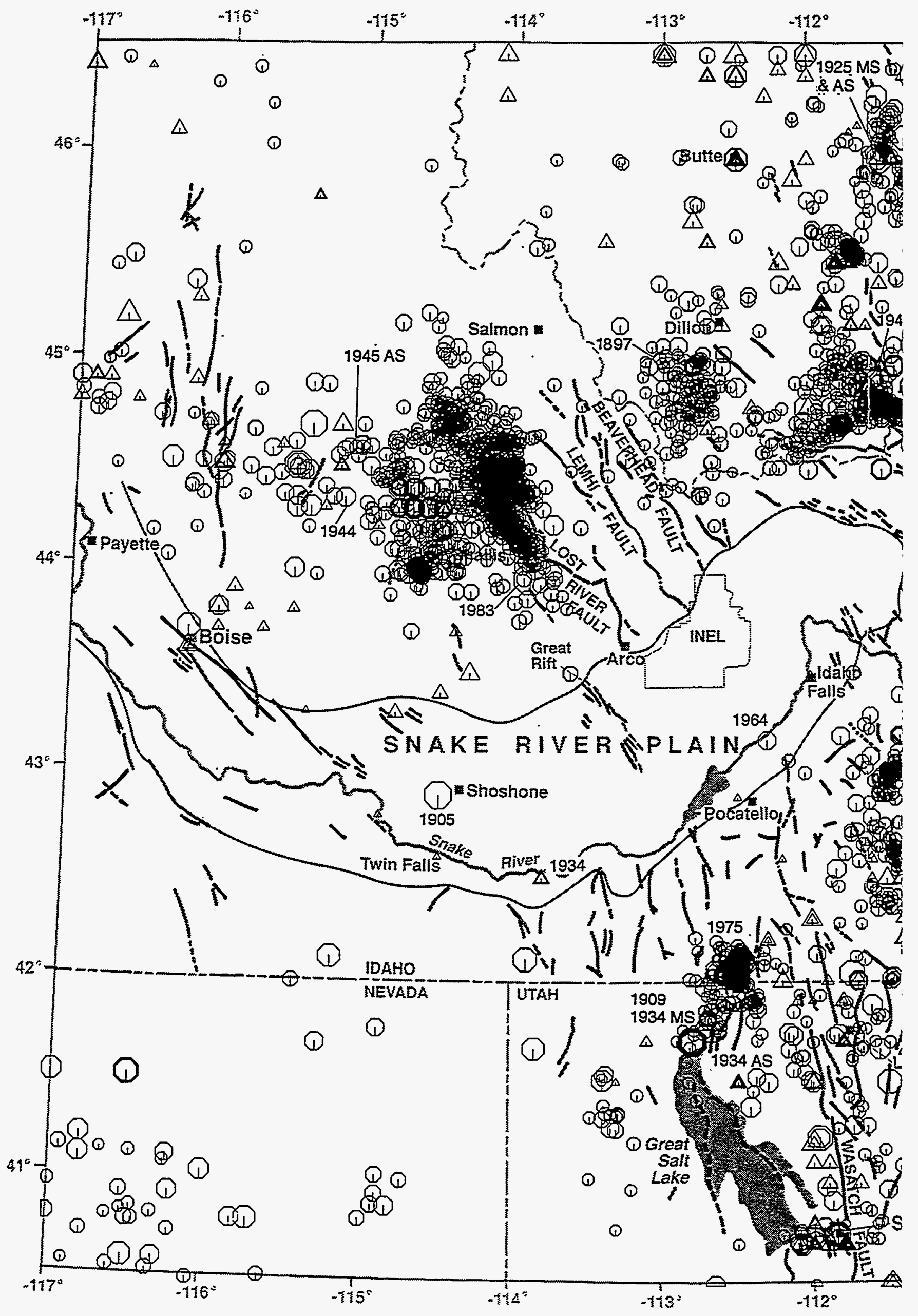



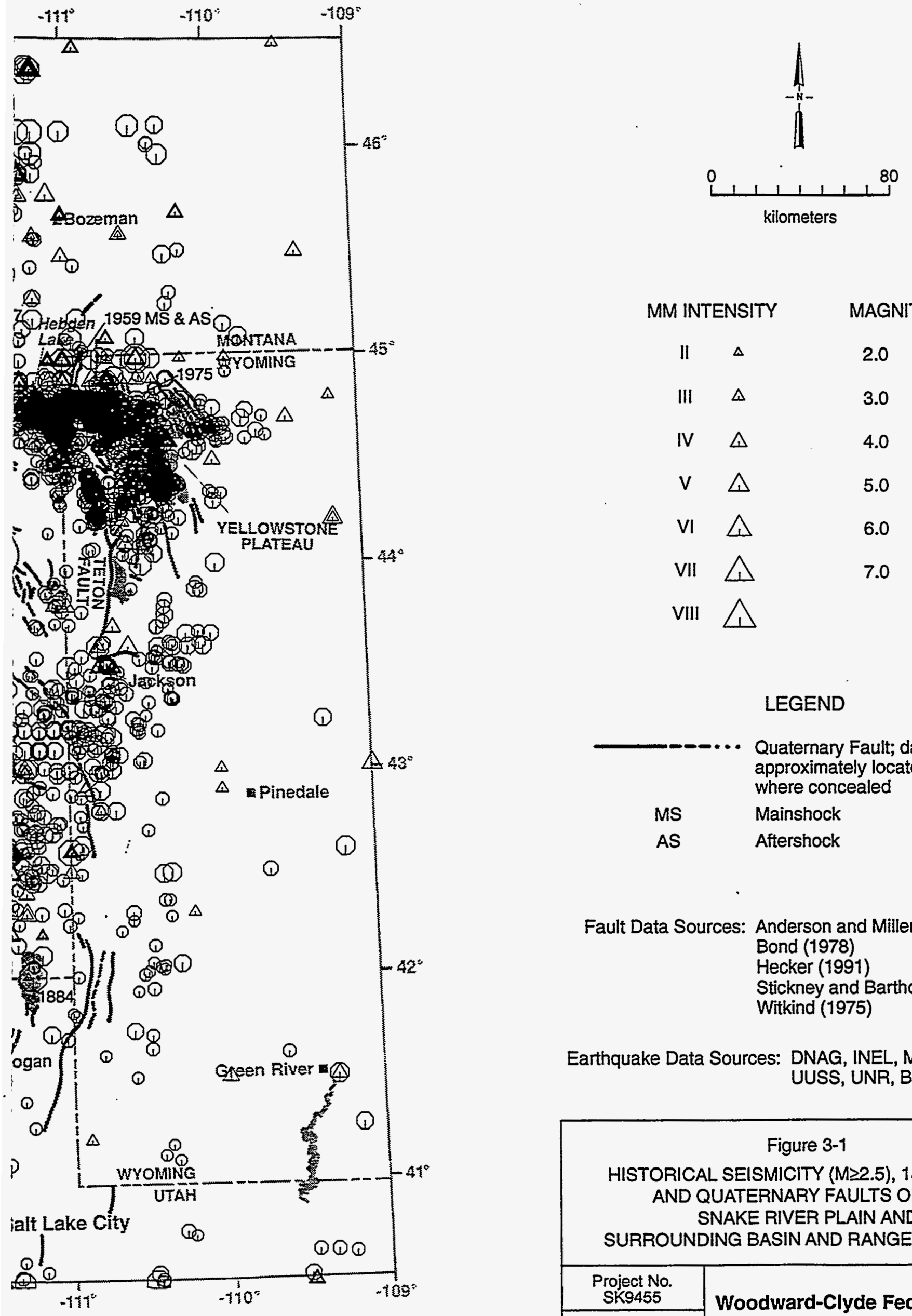

MM INTENSITY

$\begin{array}{llll}\text { II } & \Delta & 2.0 & 0 \\ \text { III } & \Delta & 3.0 & 0 \\ \text { IV } & \Delta & 4.0 & 0 \\ V & \Delta & 5.0 & \varnothing \\ \text { VI } & \Delta & 6.0 & \square \\ \text { VII } & \Delta & 7.0 & 0 \\ \text { VIII } & \Delta & & \end{array}$

\section{LEGEND}

Quaternary Fault; dashed where approximately located, dotted where concealed

MS

Mainshock

AS Aftershock

Fault Data Sources: Anderson and Miller (1979) Bond (1978)

Hecker (1991)

Stickney and Bartholomew (1983) Witkind (1975)

Earthquake Data Sources: DNAG, INEL, MBMG, USBR, UUSS, UNR, BSU, SRA, USGS

Figure 3-1

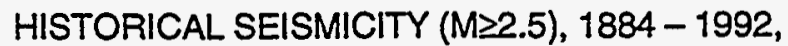
AND QUATERNARY FAULTS OF THE SNAKE RIVER PLAIN AND SURROUNDING BASIN AND RANGE PROVINCE

Project No. SK9455

INEL 


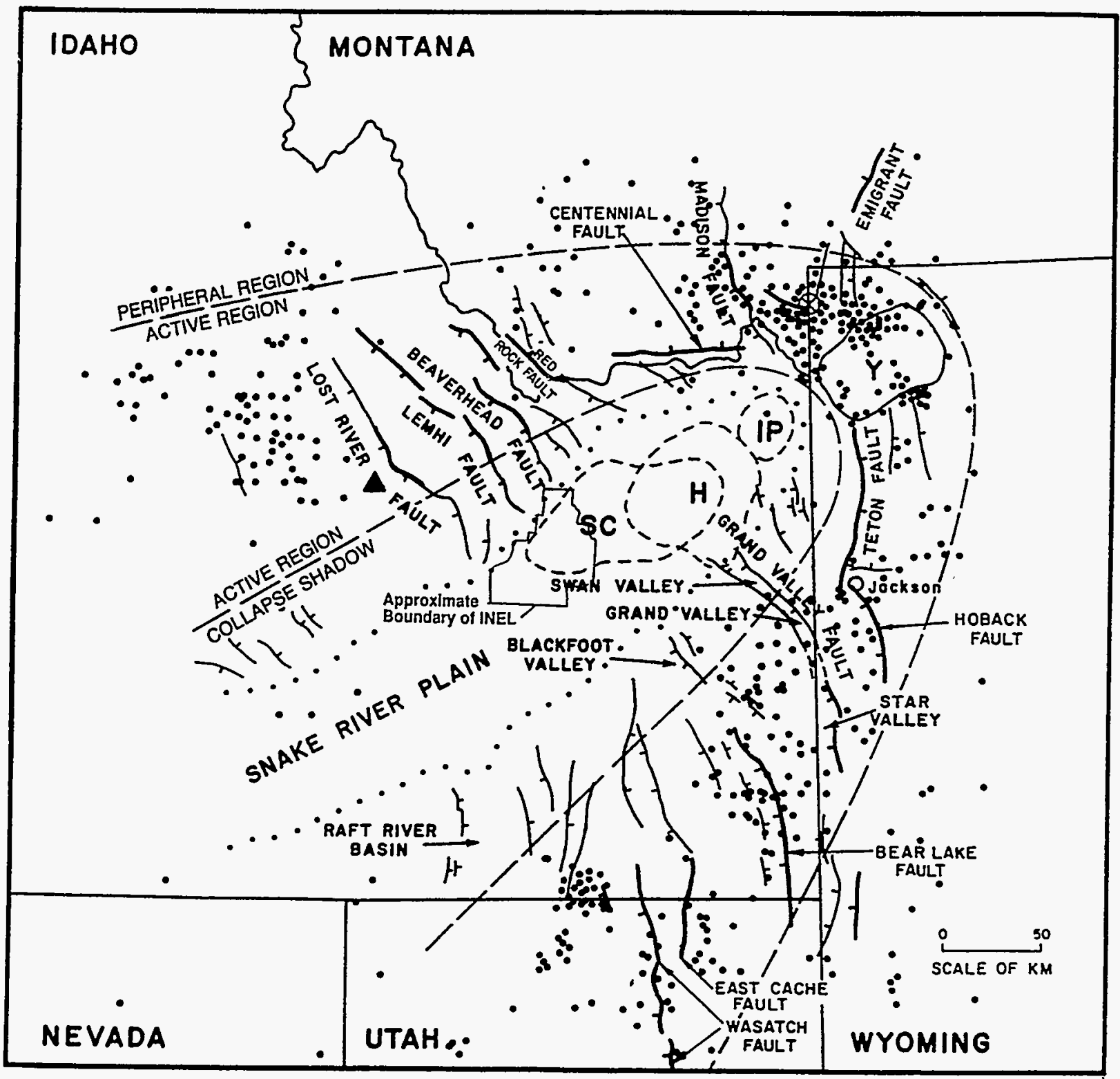

Note: Distribution of earthquakes greater than $M_{S}=3$ (large dots) since 1961 and of latest Quatemary (dark curves) and Cenozoic (light curves) normal faults. Dotted curve is the limit of the Snake River Plain and dashed curves represent boundaries between the "collapse shadow" or seismically quiescent region, the "active region" or region of historical seismicity and latest Quaternary faulting, and the "peripheral region" of less active Basin and Range extension. The dashed curves are referred to in the text as the interior and exterior parabolas. Dashed circles represent approximate locations of silicic eruptive calderas; "SC" 6.5 Ma, "H" 4.3 Ma, between "IP" and "Y" $2.0 \mathrm{Ma}$, and "Y" $1.2 \mathrm{Ma}$ and $0.6 \mathrm{Ma}$. Triangle represents the 1983 Borah Peak $M_{S}=7.3$ earthquake and large circle with a cross in it represents the 1959 Hebgen Lake $M_{S}=7.5$ earthquake.

(from Anders et al., 1989)

Project No. SK9455
INEL-Probabilistic Analyses

Woodward-Clyde Federal Services
COLLAPSE SHADOW, ACTIVE REGION AND PERIPHERAL REGION AROUND ESRP
Figure

3-2 


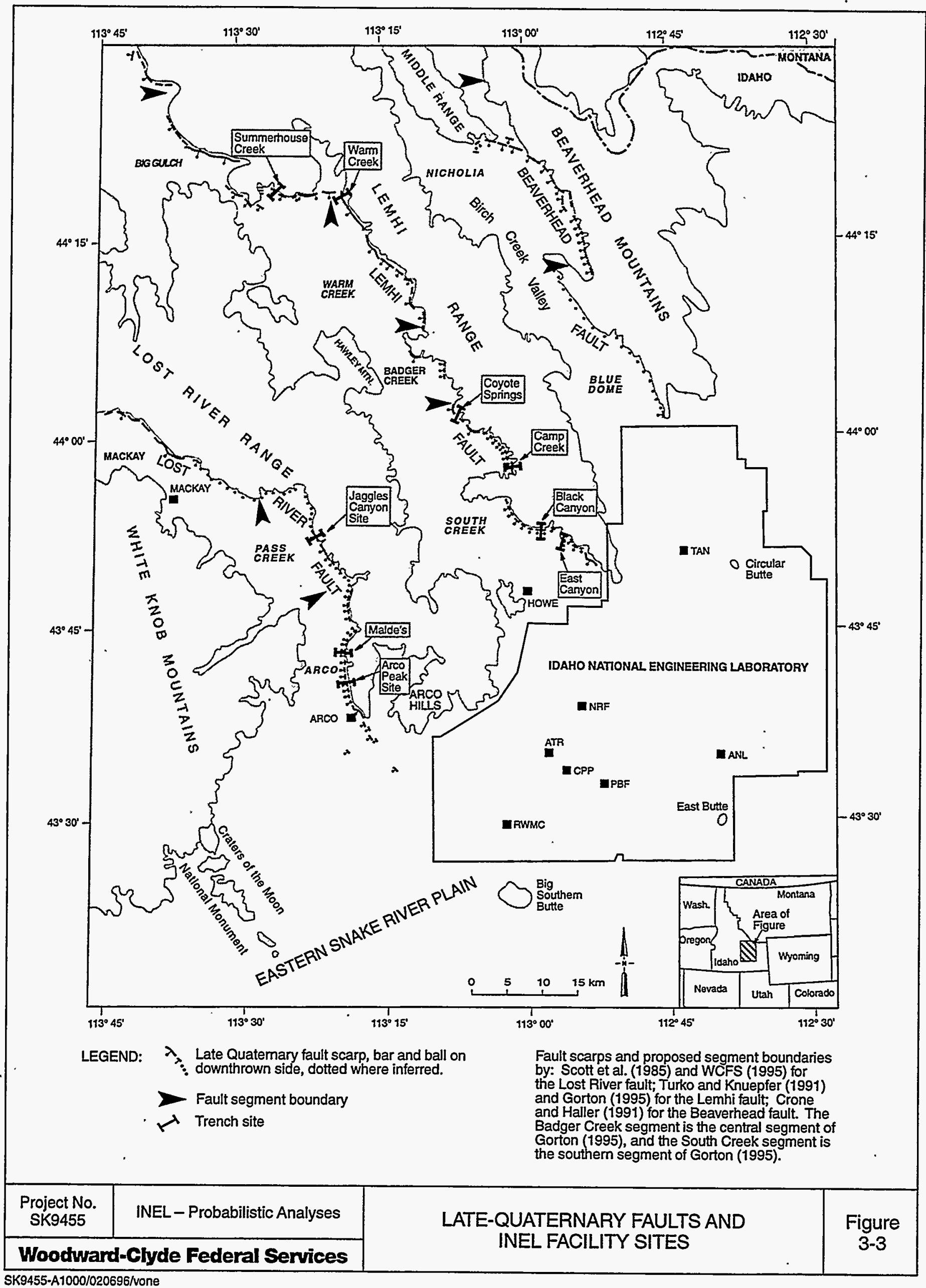





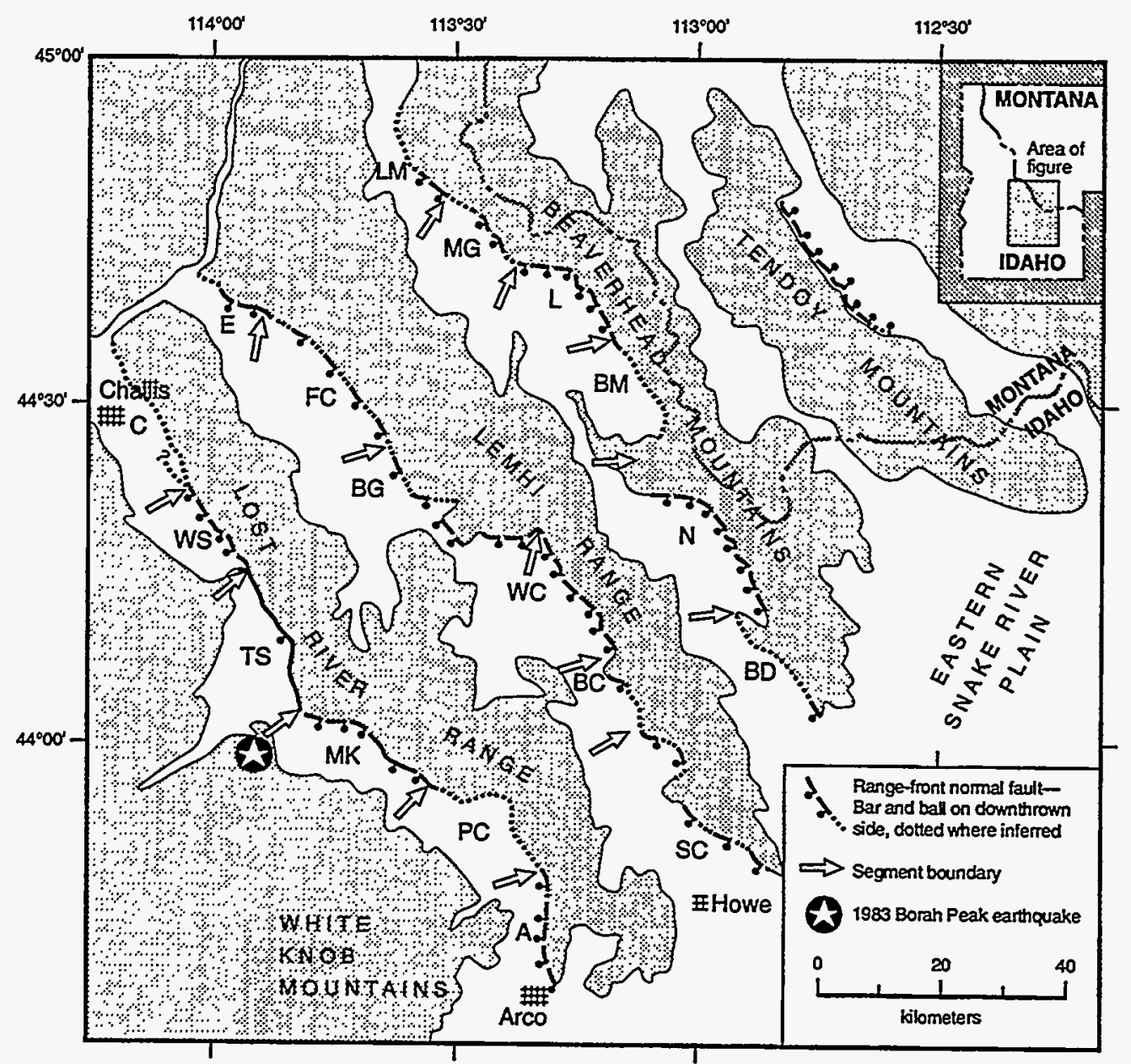

Note: The star shows the epicenter of the 1983 Borah Peak earthquake.

Arrows show boundaries between segments.

Segments are labeled as follows:

Lost River fault - A, Arco; PC, Pass Creek; MK, Mackay;

TS, Thousand Springs; WS, Warm Springs; C, Challis.

Segment boundaries from Scott et al., 1985 and Olig et al., 1995.

Lemhi fault - SC, South Creek; BC, Badger Creek; WC, Warm

Creek; BG, Big Gulch; FC, Falls Creek; E, Ellis.

Segment boundaries from Turko and Knuepfer, 1991 and Gorton, 1995.

Beaverhead fault - BD, Blue Dome; N, Nicholia; BM, Baldy Mountain;

L, Leadore; MG, Mollie Gulch; LM, Lemhi.

Segment boundaries from Crone and Haller, 1991.

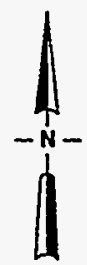

(Modified from Crone and Haller, 1991)

Project No. SK9455
INEL - Probabilistic Analyses

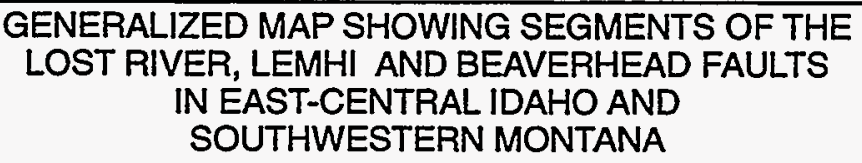

Figure 



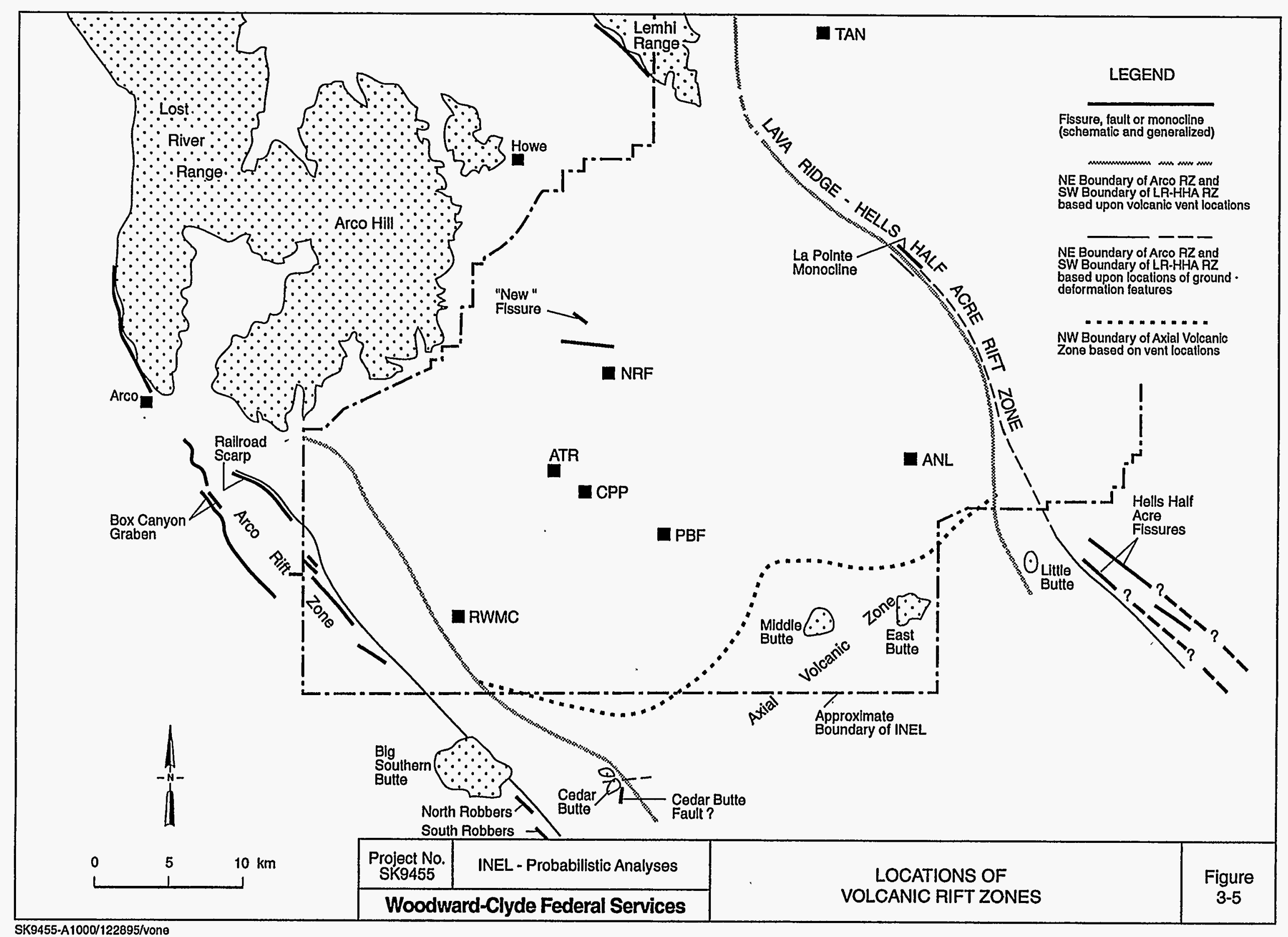


In this section, the characteristics of each potential earthquake source significant to the INEL are presented (Figure 4-1). The source characteristics are incorporated into the seismic hazard analysis through the use of logic trees. In Section 2.2, the basic elements of the logic trees were discussed. In this section, the parameter values and associated weights that are included in the logic trees are documented. The historical earthquake catalogue, which was used to characterize the regional seismic source zones, is described in Appendix A.

\subsection{FAULT SOURCES}

The Lost River, Lemhi, and Beaverhead faults are the closest Quaternary faults to the INEL (Figures 3-1 and 3-3) and because of their significance, they have been individually characterized for this analysis. Logic trees show the source characteristics used for each fault (Figures 4-2 to 4-4) and this section discusses the bases for these characteristics. The logic trees have been extensively revised from the draft report to address reviewers' comments and incorporate new data on the southern Lemhi and southern Lost River faults (Wu and Bruhn, 1994; Woodward-Clyde Federal Services, 1995; Gorton, 1995; Jackson et al., 1995).

\subsubsection{Source Parameters}

Many source parameters are similar for all three faults, including: dip, depth, recurrence models, weights on segmented versus unsegmented rupture behavior, and empirical relations used to estimate maximum magnitudes (Figures 4-2 to 4-4). These common parameters are discussed in this introductory section. We also note here that although the branches for fault dip and recurrence model appear before the segmentation model branches in Figures 4-2 through 4-4 to streamline the graphical presentation of the logic trees, these parameters actually vary independently for each fault segment in the analysis. 


\subsubsection{Fault Dip}

Fault dips are based on structural and seismological data, and range from $40^{\circ}$ to $60^{\circ}$ toward the southwest, with a preferred value of $50^{\circ}$. The dip of the 1983 Borah Peak earthquake rupture on the Thousand Springs segment of the Lost River fault was: (1) $45^{\circ} \pm 3^{\circ} \mathrm{SW}$ based on the mainshock focal mechanism (Doser and Smith, 1985); (2) $49^{\circ}$ based on inversion of geodetic data (Barrientos et al., 1985); and (3) about $45^{\circ}$ based on the dip of the aftershock zone (Richins et al., 1987). Main and subsidiary bedrock fault surfaces measured along the Pass Creek segment of the Lost River fault dominantly dip about $57^{\circ}$ (Wu and Bruhn, 1994). To the south along the Arco segment, subsidiary bedrock faults dominantly dip between $56^{\circ}$ and $65^{\circ}$; however, these smaller structures may not be reliable indicators of the dip of the main Arco fault segment (Wu and Bruhn, 1994). An average dip of $50^{\circ} \pm 5^{\circ}$ is suggested for the southern Lemhi fault from measurements of well-exposed fault surfaces in bedrock and by inferring the dip of the fault from the orientation of secondary extension fractures (Woodward-Clyde Consultants, 1992a). Doser and Smith (1989) have assessed the fault dip of about 50 Basin and Range earthquake ruptures from modeling body waves and conclude that the average dip of fault rupture is about $60^{\circ}$ with a range of $40^{\circ}$ to $90^{\circ}$. We chose our preferred value of $50^{\circ} \pm 10^{\circ}$ primarily based on all these fault-specific data, which compare reasonably well with regional observations.

\subsubsection{Seismogenic Depth}

Depth refers to seismogenic depth or the thickness of the seismogenic crust. Together with the fault dip, depth constrains the downdip width of the faults, which in turn affects both maximum magnitudes and distances calculated in the analysis. The mainshock of the Borah Peak earthquake was initiated at a depth of $16 \pm 4 \mathrm{~km}$ (Doser and Smith, 1989). Focal depths of aftershocks are better constrained and are confined to $16 \mathrm{~km}$ or less (Richins et al., 1987). The hypocenter for the Borah Peak event is interpreted to lie at or near the base of the seismogenic crust and the rupture propagated unilaterally to the northwest (Doser and Smith, 1985; Richins:et al., 1987). More regionally, compilations of the focal depths of moderate to large Basin and Range earthquakes indicate that these events occurred at or near the base of the seismogenic crust and that nearly all of the events had focal depths of $15 \mathrm{~km}$ or less (Doser and Smith, 1989). Based on these observations, we have assessed the depth to the bottom of the seismogenic crust to range from 14 to $18 \mathrm{~km}$ for all three faults, with 
a preferred depth of $16 \mathrm{~km}$ (Figures 4-2 through 4-4). The basis for the preferred $16 \mathrm{~km}$ is the depth of the Borah Peak earthquake. Of the alternative depths of 14 or $18 \mathrm{~km}$, slightly greater weight is given to the $14 \mathrm{~km}$ value because of the region-wide observations of Basin and Range earthquakes.

\subsubsection{Earthquake Recurrence Model}

Several elements of the logic trees relate to earthquake recurrence. In order to define the "shape" of the earthquake recurrence curves, a recurrence model must be selected that specifies the relative magnitude distribution throughout the range of magnitudes up to the maximum. Both modified exponential and characteristic recurrence models (Section 2.2) were used to model earthquake recurrence on fault-specific sources (Figures 4-2 to 4-4). The modified exponential model assumes that magnitudes are exponentially distributed throughout the range of magnitudes, and assumes a truncated density function at the maximum. The characteristic model is based on paleoseismic observations from some faults which suggest that surface-faulting earthquakes tend to repeatedly rupture with similar size displacements and lengths (Schwartz and Coppersmith, 1984), suggesting that these events were similar in magnitude. This model has a distinct nonlinear shape (Figure 2-2), implying that larger size events occur reiatively more frequently than intermediate size events as compared to the exponential model. We used characteristic distributions after Youngs and Coppersmith (1985). We weighted characteristic models greater based on: 1) displacement data from paleoseismic studies of the Lemhi and Lost River faults that suggest dominantly characteristic behavior for many fault segments (Schwartz and Crone, 1985; Schwartz, 1989; Baltzer, 1990; Woodward-Clyde Consultants, 1992c; Woodward-Clyde Federal Services, 1995); and 2) studies elsewhere in the Basin and Range province that indicate it is more appropriate than the exponential model for fault-specific sources (Schwartz and Coppersmith, 1984).

\subsubsection{Earthquake Recurrence}

Slip rates used in the analysis are discussed in the following fault-specific sections, but a general note about all slip-rate measurements is included here. Net slip rates averaged over the area of the fault rupture are used to characterize seismic moment rates and earthquake recurrence in the analysis. Types of displacement measurements along faults typically vary 
from scarp heights to surface offsets (e.g., Haller, 1988) to net vertical tectonic displacements (e.g., Woodward-Clyde Federal Services, 1995) to net slip measurements (e.g., Crone et al., 1987). These differences can be significant, particularly for shallow dipping faults offsetting sloping surfaces (Caskey, 1995). For example, a $50^{\circ}$ dipping normal fault offsetting a $5^{\circ}$ sloping alluvial-fan surface will result in a dip-slip measurement that is $41 \%$ greater than the surface offset measured. In addition, Crone et al. (1987) found roughly a $17 \%$ component of lateral slip for the Borah Peak earthquake by measuring offset piercing points at the surface. Therefore, whenever possible, we attempted to convert measurements to dip slip assuming a $50^{\circ}$ dipping fault and where a component of lateral slip is indicated, we used an amount comparable to that observed during the Borah Peak earthquake. Determining representative average offsets is more difficult because measurements are few and typically are located where geomorphic expression is best and offsets can be closer to the maximum than an average. We considered observations from the Borah Peak earthquake, where the ratio between the average and the maximum throw was about one third, tempered with more fault-specific information to determine average values where appropriate.

\subsubsection{Fault Segmentation}

Numerous studies have found paleoseismic, structural, geomorphic, seismological, and other geophysical evidence that the Lost River, Lemhi, and Beaverhead faults are segmented, with segments or portions of the fault tending to rupture independently of each other during large earthquakes (e.g., Scott et al., 1985; Crone et al., 1987; Crone and Haller, 1989; Schwartz, 1989; Knuepfer et al., 1990; Turko and Knuepfer, 1991; Gorton and Knuepfer, 1993; Hemphill-Haley et al., 1994; Knuepfer, 1994; Woodward-Clyde Federal Services, 1995). However, these studies also found evidence for complexities in surface-faulting patterns. These complexities include some historic and prehistoric ruptures that: 1) extend through apparent segment boundaries, rupturing a portion of an adjacent segment (e.g., Crone et al., 1987; Hemphill-Haley et al., 1994); 2) possibly ruptured two segments (e.g., WoodwardClyde Federal Services, 1995); and 3) only ruptured a portion of a segment (e.g., Woodward-Clyde Consultants, 1992c). Therefore, to account for these complexities and uncertainties, we consider both segmented (weighted 0.7) and unsegmented (0.3) rupture models for all three faults. We weigh the former more heavily because we believe that the evidence supports dominantly segmented behavior with boundaries that are relatively 
persistent. Specific segmentation models are discussed in the following sections for each fault.

In the unsegmented model, continuous sections of the fault are allowed to rupture unconstrained by segment boundaries. To determine rupture lengths for this model, we first calculated average segment lengths (from the segmented models) for each scenario on each fault (Table 4-1). We then considered ruptures with this length (22 to $29 \mathrm{~km})$, twice this length (44 to $58 \mathrm{~km}$ ), and triple this length ( 66 to $87 \mathrm{~km}$ ), weighted $0.185,0.63$, and 0.185 , respectively. The greater weight for longer, "multiple segment" ruptures in the unsegmented model is primarily to account for uncertainty and the possibility of longer ruptures not accounted for in the segmented model.

Observations of surface-faulting earthquakes in the Basin and Range province indicate that ruptures with lengths comparable to those that we use in the unsegmented model have occurred in the past. dePolo et al. (1991) analyzed characteristics for 11 historical surfacefaulting earthquakes in the Basin and Range, with rupture lengths ranging between 9 and 110 $\mathrm{km}$ and averaging about $50 \mathrm{~km}$. They found that nine ruptures involved more than one structural segment, typically with two and sometimes three or more structural segments. Structural segments are defined based primarily on kinematic and geometric considerations. Thus, structural segments may not necessarily correlate with rupture segments, which are defined based on paleoseismic behavior and directly reflect past rupture behavior of a fault. dePolo et al.'s analysis included the 36-km-long 1983 Borah Peak earthquake, which ruptured the Thousand Springs segment and part of the Warm Spring segment. However, it is noteworthy that other studies have concluded that the primary rupture was probably confined to the 22-km-long Thousand Springs segment (Crone et al., 1987; Doser and Smith, 1989).

In addition, the identification of structural segments in general needs to be considered with the following caveat. Ideally, fault segmentation models are based on more than just structural or geometric considerations, using extensive paleoseismic information to reconstruct temporal and spatial patterns of surface faulting (e.g., Machette et al., 1991). However, paleoseismic data sets that are detailed and comprehensive enough to reconstruct complete rupture histories are rare and more typically an incomplete paleoseismic database must be heavily supplemented by other data to develop segmentation models. 


\subsubsection{Maximum Magnitude}

To estimate maximum magnitudes for each fault, we used the empirical relations of Wells and Coppersmith (1994) that relate $M_{w}$ to surface rupture length or rupture area for all fault types. These relationships are considered to be the best relationships available to estimate maximum magnitude. When data on displacements per event were available, we also used their appropriate relation for estimating $M_{w}$ from displacements. Rupture lengths used in the analysis are shown in Table 1 . These lengths are determined by segmentation models and scenarios developed to characterize uncertainty in the southern termination of all three faults. Models and scenarios are discussed in the following sections for each fault. Areas were computed from lengths and down-dip widths. Displacements are also discussed in the following fault-specific sections.

The statistical variability of the data about the empirical relationships between rupture dimensions and magnitude was not incorporated into the uncertainty assessment of maximum magnitude. As discussed in Section 2.2, the maximum or "characteristic" event on a fault segment is considered to have a random magnitude in the range of $\pm^{1 / 4}$ magnitude units about the expected magnitude for this event. This variability is taken to represent the random nature of earthquake ruptures and is representative of the scatter of individual data points in the empirical relationships. The logic trees are used to model in uncertainty in specifying the expected maximum event magnitude. Therefore, one should consider the uncertainty in the mean relationship between rupture dimensions and earthquake magnitude. This uncertainty is given by the standard deviation of the individual data points divided by the square root of the sample size. The standard errors reported by Wells and Coppersmith (1994) are on the order of 0.25 magnitude units and the sample sizes are typically greater that 100 events. Thus, the uncertainty in the expected maximum magnitudes from a given empirical model are on the order of 0.02 magnitude units or less and can be neglected. Figures 4-5 to 4-7 show the resulting maximum magnitude distributions calculated for each fault using the values and weights shown on the logic trees. Distributions for each fault are generally similar with the Pass Creek and Big Gulch segments generally showing the largest maximum magnitudes due to greater displacements and/or longer lengths. 


\subsubsection{Lost River Fault}

\subsubsection{Segmentation}

Scott et al. (1985) subdivided the Lost River fault into six rupture segments based on late Quaternary fault activity. From south to north, these segments were named: 1) Arco; 2) Pass Creek; 3) Mackay; 4) Thousand Springs; 5) Warm Spring; and 6) northernmost. Crone et al. (1987) proposed the name Challis segment for the northernmost segment and we retain that name here. Based on patterns. of late Quaternary scarps and kinematic considerations, Janecke (1993) and Wu and Bruhn (1994) proposed slight changes for southern segment boundaries which are discussed in more detail by Woodward-Clyde Federal Services (1995). We used the segmentation model of Scott et al. (1985) with these slight modifications for the Pass Creek and Arco Segments (Figures 3-3 and 3-4).

\subsubsection{Southern Termination}

The location of the southern rupture boundary of the Arco segment of the Lost River fault is not well-defined (Woodward-Clyde Federal Services, 1994; Woodward-Clyde Federal Services, 1995). Three rupture scenarios were selected to represent reasonable possibilities for the southern rupture termination of the Arco segment (Figure 4-8). In scenario 1, the rupture terminates less than $1 \mathrm{~km}$ southeast of Arco, coincident with the southern end of the Lost River Range and late Pleistocene range-front scarps (Scott, 1982; Pierce, 1985; Kuntz et al., 1994). We weighted this scenario highest $(0.5)$ because the nearly continuous late Pleistocene fault scarps at the base of the Lost River Range indicate that ruptures have most recently and persistently extended at least this far south to create the topographic and structural relief of the range, although fault scarps have been modified by paleochannels of the Big Lost River at the south end of the range (Woodward-Clyde Federal Services, 1994; Wu and Bruhn, 1994).

- In scenario 2, the rupture terminates less than $2 \mathrm{~km}$ west-southwest of Butte City (Figure 4-8), at the southern end of scarps on alluvium (Kuntz et al., 1994). The age of these scarps and their relation to the most recent activity on the range-front fault scarps near Arco is not well-understood (Woodward-Clyde Federal Services, 1994; Woodward-Clyde Federal 
Services, 1995). However, these scarps near Butte City could represent the southern extent of the Arco segment rupture based on multiple lines of evidence: (1) they are along strike with the range-front scarps of the Arco segment; (2) a normal fault in this location could account for the structural and topographic high in the Arco Hills to the northeast; and (3) interpretation of seismic reflection lines across these scarps indicates that near-surface strata (roughly between $1 / 4$ and $1 \mathrm{~km}$ deep) are displaced as much as $85 \mathrm{~m}$ (Jackson et al., 1995). Although there is strong evidence for fault displacement as far south as Scenario 2, the age of the offset strata and whether these offsets correlate with faulting events on the Arco segment remains unknown. Considering these uncertainties and because these scarps are not directly associated with a range front, we weight this scenario 0.4 , slightly less than Scenario 1.

The rupture for Scenario 3 terminates $12 \mathrm{~km}$ southeast of Arco (Figure 4-8), at the southern end of monoclinal scarps and graben within the northern portion of the Arco volcanic rift zone (Smith et al., 1989; Kuntz et al., 1994). Evidence as to whether these structures that show such small total displacements (typically less than $10 \mathrm{~m}$; Wu and Bruhn, 1994) are seismogenically part of the Arco segment is equivocal. They could have formed as a result of dike injection (Smith et al., 1989). However, they are also along strike with range-front fault scarps of the Arco segment and their sense of net surface offset (as measured across the entire zone of deformation) is down to the southwest, consistent with displacement on the Lost River fault (Wu and Brubn, 1994). Boundary element modeling of observed displacements and geometry of the monoclinal flexures yields several non-unique possible mechanisms for their formation, including igneous dike injection, displacement along buried faults, and a mixed-mode of dike injection and faulting (Wu and Bruhn, 1994). Smith et al. (1989) noted that slip rates comparable to those for the Arco segment would have resulted in 50-150 m of throw across these scarps in the volcanic rift zone, which is an order of magnitude larger than what is actually observed. Seismic reflection data shows no evidence for net displacements of near-surface strata (roughly between $1 / 4$ and $1 \mathrm{~km}$ deep) in this part of the volcanic rift zone (Jackson et al., 1995). Thus, rupture of the Arco segment does not appear to have resulted in significant displacement ( $>30 \mathrm{~m}$ based on estimates of minimum resolution from the seismic data) this far south during the late Quaternary. Therefore, we only weighted this scenario 0.1 . 


\subsubsection{Displacements Per Event}

Displacements per event used for the Lost River fault (Figure 4-2) were based on data from historic ruptures and trench investigations. Crone et al. (1987) measured an average throw along the surface rupture for the 1983 Borah Peak earthquake of $0.8 \mathrm{~m}$ and a maximum throw of $2.7 \mathrm{~m}$. Stratigraphic and geomorphic evidence along the Thousand Springs segment indicates that net vertical displacements for the penultimate event were similar to those for the Borah Peak event (Vincent, 1985; Salyards, 1985; Schwartz and Crone, 1985; Crone et al., 1987). Therefore, we weighted these values the greatest for this segment and adopted a range to reflect uncertainties in future ruptures on this segment (Figure 4-2). Data for the Pass Creek and Arco segments are limited to trench investigations that suggest net vertical displacements that average 1.2 to $1.5 \mathrm{~m}$ per event on the Arco segment and 2.0 to $2.6 \mathrm{~m}$ per event on the Pass Creek segment (Woodward-Clyde Federal Services, 1995). We use these as our preferred average displacements and adopted a range to reflect uncertainty in how well these observations from individual sites might represent slip distributions over the entire segment. Estimated net vertical displacements per event range from less than $1 \mathrm{~m}$ to just over $4 \mathrm{~m}$ on the Pass Creek segment and from about 0.5 to $2.5 \mathrm{~m}$ on the Arco segment (Woodward-Clyde Federal Services, 1995). In using this data to determine maximum displacements per event, we consider uncertainties in the trench data, the expected variability of displacements along strike, and the fact that trenches were centrally located along each segment where displacements are often largest for surface ruptures (e.g., Borah Peak earthquake; Crone and Machette, 1984).

\subsubsection{Earthquake Recurrence}

We use both slip rates and recurrence intervals to characterize rates of earthquake recurrence on the Pass Creek and Arco segments (Figure 4-2). We weight the latter slightly more because recurrence interval data is adequate, and the slip rate data has larger uncertainties due to larger uncertainties in determining average displacements.

Deep trenches excavated across 100,000 - to 200,000-year-old faulted alluvial-fan deposits along the southern segments provide an unusually long record of multiple surface-faulting events (Malde, 1971; 1985; Pierce, 1985, 1988) that are variably spaced in time, with 
recurrence intervals varying by an order of magnitude or more (Woodward-Clyde Federal Services, 1995). As temporal patterns do not clearly indicate whether the segments are presently within or between clusters of surface-faulting activity, we consider three behavioral possibilities: 1) segments are entering into or are still within a period of accelerated activity (intra-cluster); 2) segments are in the initial stages of a quiescent stage in the seismic cycle (intercluster); and 3) activity can be represented by an average recurrence as events are not necessarily always clustered in time (average) (Figure 4-2).

Distributions of recurrence intervals and slip rates for the Arco and Pass Creek segments (Figure 4-2) are based on paleoseismic studies (Malde, 1971, 1987; Pierce, 1985, 1988; Woodward-Clyde Federal Services, 1995). Evidence on the Arco segment for at least seven surface-faulting events since $160 \mathrm{ka}$ suggests that: 1) average recurrence values range between 11,000 and 25,000 years; 2) recurrence intervals have been 1,000 years or shorter within clusters; and 3) recurrence intervals have been roughly 30,000 and 40,000 years or more between clusters (Woodward-Clyde Federal Services, 1995). Evidence on the Pass Creek segment suggests that at least six, and possibly eight, events have occurred since 140 to $220 \mathrm{ka}$, with a cluster of three events having occurred between 13 and $21 \mathrm{ka}$ (WoodwardClyde Federal Services, 1995). Preferred age estimates for events within this cluster would suggest that average recurrence intervals are on the order of 500 years. Recurrence intervals between older events are poorly constrained, but buried soils suggest intervals between clusters are as long or longer than those on the Arco segment. Average recurrence estimates for the past 140 to $220 \mathrm{ka}$ range from 18,000 to 37,000 years. Depending on the time period of interest, Woodward-Clyde Federal Services (1995) estimate vertical slip rates of: 1) 0.05 to $1.1 \mathrm{~mm} / \mathrm{yr}$ for the Arco segment; and 2) about 0.05 to over $1 \mathrm{~mm} / \mathrm{yr}$ for the Pass Creek segment.

Only slip rates were used to characterize earthquake recurrence on the central and northern segments of the Lost River fault because the paleoseismic record is much shorter, although the timing of recent events is better constrained (e.g., Schwartz, 1989). In addition, these segments are farther from the INEL than the southern segments and are not as significant to the hazard.

From offsets of 3.5 to $4.5 \mathrm{~m}$ on the Willow Creek alluvial-fan surface, estimated to be roughly 15,000 years old, Scott et al. (1985) determined a "mean" slip rate of $0.3 \mathrm{~mm} / \mathrm{yr}$ 
for the Thousand Springs segment. Vincent (1985) estimated "an average relative neotectonic uplift rate" for this same location of $0.3 \mathrm{~mm} / \mathrm{yr}$. In their scarp morphology analysis, Hanks and Schwartz (1987) calculated "relative uplift" rates of 0.18 to $0.25 \mathrm{~mm} / \mathrm{yr}$ based on vertical offsets of 1.5 to $2.0 \mathrm{~m}$ every 8,000 years. Using Borah Peak earthquake data, we note here that if $0.8 \mathrm{~m}$ of average throw occurs on a $50^{\circ}$ dipping plane with a $17 \%$ component of lateral slip (Crone et al., 1987) every 6,000 to 8,000 years (Hanks and Schwartz, 1987), this yields net slip rates on the order of 0.15 to $0.2 \mathrm{~mm} / \mathrm{yr}$. Based on all this information, we chose a preferred slip rate of $0.25 \mathrm{~mm} / \mathrm{yr}$ for the Mackay, Thousand Springs and Warm Springs segments. We use similar slip rates for the Warm Spring and Mackay segments even though they show less topographic relief than the Thousand Springs segment, because all three segments show similar behavior since the latest Pleistocene, with two events having occurred since about $15 \mathrm{ka}$ (Schwartz, 1989). We considered slip rates as high as $1.0 \mathrm{~mm} / \mathrm{yr}$ to address the uncertainty as to whether future events may be temporally clustered on these segments, as observed along the Arco and Pass Creek segments.

Little is known about the activity on the Challis segment. The absence of fault scarps on older Quaternary alluvium and the relatively poor geomorphic expression, suggest that this segment had the lowest rates of late Quaternary activity for the entire Lost River fault (Crone and Haller, 1991; Scott et al., 1985). Due to the lack of more detailed data, we chose a preferred slip rate of $0.05 \mathrm{~mm} / \mathrm{yr}$ for the Challis segment, similar to lower long-term rates for the Arco and Pass Creek segments.

\subsubsection{Lemhi Fault}

\subsubsection{Segmentation}

Several previous studies concluded that the Lemhi fault can be divided into six rupture segments based primarily on variations of the morphology of fault scarps formed in alluvium, apparent discontinuities in the trace of the fault along its extent, variations in range-front morphology, and structural relief (Turko and Knuepfer, 1991; Crone and Haller, 1991; Knuepfer et al., 1990; Haller, 1988; Turko, 1988). However, preferred interpretations for locations of many segment boundaries have changed through time as a result of more data from more focused and detailed investigations. We followed the 
segmentation model of Turko and Knuepfer (1991) for the northern part of the fault (from the Warm Creek segment north) and modified Turko and Knuepfer's (1991) model to incorporate results from more recent mapping, scarp profiling, and trenching studies along the southern part of the fault (Woodward-Clyde Consultants, 1992c; Hemphill-Haley et al., 1994; Gorton, 1995). From south to north, the segments are: 1) South Creek; 2) Badger Creek; 3) Warm Creek; 4) Big Gulch; 5) Falls Creek; and 6) Ellis (Figures 3-3 and 3-4).

\subsubsection{Southern Termination}

Similar to the Lost River fault, there is uncertainty in the southern extent of expected rupture for the Lemhi fault (Woodward-Clyde Consultants, 1992a). Two rupture scenarios after Woodward-Clyde Consultants (1992a) were selected to represent reasonable possibilities for the southern termination of the Lemhi fault (Figure 4-8). Scenario 1 terminates at a crossfault junction about $1 \frac{112}{2} \mathrm{~km}$ north of Highway 33 , and is the same as Scenario A in Woodward-Clyde Consultants (1992a). Range-bounding, late Quaternary fault scarps die out a couple of kilometers north of Scenario 1, where they are buried by very young eolian deposits (Gorton, 1995). Thus, it is not clear how far south late Quaternary ruptures actually extended in the past but it is noteworthy that displacement has not kept pace with - latest Quaternary deposition south of Scenario 1. Based on this and the presence of the cross-fault in the footwall coincident with a rapid decrease in the structural and vertical topographic relief in the range, we considered Scenario 1 with a weight of 0.3 . Scenario 2 terminates very close to the southern end of Scenario $C$ in Woodward-Clyde Consultants (1992a). The basis for this scenario is very similar to that outlined in Woodward-Clyde Consultants (1992a) with additional information from seismic lines in this area that indicate that near-surface strata are offset in the vicinity of Highway 33, but strata do not appear to be offset $2 \mathrm{~km}$ south of the highway (Jackson et al., 1995). Scenario 2 lies between these two seismic lines about $1 / 2 \mathrm{~km}$ south of Highway 33, south of the southern end of range and coincident with the northern edge of a northeast-trending gravity trough in the Lost River Sinks area (Woodward-Clyde Consultants, 1992a). Because of the new seismic data, we weighted Scenario $2(0.70)$ more than Scenario $1(0.30)$. 


\subsubsection{Displacements Per Event}

Our preferred displacements per event for the Lemhi fault were based on available data from trenching, scarp-profiling, and mapping studies (Malde, 1987; Baltzer, 1990; Turko and Knuepfer, 1991; Woodward-Clyde Consultants, 1992c). Similar to our approach for developing displacement distributions for the Lost River fault, we consider along-strike variations and the degree to which we believe measurements reflect actual average or maximum displacements. Woodward-Clyde Consultants (1992c) estimated vertical displacements per event of generally between 1 and $3 \mathrm{~m}$, with an average of $2.0 \mathrm{~m}$ for 11 measurements on the South Creek segment. However, it is noteworthy that many events did not necessarily rupture along the entire length of the segment. Displacements per event along the Warm Creek segment show a similar range and average, even though the Warm Creek segment is shorter. Surface offsets across scarps thought to be formed in one faulting event range between 1.1 and $2.7 \mathrm{~m}$, and average $1.9 \mathrm{~m}$ for the Warm Creek segment (Turko and Knuepfer, 1991). Trench exposures of this segment show vertical stratigraphic separations of $1.7 \mathrm{~m}$ and 0.9 to $1.3 \mathrm{~m}$ for the most-recent event, and $1.7 \mathrm{~m}$ for the penultimate event (Baltzer, 1990). In contrast, surface offsets across single-event scarps along the relatively long Big Gulch segment range between 1.5 and $5.0 \mathrm{~m}$, and average $2.8 \mathrm{~m}$ (Turko and Knuepfer, 1991). Trench exposures along this segment also support larger displacements per event, as large as 3.5 to $.4 \mathrm{~m}$ for the most recent event (Knuepfer et al., 1990). Finally, surface offsets measured along the Falls Creek segment range from nearly 1 to $2.1 \mathrm{~m}$, and average $1.5 \mathrm{~m}$ (Turko and Knuepfer, 1991). The net vertical tectonic displacement measured for the most recent event at the Falls Creek trench site is less than $1 \mathrm{~m}$ (Baltzer, 1990). Haller (1988) measured stratigraphic throw of 1.1 to $1.2 \mathrm{~m}$, presumably for the most recent event, on faulted buried soil horizons exposed on the south side of Patterson Creek (note she refers to this part of the Lemhi fault as the Patterson segment).

\subsubsection{Earthquake Recurrence}

The Lemhi fault has been the subject of several recent geologic studies of late Quaternary behavior, including the assessment of recurrence intervals along various segments (e.g., Malde, 1971, 1987; Baltzer, 1990; Knuepfer et al., 1990; Woodward-Clyde Consultants 
1992c, Hemphill-Haley et al., 1994) (see Figure 3-3 for trench site locations). Accordingly, we considered both slip rates and recurrence intervals to characterize earthquake recurrence on the South Creek, Warm Creek and Big Gulch segments (Figure 4-3). Different weights for each method reflect the type of data available for each segment.

Paleoseismic data from four exploratory trench sites (Figure 3-3) (Malde, 1987; WoodwardClyde Consultants, 1992c) are used to develop recurrence interval distributions for the South Creek segment (Figure 4-3). Although these data suggest that temporal clustering of events occurred during latest Pleistocene time (Woodward-Clyde Consultants, 1992c), the limited length of a complete paleoseismic record leaves considerable behavioral uncertainties. Thus, the temporal behavior of earthquake occurrences could range from relatively uniform (i.e., evenly-spaced intervals) to highly clustered (Woodward-Clyde Consultants, 1992a). To incorporate this uncertainty, we have included three behavioral possibilities for the South Creek segment, similar to the Lost River fault, with intracluster, average, and intercluster branches (Figures 4-2 and 4-3).

For recurrence intervals within clusters of activity, paleoseismic data from the Camp Creek and Coyote Springs sites suggest intervals of 6,000 years or less, whereas the three events in 7,000 years observed at the Black Canyon site (Woodward-Clyde Consultants, 1992c) suggest an average intra-cluster recurrence interval of 3,500 years. These values are conservative, however, as not all of the events that define these intervals ruptured the entire South Creek segment (Woodward-Clyde Consultants, 1992c). Data to constrain recurrence intervals between clusters is limited. Minimum values are based on the interval between the most-recent and penultimate events at the Coyote Springs site, estimated to be from about 14,000 to 20,000 years (Woodward-Clyde Consultants, 1992c). The preferred value is based on the interval between the oldest event and penultimate event at the Camp Creek site, which is probably between 30,000 and 50,000 years (Woodward-Clyde Consultants, 1992c). Maximum values are based on paleoseismic data from the Black Canyon site, where at least five events offset older alluvial-fan deposits (Malde, 1985), with the three youngest events occurring since $24 \mathrm{ka}$ (Woodward-Clyde Consultants, 1992c). If the two older events were post-Bull Lake (Knuepfer et al., 1990), but occurred shortly thereafter, say around 120 to $130 \mathrm{ka}$, then recurrence intervals between clusters could be as long as 100,000 years. Average recurrence values were based on: 1) two events since 24 to $25 \mathrm{ka}$ (Camp Creek site; Woodward-Clyde Consultants, 1992c); 2) three events since 24 ka (Black Canyon site; 
Woodward-Clyde Consultants, 1992c); and 3) five post-Bull Lake events ( $\leq 130 \mathrm{ky}$ ) (Knuepfer et al., 1990).

Slip rate distributions for the South Creek segment are based on long and short term rates. Preferred values are based on vertical slip rates since $24 \mathrm{ka}$, which range from 0.15 to 0.25 $\mathrm{mm} / \mathrm{yr}$ and average about $0.2 \mathrm{~mm} / \mathrm{yr}$ (Woodward-Clyde Consultants, 1992c). In comparison, a post-Bull-Lake rate of about $0.1 \mathrm{~mm} / \mathrm{yr}$ can be estimated if all $15 \mathrm{~m}$ of vertical displacement at the Black Canyon site (Malde, 1985) is assumed to have occurred since $130 \mathrm{ka}$. Slip rates as high as $1 \mathrm{~mm} / \mathrm{yr}$ are considered to incorporate uncertainties in temporal clustering of events.

The Badger Creek segment is a newly identified, short segment that has no unambiguous fault scarps younger than early Wisconsin, in comparison to prominent late Pinedale (15 to $25 \mathrm{ka}$ ) scarps on adjacent segments (Gorton, 1995). Gorton referred to this segment as the central segment. Slip rates for the Badger Creek segment in the segmented model are assumed to be similar to the Ellis segment (P.L.K. Knuepfer, Binghamton University, personal communication, 1994), which also shows no evidence for activity since early Wisconsin time (since $60 \mathrm{ka}$ ). Multiple events probably occurred on the Ellis segment between 60 and $160 \mathrm{ka}$ (Knuepfer et al., 1990), and our slip rates for this segment are based on observations of 10-m-high scarps on pre-Wisconsin alluvial-fan surfaces (Baltzer, 1990). In the unsegmented model, we used slip rates similar to the South Creek segment for the section of the fault along the Badger Creek segment because the model requires this, as the Badger Creek segment lies between two higher slip-rate sections (i.e., the South Creek and Warm Creek segments). However, we do not believe this approach is overly conservative because the structural and topographic relief along the Badger Creek segment suggest slip rates have not necessarily always been lower than along adjacent segments, and these higher rates for the Badger Creek section in the unsegmented model address this uncertainty.

Slip rates and recurrence intervals for the Warm Creek and Big Gulch segments are primarily based on data from trenches (Baltzer, 1990) and surface-offsets measured for fault scarps on late Pinedale (14 to $20 \mathrm{ka}$ ) alluvial-fan surfaces (Turko and Knuepfer, 1991). On the Warm Creek segment, an average surface offset of $1.9 \mathrm{~m}$ since 14 to $20 \mathrm{ka}$ (Turko and Knuepfer, 1991) yields dip-slip values ranging from 0.15 to $0.25 \mathrm{~mm} / \mathrm{yr}$, assuming a fault dip of $50^{\circ}$ and that the alluvial-fan surfaces generally slope at least $5^{\circ}$. Baltzer (1990) 
identified both a late Holocene and late Pinedale event, which is the basis for our preferred recurrence interval of 10,000 years for this segment.

On the Big Gulch segment, an average surface offset of $2.8 \mathrm{~m}$ since 14 to $20 \mathrm{ka}$ (Turko and Knuepfer, 1991) yields dip-slip values ranging from 0.2 to $0.28 \mathrm{~mm} / \mathrm{yr}$ (with the same previous assumptions). Evidence from trench exposures indicate at least one or possibly two post-late Pinedale events have occurred (Baltzer, 1990). However, similar-sized displacements on early Wisconsin alluvial-fan surfaces suggest a relatively long (perhaps $>50 \mathrm{ka}$ ) period of seismic quiescence preceded the most recent activity on this segment (P.L.K. Knuepfer, Binghamton University, personal communication, 1994). Based on this, we consider recurrence intervals as long as 60,000 years for the Big Gulch segment (Figure 4-3).

Finally, on the Falls Creek segment, an average surface offset of $1.5 \mathrm{~m}$ since 14 to $20 \mathrm{ka}$ (Turko and Knuepfer, 1991) yields dip-slip values ranging from 0.1 to $0.15 \mathrm{~mm} / \mathrm{yr}$ (with same previous assumptions). A trench exposure at Falls Creek indicates the most-recent event occurred between 7 and $12 \mathrm{ka}$ (Baltzer, 1990).

\subsubsection{Beaverhead Fault}

\subsubsection{Segmentation}

The segmentation model for the Beaverhead fault was adopted from Crone and Haller (1991) and also includes six segments (Figures 3-3 and 3-4). From south to north, the segments include: 1) Blue Dome; 2) Nicholia; 3) Baldy Mountain; 4) Leadore; 5) Mollie Gulch; and 6) Lemhi. Rupture lengths are shown in Table 4-1. Due to a lack of data for displacements per event, only empirical relations for length and area were used to determine maximum magnitudes (Figure 4-4).

\subsubsection{Southern Termination}

Similar to the other faults, the southern extent of expected rupture of the Beaverhead fault is uncertain, but mapping along the Blue Dome segment indicates it has been less active during the late Quaternary than the southernmost segments of the Lemhi and Lost River 
faults (Haller, 1988; Embree, 1989). Three rupture scenarios were selected to represent uncertainties in the southern rupture termination of the Beaverhead fault (Figure 4-8). Both Embree (1989) and Crone and Haller (1991) found no evidence for fault scarps on alluvium along the Blue Dome segment, and thus there is no direct evidence for late Quaternary activity on this segment. Based on these observations, the Blue Dome segment is not considered active in Scenario 1 and the southern termination of the rupture is at the southern end of the Nicholia segment near Timber Creek (Haller, 1988). This scenario was assigned a weight of 0.5 . In 'Scenario 2, the rupture terminates at the southern end of the range (Figure 4-8), coincident with the southern end of the most southwestern bedrock splay of the Blue Dome segment (Kuntz et al., 1994). As the range-front morphology is suggestive of some Quaternary activity (Haller, 1988) and to include the possibility that the Blue Dome segment is active and nearing the end of a long period of seismic quiescence, we weighted this scenario 0.4 .

In Scenario 3 for the Blue Dome segment, we extended the rupture about $8 \mathrm{~km}$ south of the southern end of the range to Richard Butte (Figure 4-8). Although there is no surficial expression of a recently active structure extending this far into the Snake River Plain, a gravity trough in the Birch Creek Valley partially extends into the Plain at this location (Bankey et al., 1985) and Richard Butte is constructed of early Pleistocene basaltic rocks along the projected strike of the southwesternmost fault splay of the Blue Dome segment. This evidence is suggestive of a possible older (early Pleistocene?) buried structure in this area that could be the southern extension of the Blue Dome segment. Without further subsurface data, however, this scenario is somewhat speculative and so we assign a weight of only 0.1 for this scenario.

\subsubsection{Earthquake Recurrence}

Fault-specific recurrence interval data are not available for the Beaverhead fault because paleoseismic trenching studies have not been conducted. Therefore, only slip rate estimates were used to characterize earthquake recurrence (Figure 4-4). Slip rates were based on data from Crone and Haller (1991) and Haller (1988), who profiled fault scarps and estimated ages of offset surfaces primarily based on soil development and relative geomorphic position. 
Haller (1988) found the youngest activity and highest rates along the central Nicholia and Leadore segments, with surface offsets of 0.8 to $2 \mathrm{~m}$ on late Pinedale deposits. Assuming all the displacement occurred since $15 \mathrm{ka}$ yields dip-slip rates on the order of 0.08 to 0.19 $\mathrm{mm} / \mathrm{yr}$. Based on this, we used a preferred slip rate of $0.15 \mathrm{~mm} / \mathrm{yr}$ for these two segments. We considered rates as high as $1.0 \mathrm{~mm} / \mathrm{yr}$ (Figure 4-4) to include the possibility that events may be temporally clustered (as observed along the Lost River and Lemhi faults) because the limited paleoseismic data do not preclude this possibility.

Very little is known about rates of faulting activity on the Blue Dome, Baldy Mountain and Lemhi segments. The general absence of scarps on the late Quaternary alluvium (Crone and Haller, 1991) is suggestive of much lower rates of recent activity than along the Nicholia and Leadore segments. For example, although bedrock fault scarps are present along the Baldy Mountain segment, Haller (1988) found no scarps on Pinedale deposits and so she infers that no activity occurred since at least $25 \mathrm{ka}$. From the range-front morphology and the lack of scarps on older alluvium on the Blue Dome segment, she infers no activity occurred during the past $100 \mathrm{ka}$. Based on this limited information, we assume slip rates for the Blue Dome, Baldy Mountain and Lemhi segments that are roughly one third that of the Nicholia and Leadore segments, which, for comparison, show evidence for probably two events offsetting Pinedale deposits and three or more events offsetting older alluvium (Haller, 1988).

Finally, we note that, in the unsegmented model, the portion of the fault along the Baldy Mountain segment has the same slip rates as the portions along the Nicholia and Leadore segments because this is required by the model. The Baldy Mountain segment lies between the other two segments (Figure 3-4). However, the higher rates used in this model are supported by the topographic relief along the Baldy Mountain segment, which is intermediate between that of the Leadore and Nicholia segments (Haller, 1988). Thus, although recent rates of activity appear lower along the Baldy Mountain segment, very long-term rates could be more comparable to the adjacent Nicholia and Leadore segments and the higher rates in the unsegmented model attempt to account for this uncertainty.

\subsubsection{Predicted Earthquake Frequency}

Figure 4-9 presents the earthquake recurrence curves for the Lemhi, Lost River, and Beaverhead faults based on the source characterization discussed above. The recurrence 
estimates are computed using a $b$-value of $0.85 \pm 0.1$ for the exponential portion of the recurrence curves. Each plot shows the mean recurrence estimate for the fault and the $5^{\text {th }}$ and $95^{\text {th }}$-percentiles of the computed distribution in earthquake frequency. Also shown for the Lost River and Lemhi faults are the mean recurrence estimates using only slip rates for those segments where both slip rates and recurrence intervals are given and mean recurrence estimates using only recurrence interval estimates for those segments where both are given. A comparison between the observed and predicted seismicity in the vicinity of the three faults is discussed below in Section 4.3.

\subsection{ESRP VOLCANIC RIFT ZONES}

Volcanic rift zones are characterized as potential seismic sources that are distinct from the rest of the ESRP. Although both the volcanic rift zones and the ESRP have been seismically quiescent during the historical period, studies of active volcanic rift zones worldwide suggest that during times of volcanic activity, the rift zones are usually the locus of dike injection and associated seismic activity. Discussion of the earthquake potential of the ESRP volcanic rift zones is based largely on analogues of active volcanic-rift zones worldwide (Smith et al., 1989; Woodward-Clyde Consultants, 1992a; Jackson, 1994; Hackett et al., 1996).

The criteria that are used to identify volcanic rift zones in the INEL vicinity are the spatial distribution of volcanic vents and dike-induced faults and fissures. Based on this criteria, the Great Rift, Arco; and Lava Ridge-Hell's Half Acre volcanic rift zones are identified (Figure 3-5). As described in Section 3.3.2, because the axial volcanic zone is also associated with processes of magma intrusion, it too must be considered as a seismic source. Another postulated volcanic rift zone, called the Howe-East Butte rift zone (Kuntz, 1978) is also considered in this analysis as a potential seismic source. Kuntz (1978) notes that the Howe-East Butte volcanic rift zone is poorly defined relative to other volcanic rift zones of the ESRP and the basaltic lavas tend to be older. Because the density of vents is extremely low (consisting of only four to five vents total), a low probability of existence (0.1) is assigned to the Howe-East Butte volcanic rift zone. Equivalently, the low probability reflects the very small likelihood that the Howe-East Butte is a seismic source and, therefore, would localize seismicity above the random seismicity that is assumed to occur within the ESRP. In the cases where the Howe-East Butte is not considered a source ( $90 \%$ of the cases), the ESRP source includes the region containing the Howe-East Butte zone. 


\subsubsection{Maximum Magnitude}

As part of the deterministic ground motion assessment for the NPR (Woodward-Clyde Consultants, 1992a), worldwide volcanic-rit zones were evaluated to form the basis for estimating potential deformation processes and maximum volcanic earthquake magnitudes for the ESRP volcanic rift zones. Based on analogues to other basaltic volcanic rift zones, such as Kilauea, Hawaii; Krafla, Iceland; Afar, Africa; Taupo, New Zealand; and Long Valley, California, it was concluded that the maximum magnitude earthquake that can be associated with dike injection in the volcanic rift zones is a $\mathrm{M}_{\mathrm{W}} 5.0$ (Jackson, 1994; Smith et al., 1996; Hackett et al., 1996; Woodward-Clyde Consultants, 1992a). Earthquakes of this size are generated at shallow depths along faults above the intruding dikes. Field, geodetic, and seismological observations suggest that the depth extent of normal faults above or ahead of propagating dikes is about 2 to $4 \mathrm{~km}$ (Karpin and Thurber, 1987; Klein et al., 1987; Du and Aydin, 1992; Rubin, 1992). The logic trees for the volcanic rift zones (Figure 4-10) reflect a preference for $2 \mathrm{~km}$ based on the geometry of the fissures and worldwide analogues (e.g., Jackson, 1994; Smith et al., 1989). In this study, the maximum dimensions of faults and fissures within the ESRP volcanic rift zones have been re-examined and it is now concluded that their dimensions would be most compatible with a maximum magnitude of $\mathrm{M}_{\mathrm{W}} 5.0$ (Jackson, 1994). For this probabilistic seismic hazard analysis, preference for the maximum magnitude of $\mathrm{M}_{\mathrm{W}} 5.0$ is expressed in the logic tree (Figure 4-10) and an uncertainty in that assessment of about $1 / 2$ magnitude unit is included.

Although the volcanic zones are modeled in the seismic hazard analysis as source zones, they are currently observed to be aseismic, thus no recurrence relationship based on observed seismicity can be established. To constrain recurrence rates, we consider the association of seismicity with volcanic eruptive episodes. Observations of active rift zones show that earthquakes typically occur during magmatic intrusive and eruptive episodes. Because of this genetic link between eruptive episodes and earthquakes, we can use the recurrence rates of eruptive episodes to estimate the recurrence rates of earthquakes.

\subsubsection{Earthquake Recurrence}

In the logic trees for the volcanic zones, the earthquake recurrence model also needs to be considered (Figure 4-10). In general, the exponential model is usually deemed to be more 
appropriate for seismic source zones that contain several individual faults; the characteristic model best describes the recurrence behavior of individual faults and fault segments. We envision the volcanic zones to contain a number of dikes and fissures having a variety of dimensions. Hence, the expected recurrence behavior is exponential and a probability of 1.0 is assigned to this model (Figure 4-10).

Recurrence intervals were estimated using two approaches based on (Table 4-2): (1) counting of individual vents and fissures which results in conservative bounding values of minimum (shortest) recurrence intervals; and (2) grouping of vents and fissures into geologically reasonable cogenetic rupture sets. Groups were selected using the following criteria: (1) vent/fissure groups each cover a $2 \times 5-\mathrm{km}$ geographic area as observed for many vent/fissure sets of discrete ESRP fissure eruptions; (2) consistency with geologic map relations; and (3) northwest alignment of vent/fissure groups. Estimated uncertainties indicate a range of recurrence values (and relative weights) that are defensible from map relations, geochronometry, and judgment (Hackett and Smith, 1994).

Recurrence rates for eruptive episodes are assessed based on counts of volcanic vents and fissures that have occurred over particular periods of time. In order to accomplish this, we have defined specific boundaries for the ESRP volcanic zones and counted the number of volcanic vents and fissure swarms within each (maps used are LaPoint, 1977; Kuntz et al., 1994). All volcanic zones with the exception of the Howe-East Butte zone include Holocene ("zero-age") vents, hence, the time interval of volcanism in each zone is given by the oldest surficially exposed volcanic rocks, using the K-Ar dates and paleomagnetic data of Kuntz et al. (1994). Because of overlapping volcanic zones and other uncertainties, we usually give upper and lower limits for the number of vents/fissures/faults in a given zone. The maximum vent number (upper limit) is calculated by counting each individual vent within vent clusters (using $1: 100,000$ or 1:250,000 map bases), counting groups of "dry" fissures/faults that are seemingly unrelated to vents (each of these would represent a noneruptive dike-intrusion episode), and by counting all vents in the overlap zones (vents in overlap areas are therefore counted twice, once for each of the two zones that overlap) (recurrence interval 1; Table 4-2). The minimum (lower limit) of a vent number is calculated by grouping vent cluster and cogenetic fissure eruptives into eruptive events (recurrence interval 2; Table 4-2). 
Because of the subjective nature of vent-counting, fissure-counting, and defining the areas of the overlapping volcanic zones, we estimate an uncertainty of $\pm 10 \%$ for the number of magma-intrusion events within the Arco and Lava Ridge-Hells Half Acre volcanic rift zones and axial volcanic zones. In addition, we emphasize that the exercise is almost entirely based on geologic map data and therefore assumes that the surficial geology is representative of long-term magmatic processes on the ESRP. This assumption seems justified in light of geochronologic results (Kuntz et al., 1994), which show that surficial basalts in the INEL area range widely in age, from about $5 \mathrm{Ka}$ to $1.2 \mathrm{Ma}$.

The estimated recurrence intervals and their weights for each volcanic zone are averages based on our evaluation of complex geologic information including geochronometry, magnetic polarity, the distribution of mapped Quaternary basalts, vent locations, and in a few cases, borehole data. Values have been rounded off in order not to imply undue precision. Despite the inherent uncertainties, the results are internally consistent and seem reasonable in light of what is known about the timing and location of ESRP Quaternary volcanism and dike-induced surface deformation.

The interpretations of vent numbers, fissure-swarm numbers, and recurrence intervals for each volcanic zone are summarized in Table 4-2. The well-constrained record of Holocene volcanism along the Great Rift provides a minimum (upper limit) recurrence interval for ESRP volcanism at about 2,000 years; all other volcanic zones on the Plain have erupted less voluminously and less frequently during the past 15,000 years. At the other end of the spectrum are the "old, relatively inactive" Lava Ridge-Hells Half Acre and Howe-East Butte volcanic rift zones, for which we estimate recurrence intervals of about 120,000 years. The Arco volcanic rift zone (recurrence interval $\sim 35,000 \mathrm{yr}$ ) and axial volcanic zone (recurrence interval $\sim 35,000 \mathrm{yr})$ have similar, relatively short magma-recurrence intervals. The comparatively short recurrence interval for the axial volcanic zone reflects its relatively frequent Holocene events (Table 4-2). Exclusive of the Great Rift, all Holocene volcanism on the ESRP has occurred along the axial volcanic zone and its areas of overlap with northwest-trending rift zones.

A $b$-value of $1.3 \pm 0.3$ was also used in defining the exponential portion of the recurrence curves for the volcanic zones (Figure 4-11). This value is based on an estimated average $b$-value observed in volcanic rift zones worldwide (e.g., Klein et al:, 1987). The calculated 
recurrence relationships incorporating the selected maximum magnitude values for the individual volcanic zones and for the combined effects of all volcanic earthquakes is shown in Figure 4-11.

\subsection{REGIONAL SOURCE ZONES}

In addition to the fault sources and volcanic zones, several regional seismic source zones are also included in the hazard analysis (Figure 4-1). Most of these source zones lie at relatively large distances from the INEL and details of their source characteristics are relatively unimportant to the seismic hazard analysis. The exception is the northern Basin and Range source zone that lies to the north of the INEL. The major faults within this zone have been explicitly modeled in the hazard analysis (Section 4.1). This source zone is used to represent the potential for earthquakes other than those occurring on the Lost River, Lemhi, or Beaverhead faults. The other source zones are used to represent both earthquakes occurring on the mapped faults that lie within them and seismicity occurring on small, unmapped, faults. Because the details of fault geometry are unimportant for all but the northern Basin and Range zone, and àre unknown for the background earthquakes modeled by the northern Basin and Range Zone, the two source characteristics assessed for the regional source zones are their maximum earthquake magnitude and earthquake recurrence rates. Maximum earthquakes are usually derived from consideration of the dimensions of faults within the source zone. Earthquake recurrence rates are estimated directly from the observed seismicity, accounting for catalogue incompleteness.

Three alternative models were developed to represent seismic source zonation in the region: The alternative models address the uncertainty in zonation of the ISB and northern Basin and Range (Figure 4-12). The alternatives are: (1) the northern ISB (north of Yellowstone), the central ISB (south of Yellowstone), and the northern Basin and Range are a single source zone (the 7-zone model); (2) the northern ISB and the northern Basin and Range are one source zone and the central ISB is a separate source zone (the 8-zone model); and (3) the northern and central ISB and the northern Basin and Range are three separate source zones (the 9-zone model). For these models, the treatment of earthquake recurrence and maximum magnitude is shown in Figure 4-12. The reason for defining three alternative models is based on the possibility that the seismogenic potential may differ between the northern and central ISB and northern Basin and Range province to varying degrees. This is discussed 
in the following section. We have assigned the 7-, 8-, and 9-zone models weights of 0.4 , 0.4 , and 0.2 , respectively (Figure 4-12). These three alternative source zone models were used to evaluate the earthquake catalogue completeness (Appendix A) and to compute earthquake recurrence parameters for the source zones. Table 4-3 lists the recurrence parameters for the regional source zones. Figures 4-13 through 4-25 show the logic trees and distribution of recurrence models of the source zones used in the seismic hazard analysis.

\subsubsection{Eastern Snake River Plain}

The boundaries of the ESRP tectonic province are defined by topographic changes, the boundaries of the basaltic volcanic deposits, and by the distinctly low levels of observed seismicity that separate it from the adjacent Basin and Range province and the Yellowstone region. The normal faulting and basin and range development that occurs in the provinces to the north and south of the ESRP are absent within the Plain. It is likely that the northeast-southwest tectonic extension that occurs outside of the Plain as exhibited by the range-bounding normal faults is accommodated by magma emplacement and dike injection in the ESRP (Rodgers et al., 1990; Parsons and Thompson, 1991).

The logic tree for the ESRP source zone is shown in Figure 4-13. The thickness of the seismogenic crust. is uncertain within the ESRP because of the very low levels of seismicity and very few earthquakes for which accurate focal depths are known. Based on the arguments presented in Section 3.2.2, the depth or thickness of the seismogenic crust within the ESRP source is assessed to be about $8 \mathrm{~km}$ with an uncertainty of about $\pm 2 \mathrm{~km}$. Note that this depth is significantly less than north of the ESRP where the seismogenic crust appears to be about $16 \mathrm{~km}$ thick (Section 4.1.1.2).

Because very few earthquakes have occurred within the ESRP, the location and size of the 1905 Shoshone, Idaho earthquake is a critical determinant in estimating the maximum magnitude for the ESRP source zone. As described in Section 3.2.2.1, uncertainties in the location of the event allow for the possibility that the earthquake occurred within the ESRP, although the available data suggests that the event occurred near the Idaho-Utah border. This preference is included in the logic tree (Figure 4-13). The size of the event is also uncertain but the available evidence suggests that it was approximately $M_{W} 51 / 2 \pm 1 / 2$ (Oaks et al., 1992). If the 1905 event is assumed to have occurred within the ESRP (assigned 
likelihood 0.33), the maximum magnitude for the ESRP is judged to range from $M_{W} 5^{1 / 2}$ to 6, with the two alternatives equally weighted (Figure 4-13). If the 1905 event is assumed to have occurred outside the ESRP (assigned likelihood 0.67), the preferred magnitude is $M_{W}$ 5.5 and a range of magnitude values of $M_{W} 5$ to 6 is included.

Recurrence relationships are shown for the ESRP source zone assuming the 1905 earthquake occurred within the Plain and one assuming it occurred outside of the Plain within the central Basin and Range (Figure 4-14).

\subsubsection{Other Seismic Source Zones}

The northern Basin and Range source zone includes the region of Quaternary extensional faulting and seismicity north of the ESRP and east of the Idaho Batholith (Figure 4-1). The Lost River, Lemhi, and Beaverhead faults are part of the northern Basin and Range province, but are also considered as distinct sources of seismicity within the areal source zone that contains them. The northern Basin and Range source zone is considered to include the area in the vicinity of the faults. The level of seismicity within the northern Basin and Range source zone is notably higher than the adjacent Idaho Batholith and ESRP, but is lower than the Yellowstone source zone to the east. In the 7- and 8-zone models 1 and 2, we have considered the northern Basin and Range province as part of the northern ISB; conversely in the 9-zone model, it is considered a separate seismic source zone (Figure 4-12). Because they have been characterized as fault sources, the Lost River, Lemhi, and Beaverhead faults, are excluded from the assessment of maximum magnitude. The maximum magnitude distribution is $M_{\mathrm{W}} 61 / 2 \pm 1 / 4$ for the northern Basin and Range source zone (Figure 4-15). The recurrence for the three models for the northern Basin and Range is shown in Figure 4-16.

The ISB (Figure 4-1) contains numerous faults that can generate significant earthquakes. North of Yellowstone; the late-Quaternary faults in the northern ISB or the western Montana portion of the ISB strike northwesterly. South of Yellowstone along the Idaho-Wyoming border and central Utah, the faults in the central ISB trend north-south (e.g., Teton and Wasatch faults). There is little difference between the seismicity rates for the northern and central ISB; however, we have treated them as separate seismic source zones in the 8-zone and 9-zone models (Figure 4-12). For the ISB, either northern or central portions, the 
assigned maximum magnitude distribution is $M_{w} 7^{1 / 2} \pm 1 / 4$ (Figure 17). The recurrence for the ISB are shown in Figures 4-18 and 4-19.

The Yellowstone source zone (Figure 4-1) encompasses the region of intense seismicity and the associated silicic volcanism in the Yellowstone region. The presence of young calderas and elevated hydrothermal activity mark a clear distinction between this region, the basaltic volcanism of the ESRP, and the adjacent Basin and Range province. The maximum earthquake magnitude for the Yellowstone source is based on the $1959 M_{w} 7.3\left(M_{s} 7.5\right)$ Hebgen Lake earthquake. The maximum magnitude distribution, defined as branches of the logic tree, is $M_{w} 7 \frac{1}{2}$ to $1 / 4$ (Figure 4-20). The best estimate seismogenic depth of $12 \mathrm{~km}$ is less than the surrounding source zones because of the high heat flow in the Yellowstone region (e.g, Smith and Arabasz, 1991). Figure 4-21 shows the recurrence for the zone.

The Idaho Batholith source zone (Figure 4-1) is a seismically quiet region defined by the boundaries of the granitic rocks making up the province. No extensive or well-defined Quaternary faults are mapped within the Idaho Batholith, and the seismic potential is relatively low (Smith and Arabasz, 1991; Woodward-Clyde Consultants, 1992b). The largest known earthquakes were the 1944 M 6.1 and 1945 M 6.0 Seafoam events. The maximum magnitude distribution for the source zone is $M_{W} 6 \pm 1 / 2$ (Figure 4-22). The recurrence for the Idaho Batholith source zone is shown in Figure 4-23.

The central Basin and Range source zone is defined as the region lying to the south of the ESRP and to the west of the more seismically active Intermountain seismic belt (Figure 4-1). In the region near the ESRP, the central Basin and Range province is characterized by only a few short normal fauits; however, farther to the south the province contains a number of late-Quaternary faults and has been the location of some of the largest historical earthquakes in the whole of the Basin and Range province. The 1915 Pleasant Valley and 1954 Dixie Valley earthquakes were considered in estimating the following maximum magnitude distribution of $M_{w}, 7 \frac{1 / 4}{1 / 4}$ (Figure 4-24). The recurrence is shown in Figure 4-25. We have assumed that if the 1905 Shoshone earthquake occurred outside the ESRP, it was located within the central Basin and Range province. 


\section{RUPTURE LENGTHS FOR FAULT SOURCES}

\begin{tabular}{|c|c|}
\hline Segment & Length $(\mathbf{k m}) *$ \\
\hline \multicolumn{2}{|l|}{ Lost River Fault } \\
\hline Arco - Scenario 1 & 22 \\
\hline Arco - Scenario 2 & 28 \\
\hline Arco - Scenario 3 & 33 \\
\hline Pass Creek & 44 \\
\hline Mackay & 28 \\
\hline Thousand Springs & 25 \\
\hline Warm Spring & 17 \\
\hline Challis & 25 \\
\hline Average - Scenario $1^{* *}$ & 27 \\
\hline Avērage - Scenario $2 * *$ & 28 \\
\hline Average - Scenario $3 * *$ & 29 \\
\hline \multicolumn{2}{|l|}{ Lemhi Fault } \\
\hline South Creek - Scenario 1 & 30 \\
\hline South Creek - Scenario 2 & 32 \\
\hline Badger Creek & 20 \\
\hline Warm Creek & 24 \\
\hline Big Gulch & 31 \\
\hline Falls Creek & 34 \\
\hline Ellis & 13 \\
\hline Average - Scenario $1 * *$ & 25 \\
\hline Average - Scenario $2 * *$ & 26 \\
\hline \multicolumn{2}{|l|}{ Beaverhead Fault } \\
\hline Blue Dome - Scenario 1 & 0 (Not Active) \\
\hline Blue Dome - Scenario 2 & 30 \\
\hline Blue Dome - Scenario 3 & 35 \\
\hline Nicholia & 32 \\
\hline Baldy Mountain & 21 \\
\hline Leadore & 22 \\
\hline Mokie Gulch & 17 \\
\hline Lemhi & 19 \\
\hline Average - Scenario $1^{* *}$ & 22 \\
\hline Average - Scenario $2 * *$ & 24 \\
\hline Average - Scenario $3 * *$ & 24 \\
\hline
\end{tabular}

*Continuous along trace length approximated by straight line sections **Used for unsegmented model (weighted 0.185 ), with double this length weighted 0.63 and triple this length weighted 0.185 . 

TABLE 4-2

ESTIMATED VOLCANIC RECURRENCE INTERVALS FOR VOLCANIC ZONES

\begin{tabular}{|c|c|c|c|c|c|}
\hline $\begin{array}{l}\text { VOLCANIC ZONE } \\
\text { OR BOREHOLE }\end{array}$ & $\begin{array}{l}\text { DATA } \\
\text { SOURCES }\end{array}$ & \begin{tabular}{|l|} 
TIME INTERVAL \\
OF VOLCANISM \\
[yrs before present]
\end{tabular} & $\begin{array}{l}\text { NUMBER OF VENTS, } \\
\text { FISSURES OR FLOW } \\
\text { GROUPS }\end{array}$ & COMMENTS & $\begin{array}{l}\text { ESTIMATED } \\
\text { RECURRENCE } \\
\text { (\& weights) }\end{array}$ \\
\hline $\begin{array}{l}\text { Great Rift } \\
(25 \mathrm{~km} \text { southwest of } \\
\text { iNEL) }\end{array}$ & $\begin{array}{l}\text { Kuntz et al., } \\
1986,1988\end{array}$ & $\begin{array}{l}2,100-15,000 \text { yrs } \\
\text { (radiocarbon dating) }\end{array}$ & $\begin{array}{l}>100 \text { vents } \\
8 \text { Holocene eruptive } \\
\text { periods (each lasting a few } \\
\text { decades or centuries, and } \\
\text { each including multiple } \\
\text { flows and cones). }\end{array}$ & $\begin{array}{l}\text { no impact on INEL; } \\
\text { most recently and frequently } \\
\text { active of all ESRP rift zones; } \\
\text { thus provides minimum- } \\
\text { recurrence for entire ESRP; } \\
\text { most probable area of future } \\
\text { ESRP volcanism }\end{array}$ & $\begin{array}{l}150 \text { yrs }(0.185) \\
2,000 \text { yrs }(0.63) \\
4000 \text { yrs }(0.185)\end{array}$ \\
\hline $\begin{array}{l}\text { Axlal Volcanlc Zone } \\
\text { (southern INEL) }\end{array}$ & $\begin{array}{l}\text { Kuntz et al., } \\
1986,1994\end{array}$ & $\begin{array}{l}5,000-730,000 \text { yrs } \\
\text { (K-Ar dating; } \\
\text { radiocarbon; } \\
\text { paleomagnetic data) }\end{array}$ & $\begin{array}{l}73 \text { vents \& fissure sets; } \\
4 \text { Holocene lava fields, } \\
3 \text { of them shared by } \\
\text { volcanic rift zones. } \\
45 \text { cogenetic vent/fiss gps }\end{array}$ & $\begin{array}{l}\text { could affect much of southern } \\
\text { INEL; most recently and } \\
\text { frequently active of all volcanic } \\
\text { zones that could impact INEL }\end{array}$ & $\begin{array}{l}10,000 \text { yrs }(0.185) \\
16,000 \text { yrs }(0.63) \\
32,000 \text { yrs }(0.183)\end{array}$ \\
\hline $\begin{array}{l}\text { Arco } \\
\text { Volcanic RIft Zone } \\
\text { (southwestern INEL) }\end{array}$ & $\begin{array}{l}\text { Kuntz, 1978; } \\
\text { Smith et al., } \\
\text { 1989; Kuntz } \\
\text { et al., } 1994\end{array}$ & $\begin{array}{l}10,000-600,000 \text { yrs } \\
\text { (radiocarbon, K-Ar and } \\
\text { TL dating; } \\
\text { paleomagnetic data) }\end{array}$ & $\begin{array}{l}3 \text { vents \& fissure sets; } \\
2 \text { Holocene lava fields. } \\
35 \text { cogenetic vent/fiss gps }\end{array}$ & $\begin{array}{l}\text { volcanism could affect } \\
\text { southwestern INEL }\end{array}$ & $\begin{array}{l}7,000 \text { yrs }(0.183) \\
17,000 \text { yrs }(0.63) \\
34,000 \text { yrs }(0.183)\end{array}$ \\
\hline $\begin{array}{l}\text { Lava Ridge-Hells } \\
\text { Half Acre Volcanic } \\
\text { Rift Zone (Includes } \\
\text { Clrc Butte/Kettle } \\
\text { Butte volc rift zone) } \\
\text { (north \& eastern INEL) }\end{array}$ & $\begin{array}{l}\text { Kuntz et al., } \\
1986,1994\end{array}$ & $\begin{array}{l}5,000-1,200,000 \text { yrs } \\
\text { (K-Ar dating; } \\
\text { radiocarbon; } \\
\text { paleomagnetic data) }\end{array}$ & $\begin{array}{l}48 \text { vents \& fissure sets; } \\
1 \text { Holocene lava field: } \\
\text { Hells Half Acre. } \\
30 \text { cogenetic vent/fiss gps }\end{array}$ & $\begin{array}{l}\text { could affect northern \& } \\
\text { eastern INEL; extremely long } \\
\text { eruptive history; includes } \\
\text { oldest and youngest basalts in } \\
\text { the INEL area }\end{array}$ & $\begin{array}{l}25,000 \text { yrs }(0.183) \\
40,000 \text { yrs }(0.63) \\
80,000 \text { yrs }(0.183)\end{array}$ \\
\hline $\begin{array}{l}\text { Howe-East Butte } \\
\text { VolcanIc Rlft Zone } \\
\text { (central INEL) }\end{array}$ & $\begin{array}{l}\text { Kuntz, 1978, } \\
\text { 1992; Golder } \\
\text { Associates, } \\
1992\end{array}$ & $\begin{array}{l}230,000-730,000 \text { yrs } \\
\text { (K-Ar dating; } \\
\text { paleomagnetic data) }\end{array}$ & $\begin{array}{l}7 \text { vents \& fissure sets; } \\
\text { no Holocene features. } \\
5 \text { cogenetic vent/fissure } \\
\text { groups }\end{array}$ & $\begin{array}{l}\text { old, poorly exposed and } \\
\text { sediment-covered; identified } \\
\text { in part by subsurface } \\
\text { geophysical anomalies }\end{array}$ & $\begin{array}{l}70,000 \text { yrs }(0.183) \\
100,000 \text { yrs }(0.63) \\
200,000 \text { yrs }(0.183)\end{array}$ \\
\hline
\end{tabular}


TABLE 4-3

SEISMIC SOURCE ZONE RECURRENCE PARAMETERS

\begin{tabular}{|c|c|c|c|c|}
\hline SOURCE & AREA & $\mathbf{m}^{0}$ & $\mathrm{~N}\left(\mathrm{~m}^{0}\right)$ & b-VALUE \\
\hline \multicolumn{5}{|l|}{ Assuming 7-source zone model } \\
\hline ESRP w/ 1905 & 29616. & 2.33 & $0.806( \pm 0.319)$ & $0.901( \pm 0.174)$ \\
\hline ESRP w/o 1905 & 29616. & 2.33 & $0.823( \pm 0.333)$ & $1.072( \pm 0.185)$ \\
\hline Northern Basin and Range/ISB & 127854. & 2.33 & $116.318( \pm 4.342)$ & $0.902( \pm 0.023)$ \\
\hline Central Basin and Range w/o 1905 & 45056. & 2.33 & $2.397( \pm 0.754)$ & $0.720( \pm 0.154)$ \\
\hline Idaho Batholith & 14098. & 2.33 & $2.325( \pm 0.744)$ & $0.728( \pm 0.158)$ \\
\hline Yellowstone & 10125. & 2.33 & $50.665( \pm 2.691)$ & $0.944( \pm 0.034)$ \\
\hline Northern Idaho & 21845 . & 2.33 & $3.059( \pm 0.816)$ & $0.826( \pm 0.148)$ \\
\hline East of Intermountain Seismic Belt & 61932. & 2.33 & $8.671( \pm 1.502)$ & $1.050(+0.119)$ \\
\hline \multicolumn{5}{|l|}{ Assuming 8-source zone model } \\
\hline ESRP w/ 1905 & 29616. & 2.33 & $0.788( \pm 0.352)$ & $0.889( \pm 0.270)$ \\
\hline ESRP w/o 1905 & 29616. & 2.33 & $0.977( \pm 0.411)$ & $1.391( \pm 0.406)$ \\
\hline Northern Basin and Range/NISB & 69551. & 2.33 & $79.251( \pm 3.861)$ & $0.907( \pm 0.030)$ \\
\hline Central Basin and Range w/o 1905 & 45056. & 2.33 & $2.819( \pm 0.950)$ & $0.745( \pm 0.168)$ \\
\hline Central Basin and Range w/ 1905 & 45056. & 2.33 & $2.701( \pm 0.918)$ & $0.694( \pm 0.160)$ \\
\hline Idaho Batholith & 14098. & 2.33 & $2.736( \pm 0.937)$ & $0.753( \pm 0.173)$ \\
\hline Intermountain Seismic Belt & 58303. & 2.33 & $38.146( \pm 2.170)$ & $0.874( \pm 0.034)$ \\
\hline Yellowstone & 10125. & 2.33 & $46.415( \pm 2.413)$ & $0.919( \pm 0.033)$ \\
\hline Northern Idaho & 21845. & 2.33 & $3.401( \pm 0.928)$ & $0.841( \pm 0.153)$ \\
\hline East of Intermountain Seismic Belt & 61932. & 2.33 & $10.514(+1.908)$ & $1.091(+0.128)$ \\
\hline \multicolumn{5}{|l|}{ Assuming 9-sounce zone model } \\
\hline ESRP w/ 1905 & 29616. & 2.33 & $0.686( \pm 0.268)$ & $0.883( \pm 0.171)$ \\
\hline ESRP w/o 1905 & 29616. & 2.33 & $0.694( \pm 0.278)$ & $1.055( \pm 0.184)$ \\
\hline Northern Basin and Range & 38185. & 2.33 & $23.821( \pm 1.738)$ & $0.808( \pm 0.041)$ \\
\hline Central Basin and Range w/o 1905 & 45056. & 2.33 & $1.576( \pm 0.429)$ & $0.657( \pm 0.126)$ \\
\hline Central Basin and Range w/ 1905 & 45056. & 2.33 & $1.538( \pm 0.418)$ & $0.613( \pm 0.119)$ \\
\hline Northern Intermountain Seismic Belt & 31366. & 2.33 & $36.098( \pm 2.180)$ & $0.908( \pm 0.038)$ \\
\hline Yellowstone & 10125 & 2.33 & $48.147( \pm 2.527)$ & $0.931( \pm 0.033)$ \\
\hline Northern Idaho & 21845 & 2.33 & $2.114( \pm 0.512)$ & $0.764( \pm 0.128)$ \\
\hline East of Intermountain Seismic Belt & 61932. & 2.33 & $5.289(+0.840)$ & $0.950( \pm 0.103)$ \\
\hline
\end{tabular}





\section{LEGEND}

FAULTS

BH Beaverhead

LEM Lemhi

LR Lost River

VOLCANIC RIFT ZONES

AR Arco

AVZ Axial volcanic zone

GR Great Rift

HHA Lava Ridge-Hells Half Acre

HEB Howe-East Butte

\section{REGIONAL SOURCE ZONES}

ESRP Eastern Snake River Plain

ISB Central Intermountain

NISB Northern Intermountain

NBR Northern Basin and Range

CBR Central Basin and Range

IB Idaho Batholith

YS Yellowstone

NI Northern Idaho

EZ Eastern Zone

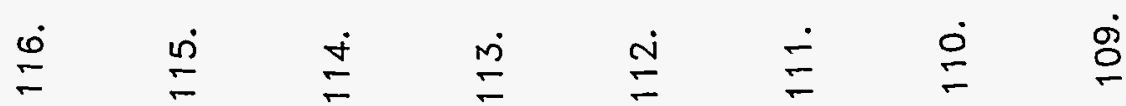

46.

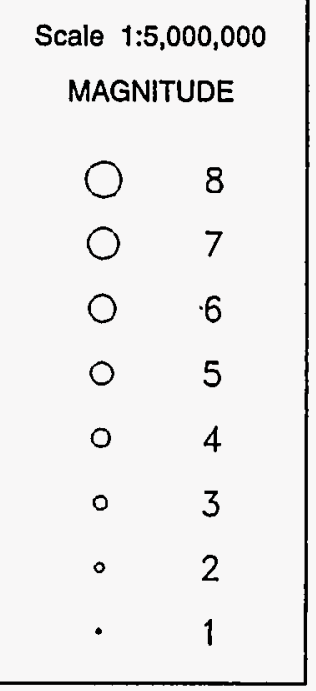

43.

45.
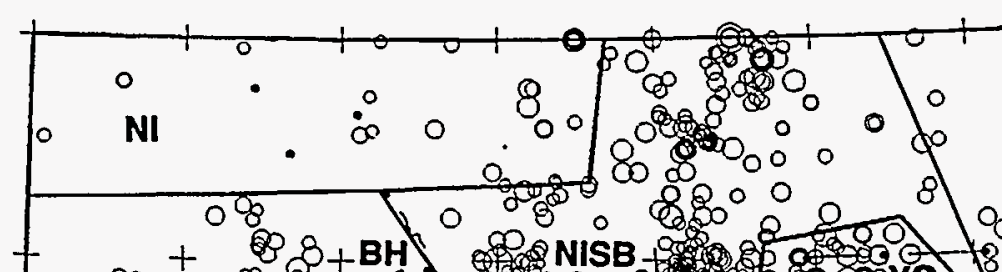

44.

.

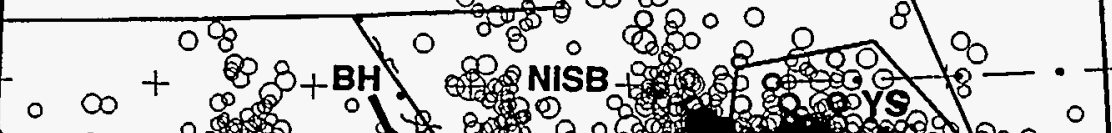

45.

42.
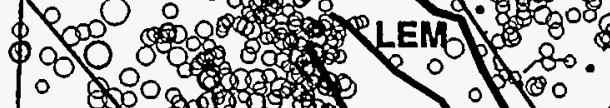

4.

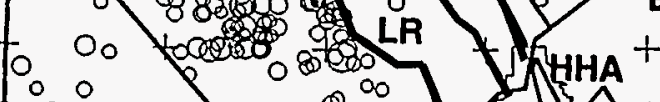

IB

ESRP

NBR

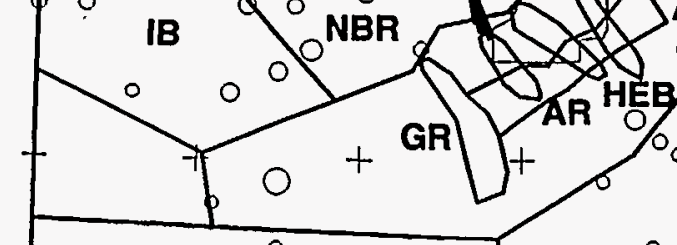

AVZ

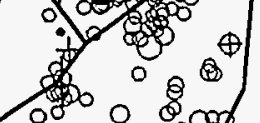

0

41.

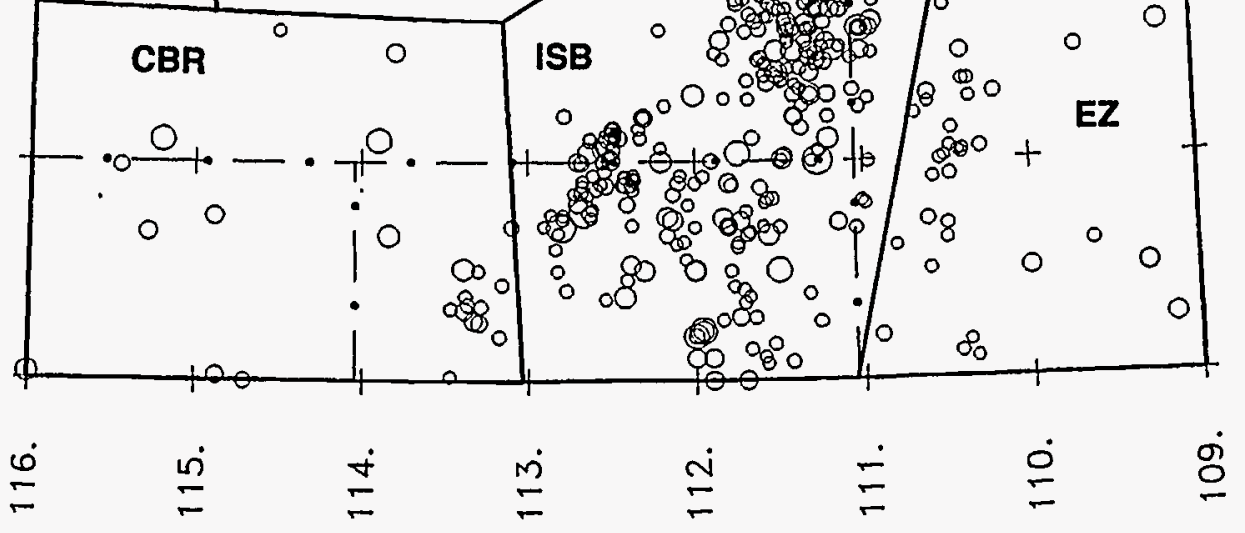

\begin{tabular}{|c|c|c|c|}
\hline $\begin{array}{l}\text { Project No. } \\
\text { SK9455 }\end{array}$ & INEL - Probabilistic Analyses & \multirow{2}{*}{$\begin{array}{l}\text { SEISMIC SOURCES AND } \\
\text { SPATIAL DISTRIBUTION OF } \\
\text { INDEPENDENT EARTHQUAKES }\end{array}$} & \multirow{2}{*}{$\begin{array}{c}\text { Figure } \\
4-1\end{array}$} \\
\hline \multicolumn{2}{|c|}{ Woodward-Clyde Federal Services } & & \\
\hline
\end{tabular}





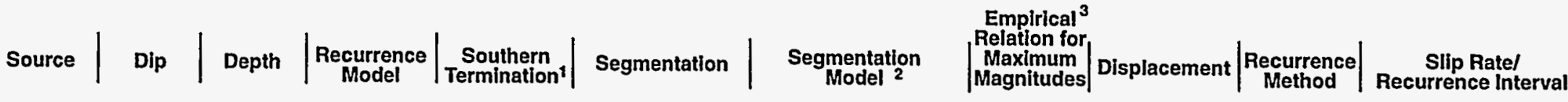

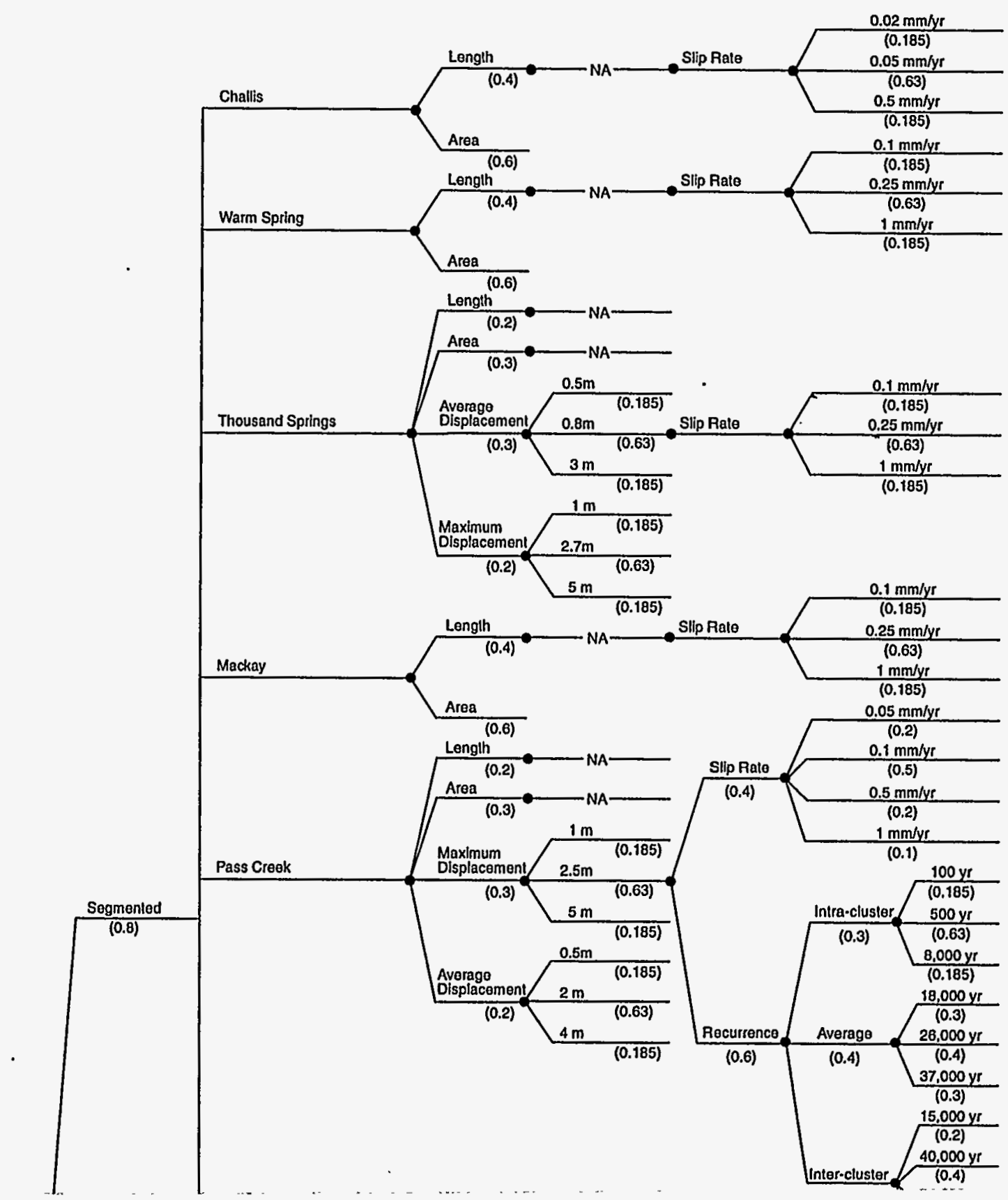




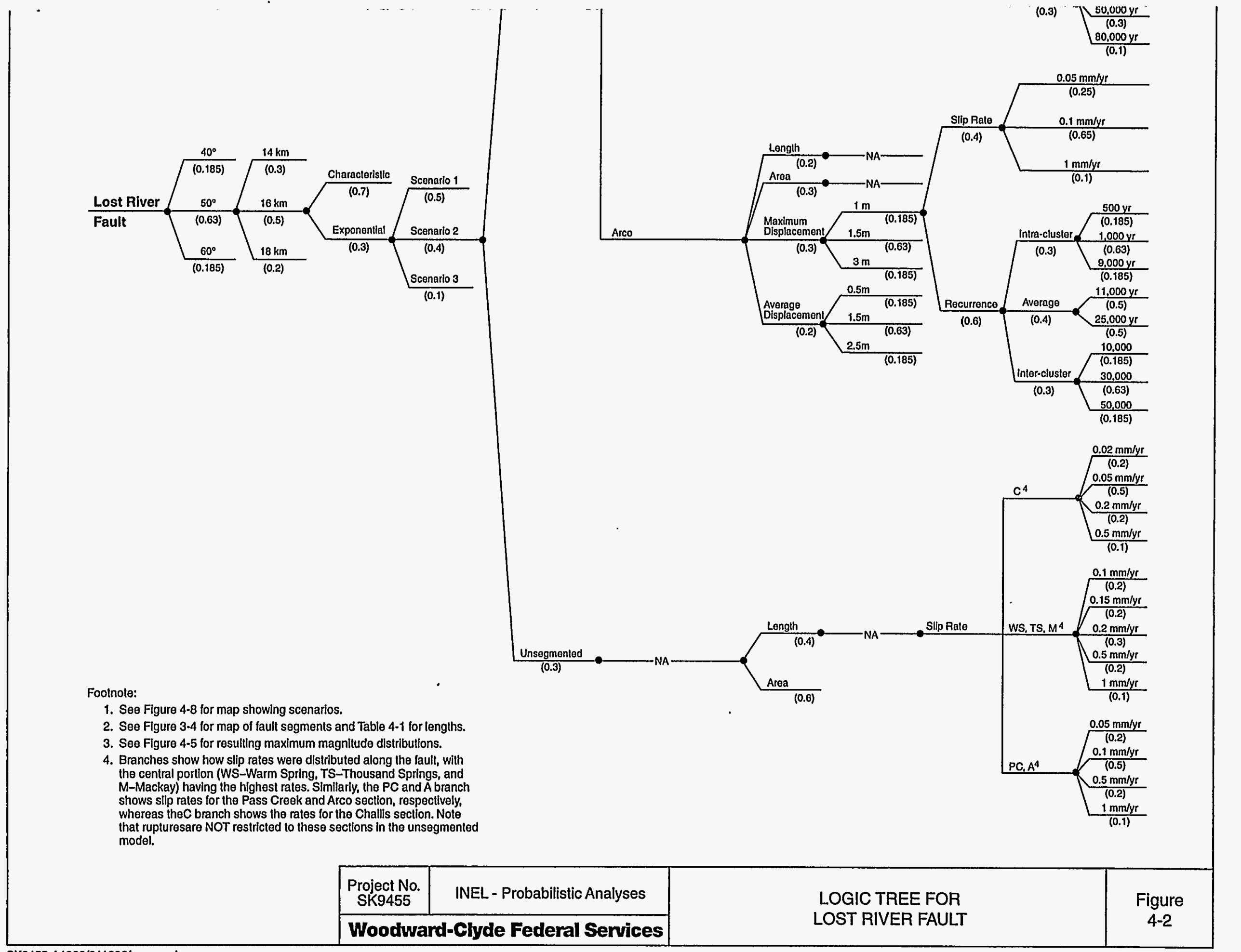




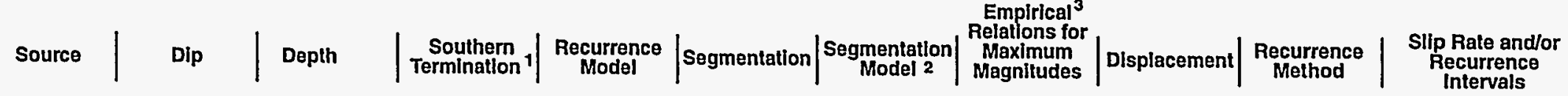




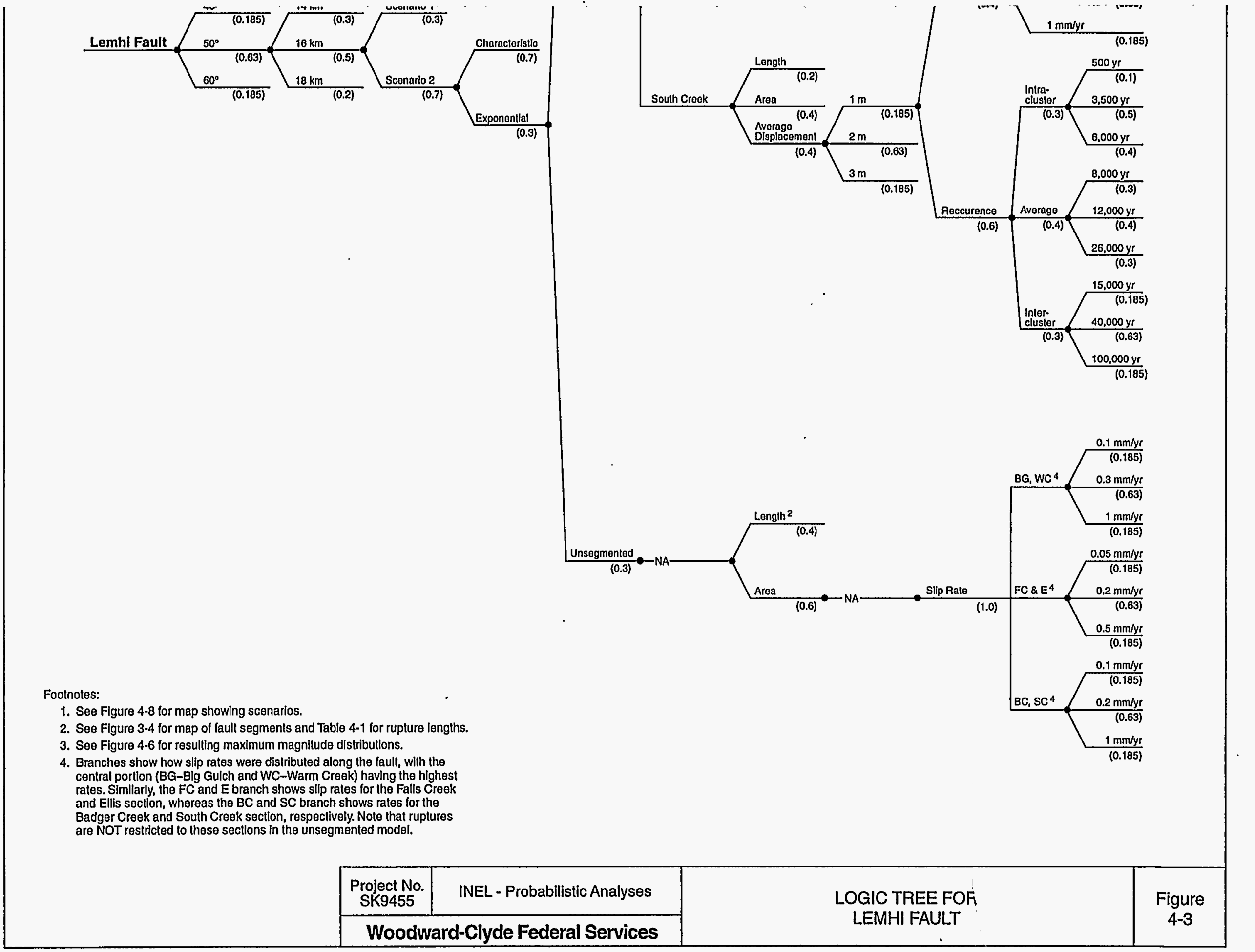




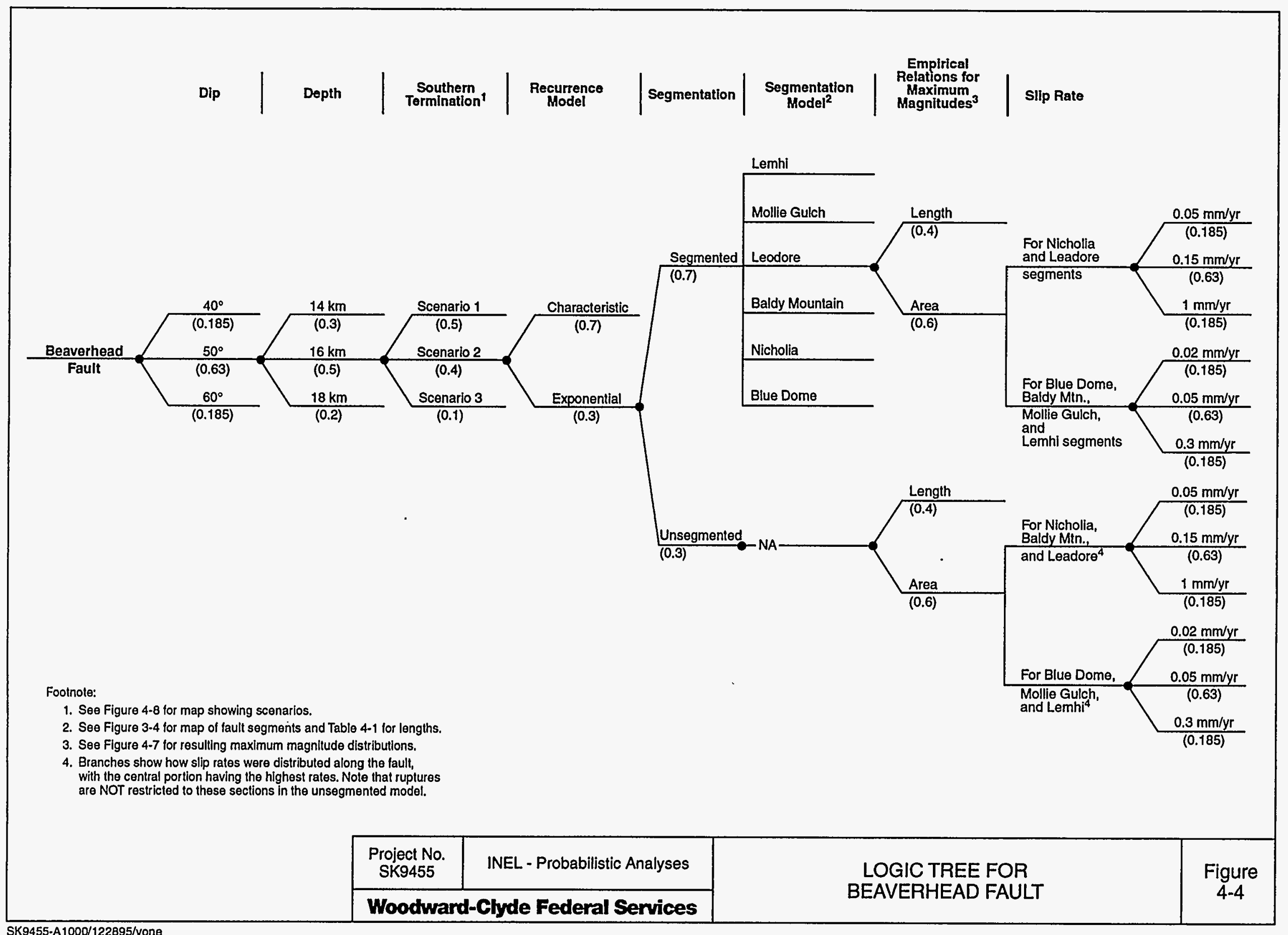

SK9455-A1000/122895/vone 


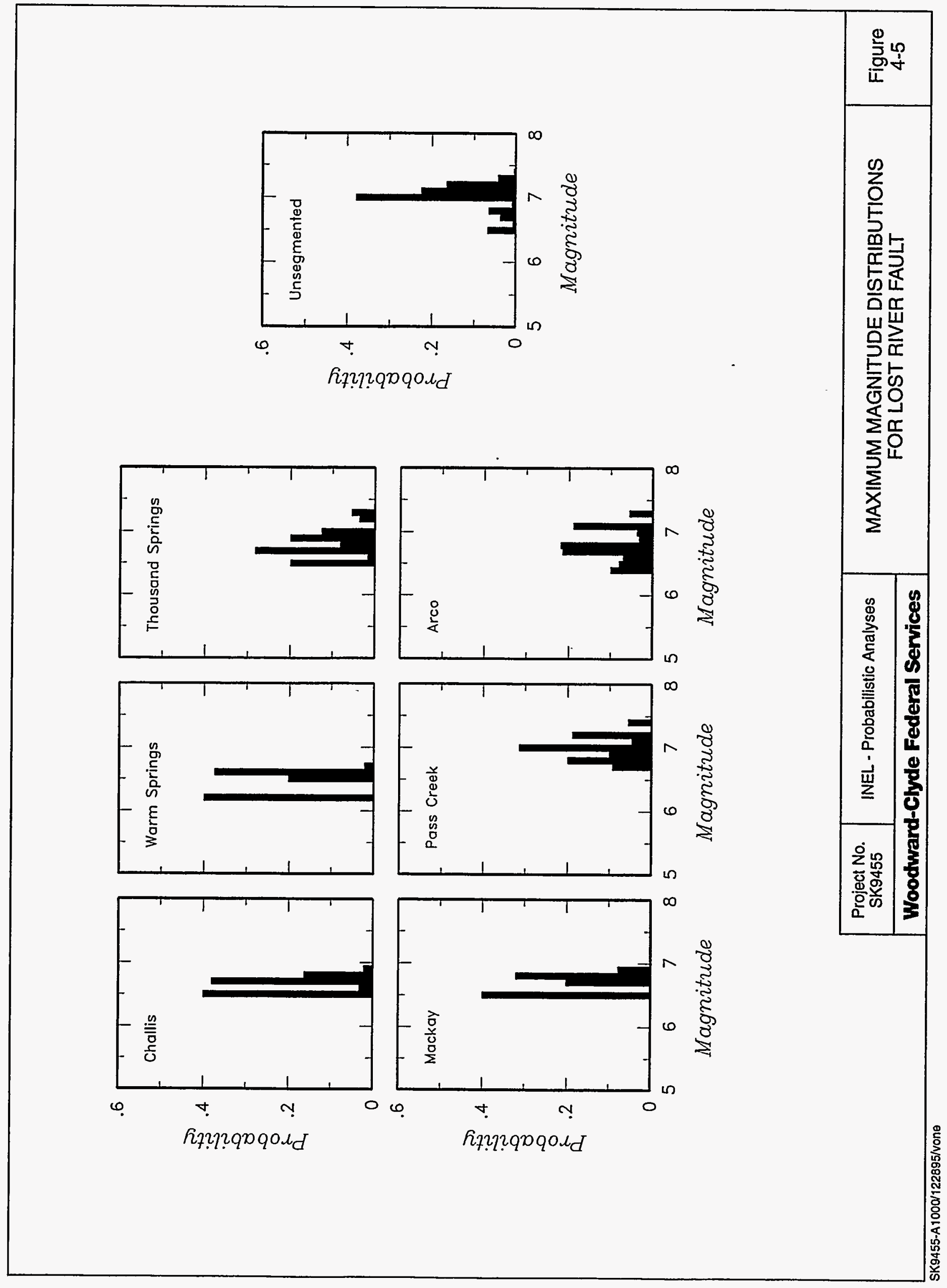




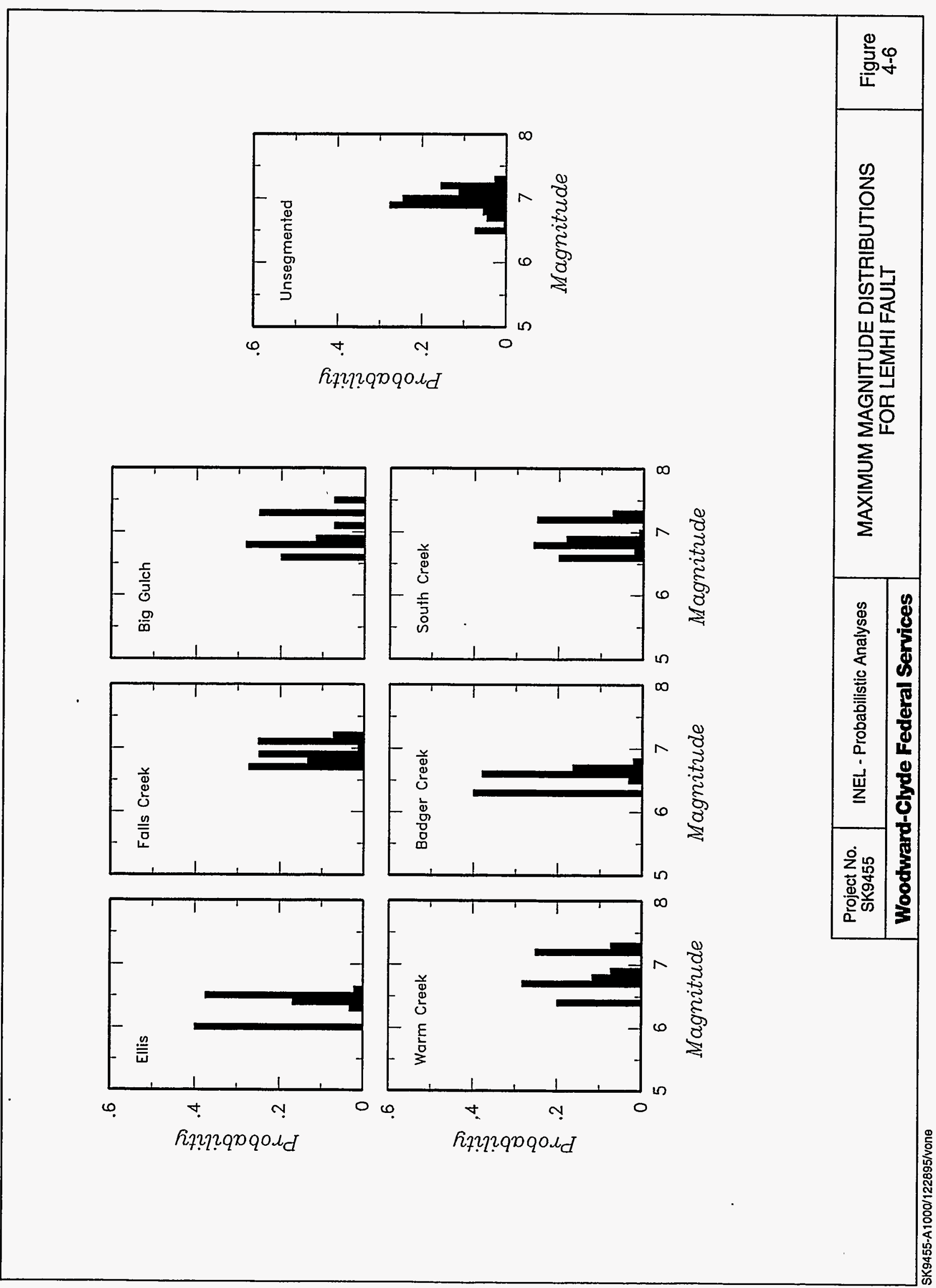




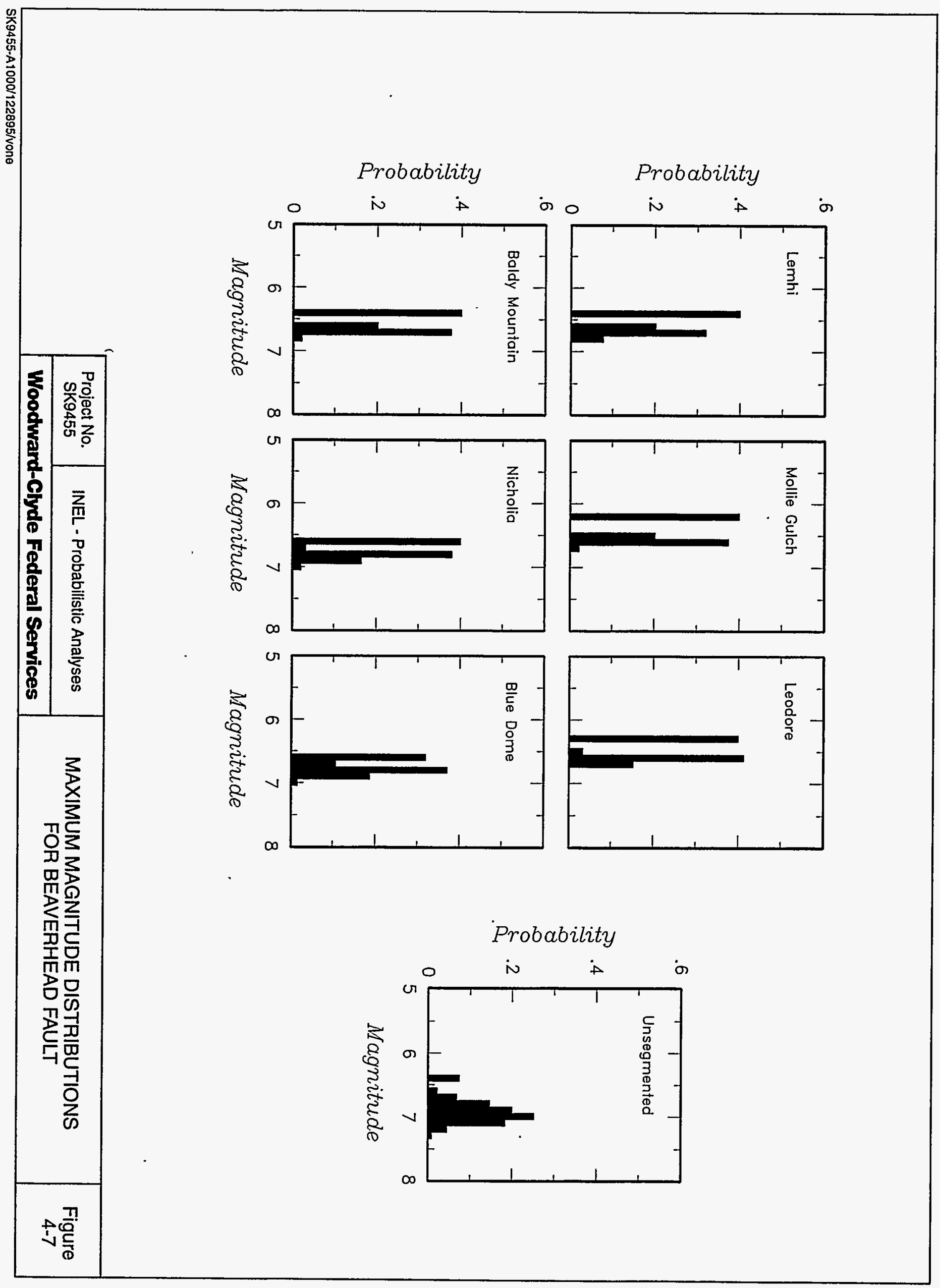


EXPLANATION

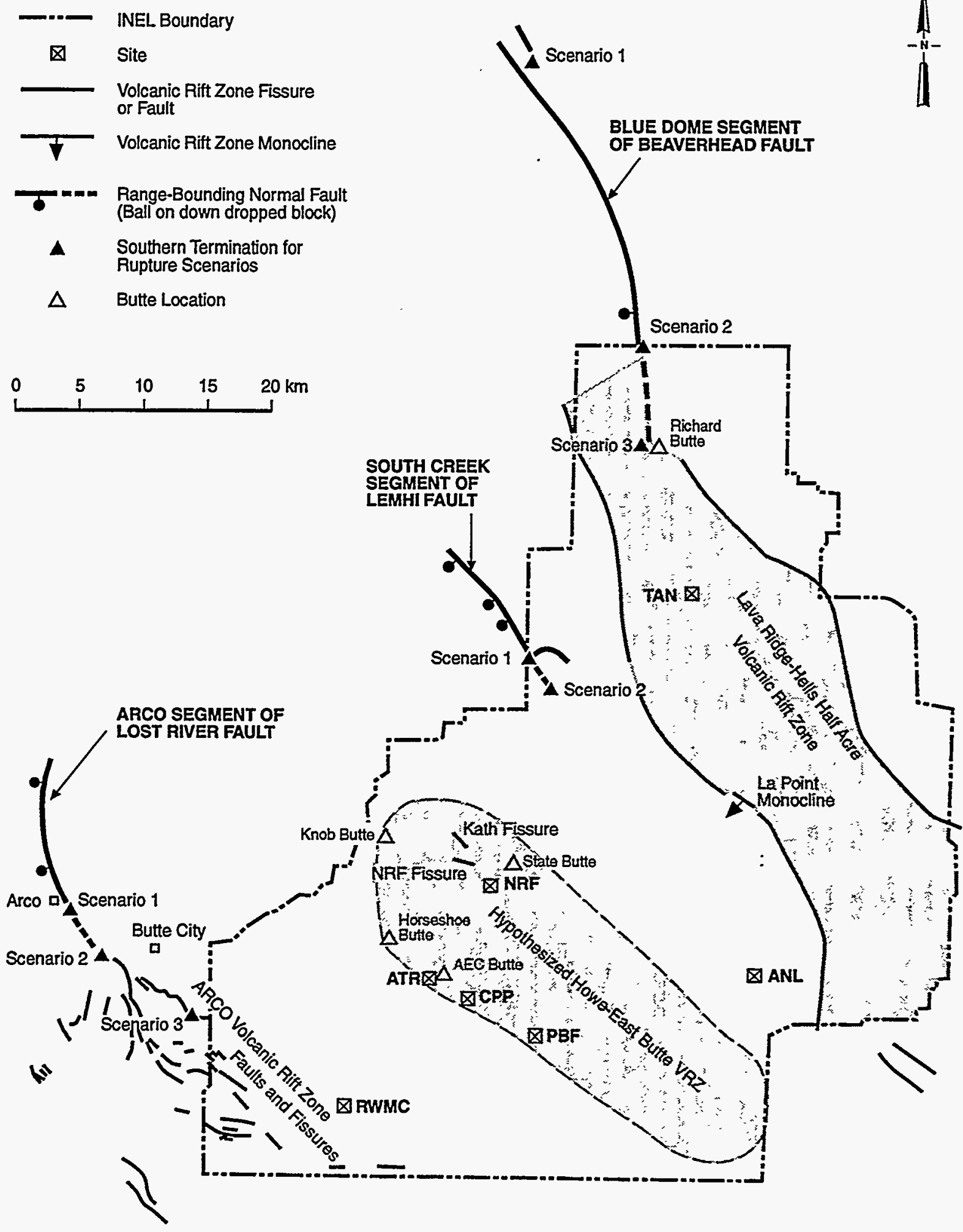

\begin{tabular}{|c|c|c|c|}
\hline $\begin{array}{c}\text { Project No. } \\
\text { SK9455 }\end{array}$ & INEL Probabilistic Analyses & $\begin{array}{c}\text { SOUTHERN TERMINATIONS AND } \\
\text { RUPTURE SCENARIOS FOR FAULTS }\end{array}$ & $\begin{array}{c}\text { Figure } \\
4-8\end{array}$ \\
\hline \multicolumn{2}{|c|}{ Woodward-Clyde Federal Services } & &
\end{tabular}




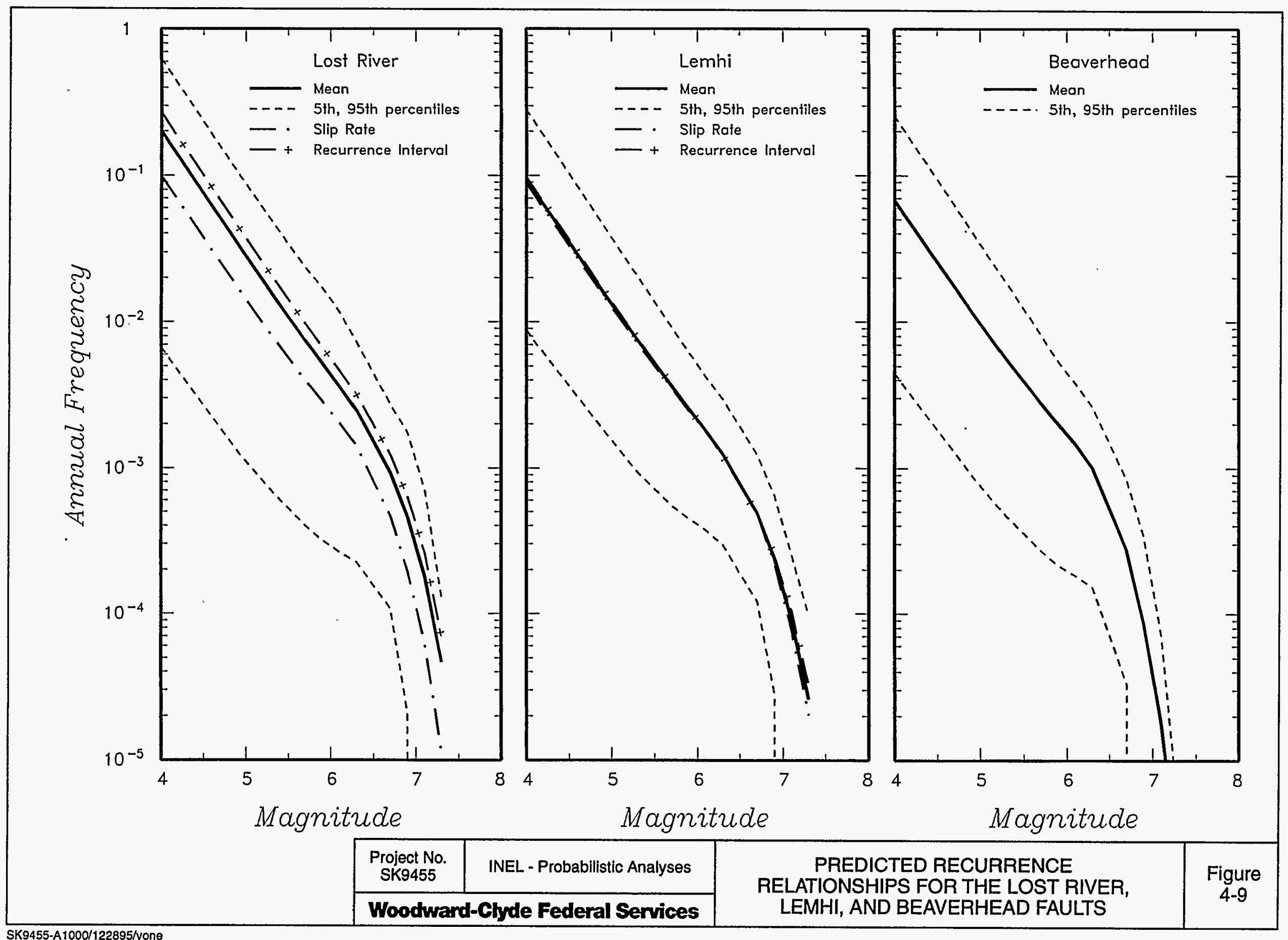



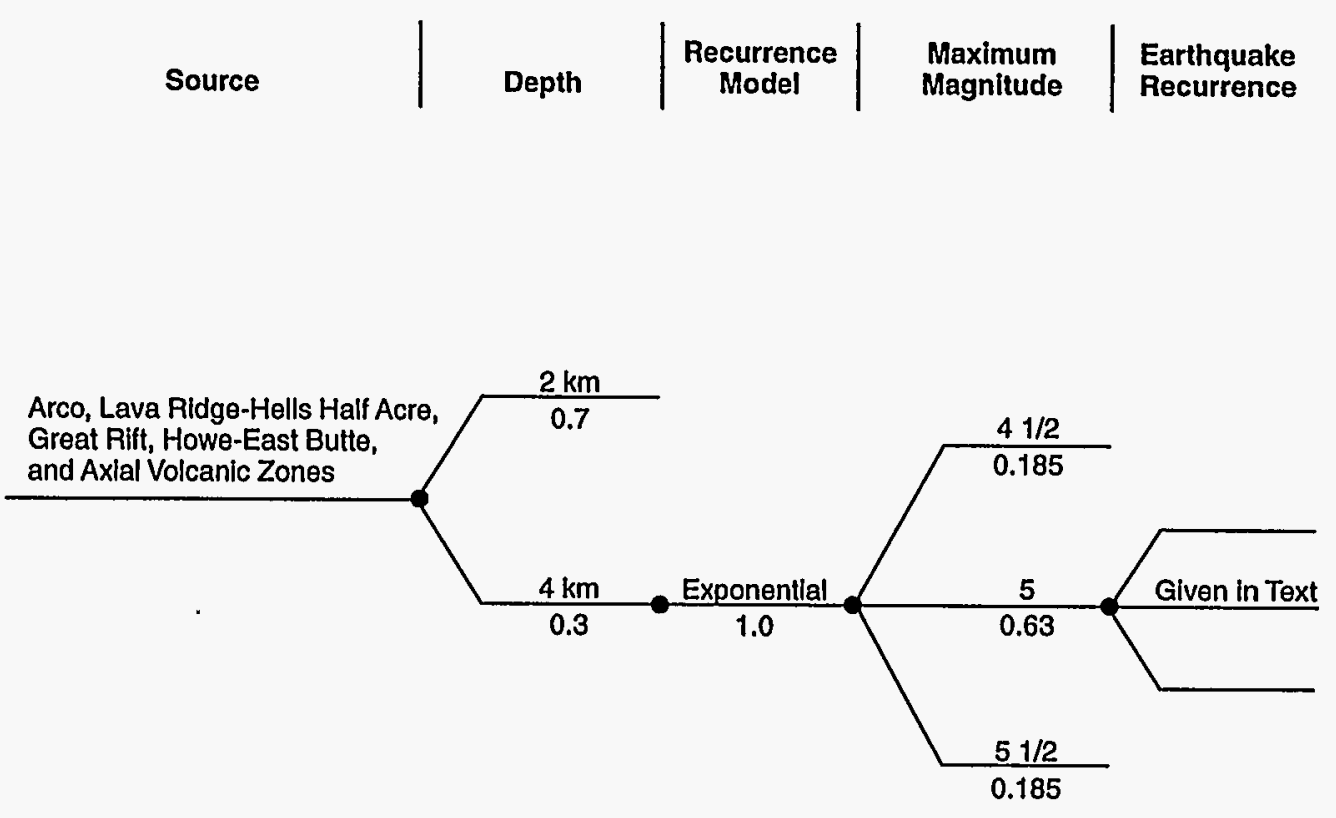

\begin{tabular}{|c|c|c|c|}
\hline $\begin{array}{c}\text { Project No. } \\
\text { SK9455 }\end{array}$ & INEL - Probabilistic Analyses & LOGIC TREE FOR & Figure \\
$4-10$
\end{tabular}




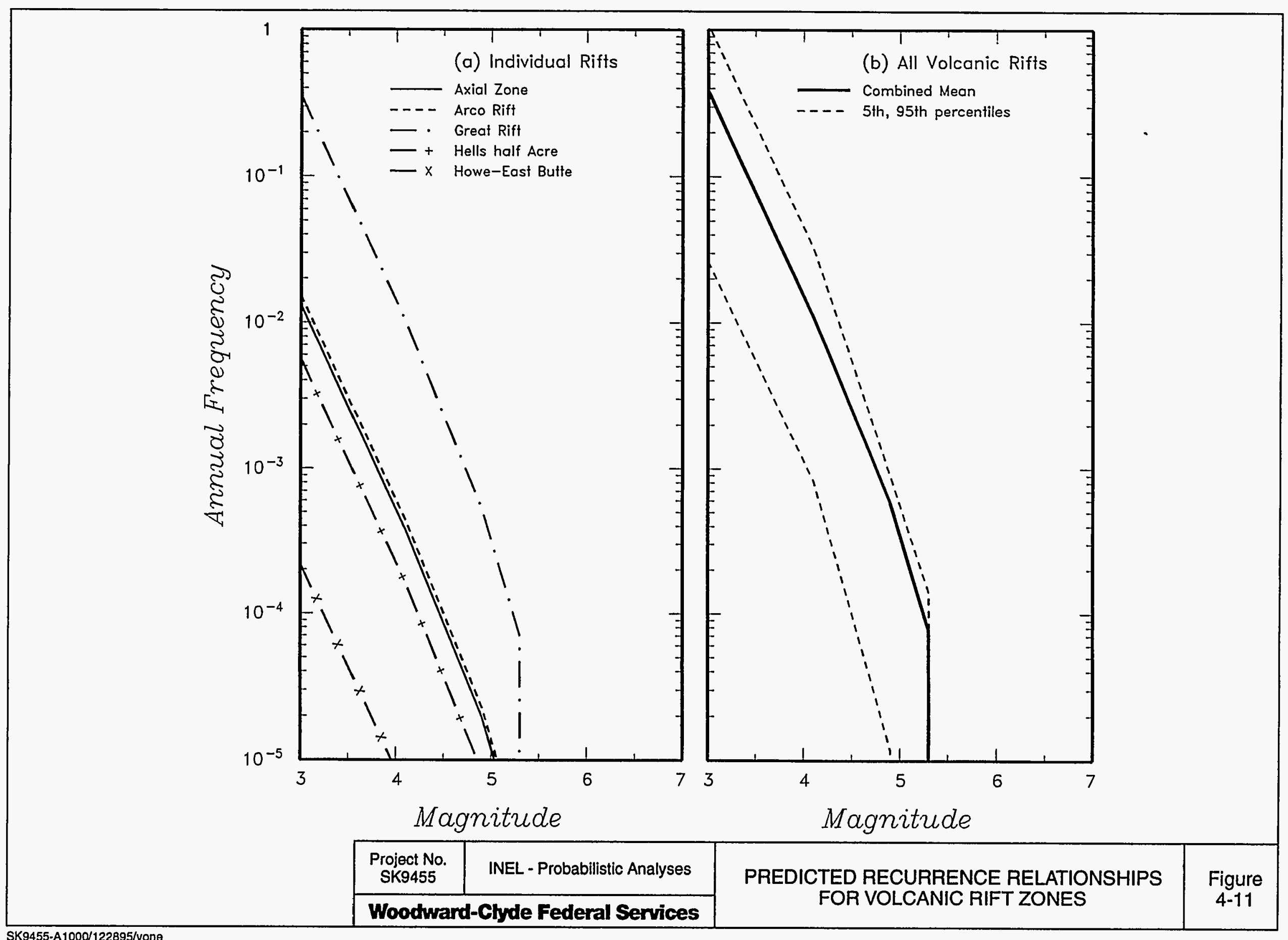




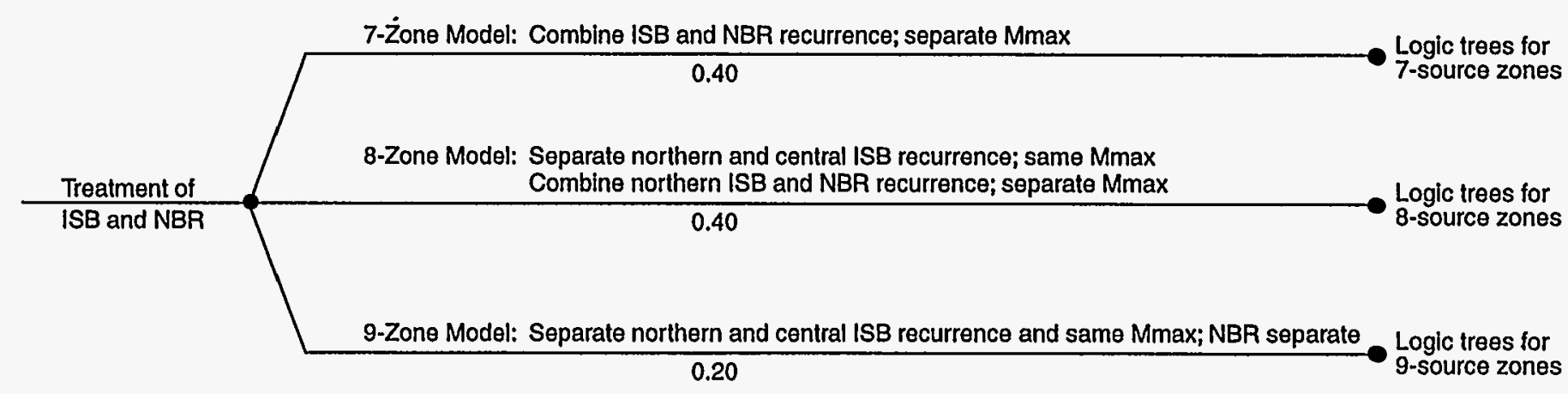

\begin{tabular}{|c|c|c|c|}
\hline $\begin{array}{l}\text { Project No. } \\
\text { SK } 9455\end{array}$ & INEL - Probabilistic Analyses & \multirow{2}{*}{$\begin{array}{l}\text { LOGIC TREE FOR TREATMENT OF } \\
\text { NORTHERN BASIN AND RANGE } \\
\text { AND ISB SEISMIC SOURCE ZONES }\end{array}$} & \multirow{2}{*}{$\begin{array}{c}\text { Figure } \\
4-12\end{array}$} \\
\hline \multicolumn{2}{|c|}{ Woodward-Clyde Federal Services } & & \\
\hline
\end{tabular}




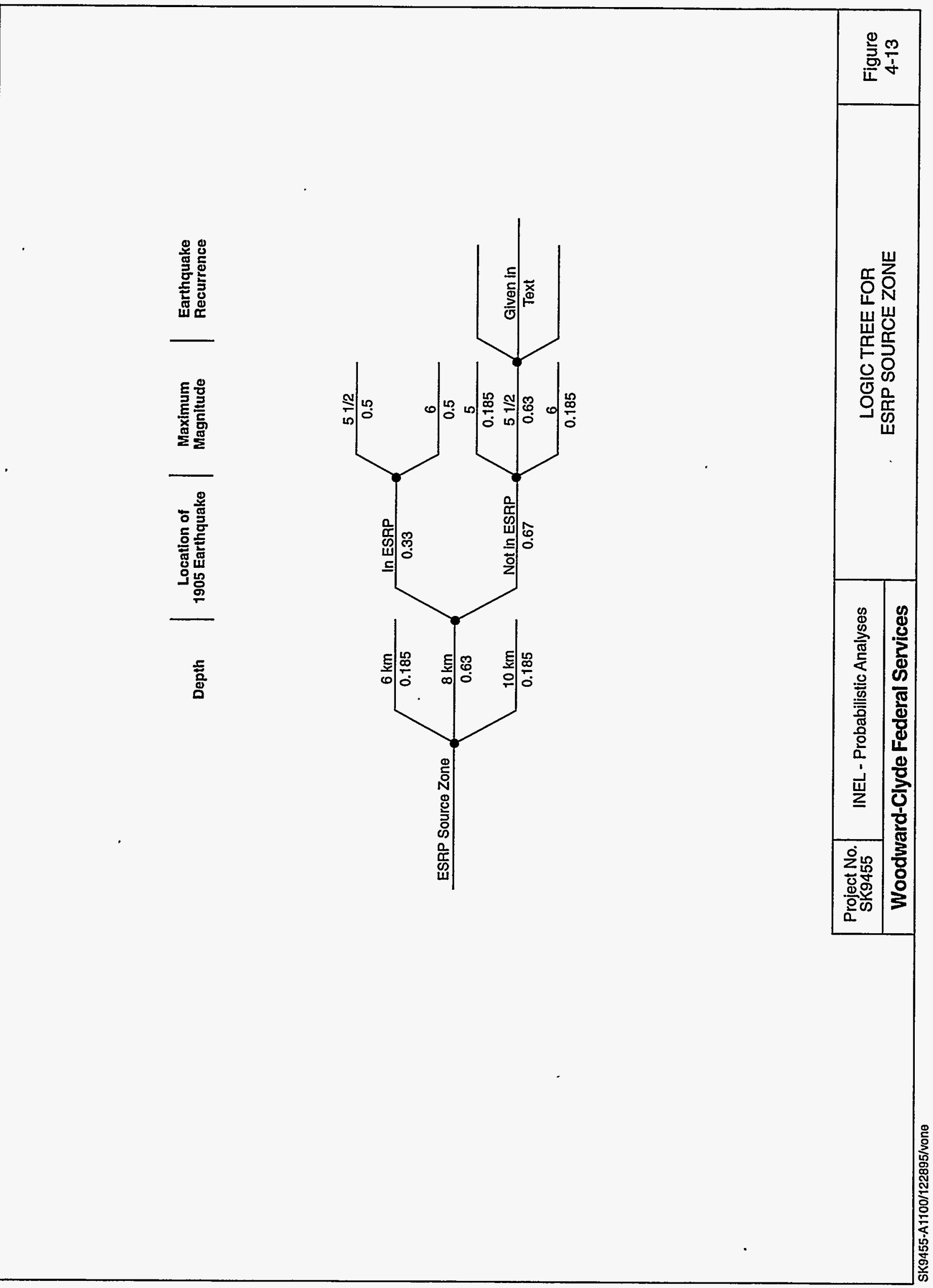




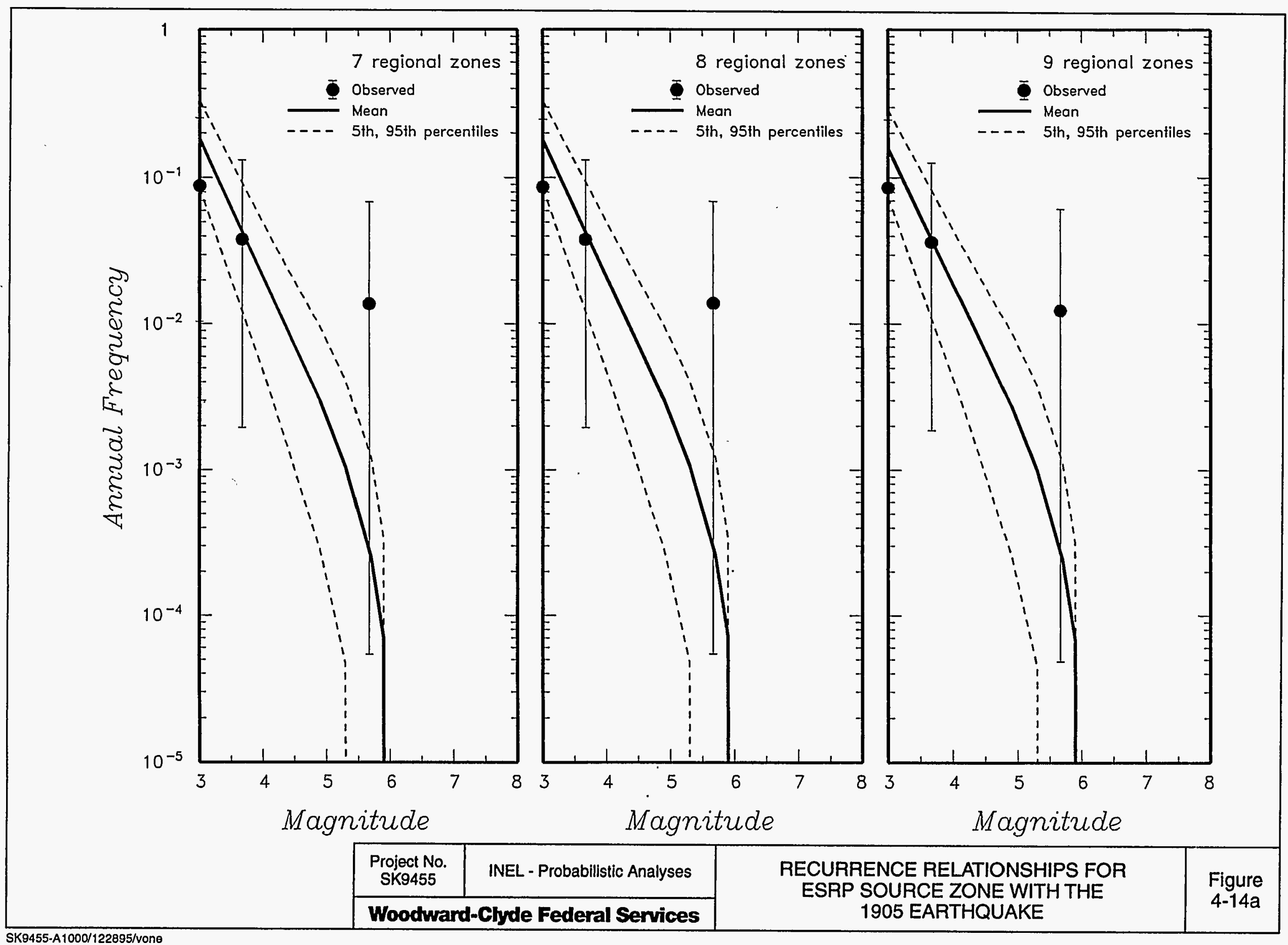




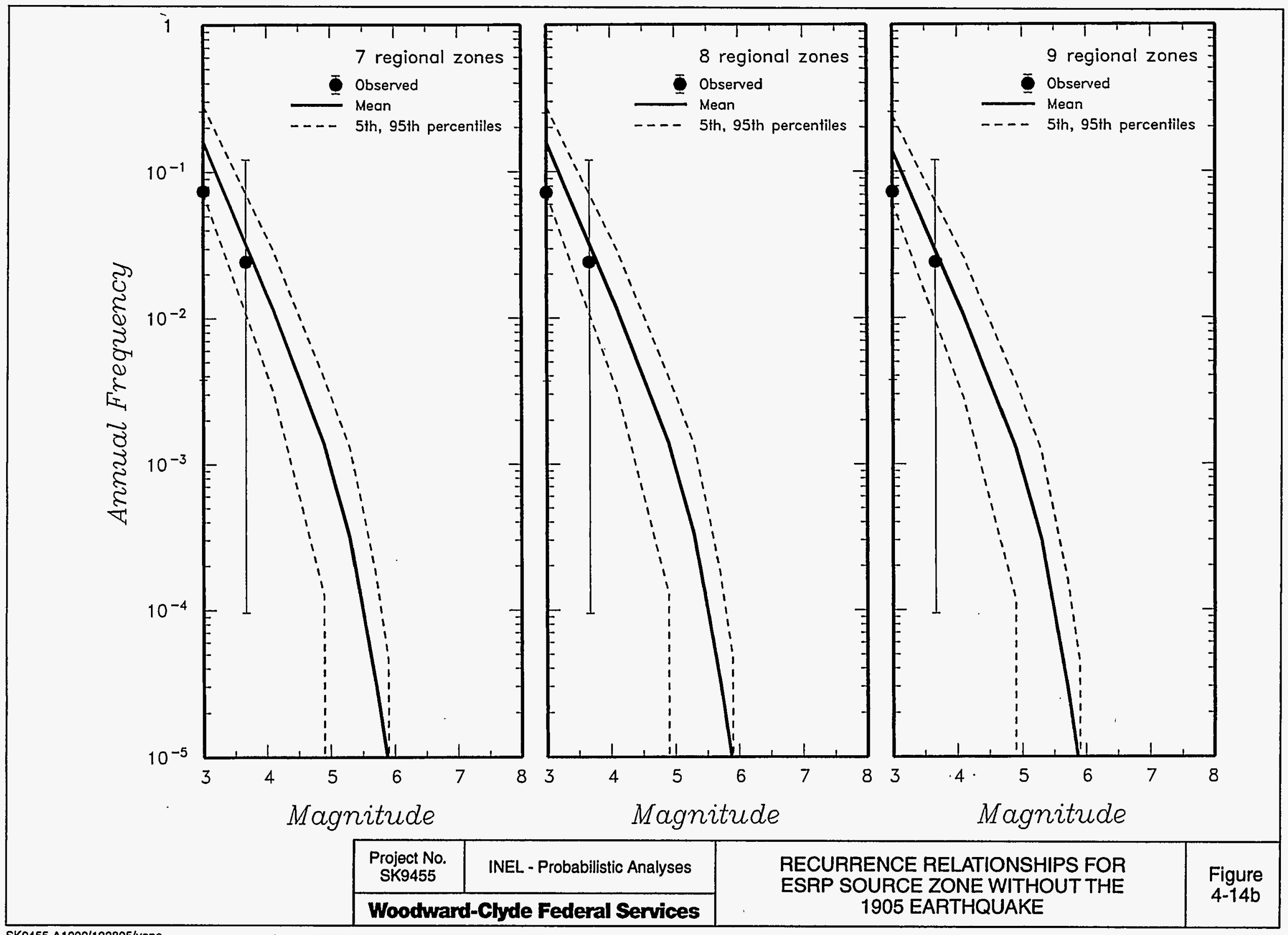




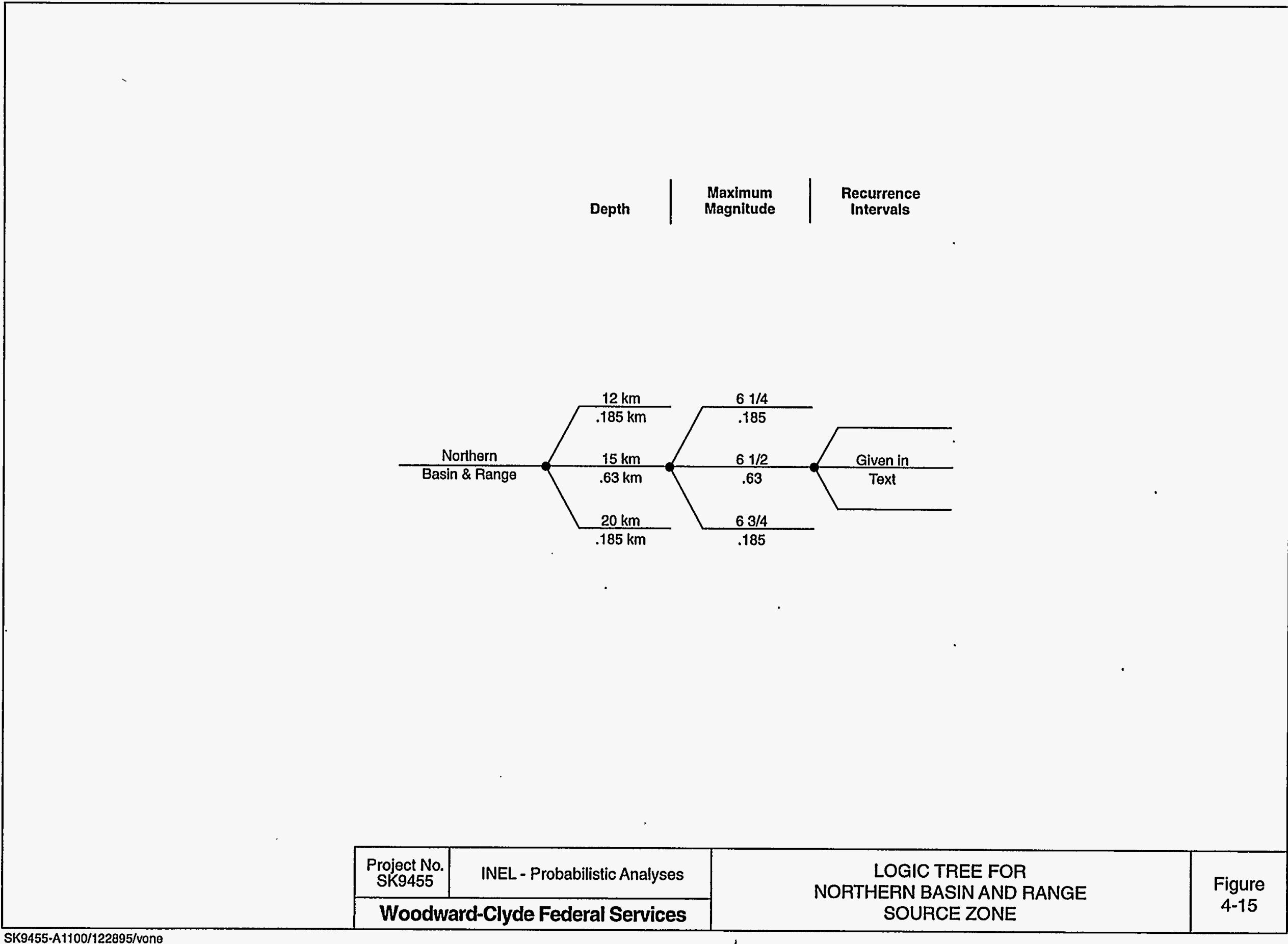




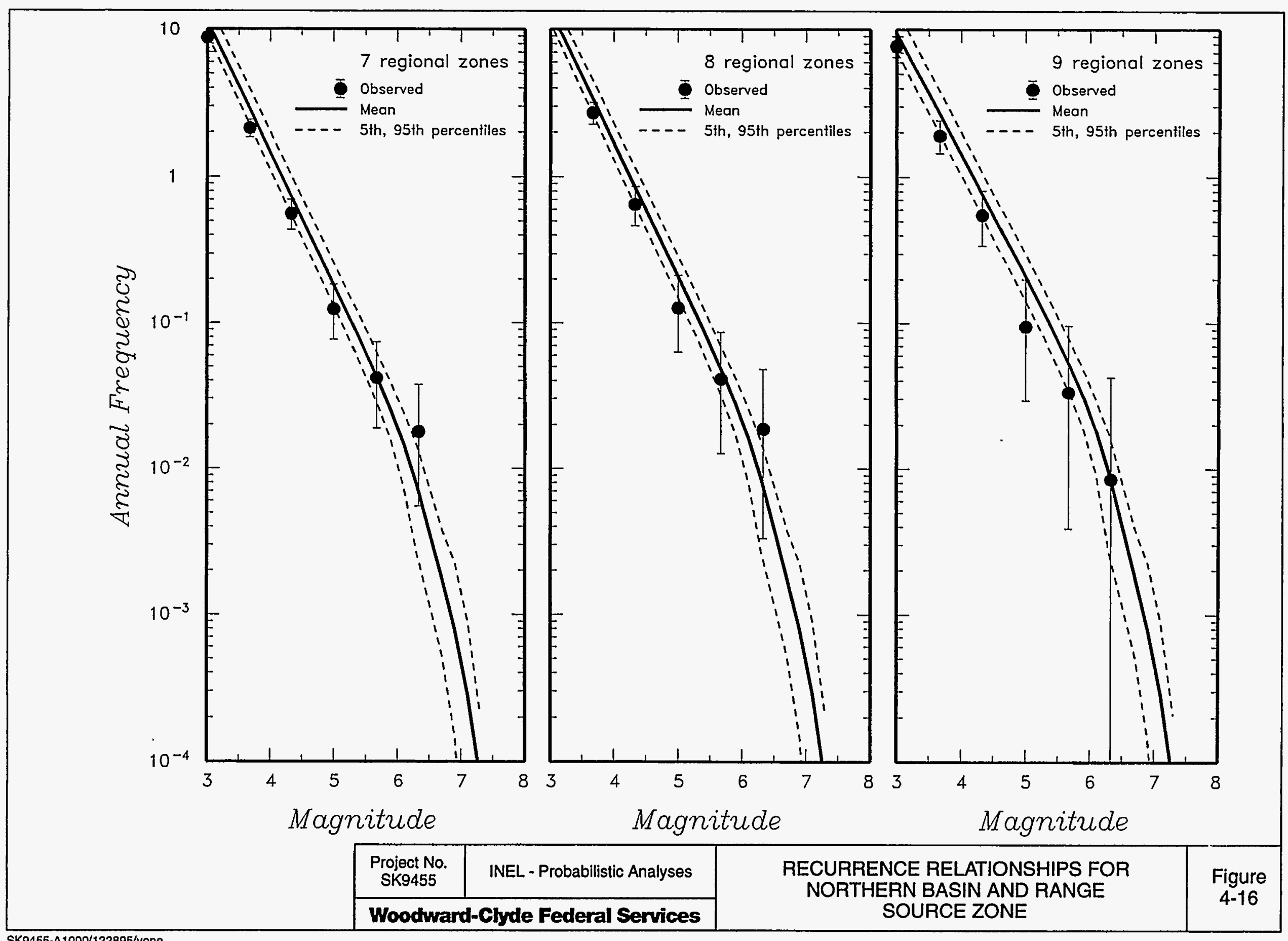




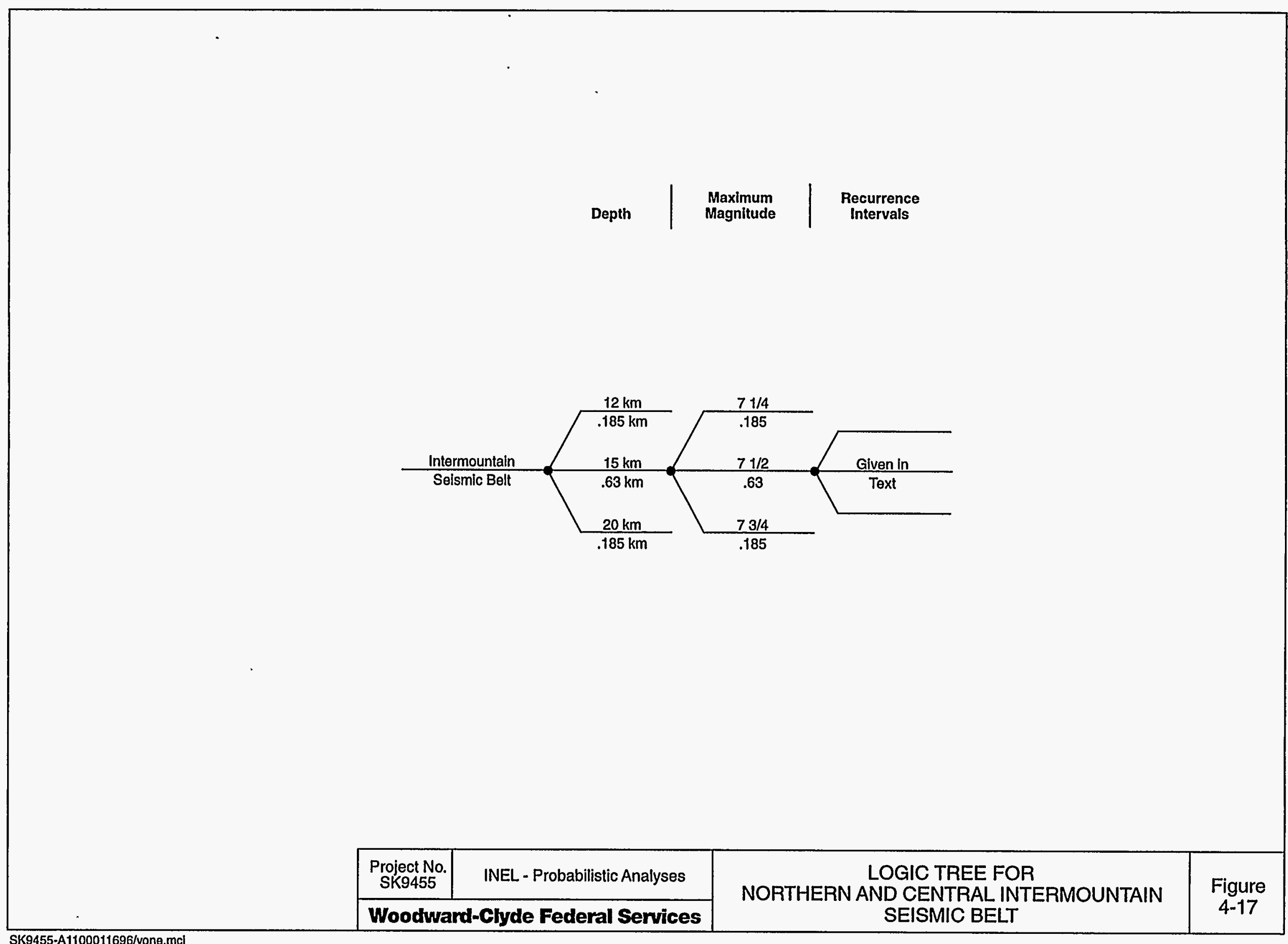




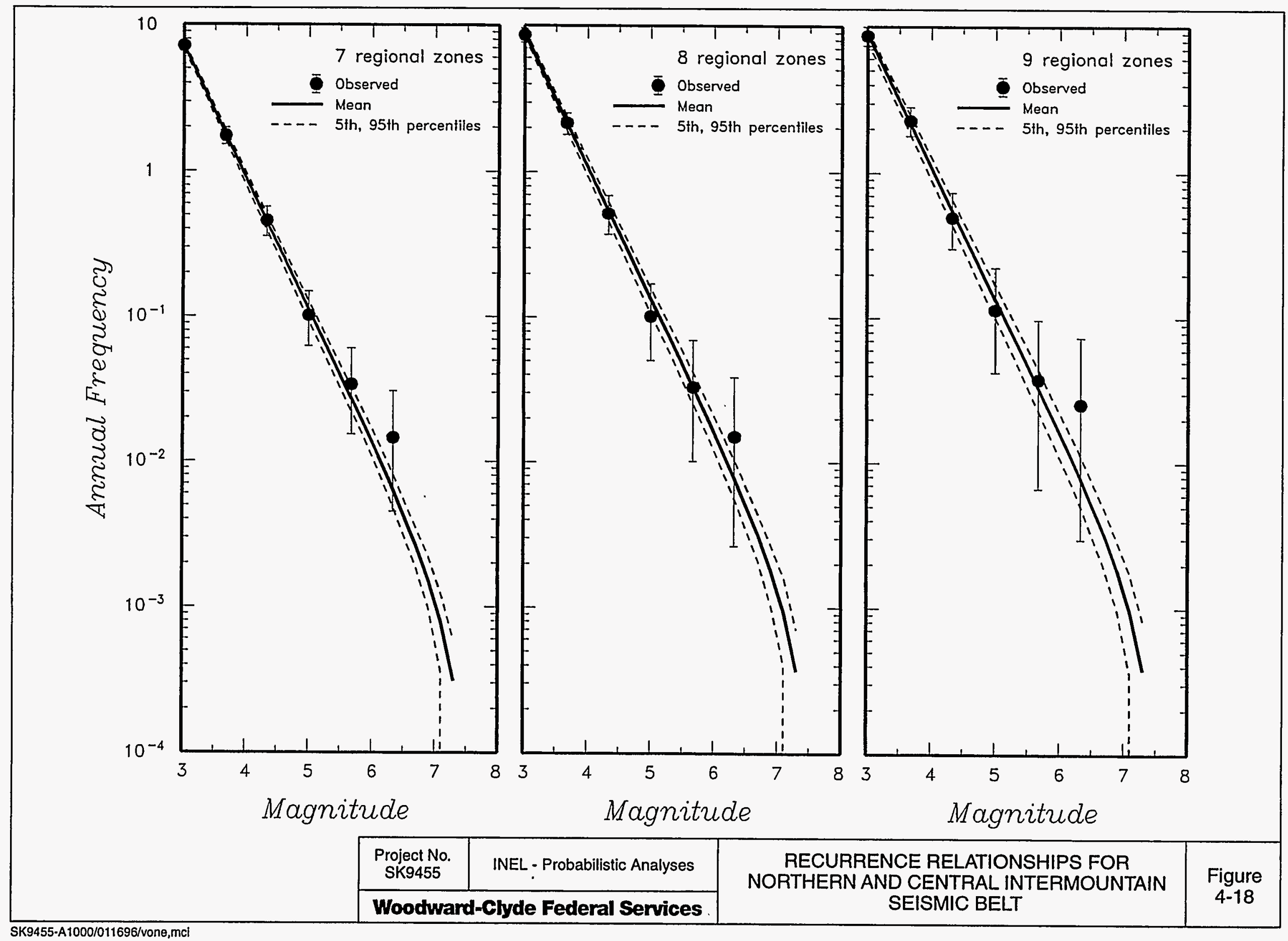

SK9455-A1000/011696/vone,mcl 


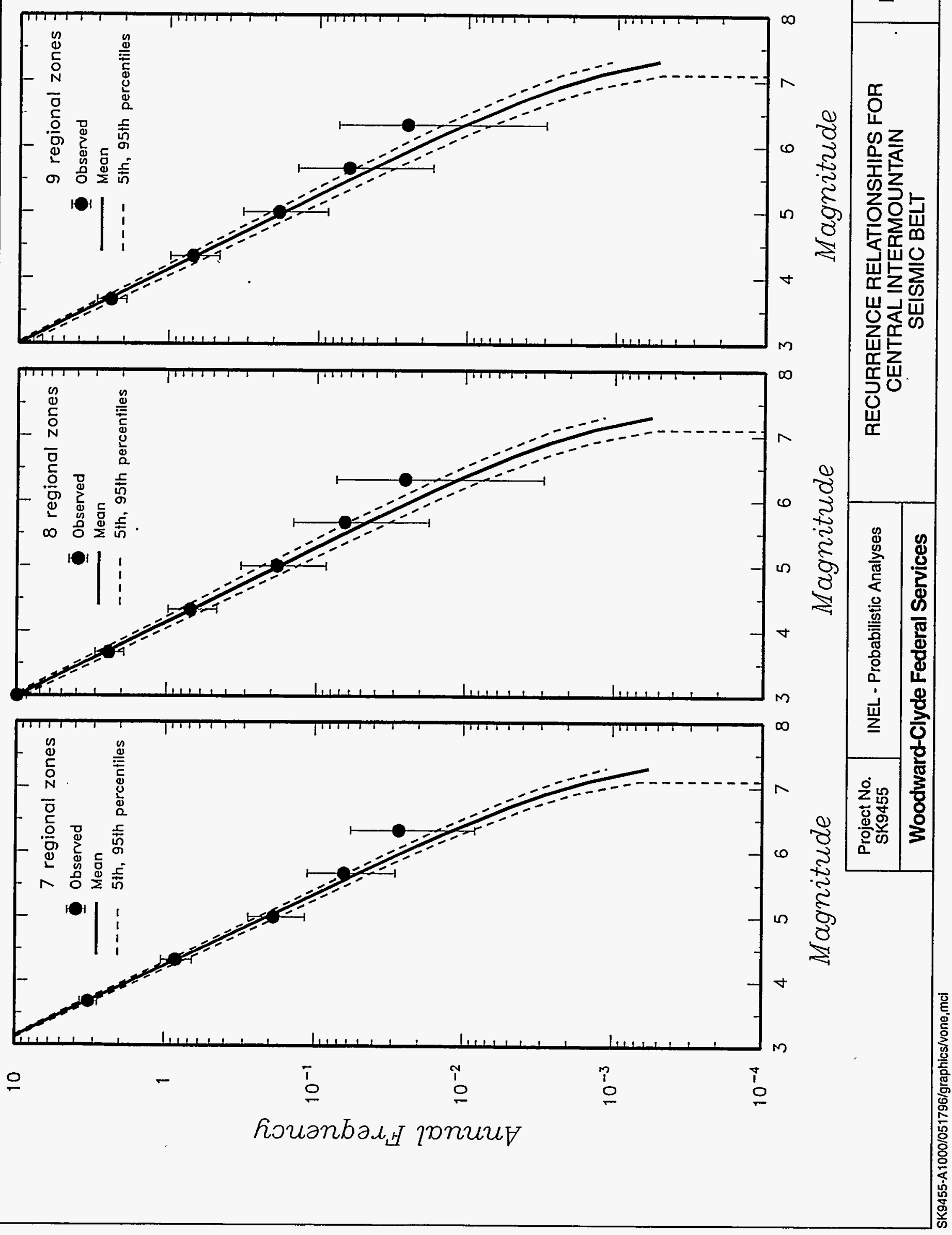




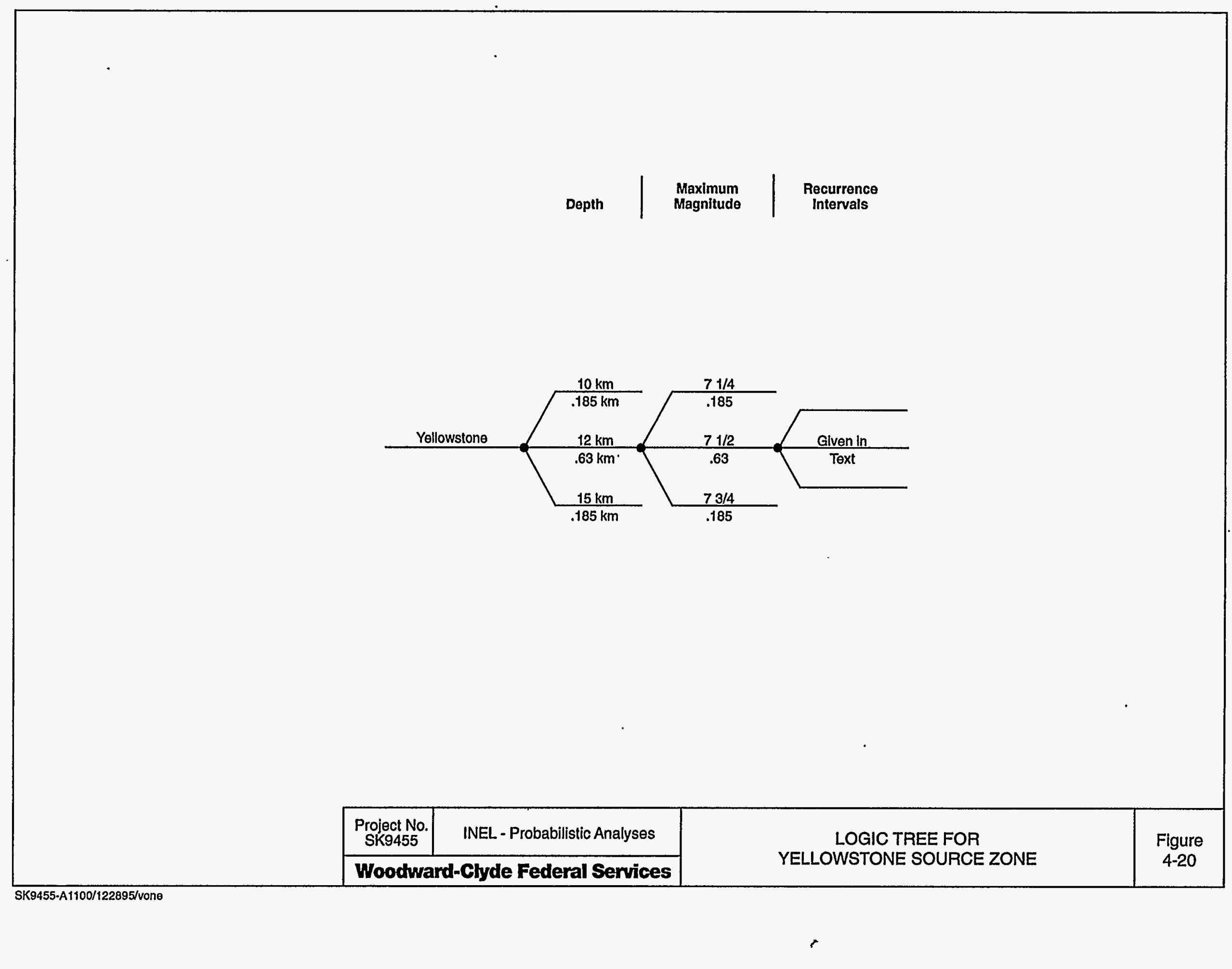




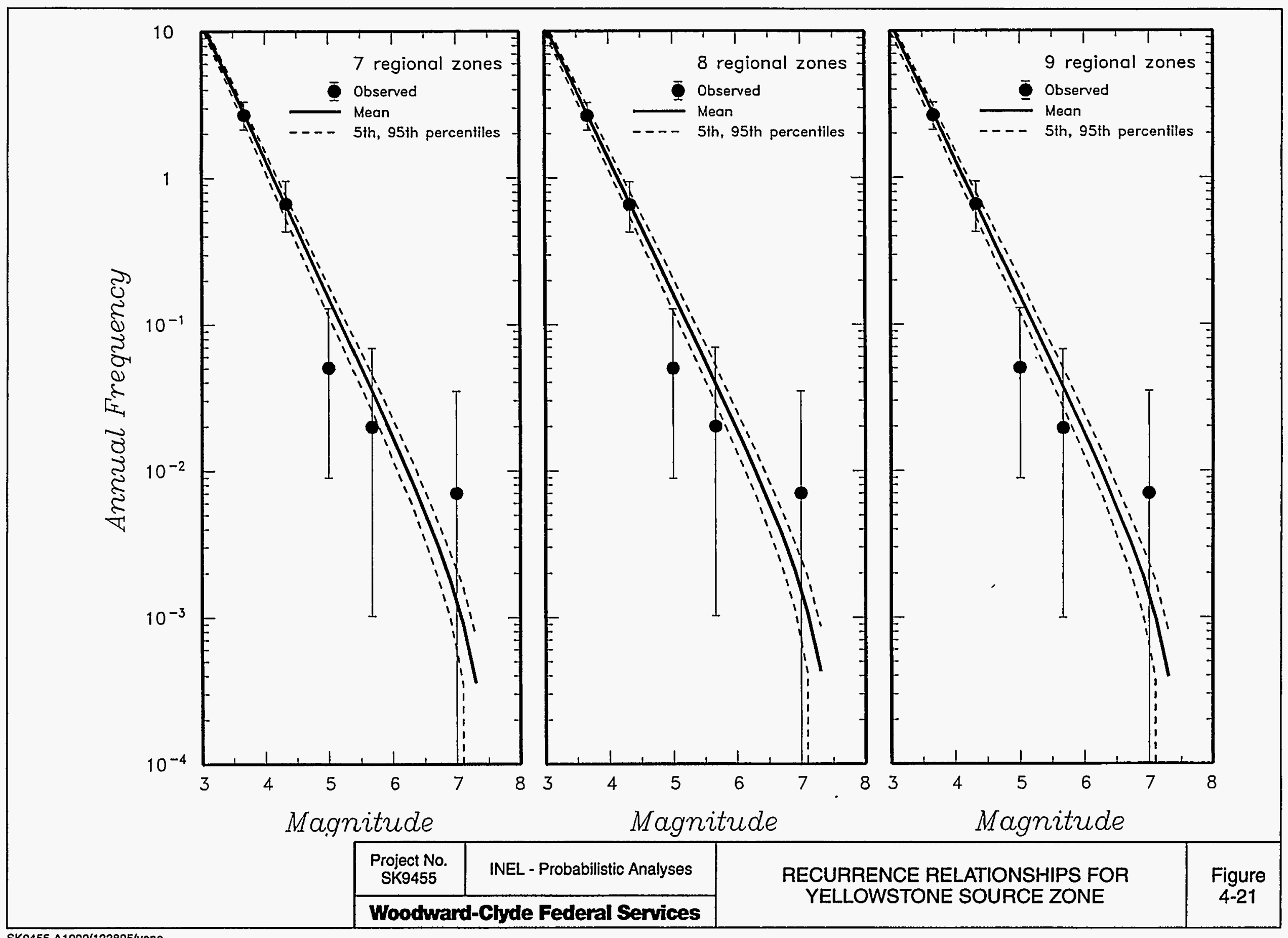




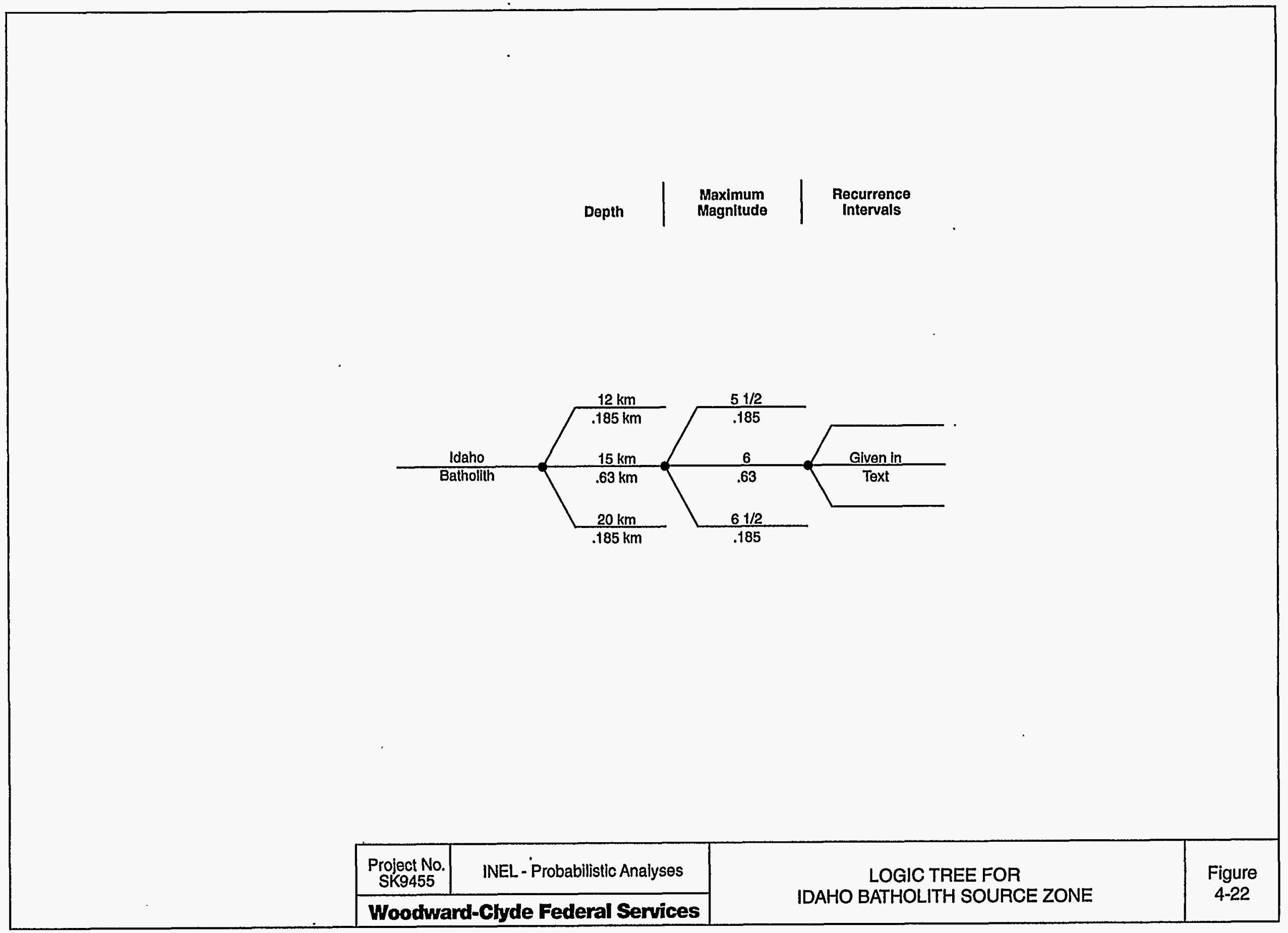




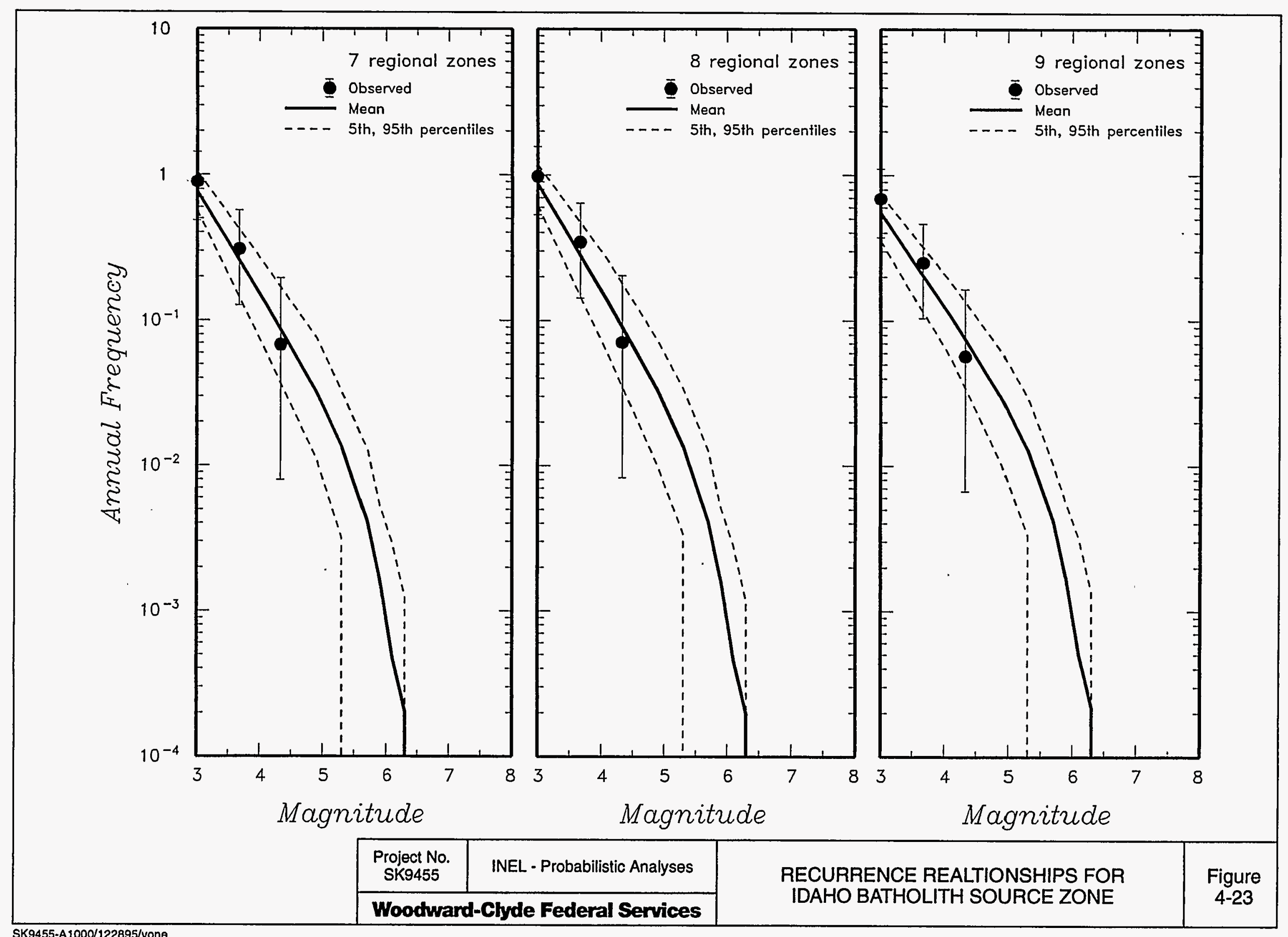




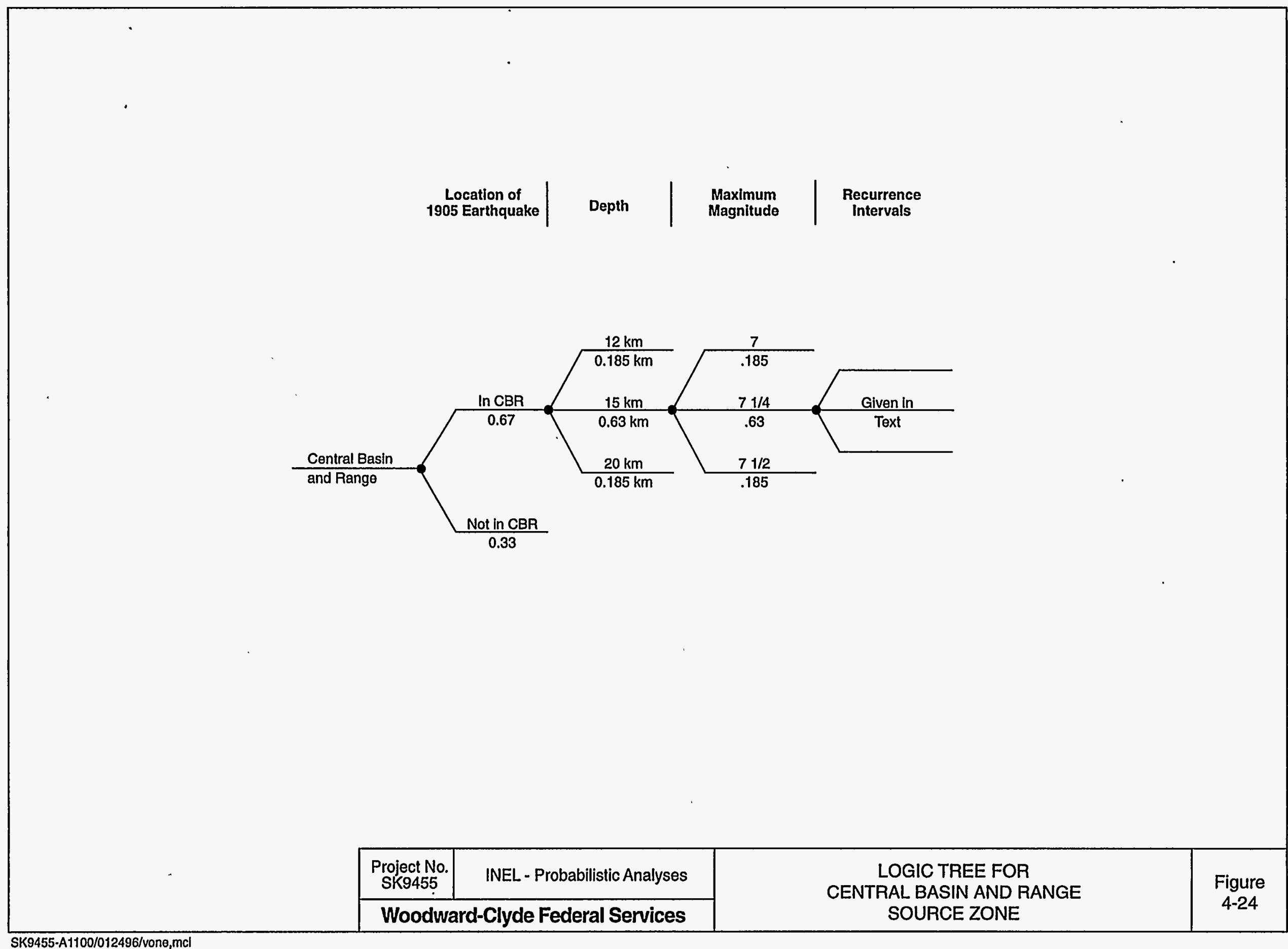




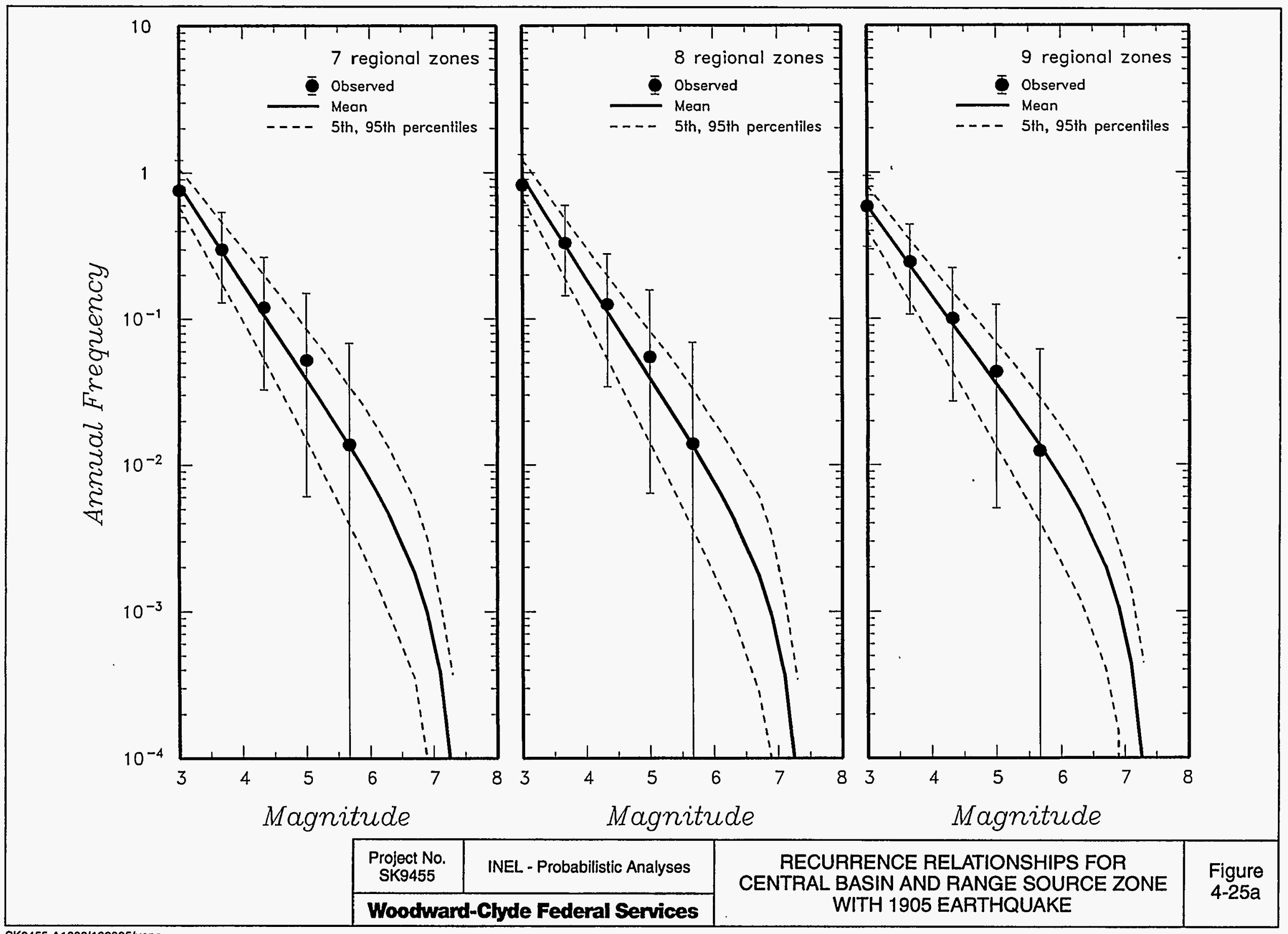




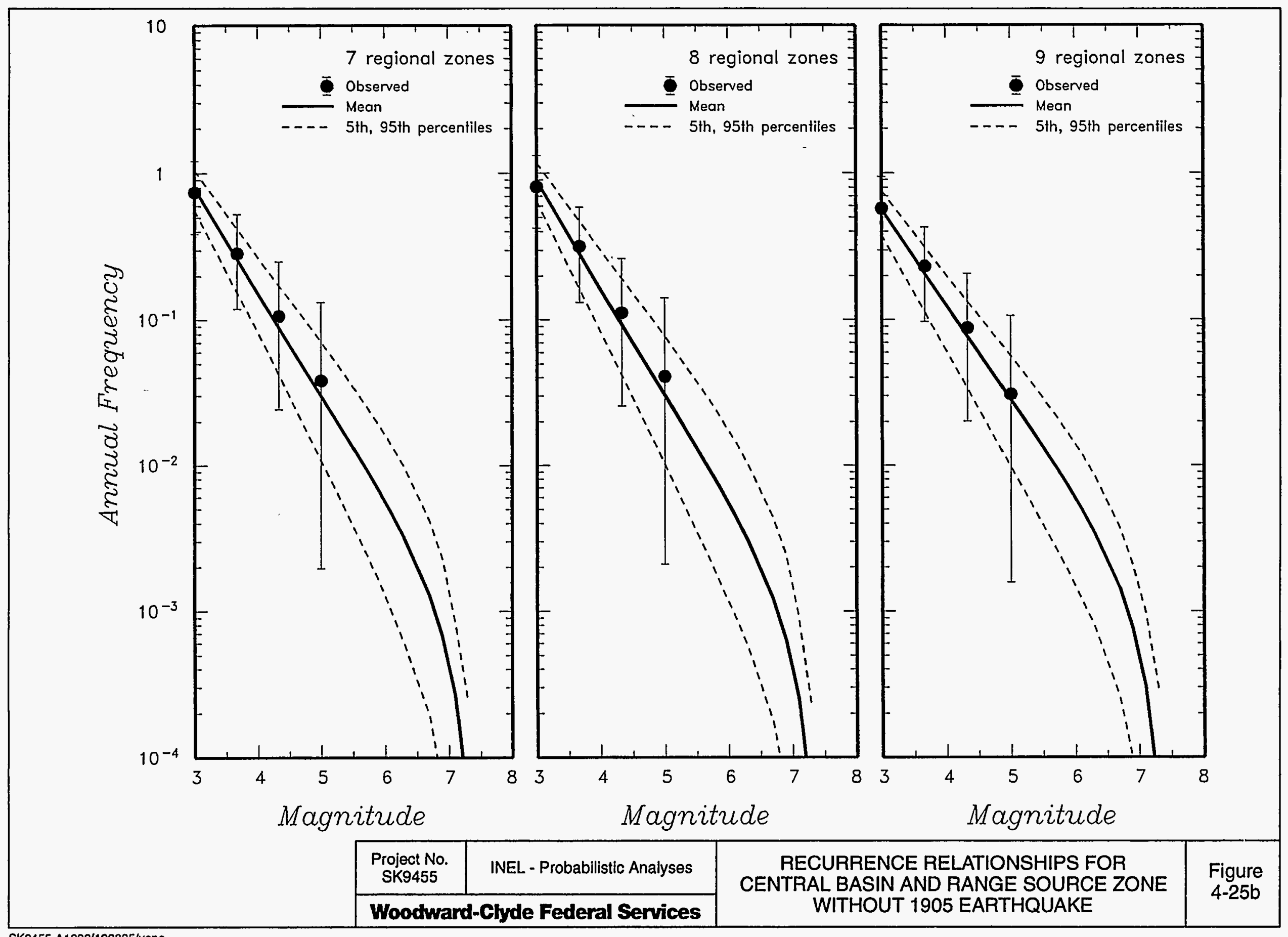


The INEL is located adjacent to the Basin and Range province which is characterized by extensional tectonics and associated normal-faulting earthquakes. There is limited empirical strong ground motion data from the Basin and Range province necessitating the use of empirical data from other regions and direct modeling of ground motions using numerical techniques. The comparisons presented in Woodward-Clyde Consultants (1992a) indicate that empirical attenuation relationships developed to model strike-slip earthquake motions in California provide a reasonable estimate of the ground motions that may be experienced at the INEL from predominantly normal-faulting earthquakes occurring in the region. Thus, four empirical attenuation relationships were used in the analysis to represent the uncertainty in modeling ground motions in the region.

In addition, to incorporate the effects of site geology into the characterization of ground motions, a state-of-the-art stochastic ground motion modeling approach was used to develop site-specific attenuation relationships for each of the seven facility sites. The earthquake source model, called the Band-Limited-White-Noise (BLWN) model, combined with random vibration theory (RVT) is appropriate for an engineering characterization of ground motion since it captures the general features of strong ground motion with a minimum of free parameters. In applications to strong ground motion, this stochastic methodology has been especially effective in the frequency range of engineering interest, 1 to $35 \mathrm{~Hz}$.

\subsection{EMPIRICAL GROUND MOTION RELATIONSHIPS}

Four empirical relationships were chosen to represent the uncertainty in empirical estimation of ground motions: Joyner and Boore (1982), Idriss (1991), Sadigh et al. (1993), and Campbell (EQE International, written communication, 1994; cited in future as Campbell [1994]) (Figure 5-1). The relationships developed by Sadigh et al. (1993) and Campbell (1994) represent the latest efforts of researchers to analyze the available recorded strong motion data and were developed as part of the seismic safety review of the Diablo Canyon 
Nuclear Power Plant. The relationships developed by Sadigh et al. (1993) are based on analysis of strong motion data recorded on rock sites, including data recorded during the $1989 M_{w} 7.0$ Loma Prieta, California earthquake. The relationships developed by Campbell (1994) combine the peak acceleration attenuation relationships developed by Campbell and Bozognia (1994) with the spectral attenuation relationships developed by Campbell (1993) and explicitly include factors for predicting ground motions on hard rock sites. The relationships developed by Idriss (1991) are also based on evaluations of the extensive rock site strong motion data set from California. The relationships for the standard error were revised by Idriss (University of California at Davis, written communication, 1993). The relationships developed by Joyner and Boore (1982) are less current than the other three, but they are the standard by which many other relationships are evaluated and they represent an alternative approach to modeling the empirical data. The relationships of Campbell (1994), Idriss (1991), and Sadigh et al. (1993) include a term to account for differences between reverse faulting earthquakes and other styles of faulting. They all consider that normal faulting earthquakes produce ground motions similar to strike-slip earthquakes.

Figure 5-1 compares the four sets of median peak horizontal acceleration relationships for $M_{w} 5,6$, and 7 earthquakes. The relationships all define magnitude in terms of $M_{w}$. As shown, all four relationships yield similar estimates, except at very close distances to the fault. Part of the differences in the empirical relationships at close source-to-site distances is due to the different distance measures used by the four sets of relationships. Joyner and Boore (1982) used shortest horizontal distance to the surface projection of the earthquake rupture. Idriss (1991) and Sadigh et al. (1993) used the shortest distance to the fault rupture plane. Campbell (1994) used the shortest distance to the fault rupture plane at a depth where high-frequency seismic waves can be generated (typically at depths of 2 to $4 \mathrm{~km}$ ). Use of the four relationships provides a measure of the uncertainty in modeling earthquake ground motions in the near-field. The comparisons shown on Figure 5-1 were developed considering the distance to a vertical strike-slip fault with a seismogenic depth of $2 \mathrm{~km}$ used for the Campbell attenuation relationship.

Figures 5-2a and 5-2b compare the median 5\%-damped response spectra predicted by the four sets of relationships for $M_{w}, 5,6$, and 7 events at a distances of 15 and $50 \mathrm{~km}$, 
respectively. The four relationships tend to diverge in their estimates of the response spectra for smaller magnitude events.

Figure 5-3 compares the estimates of the standard error in the natural log of peak ground motion used by each of the relationships. The Campbell (1994), Idriss (1991), and Sadigh et al. (1993) relationships incorporate magnitude-dependent values of standard error.

\subsection{STOCHASTIC GROÚND MOTION RELATIONSHIPS}

The BLWN-RVT approach was used to develop site-specific attenuation relationships for use in the hazard analysis. The following describes the BLWN-RVT point-source methodology and its application in developing site-specific attenuation relationships. Both point source and finite fault versions of the methodology have been developed. The latter is described in Woodward-Clyde Consultants (1992a).

\subsubsection{Band-Limited-White-Noise Point Source Model}

The BLWN ground motion model first developed by Hanks and McGuire (1981) (sometimes referred to as the stochastic model), in which the energy is distributed randomly over the duration of the source, has proven remarkably effective in correlating with a wide range of ground motion observations. Time-domain measures, such as peak acceleration and peak velocity, Wood-Anderson magnitude, and short-period P- and S-wave amplitudes, as well as frequency domain measures, such as relative velocity response and Fourier amplitude spectra, have been predicted with reasonable accuracy using the BLWN ground motion model (Hanks and McGuire, 1981; Boore, 1983, 1986; Boore and Atkinson, 1987; Silva and Lee, 1987; Toro and McGuire, 1987). The ground motion model employed here uses an $\omega^{-2}$ Brune source model (Brune, 1970, 1971) with a single corner frequency and a constant-stress parameter (Boore, 1983; Atkinson, 1984). 
The acceleration spectral density $a(f)$, where $f$ is frequency, is given by

$$
a(f)=C \frac{f^{\prime}}{1+\left(f f f^{2}\right)^{2}} \frac{M_{0}}{R} P(f) A(f) e^{-\overline{\beta_{0} Q(f)}}
$$

where:

$$
\begin{array}{ll}
M_{o}= & \text { Seismic moment } \\
R= & \text { Distance to the equivalent point source } \\
\beta_{o}= & \text { Shear-wave velocity at the source } \\
Q(f)= & \text { Frequency-dependent quality factor model where } Q(f)=Q_{0} f^{\prime} ; Q_{o} \\
& \text { and } \eta \text { are model parameters } \\
A(f)= & \text { Near-surface amplification factors } \\
P(f)= & \text { High-frequency truncation filter } \\
f_{c}= & \text { Source corner frequency and } \\
\mathrm{C}= & \left(1 / \rho_{0} \beta_{o}{ }^{3}\right) \times(2) \times(0.55) \times(1 / 2) \times \pi .
\end{array}
$$

C is a constant which contains source region density $\rho_{o}$ and shear-wave velocity terms and accounts for the free-surface effect (factor of 2), the source radiation pattern averaged over a sphere (0.55) (Boore, 1986), and the partition of energy into two horizontal components $(1 / N 2)$.

Source scaling is provided by specifying two independent parameters, the seismic moment $\left(\mathrm{M}_{\mathrm{o}}\right)$ and the high-frequency stress parameter $(\Delta \sigma)$ (Figure 5-4). The seismic moment is related to $\mathrm{M}_{\mathrm{w}}$ by the relation

$$
\log \mathrm{M}_{0}=1.5 \mathrm{M}_{\mathrm{w}}+16.1
$$

The stress parameter $\Delta \sigma$ relates the corner frequency $f_{c}$ to $M_{0}$ through the relation

$$
\mathrm{f}_{\mathrm{c}}=\beta_{\mathrm{o}}\left(\Delta \sigma / 8.44 \mathrm{M}_{\mathrm{o}}\right)^{1 / 3}
$$


The spectral shape of the single-corner-frequency $\omega^{-2}$ source model is then described by the two free parameters $M_{o}$ and $\Delta \sigma$. The corner frequency increases with the shear-wave velocity and with increasing stress, both of which are region dependent.

\subsubsection{Random Vibration Theory}

In order to compute peak time-domain values, i.e., peak acceleration, peak particle velocity, and peak oscillator response, RVT is used to relate rms calculations to peak value estimates (Boore, 1983; Boore and Joyner, 1984). The procedure, in general, involves computing the rms value by integrating the power spectrum from zero frequency to the Nyquist frequency and applying Parseval's relation. Extreme value theory is then used to estimate the expected ratio of the peak value to the rms value of a specified duration of the BLWN time history. The duration is generally taken as the inverse of the comer frequency (Boore, 1983).

\subsubsection{Stress Drop}

The stress parameter, for earthquakes which have a source spectrum consistent with a singlecorner-frequency $\omega^{-2}$ model, is the stress drop of the earthquake. In this case, the stress drop may be computed by determining $M_{0}$ and $f_{c}$ and inverting Equation 5-3 and is generally referred to as the Brune stress drop. A convenient way of assessing the appropriateness of the BLWN source model used here is to compare stress drops using Equation 5-3 with the root-mean-square (rms) stress drops, both computed from data recorded in the region of interest.

The rms stress drop was introduced by Hanks (1979) and is defined as the stress drop required in the single-corner-frequency $\omega^{-2}$ Brune model to predict observed rms accelerations. If both the rms stress drops and the Brune stress drops are equivalent, then the observed source spectra are consistent with Equation 5-1. 


\subsubsection{Near-Surface Crustal Amplification}

In a half-space model, the near-surface amplification factors, $A(f)$, account for the increase in amplitude as the seismic energy travels through lower velocity crustal materials near the surface (Boore, 1986; Silva and Darragh, 1995) (Figure 5-4). These factors depend on average crustal and near-surface shear-wave velocity and density. In this study, amplification by near-surface velocity gradients is accounted for in the detailed velocity model.

\subsubsection{Near-Surface Crustal Damping}

The $P(f)$ filter models the observation that acceleration spectral density appears to fall off rapidly beyond some region-dependent maximum frequency. This observed phenomenon truncates the high frequency portion of the spectrum and is responsible for the band-limited nature of the stochastic model. This spectral fall-off has been attributed to near-site attenuation (Hanks, 1982; Anderson and Hough, 1984) or to source processes (Papageorgiou and Aki, 1983) or perhaps to both effects. Hanks (1982) ternied the phrase $f_{\max }$ to describe this site-dependent corner frequency. In the Anderson and Hough (1984) attenuation model, which is adopted in this study, the form of the $P(f)$ filter is taken as

$$
P(f)=e^{-\pi k(r) f}
$$

$\kappa(r)$ is a site- and distance-dependent parameter that represents the effect of intrinsic attenuation on the seismic waves as they propagate through the crust from source to receiver. $\kappa$ depends on epicentral distance (r) and on both the shear-wave velocity $\left(\beta_{R}\right)$ and quality factor $\left(Q_{s}\right)$ averaged over a depth of $H$ beneath the receiver or site. At zero epicentral distance, $k$ is given by

$$
\kappa(0)=\frac{H}{\bar{\beta}_{R} \bar{Q}_{s}}
$$


The value of $k(0)$ (herein referred to as kappa) is attributed to attenuation in the very shallow crust directly beneath the site (Hough and Anderson, 1988) (Figure 5-4). Silva and Darragh (1995) suggest that the predominant kappa effects extend from the surface down to several hundred meters and possibly as deep as 1 to $2 \mathrm{~km}$. The intrinsic attenuation along this part of the path is thought to be frequency-independent, but site-dependent (Hough et al., 1988). Kappa has been determined for several rock and soil sites representative of western North America (WNA) (Anderson and Hough, 1984; Anderson, 1986). For an average WNA rock site, a value between 0.02 and $0.06 \mathrm{sec}$ is appropriate (Boore, 1986; Silva and Darragh, 1995).

\subsubsection{Path Attenuation}

The anelastic attenuation from the source to just below the site is modeled with the frequency-dependent quality factor $Q(f)$ (Figure 5-4). Geometrical attenuation is taken as $1 / \mathrm{R}$ or $1 N \mathrm{R}$ (for distances greater than $100 \mathrm{~km}$ ). In order to accommodate the effects of direct and supercritically reflected waves in a crustal structure, this simple geometrical attenuation can be replaced by a formulation developed by Ou and Herrmann (1990). With this technique, the geometrical attenuation and duration for direct plus post-critical reflections in a manner appropriate for the BLWN-RVT model may be computed.

\subsubsection{Lavered Crustal and Site Structures}

The Fourier amplitude spectrum $(a(f))$ models direct shear waves in a homogeneous halfspace (with effects of a velocity gradient through the $A(f)$ transfer function). For vertically inhomogeneous layered structures, the plane-wave propagators of Silva (1976) are used to propagate $S_{\mathrm{H}}$ motion through the layered structure.

\subsubsection{Input Parameters}

To calculate the point-source estimates of ground motions for the range of relevant magnitudes and distances upon which the stochastic site-specific attenuation relationships will be derived, source, path and site parameters need to be defined. They are described in the 
following and summarized in Table 5-1 with their associated uncertainties which were incorporated into the analyses.

\subsubsection{Source Parameters}

Ground motions were calculated for a range of magnitudes: $M_{w} 5,6,7$, and $71 / 2$. The range of stress drops considered in the analyses was from 25 to 150 bars with the distribution and weights shown in Table 5-1. Our preferred value of about 75 bars is based on an analyses of stress drops for Basin and Range normal faulting earthquakes (Appendices B and C). The magnitude-dependent focal depth distributions was based on instrumental observations of contemporary seismicity in the Basin and Range province (e.g., Richins et al., 1987).

\subsubsection{Path Parameters}

The epicentral distances considered in developing the stochastic attenuation relationships ranged from 0 to $200 \mathrm{~km}$. Ground shaking from seismic sources beyond $200 \mathrm{~km}$ is insignificant to any site in the western U.S. The seismic attenuation along the path from source to site is parameterized in the model by $Q_{0}$ and $\eta$ and Equation 5-1. Based on an analysis of $\mathrm{L}_{\mathrm{g}}$ waves recorded at a seismographic station in Hailey, Idaho, Singh and Herrmann (1983) determined a regional crustal coda $Q_{0}$ of 450 and an $\eta$ of 0.2 for the frequency-dependent quality factors $Q(f)$. These values were considered to be average values since it is unlikely that the $Q_{0}$ and $\eta$ are the same for both the Basin and Range province and the ESRP. For example, Braile et al. (1982) observed high attenuation in a seismic refraction experiment within the ESRP and they attribute it to low $Q$ values in the volcanic rocks $\left(Q_{p} 20\right.$ to 200$)$ and throughout the crust $\left(Q_{p} 160\right.$ to 300$)$ where $Q_{p}$ is the $P$-wave quality factor. A study of $\mathrm{Lg}$ waves by Chávez and Priestley (1986) in the southwestern portion of the Basin and Range province estimate $Q_{0}$ of 214 and $\eta$ of 0.54 .

Based on an inversion of regional earthquakes recorded by a 16-station temporary network operated at the INEL in 1989 (Woodward-Clyde Consultants, 1990) and a seismic experiment performed by the University of Oregon in 1993 and Borah Peak aftershocks, a best estimate value of $Q(f)=150 f^{0.6}$ were calculated (Appendix B) and used in our analyses 
(Table 5-1). Lower and upper-bound values of 100 and 660, respectively, were also considered to incorporate the uncertainty in $Q_{0}$. The latter is a typical central U.S. value. These estimates are based on earthquakes to the north, east, and south of the INEL. A halfspace shear wave velocity of $3.55 \mathrm{~km} / \mathrm{sec}$ and density of $2.7 \mathrm{~g} / \mathrm{cm}^{3}$ were assumed appropriate for the path between the bottom of the site profiles (see following discussion) and the earthquake source.

\subsubsection{Site Parameters}

The subsurface geology at a site influences the ground motions in two ways. A gradient of increasing velocity with depth amplifies motions, while material damping reduces the motions. In our model, the near-surface damping is parameterized by kappa and the amplification is modeled by propagation through a site-specific velocity profile. The inversion of regional earthquakes and Borah Peak aftershocks described in Appendix B provided estimates of kappa at several seismograph stations at the INEL. These values were used for sites ANL, PBF, and RWMC, where instruments were actually located. For ATR, kappa from the nearest station TRAW was used, and for TAN, kappa was derived from the nearby LOFT. There were no seismic recordings near CPP or NRF so the log-average kappa (over the INEL) of $0.024 \mathrm{sec}$ was assigned to these sites (Table 5-2). The $K$ values ranged from a low value of 0.012 at ANL to 0.033 at PBF. The log-average $\kappa$ for the INEL is at the slightly lower end of typical western U.S. rock values (Section 5.2.1.4).

$\kappa$, as previously stated, is inversely proportional to the shear wave velocities and $\mathrm{Q}_{\mathrm{s}}$ beneath each site. The lower the $k$, the more efficient the transmission of seismic energy up through the geologic profile. The presence of relatively dense, high-velocity basalts probably accounts for the generally lower than typical western U.S. $k$ values at the INEL sites.

This effect, however, is probábly offset by the low velocity sedimentary interbeds within the basalt section. An evaluation of borehole data at the INEL suggests that the number and thicknesses of interbeds generally increases towards the Big Lost River, their probable source (Woodward-Clyde Consultants, 1992a). ANL which is quite distant from the Big Lost River has few interbeds (Bartholomay, 1990), consistent with the lowest $k$ value (Table 5-2). PBF, 
which is located near the floodplain, probably has numerous interbeds and thus a higher $k$ value. ATR, TAN, and RWMC are also located within the floodplain.

Lithologic and velocity profiles were developed at each site for the stochastic site-specific modeling (Appendix D). The deepest drill hole or well at each site was used to develop the lithologic profiles. The profile at each site was estimated to depths below the bottom of each site's deepest drill hole by appending the lithology of several deep exploration drill holes to the deepest site drill hole. The deep exploration drill holes used for this purpose are INEL-1 in west-central INEL, Corehole 2-2A in north-central INEL, and WO-2 in central INEL. The deep parts of these holes were appended singly or in combination, depending on the proximity of the sites to various of the deep holes. Based on several different data sets, a shear wave velocity and density profile were estimated for each hole. The data include cross-hole compressional and shear wave velocity measurements at the NPR site and at CPP; borehole sonic logs and density logs from INEL-1, Corehole 2-2A, and WO-2; laboratory determinations of velocity and density for samples from INEL-1 and Corehole 2-2A; and detailed surface-to-borehole and suspension logs of compressional and shear wave velocities in corehole ANL-1 (Appendix D). The velocities with greatest uncertainties are those for the sediment interbeds. The velocity profiles for sediment interbeds are constrained by nearsurface cross-hole logs and refraction surveys, by some sonic logs from Corehole 2-2A, by measured velocities in core samples, and by analogy to density and velocity profiles developed for sediments which have lithologies similar to ESRP sediment interbeds in young geologic basins. The compressional wave velocity profiles developed with these constraints were then used in conjunction with an estimated Poisson's ratio of 0.35 for the interbed sediments to estimate the shear wave velocity profiles.

\subsubsection{Site-Specific Relationships}

Based on the BLWN-RVT methodology and the input parameters previously described, sitespecific relationships were developed for use in the hazard analysis. Point-source ground motions were simulated for a range of magnitudes and source-to-site distances using the 
parameter variability described in Section 5.2.2. The simulations were performed using a magnitude-dependent distribution of point-source depth and a distribution of stress drops to represent the randomness in ground motions from earthquake to earthquake.

The parameters $Q(f)$ and $k$ were treated as uncertain variables in the seismic hazard model and attenuation relationships were developed for each site for the alternative $Q(f)$ and $k$ values. Because it is believed that a single value of $Q(f)$ should be appropriate for estimating ground motions in the region, the choice of $Q(f)$ was treated explicitly in the hazard model logic tree (Figure 2-1). Similarly, it is believed that a single value of $k$ is appropriate for a given site. Uncertainty in $k$ for a site was modeled by considering the best estimate value listed in Table 5-2 and values that were larger or smaller by a factor of two. Thus, nine different stochastic models were developed for each site.

Attenuation relationship for peak ground acceleration and peak spectral accelerations for the seven sites were obtained by fitting the simulated data with the functional form

$$
\begin{array}{cc}
\ln (Y)=C_{1}+C_{2}(M-6)+C_{3}(M-6)^{2}+C_{4} \ln \left(R^{\prime}\right)+C_{6} R & \text { for } R \leq 90 \mathrm{~km} \\
\ln (Y)=C_{1}+C_{2}(M-6)+C_{3}(M-6)^{2}+C_{4} \ln (90)+C_{5} \ln \left(R^{\prime} / 90\right)+C_{6} R & \text { for } R>90 \mathrm{~km} \\
R^{\prime}=R+\exp \left(C_{7}+C_{8} M\right) &
\end{array}
$$

where $Y$ is the peak ground motion parameter, $M$ is moment magnitude, $R$ is the shortest distance to the surface projection of rupture (similar to the Joyner and Boore [1982] empirical attenuation model), and $C_{1}$ through $C_{8}$ are parameters fit to the data. The change in distance attenuation coefficient at $90 \mathrm{~km}$ matches the geometric spreading model used in the stochastic estimates (Section 5.2.1.5). Figure 5-5 shows and example of the results of the simulations and the fitted attenuation model.

The standard error associated with each attenuation relationship was specified by combining the standard error generated by the random depths and stress drops with the modeling error. The standard error was computed for distances less than $10 \mathrm{~km}$, where the effect of random depth is the largest and for distances greater than $10 \mathrm{~km}$. Figures $5-6 \mathrm{a}$ and $5-6 \mathrm{~b}$ show the 
modeling standard error and the total standard error for each site (averaged over the nine attenuation models) for the distance range of 0 to $10 \mathrm{~km}$ and gxeater than $10 \mathrm{~km}$, respectively.

Figures 5-7 through 5-13 compare response spectra predicted by the stochastic and empirical attenuation relationships at distances of 15 and $50 \mathrm{~km}$. The nine stochastic response spectra correspond to the possible combinations of $Q(f)$ and $k$ as previously described. At short periods $(0.02$ to $0.5 \mathrm{sec})$ or high frequencies, the stochastic relationships are lower than the empirical relationships with the exception of ANL. At longer periods, $0.5 \mathrm{sec}$ and beyond, the two types of relationships generally agree (Figure 5-7). The high frequency difference is probably due to the attenuating effects of the interbedded volcanic stratigraphy beneath the INEL and its relatively low velocity gradient which results in lower ground motions. At ANL, there are few interbeds as reflected in its relatively low kappa value of $0.012 \mathrm{sec}$ and so the high frequency spectral accelerations as predicted by the stochastic model may exceed $\left(M_{w} 7\right.$ at $\left.15 \mathrm{~km}\right)$ or be similar to the values predicted by the empirical relationships.

\subsection{REPRESENTATION OF UNCERTAINTY IN GROUND MOTION MODELING}

As shown in the general logic tree for the hazard analysis (Figure 2-1), three levels of uncertainty in specifying attenuation relationships were considered in the hazard model. The first represents a choice between empirical attenuation relationships developed generally from California strong motion data and the site-specific stochastic ground motion estimates. The site-specific modeling results are weighted more favorably $(0.6)$ because they rely on local data on crustal properties and because the local site conditions are significantly different than those of a typical California rock site. The empirical relationships are credible because the comparisons shown in Woodward-Clyde Consultants (1992a) indicate that they provide a reasonable estimate of normal faulting ground motions.

Geomatrix Consultants (1995) developed relative weights for the Idriss (1991), Joyner and Boore (1982), and Sadigh et al. (1993) attenuation relationships in terms of their relative ability to match the distribution of peak accelerations and peak spectral accelerations of California strong motion data recorded on rock sites. They used a relative likelihood 
statistical measure to develop weights of $0.4,0.25$, and 0.35 , respectively, for the three relationships. For this analysis, we have included the relationship of Campbell (1994) because they provide specific estimates for hard rock sites (older sedimentary deposits, metamorphic rock and crystalline rock). Given that the INEL sites are located on basalt, we judge that the Campbell (1994) relationships should be given equal weight as the highest weighted of the three general California rock site attenuation relationships. Accordingly, the weights assigned to the four models are Campbell (1994) (0.285), Idriss (1991) (0.285), Joyner and Boore (1982) (0.18), and Sadigh et al. (1993) (0.25).

Conditional on use of the site-specific attenuation models, two levels of uncertainty were modeled in the hazard analysis, regional $\mathrm{Q}$ and site-specific $\kappa$. The weights assigned to the $Q_{0}$ values were $100(0.185), 150(0.63)$, and $660(0.185)$ under the assumption that these represent, $5^{\text {th }}, 50^{\text {th }}$, and $95^{\text {th }}$ percentile values of the distribution of regional $Q$ (Figure 2-1). Similarly, the weights assigned to the site-specific $\kappa$ values were 0.63 for the best estimate and 0.185 each to values that are larger or smaller by a factor of two. 


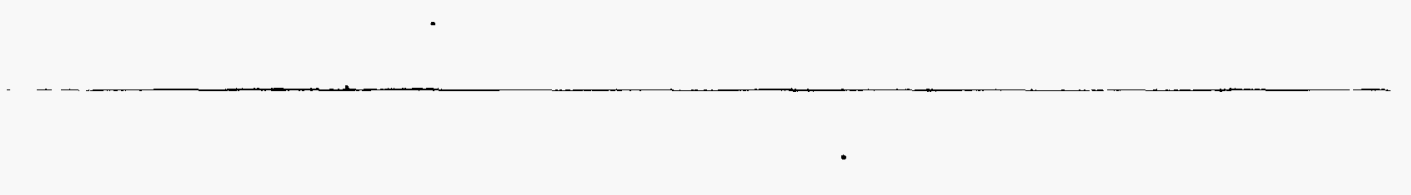



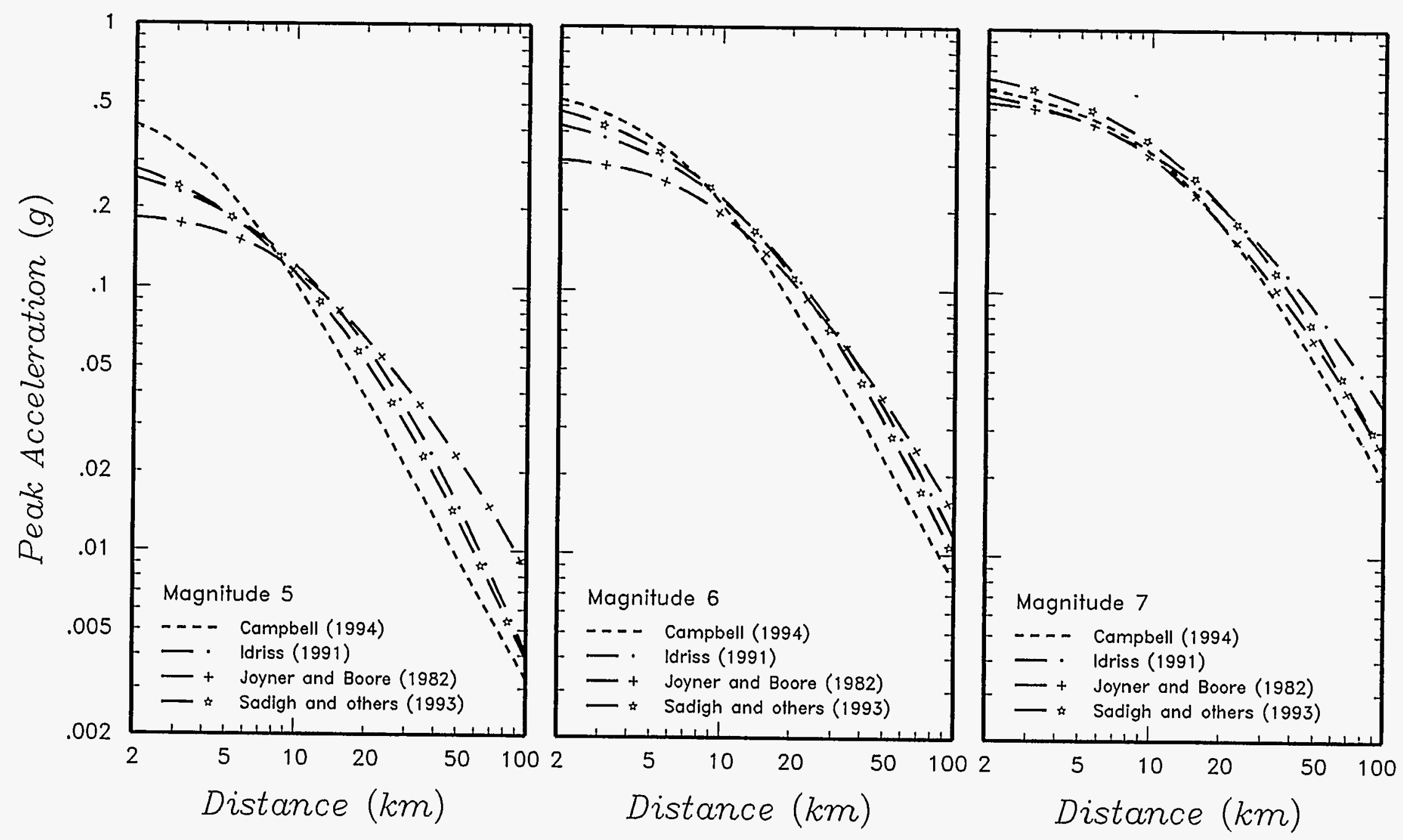



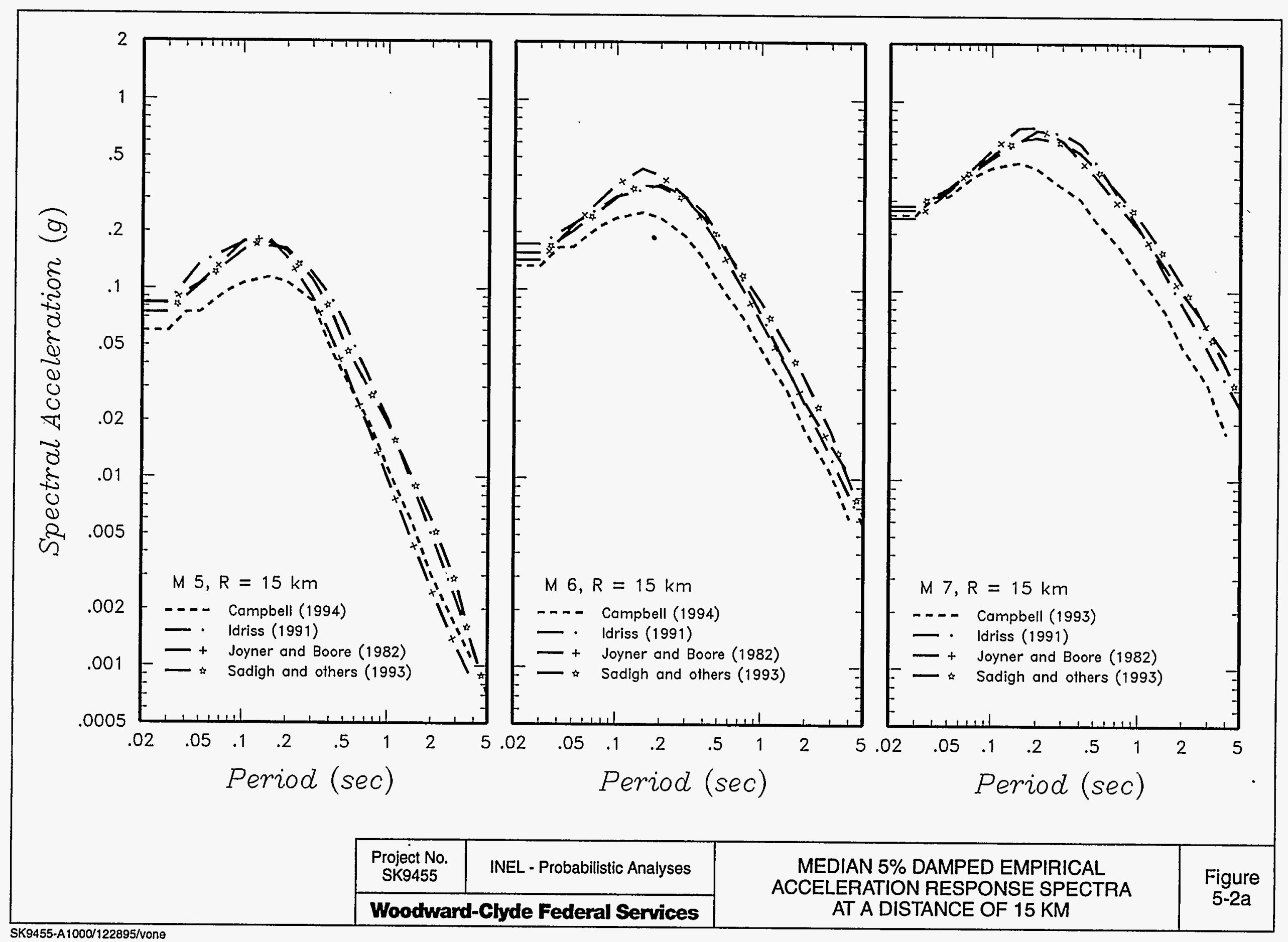




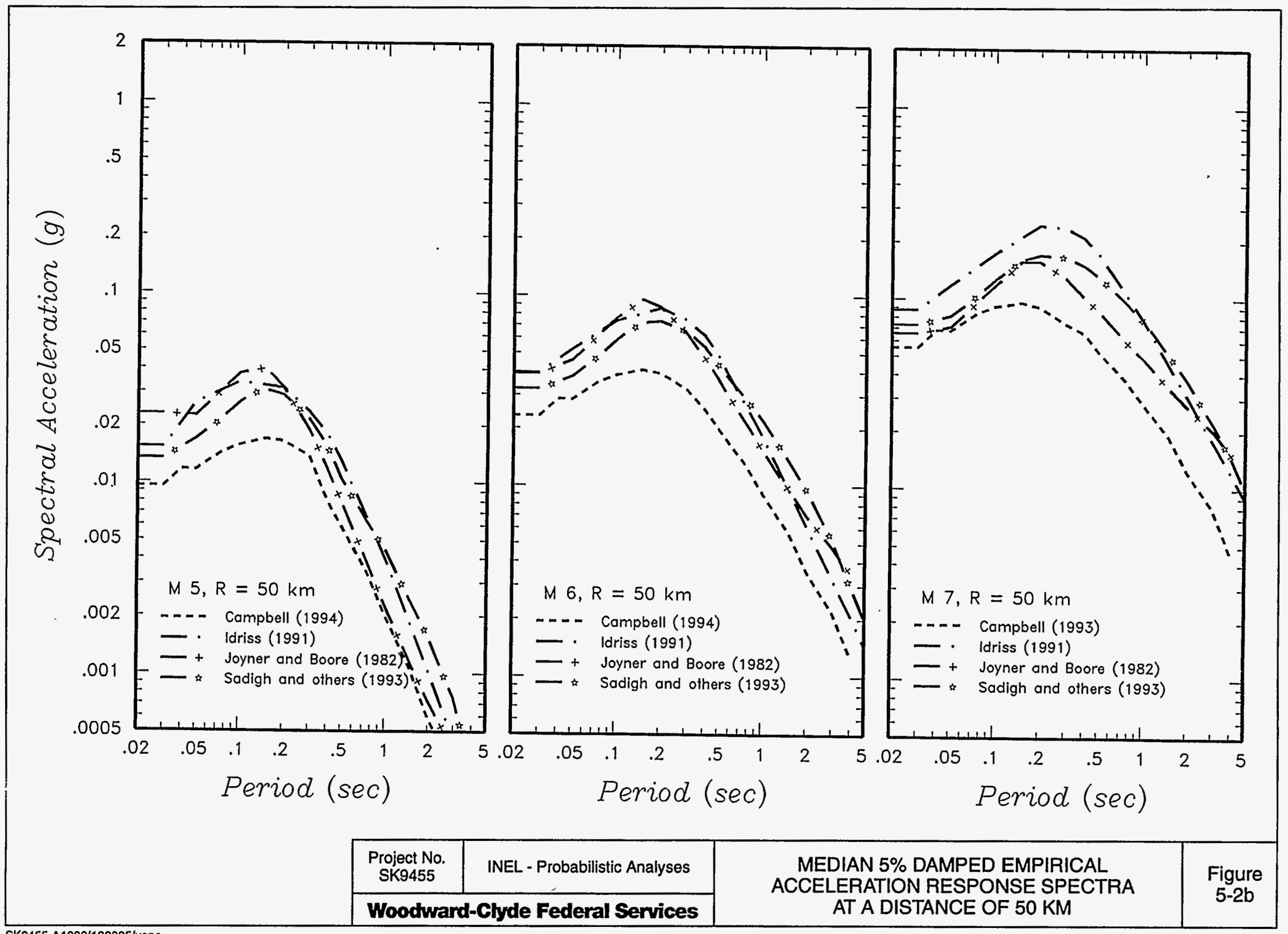

SK9455-A1000/122895/vone 



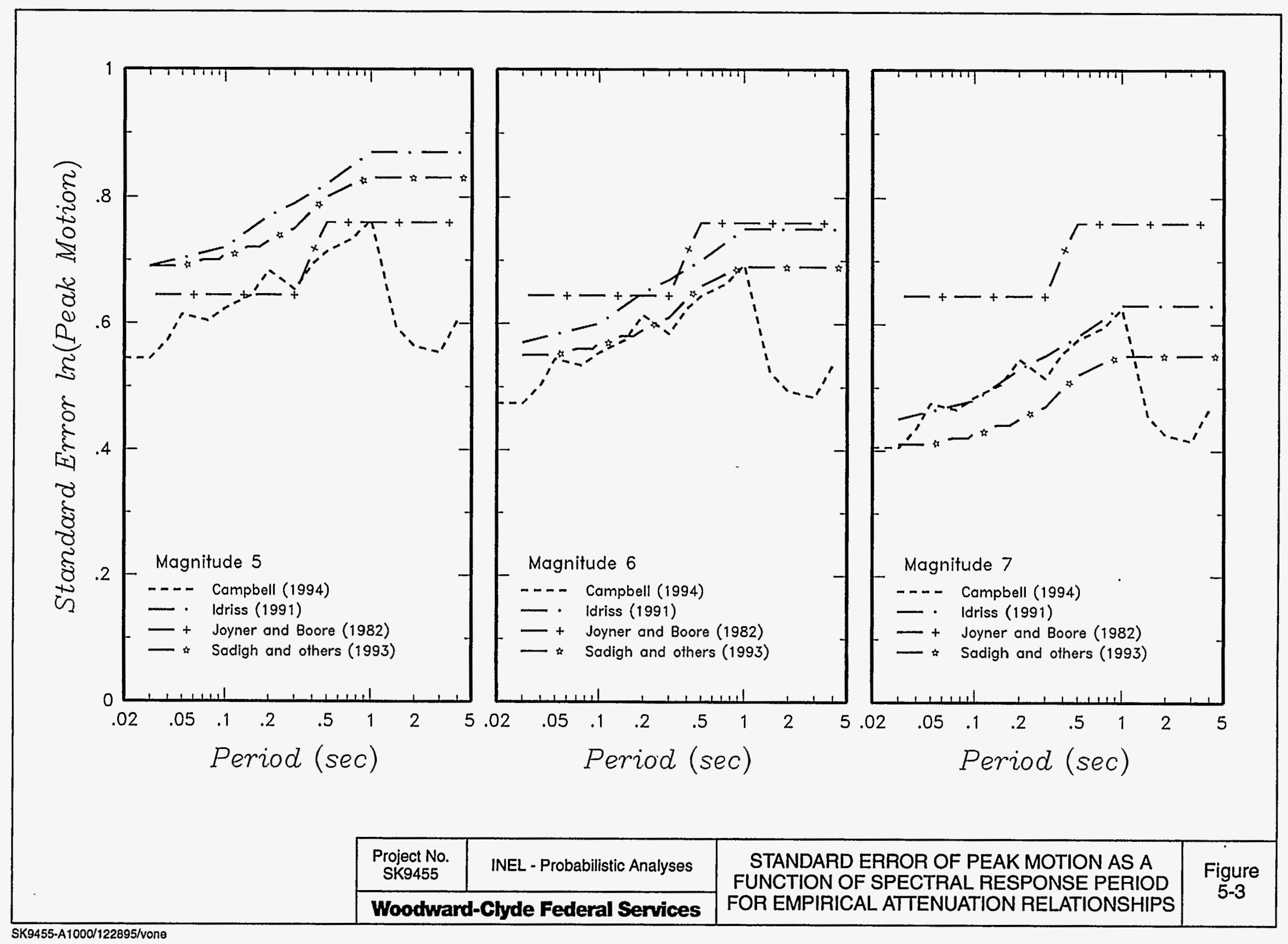





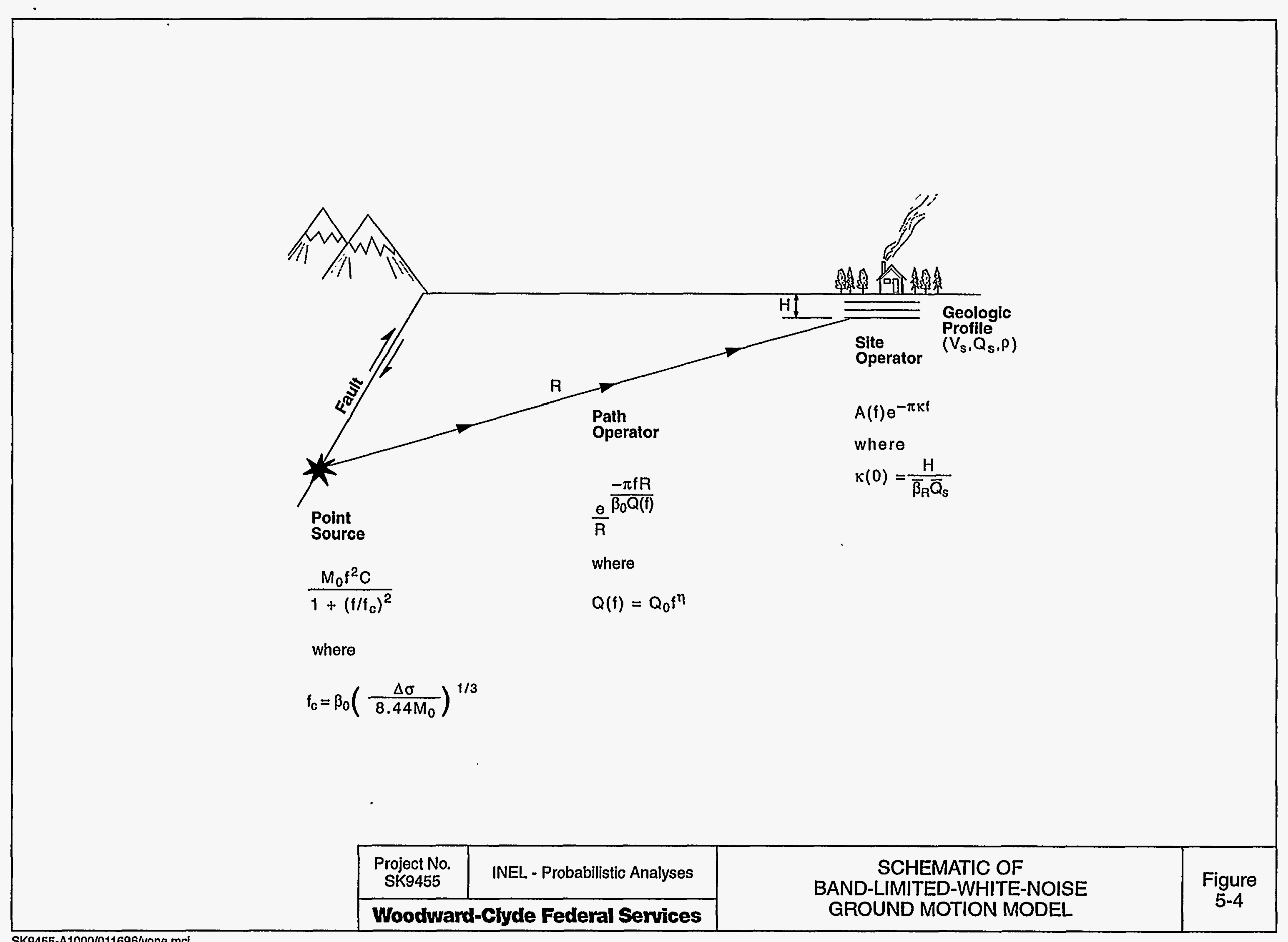




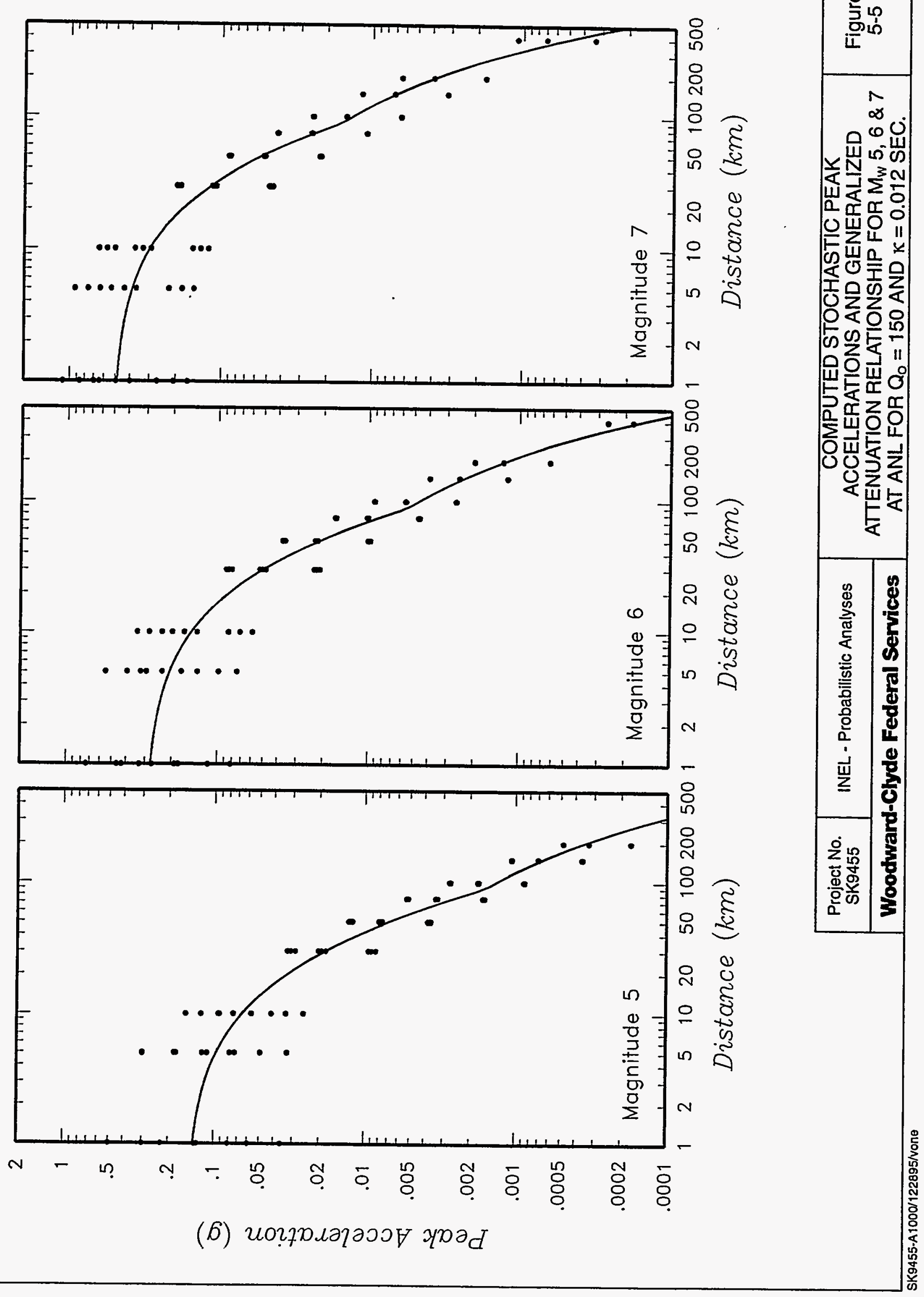





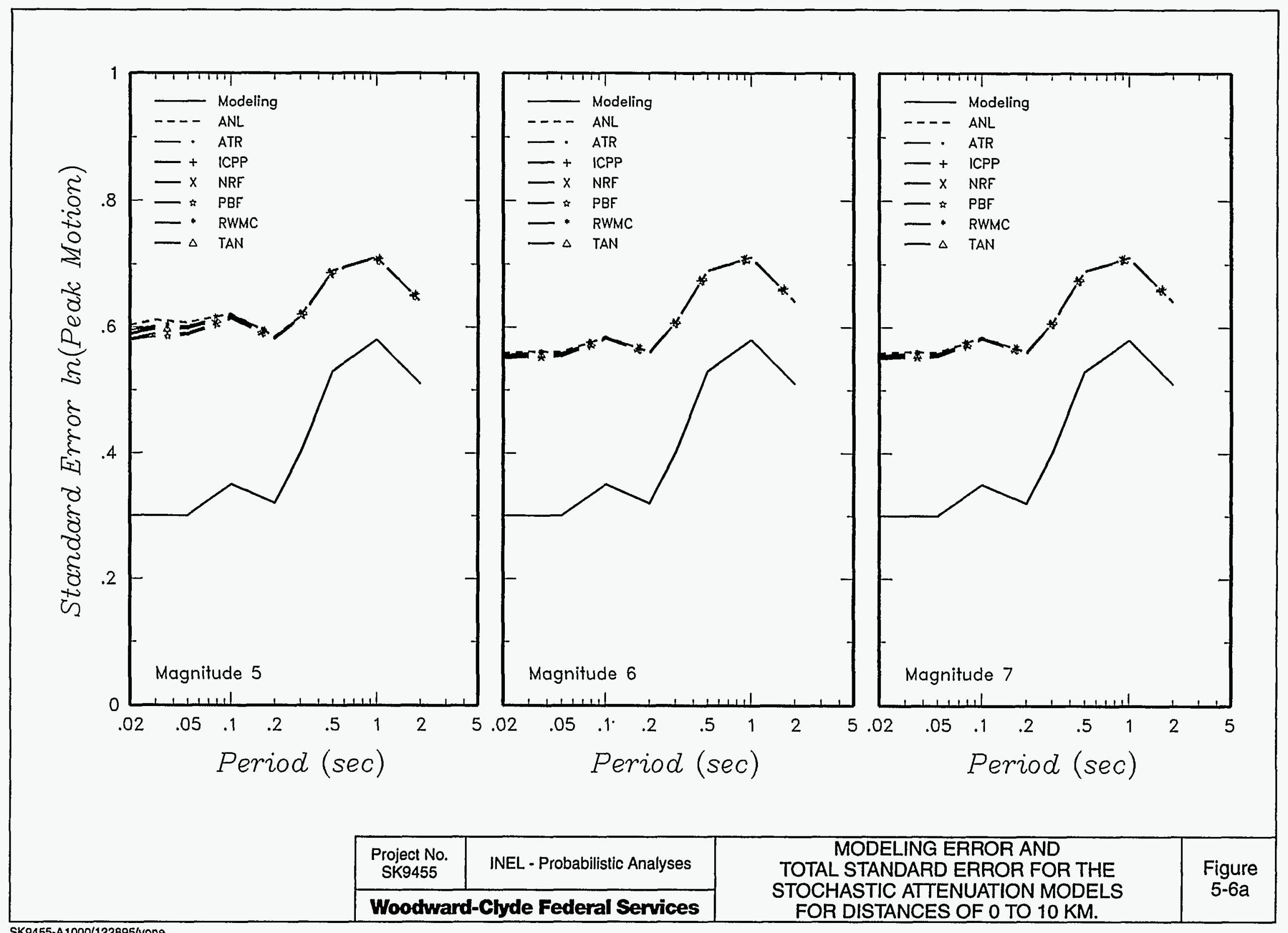




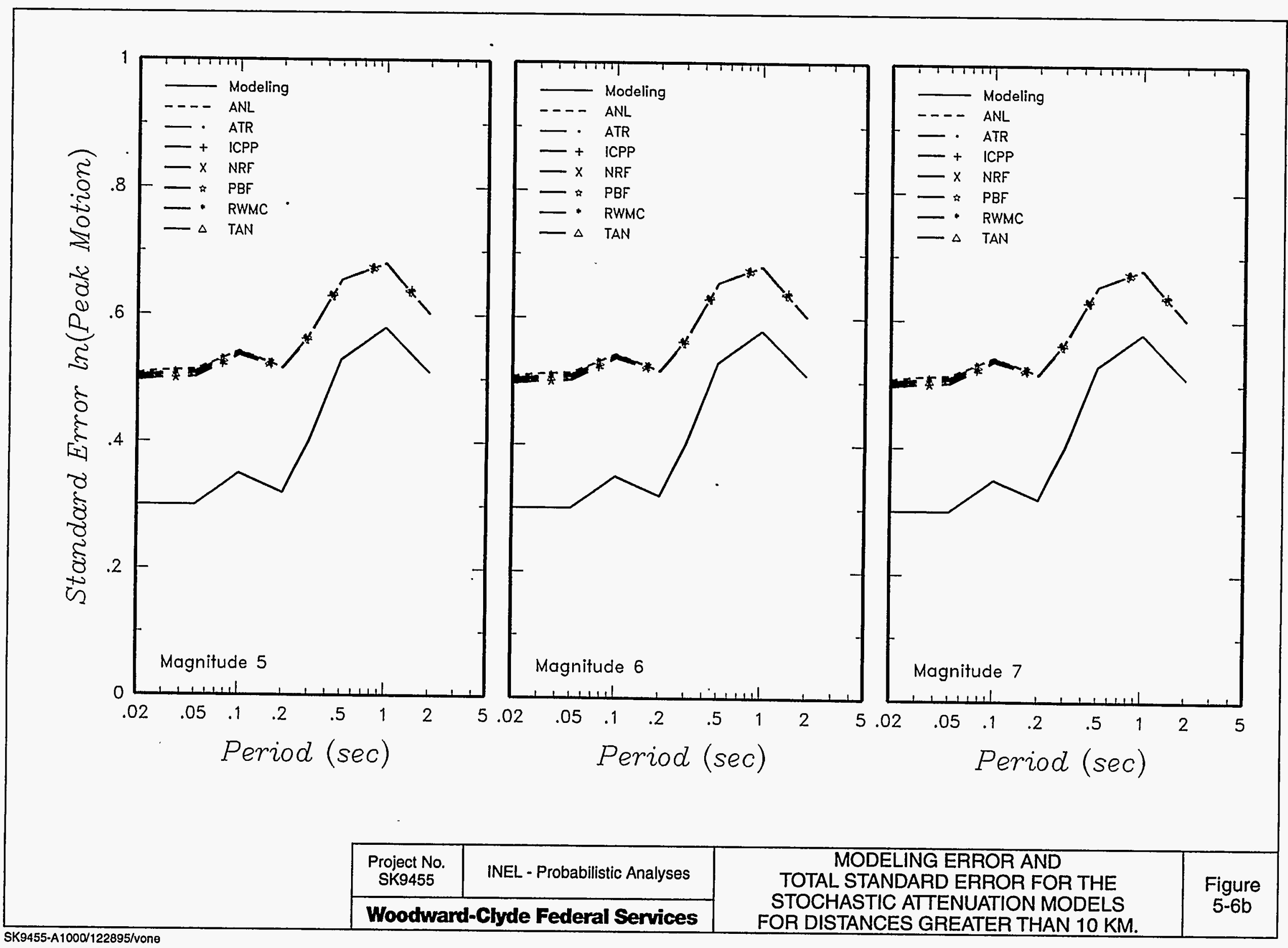





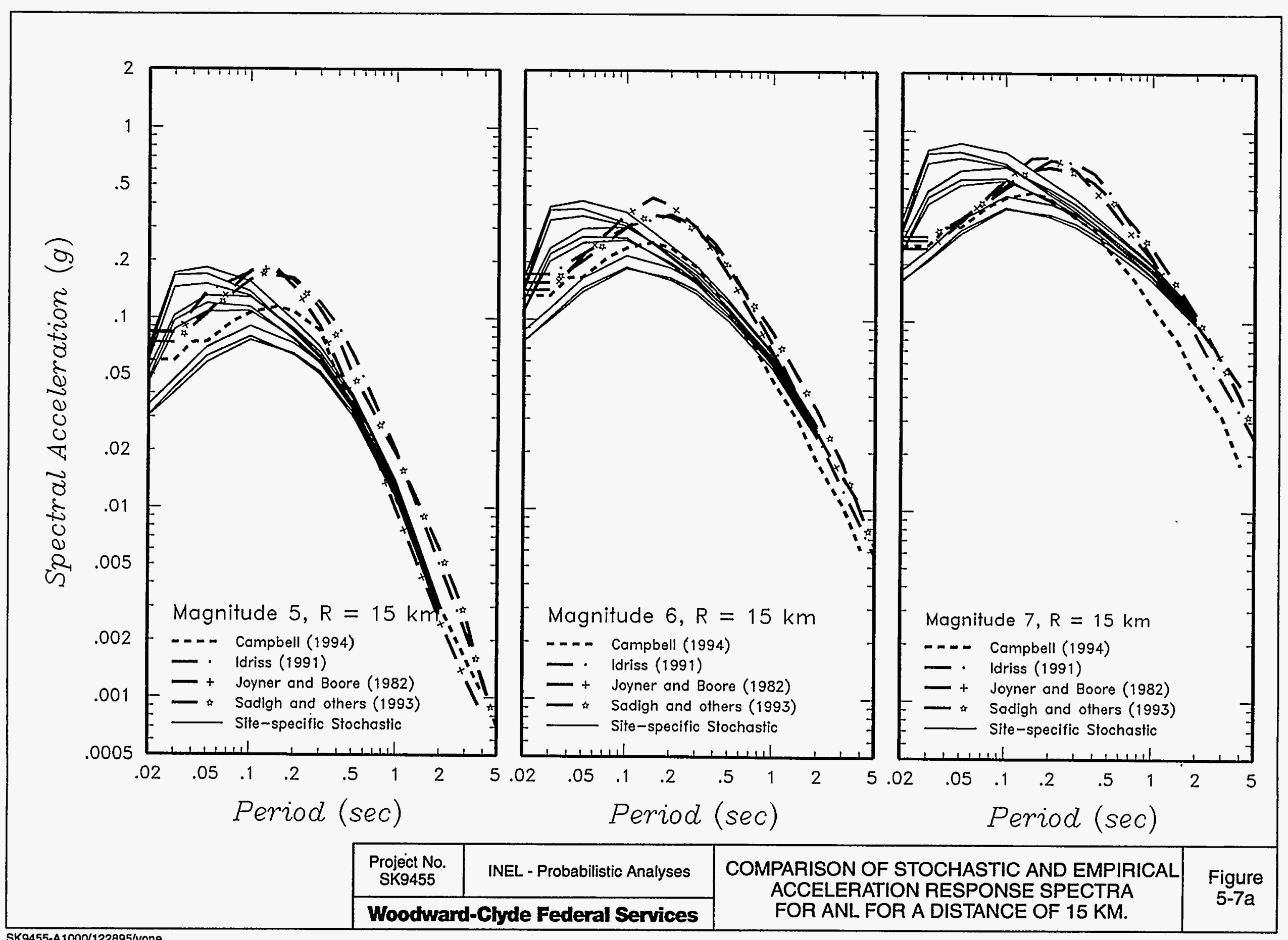




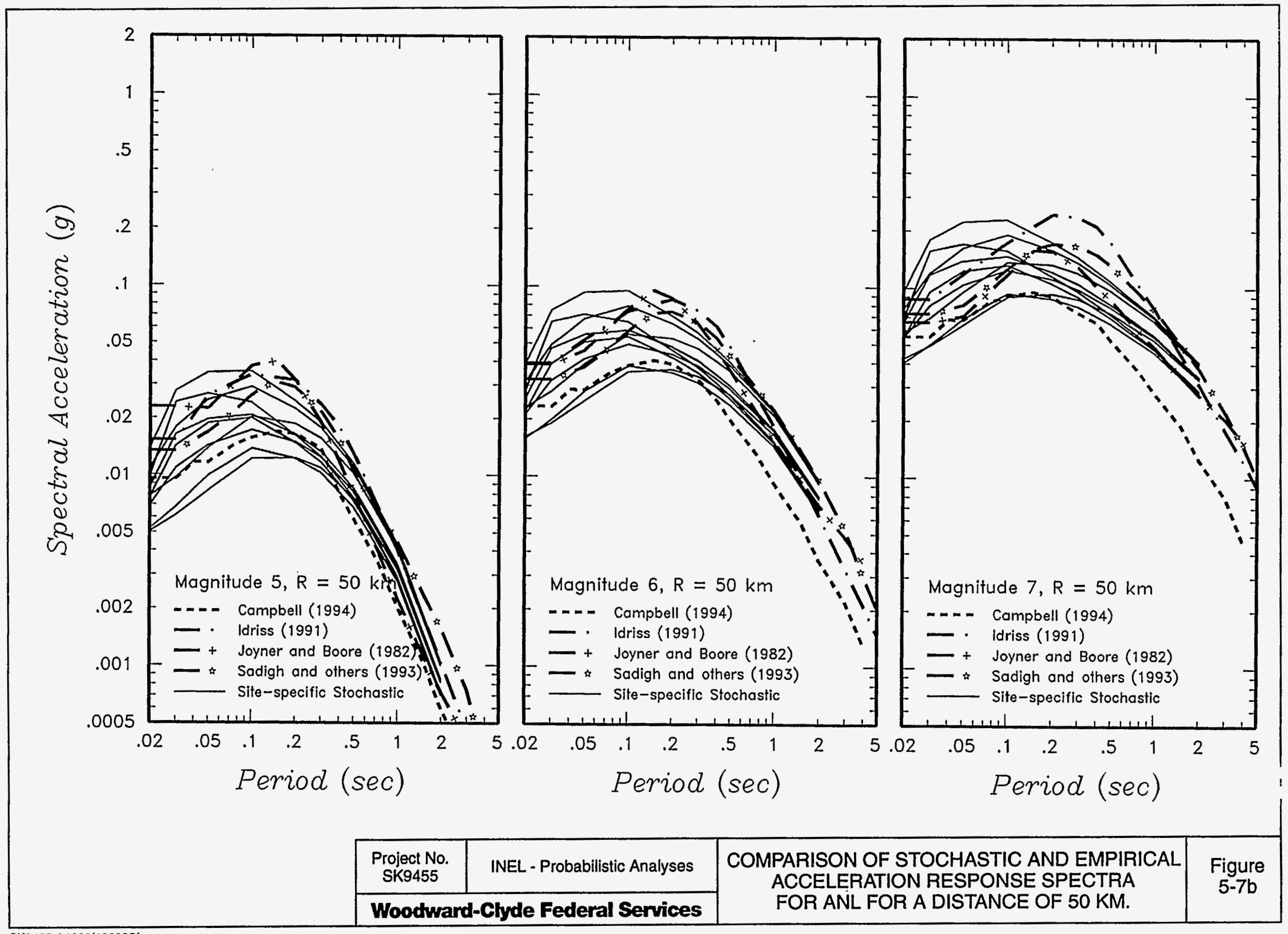




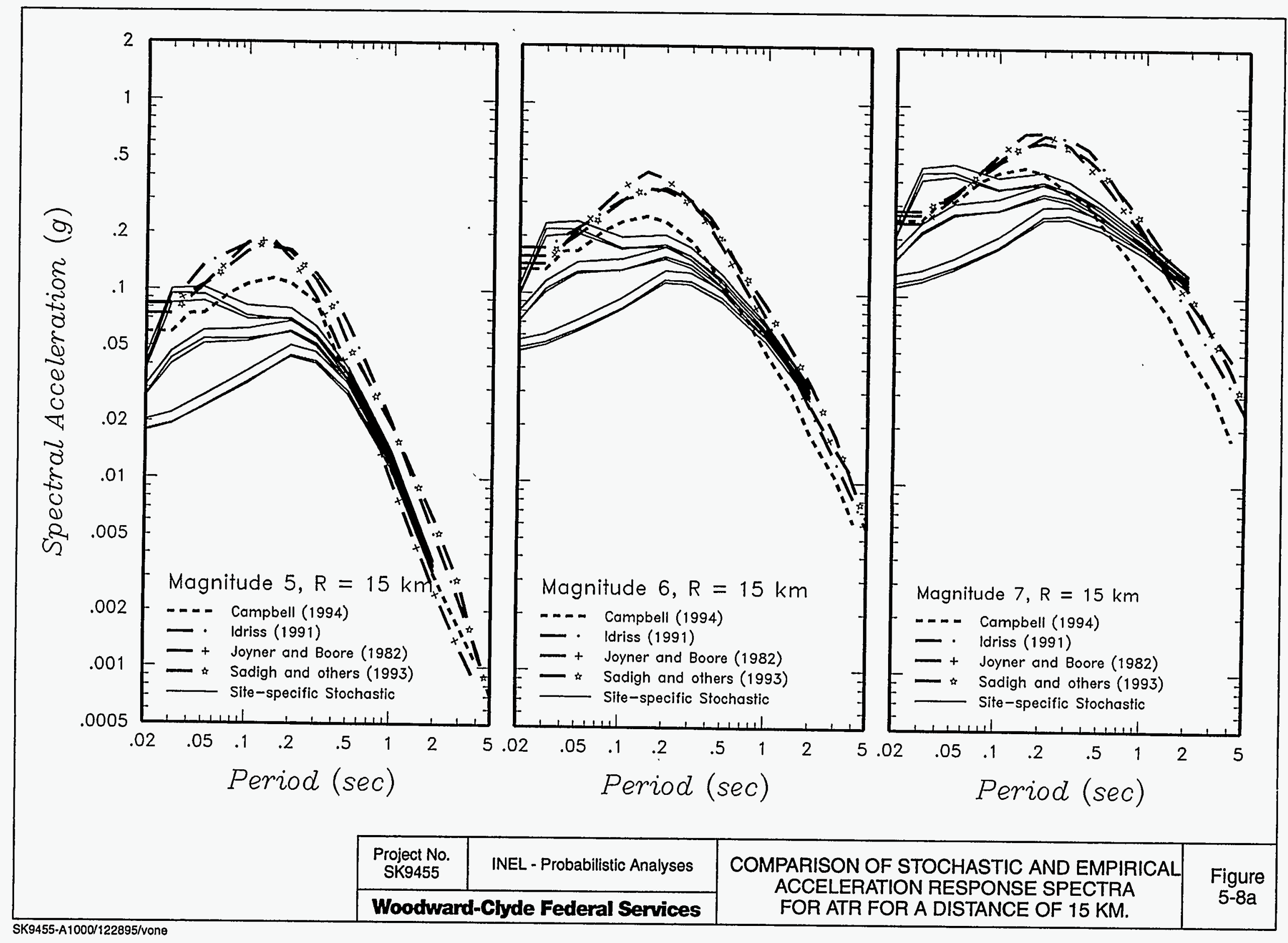




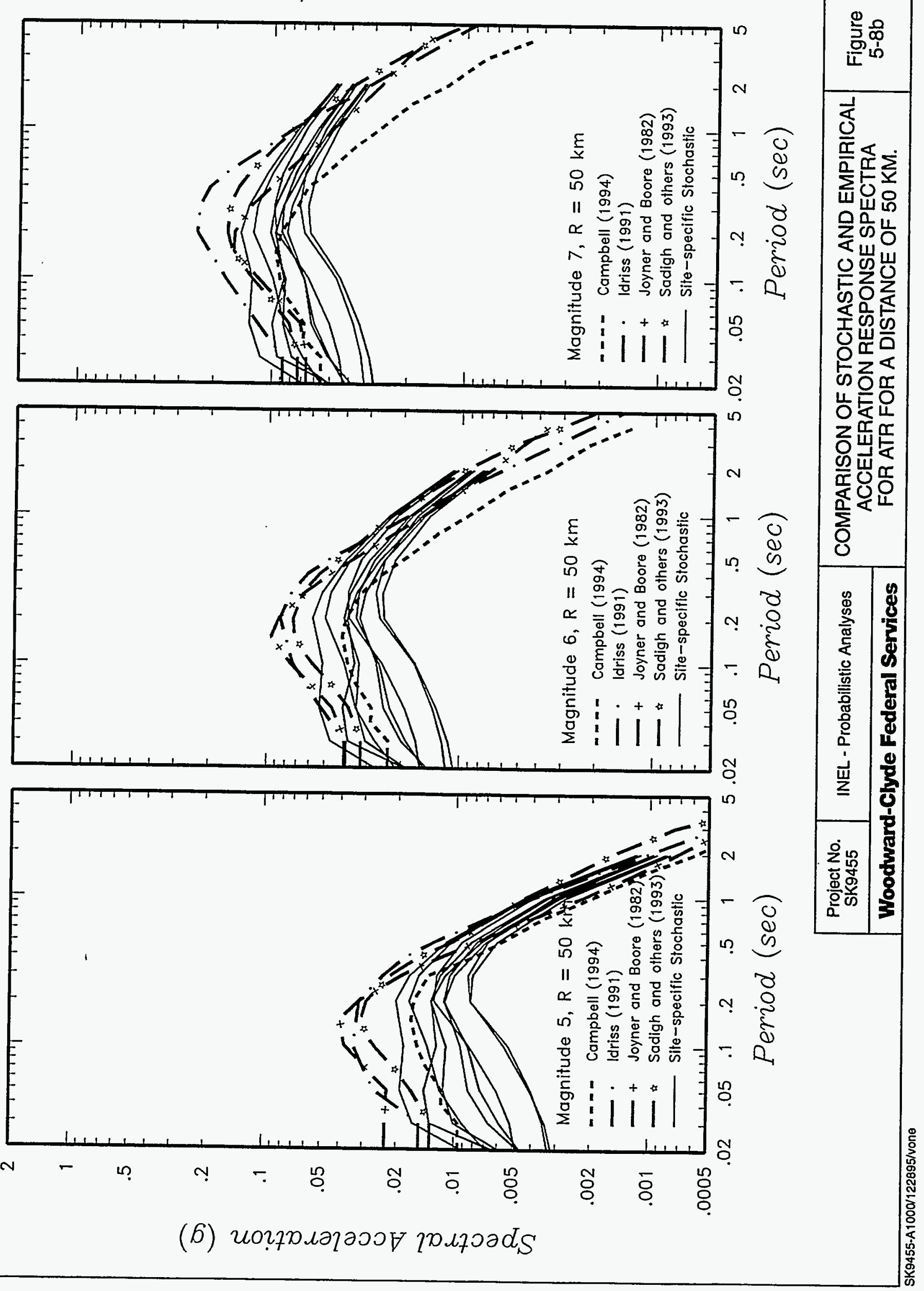




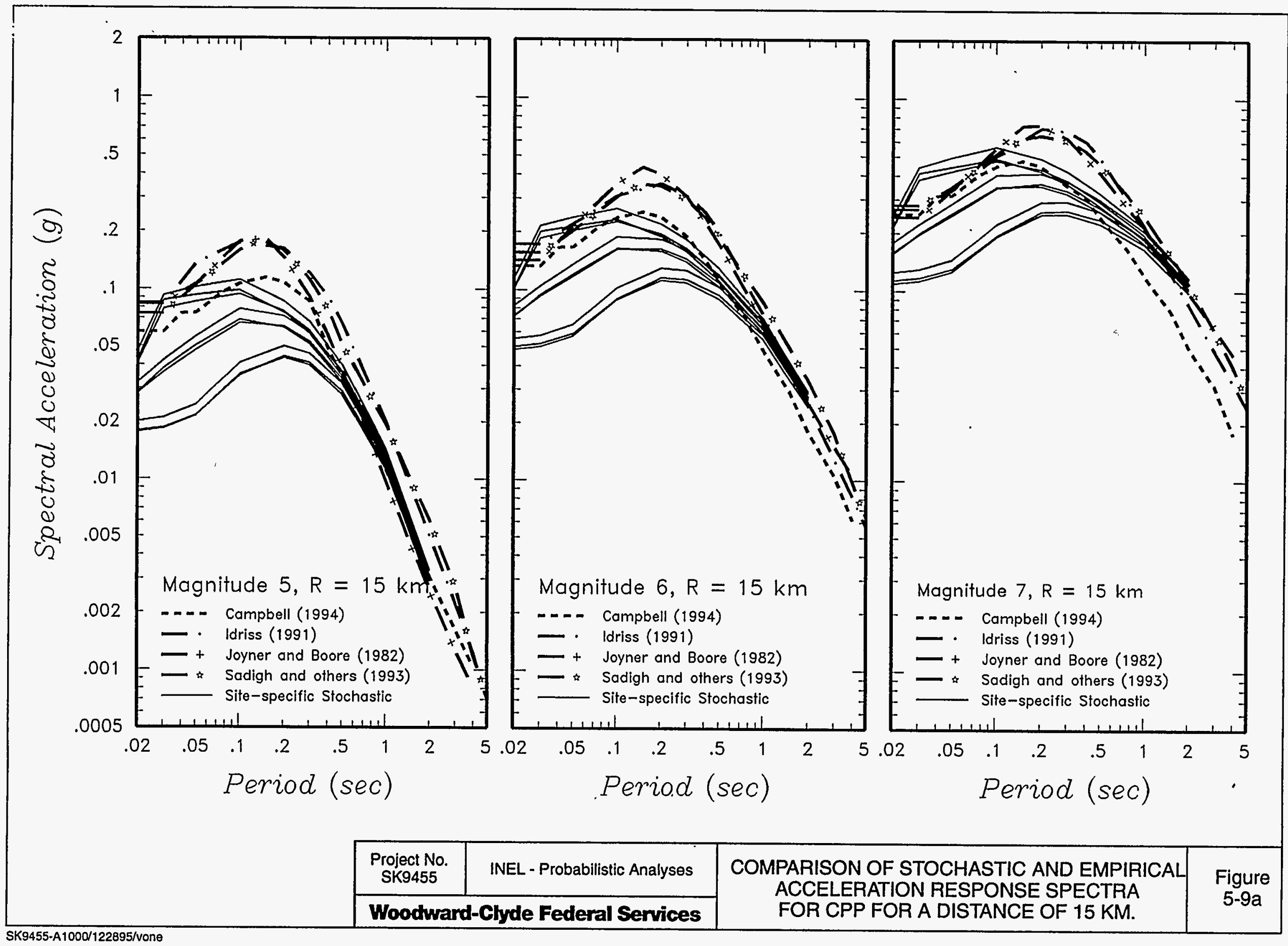




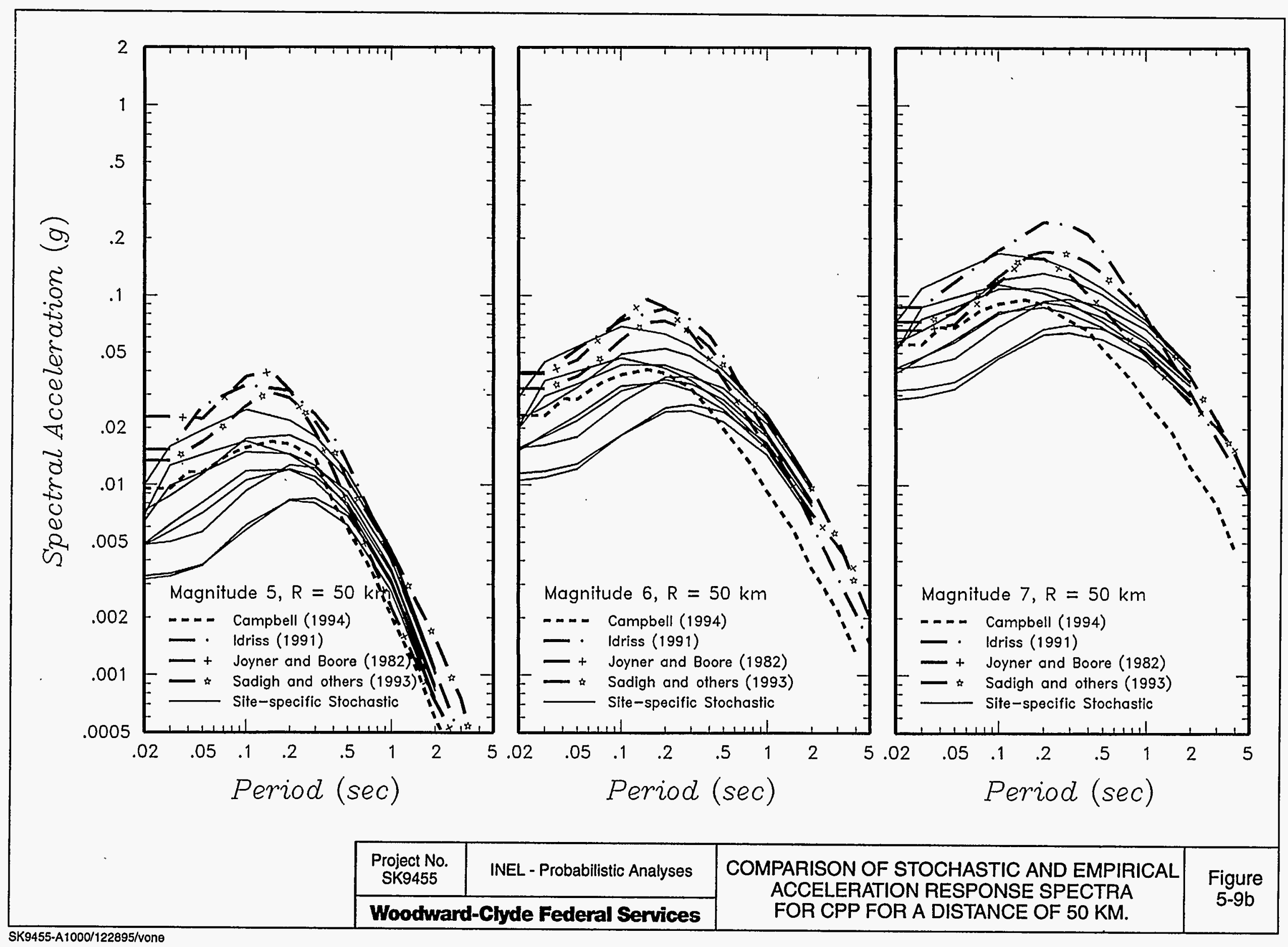




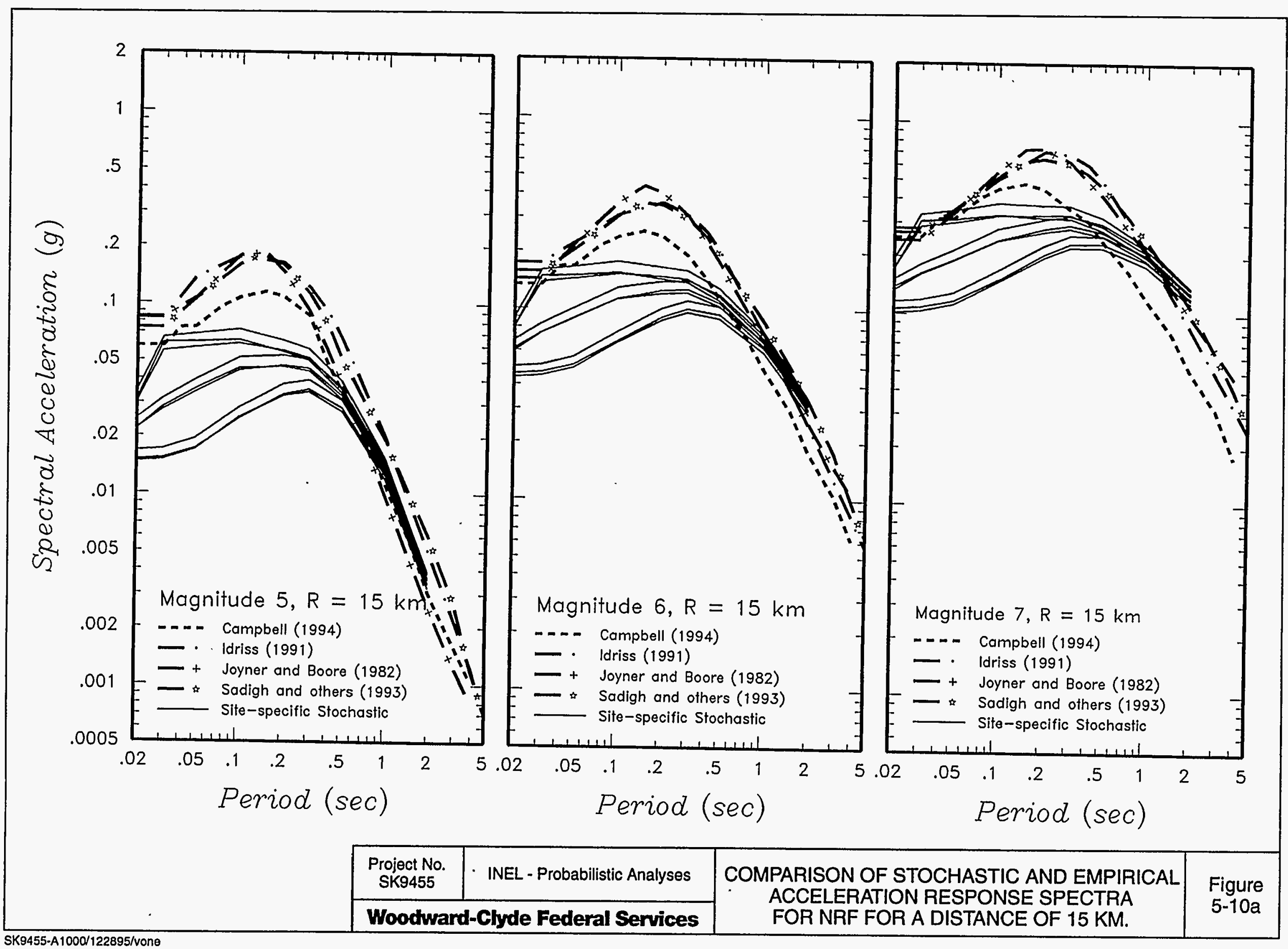




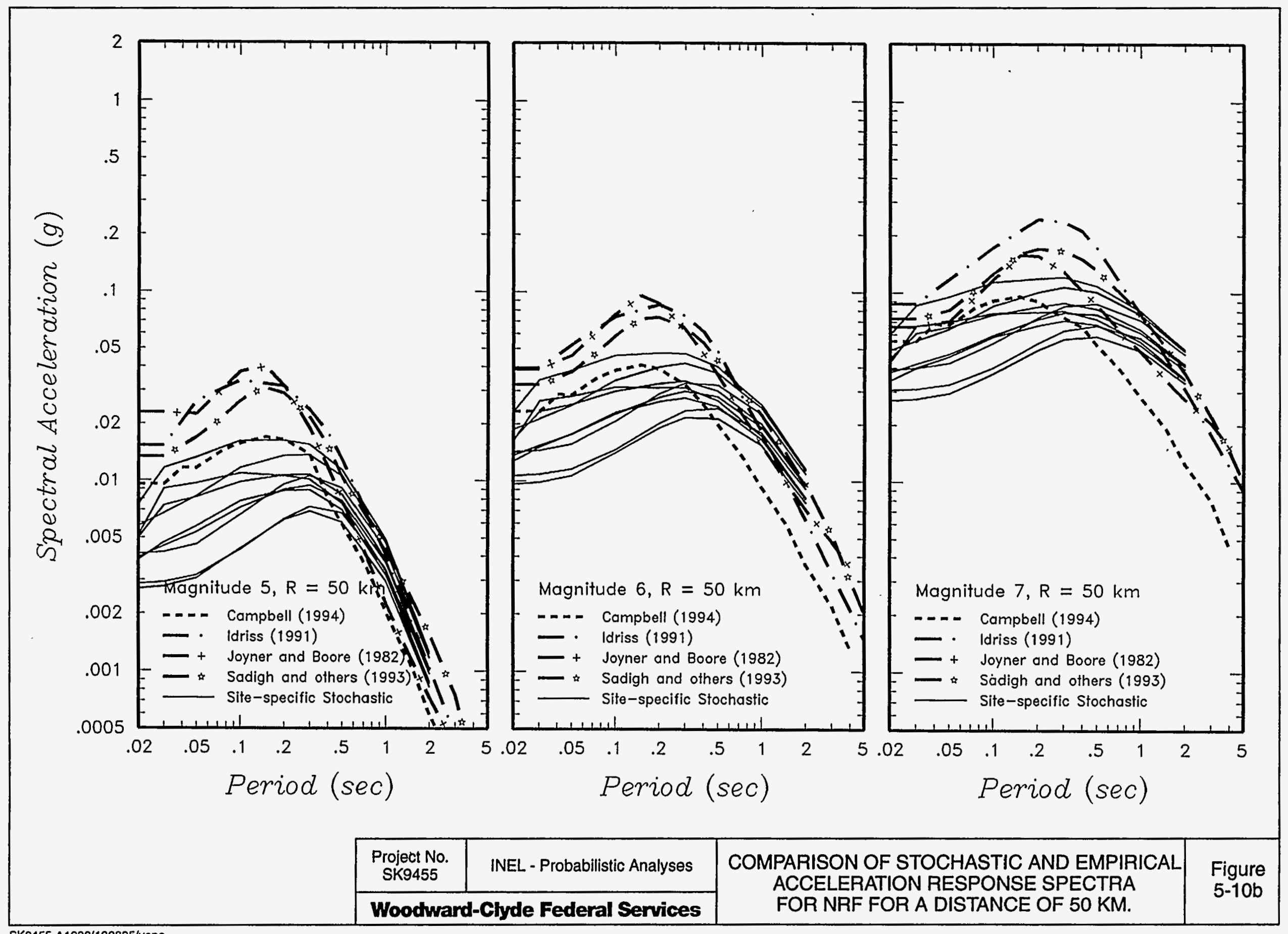




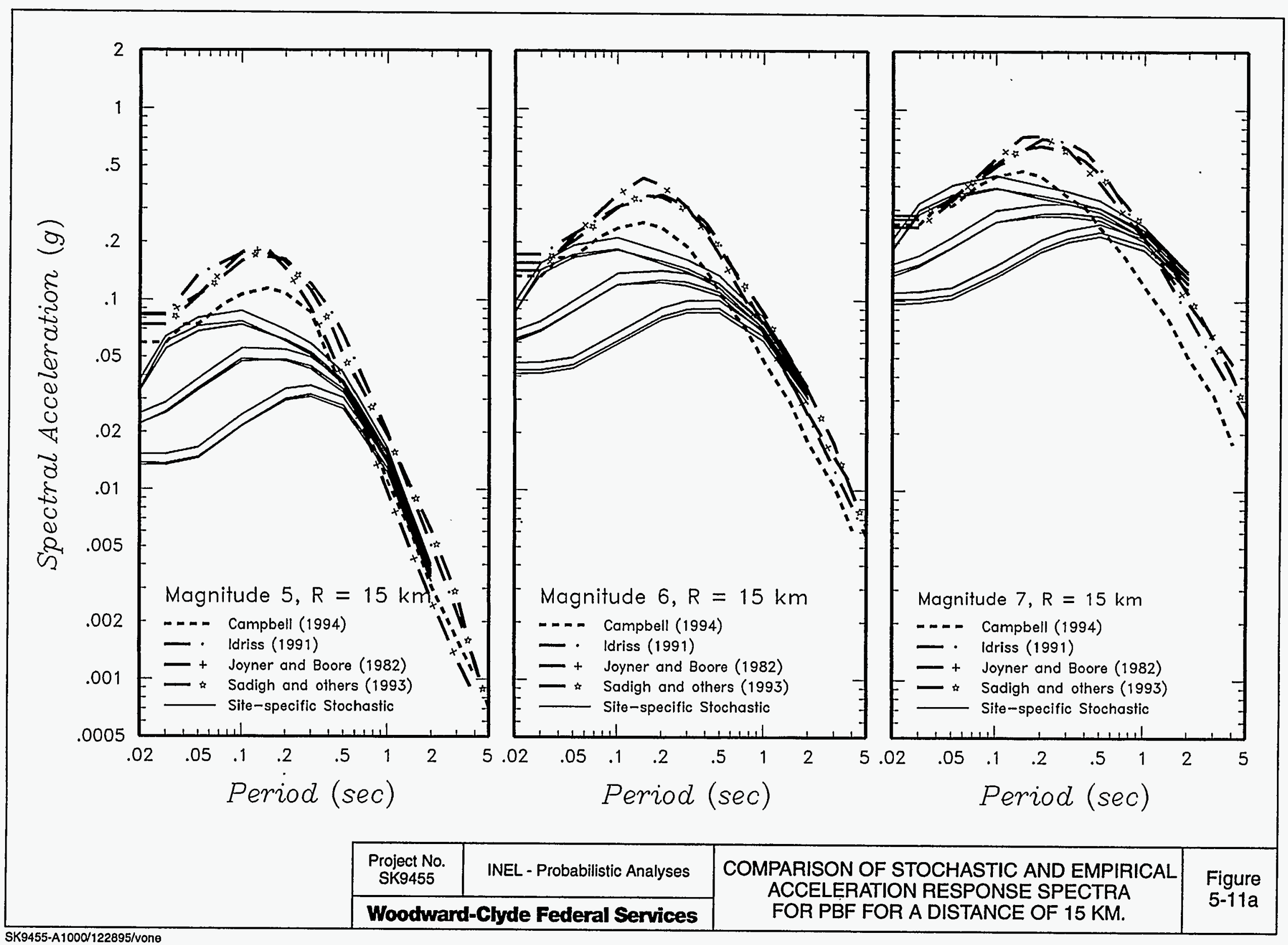




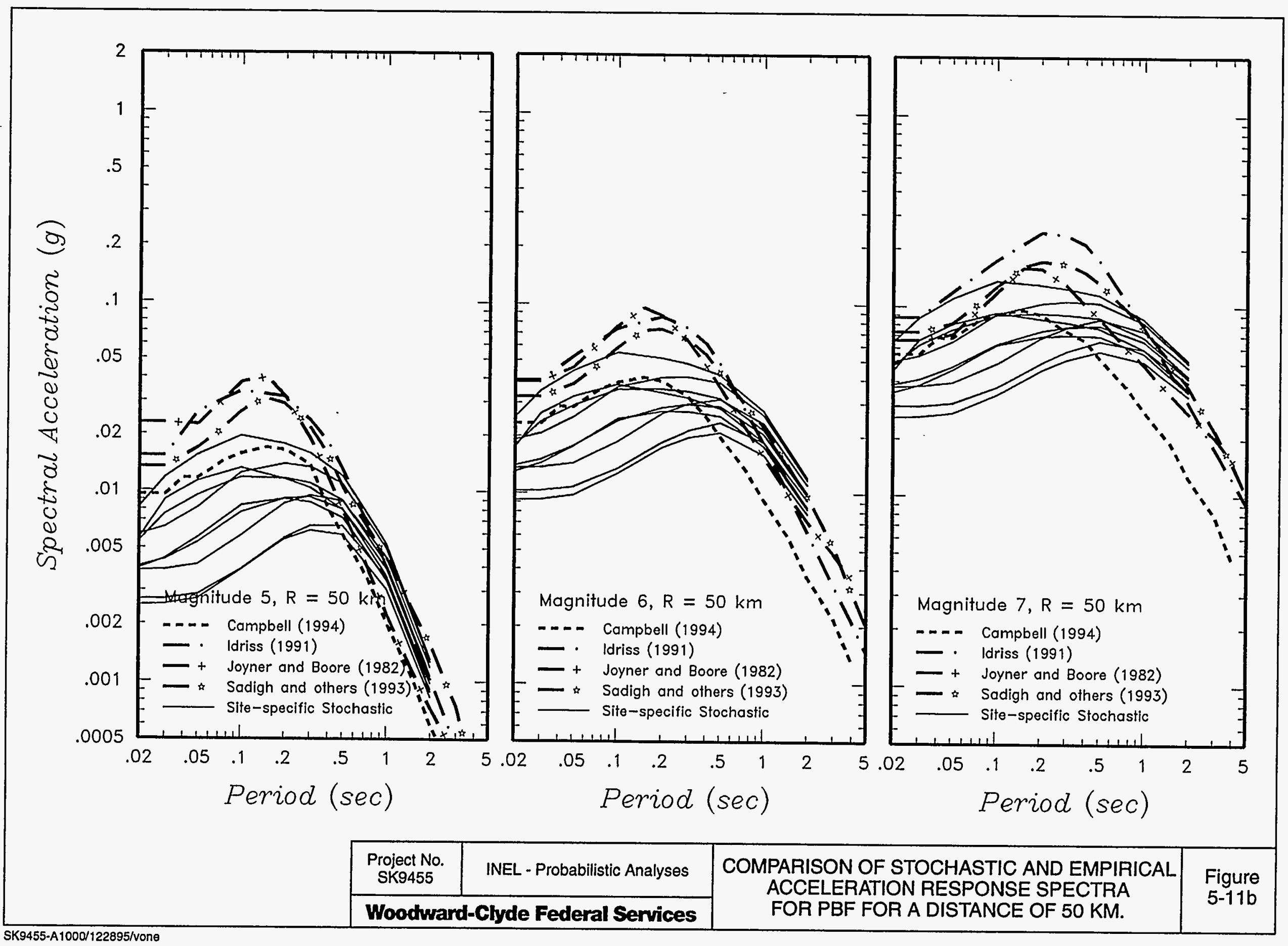




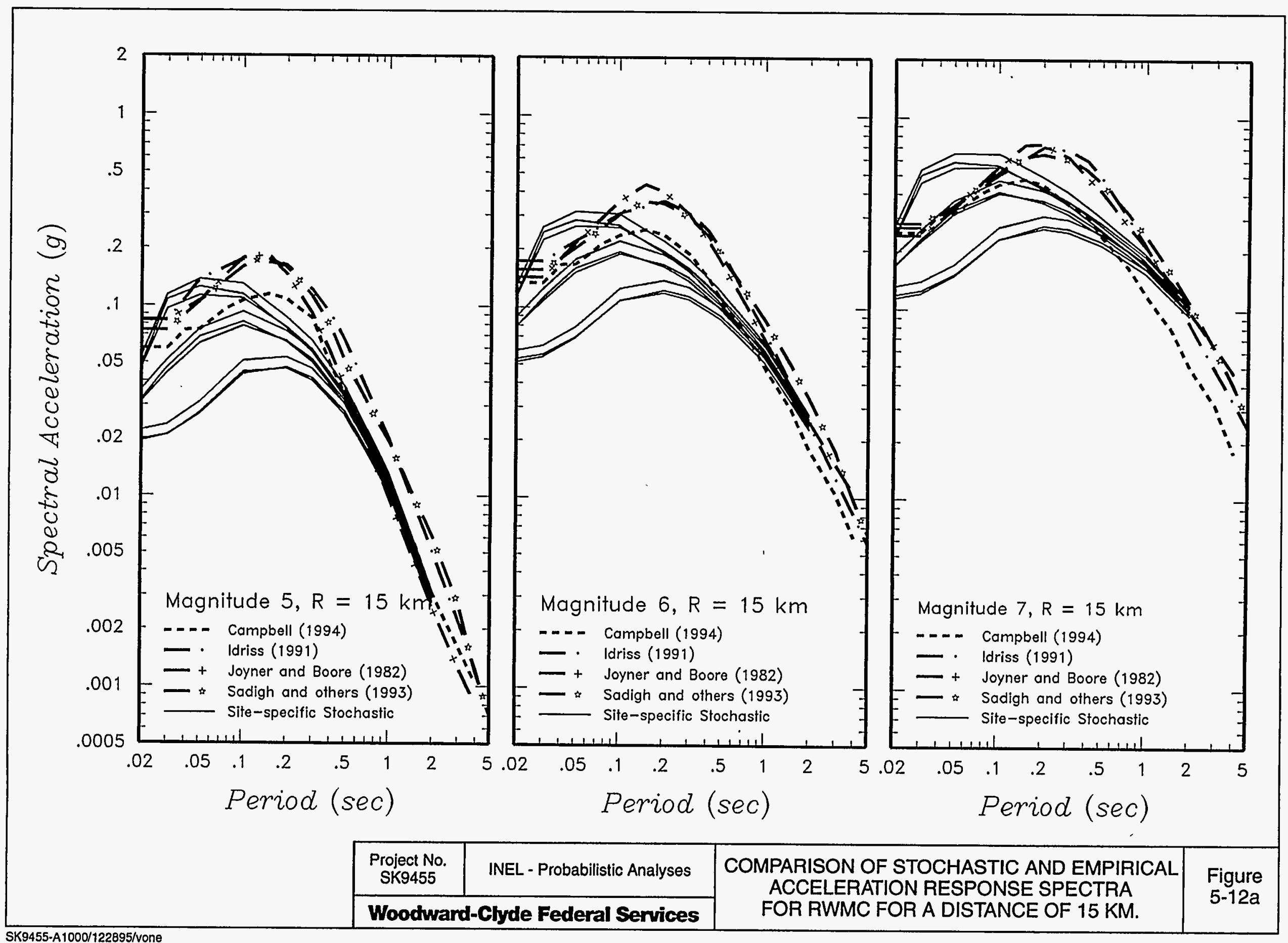




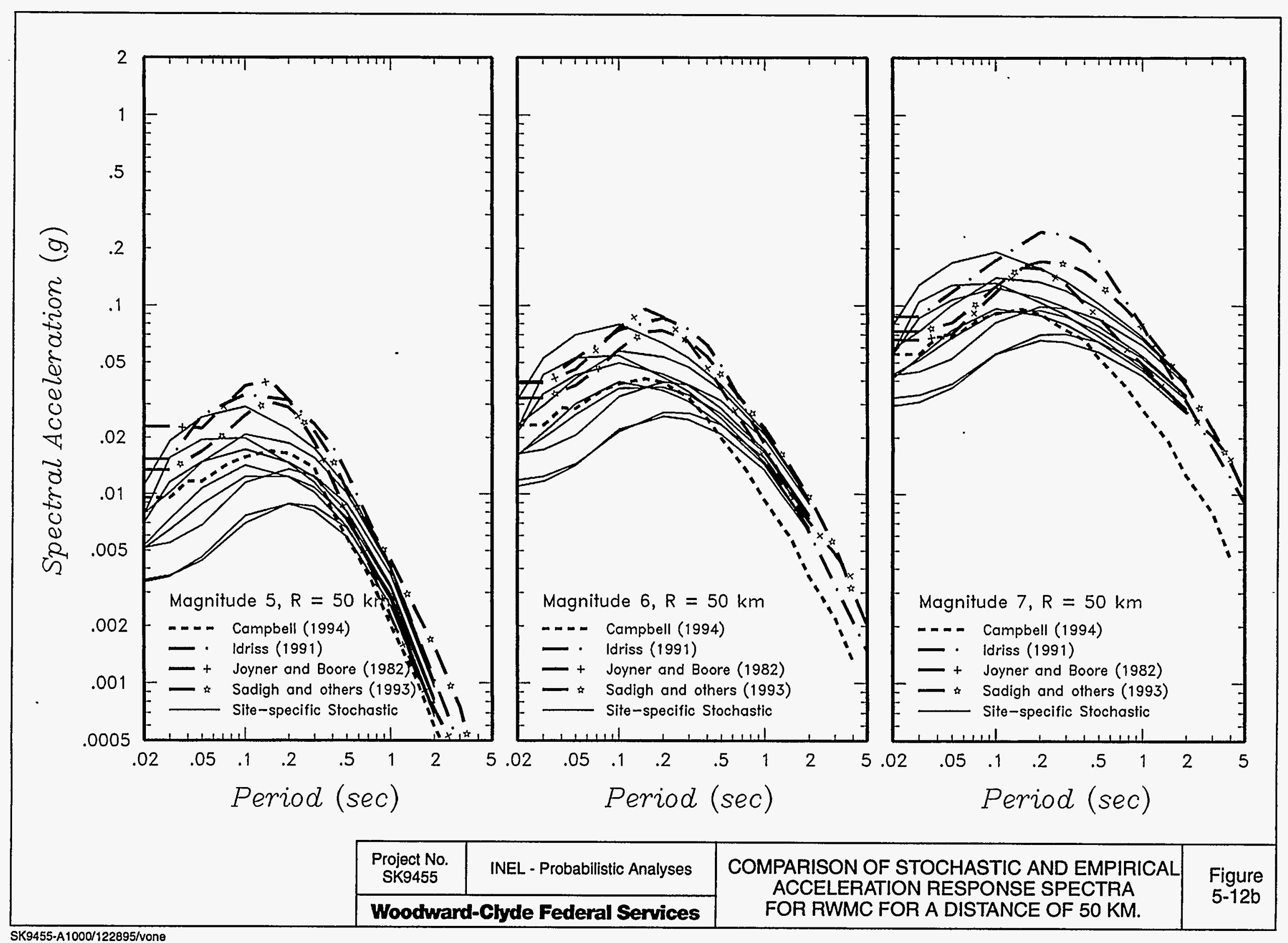




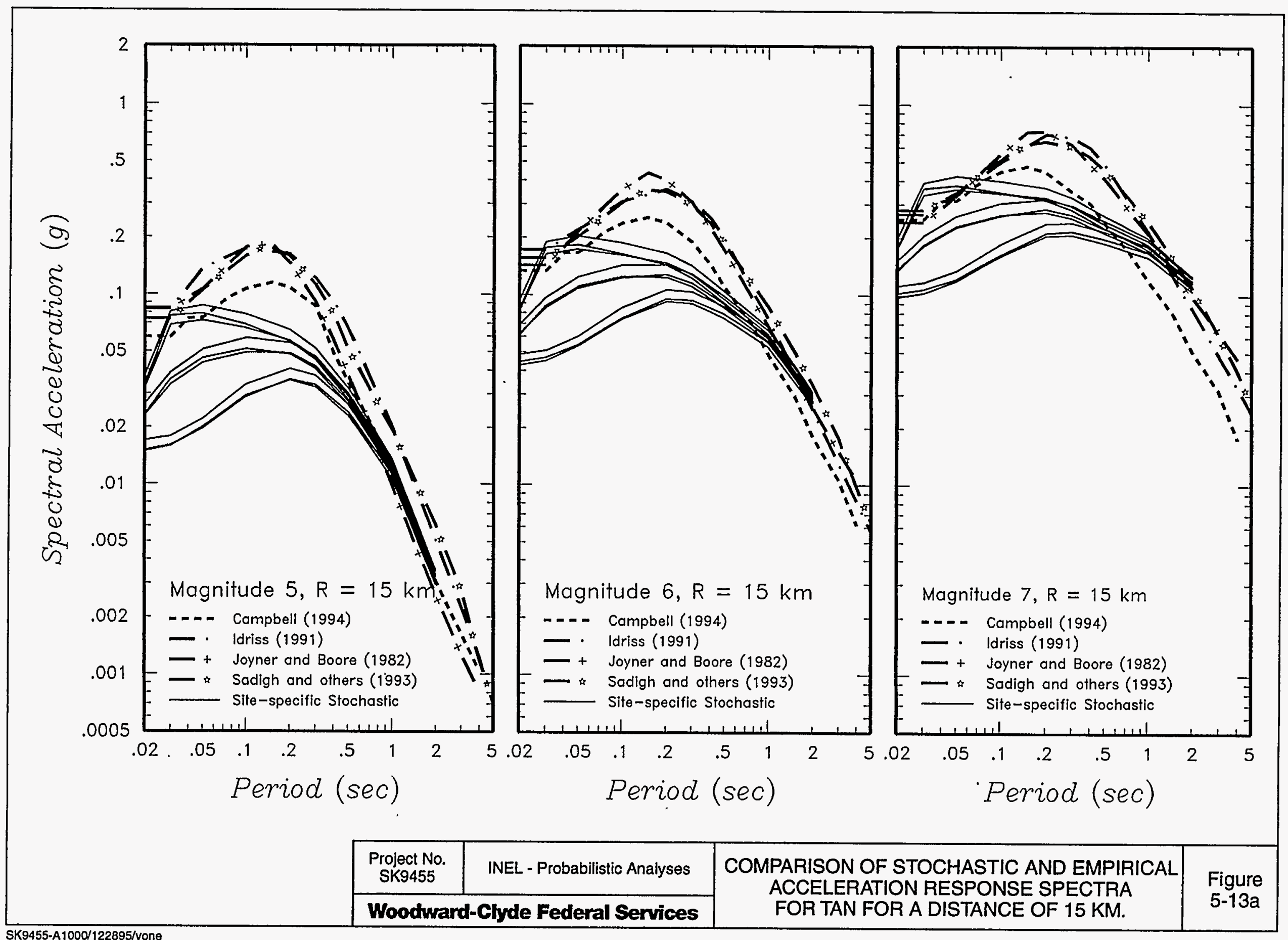




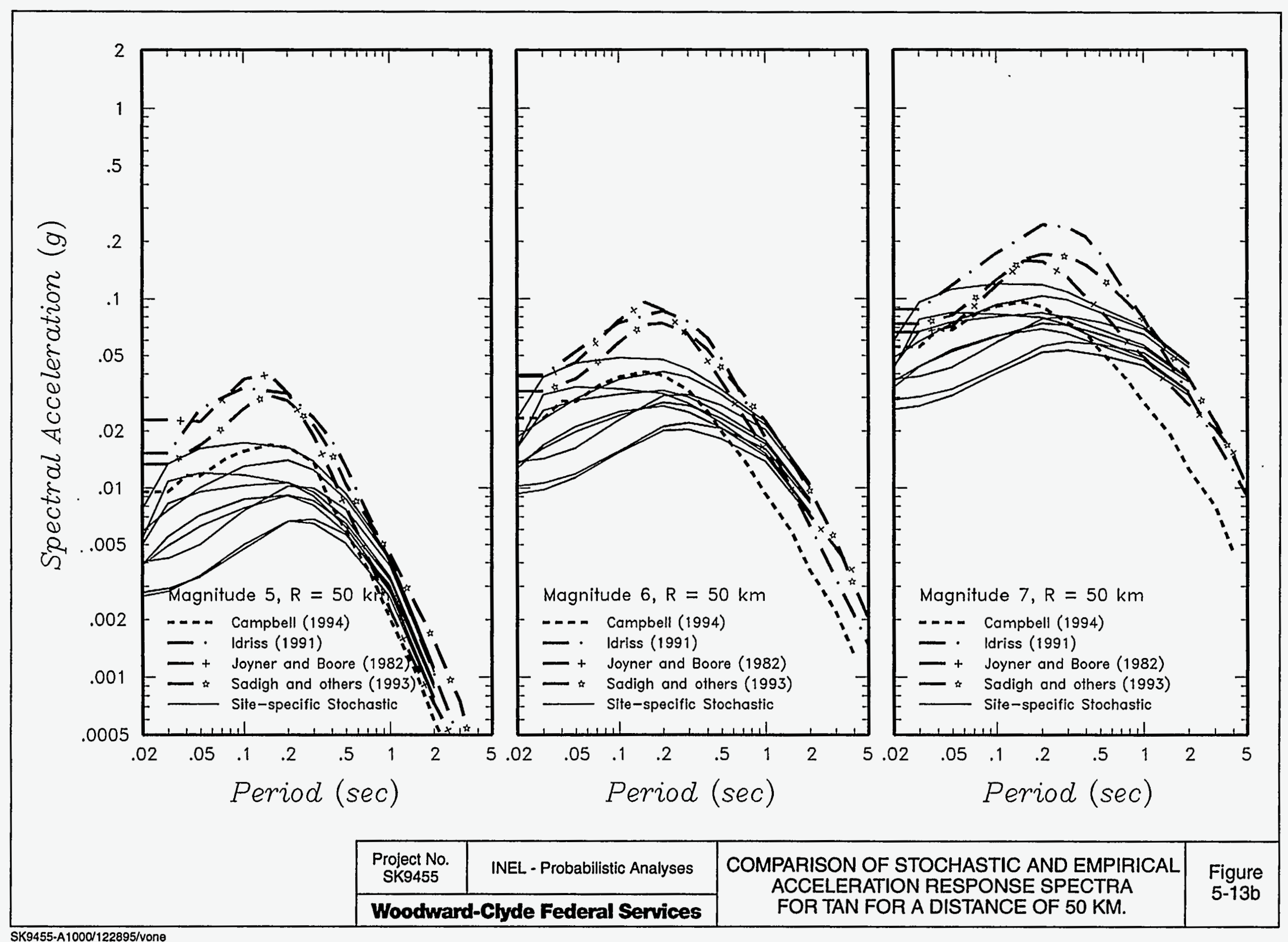


SEISMIC HAZARD ANALYSIS RESULTS

Seismic design criteria for DOE facilities are probabilistically based. To evaluate the levels of ground motions associated with the probability or likelihood of being exceeded in a specified time period, a probabilistic seismic hazard analyses was performed. The following presents the results of the probabilistic analysis of the seven INEL sites.

\subsection{ANALYSIS PROCEDURE}

Seismic hazard calculations were made for peak horizontal ground acceleration (assumed to be at $50 \mathrm{~Hz}$ ) and $5 \%$-damped response spectral accelerations at periods of $0.03,0.05,0.1$, $0.2,0.3,0.5,1.0$, and $2.0 \mathrm{sec}(30,20,10,5,3.3,2,1$, and $0.5 \mathrm{~Hz}$, respectively). The attenuation relationships used to compute the hazard use a distance measure of minimum distance to the fault rupture or minimum distance to the surface projection of the fault rupture. Therefore, the seismic sources were modeled as fault planes with randomly located rupture areas. The rupture size of an event was specified by the relationship $\ln ($ rupture area) $=2.095 \mathrm{M}_{\mathrm{w}}-8.007$ developed by Wells and Coppersmith (1994). This relationship gives the mean rupture area for a specific magnitude rather than the median (mean log) rupture area. Studies by Bender (1984) have shown that the use of mean estimates of rupture size in the computation of hazard yields results nearly equal to those obtained when the statistical uncertainty in the size of individual ruptures is incorporated in the analysis. The faultspecific sources were modeled as segmented planar fault surfaces.

The areal source zones were modeled as a set of closely spaced parallel fault planes occupying the source regions defined in Figure 4-1, allowing for consideration of magnitudedependent rupture dimensions in defining the distribution of source-to-site distance. The fault planes were oriented parallel to the general trend of mapped faults in each source zone. Seismicity was assigned to each fault in proportion to the fraction of the total source area that it occupies (fault length $\mathrm{x}$ fault spacing). The depth distribution of earthquake hypocenters was set equal to the observed depth distribution of earthquakes in the region. The hazard was computed with the distribution in peak ground motion about the median attenuation relationships truncated at three standard deviations. 
peak horizontal accelerations for the four PC annual exceedance probabilities (or return periods) for each site are summarized in the Executive Summary. For all return periods, the highest peak accelerations are at TAN and the lowest at ANL. The values range from 0.06 to $0.09 \mathrm{~g}$ for 500 years and 0.16 to $0.33 \mathrm{~g}$ for 10,000 years. The highest hazard is at TAN because it is the closest site to the northern Basin and Range province including the three major faults and the background zone and conversely, ANL has the lowest ground motions because it is the furthest site from the province. Sites near the central part of the INEL have similar ground motions due to their proximity to each other.

Figures 6-2a through 6-2g show the contributions of the three main source types to the mean hazard at the seven sites. The regional source zones and the fault sources have similar contributions to the total hazard as compared to the volcanic rift zones which contribute very little to the total hazard. The fault sources become more significant at lower probability levels and at the sites nearer to the Lost River and Lemhi faults. Note for TAN which is the closest site to the Beaverhead fault, the contribution of the faults is not as pronounced as at ATR or NRF because the Beaverhead fault is not as significant in terms of hazard as the Lost River or Lemhi faults (see following discussion). The relative contribution of the fault sources increases as one considers longer period motions because of the increased effect of magnitude on ground motion levels at longer periods, resulting in an increased domination of the hazard by larger magnitude events. The fault zones are expected to have higher frequency of large-magnitude events and the largest maximum magnitudes compared to the nearby regional source zones.

Figures 6-3a through 6-3g show the relative contribution of the three fault sources. For ATR, CPP, $\mathrm{PBF}$, and RWMC, the Lost River fault contributes the most hazard at these sites because of its proximity and its relatively higher recurrence rates than the other two faults (Figure 6-3). For ANL and $\mathrm{NRF}$, the Lost River fault contributes the most to hazard at shorter return periods and the Lemhi fault at periods longer than about 2000 years. At TAN, the Lemhi fault is generally the most significant contributor to hazard. The Beaverhead fault is the least significant of the faults because of its lower slip rate.

Figures $6-4 \mathrm{a}$ through $6-4 \mathrm{~g}$ show the contributions to the mean hazard from the volcanic sources. Note the scale change on the vertical axis. The volcanic sources have minimal contribution to the 


\subsubsection{Sources of Uncertainty and Sensitivity}

The distributions in the computed hazard shown in Figure 6-1 represent the cumulative effect of all levels of parametric uncertainty included in the hazard model logic trees (Figure 2-1 and Section 4). The relative contribution of various components of the model to the overall uncertainty can be identified readily from the logic tree formulation by computing the hazard holding individual parameters fixed at specific values.

For example, the contribution of uncertainty in selecting the appropriate type of attenuation model can be obtained by computing the mean hazard assuming each of the two approaches, site-specific stochastic or empirical is, in turn, the "correct" approach, with weight of 1.0, and the other approach has zero weight. The resulting hazard curves are shown on Figures $6-7 \mathrm{a}$ through $6-7 \mathrm{~g}$. The difference between the resulting mean hazard for the empirical and stochastic attenuation approaches represents the uncertainty in the computed hazard due to uncertainty in selecting the appropriate attenuation approach.

The results shown on Figures 6-7 indicate that the choice of attenuation relationship is a major portion of the uncertainty for short-period motions. This results from the effect of the local geology on the site-specific attenuation model predictions as discussed in Section 5.2.3 which can lead to significantly different predictions of site-specific ground motions than are obtained using the empirical rock relationships. The stochastic model ground motion predictions tend to be lower than those obtained using empirical attenuation relationships at periods lower than about $0.1 \mathrm{sec}$. At longer periods such as $1.0 \mathrm{sec}$, the two approaches lead to similar estimates of ground motion hazard. Thus the effects of site geology at the INEL and differences with typical western U.S. rock sites are most pronounced at high frequencies ( $>10 \mathrm{~Hz}$ ). Note the smallest difference between the empirical and stochastic approaches to attenuation is at ANL (Figure 6-7a). This is probably due to the general absence of sedimentary interbeds beneath ANL which are important in reducing highfrequency ground motions at the other sites where they are present (e.g., NRF).

Figures 6-8a through 6-8g show the effect of uncertainty in the choice of empirical attenuation relationship on the hazard computed using only the empirical attenuation models. As indicated, the model developed by Campbell (1994) (designated C94) produces the lowest hazard, with the greatest difference at a period of 1.0 seconds. This large difference results 
at most sites. The influence is greatest on the hazard from the Beaverhead fault at the TAN site. However, the hazard at TAN is controlled by the other fault sources.

Figures $6-16 \mathrm{a}$ through $6-16 \mathrm{~g}$ show the effect of the alternative regional source zonation models on the computed hazard. Because the recurrence rate for the dominate source zone, the northern Basin and Range, is similar for all three zonation models, there is negligible effect on hazard.

The impact of the 1905 Shoshone earthquake occurring in the ESRP or to the south in the central Basin and Range province on computed hazard from the regional source zones is indicated on Figures 6-17a through 6-17g. Assuming that the event occurred in the ESRP results in higher hazard because it results in higher estimated rates for events of $M_{w} 5$ and greater (Figure 4-14) and results in higher estimates for maximum magnitude. This results in a higher hazard from the ESRP source. However, the contribution of the ESRP source to hazard becomes noticeable only at very low probability levels $\left(<10^{-4}\right)$ and so the effect of the 1905 earthquake location is, in general, insignificant.

In summary, the greatest source of uncertainty in the ground motion estimates is the selection of the attenuation model. The rates of seismicity for both the faults and areal source zones and the value of kappa at the individual sites at high frequencies are also significant sources of uncertainty. At low ground motion levels, the magnitude distribution (i.e. characteristic versus exponential models) and at high ground motion levels, the $b$-value for the ESRP source zone are important parameters.

\subsection{EQUAL-HAZARD SPECTRA}

Equal-hazard spectra were developed for the seven facility sites by selecting the peak ground motion levels from the mean hazard curves at the various spectral acceleration periods for the PC return periods of 500,1,000, 2,000 and 10,000 years (annual frequencies of exceedance of $0.002,0.001,0.0005$, and 0.0001 , respectively). Figures 6-18a through 6$18 \mathrm{~g}$ present composite plots of the mean hazard curves computed for the nine spectral periods (0.02 [PGA], 0.03, 0.05, 0.1, 0.2, 0.3, 0.5, 1.0, and 2.0 seconds). Peak spectral amplitudes were interpolated from these hazard curves for the four return periods and these are summarized in Table 6-1. 
for the NPR site, the values for CPP, which is located just to the west, are nearly identical (Table 61). Despite the differences in approaches (multiple experts versus team of experts and seismic source and ground motion input), the results are somewhat surprisingly similar. 
TABLE 6-1

EQUAL HAZARD SPECTRAL ACCELERATIONS (5\% DAMPING)

\begin{tabular}{|c|c|c|c|c|}
\hline & $1, \sqrt{1}$ & $\begin{array}{c}\text { Annual Hazard } \\
\text { (Re }\end{array}$ & $\begin{array}{l}\text { ceefdahce Próbabifity } \\
\text { n Perod) }\end{array}$ & 14 \\
\hline $\begin{array}{c}\text { Spectral Period } \\
(\mathrm{sec})\end{array}$ & $\begin{array}{l}2 \times 10^{-3} \\
(500 \mathrm{yrs})\end{array}$ & $\begin{array}{c}1 \times 10^{-3} \\
(1000 \mathrm{yrs})\end{array}$ & $\begin{array}{c}5 \times 10^{-4} \\
(2000 \mathrm{yrs})\end{array}$ & $\begin{array}{c}1 \times 10^{-4} \\
(10,000 \mathrm{yrs})\end{array}$ \\
\hline 0.02 & 0.057 & 0.075 & 0.098 & 0.163 \\
\hline 0.03 & 0.071 & 0.097 & 0.127 & 0.231 \\
\hline 0.05 & 0.084 & 0.114 & 0.151 & 0.279 \\
\hline 0.10 & 0.121 & 0.161 & 0.212 & 0.366 \\
\hline 0.20 & 0.127 & 0.170 & 0.224 & 0.390 \\
\hline 0.30 & 0.113 & 0.151 & 0.202 & 0.354 \\
\hline 0.50 & $0.086 \square$ & 0,116 & 0.153 & 0.276 \\
\hline 1.00 & 130.050 & $0.06 \%$ & $0.090 \%$ & 0.158 \\
\hline 2.00 & 0,024 & 0.033 & $11-10044 \%$ & 0.077 \\
\hline
\end{tabular}

ATR

\begin{tabular}{|c|c|c|c|c|}
\hline & \multicolumn{4}{|c|}{$\begin{array}{l}\text { Annual Hazard Exceedance Probability } \\
\text { (Return Period) }\end{array}$} \\
\hline $\begin{array}{c}\text { Spectral Period } \\
(\mathrm{sec})\end{array}$ & $\begin{array}{c}2 \times 10^{-3} \\
(500 \mathrm{yrs})\end{array}$ & $\begin{array}{c}1 \times 10^{-3} \\
(1000 \mathrm{yrs})\end{array}$ & $\begin{array}{c}5 \times 10^{-4} \\
(2000 \mathrm{yrs})\end{array}$ & $\begin{array}{c}1 \times 10^{-4} \\
(10,000 \mathrm{yIs})\end{array}$ \\
\hline 0.02 & 0.081 & 0.110 & 0.141 & 0.239 \\
\hline 0.03 & 0.093 & 0.125 & 0.163 & 0.281 \\
\hline 0.05 & 0.104 & 0.139 & 0.186 & 0.323 \\
\hline 0.10 & \% $0.160^{\circ}$ & $\% 0.221$ & $0.292 \%$ & 0.495 \\
\hline 0.20 & $1 \% 0.186$ & $190,257 \%: 1$ & 10034 & 0.599 \\
\hline 0.30 & $18 \% 0.162$ & $022 \%$ & 0,0306 & 0.543 \\
\hline 0.50 & 100.420 & $00.169 \quad \square$ & $20.23 \mathrm{I}$ & 0.426 \\
\hline 1.00 & 0.067 & 0.097 & 0.131 & 0.251 \\
\hline 2.00 & 0.033 & 0.048 & 0.066 & 0.127 \\
\hline
\end{tabular}

CPP

\begin{tabular}{|c|c|c|c|c|}
\hline & \multicolumn{4}{|c|}{$\begin{array}{l}\text { Annual Hazard Exceedance Probability } \\
\text { (Return Period) }\end{array}$} \\
\hline $\begin{array}{c}\text { Spectral Period } \\
(\mathrm{sec})\end{array}$ & $\begin{array}{c}2 \times 10^{-3} \\
(500 \mathrm{yxs})\end{array}$ & $\begin{array}{c}1 \times 10^{-3} \\
(1000 \mathrm{yrs}):=\end{array}$ & $\begin{array}{c}5 \times 10^{-4} \\
(2000 \mathrm{yrs})\end{array}$ & $\begin{array}{c}1 \times 10^{-4} \\
(10,000 \mathrm{yrs})\end{array}$ \\
\hline 0.02 & $0.075 \%$ & $0102 \%$ & $00 \% 30$ & 0.220 \\
\hline 0.03 & $0.082 \square$ & $0,41 \%$ & \% $0144: \%$ & 0.248 \\
\hline 0.05 & $00.02 \%$ & $-\quad \% 0124 \%$ & $-40163 \%$ & 0.285 \\
\hline 0.10 & 0.154 & 0.213 & 0.279 & 0.471 \\
\hline 0.20 & 0.173 & 0.238 & 0.318 & 0.551 \\
\hline 0.30 & 0.150 & 0.211 & 0.282 & 0.502 \\
\hline 0.50 & 0.113 & 0.157 & 0.215 & 0.394 \\
\hline 1.00 & 0.064 & 0.090 & 0.123 & 0.232 \\
\hline 2.00 & 0.029 & 0.042 & 0.058 & 0.110 \\
\hline
\end{tabular}


TABLE 6-1

EQUAL HAZARD SPECTRAL ACCELERATIONS (5\% DAMPING) (CONT.)

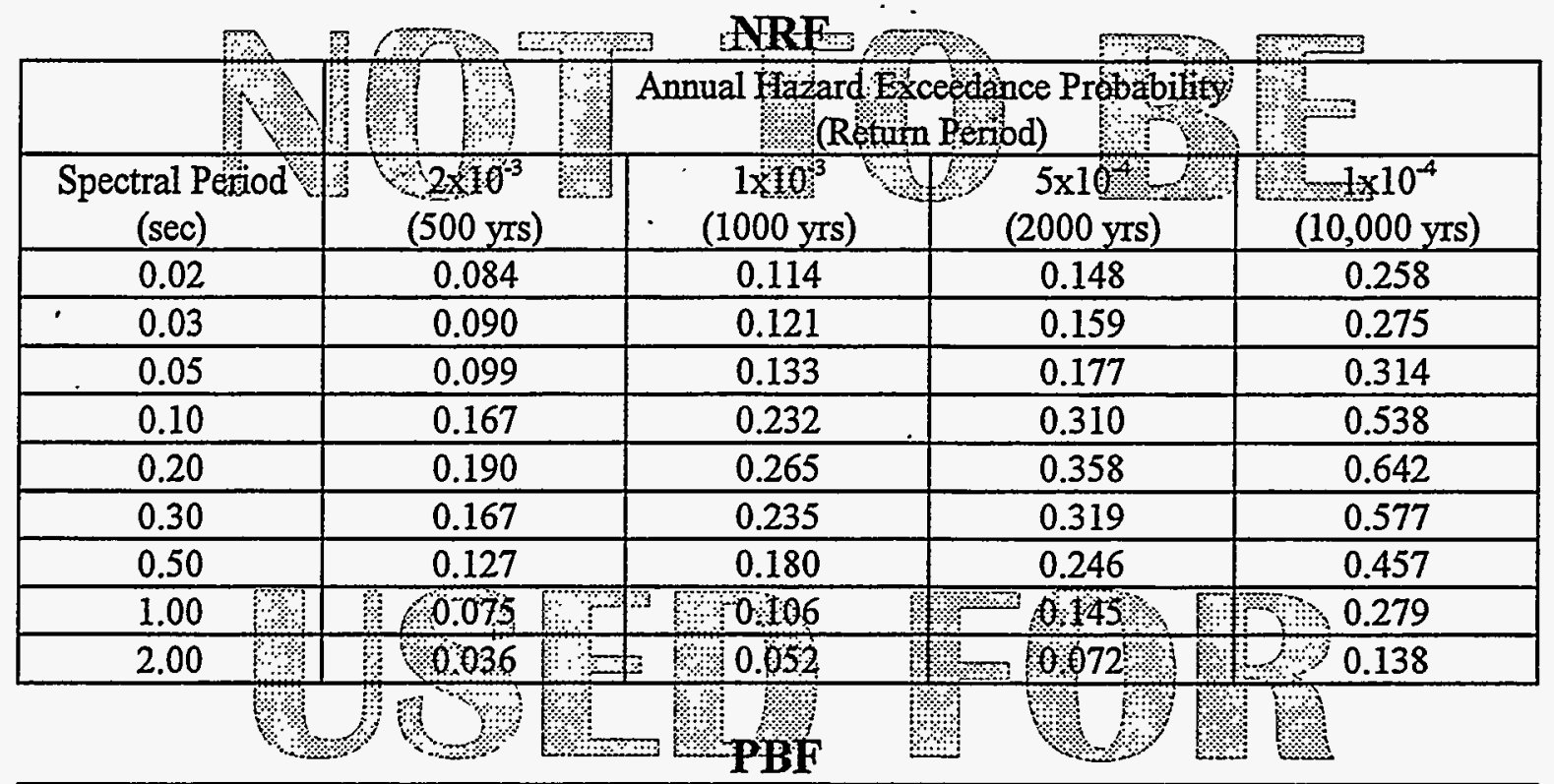

\begin{tabular}{|c|c|c|c|c|}
\hline & \multicolumn{4}{|c|}{$\begin{array}{l}\text { Annual Hazard Exceedance Probability } \\
\text { (Return Period) }\end{array}$} \\
\hline $\begin{array}{c}\text { Spectral Period } \\
(\mathrm{sec})\end{array}$ & $\begin{array}{c}2 \times 10^{-3} \\
(500 \mathrm{yrs}) \\
\end{array}$ & $\begin{array}{c}1 \times 10^{-3} \\
(1000 \mathrm{yrs})\end{array}$ & $\begin{array}{c}5 \times 10^{-4} \\
(2000 \text { yrs })\end{array}$ & $\begin{array}{c}1 \times 10^{-4} \\
(10,000 \mathrm{yrs})\end{array}$ \\
\hline 0.02 & 0.063 & 0.085 & 0.111 & 0.184 \\
\hline 0.03 & 0.066 & 0.089 & 0.115 & 0.194 \\
\hline 0.05 & 0.071 & 0.098 & 0.126 & 0.220 \\
\hline 0.10 & $-1,0.125$ & 0.170 & 0.225 & 0.383 \\
\hline 0.20 & $\because \$ 0,42$ & 60.200 & 30,264 & 0.466 \\
\hline 0.30 & $5,0.127$ & 90.176 & 10.0 .237 & 0.425 \\
\hline 0.50 & 90,102 & 0.40 & 100.191 & 0.345 \\
\hline 1.00 & 0.063 & $0.08 \overline{8}$ & 0.119 & 0.221 \\
\hline 2.00 & 0.031 & 0.044 & 0.060 & 0.111 \\
\hline
\end{tabular}

\section{RWMC}

\begin{tabular}{|c|c|c|c|c|}
\hline & \multicolumn{4}{|c|}{$\begin{array}{l}\text { Annual Hazard Exceedance Probability } \\
\text { (Return Period) }\end{array}$} \\
\hline $\begin{array}{l}\text { Spectral Period } \\
(\mathrm{sec})\end{array}$ & $\begin{array}{c}2 \times 10^{-3} \\
(500 \mathrm{yrs})\end{array}$ & $\begin{array}{c}1 \times 10^{-3} \\
(1000 \mathrm{yrs})\end{array}$ & $\begin{array}{c}5 \times 10^{4} \\
(2000 \mathrm{yrs})\end{array}$ & $\begin{array}{c}1 \times 10^{-4} \\
(10,000 \mathrm{yrs})\end{array}$ \\
\hline 0.02 & 00.076. & $\approx \theta .104 \%$ & 900184 & 0.233 \\
\hline 0.03 & $0.087 / 1$ & $-80118 \%$ & 1400156 & 0.279 \\
\hline 0.05 & $0.103 \bigcirc$ & 0.401 & $100191 \%$ & 0.344 \\
\hline 0.10 & $016 \%$ & ००223 & $\checkmark 2.0: 297<3$ & 0.513 \\
\hline 0.20 & 0.172 & 0.239 & 0.321 & 0.570 \\
\hline 0.30 & 0.148 & 0.209 & 0.282 & 0.514 \\
\hline 0.50 & 0.109 & 0.152 & 0.211 & 0.396 \\
\hline 1.00 & 0.060 & 0.085 & 0.117 & 0.226 \\
\hline 2.00 & 0.028 & 0.040 & 0.056 & 0.107 \\
\hline
\end{tabular}


TABLE 6-1

EQUAL HAZARD SPECTRAL ACCELERATIONS (5\% DAMPING) (CONT.)

\begin{tabular}{|c|c|c|c|c|}
\hline . & 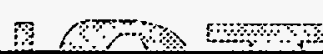 & FAN & \%ా & $\%$ \\
\hline 1, & (16) & $\begin{array}{r}\text { Annual Hazard } \\
\text { (Re }\end{array}$ & 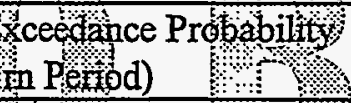 & : \\
\hline Spectral Pexiod & $132 \times 10^{-3}$ वा & $1 \times 10^{3}$ & $14 \quad 5 \times 10^{4}$ & $e^{2} \times 10^{-4}$ \\
\hline$(\mathrm{sec})$ & (500 yrs) & (1000 yrs) & (2000 yrs) & $(10,000$ yrs $)$ \\
\hline 0.02 & 0.093 & 0.129 & 0.177 & 0.328 \\
\hline 0.03 & 0.105 & 0.146 & 0.202 & 0.368 \\
\hline 0.05 & 0.117 & 0.166 & 0.230 & 0.430 \\
\hline 0.10 & 0.188 & 0.268 & 0.371 & 0.694 \\
\hline 0.20 & 0.209 & 0.299 & 0.414 & 0.788 \\
\hline 0.30 & 0.179 & 0.256 & 0.355 & 0.685 \\
\hline 0.50 & 0.128 & 0.184 & 0.255 & 0.496 \\
\hline 1.00 & $00.074 \%$ & 0.0 .105 & 610144 & 0.282 \\
\hline 2.00 & 0035 & $=0.051$ & $1 \% 0070 \%$ & 0.135 \\
\hline
\end{tabular}
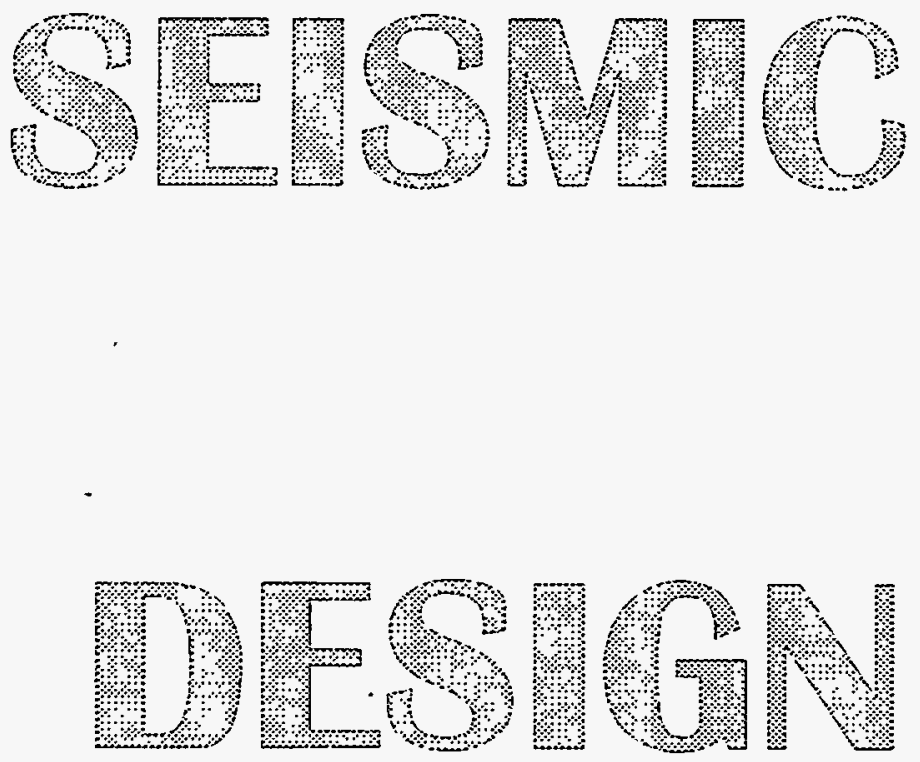


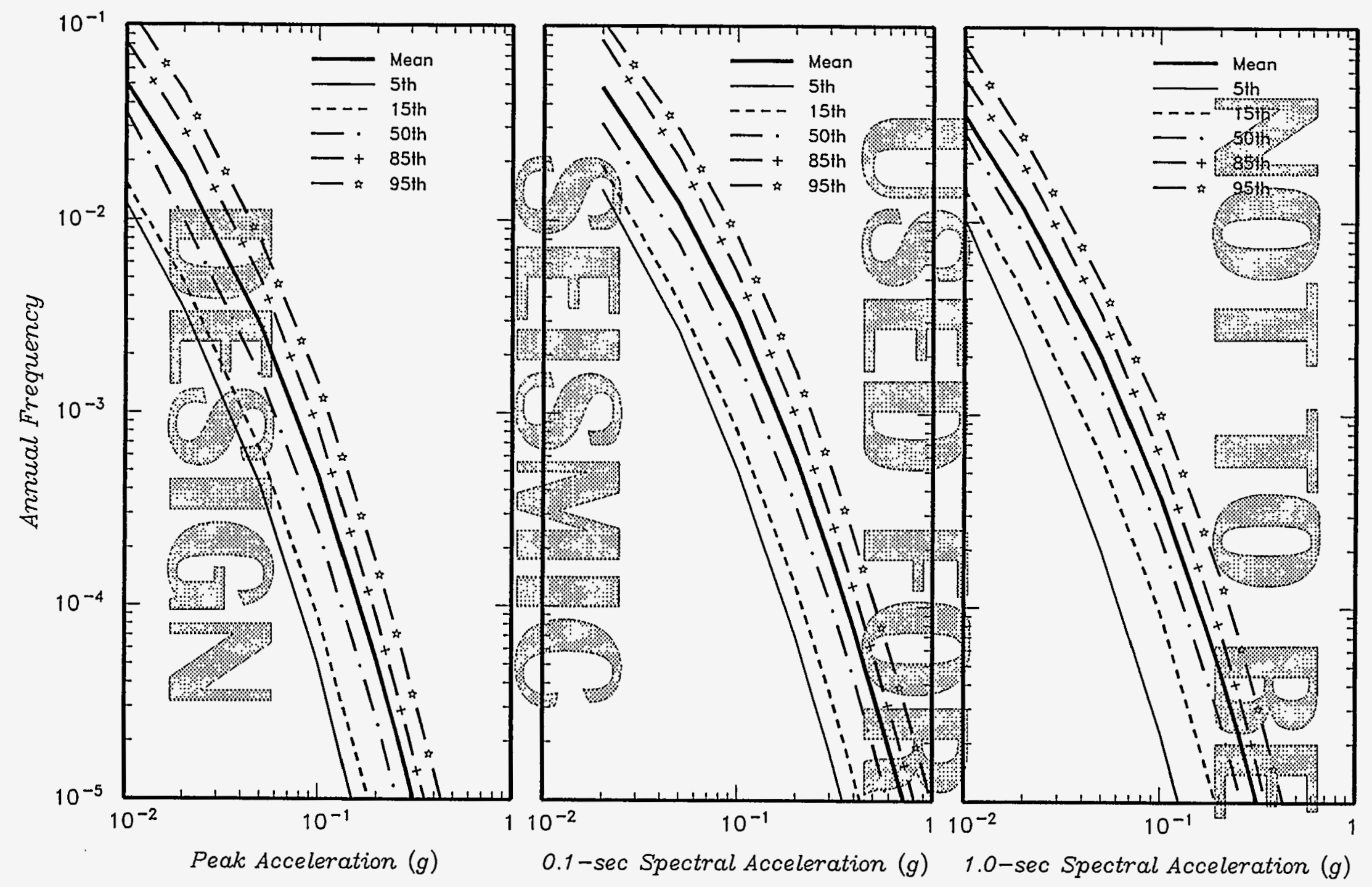

\begin{tabular}{|c|c|c|c|}
\hline $\begin{array}{l}\text { Project No. } \\
\text { SK9455 }\end{array}$ & INEL - Probabilistic Analyses & \multirow{2}{*}{$\begin{array}{c}\text { MEAN AND 5TH TO 95TH } \\
\text { PERCENTILE SEISMIC HAZARD CURVES } \\
\text { FOR ANL }\end{array}$} & \multirow{2}{*}{$\begin{array}{c}\text { Figure } \\
6-1 a\end{array}$} \\
\hline \multicolumn{2}{|c|}{ Woochward-Clyde Federal Services } & & \\
\hline
\end{tabular}



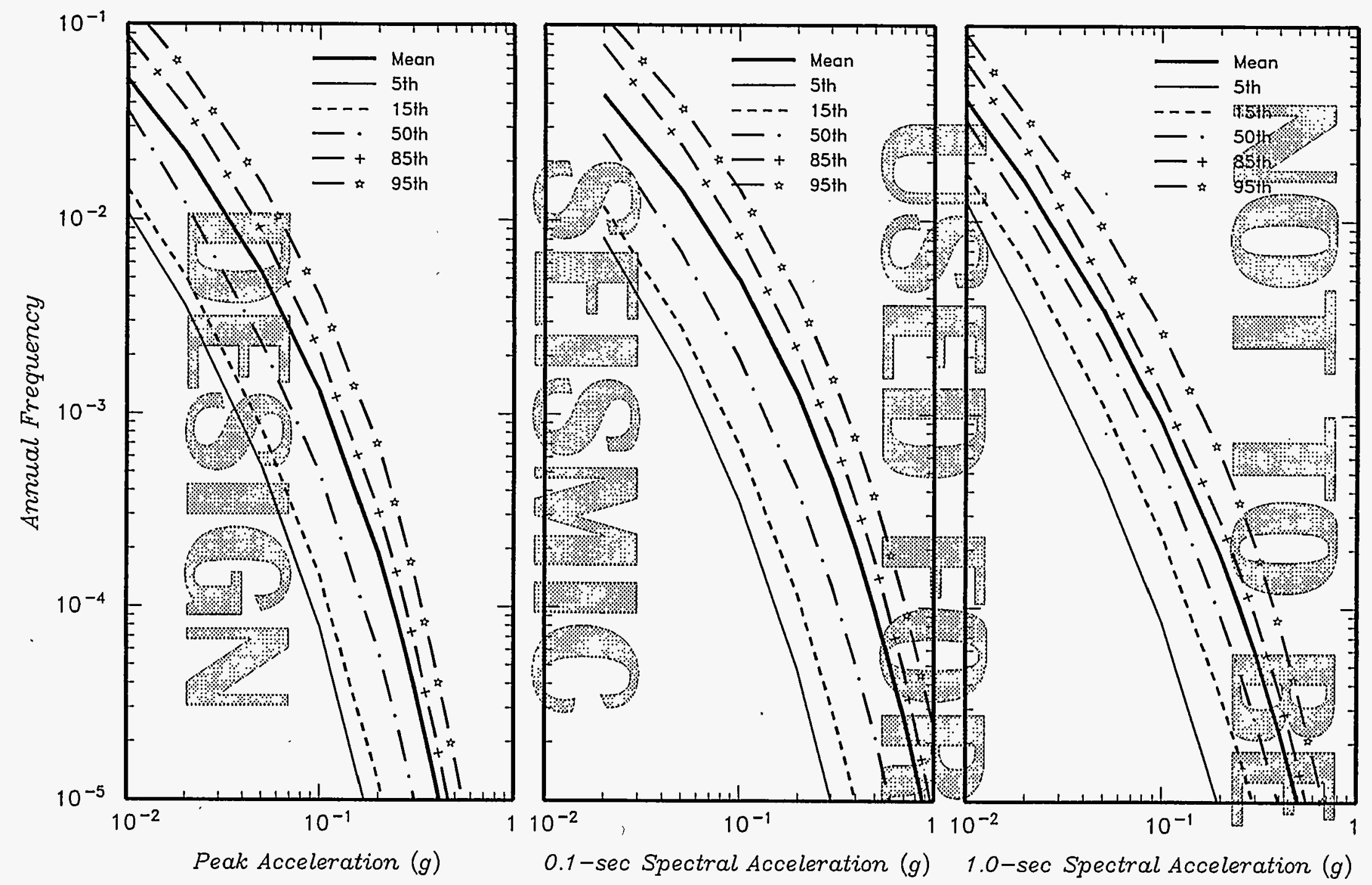

\begin{tabular}{|c|c|c|c|}
\hline $\begin{array}{c}\text { Project No. } \\
\text { SK9455 }\end{array}$ & INEL - Probabilistic Analyses & $\begin{array}{c}\text { MEAN AND 5TH TO 95TH } \\
\text { PERCENTILE SEISMIC HAZARD CURVES } \\
\text { FOR ATR }\end{array}$ & $\begin{array}{c}\text { Figure } \\
6-1 \mathrm{~b}\end{array}$ \\
\cline { 1 - 2 } Woodward-Clyde Federal Services & PER
\end{tabular}




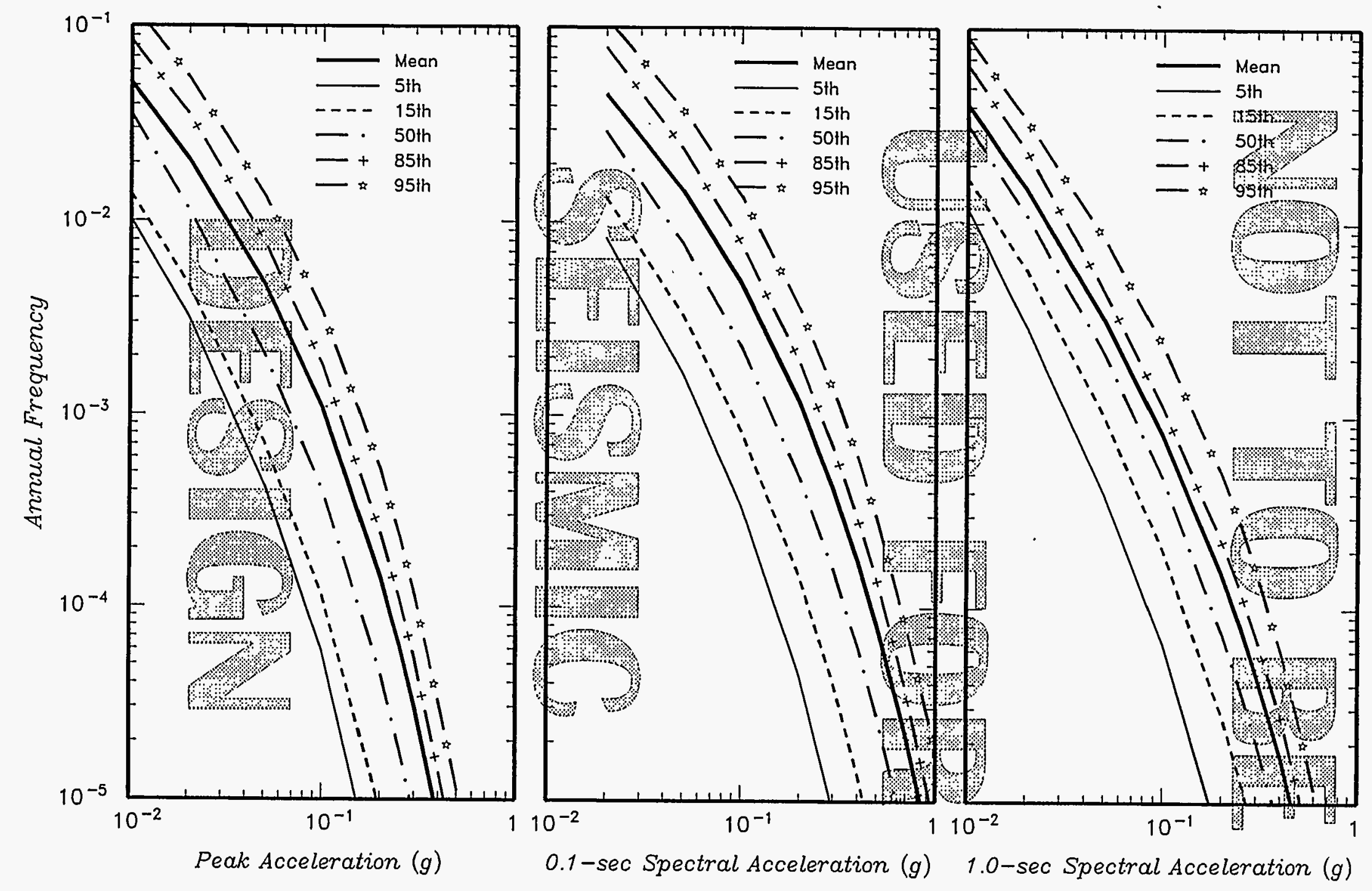

\begin{tabular}{|c|c|c|}
$\begin{array}{c}\text { Project No. } \\
\text { SK9455 }\end{array}$ & INEL - Probabilistic Analyses & MEAN AND 5TH TO 95TH \\
\cline { 1 - 1 } Woodward-Clyde Federal Services & PERCENTILE SEISMIC HAZARD CURVES \\
FOR CPP
\end{tabular}




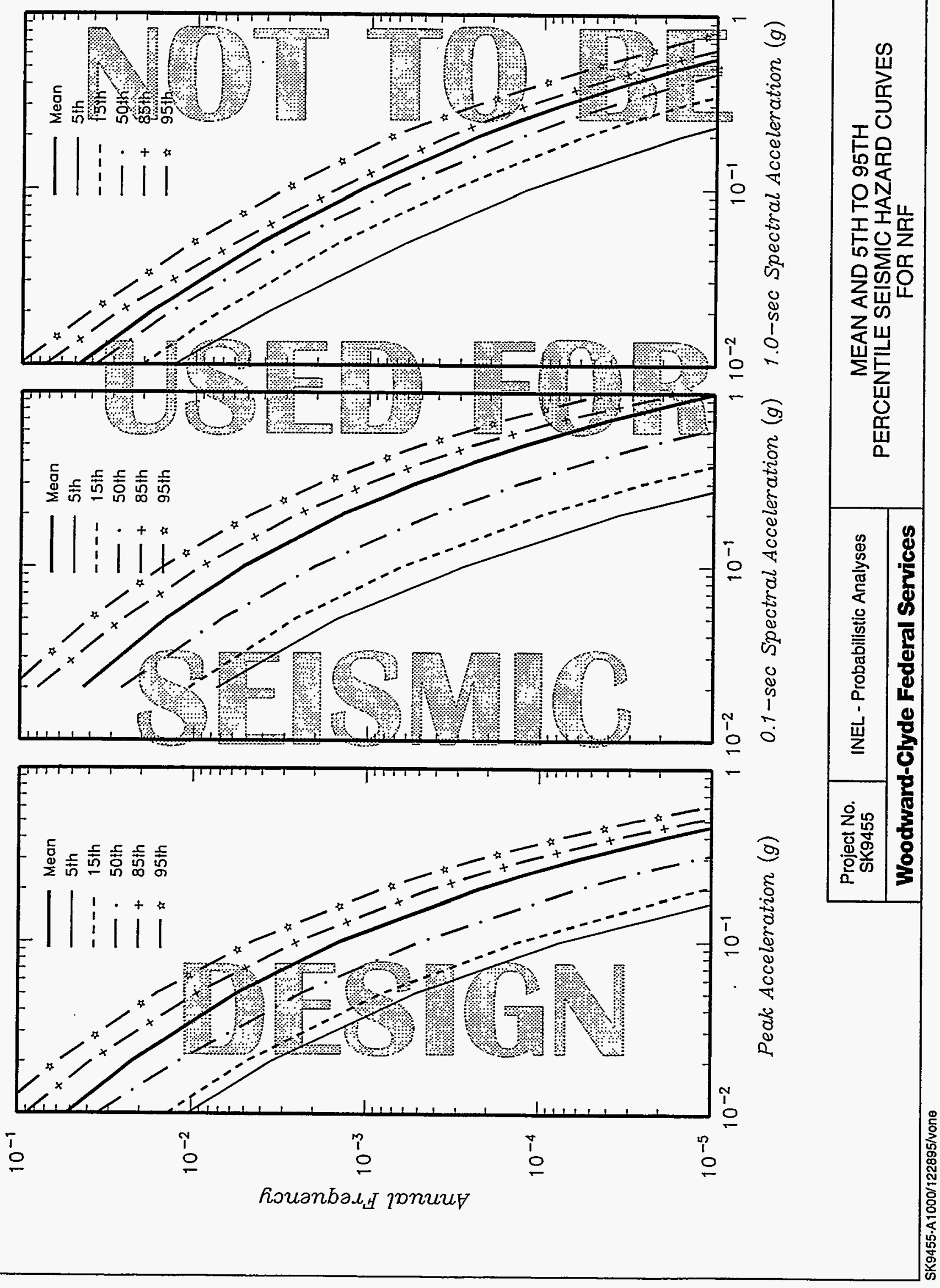



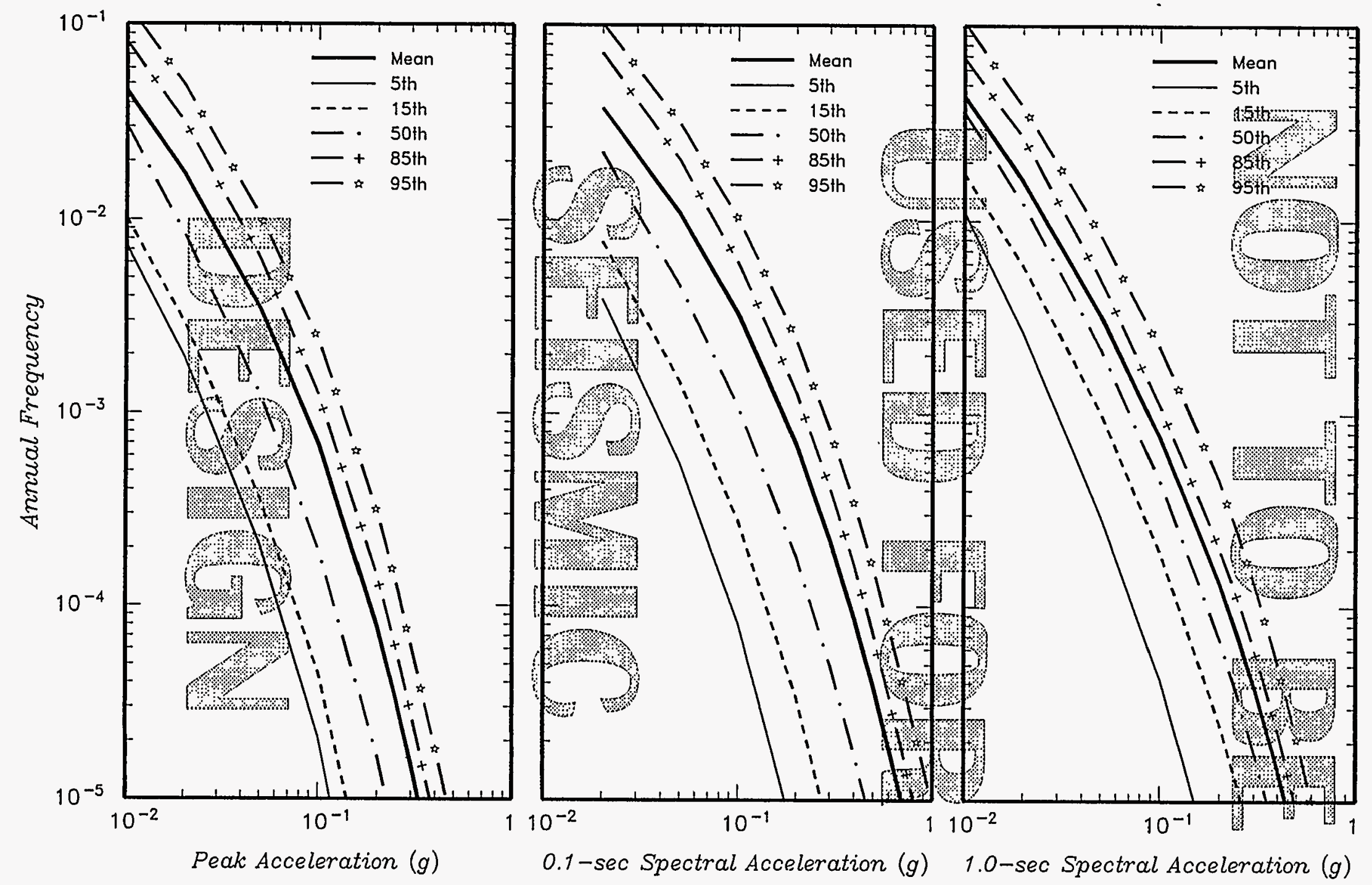
产㐫

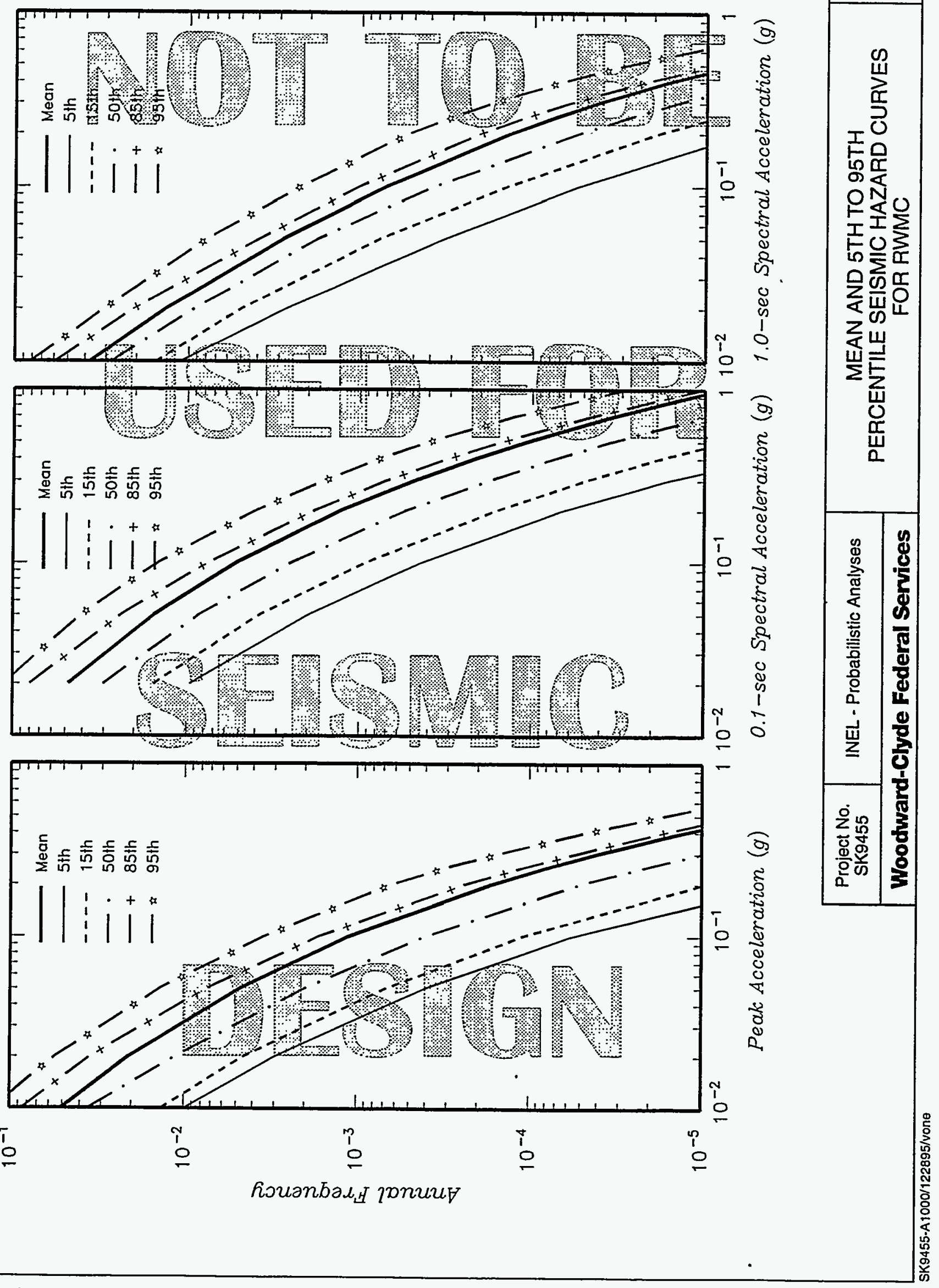




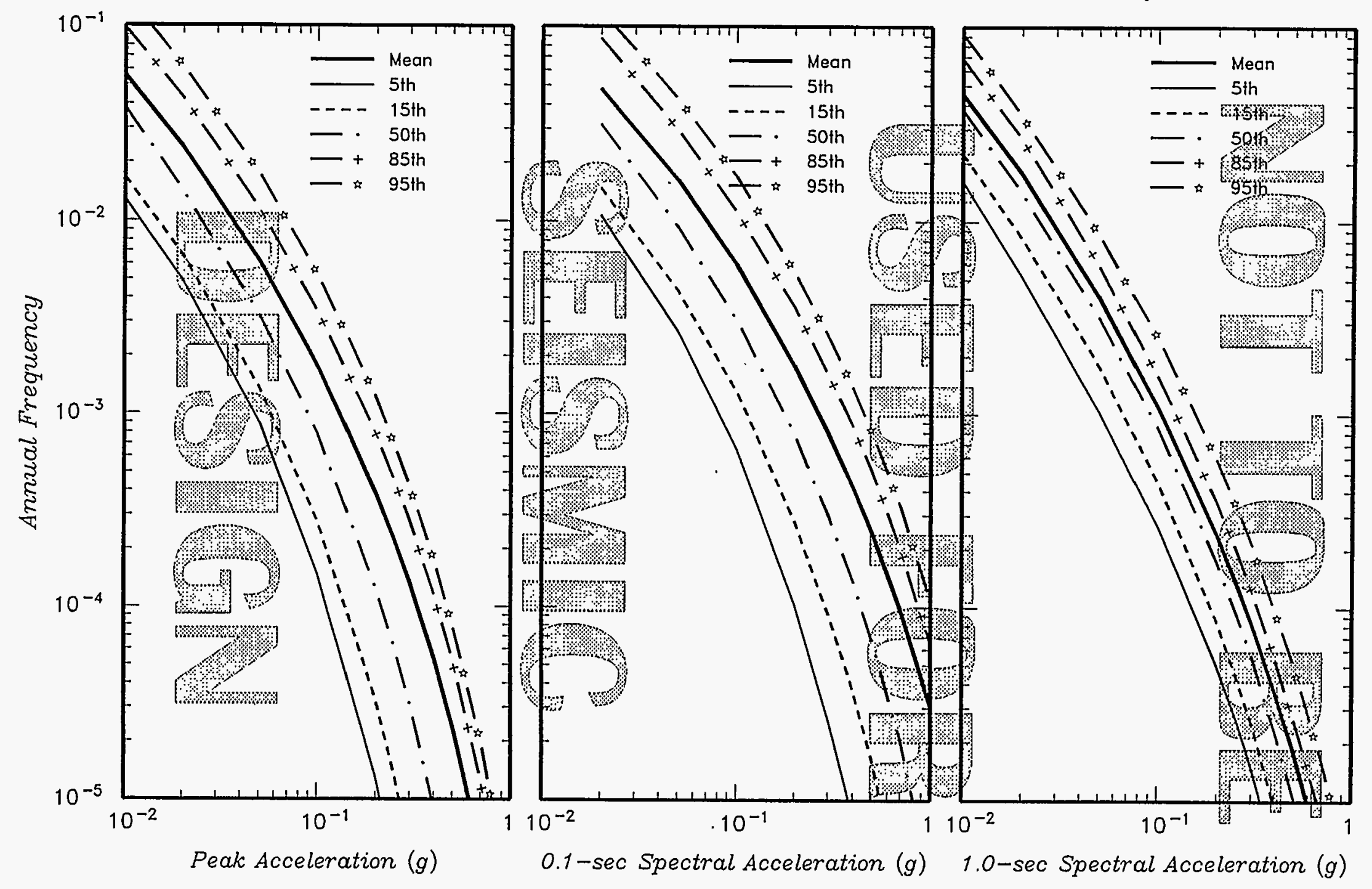

\begin{tabular}{|c|c|c|c|}
\hline $\begin{array}{c}\text { Project No. } \\
\text { SK9455 }\end{array}$ & INEL - Probabilistic Analyses & $\begin{array}{c}\text { MEAN.AND 5TH TO 95TH } \\
\text { PERCENTILE SEISMIC HAZARD CURVES } \\
\text { Foodward-Clyde Federal Services }\end{array}$ & $\begin{array}{c}\text { Figure } \\
6-1 \mathrm{~g}\end{array}$ \\
\hline Woodwan
\end{tabular}



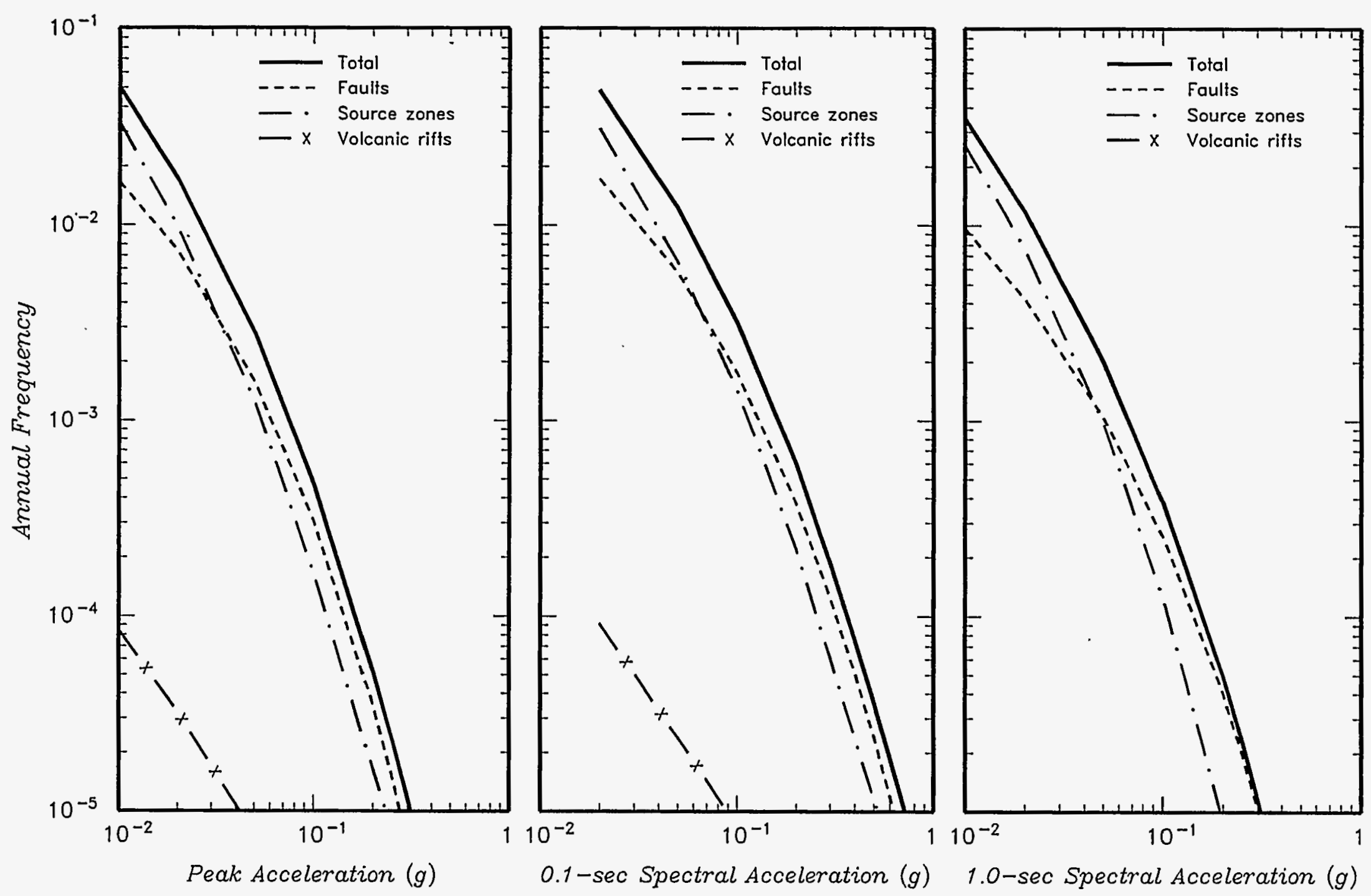

\begin{tabular}{|c|c|c|c|}
\hline $\begin{array}{l}\text { Project No. } \\
\text { SK9455 }\end{array}$ & INEL - Probabilistic Analyses & \multirow{2}{*}{$\begin{array}{l}\text { CONTRIBUTIONS OF THE } \\
\text { SEISMIC SOURCES TO THE } \\
\text { MEAN SEISMIC HAZARD AT ANL }\end{array}$} & \multirow{2}{*}{$\begin{array}{c}\text { Figure } \\
6-2 a\end{array}$} \\
\hline \multicolumn{2}{|c|}{ Woodward-Clyde Federal Services } & & \\
\hline
\end{tabular}



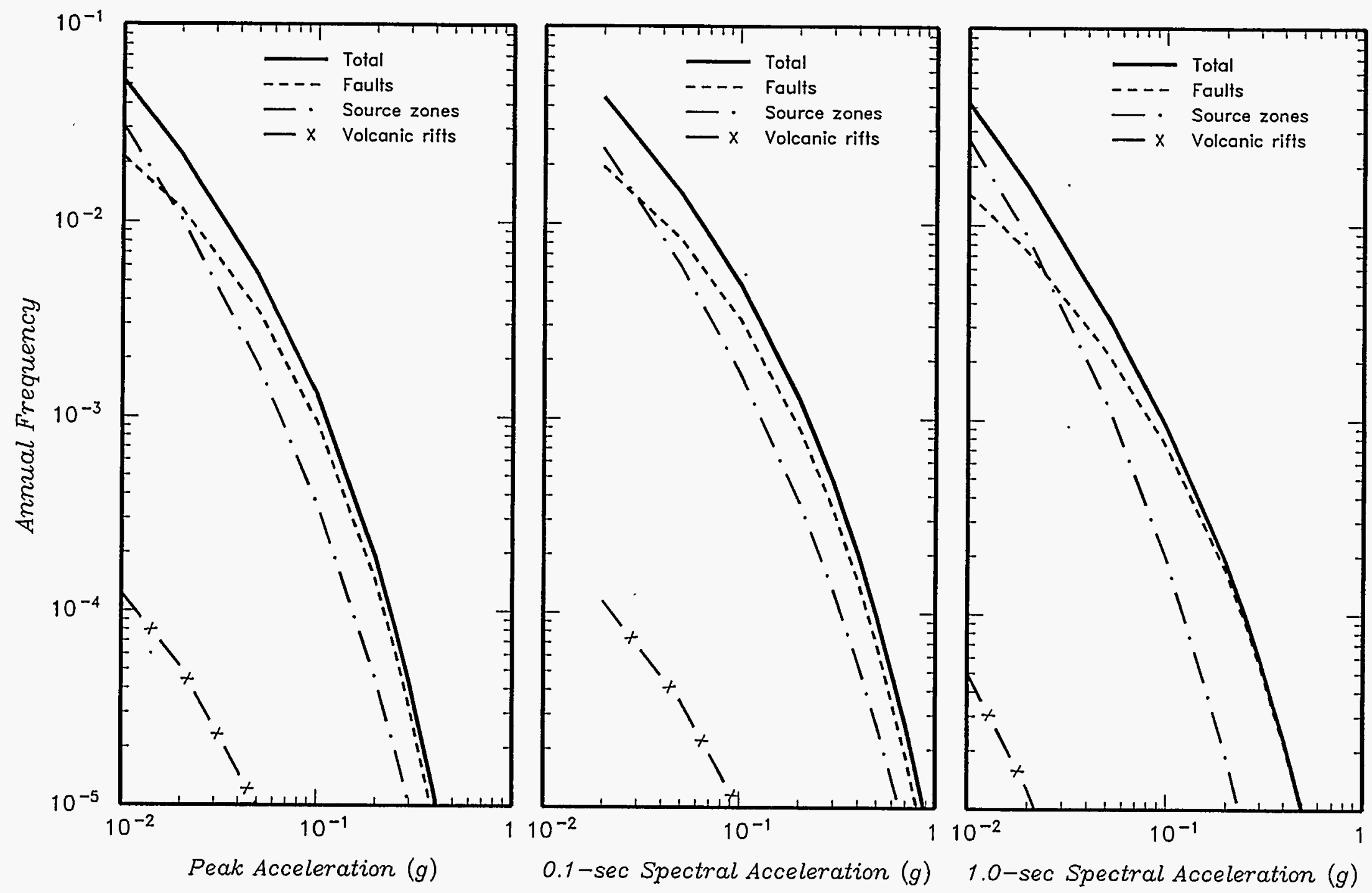

\begin{tabular}{|c|c|}
\hline $\begin{array}{c}\text { Project No. } \\
\text { SK9455 }\end{array}$ & INEL - Probabilistic Analyses \\
\hline \multicolumn{2}{|c|}{ Woodward-Clyde Federal Services } \\
\hline
\end{tabular}

CONTRIBUTIONS OF THE

SEISMIC SOURCES TO THE MEAN SEISMIC HAZARD AT ATR 

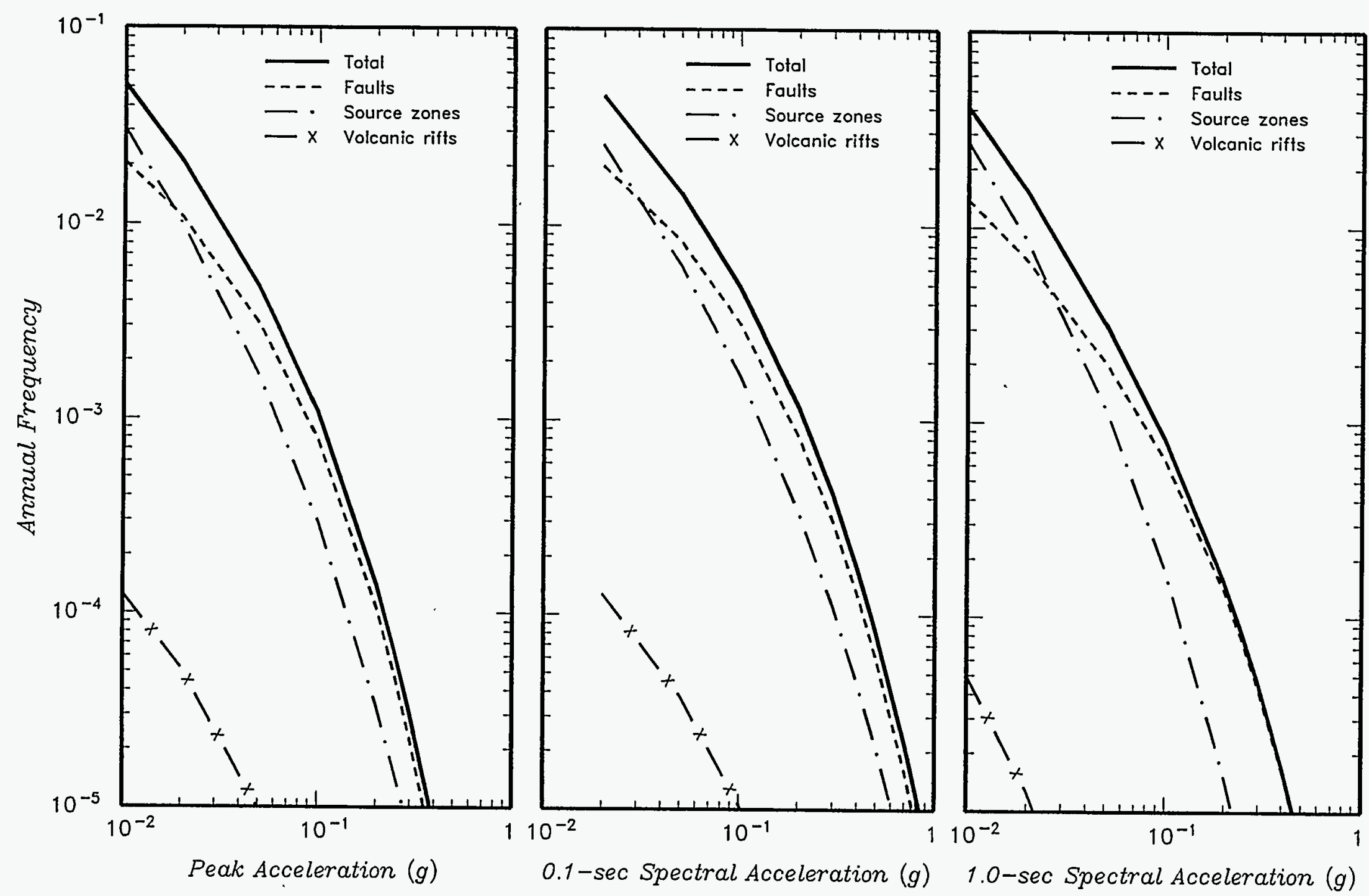

\begin{tabular}{|c|c|c|c|}
\hline $\begin{array}{c}\text { Project No. } \\
\text { SK9455 }\end{array}$ & INEL - Probabilistic Analyses & CONTRIBUTIONS OF THE & Figure \\
\cline { 1 - 1 } Woodward-Clyde Federal Services & SEISMIC SOURCES TO THE & $6-2 \mathrm{C}$ \\
\hline
\end{tabular}



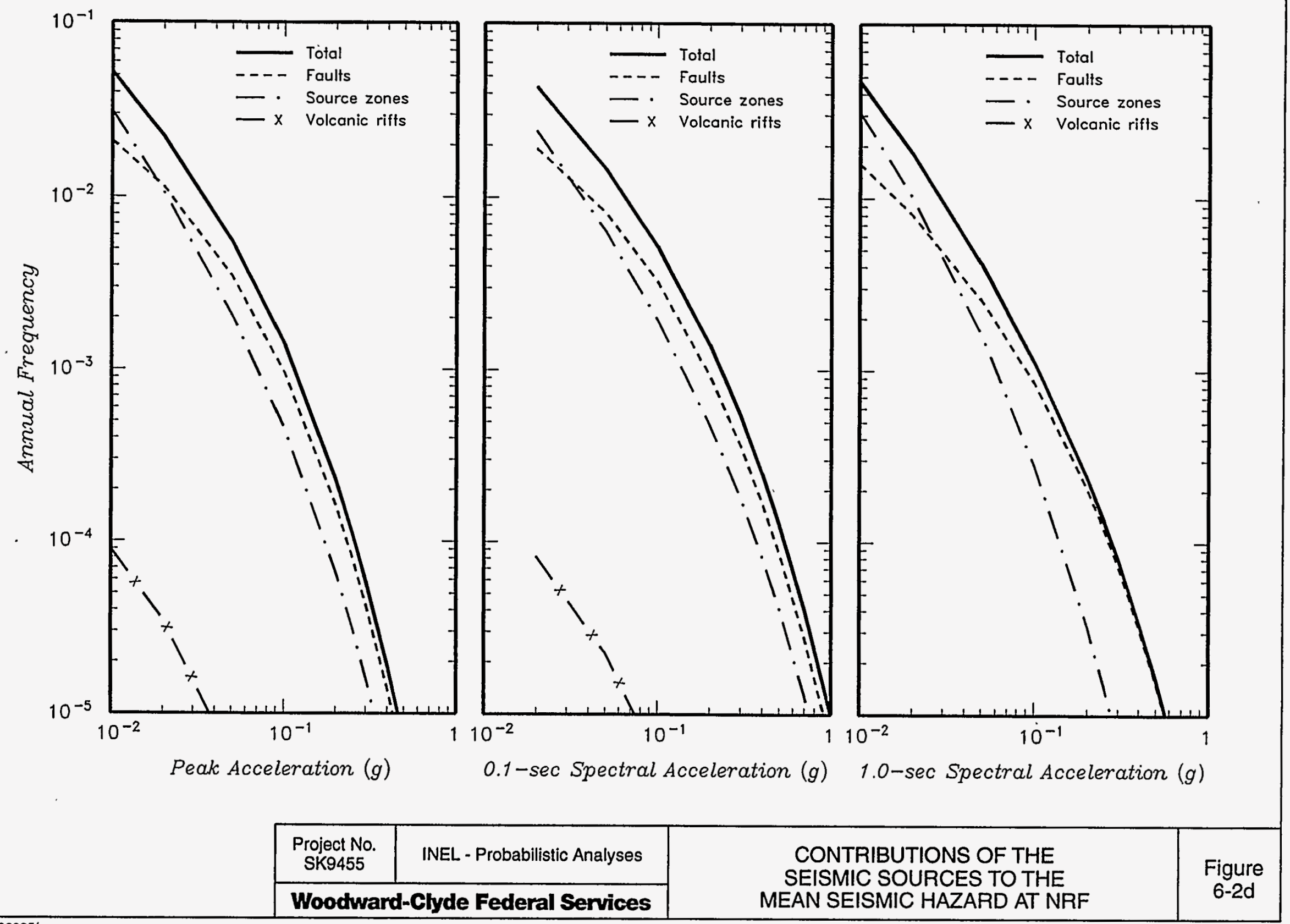

SK9455-A1000/122895/von

\begin{tabular}{|c|c|c|c|}
\hline $\begin{array}{l}\text { Project No. } \\
\text { SK9455 }\end{array}$ & INEL - Probabilistic Analyses & \multirow{2}{*}{$\begin{array}{l}\text { CONTRIBUTIONS OF THE } \\
\text { SEISMIC SOURCES TO THE } \\
\text { MEAN SEISMIC HAZARD AT NRF }\end{array}$} & \multirow{2}{*}{$\begin{array}{c}\text { Figure } \\
6-2 d\end{array}$} \\
\hline \multicolumn{2}{|c|}{ Woodward-Clyde Federal Services } & & \\
\hline
\end{tabular}




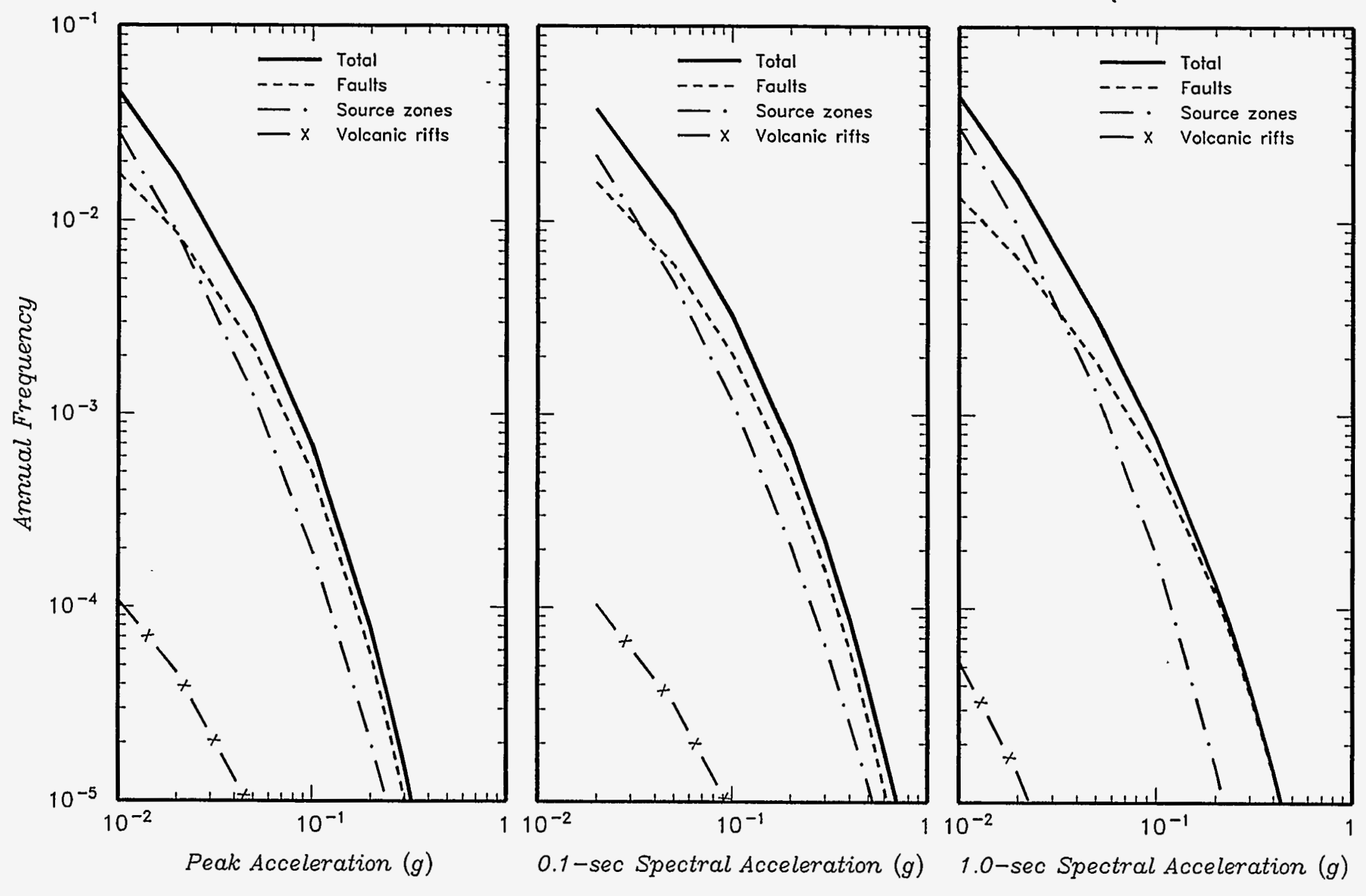

\begin{tabular}{|c|c|c|c|}
\hline $\begin{array}{c}\text { Project No. } \\
\text { SK9455 }\end{array}$ & INEL - Probabilistic Analyses & $\begin{array}{c}\text { CONTRIBUTIONS OF THE } \\
\text { SEISMIC SOURCES TO THE } \\
\text { Woodward-Clyde Federal Services }\end{array}$ & $\begin{array}{c}\text { Figure } \\
6-2 e\end{array}$ \\
\hline MEAN SEISMIC HAZARD AT PBF
\end{tabular}




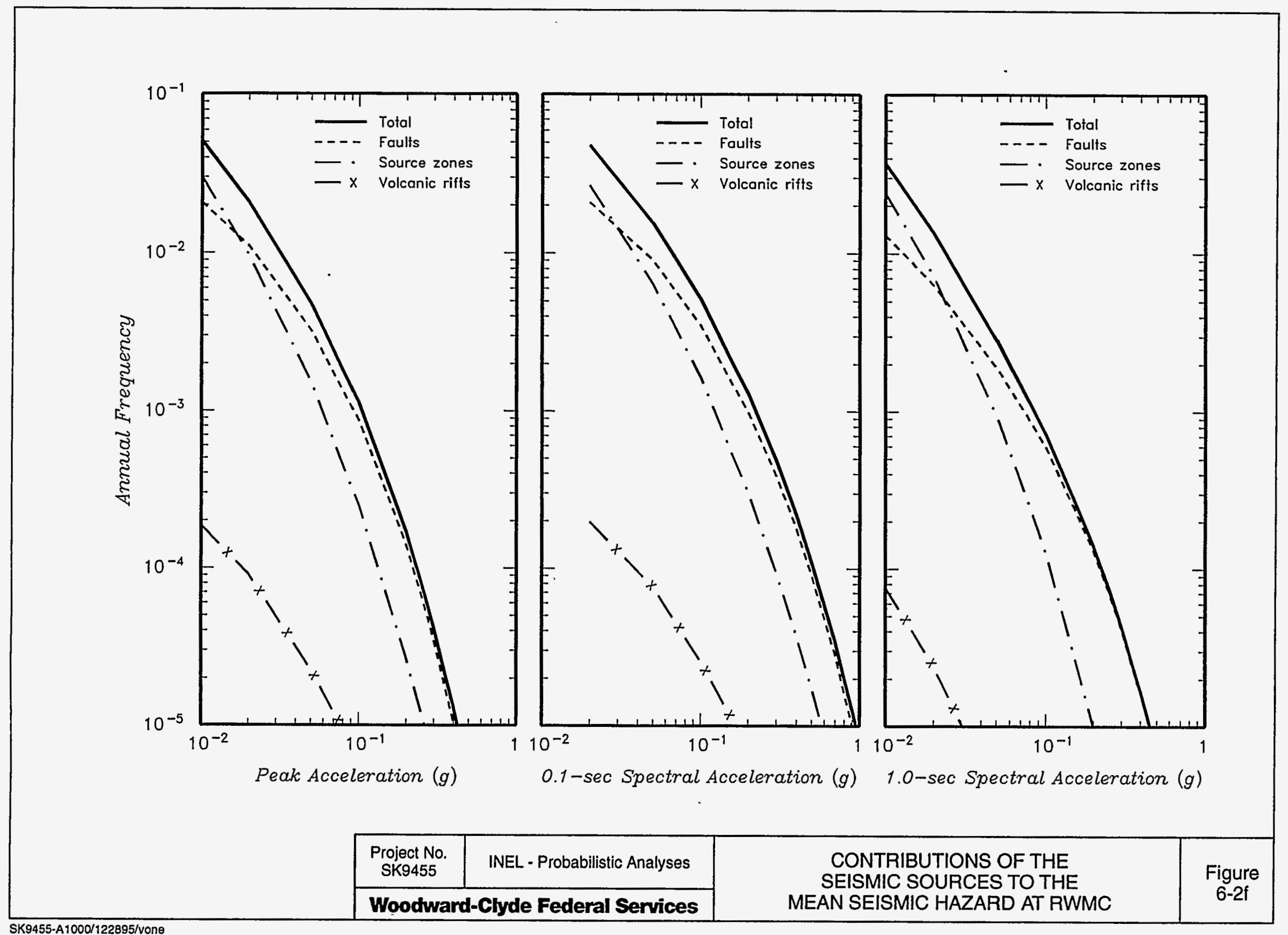



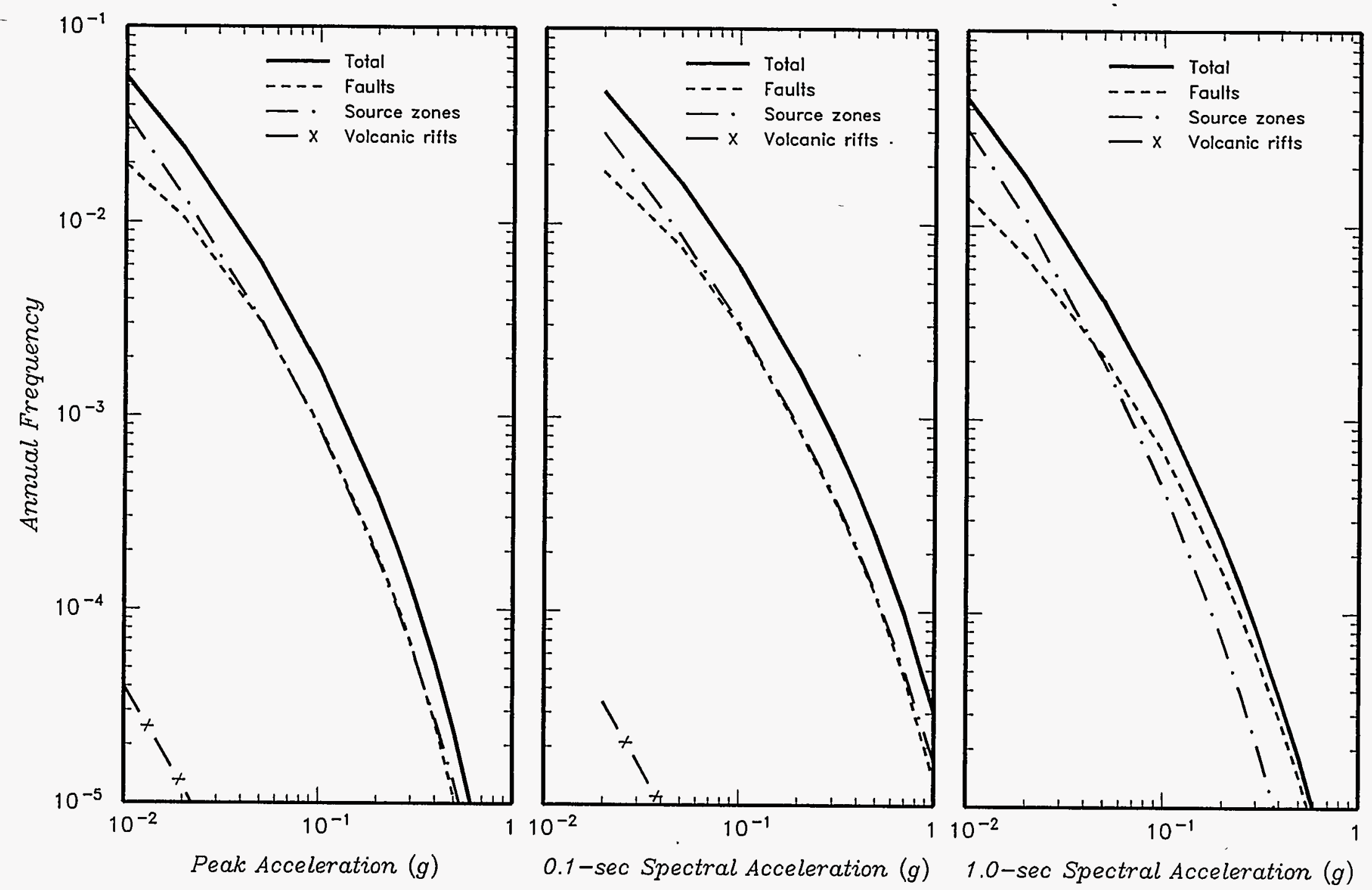

\begin{tabular}{|l|c|c|c|}
\hline & \begin{tabular}{|c|c|c|} 
Project No. \\
SK9455
\end{tabular} & INEL - Probabilistic Analyses & $\begin{array}{c}\text { CONTRIBUTIONS OF THE } \\
\text { SEISMIC SOURCES TO THE } \\
\text { MEAN SEISMIC HAZARD AT TAN }\end{array}$ \\
\cline { 2 - 2 } & Woodward-Clyde Federal Services & $\begin{array}{c}\text { Figure } \\
\text { 6-2g }\end{array}$ \\
\hline
\end{tabular}



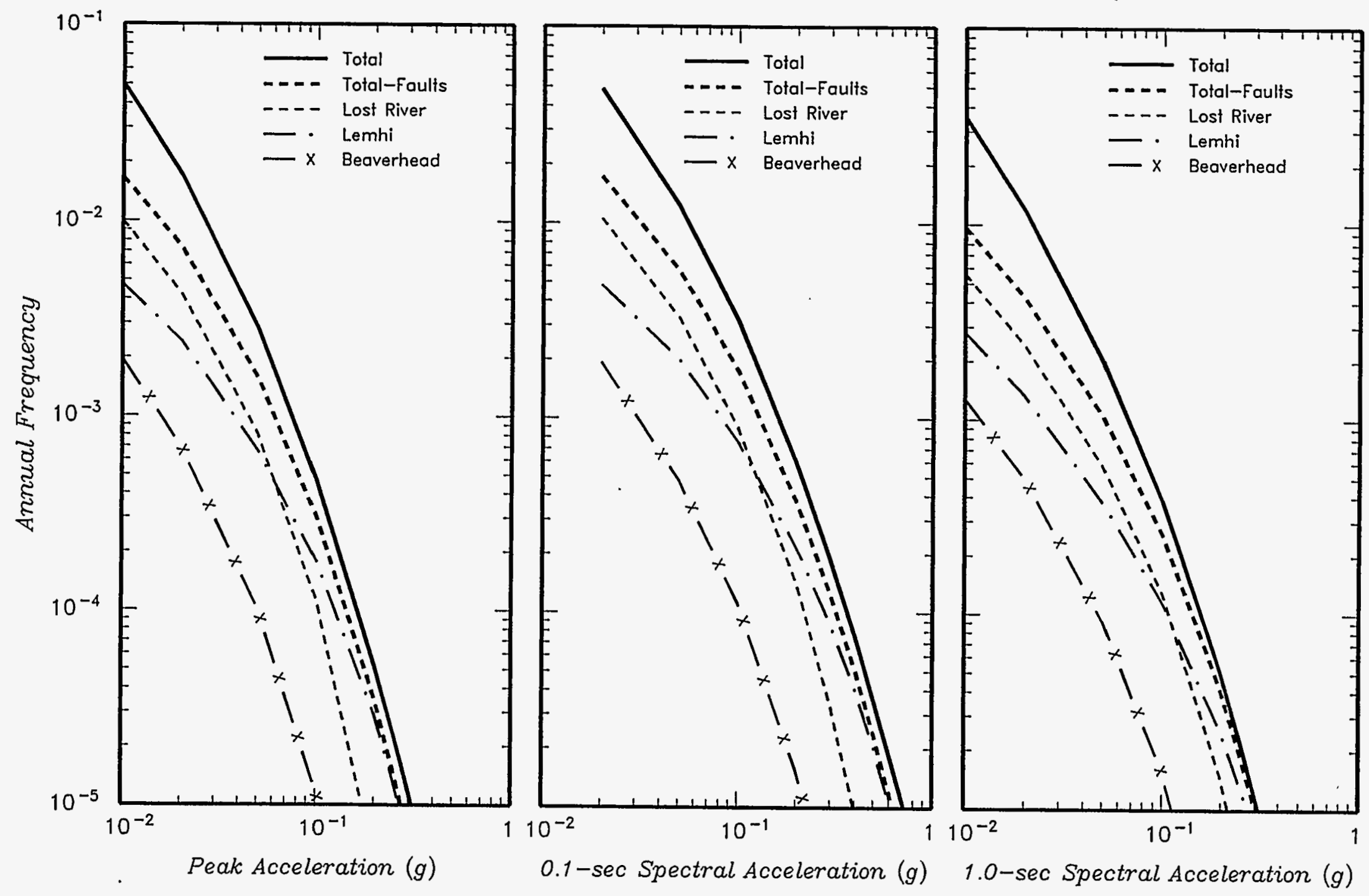

\begin{tabular}{|c|c|c|c|}
\hline $\begin{array}{c}\text { Project No. } \\
\text { SK9455 }\end{array}$ & INEL - Probabilistic Analyses & $\begin{array}{c}\text { CONTRIBUTIONS OF THE } \\
\text { FAULT SOURCES TO THE } \\
\text { Woodward-Clyde Federal Services }\end{array}$ & $\begin{array}{c}\text { Figure } \\
6-3 a\end{array}$ \\
\hline
\end{tabular}



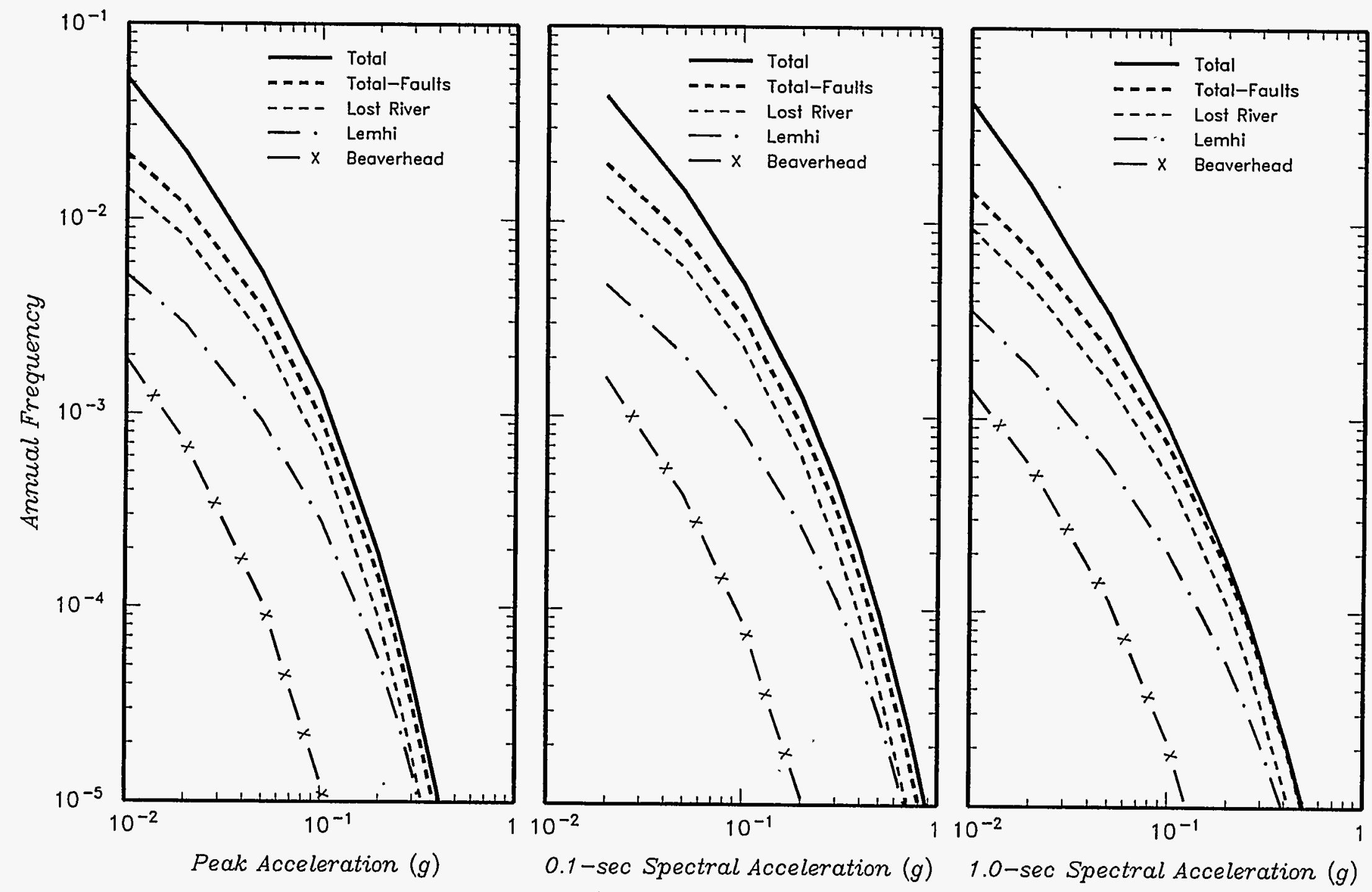

\begin{tabular}{|c|c|c|c|}
\hline $\begin{array}{c}\text { Project No. } \\
\text { SK9455 }\end{array}$ & INEL - Probabilistic Analyses & $\begin{array}{c}\text { CONTRIBUTIONS OF THE } \\
\text { FAULT SOURCES TO THE } \\
\text { Woodward-Clyde Federal Services }\end{array}$ & $\begin{array}{c}\text { Figure } \\
6-3 b\end{array}$ \\
\hline
\end{tabular}



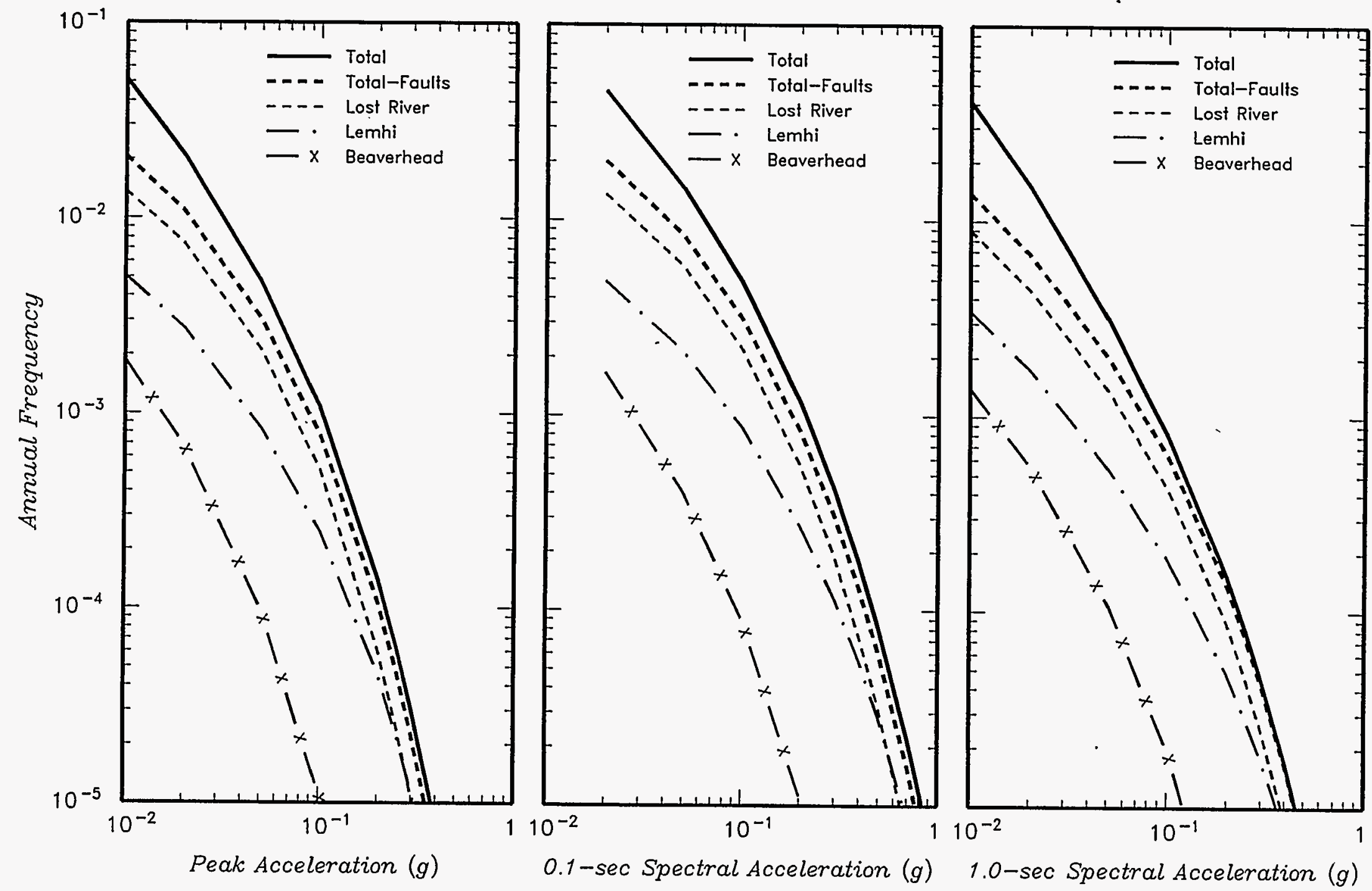

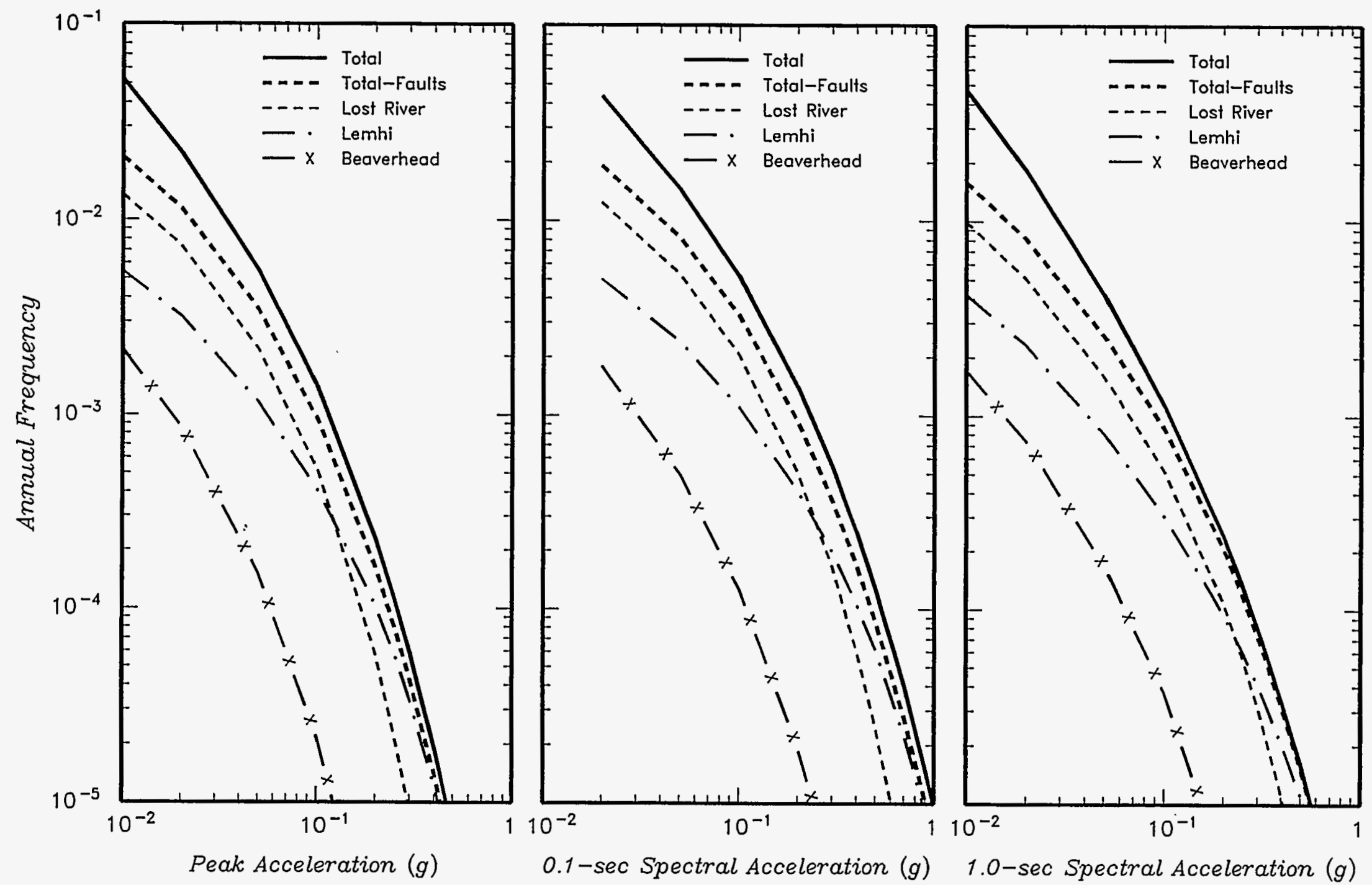

\begin{tabular}{|c|c|c|c|}
\hline $\begin{array}{c}\text { Project No. } \\
\text { SK9455 }\end{array}$ & INEL - Probabilistic Analyses & $\begin{array}{c}\text { CONTRIBUTIONS OF THE } \\
\text { FAULT SOURCES TO THE } \\
\text { MEAN SEISMIC HAZARD AT NRF }\end{array}$ & $\begin{array}{c}\text { Figure } \\
6-3 d\end{array}$ \\
\hline \multicolumn{2}{|c|}{ Woodward-Clyde Federal Services } &
\end{tabular}



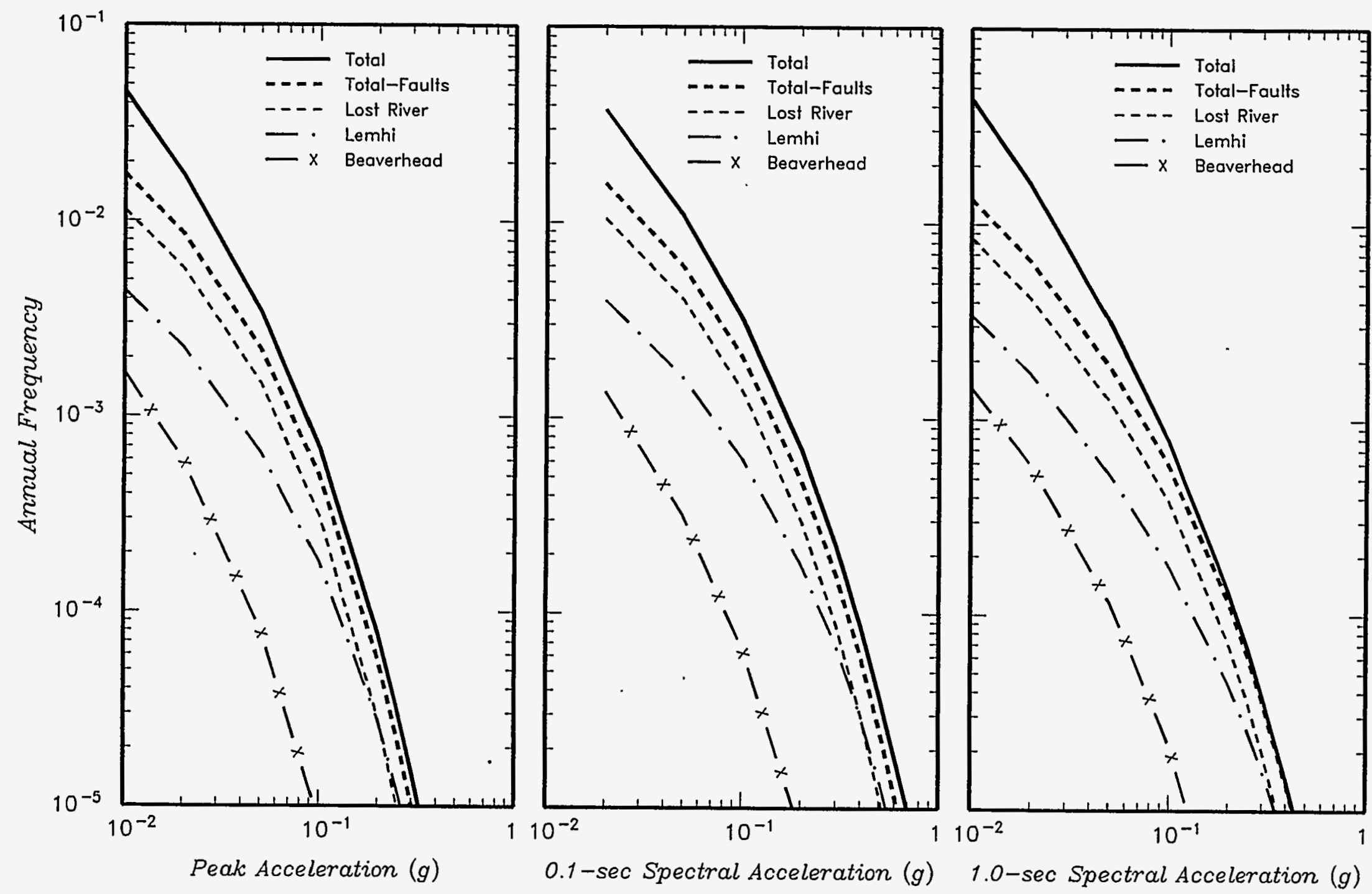

\begin{tabular}{|c|c|}
\hline $\begin{array}{c}\text { Project No. } \\
\text { SK9455 }\end{array}$ & INEL - Probabilistic Analyses \\
\hline Woodward-Clyde Federal Services \\
\hline
\end{tabular}

CONTRIBUTIONS OF THE
FAULT SOURCES TO THE
EAN SEISMIC HAZARD AT PBF




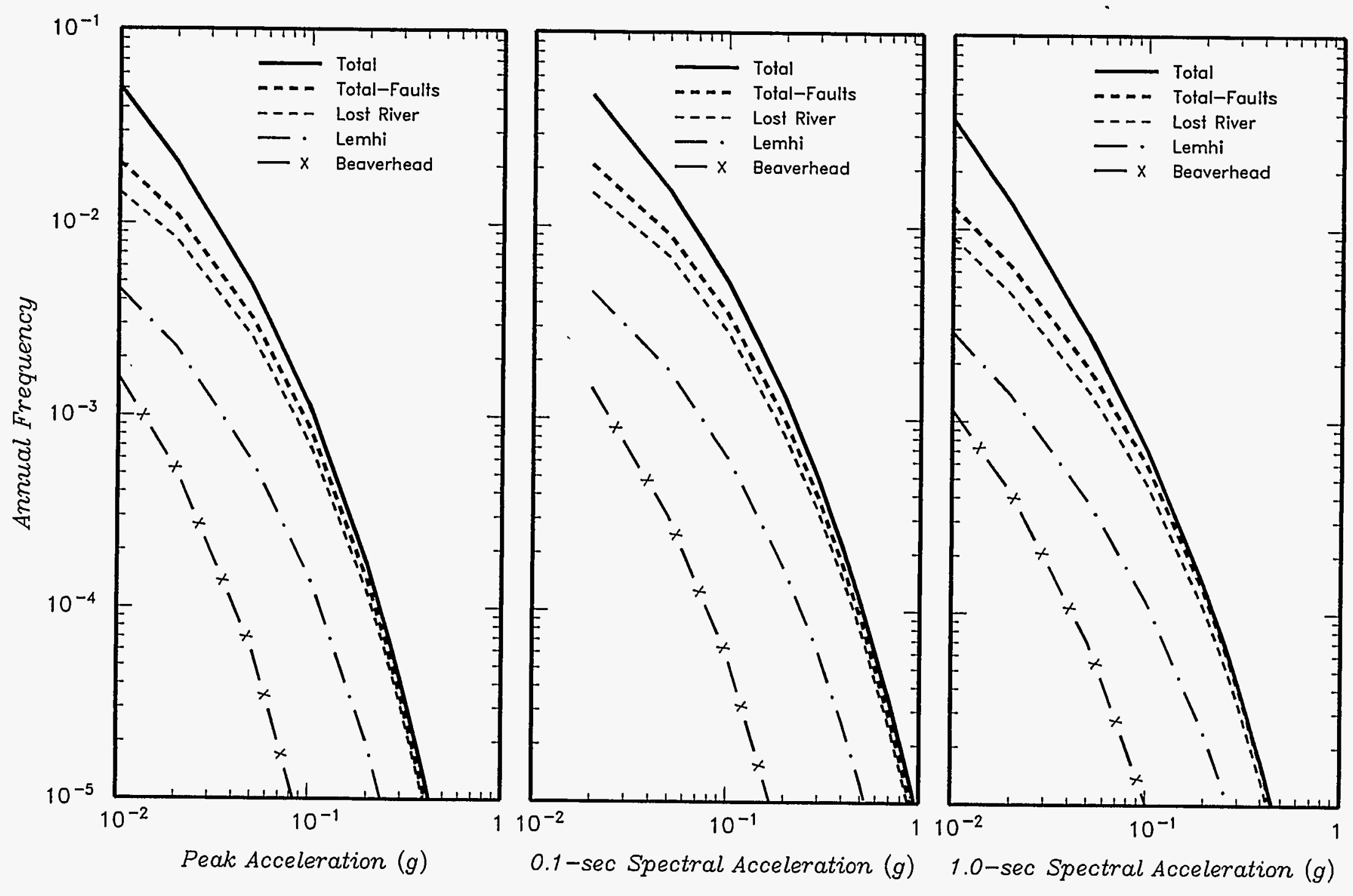

\begin{tabular}{|c|c|c|c|}
\hline $\begin{array}{c}\text { Project No. } \\
\text { SK9455 }\end{array}$ & INEL - Probabilistic Analyses & $\begin{array}{c}\text { CONTRIBUTIONS OF THE } \\
\text { FAULT SOURCES TO THE } \\
\text { Woodward-Clyde Federal Services }\end{array}$ & $\begin{array}{c}\text { Figure } \\
\text { W-3f }\end{array}$ \\
\hline
\end{tabular}




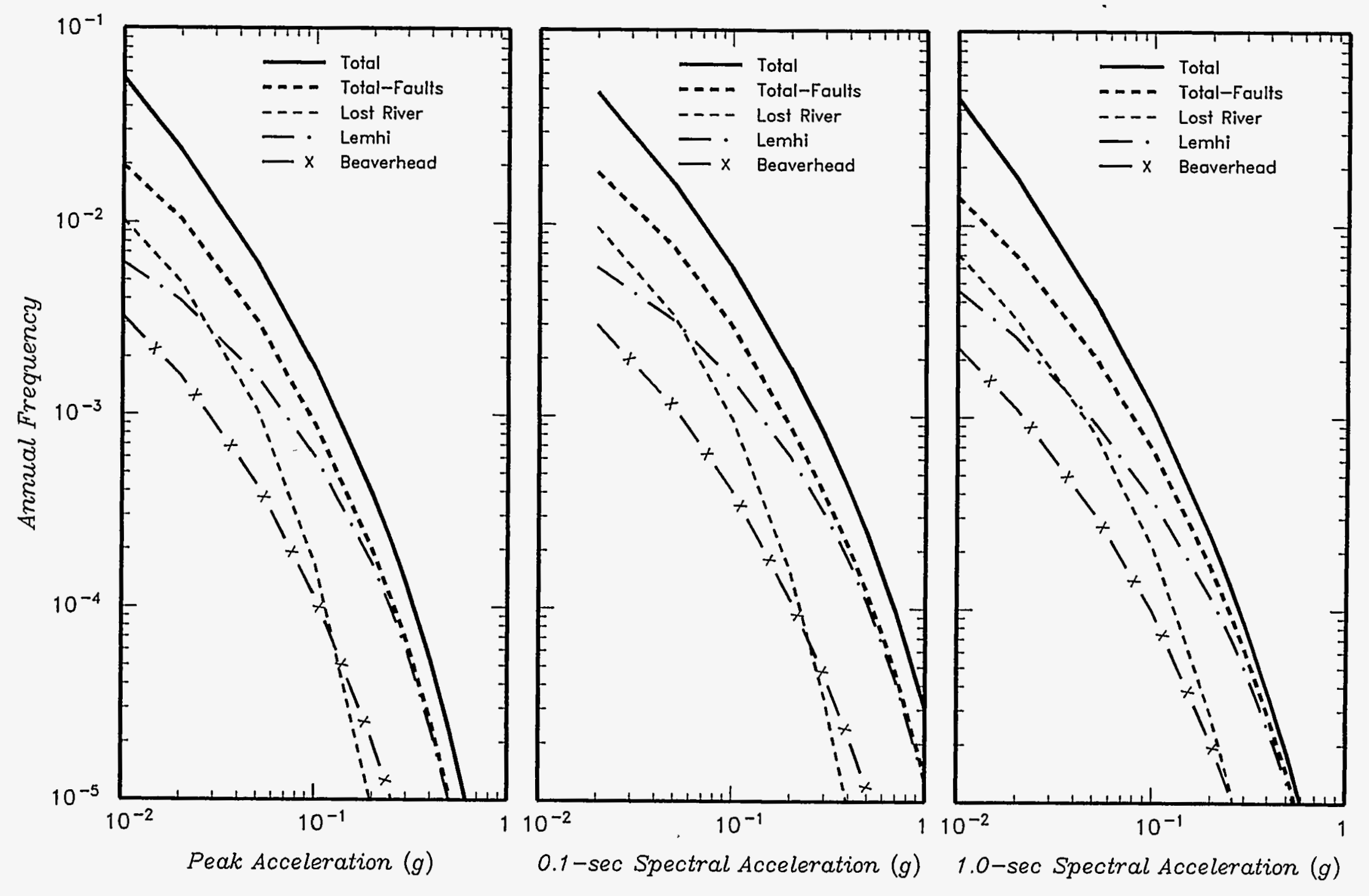

SK9455-A1000/122895/vone

\begin{tabular}{|c|c|c|c|}
\hline $\begin{array}{c}\text { Project No. } \\
\text { SK9455 }\end{array}$ & INEL - Probabilistic Analyses & $\begin{array}{c}\text { CONTRIBUTIONS OF THE } \\
\text { FAULT SOURCES TO THE } \\
\text { MEAN SEISMIC HAZARD AT TAN }\end{array}$ & $\begin{array}{c}\text { Figure } \\
6-3 \mathrm{~g}\end{array}$ \\
\hline \multicolumn{2}{|c|}{ Woodwrard-Clyde Federal Services } & MEARE
\end{tabular}



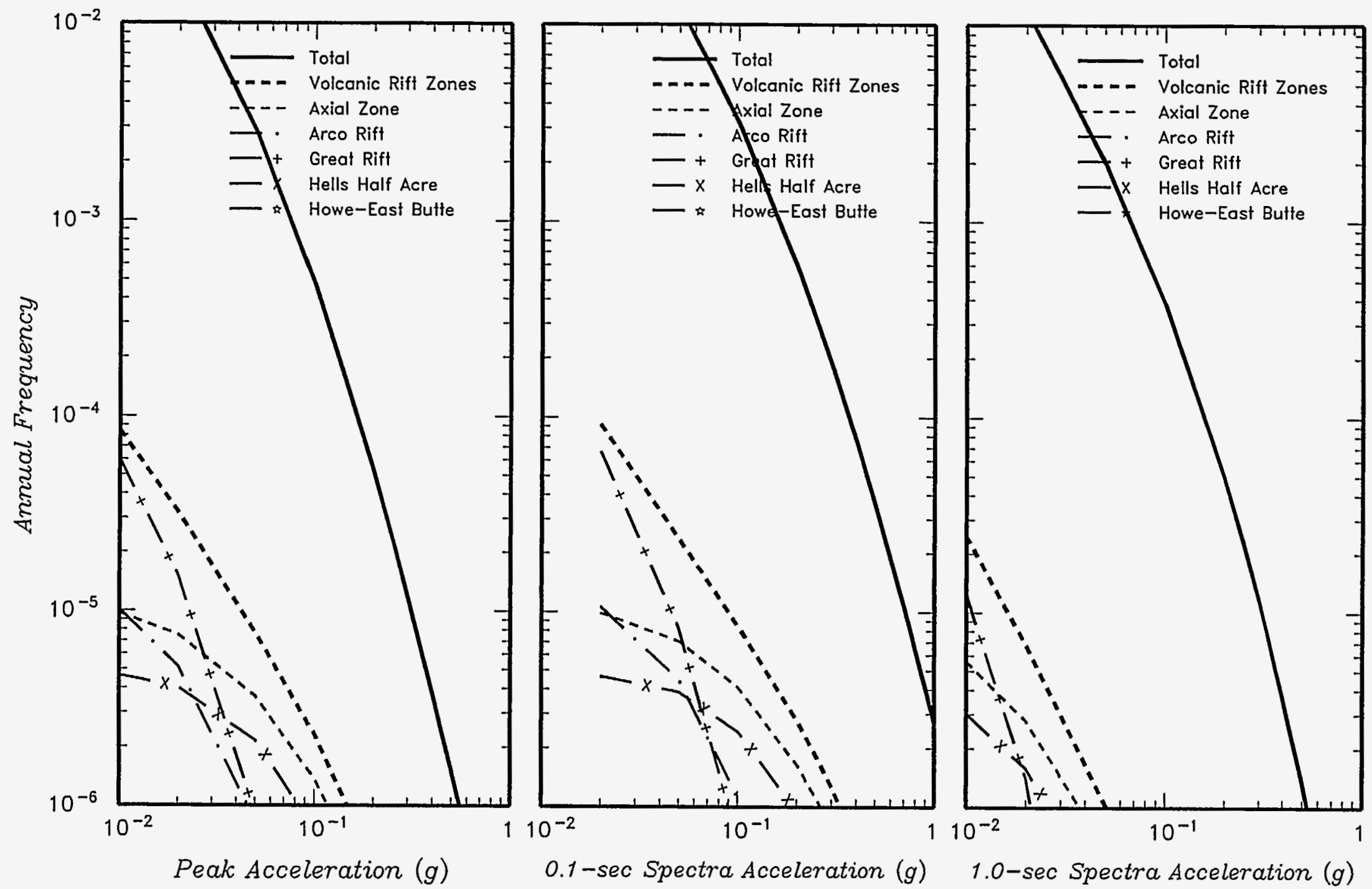

\begin{tabular}{|c|c|c|c|}
\hline $\begin{array}{c}\text { Project No. } \\
\text { SK9455 }\end{array}$ & INEL - Probabilistic Analyses & $\begin{array}{c}\text { CONTRIBUTIONS OF THE } \\
\text { VOLCANIC SOURCES TO THE } \\
\text { MEAN SEISMIC HAZARD AT ANL }\end{array}$ & $\begin{array}{c}\text { Figure } \\
6-4 a\end{array}$ \\
\hline Woodward-Clyde Federal Services & MEAR
\end{tabular}



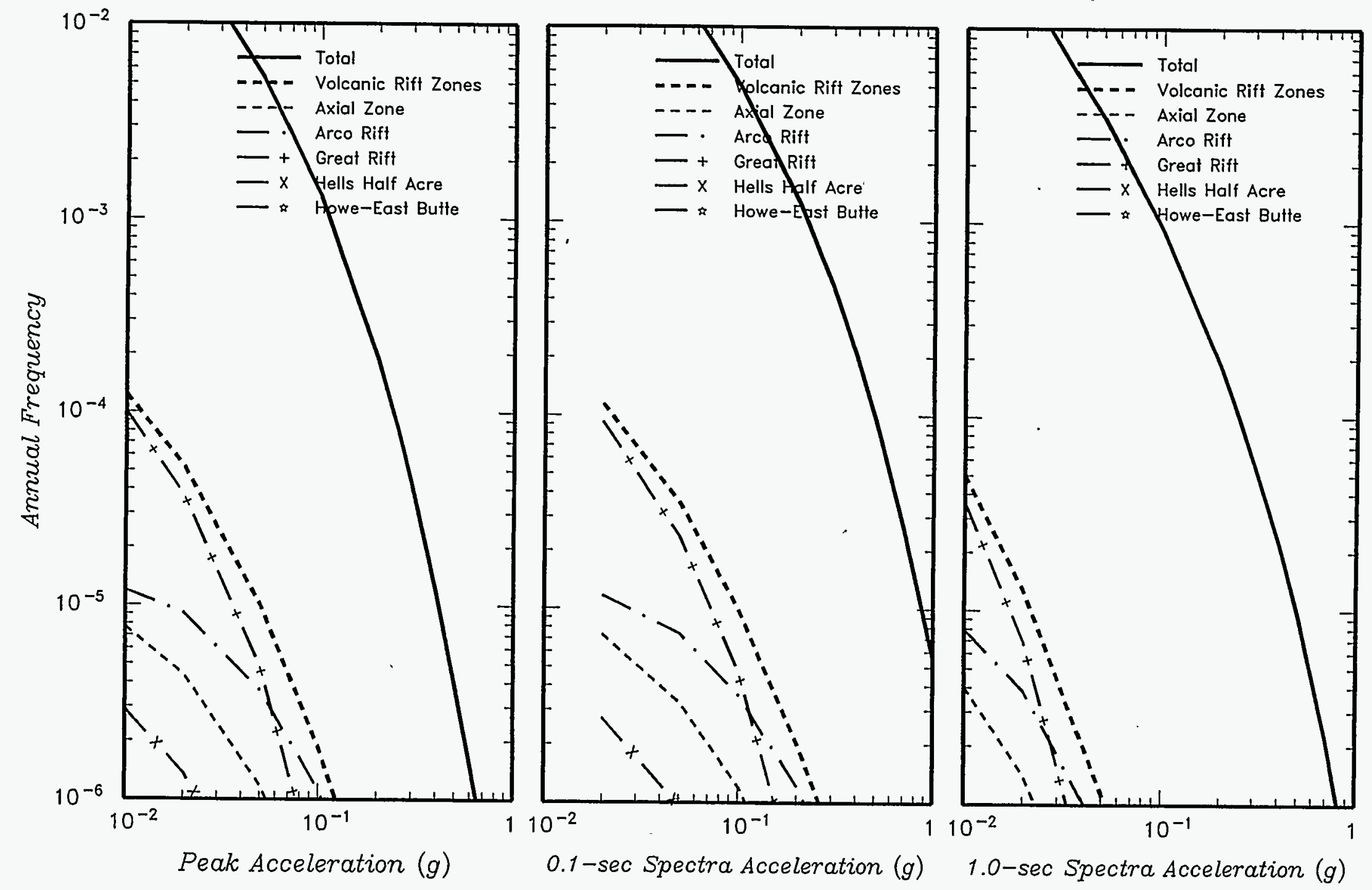

\begin{tabular}{|c|c|c|c|}
\hline $\begin{array}{l}\text { Project No. } \\
\text { SK9455 }\end{array}$ & INEL - Probabilistic Analyses & \multirow{2}{*}{$\begin{array}{l}\text { CONTRIBUTIONS OF THE } \\
\text { VOLCANIC SOURCES TO THE } \\
\text { MEAN SEISMIC HAZARD AT ATR }\end{array}$} & \multirow{2}{*}{$\underset{6-4 b}{\text { Figure }}$} \\
\hline \multicolumn{2}{|c|}{ Woodward-Clyde Federal Services } & & \\
\hline
\end{tabular}



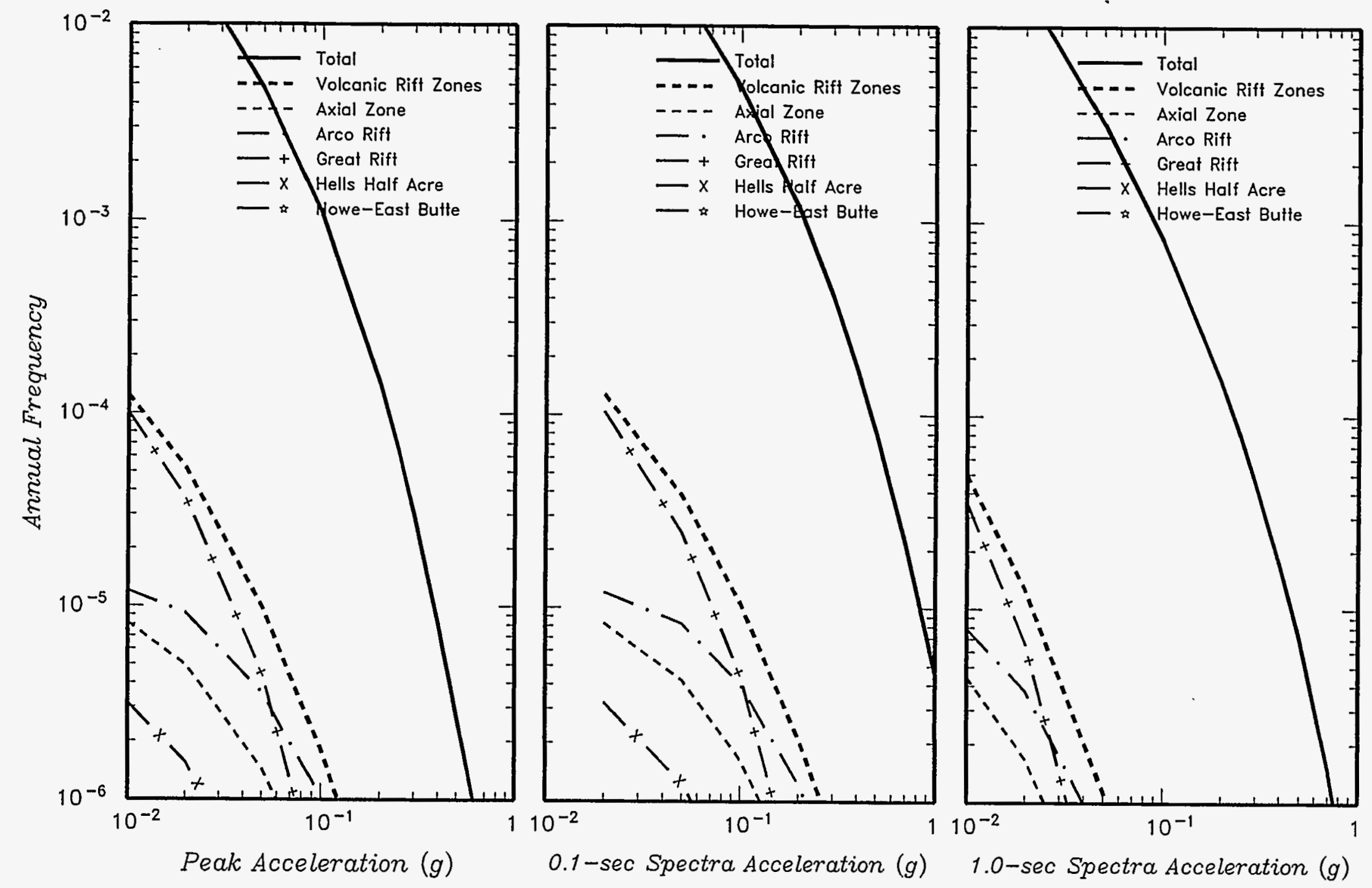

\begin{tabular}{|c|c|c|c|}
\hline $\begin{array}{c}\text { Project No. } \\
\text { SK9455 }\end{array}$ & INEL - Probabilistic Analyses & $\begin{array}{c}\text { CONTRIBUTIONS OF THE } \\
\text { VOLCANIC SOURCES TO THE } \\
\text { MEAN SEISMIC HAZARD AT CPP }\end{array}$ & $\begin{array}{c}\text { Figure } \\
6-4 C\end{array}$ \\
\hline Woodward-Clyde Federal Services & MEAR & \\
\hline
\end{tabular}




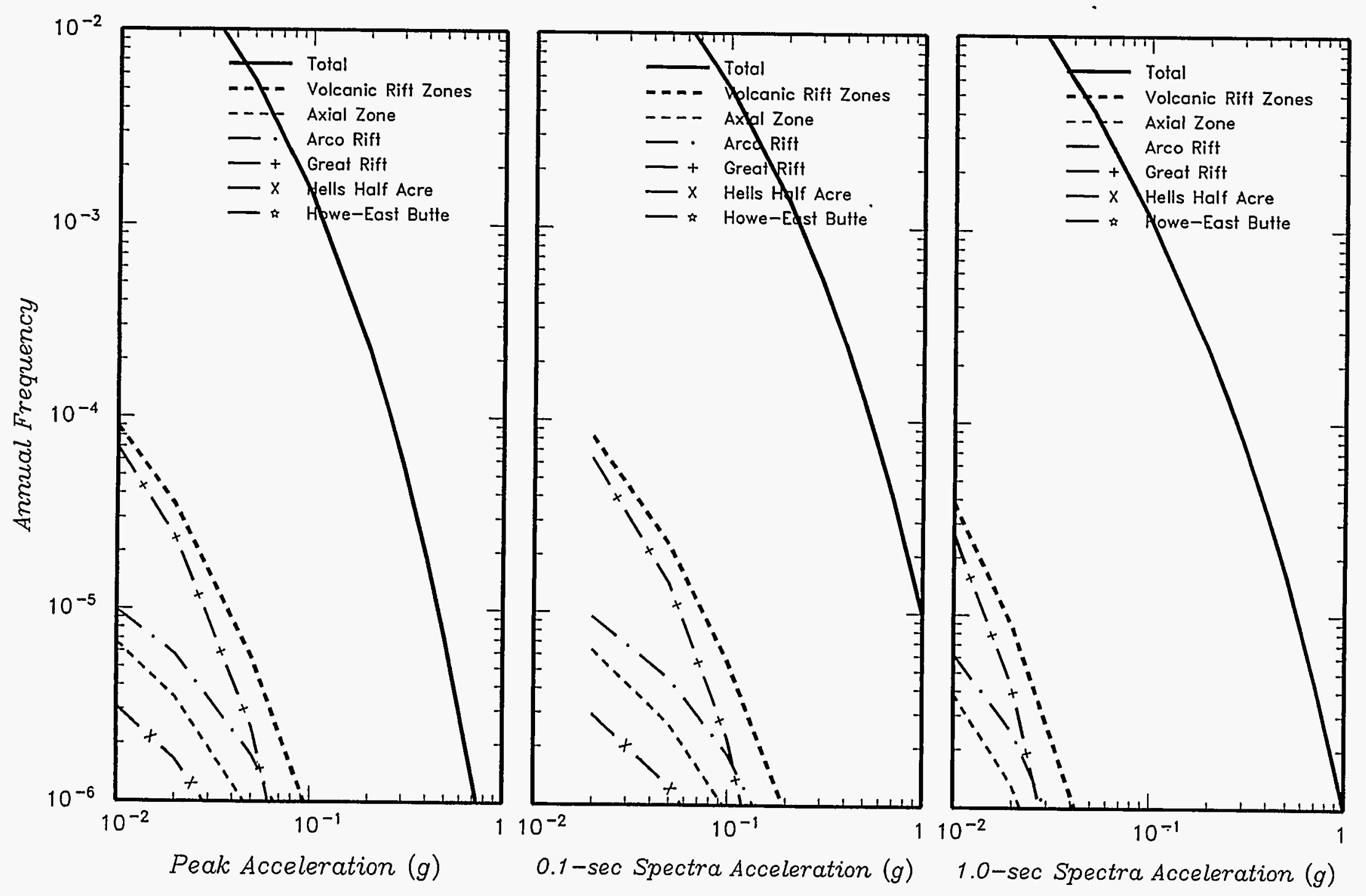

\begin{tabular}{|c|c|c|}
\hline $\begin{array}{l}\text { Project No. } \\
\text { SK9455 }\end{array}$ & INEL - Probabilistic Analyses & CO \\
\hline \multicolumn{3}{|r|}{ MEAN SEISMIC HAZARD AT NRF } \\
\hline
\end{tabular}



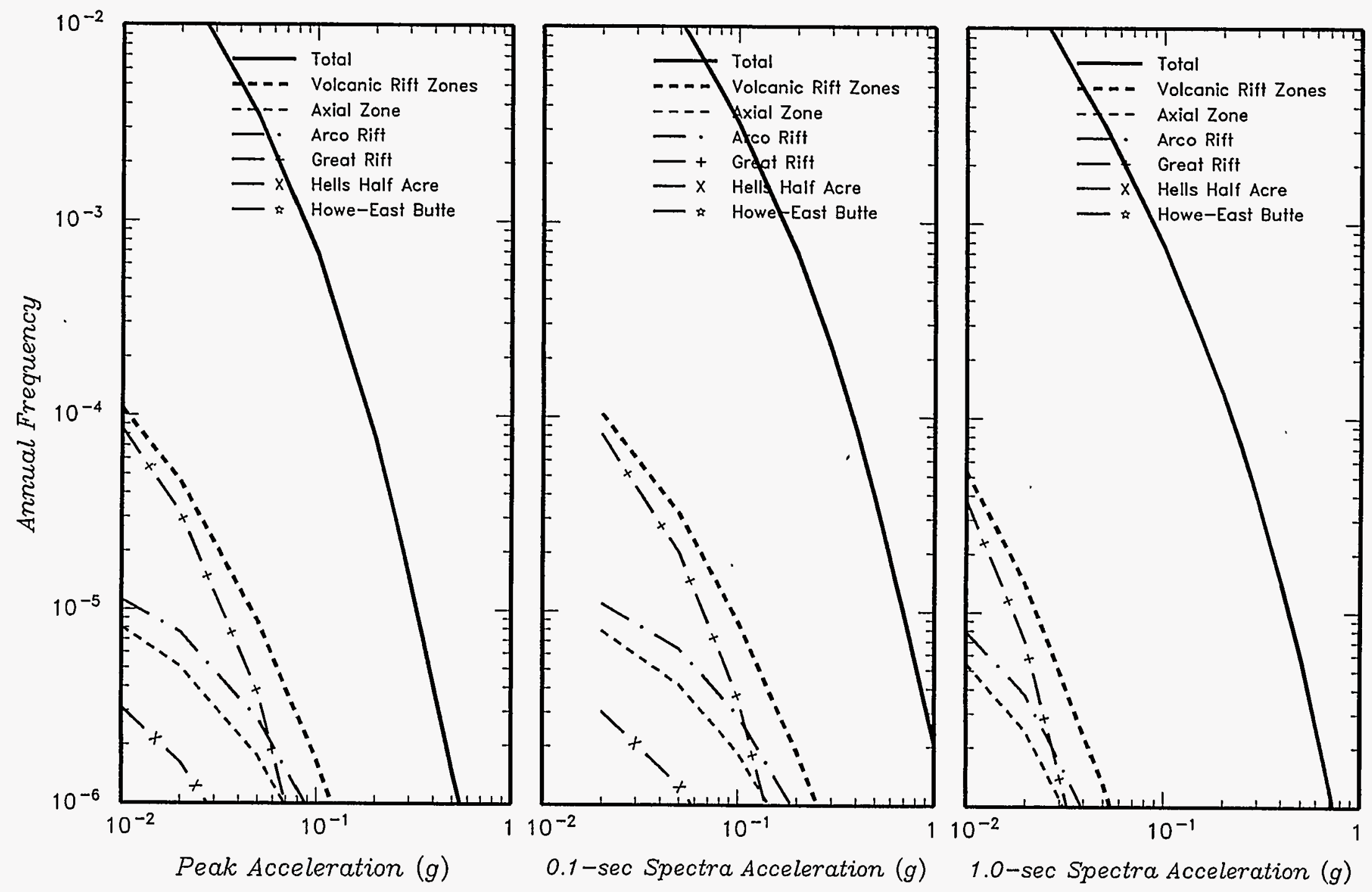

\begin{tabular}{|c|c|c|}
$\begin{array}{c}\text { Project No. } \\
\text { SK9455 }\end{array}$ & INEL - Probabilistic Analyses & CONTRIBUTIONS OF THE \\
VOLCANIC SOURCES TO THE \\
Woodward-Clyde Federal Services
\end{tabular}



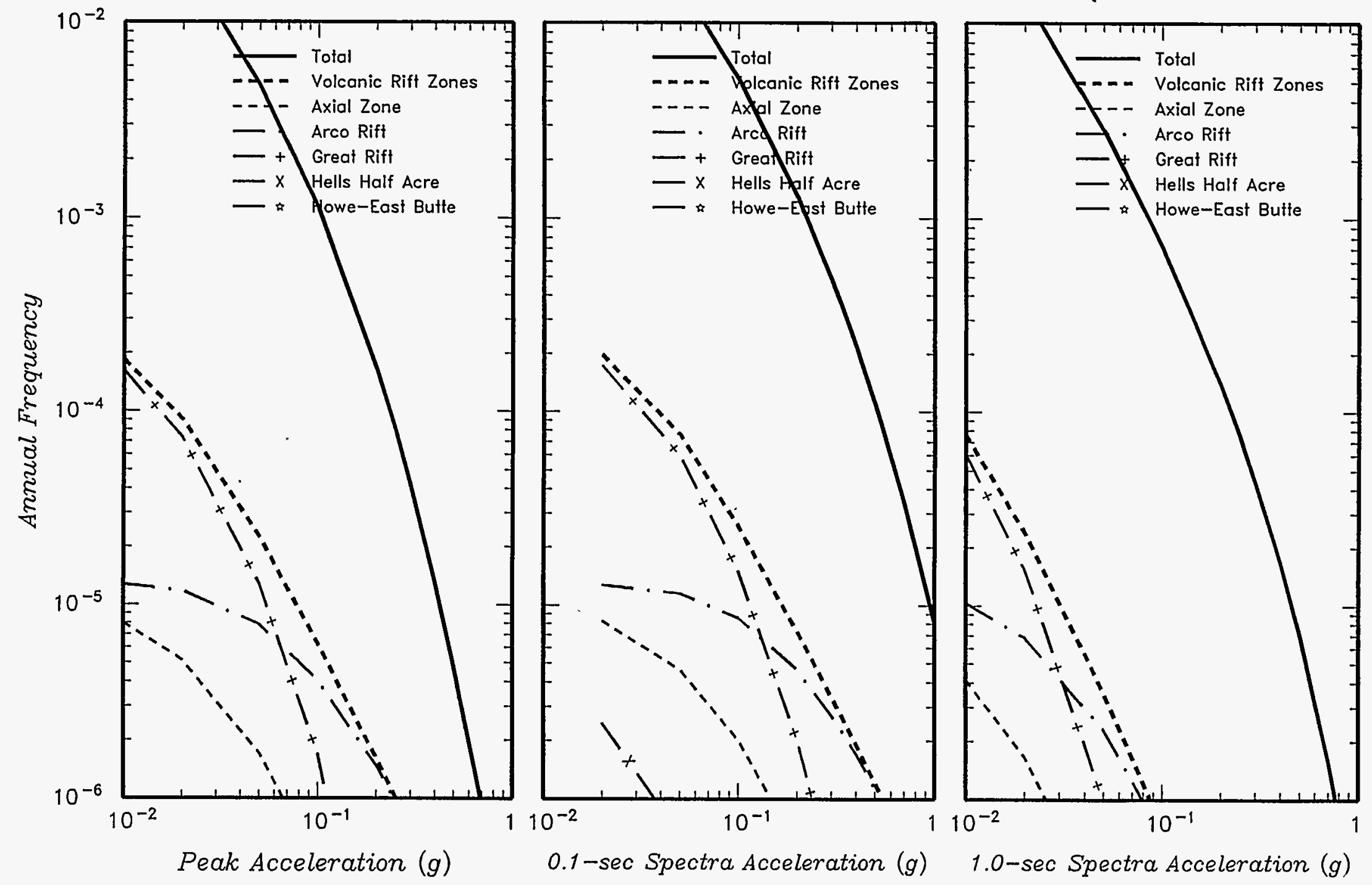

\begin{tabular}{|c|c|c|}
\hline $\begin{array}{c}\text { Project No. } \\
\text { SK9455 }\end{array}$ & INEL - Probabilistic Analyses & $\begin{array}{r}\text { CONTRIBUTIONS OF THE } \\
\text { VOLCANIC SOURCES TO THE }\end{array}$ \\
\cline { 1 - 1 } Woodward-Chyde Federal Services & MEAN SEISMIC HAZARD AT RWMC
\end{tabular}




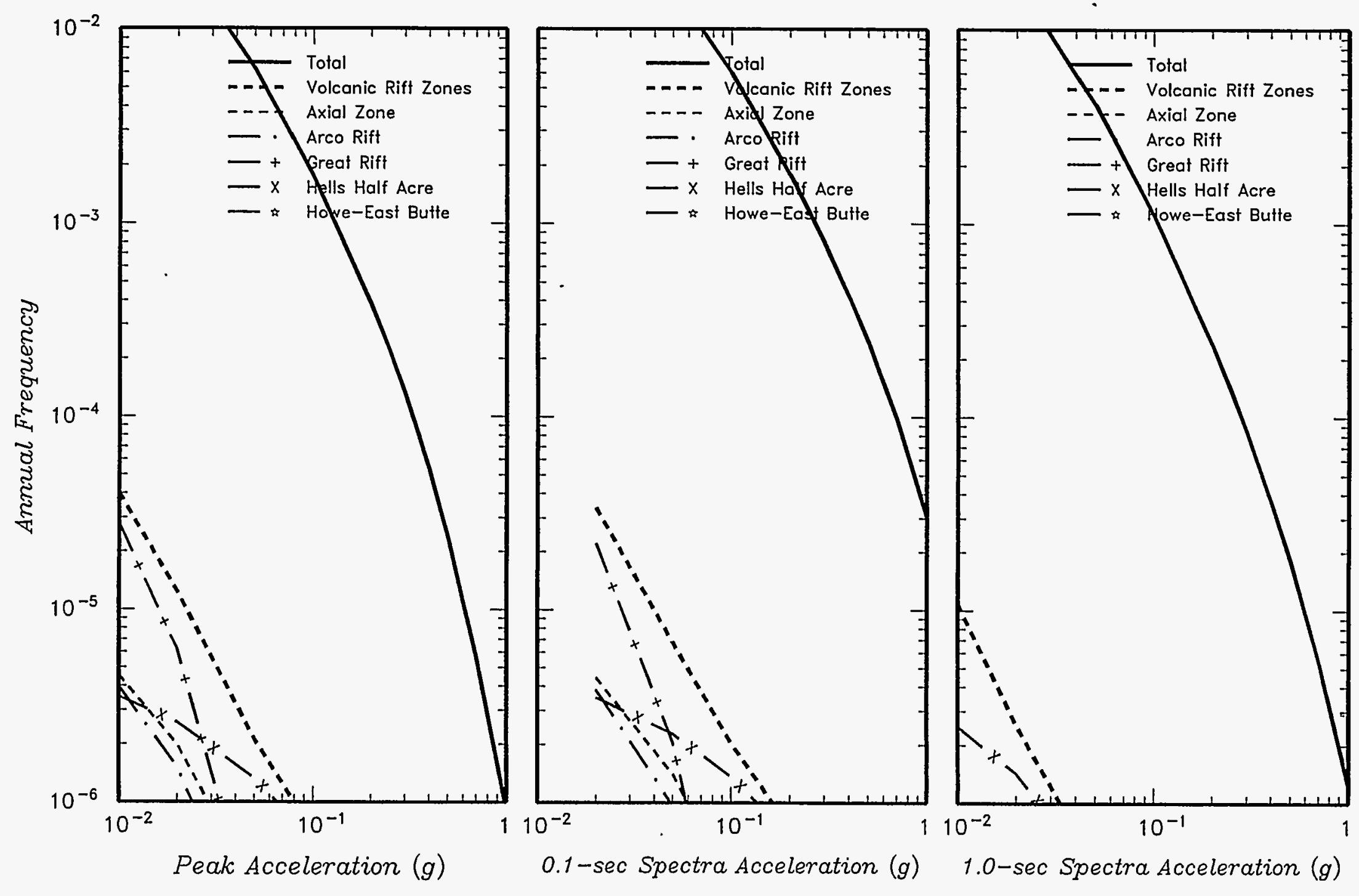

\begin{tabular}{|c|c|c|c|}
\hline $\begin{array}{c}\text { Project No. } \\
\text { SK9455 }\end{array}$ & INEL - Probabilistic Analyses & $\begin{array}{c}\text { CONTRIBUTIONS OF THE } \\
\text { VOLCANIC SOURCES TO THE } \\
\text { MEAN SEISMIC HAZARD AT TAN }\end{array}$ & $\begin{array}{c}\text { Figure } \\
6-4 \mathrm{~g}\end{array}$ \\
\hline \multicolumn{2}{|c|}{ Woodward-Clyde Federal Services } & MEAN SA
\end{tabular}




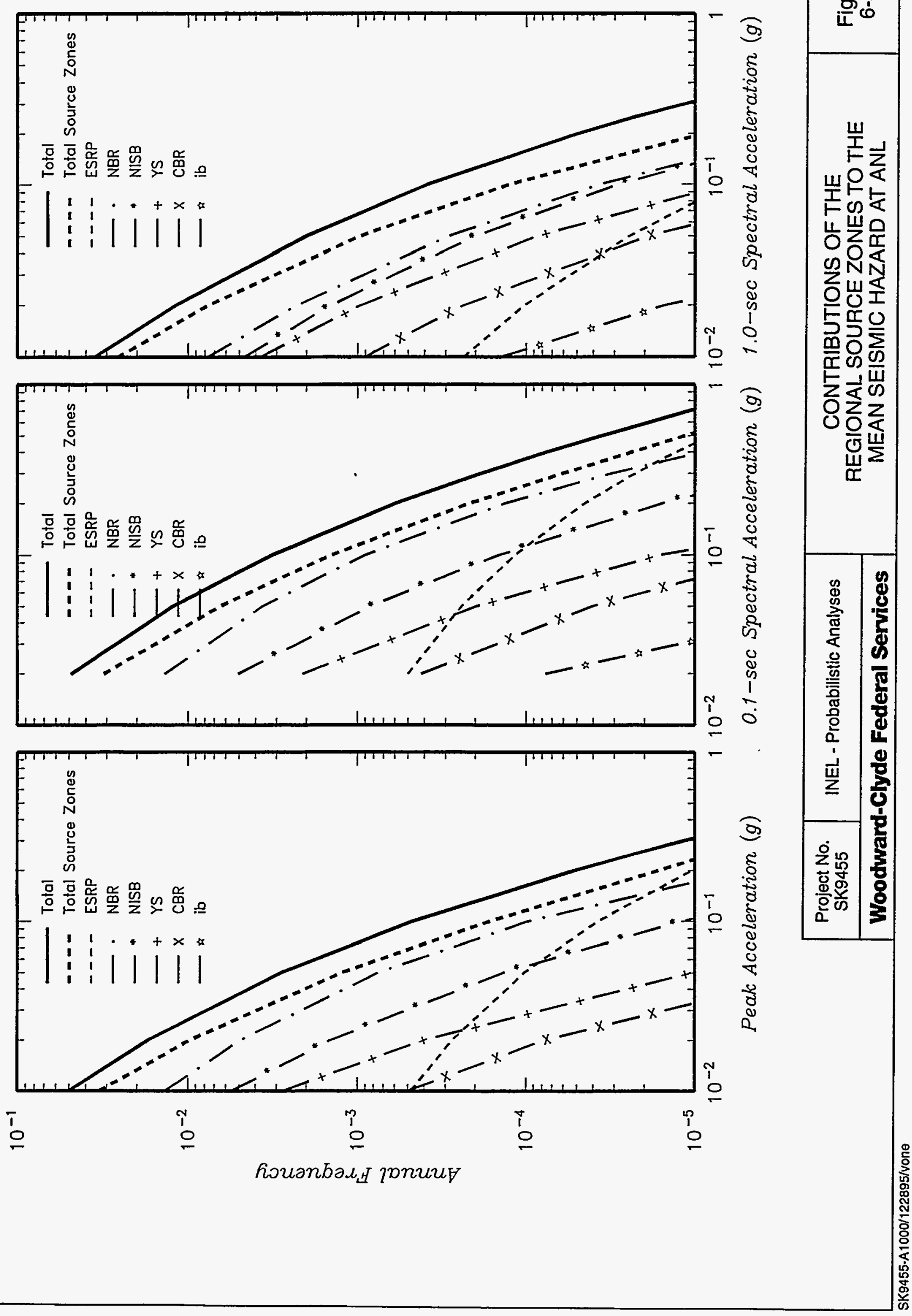



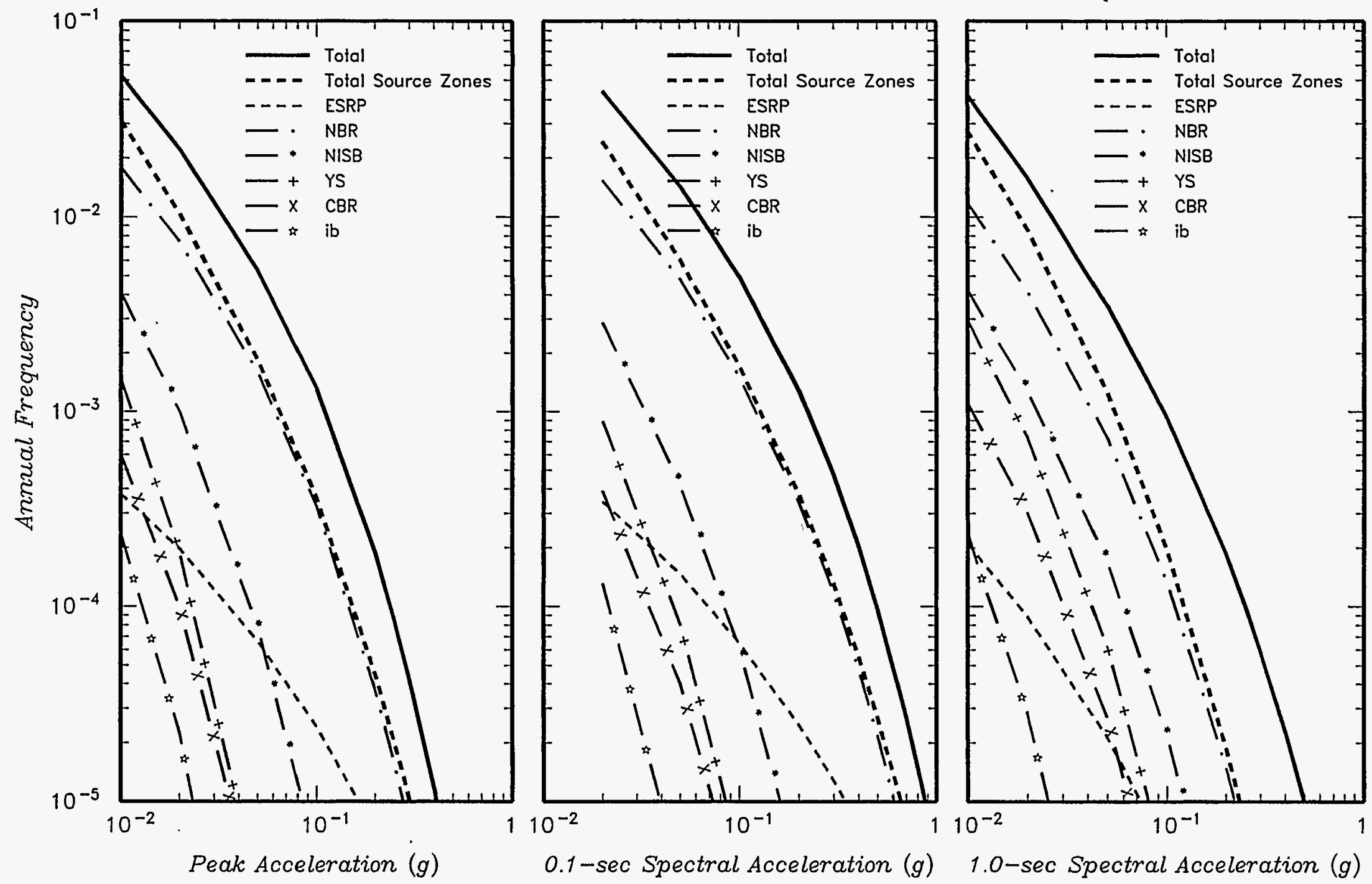

\begin{tabular}{|c|c|c|c|}
\hline $\begin{array}{c}\text { Project No. } \\
\text { SK9455 }\end{array}$ & INEL - Probabilistic Analyses & \multirow{2}{*}{$\begin{array}{l}\text { CONTRIBUTIONS OF THE } \\
\text { REGIONAL SOURCE ZONES TO THE } \\
\text { MEAN SEISMIC HAZARD AT ATR }\end{array}$} & \multirow{2}{*}{$\begin{array}{c}\text { Figure } \\
6-5 b\end{array}$} \\
\hline \multicolumn{2}{|c|}{ Woodward-Clyde Federal Senvices } & & \\
\hline
\end{tabular}



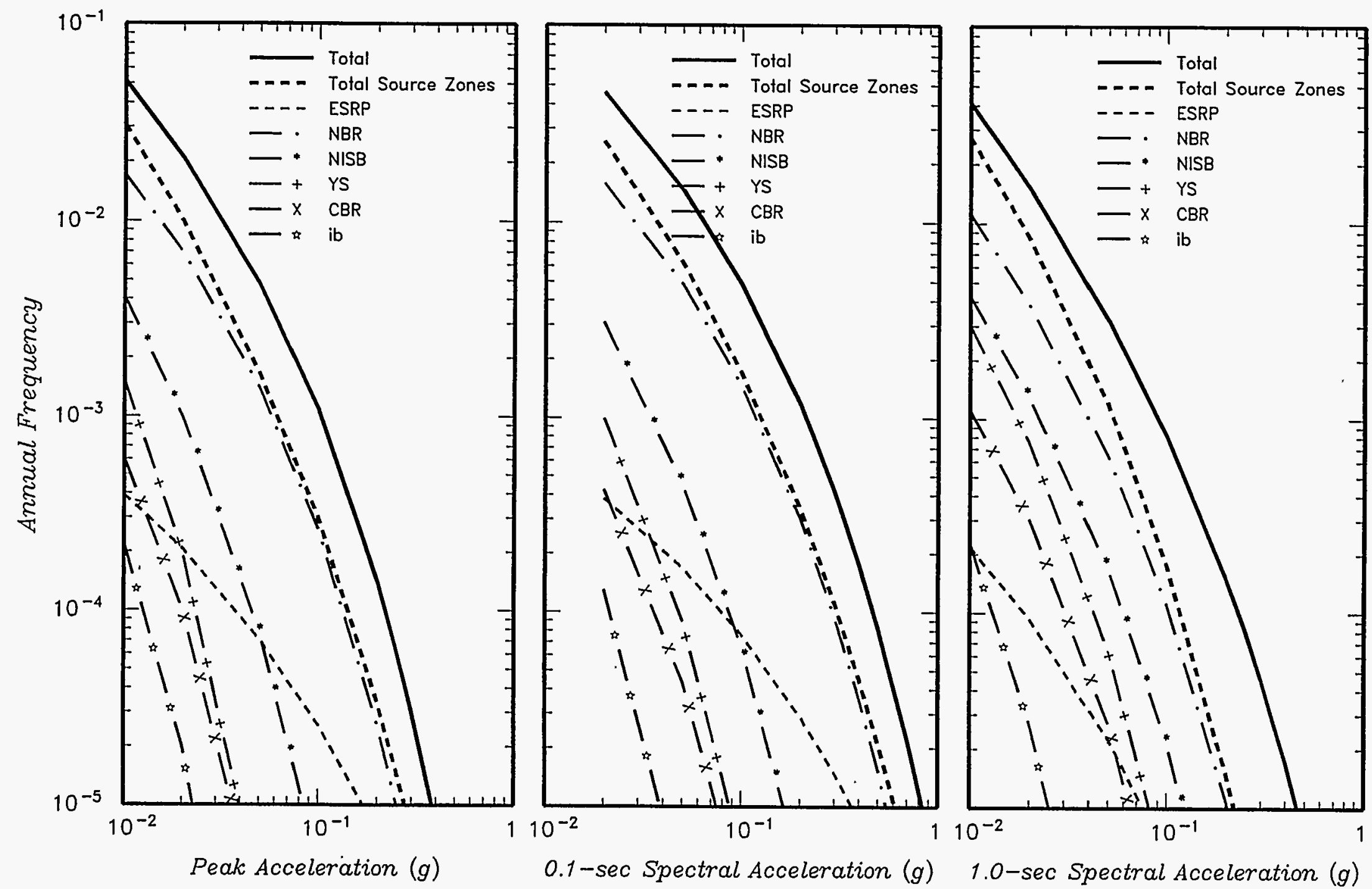

\begin{tabular}{|c|c|c|c|}
\hline $\begin{array}{c}\text { Project No. } \\
\text { SK9455 }\end{array}$ & INEL - Probabilistic Analyses & $\begin{array}{c}\text { CONTRIBUTIONS OF THE } \\
\text { REGIONAL SOURCE ZONES TO THE } \\
\text { MEAN SEISMIC HAZARD AT CPP }\end{array}$ & $\begin{array}{c}\text { Figure } \\
6-5 c\end{array}$ \\
\hline Woodward-Clyde Federal Services & MEAN SA \\
\hline
\end{tabular}



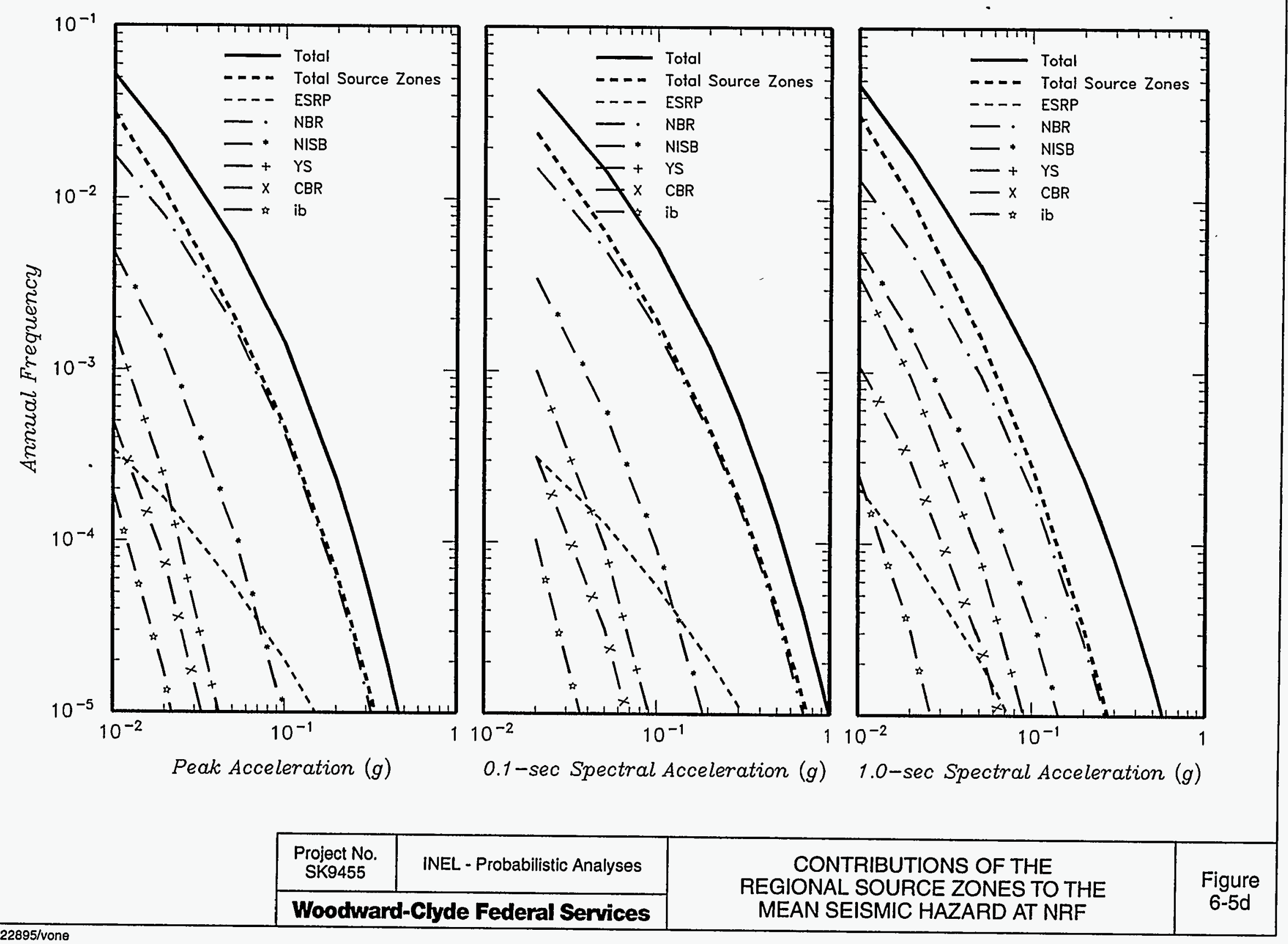

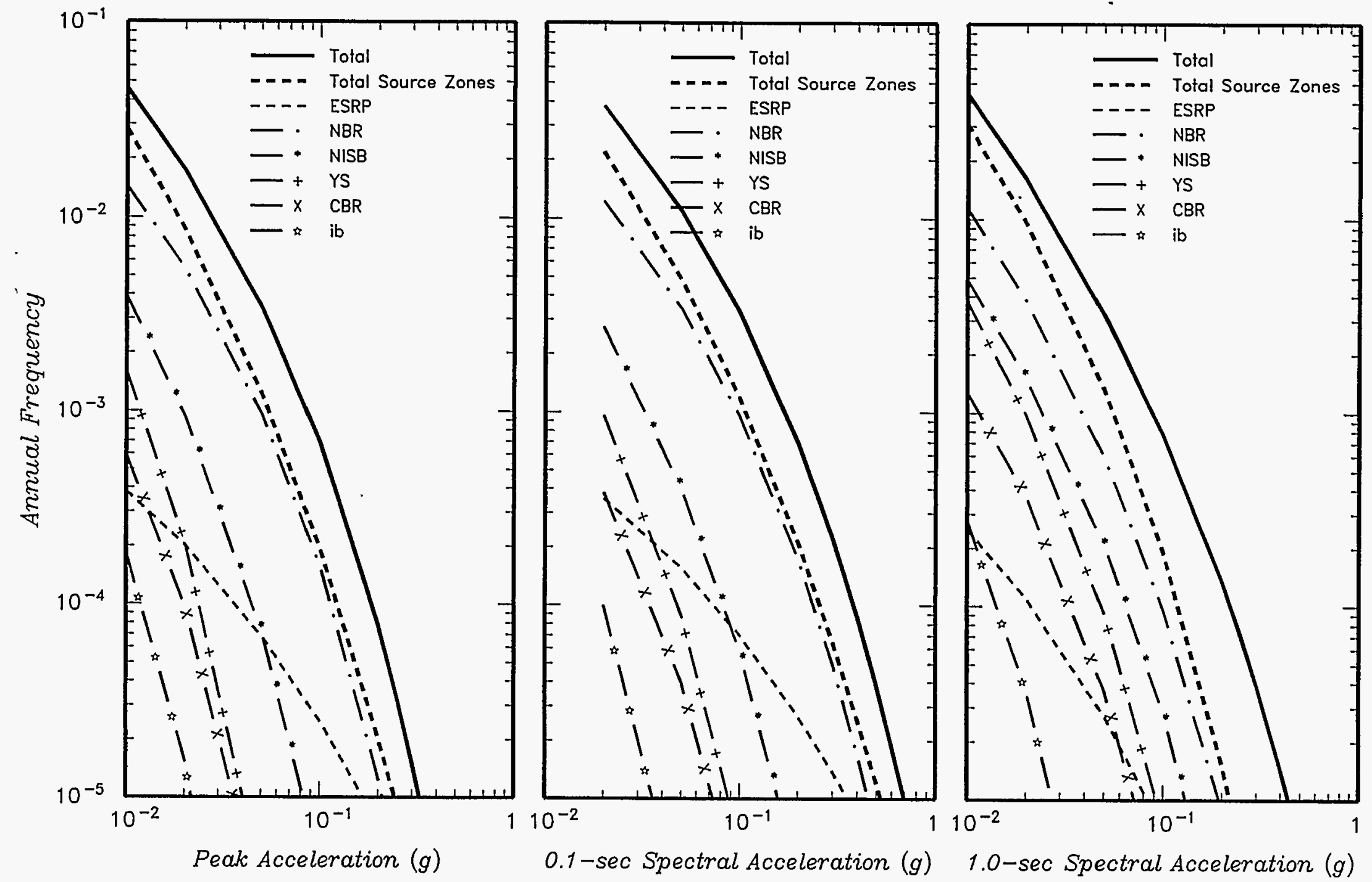

\begin{tabular}{|c|c|c|c|}
\hline $\begin{array}{c}\text { Project No. } \\
\text { SK9455 }\end{array}$ & INEL - Probabilistic Analyses & $\begin{array}{c}\text { CONTRIBUTIONS OF THE } \\
\text { REGIONAL SOURCE ZONES TO THE } \\
\text { MEAN SEISMIC HAZARD AT PBF }\end{array}$ & $\begin{array}{c}\text { Figure } \\
6-5 \mathrm{e}\end{array}$ \\
\hline Woodward-Clyde Federal Services &
\end{tabular}



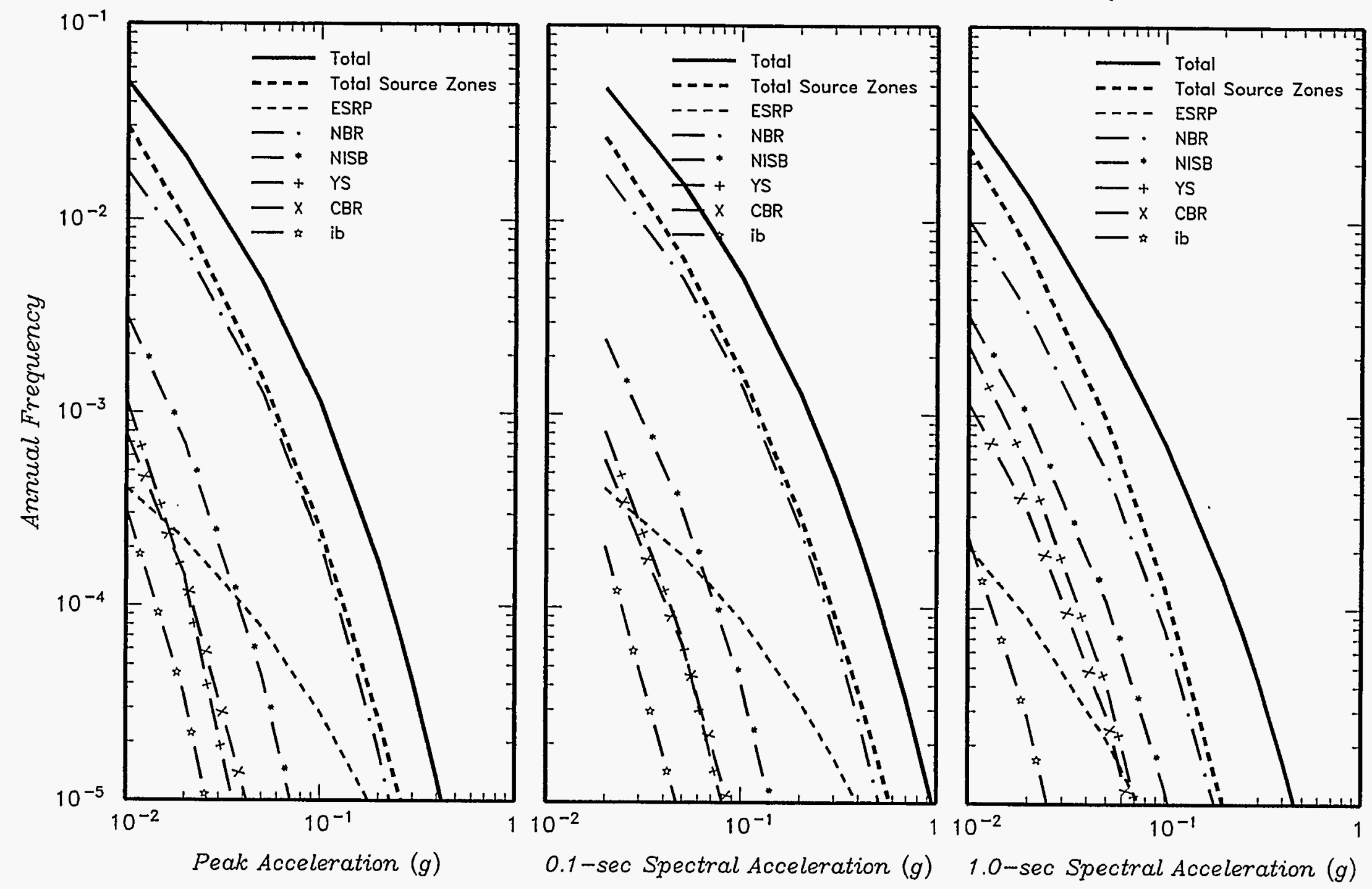

\begin{tabular}{|c|c|c|c|}
\hline $\begin{array}{c}\text { Project No. } \\
\text { SK9455 }\end{array}$ & INEL - Probabilistic Analyses & $\begin{array}{c}\text { CONTRIBUTIONS OF THE } \\
\text { REGIONAL SOURCE ZONES TO THE } \\
\text { MEAN SEISMIC HAZARD AT RWMC }\end{array}$ & $\begin{array}{c}\text { Figure } \\
6-5 f\end{array}$ \\
\hline Woodward-Clyde Federal Services & MEARI
\end{tabular}



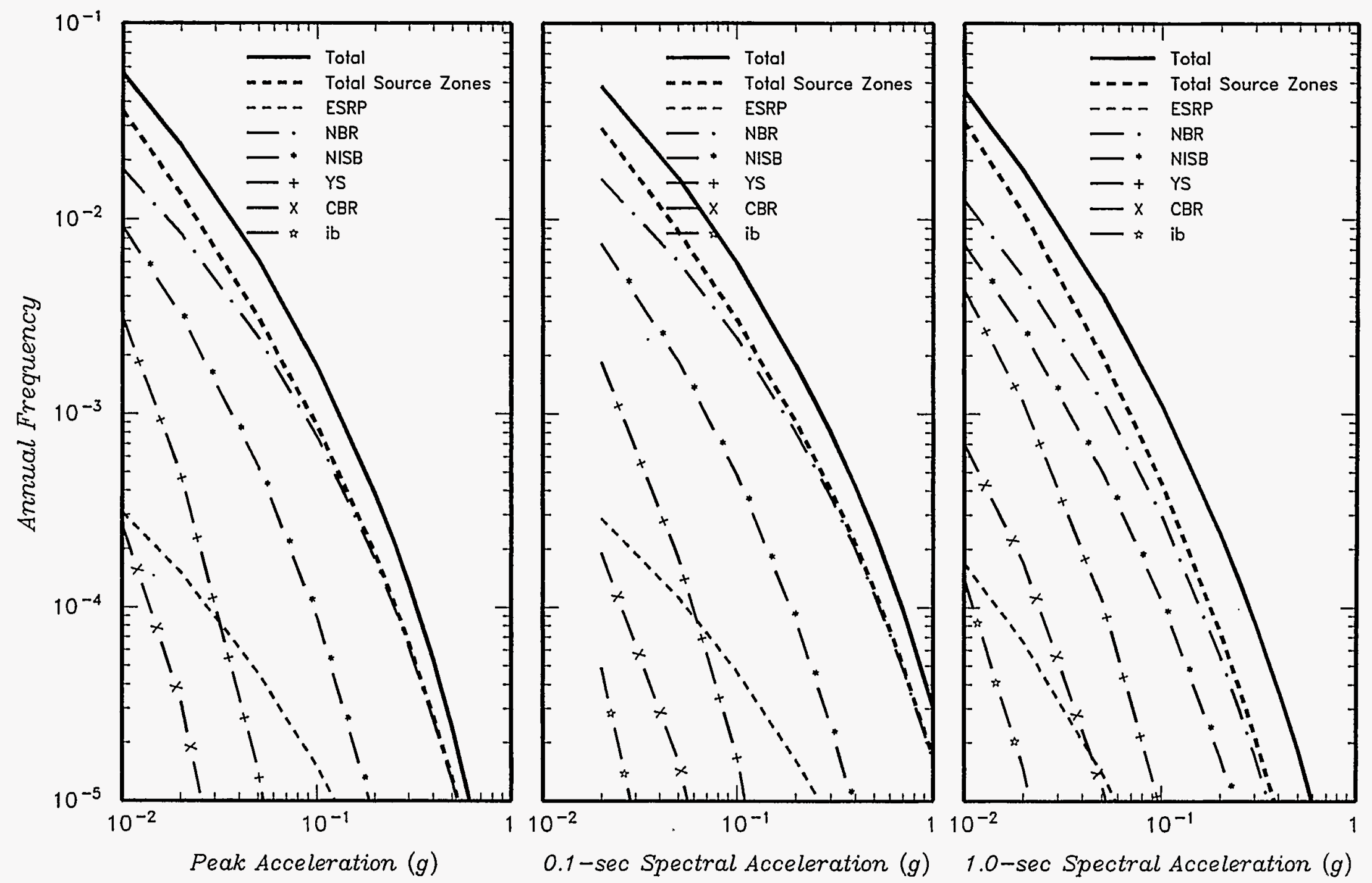

\begin{tabular}{|c|c|}
\hline $\begin{array}{c}\text { Project No. } \\
\text { SK9455 }\end{array}$ & INEL - Probabilistic Analyses \\
\hline Woodward-Clyde Federal Services \\
\hline
\end{tabular}

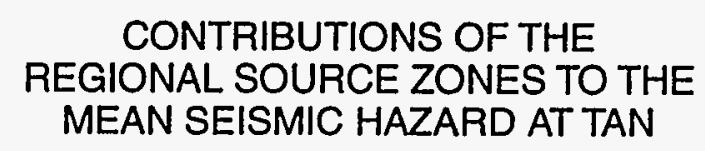




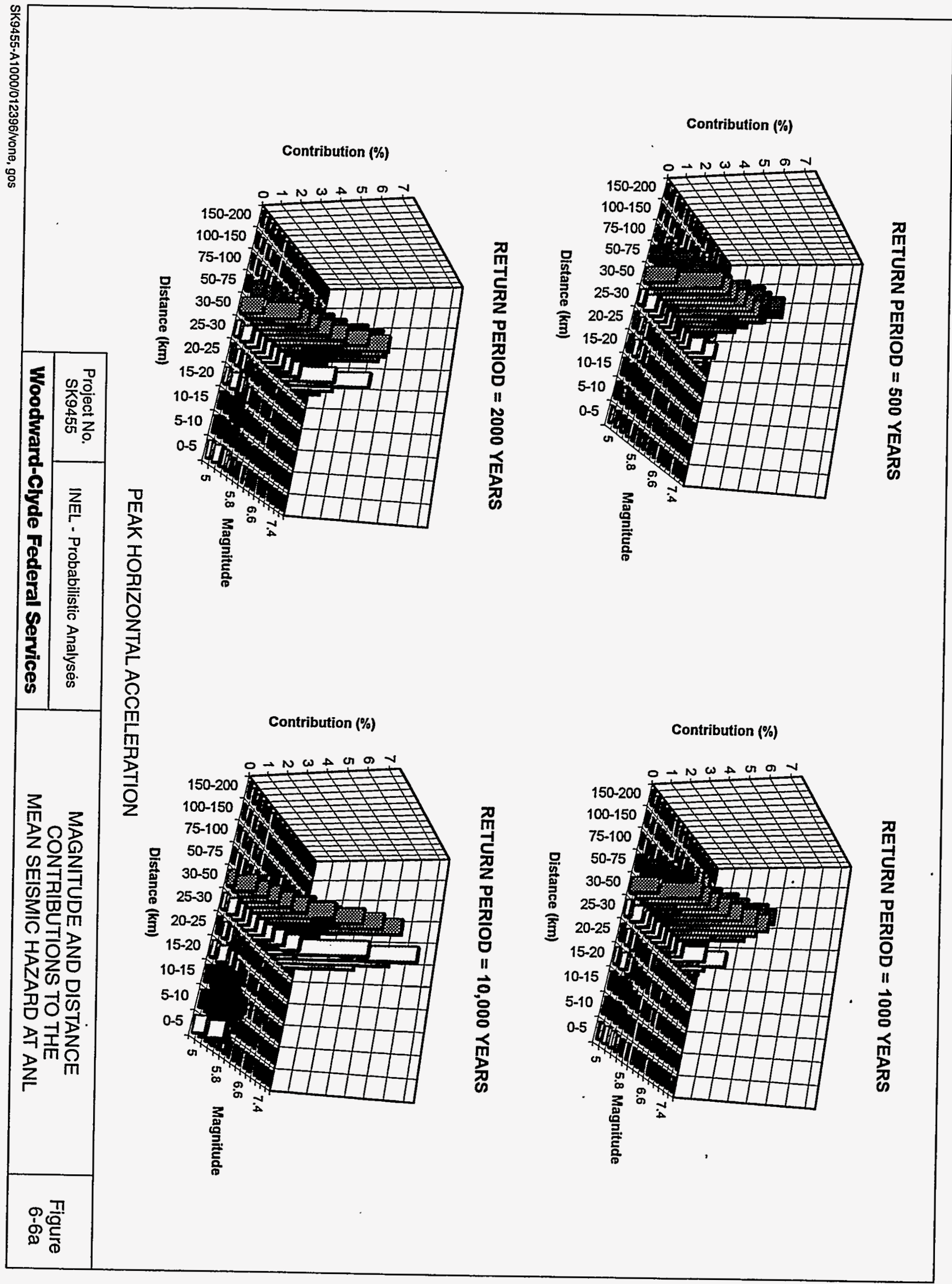




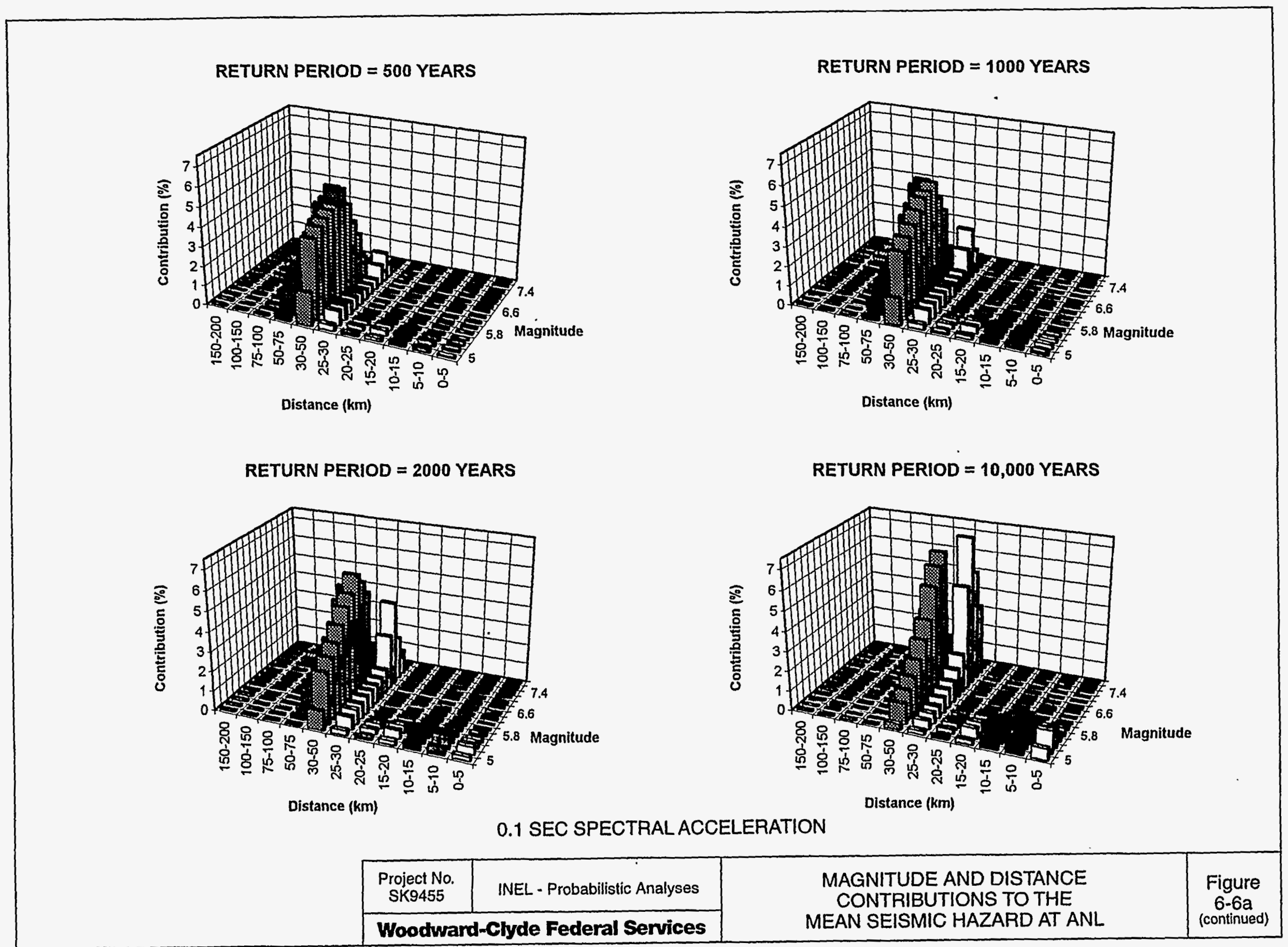

SK9455-A10001012396/vone, gos 


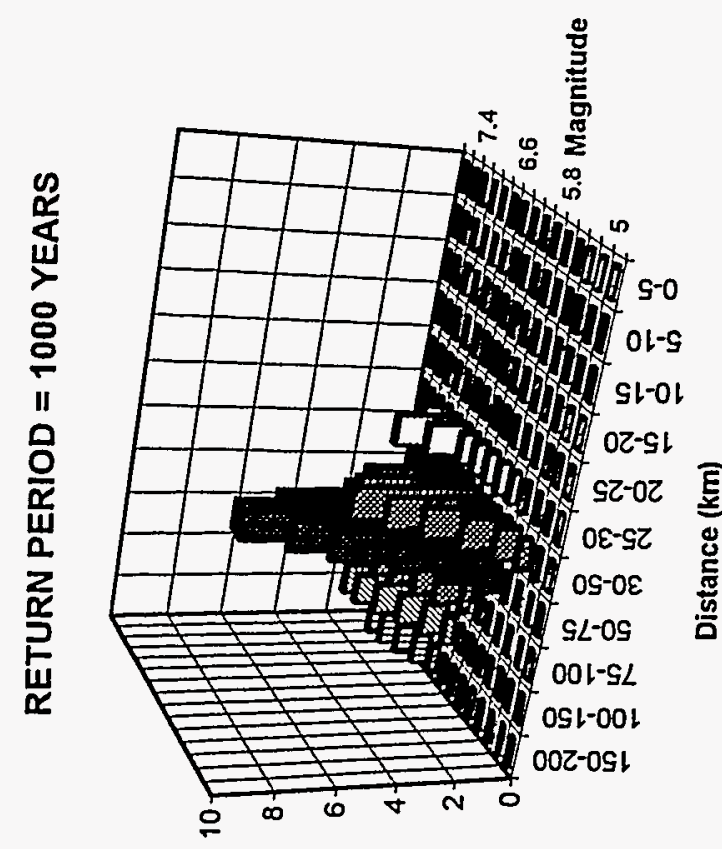

(\%) uo!mnq!ujuos

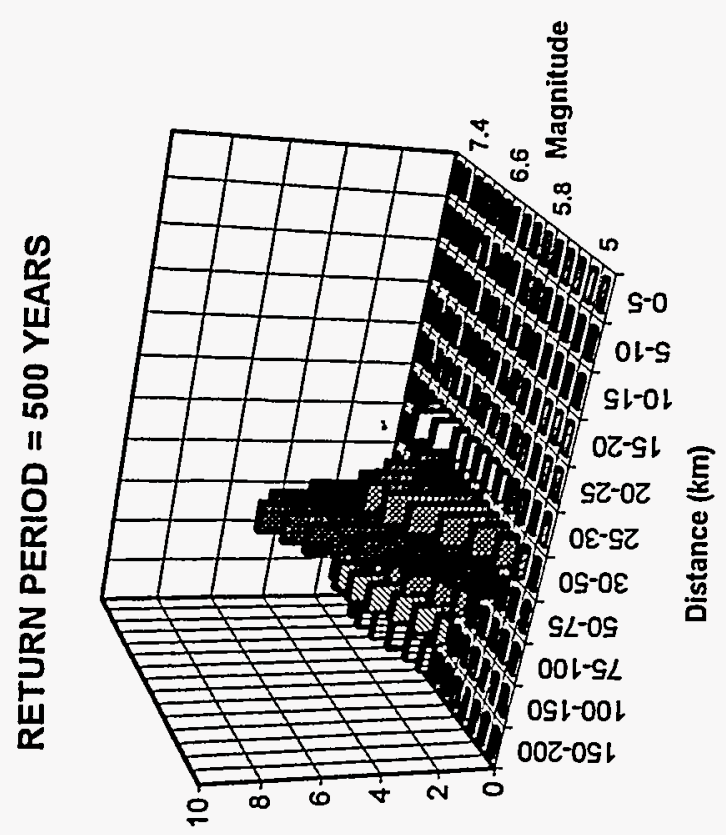

(\%) uo!nnq!ฺ\}uos

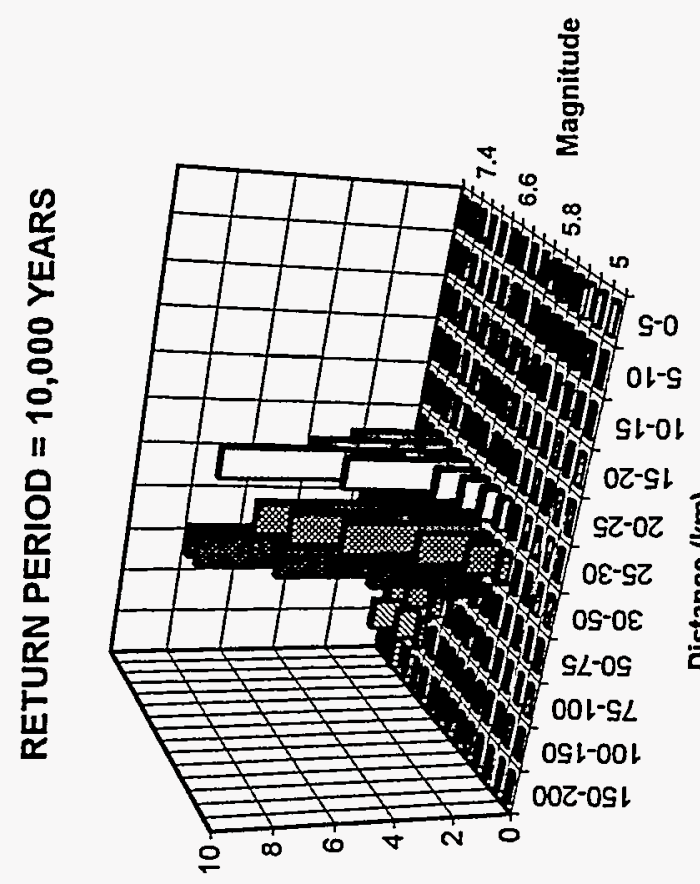

(\%) uo!̣nq!ฺฺนoว

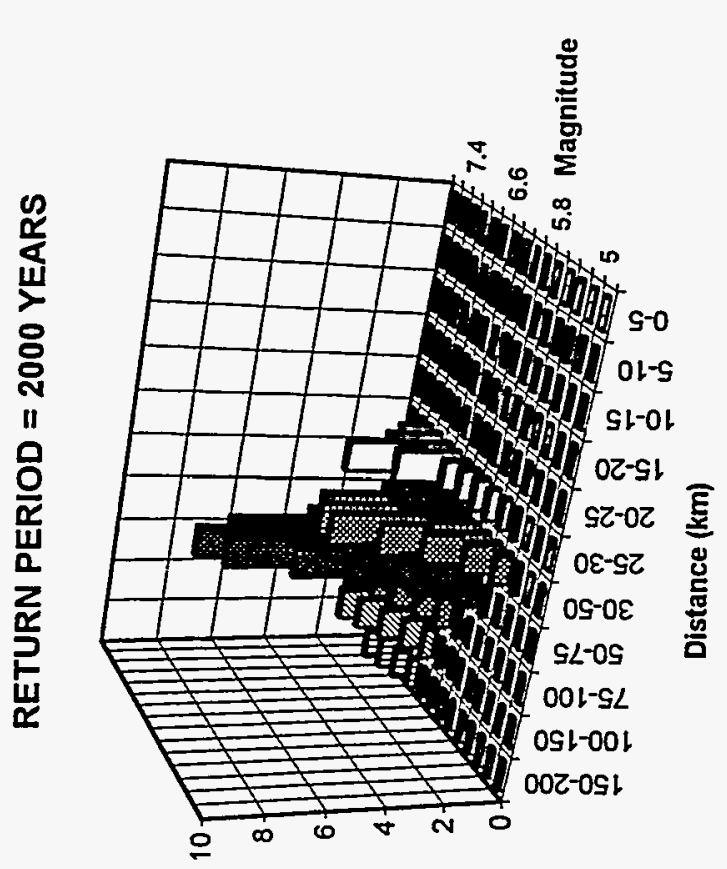

(\%) uo!̣nq!มjuoว

尼品

㟧跤

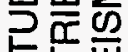

之茨胳

过

O

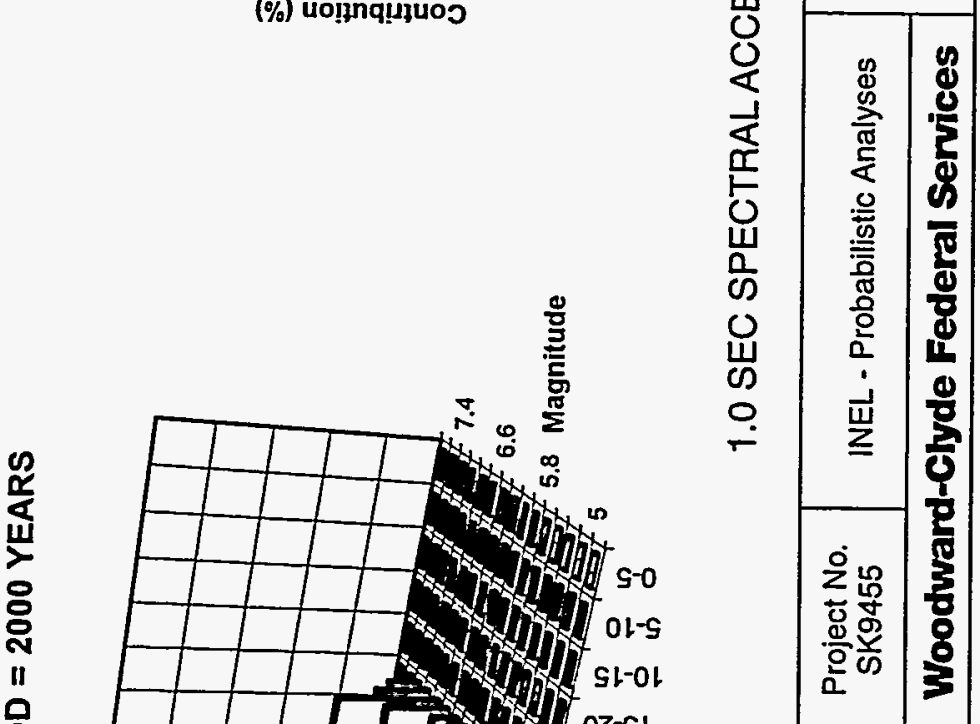




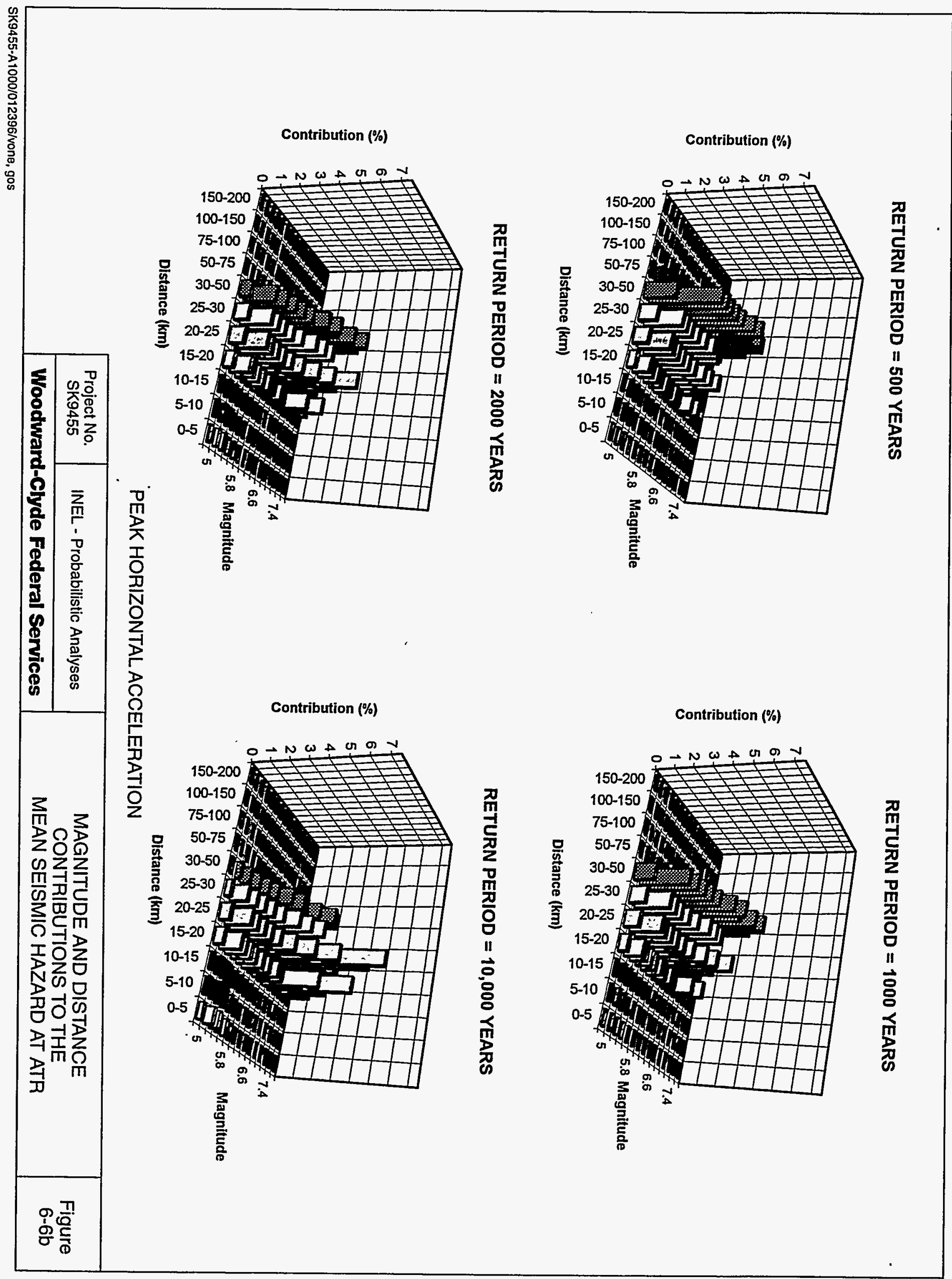




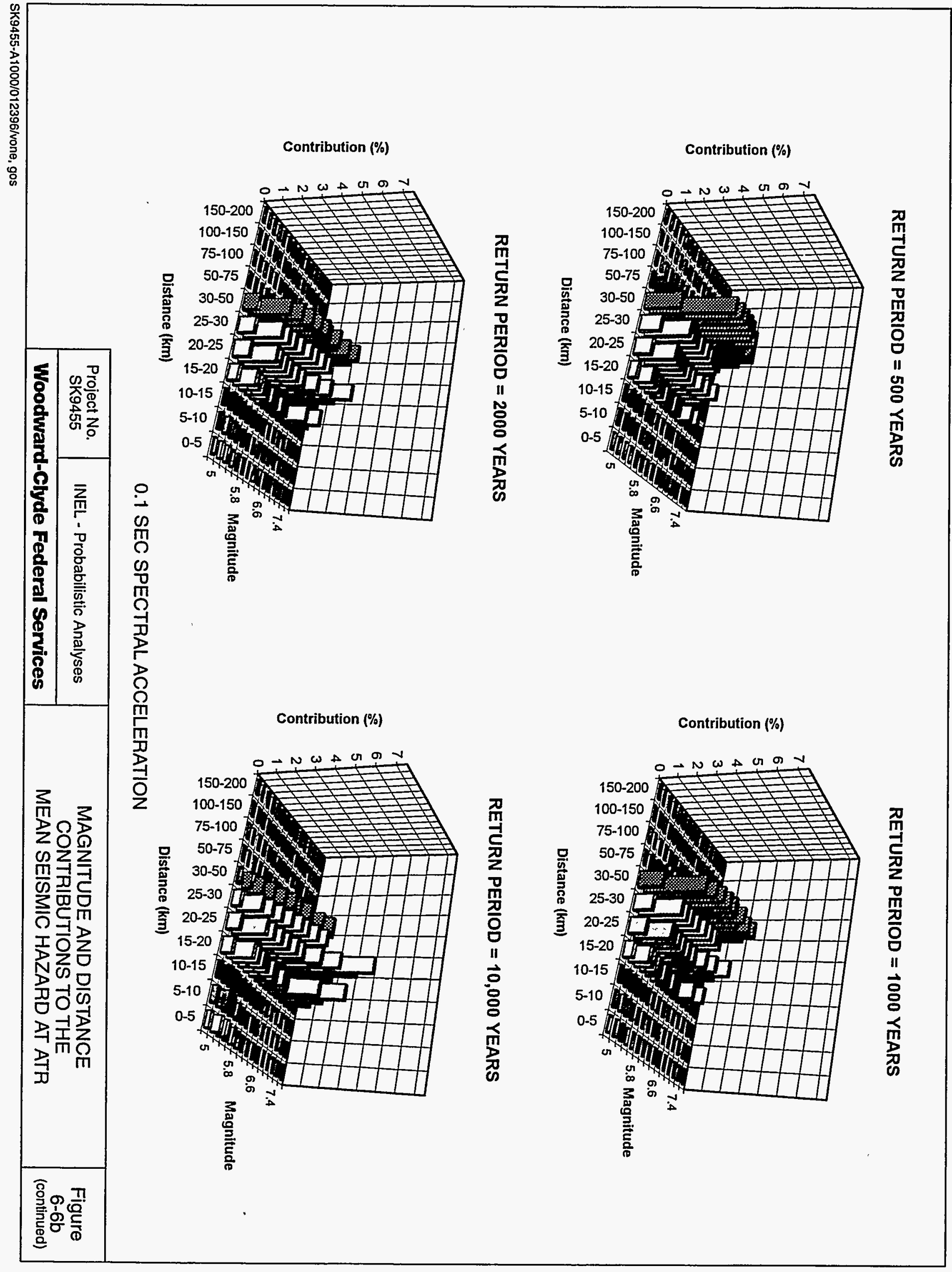




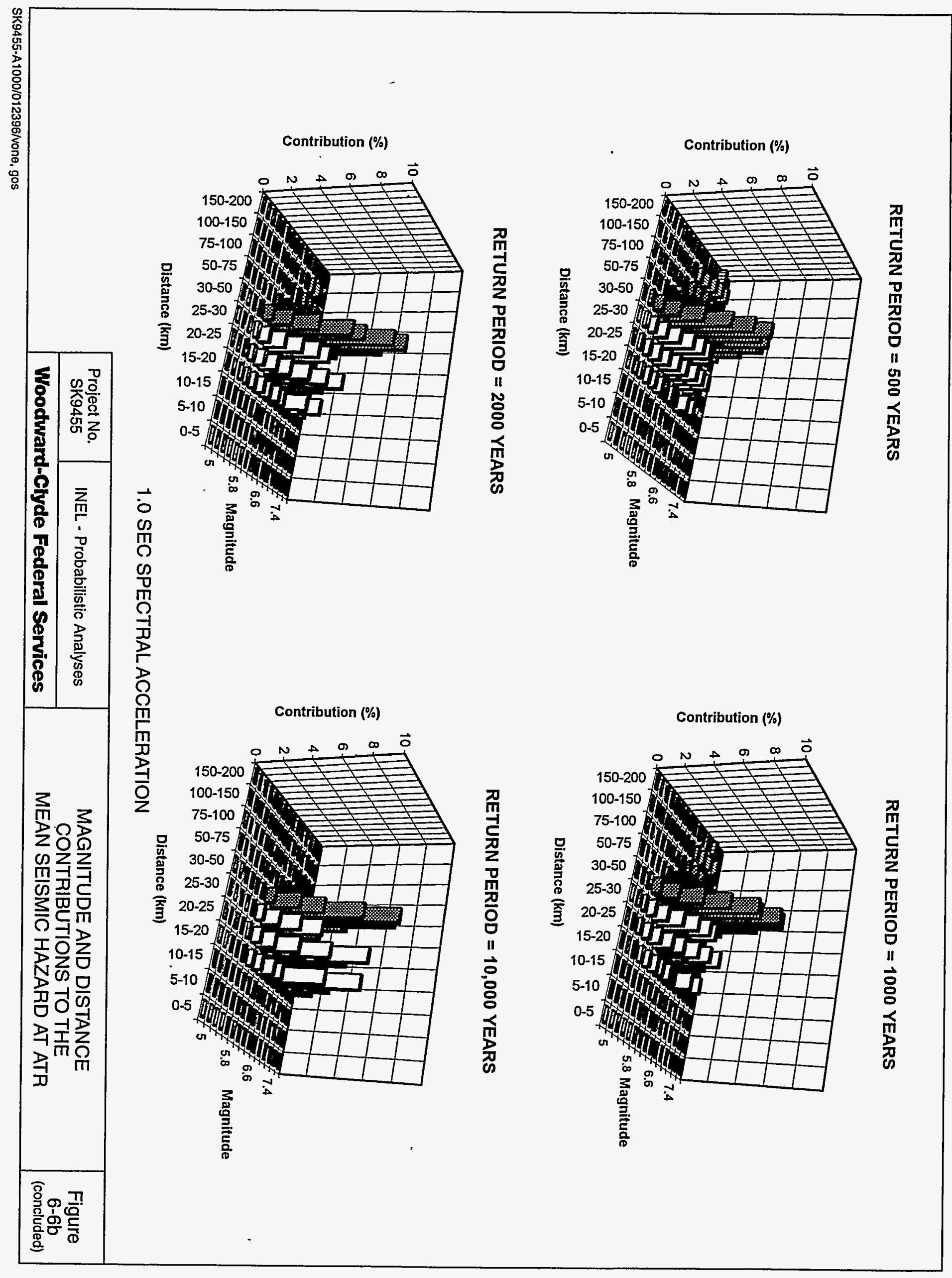


RETURN PERIOD $=500$ YEARS

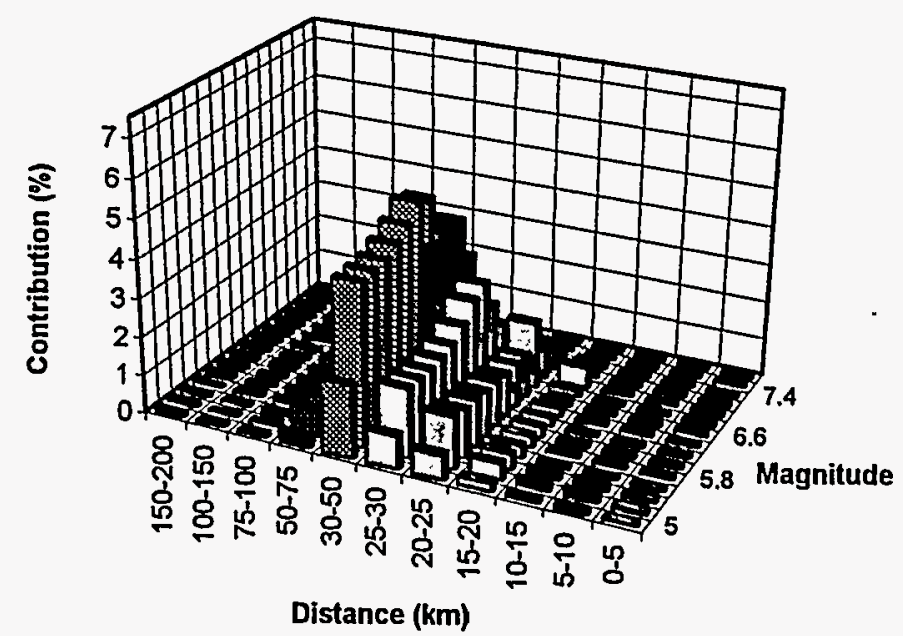

RETURN PERIOD $=2000$ YEARS

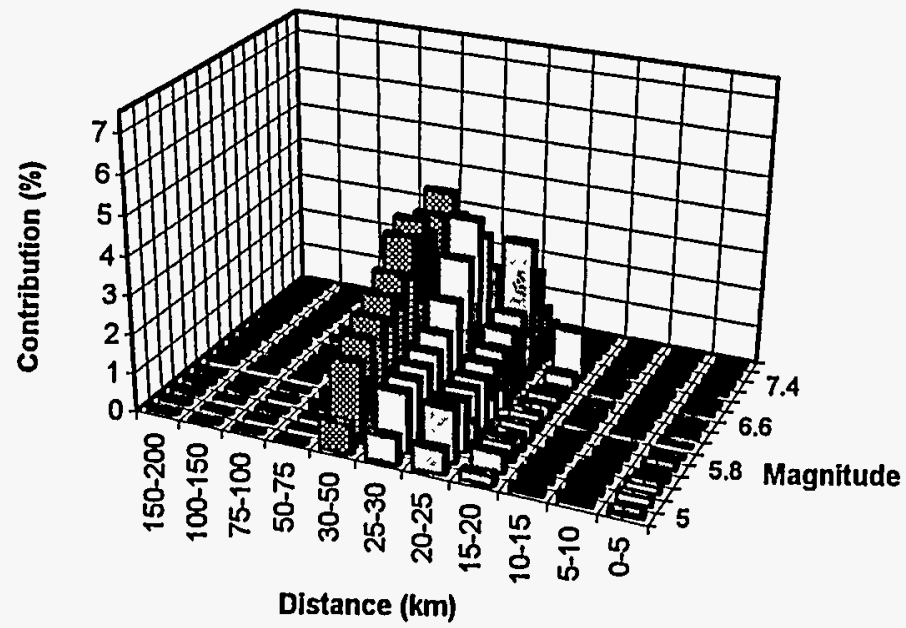

RETURN PERIOD $=1000$ YEARS

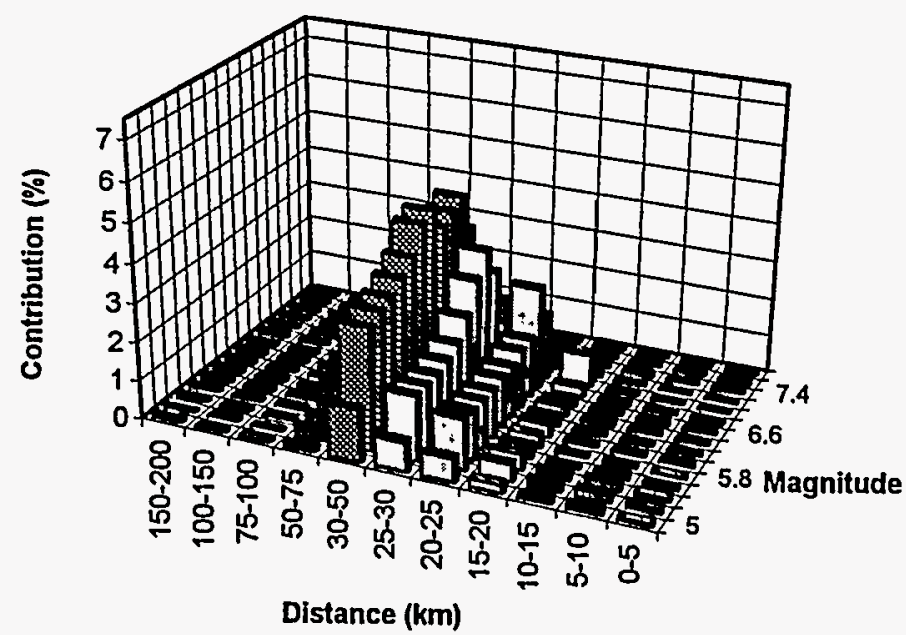

RETURN PERIOD $=10,000$ YEARS

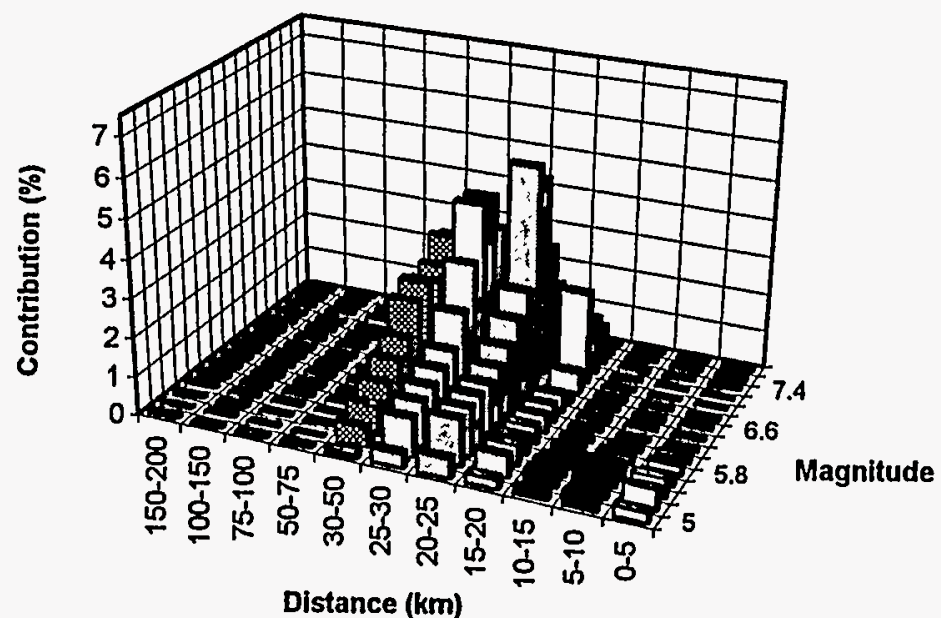

PEAK HORIZONTAL ACCELERATION

\begin{tabular}{|c|c|c|c|}
\hline $\begin{array}{c}\text { Project No. } \\
\text { SK9455 }\end{array}$ & INEL - Probabilistic Analyses & MAGNITUDE AND DISTANCE & CONTRIBUTIONS TO THE \\
\cline { 1 - 2 } Woodward-Clyde Federal Services & MEAN SEISMIC HAZARD AT CPP & $\begin{array}{c}\text { Figure } \\
6-6 c\end{array}$ \\
\hline
\end{tabular}




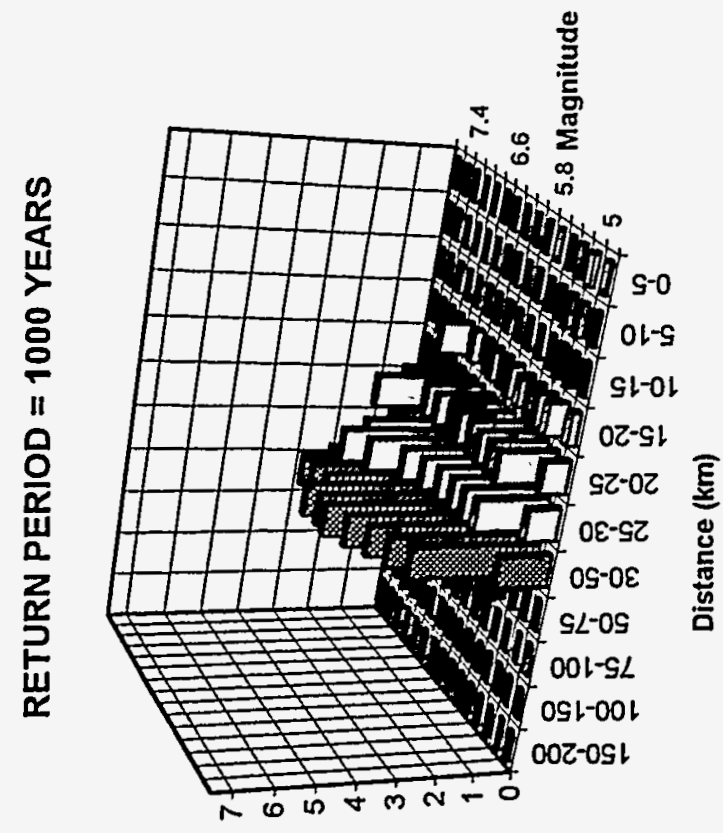

(\%) uo!!nq!!ฺuos

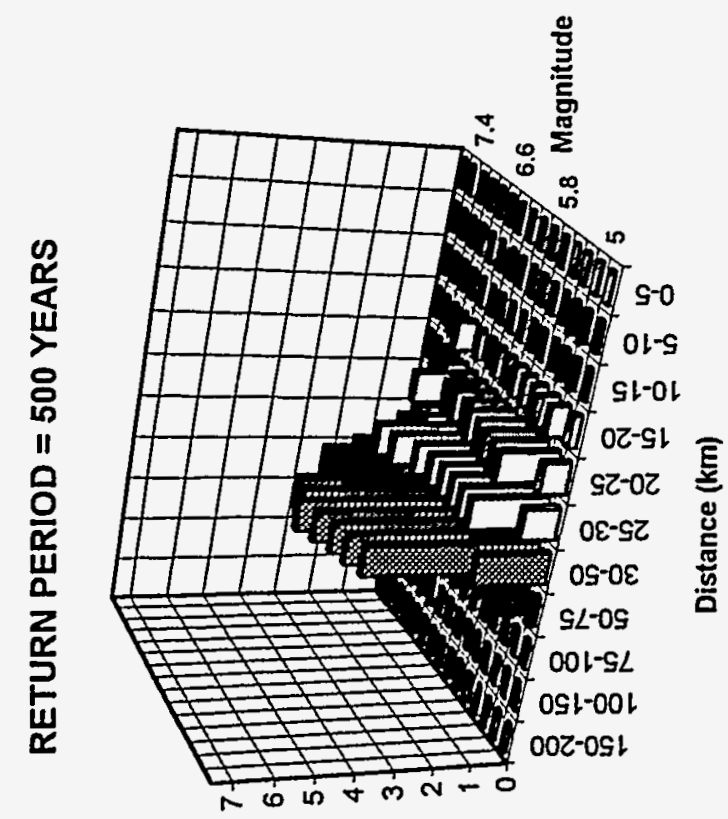

(\%) uo!̣nq!มpuos

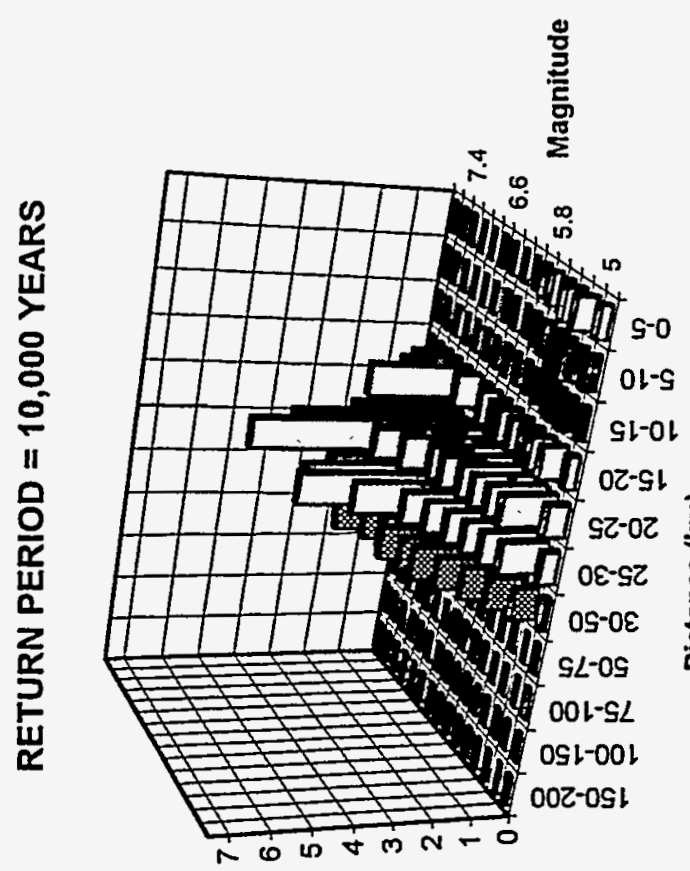

(\%) uo!̣nq!ฺนuos

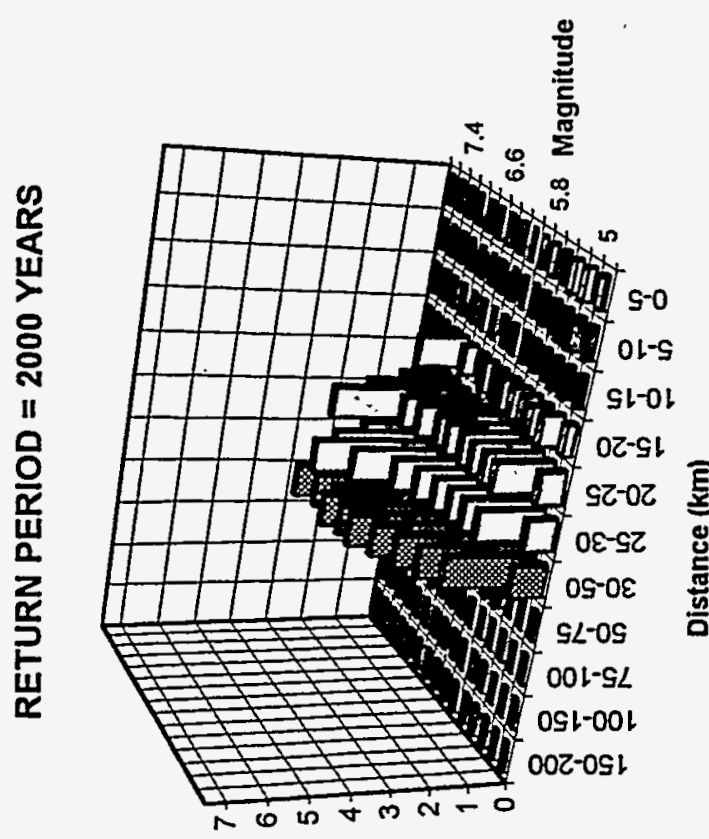

(\%) uo!̣nq!ıฺนos 
RETURN PERIOD $=500$ YEARS

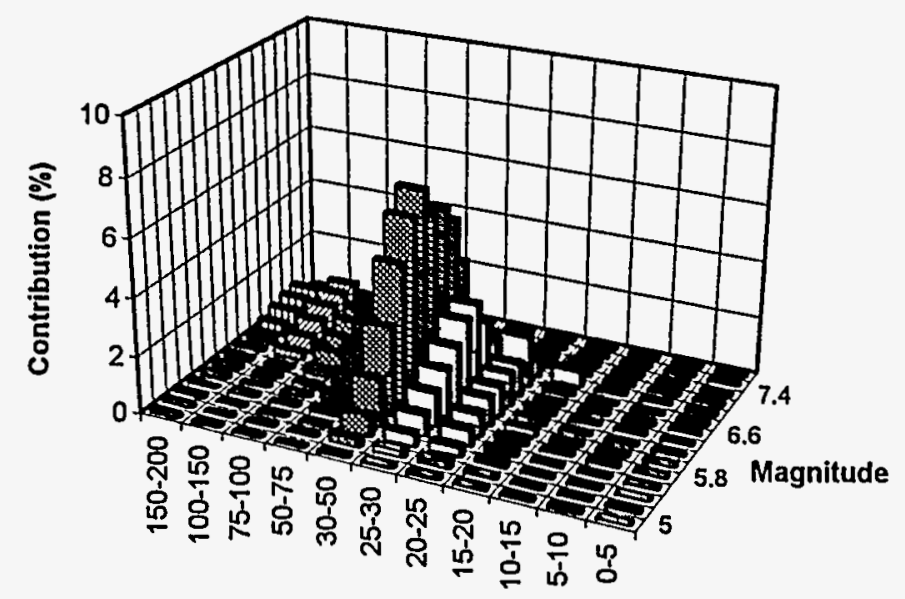

Distance (km)

\section{RETURN PERIOD $=2000$ YEARS}

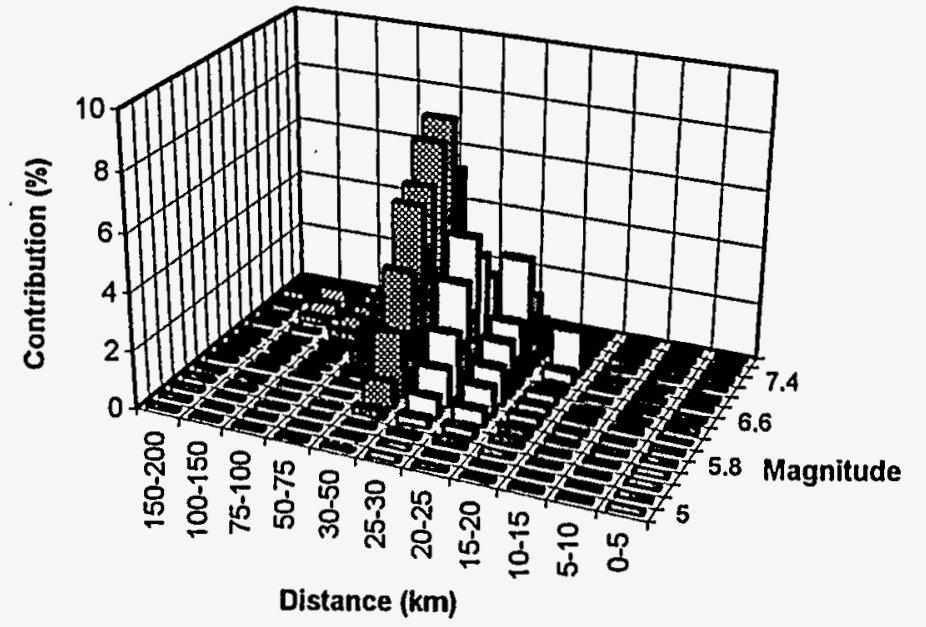

RETURN PERIOD $=1000$ YEARS

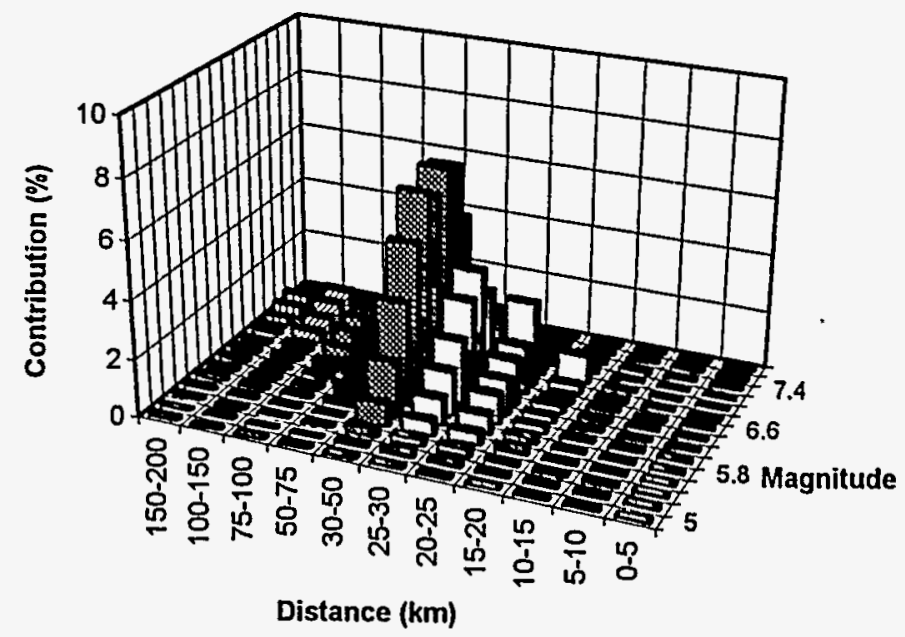

RETURN PERIOD $=10,000$ YEARS

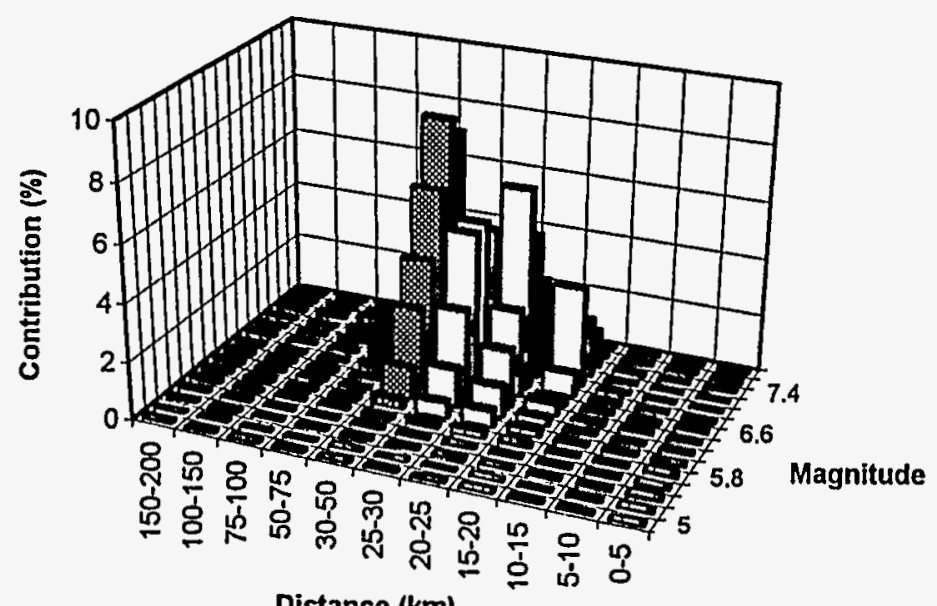

1.0 SEC SPECTRAL ACCELERATION

\begin{tabular}{|l|c|}
\hline $\begin{array}{c}\text { Project No. } \\
\text { SK9455 }\end{array}$ & INEL - Probabilistic Analyses \\
\hline \multicolumn{2}{|c|}{ Woodward-Clyde Federal Services } \\
\hline
\end{tabular}

Woodward-Clyde Federal Services
MAGNITUDE AND DISTANCE CONTRIBUTIONS TO THE MEAN SEISMIC HAZARD AT CPP
Figure

6-6c (concluded) 
RETURN PERIOD $=500$ YEARS

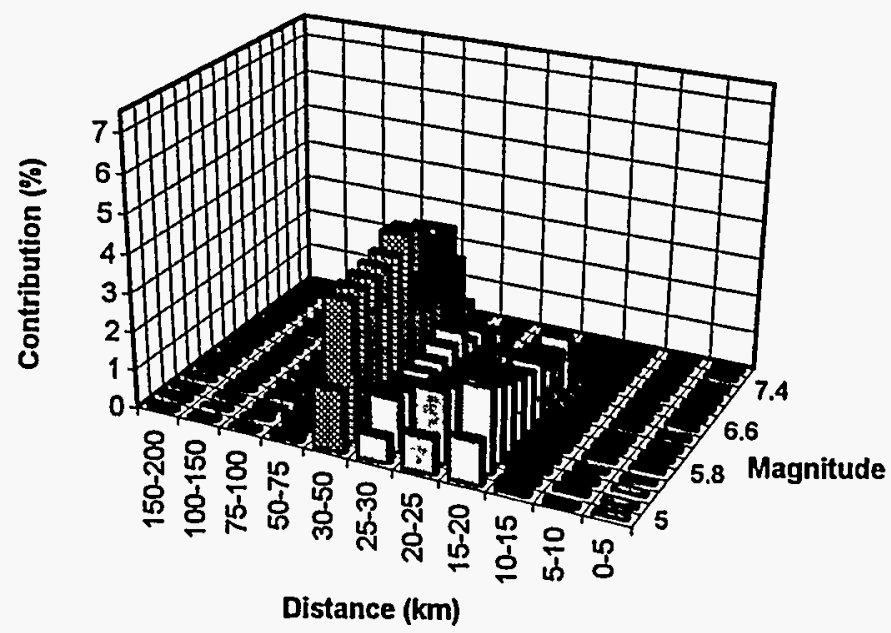

RETURN PERIOD $=2000$ YEARS

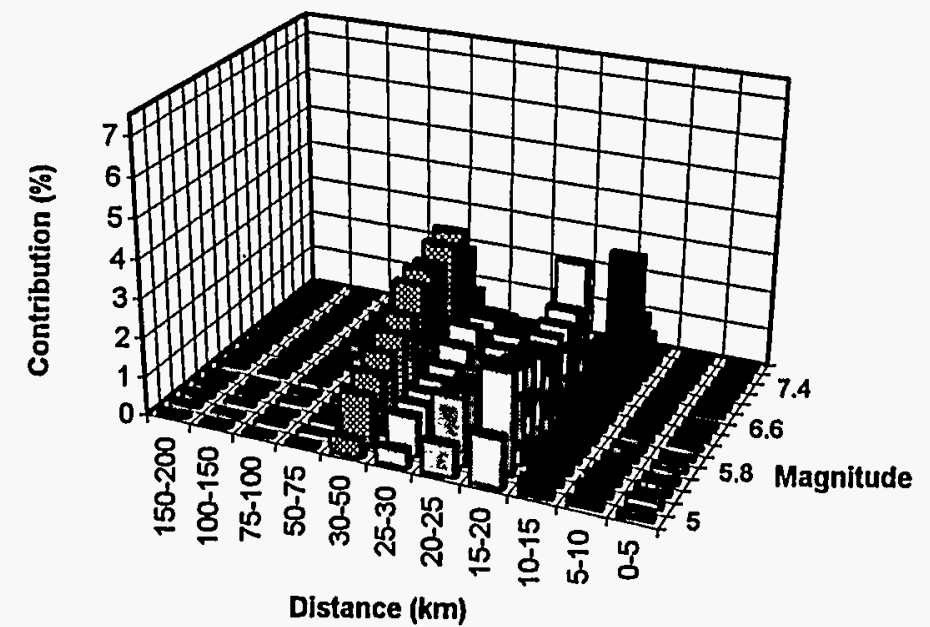

RETURN PERIOD $=1000$ YEARS

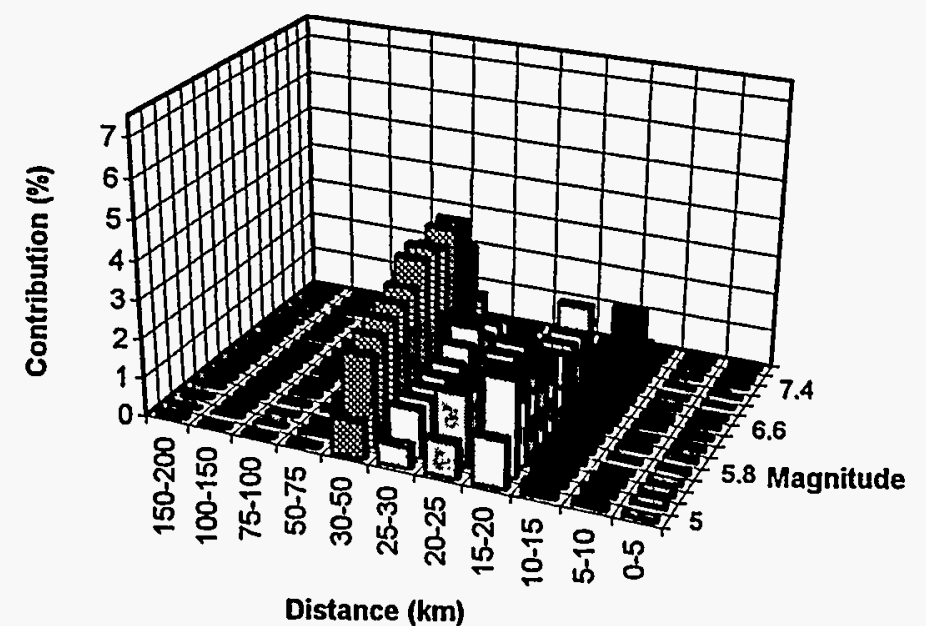

RETURN PERIOD $=10,000$ YEARS

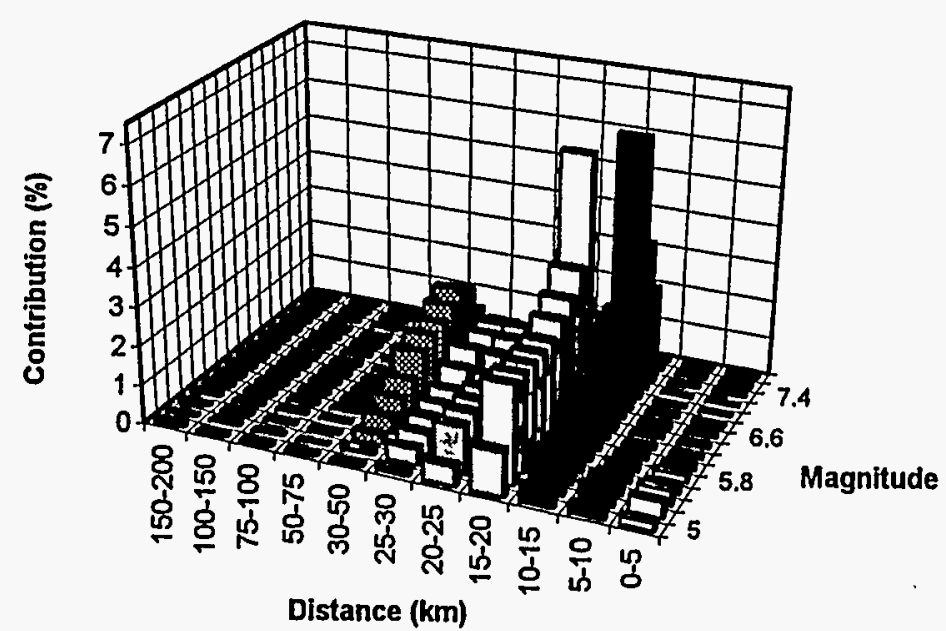

Distance (km)

PEAK HORIZONTAL ACCELERATION

\begin{tabular}{|c|c|c|c|}
\hline $\begin{array}{c}\text { Project No. } \\
\text { SK9455 }\end{array}$ & INEL - Probabilistic Analyses & MAGNITUDE AND DISTANCE & CONTRIBUTIONS TO THE \\
\hline Woodward-Clyde Federal Services & MEAN SEISMIC HAZARD AT NRF & $\begin{array}{c}\text { Figure } \\
6-6 d\end{array}$ \\
\hline
\end{tabular}




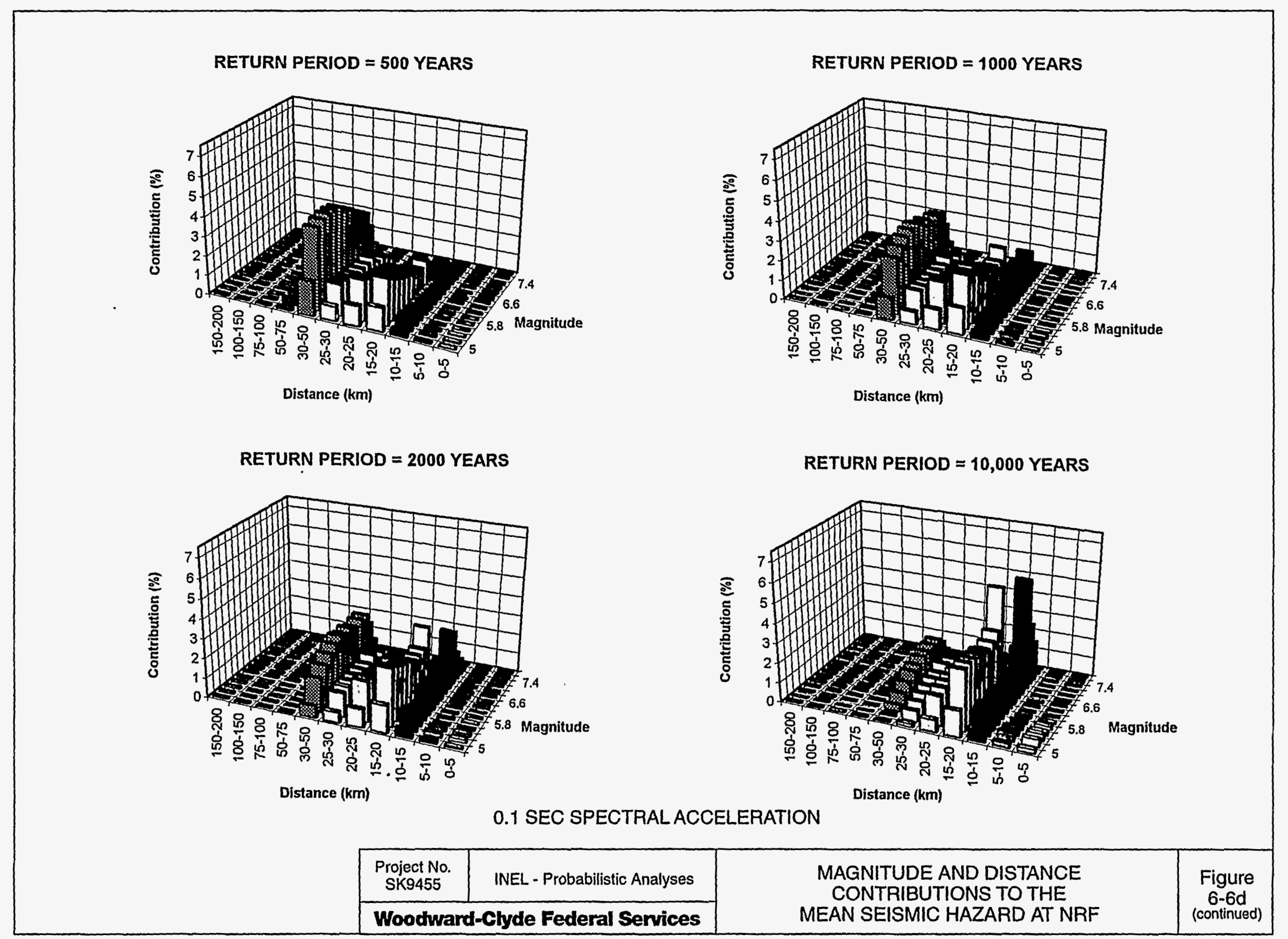

SK9455-A1000/012396/vone، gos 
RETURN PERIOD $=500$ YEARS

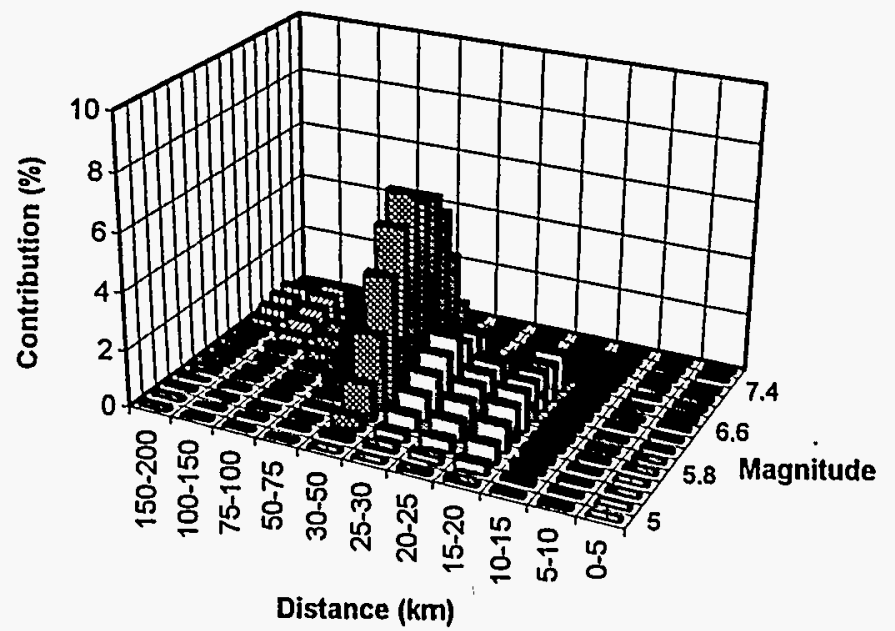

RETURN PERIOD $=2000$ YEARS

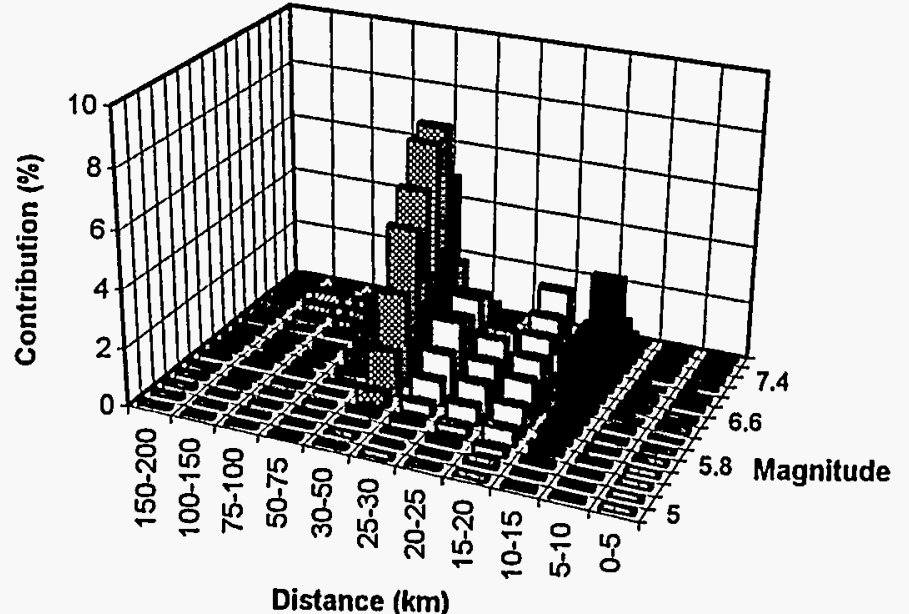

RETURN PERIOD $=1000$ YEARS

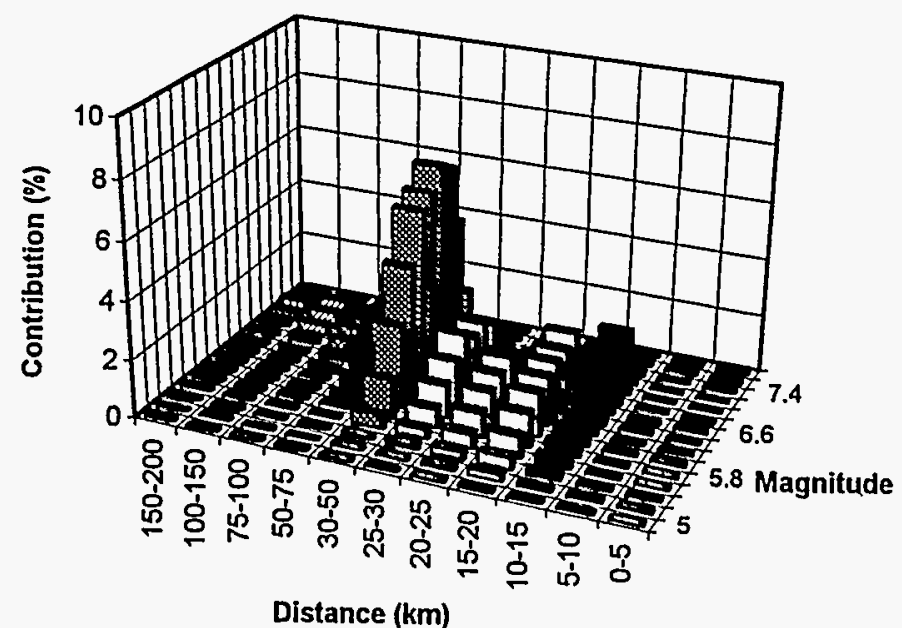

RETURN PERIOD $=10,000$ YEARS

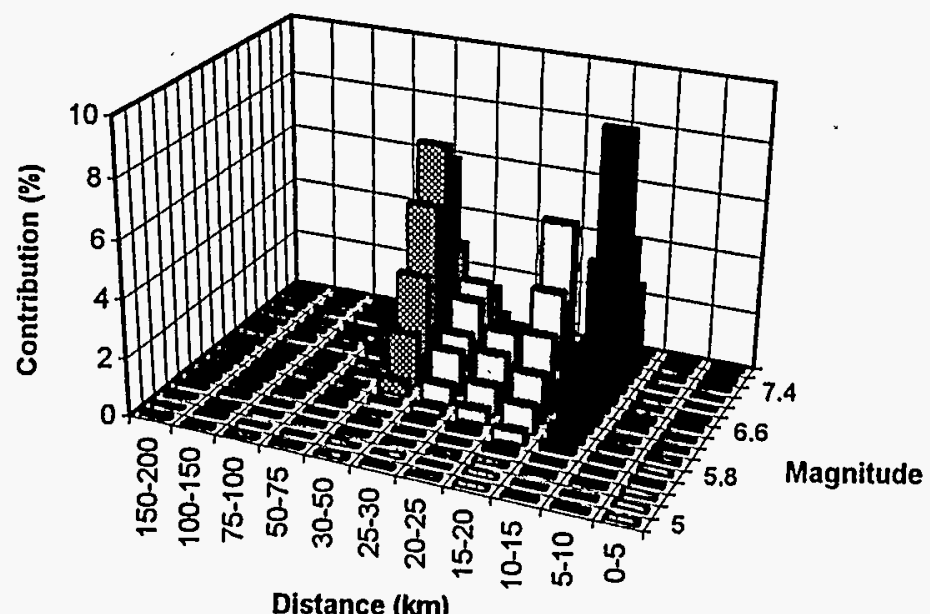

1.0 SEC SPECTRAL ACCELERATION

\begin{tabular}{|c|c|}
\hline $\begin{array}{c}\text { Project No. } \\
\text { SK9455 }\end{array}$ & INEL - Probabilistic Analyses \\
\hline \multicolumn{2}{|c|}{ Woodward-Clyde Federal Services } \\
\hline
\end{tabular}
MAGNITUDE AND DISTANCE CONTRIBUTIONS TO THE MEAN SEISMIC HAZARD AT NRF


RETURN PERIOD $=500$ YEARS

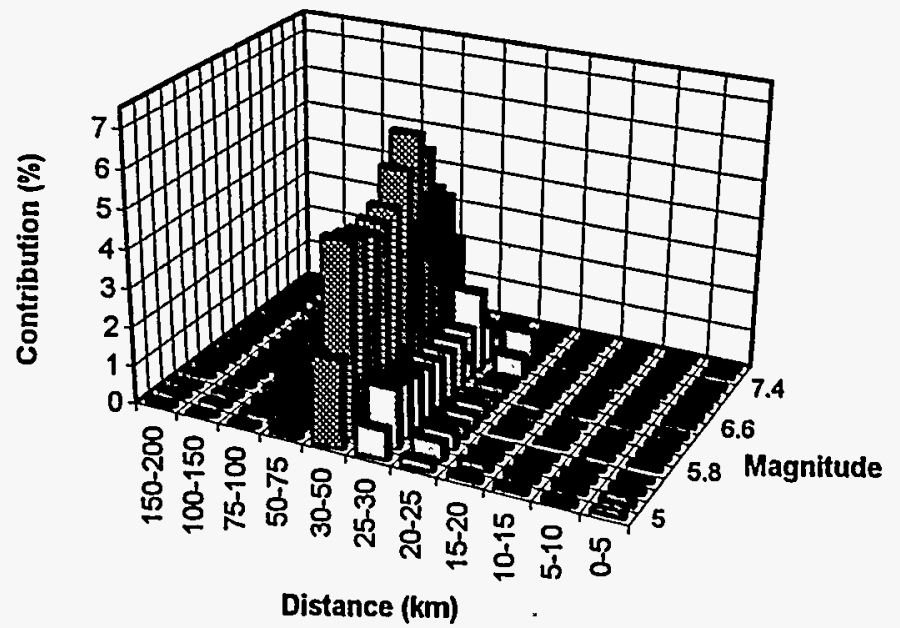

RETURN PERIOD $=2000$ YEARS

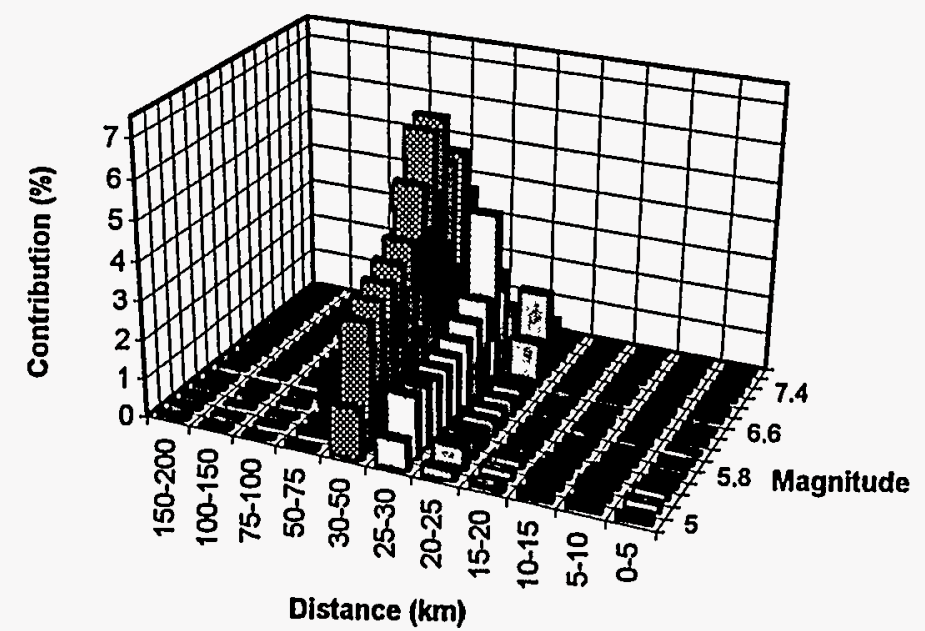

RETURN PERIOD $=1000$ YEARS

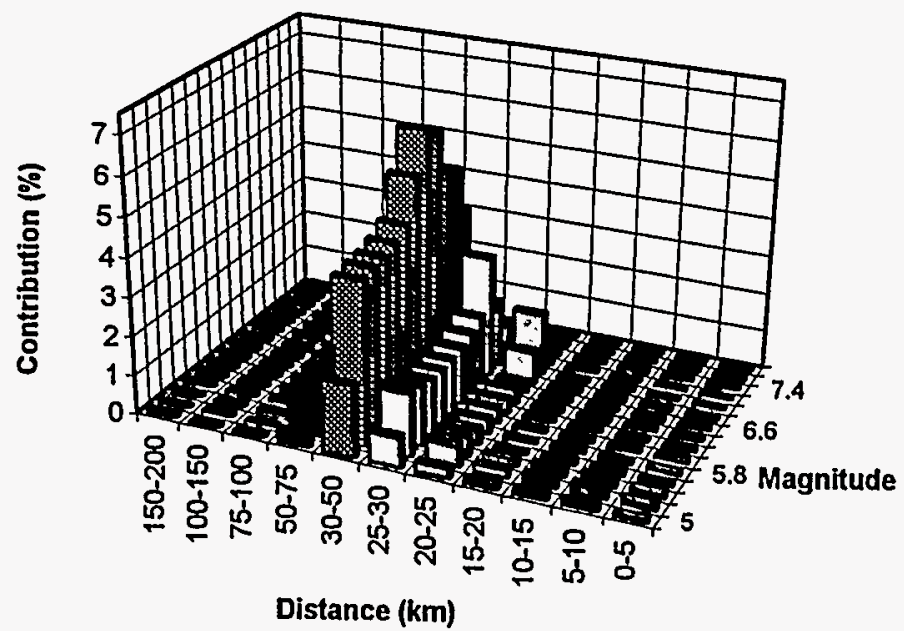

RETURN PERIOD $=10,000$ YEARS

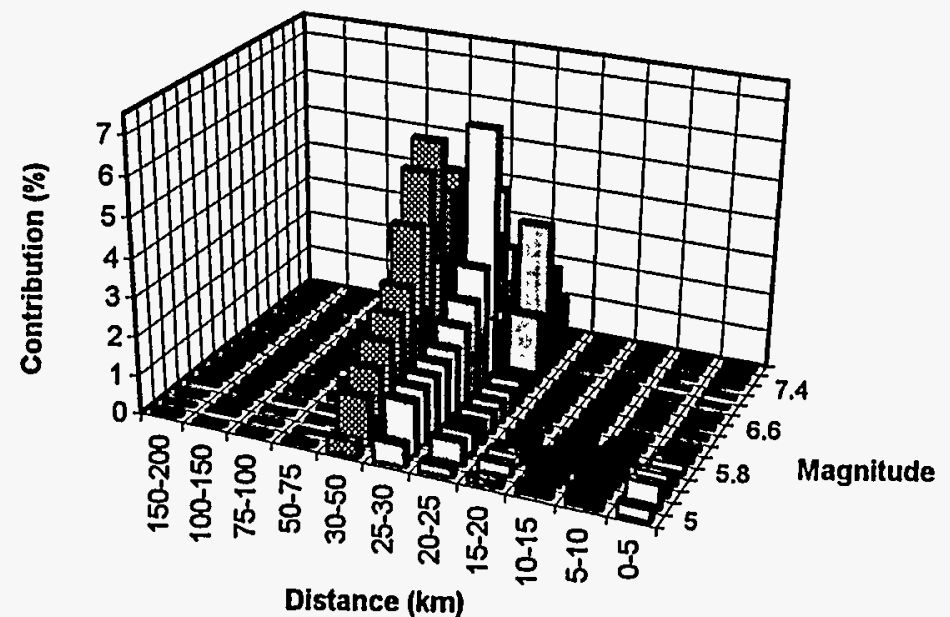

PEAK HORIZONTAL ACCELERATION

\begin{tabular}{|c|c|c|c|}
\hline $\begin{array}{c}\text { Project No. } \\
\text { SK9455 }\end{array}$ & INEL - Probabilistic Analyses & MAGNITUDE AND DISTANCE & Figure \\
\cline { 1 - 1 } Woodward-Clyde Federal Services & MEAN SEISMIC HAZARD AT PBF & $6-6 e$ \\
\hline
\end{tabular}




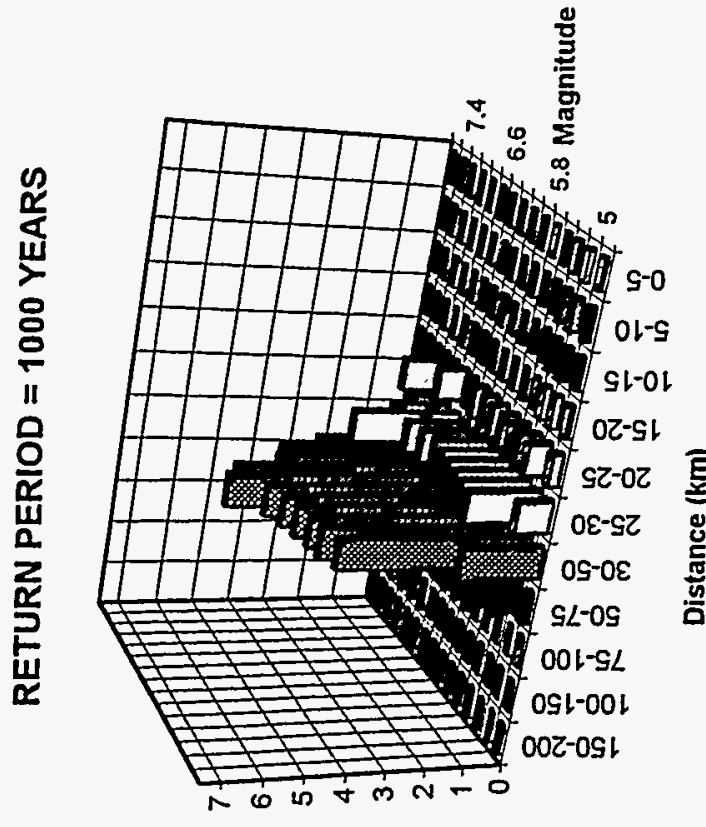

(\%) uo!nnq!nuos

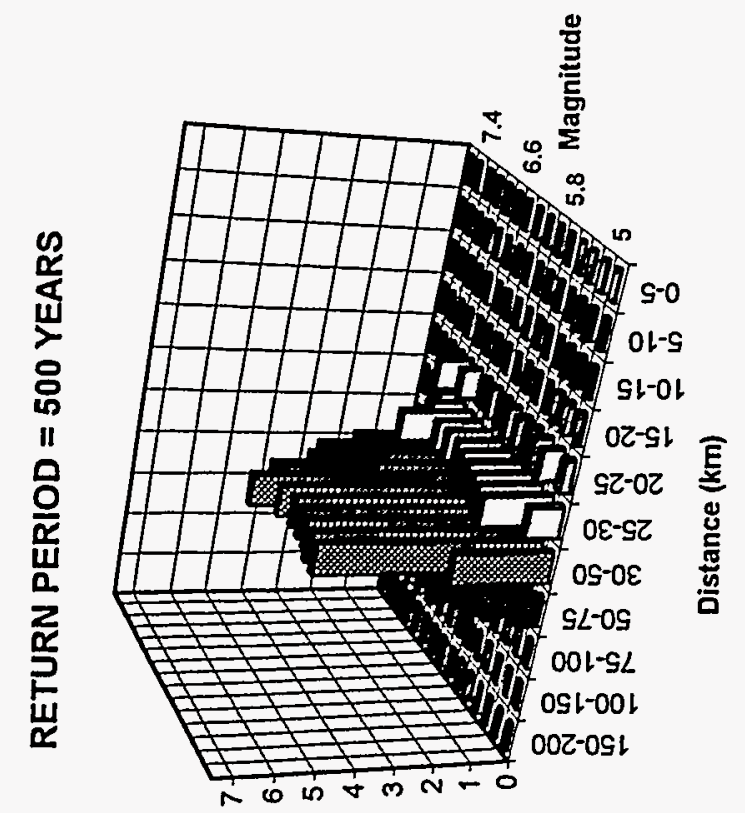

(\%) uo!!nq!ม\}บoว

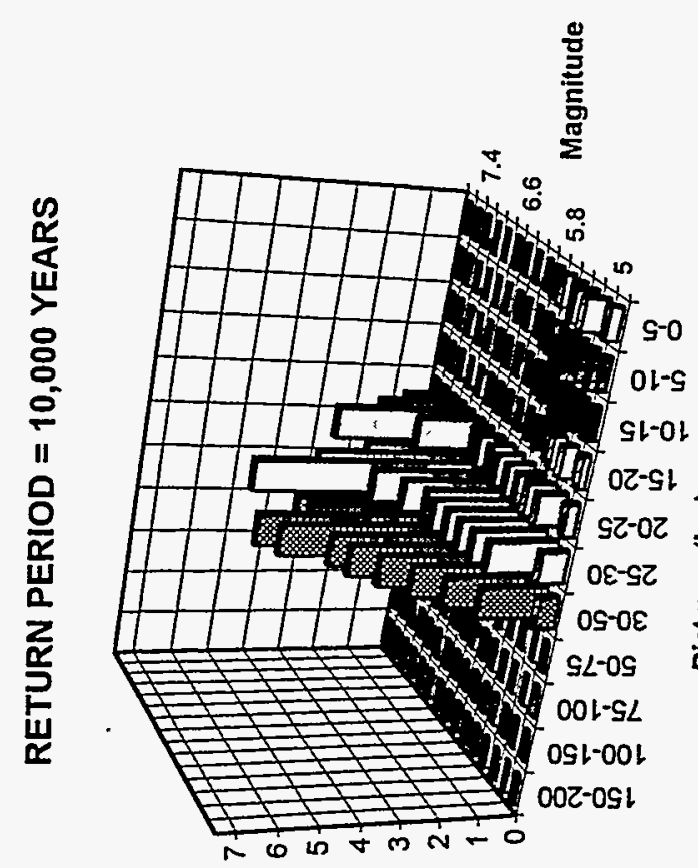

(\%) uo!̣nq!ฺนos

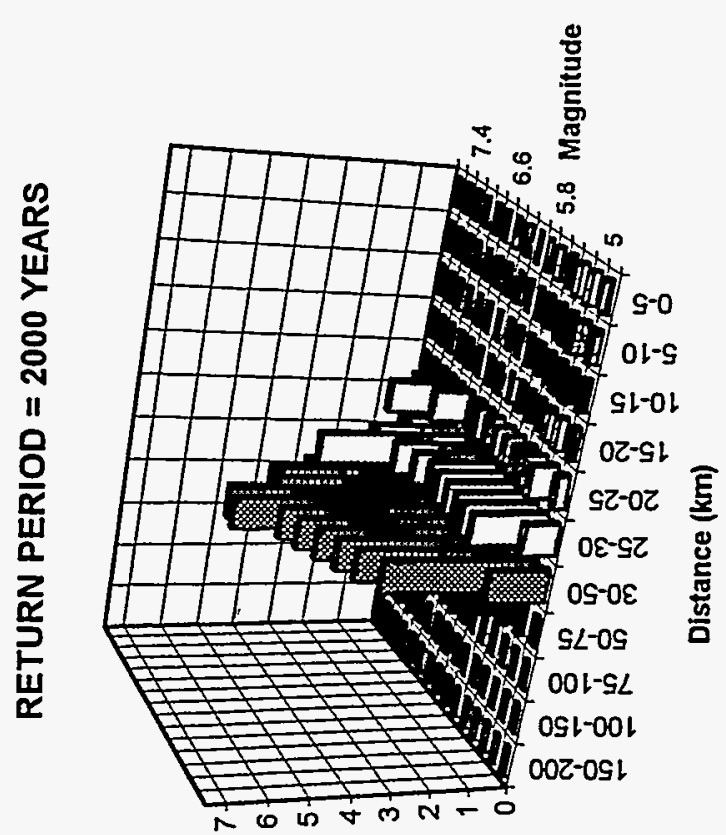

(\%) uo!nnqułuos 


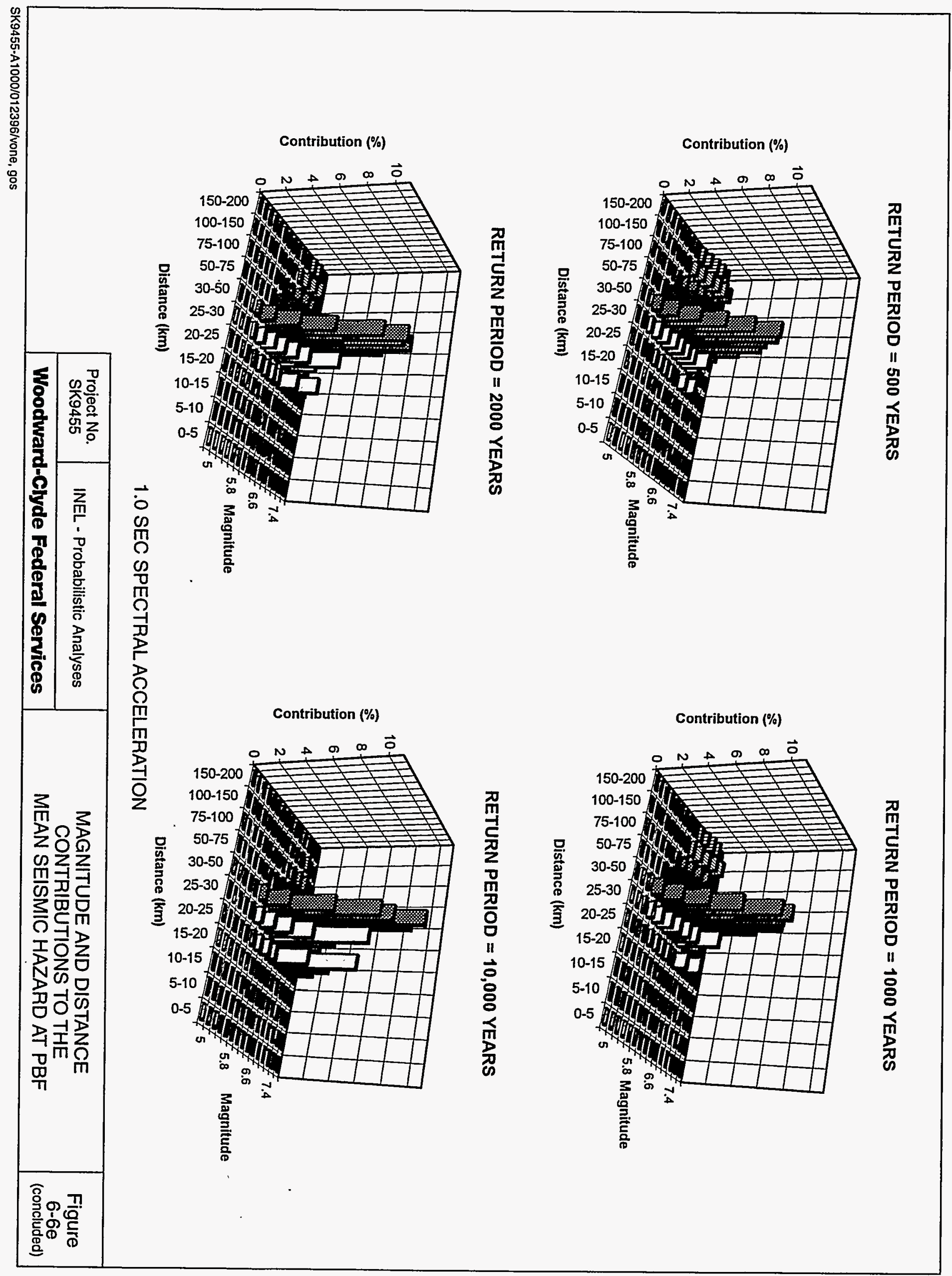


RETURN PERIOD $=500$ YEARS

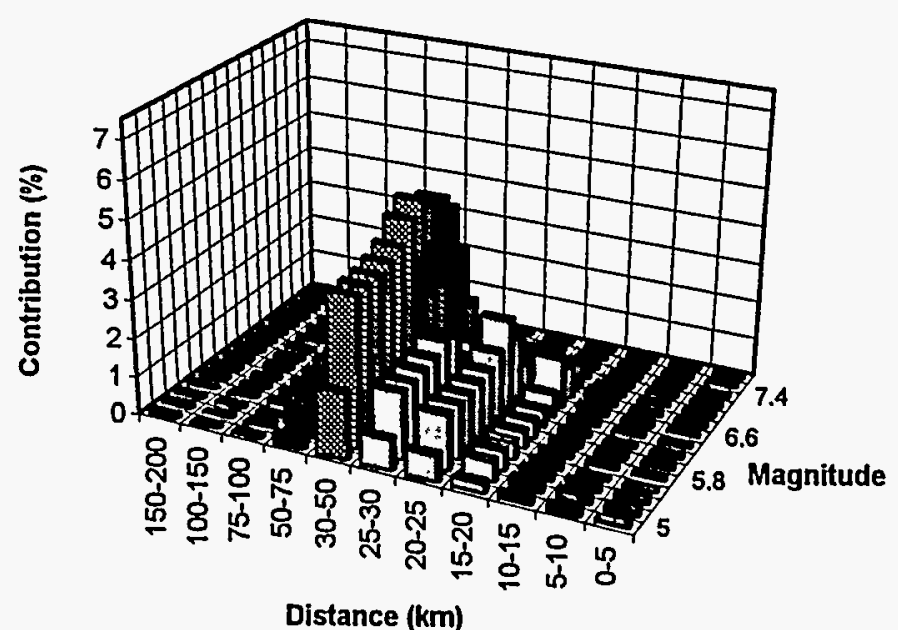

RETURN PERIOD $=2000$ YEARS

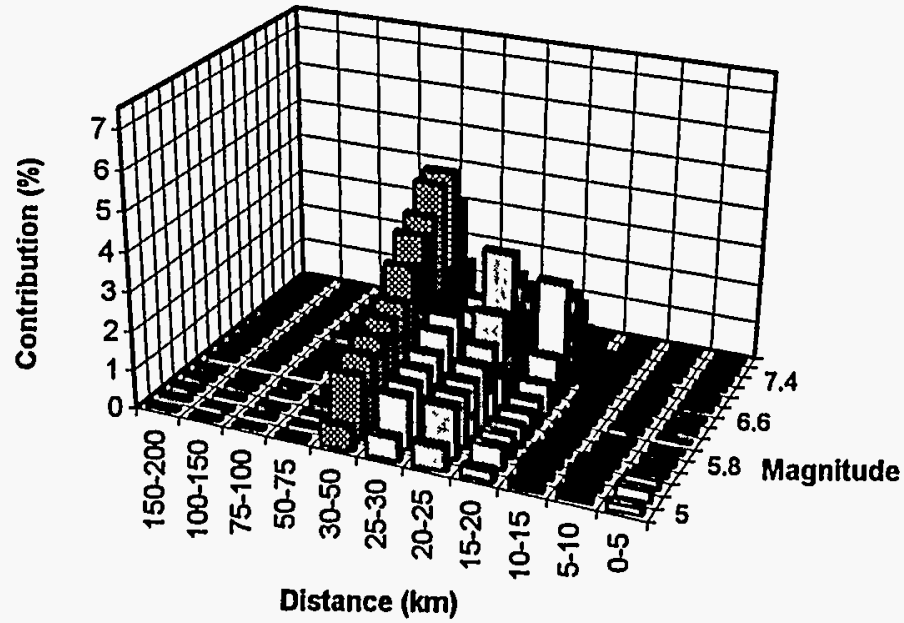

RETURN PERIOD $=1000$ YEARS

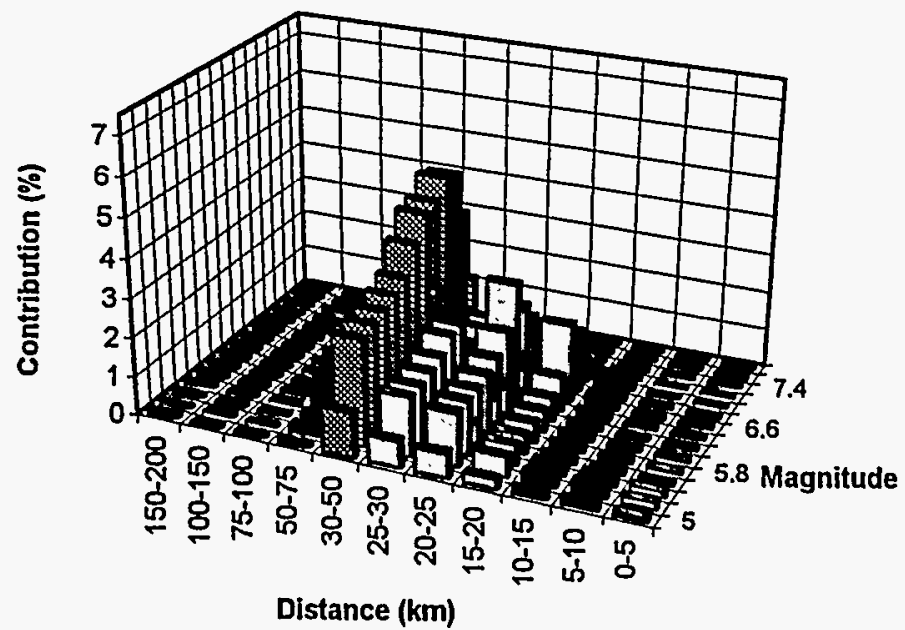

RETURN PERIOD $=10,000$ YEARS

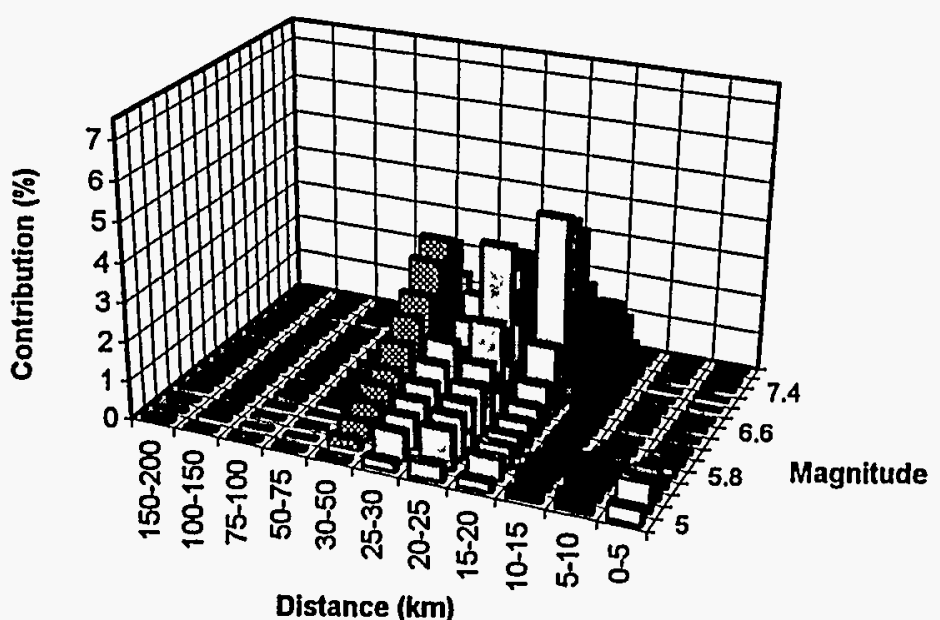

Distance (km)

PEAK HORIZONTAL ACCELERATION

\begin{tabular}{|c|c|c|c|}
\hline $\begin{array}{c}\text { Project No. } \\
\text { SK9455 }\end{array}$ & INEL - Probabilistic Analyses & MAGNITUDE AND DISTANCE & Figure \\
\cline { 1 - 1 } Woodward-Clyde Federal Services & MEAN SEISMIC HAZARD AT RWMC & $6-6 f$ \\
\hline
\end{tabular}




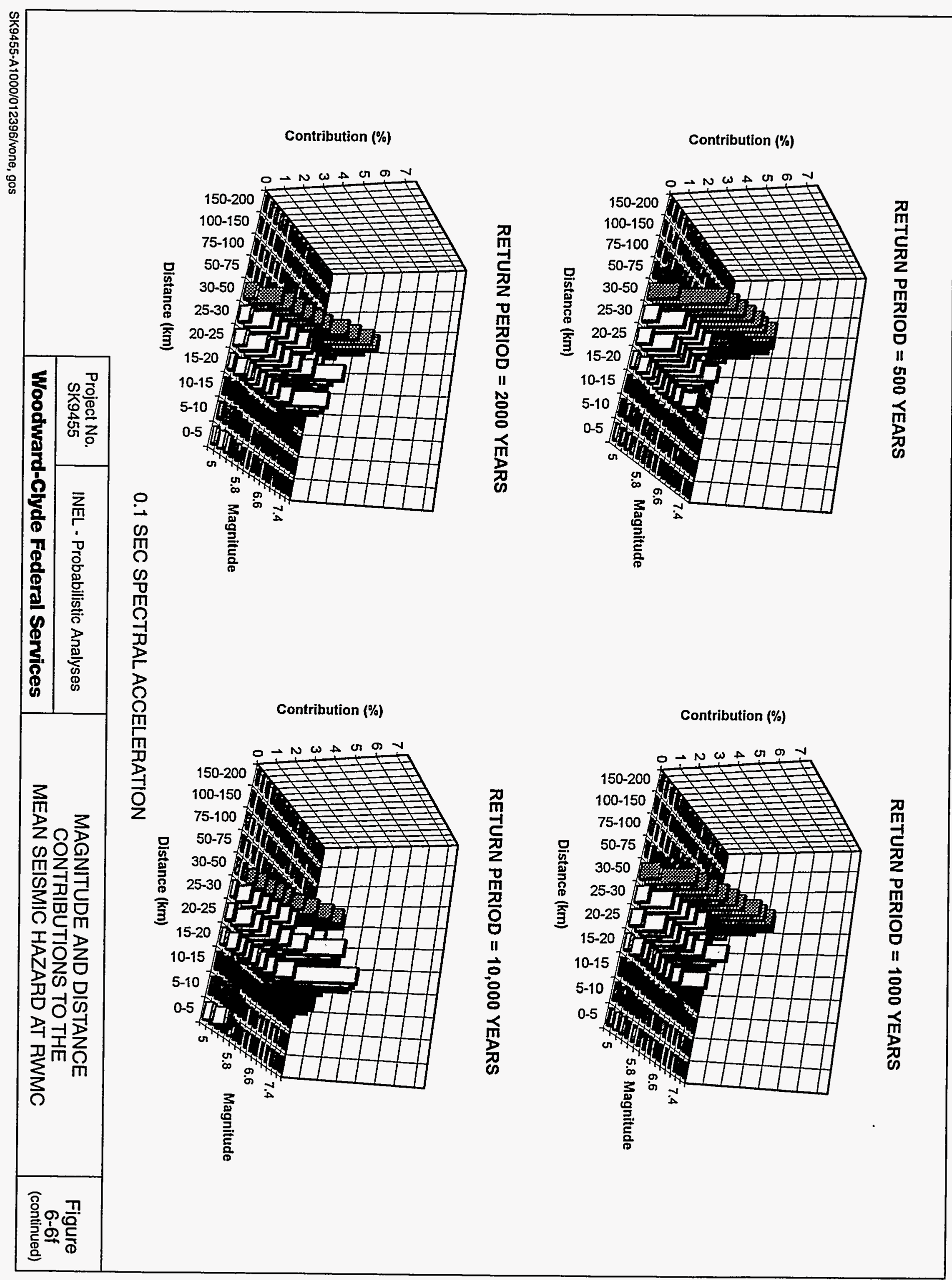


RETURN PERIOD $=500$ YEARS

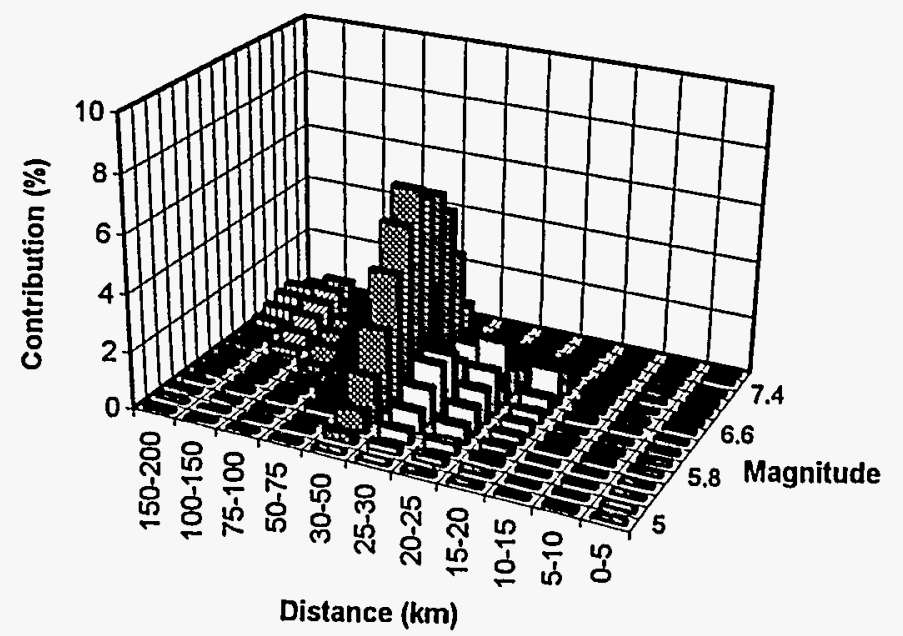

RETURN PERIOD $=2000$ YEARS

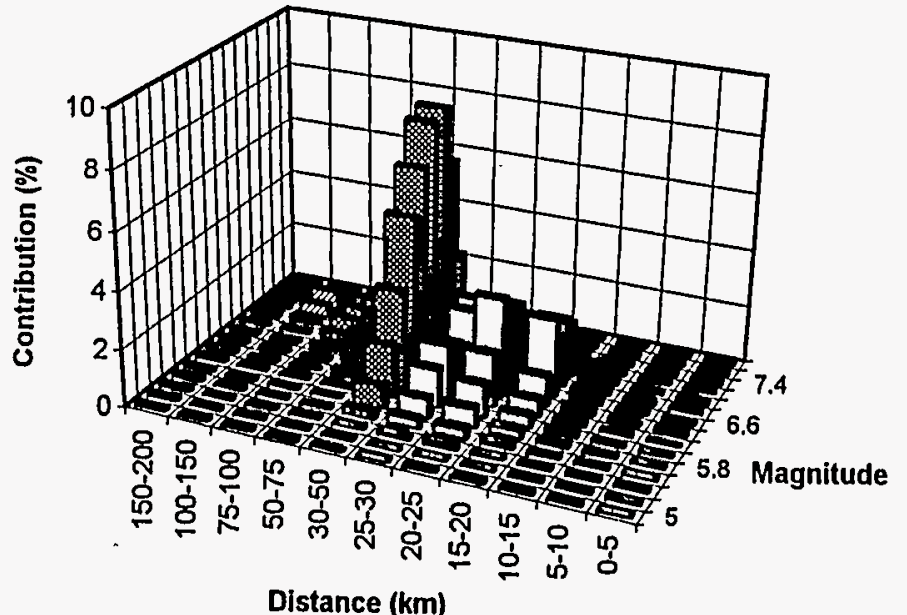

RETURN PERIOD $=1000$ YEARS

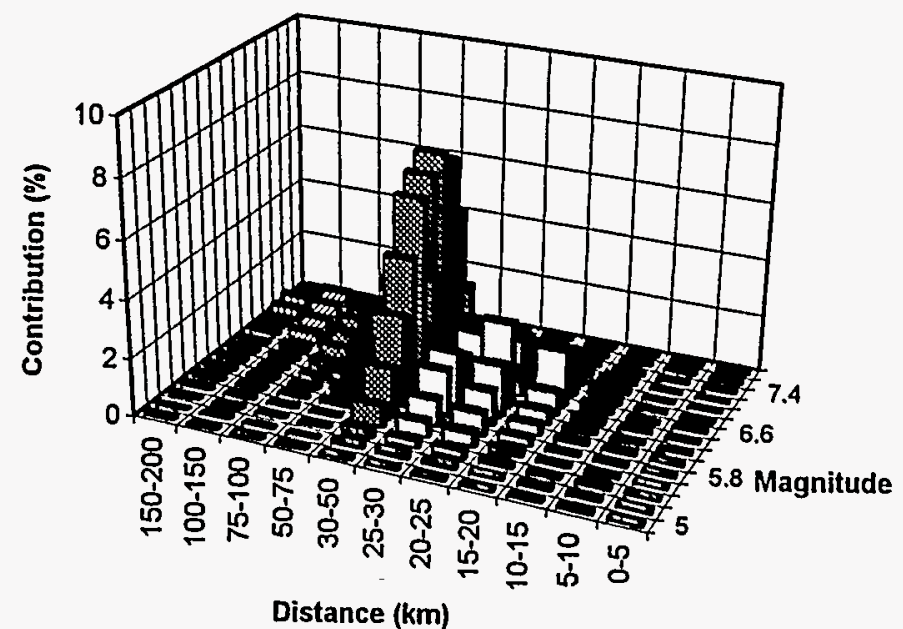

RETURN PERIOD $=10,000$ YEARS

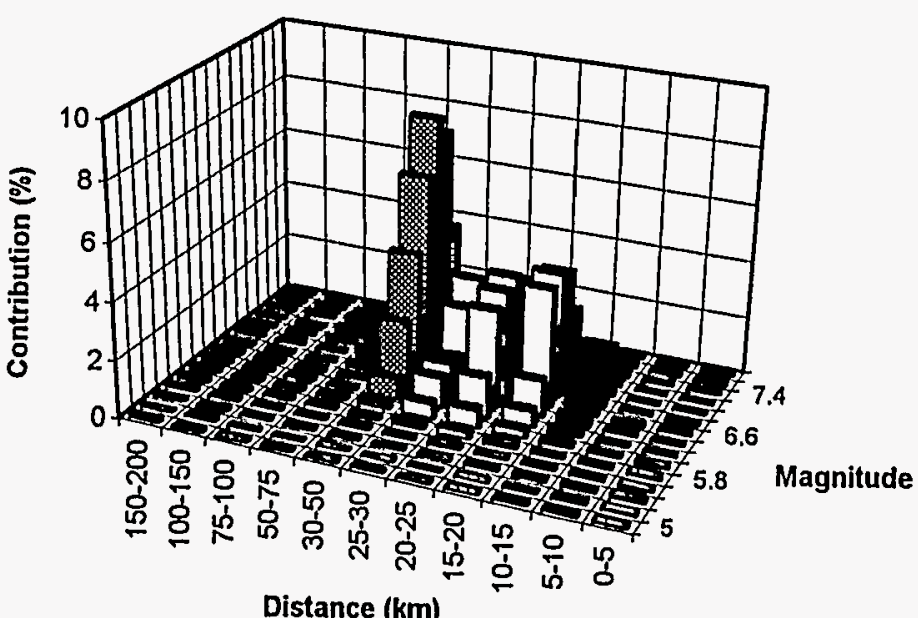

Distance (km)

1.0 SEC SPECTRAL ACCELERATION

\begin{tabular}{|c|c|c|c|}
\hline $\begin{array}{l}\text { Project No. } \\
\text { SK9455 }\end{array}$ & INEL - Probabilistic Analyses & \multirow{2}{*}{$\begin{array}{c}\text { MAGNITUDE AND DISTANCE } \\
\text { CONTRIBUTIONS TO THE } \\
\text { MEAN SEISMIC HAZARD AT RWMC }\end{array}$} & \multirow{2}{*}{$\begin{array}{c}\text { Figure } \\
6-6 f \\
\text { (concluded) }\end{array}$} \\
\hline \multicolumn{2}{|c|}{ Woodward-Clyde Federal Senvices } & & \\
\hline
\end{tabular}


RETURN PERIOD $=500$ YEARS

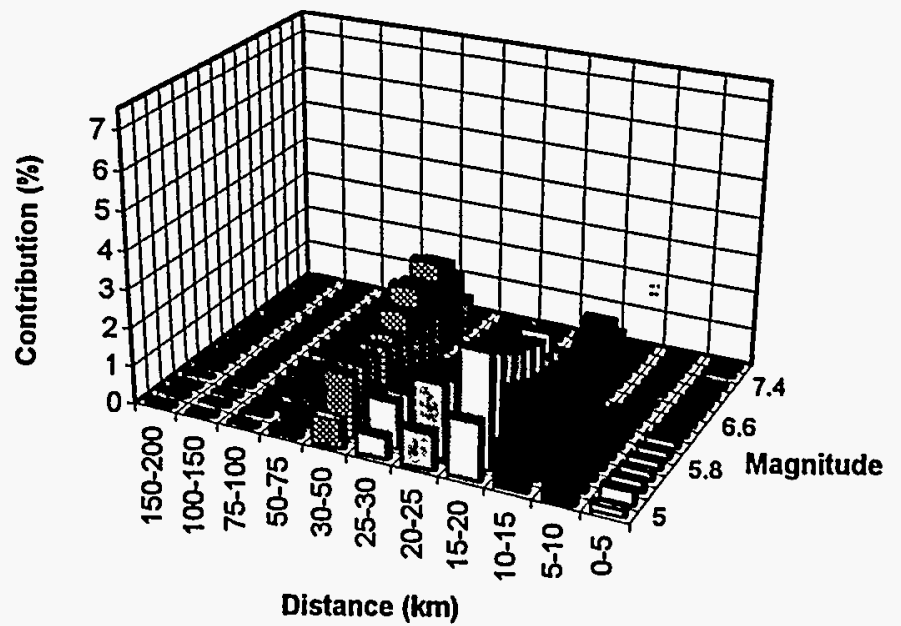

RETURN PERIOD $=2000$ YEARS

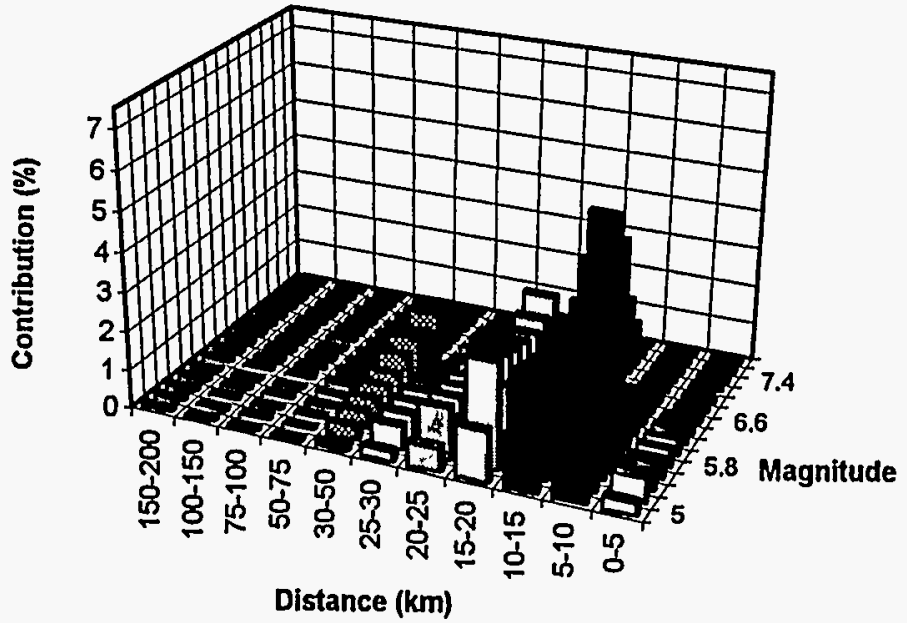

RETURN PERIOD $=1000$ YEARS

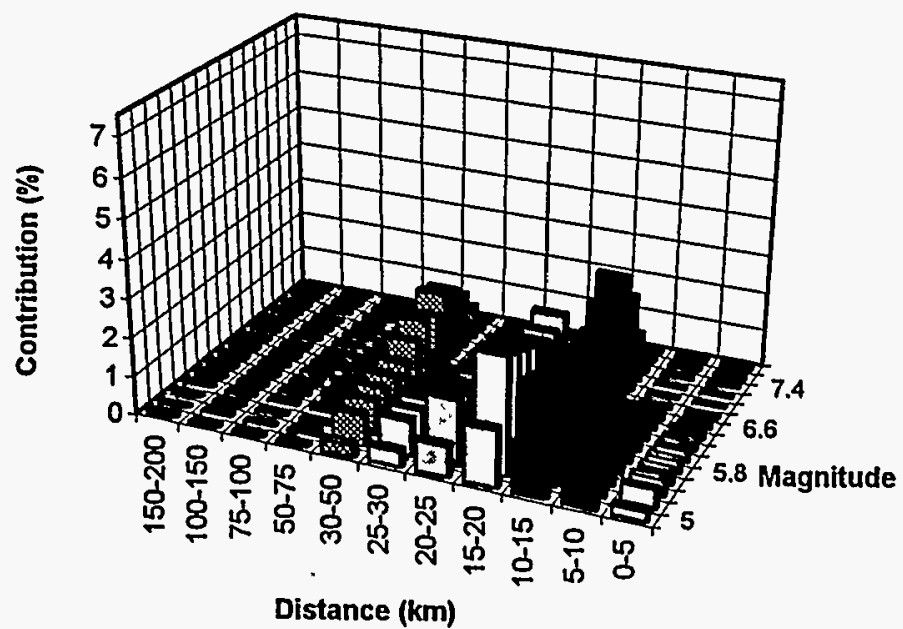

RETURN PERIOD $=\mathbf{1 0 , 0 0 0}$ YEARS

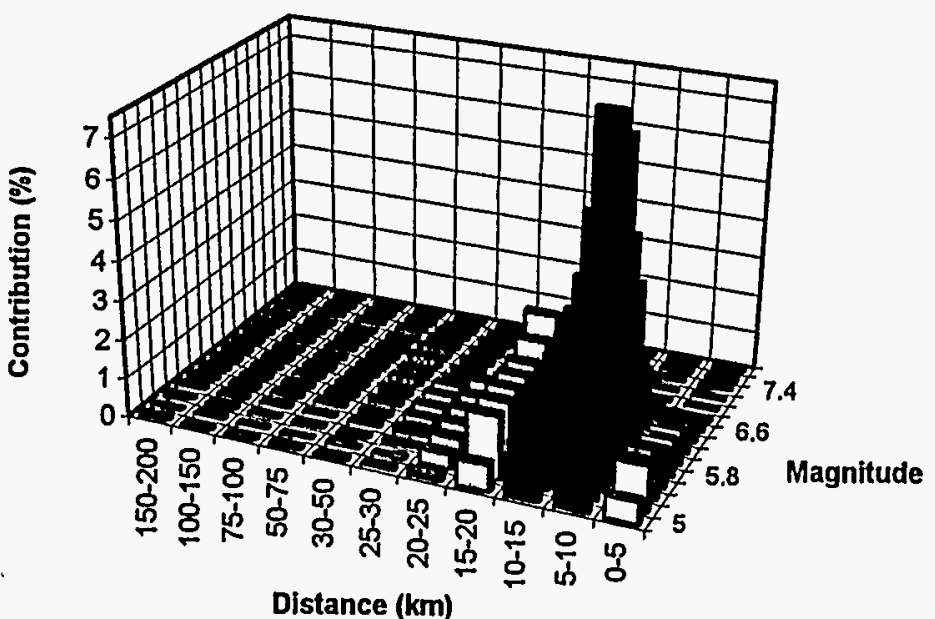

PEAK HORIZONTAL ACCELERATION

\begin{tabular}{|c|c|c|c|}
\hline $\begin{array}{c}\text { Project No. } \\
\text { SK9455 }\end{array}$ & INEL - Probabilistic Analyses & MAGNITUDE AND DISTANCE & CONTRIBUTIONS TO THE \\
\cline { 1 - 1 } Woodward-Clyde Federal Services & MEAN SEISMIC HAZARD AT TAN & $\begin{array}{c}\text { Figure } \\
6-6 \mathrm{~g}\end{array}$ \\
\hline
\end{tabular}




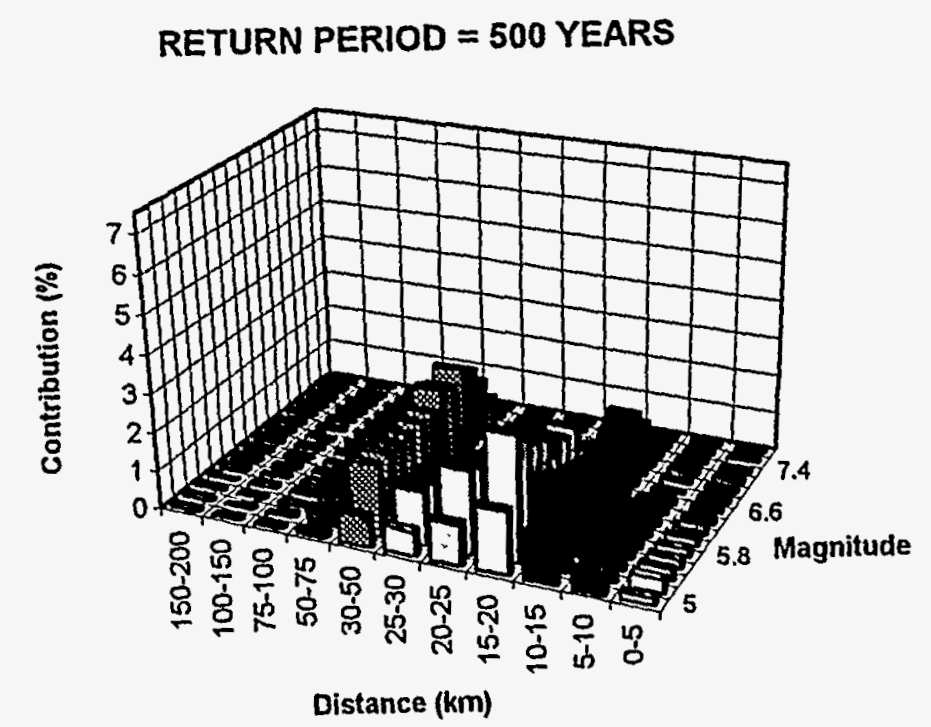

RETURN PERIOD $=2000$ YEARS

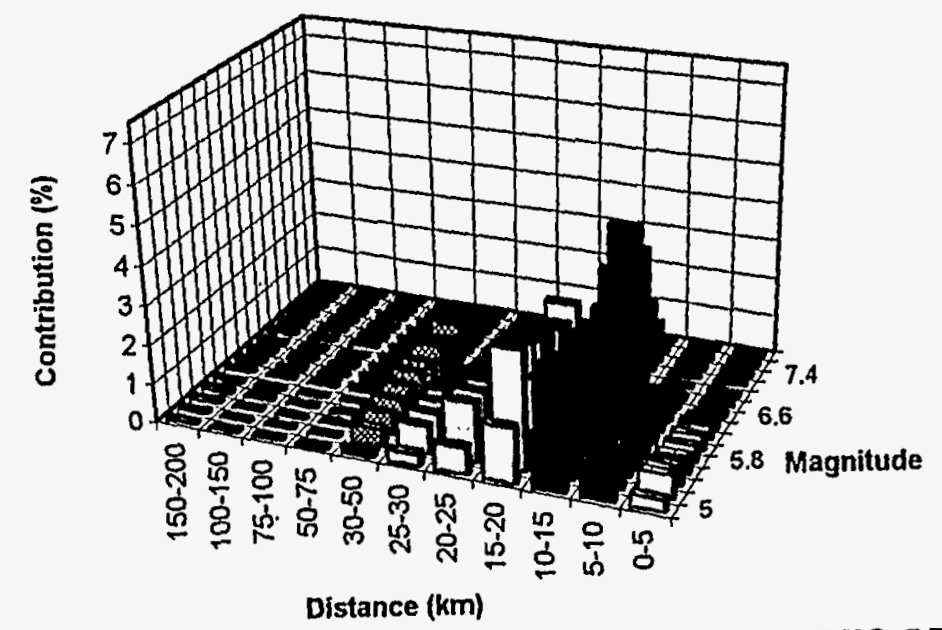

RETURN PERIOD $=1000$ YEARS

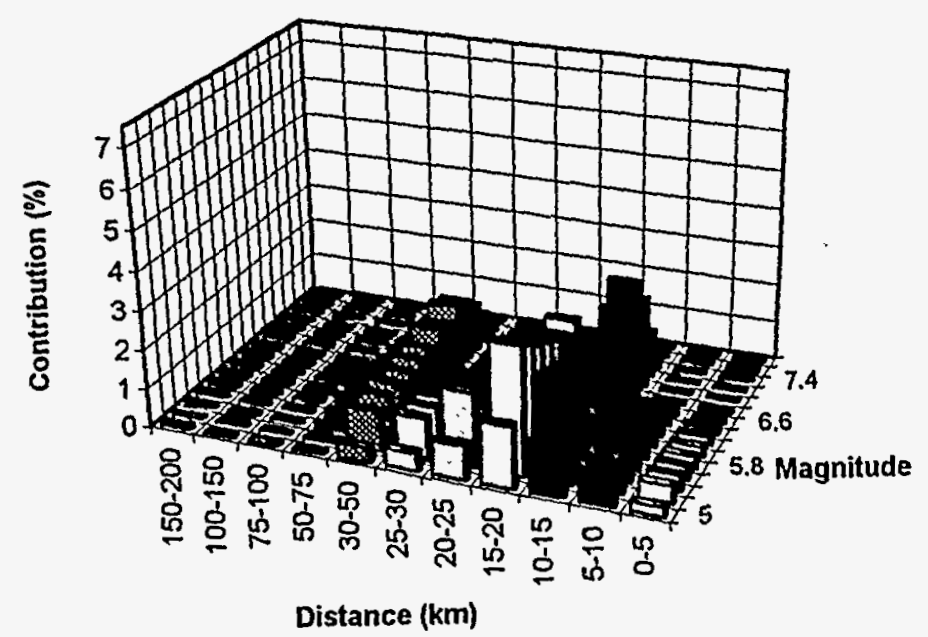

RETURN PERIOD $=10,000$ YEARS

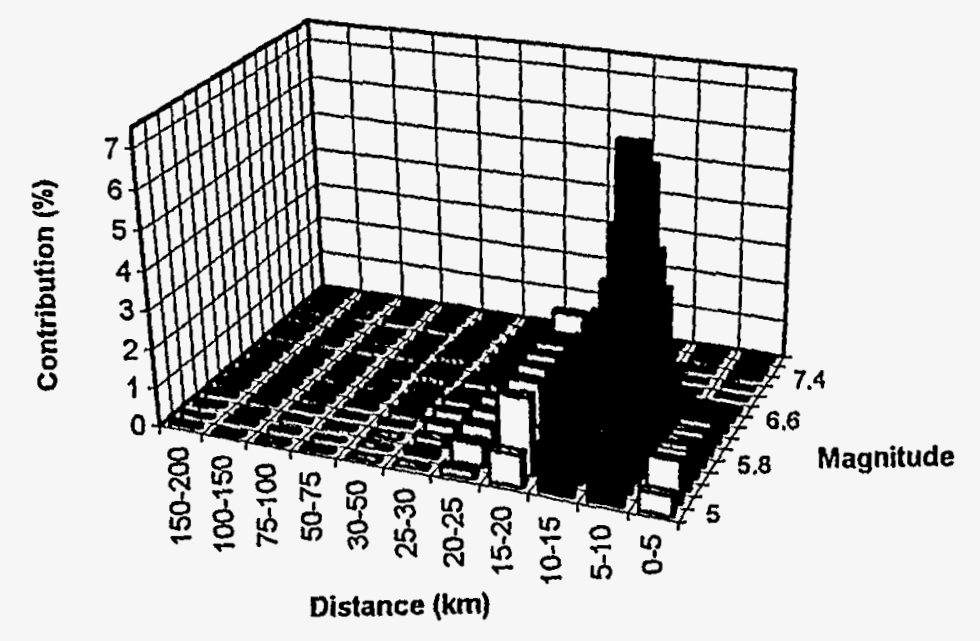

0.1 SEC SPECTRAL ACCELERATION

\begin{tabular}{|c|c|c|c|}
\hline $\begin{array}{c}\text { Project No. } \\
\text { SK9455 }\end{array}$ & INEL - Probabilistic Analyses & $\begin{array}{c}\text { MAGNITUDE AND DISTANCE } \\
\text { CONTRIBUTIONS TO THE } \\
\text { MEAN SEISMIC HAZARD AT TAN }\end{array}$ & $\begin{array}{c}\text { Figure } \\
6-6 g \\
\text { (continued) }\end{array}$ \\
\hline Woodward-Clyde Federal Services & MEANA \\
\hline
\end{tabular}

SK9455-A1000/012395/vone, gos 


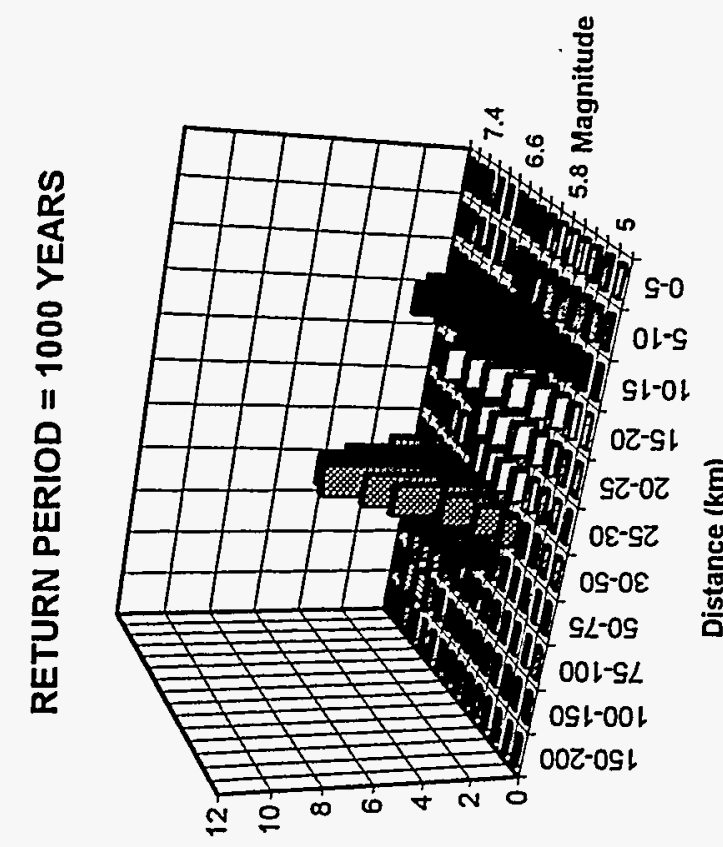

(\%) uo!!nq!’\}uos

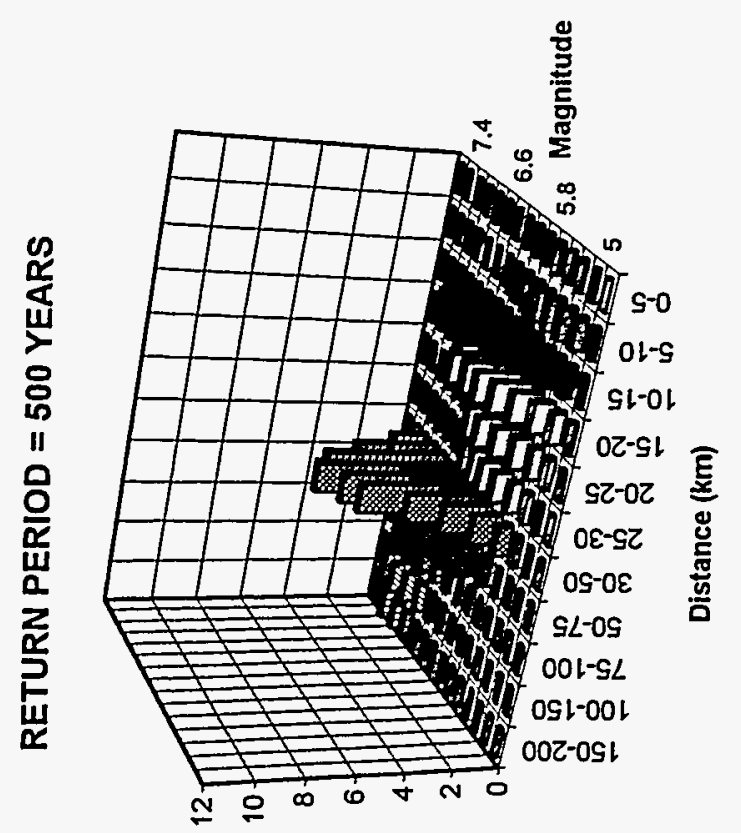

(\%) uo!̣nq!дuos

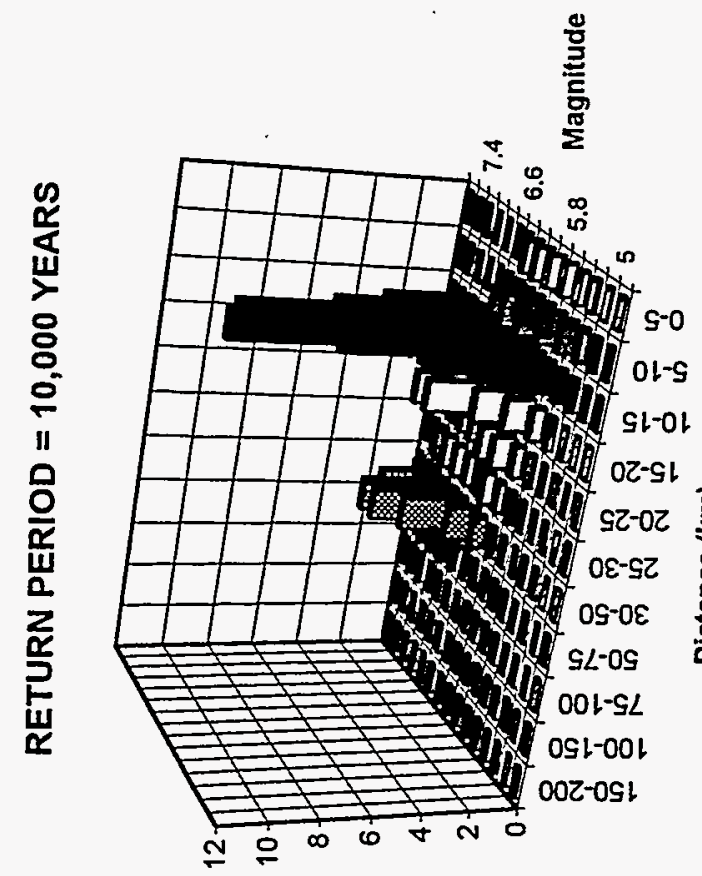

(\%) иo!̣nquมyoว

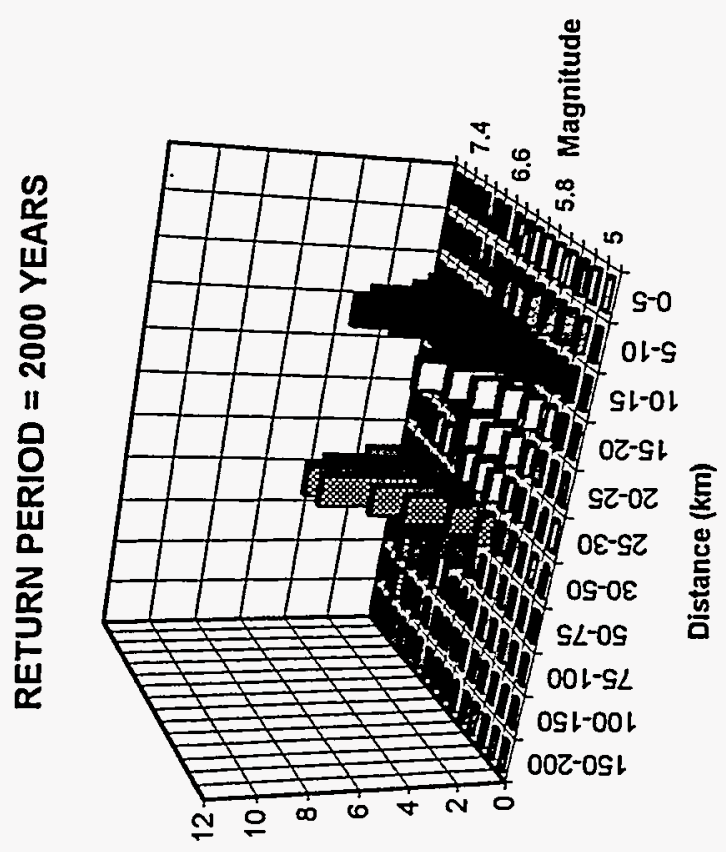

(\%) uo!!nq!!\}uoว 

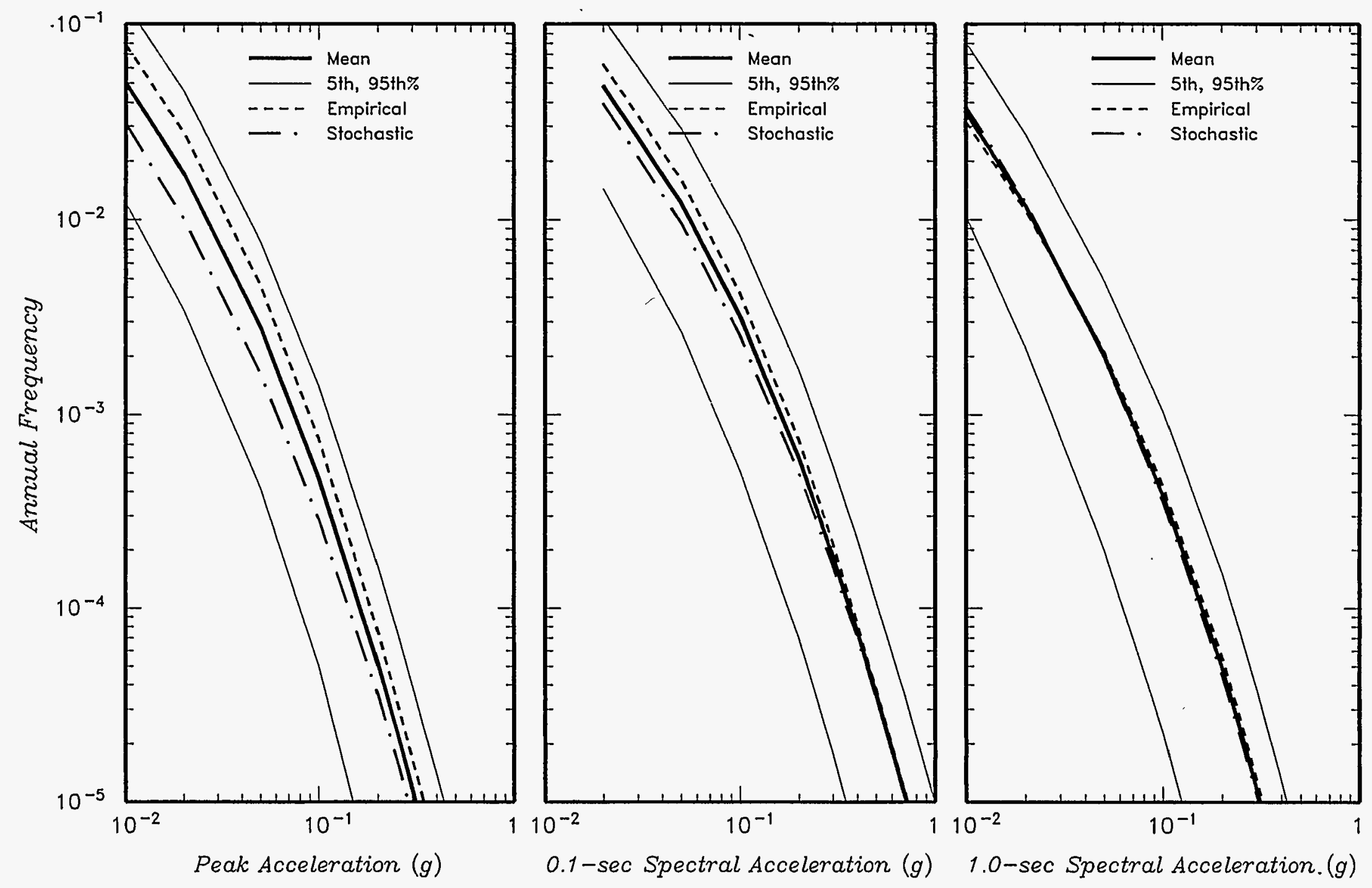

\begin{tabular}{|c|c|c|c|}
\hline $\begin{array}{l}\text { Project No. } \\
\text { SK9455 }\end{array}$ & INEL - Probabilistic Analyses & \multirow{2}{*}{$\begin{array}{l}\text { COMPARISON OF MEAN HAZARD COMPUTED } \\
\text { USING THE EMPIRICAL AND STOCHASTIC } \\
\text { ATTENUATION RELATIONSHIPS AT ANL }\end{array}$} & \multirow{2}{*}{$\begin{array}{c}\text { Figure } \\
6-7 a\end{array}$} \\
\hline Woodh & a & & \\
\hline
\end{tabular}




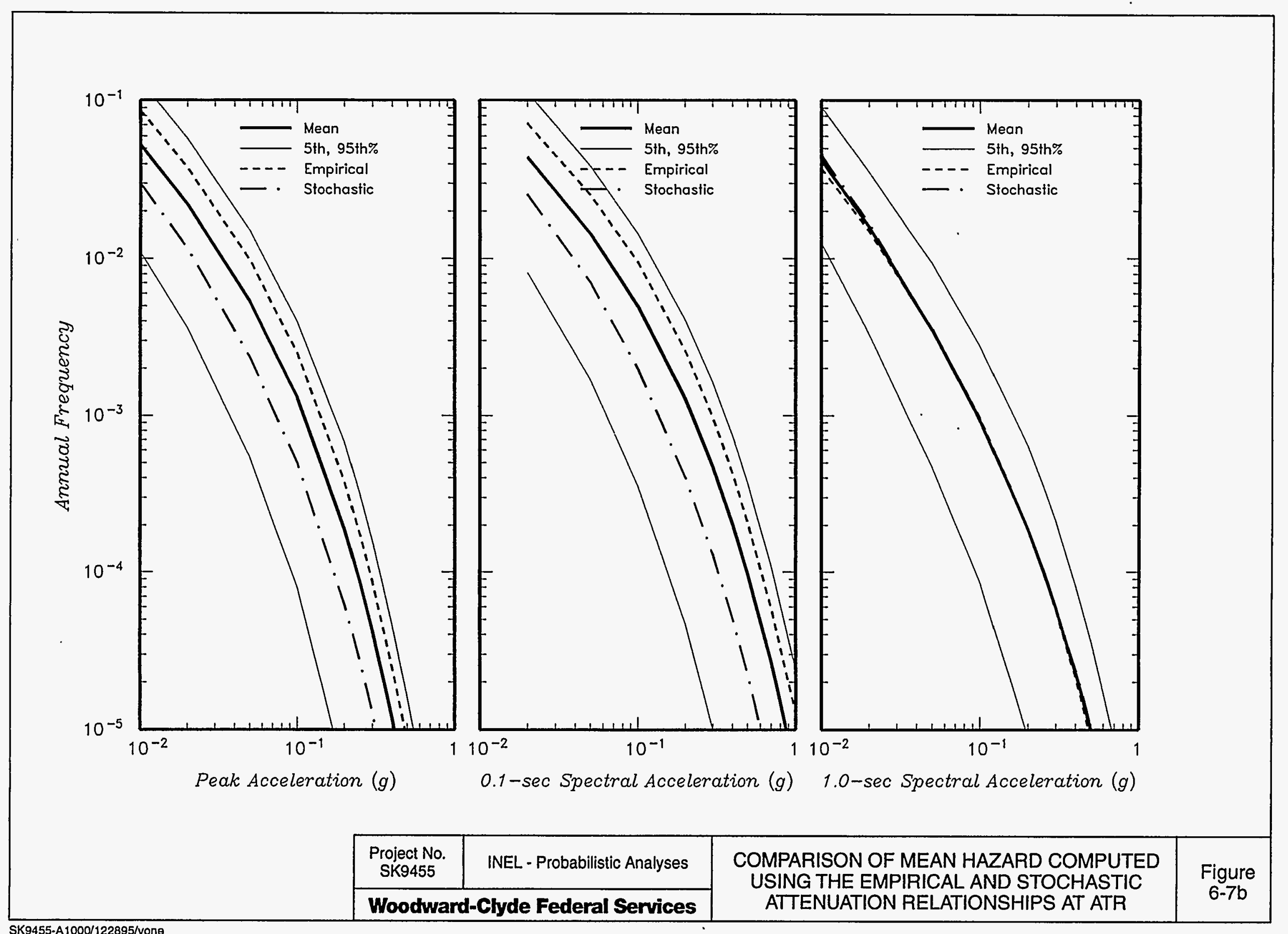



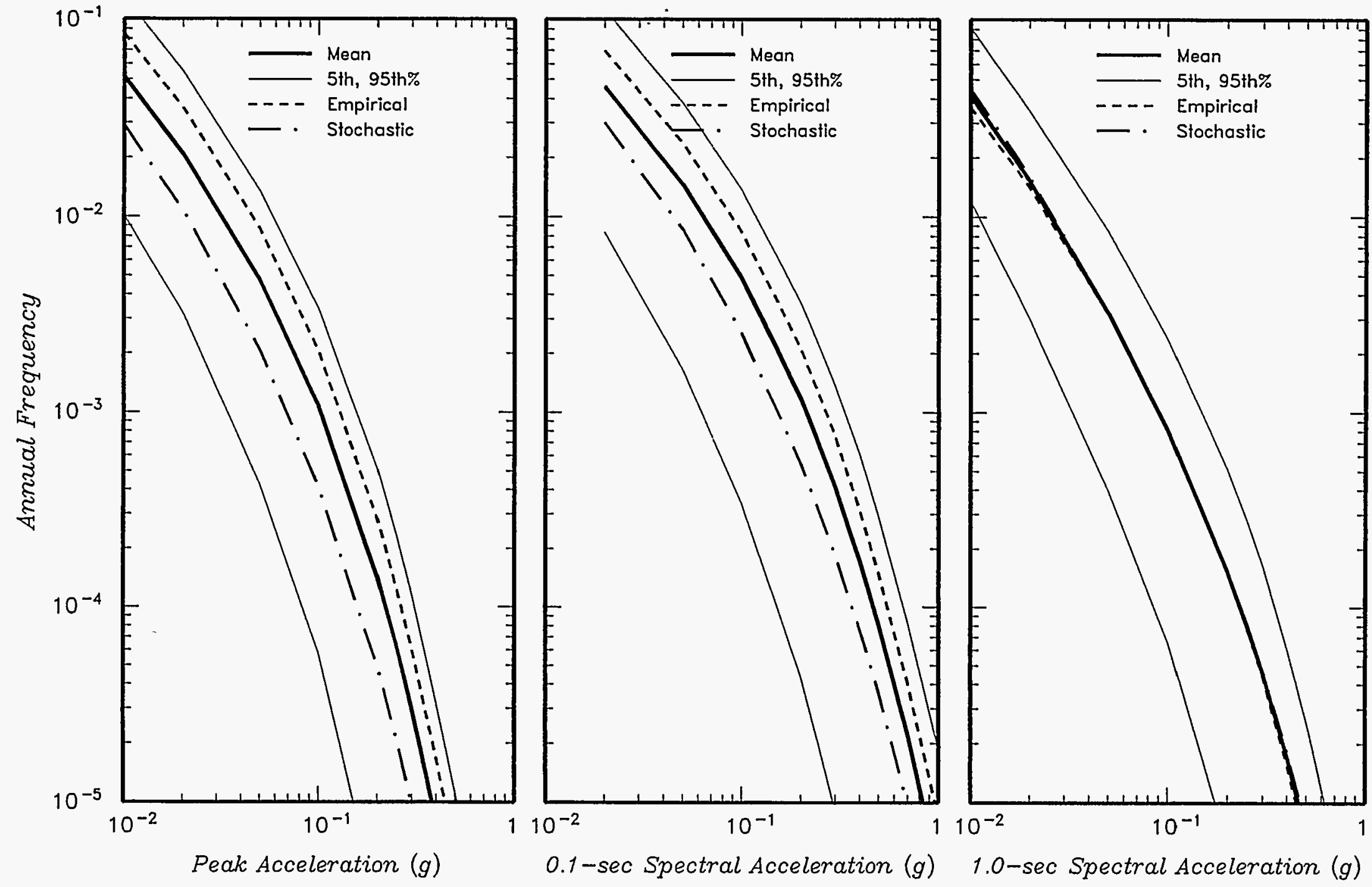

\begin{tabular}{|c|c|c|c|}
\hline $\begin{array}{l}\text { Project No. } \\
\text { SK9455 }\end{array}$ & INEL - Probabilistic Analyses & \multirow{2}{*}{$\begin{array}{l}\text { COMPARISON OF MEAN HAZARD COMPUTED } \\
\text { USING THE EMPIRICAL AND STOCHASTIC } \\
\text { ATTENUATION RELATIONSHIPS AT CPP }\end{array}$} & \multirow{2}{*}{$\begin{array}{c}\text { Figure } \\
6-7 c\end{array}$} \\
\hline \multicolumn{2}{|c|}{ Woodward-Clyde Federal Senvices } & & \\
\hline
\end{tabular}




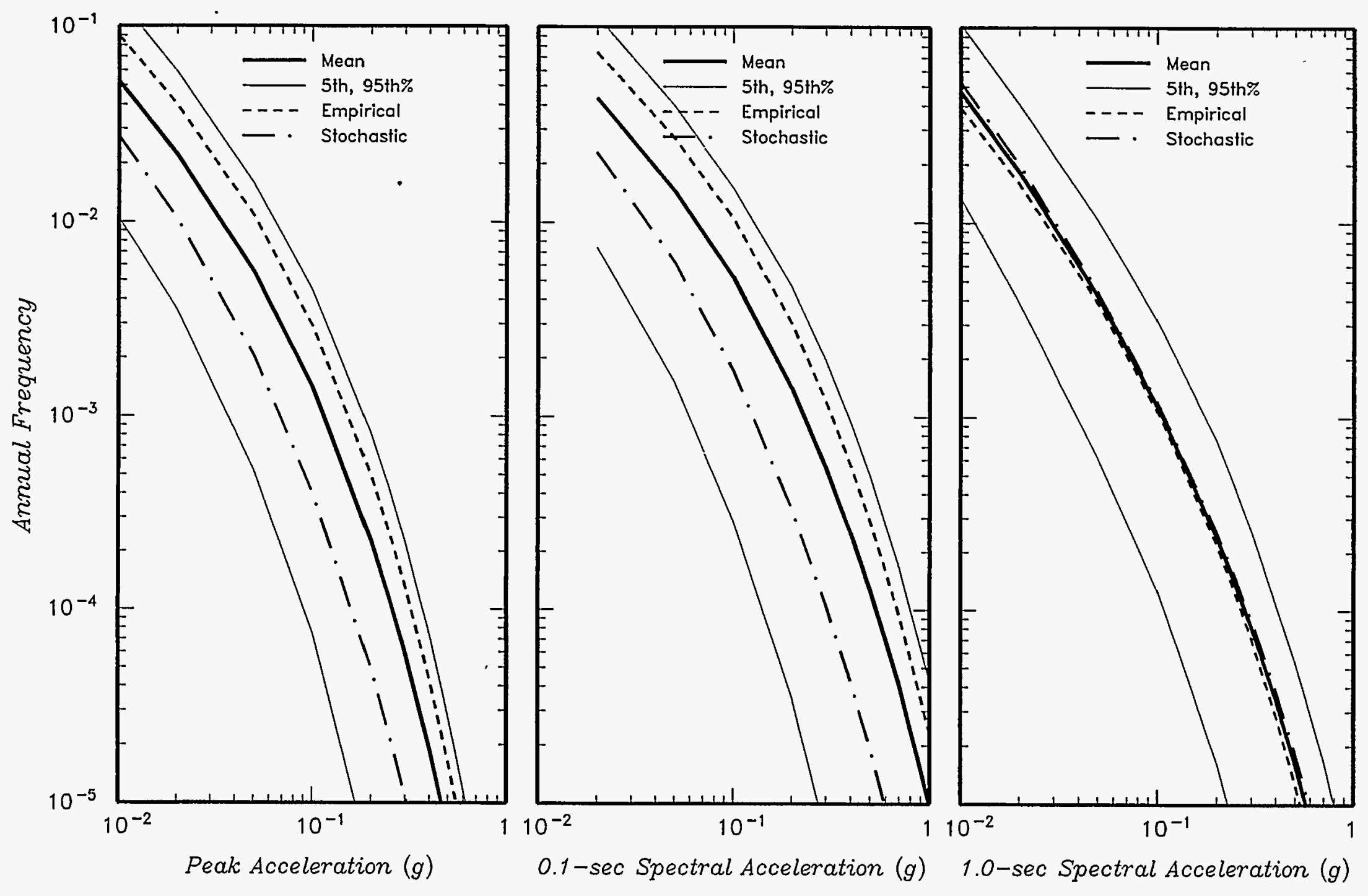

\begin{tabular}{|c|c|c|c|c|}
\hline $\begin{array}{c}\text { Project No. } \\
\text { SK9455 }\end{array}$ & INEL - Probabilistic Analyses & $\begin{array}{c}\text { COMPARISON OF MEAN HAZARD COMPUTED } \\
\text { USING THE EMPIRICAL AND STOCHASTIC } \\
\text { ATTENUATION RELATIONSHIPS AT NRF }\end{array}$ & $\begin{array}{c}\text { Figure } \\
6-7 d\end{array}$ \\
\hline Woodward-Clyde Federal Services & ATEN R \\
\hline
\end{tabular}



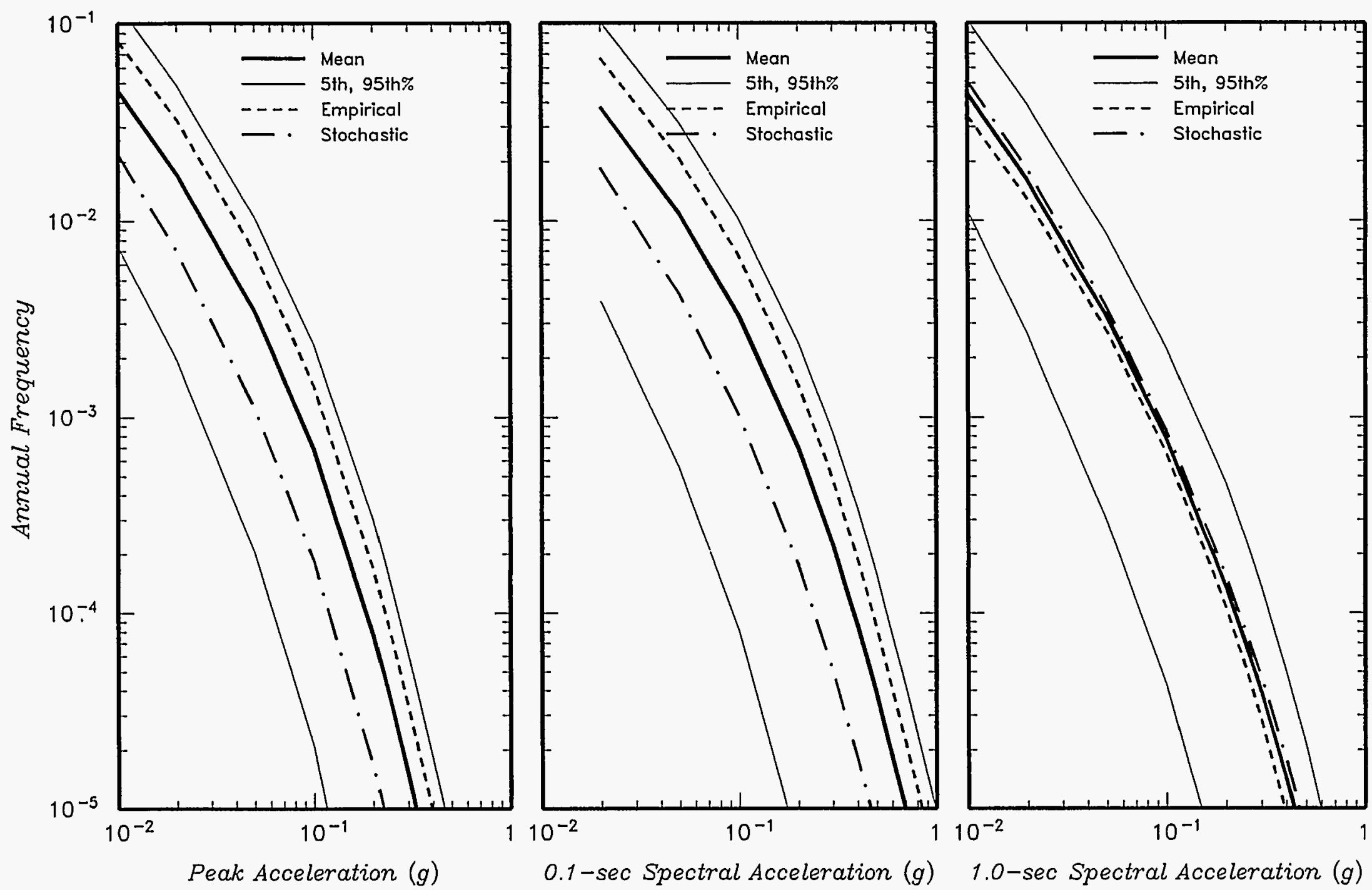

\begin{tabular}{c|c}
$\begin{array}{l}\text { Project No. } \\
\text { SK9455 }\end{array}$ & INEL - Probabilistic Analyses \\
\hline
\end{tabular}

COMPARISON OF MEAN HAZARD COMPUTED USING THE EMPIRICAL AND STOCHASTIC ATTENUATION RELATIONSHIPS AT PBF 

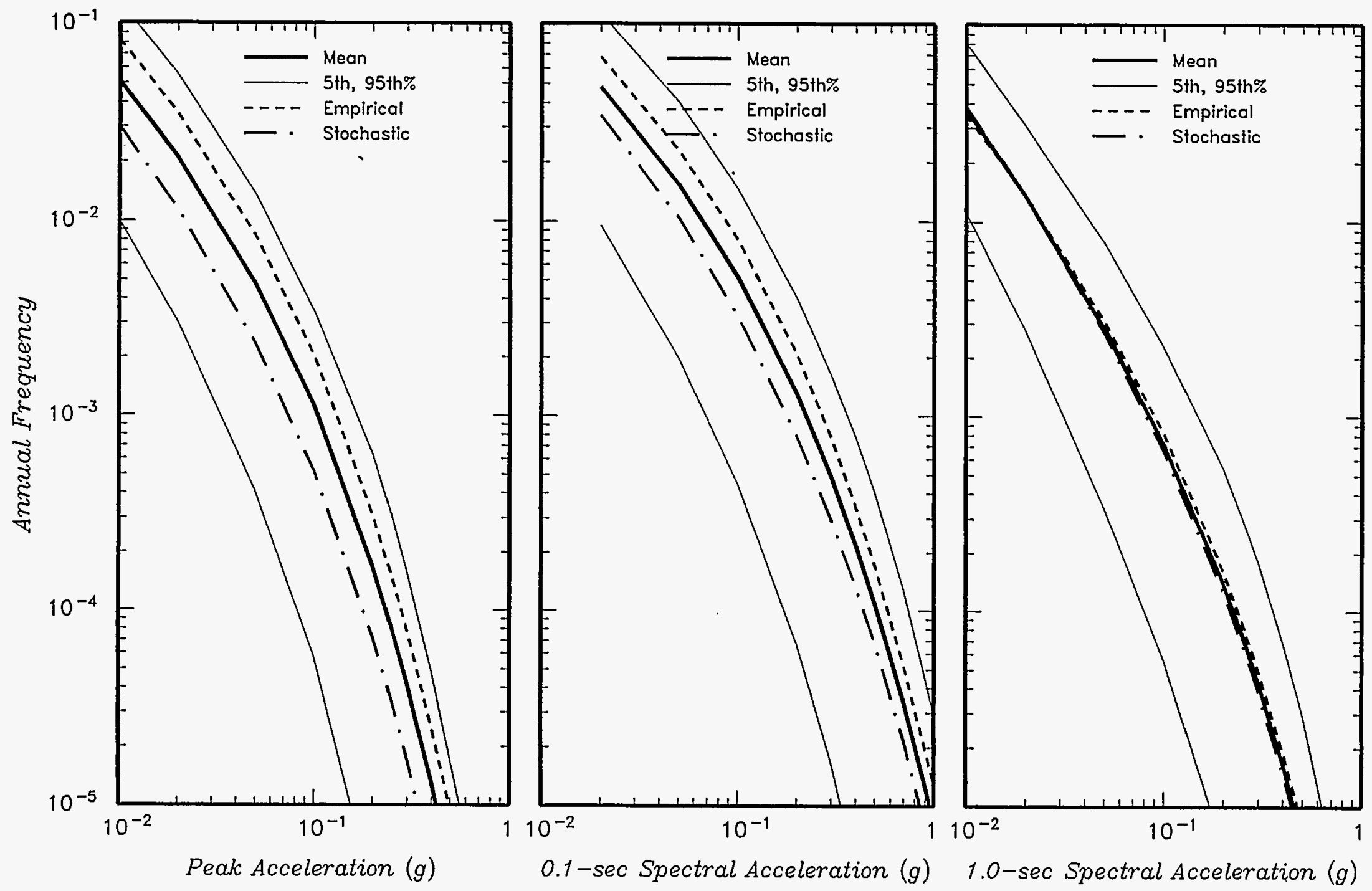

\begin{tabular}{c|c|c|}
$\begin{array}{c}\text { Project No. } \\
\text { SK9455 }\end{array}$ & INEL - Probabilistic Analyses & $\begin{array}{c}\text { COMPARISON OF MEAN HAZARD COMPUTED } \\
\text { USING THE EMPIRICAL AND STOCHASTIC }\end{array}$ \\
\cline { 1 - 1 } Woodward-Clyde Federal Services & ATTENUATION RELATIONSHIPS AT RWMC
\end{tabular}



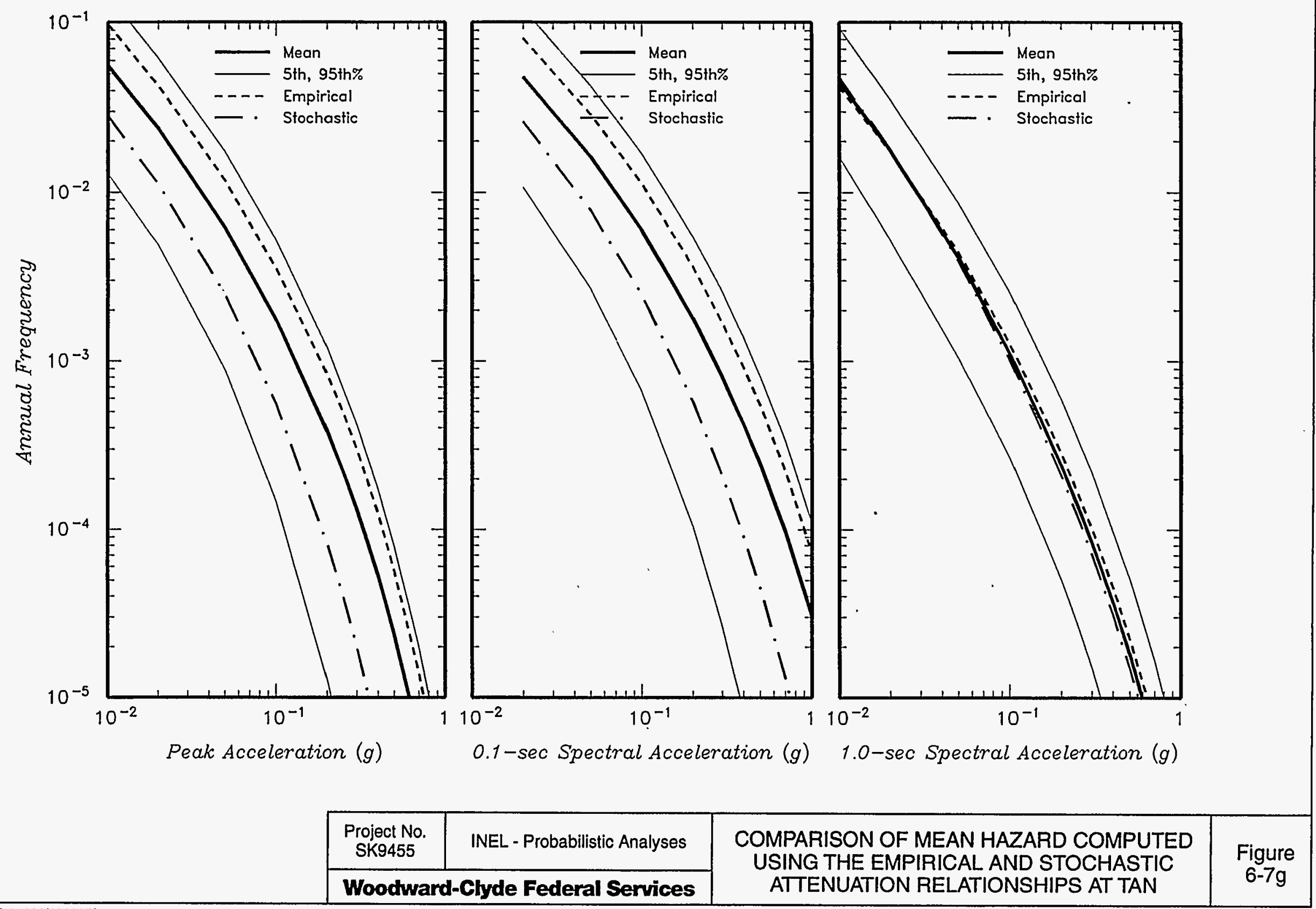

\begin{tabular}{|c|c|c|}
\hline $\begin{array}{l}\text { Project No. } \\
\text { SK9455 }\end{array}$ & INEL - Probabilistic Analyses & \\
\hline \multicolumn{2}{|c|}{ Woodward-Clyde Federal Services } & \\
\hline
\end{tabular}



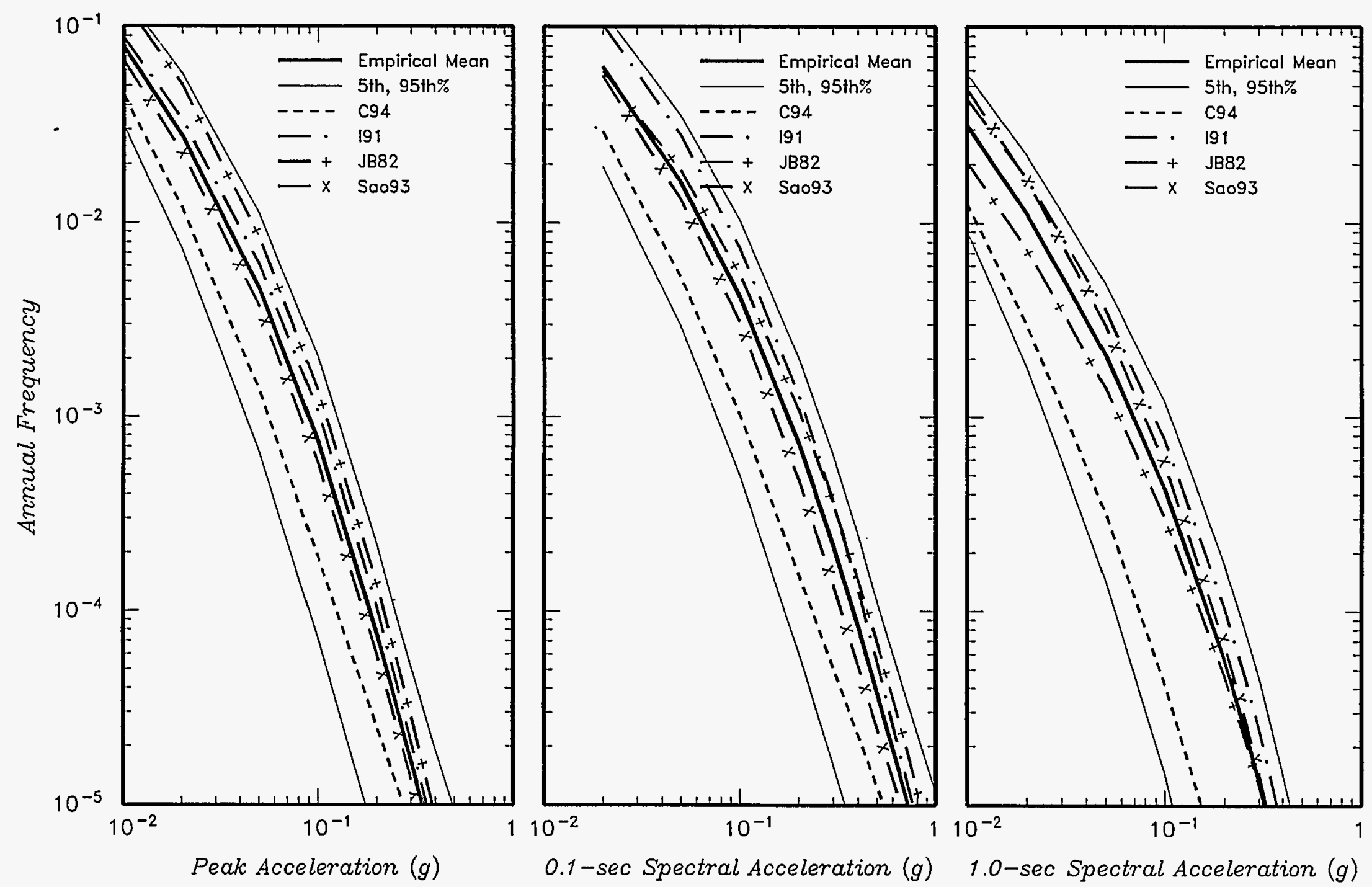

\begin{tabular}{|c|c|c|}
\hline $\begin{array}{l}\text { Project No. } \\
\text { SK9455 }\end{array}$ & INEL - Probabilistic Analyses & $\begin{array}{l}\text { COMPARISON OF HAZARD } \\
\text { USING THE INDIVIDUAL E }\end{array}$ \\
\hline I00 & & \\
\hline
\end{tabular}



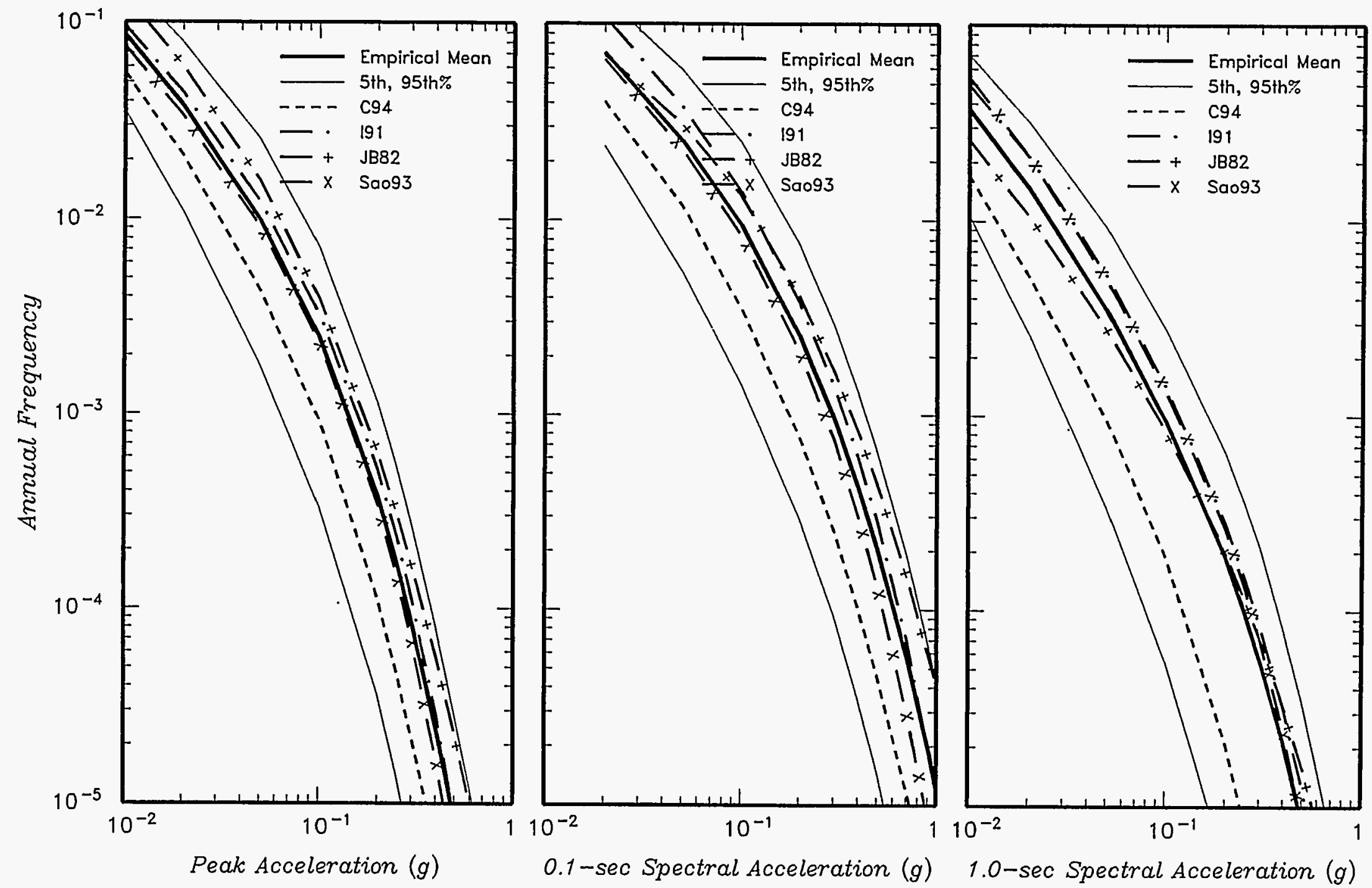

\begin{tabular}{|c|c|c|c|}
\hline $\begin{array}{l}\text { Project No. } \\
\text { SK9455 }\end{array}$ & INEL - Probabilistic Analyses & \multirow{2}{*}{$\begin{array}{l}\text { COMPARISON OF HAZARD COMPUTED } \\
\text { USING THE INDIVIDUAL EMPIRICAL } \\
\text { ATTENUATION RELATIONSHIPS AT ATR }\end{array}$} & \multirow{2}{*}{$\begin{array}{c}\text { Figure } \\
6-8 b\end{array}$} \\
\hline \multicolumn{2}{|c|}{ Woodward-Clyde Federal Services } & & \\
\hline
\end{tabular}



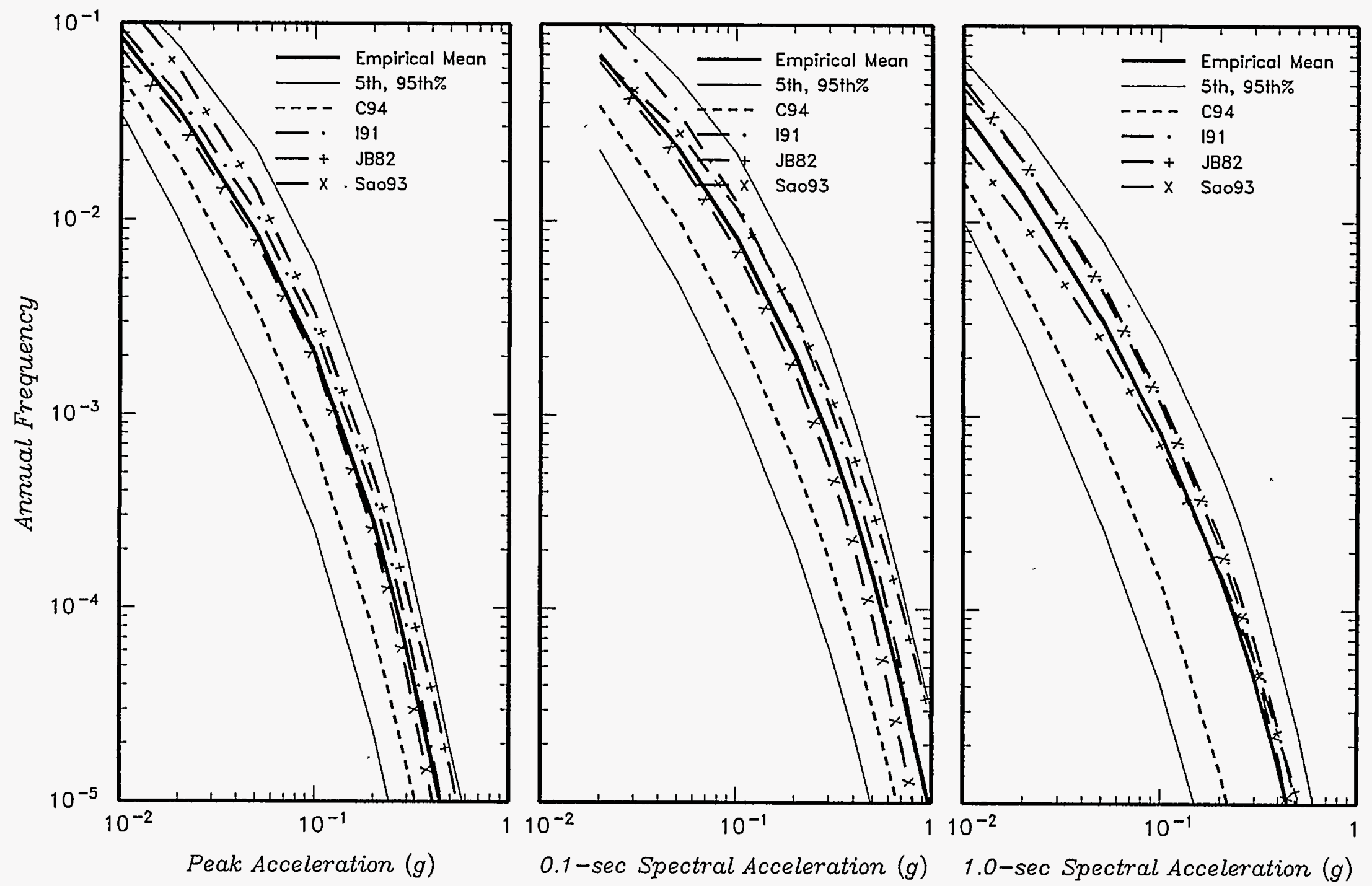

\begin{tabular}{|c|c|c|}
\hline $\begin{array}{c}\text { Project No. } \\
\text { SK9455 }\end{array}$ & INEL - Probabilistic Analyses & $\begin{array}{l}\text { COMPARISON OF HAZ } \\
\text { USING THE INDIVIDU }\end{array}$ \\
\hline Woodwe & de & \\
\hline
\end{tabular}



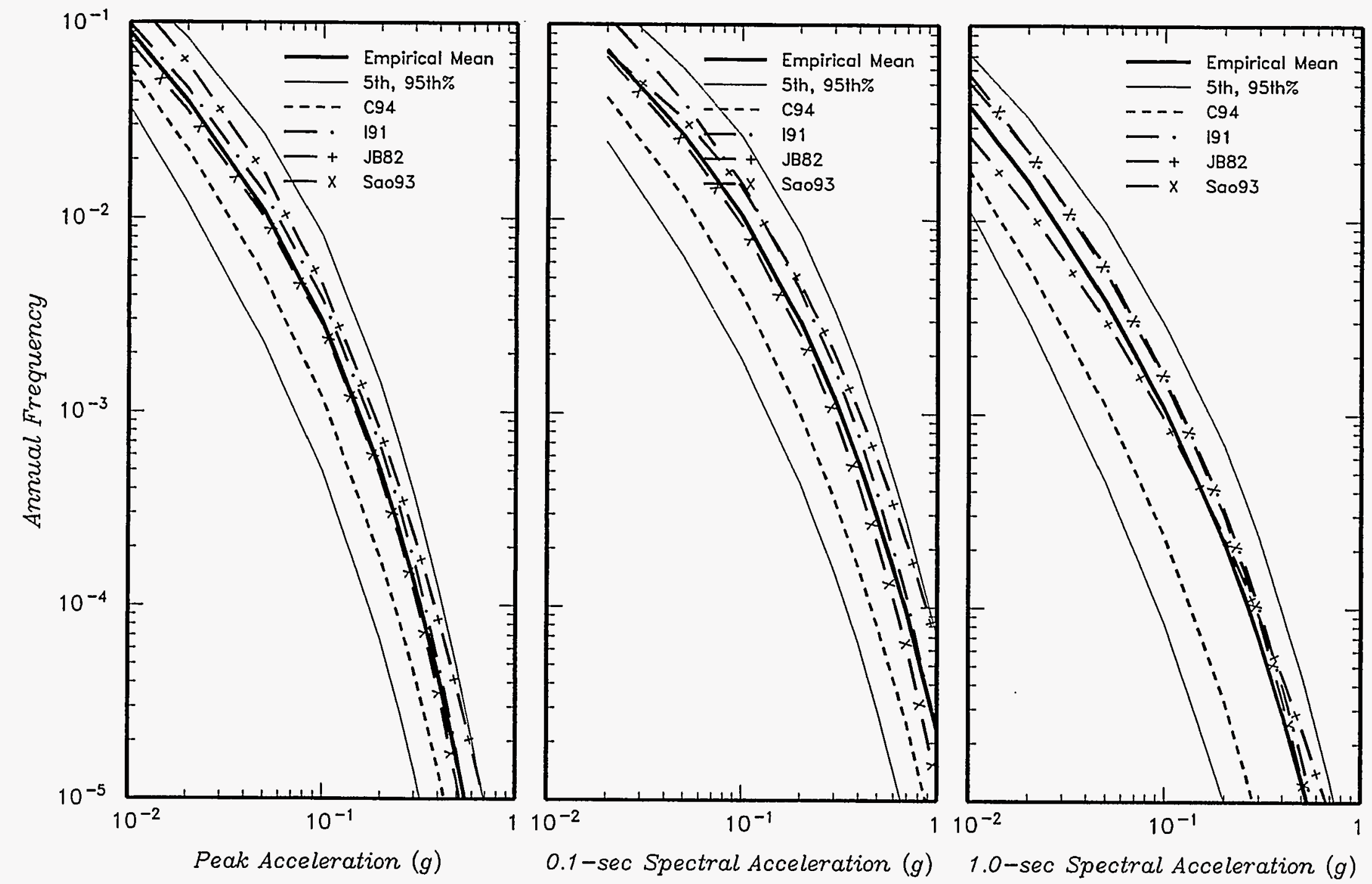

\begin{tabular}{|c|c|c|}
\hline $\begin{array}{c}\text { Project No. } \\
\text { SK9455 }\end{array}$ & INEL - Probabilistic Analyses & $\begin{array}{c}\text { COMPARISON OF HAZARD COMPUTED } \\
\text { USING THE INDIVIDUAL EMPIRICAL }\end{array}$ \\
\cline { 1 - 1 } Woodward-Clyde Federal Services & ATTENUATION RELATIONSHIPS AT NRF
\end{tabular}



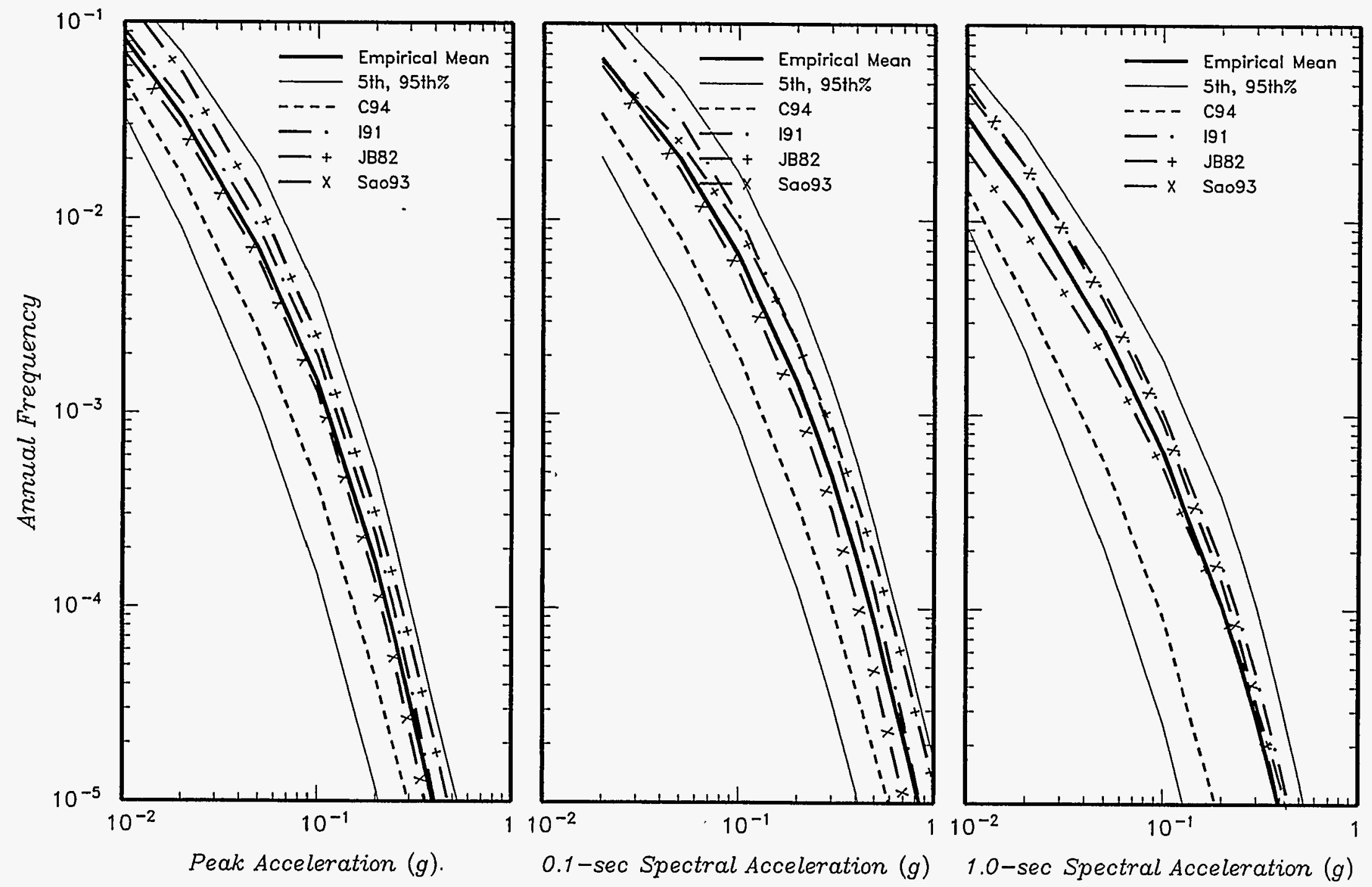

\begin{tabular}{|c|c|c|c|}
\hline $\begin{array}{c}\text { Project No. } \\
\text { SK9455 }\end{array}$ & INEL - Probabilistic Analyses & \multirow{2}{*}{$\begin{array}{l}\text { COMPARISON OF HAZARD COMPUTED } \\
\text { USING THE INDIVIDUAL EMPIRICAL } \\
\text { ATTENUATION RELATIONSHIPS AT PBF }\end{array}$} & \multirow{2}{*}{$\begin{array}{c}\text { Figure } \\
6-8 e\end{array}$} \\
\hline \multicolumn{2}{|c|}{ Woodward-Clyde Federal Services } & & \\
\hline
\end{tabular}



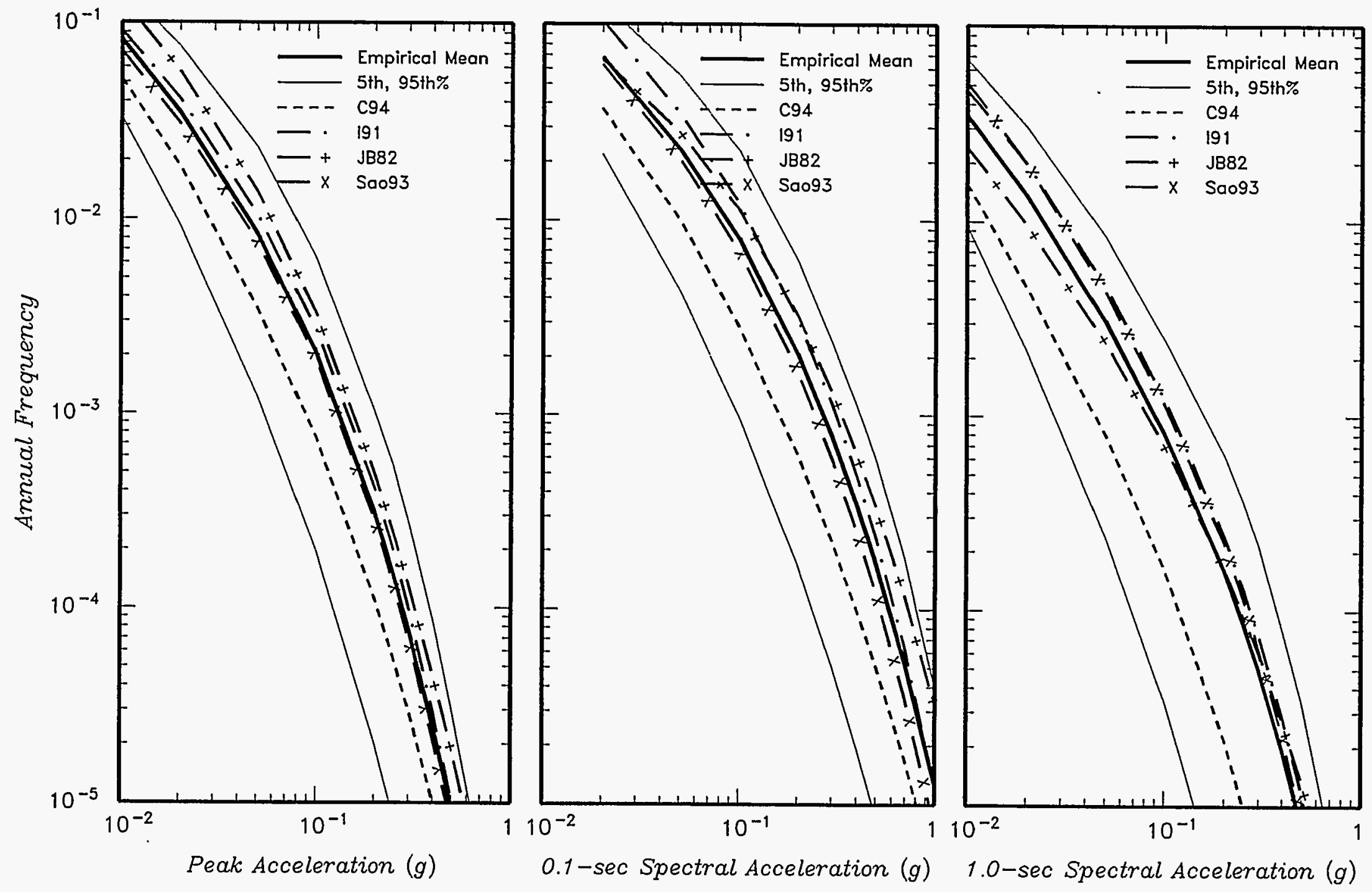

\begin{tabular}{|c|c|}
\hline $\begin{array}{c}\text { Project No. } \\
\text { SK9455 }\end{array}$ & INEL - Probabilistic Analyses \\
\hline Woodward-Clyde Federal Services \\
\hline
\end{tabular}

COMPARISON OF HAZARD COMPUTED USING THE INDIVIDUAL EMPIRICAL ATTENUATION RELATIONSHIPS AT RWMC 


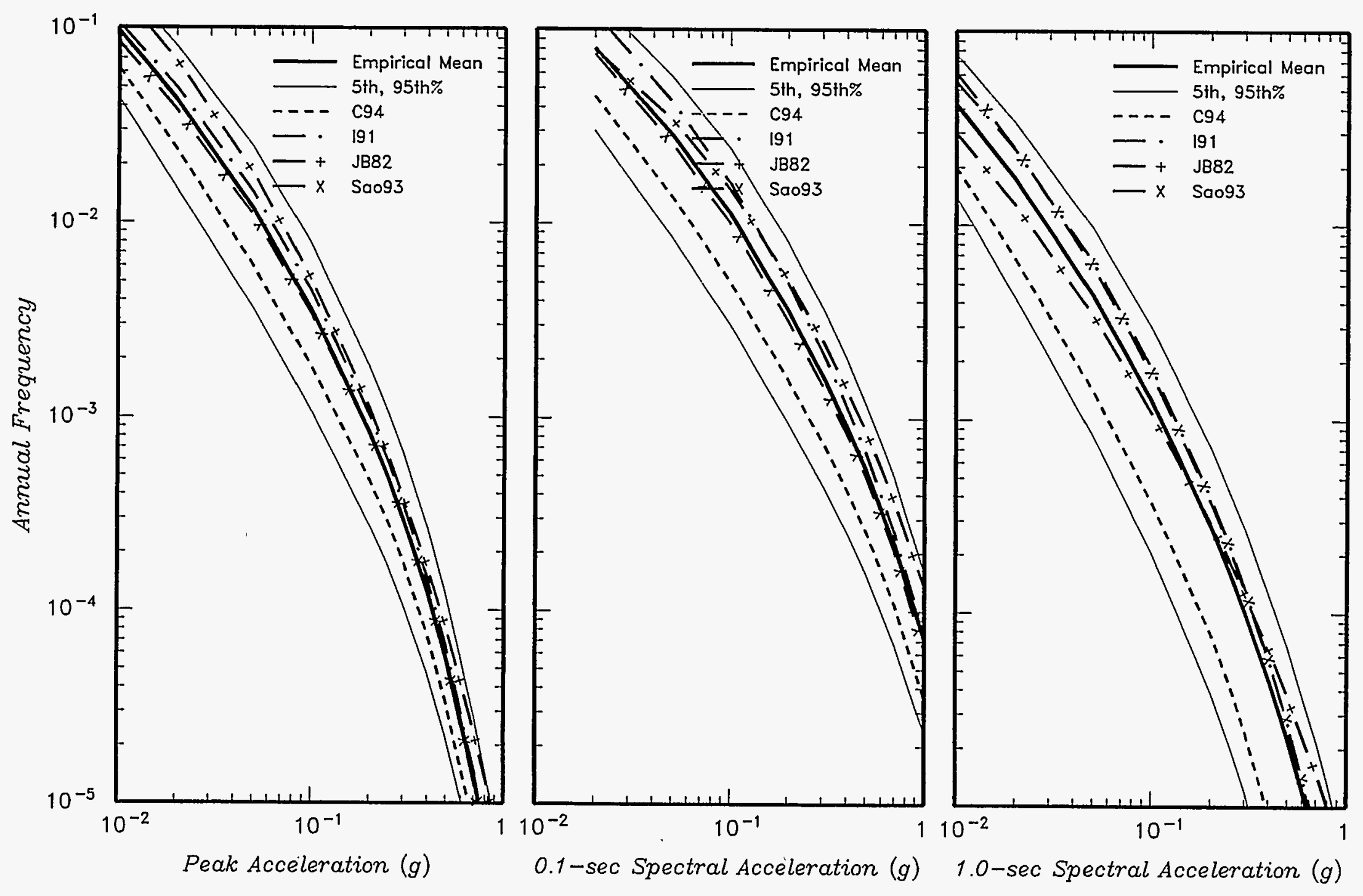



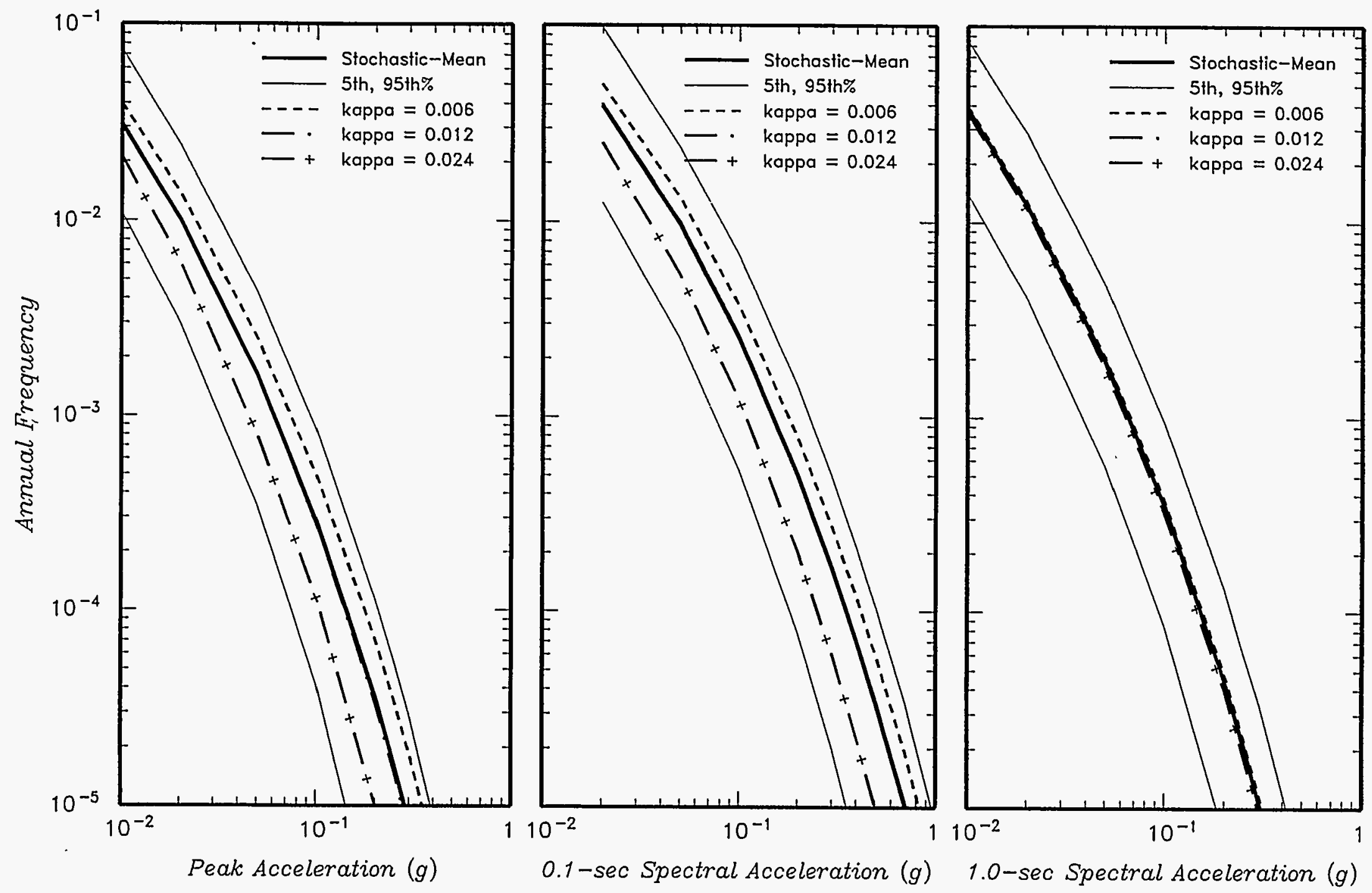

\begin{tabular}{|c|c|r|c|}
\hline $\begin{array}{c}\text { Project No. } \\
\text { SK9455 }\end{array}$ & INEL - Probabilistic Analyses & $\begin{array}{c}\text { EFFECT OF KON } \\
\text { STOCHASTIC-BASED MEAN } \\
\text { Woodward-Clyde Federal Services }\end{array}$ & $\begin{array}{c}\text { Figure } \\
6-9 a\end{array}$ \\
\hline \multicolumn{2}{|l|}{ WEISMIC HAZARD CURVE AT ANL }
\end{tabular}



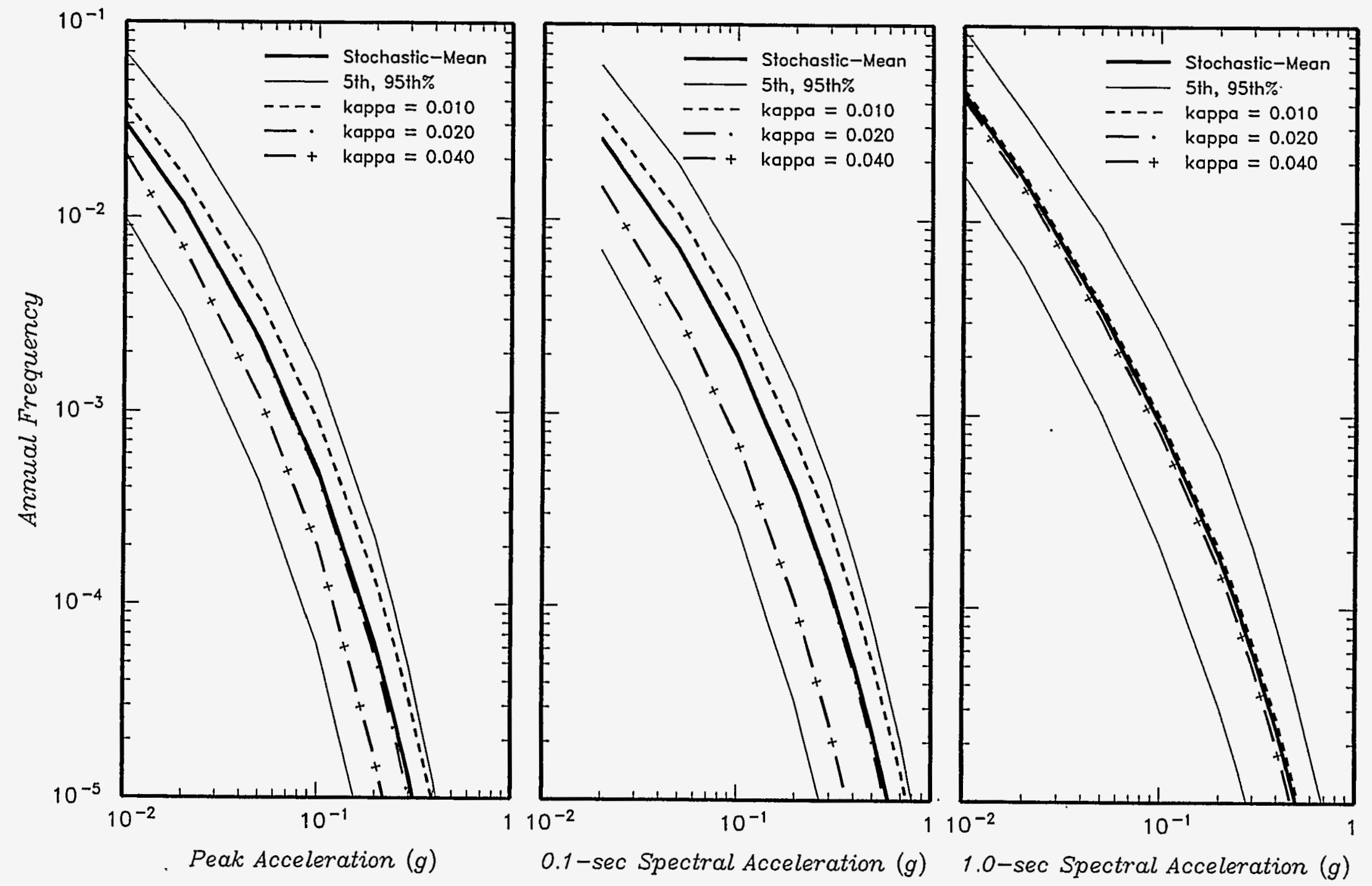

\begin{tabular}{|c|c|c|c|}
\hline $\begin{array}{c}\text { Project No. } \\
\text { SK9455 }\end{array}$ & INEL - Probabilistic Analyses & $\begin{array}{c}\text { EFFECT OF KON } \\
\text { STOCHASTIC-BASED MEAN }\end{array}$ & $\begin{array}{c}\text { Figure } \\
6-9 b\end{array}$ \\
\hline \multicolumn{2}{|c|}{ Woodward-Clyde Federal Services } & SEISMIC HAZARD CURVE AT ATR & \\
\hline
\end{tabular}



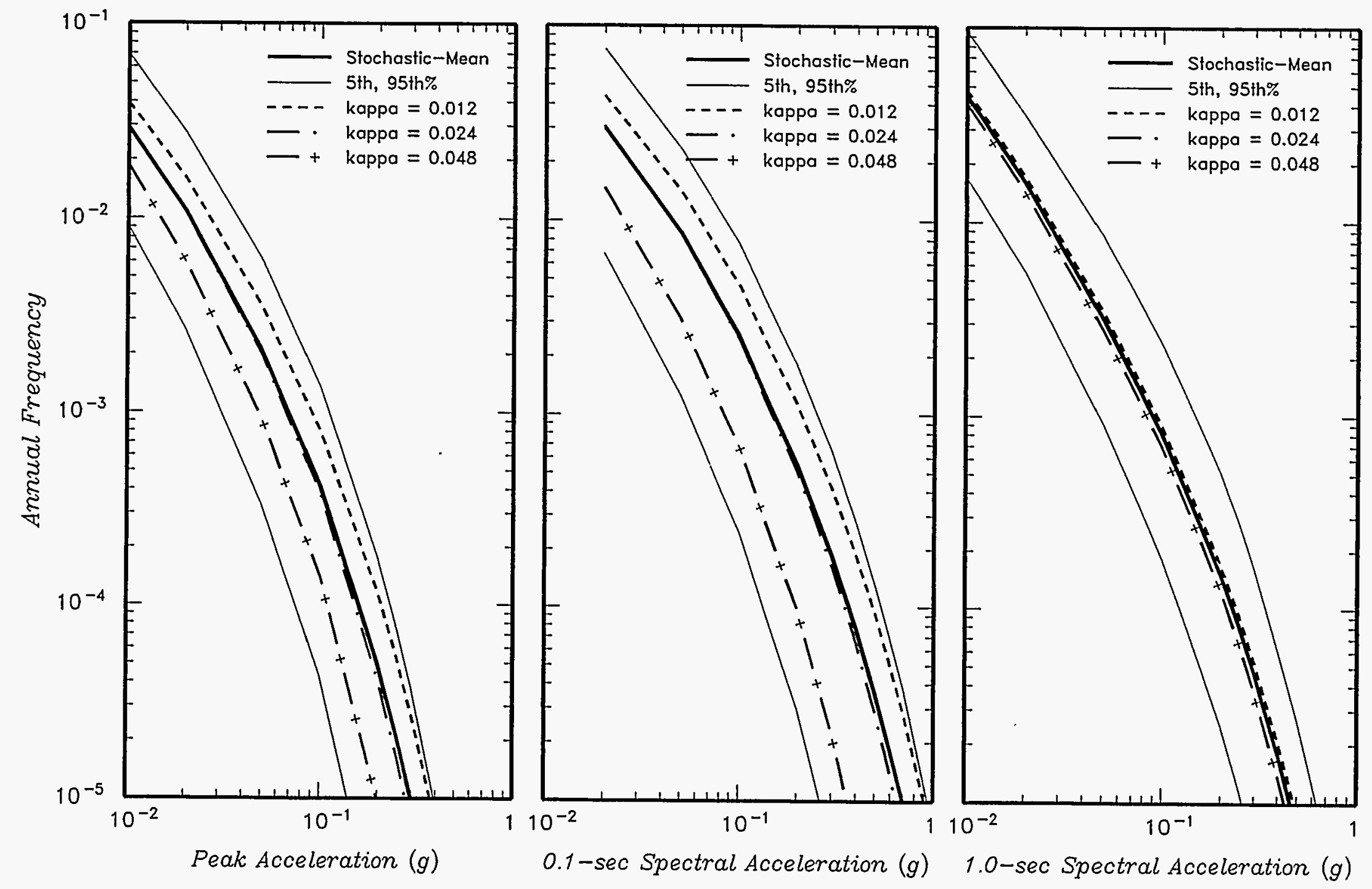

\begin{tabular}{|c|c|c|c|}
\hline $\begin{array}{c}\text { Project No. } \\
\text { SK9455 }\end{array}$ & INEL - Probabilistic Analyses & $\begin{array}{c}\text { EFFECT OF KON } \\
\text { STOCHASTIC-BASED MEAN }\end{array}$ & $\begin{array}{c}\text { Figure } \\
6-9 \mathrm{c}\end{array}$ \\
\hline \multicolumn{2}{|c|}{ Woodward-Clyde Federal Services } & SEISMIC HAZARD CURVE AT CPP & . \\
\hline
\end{tabular}



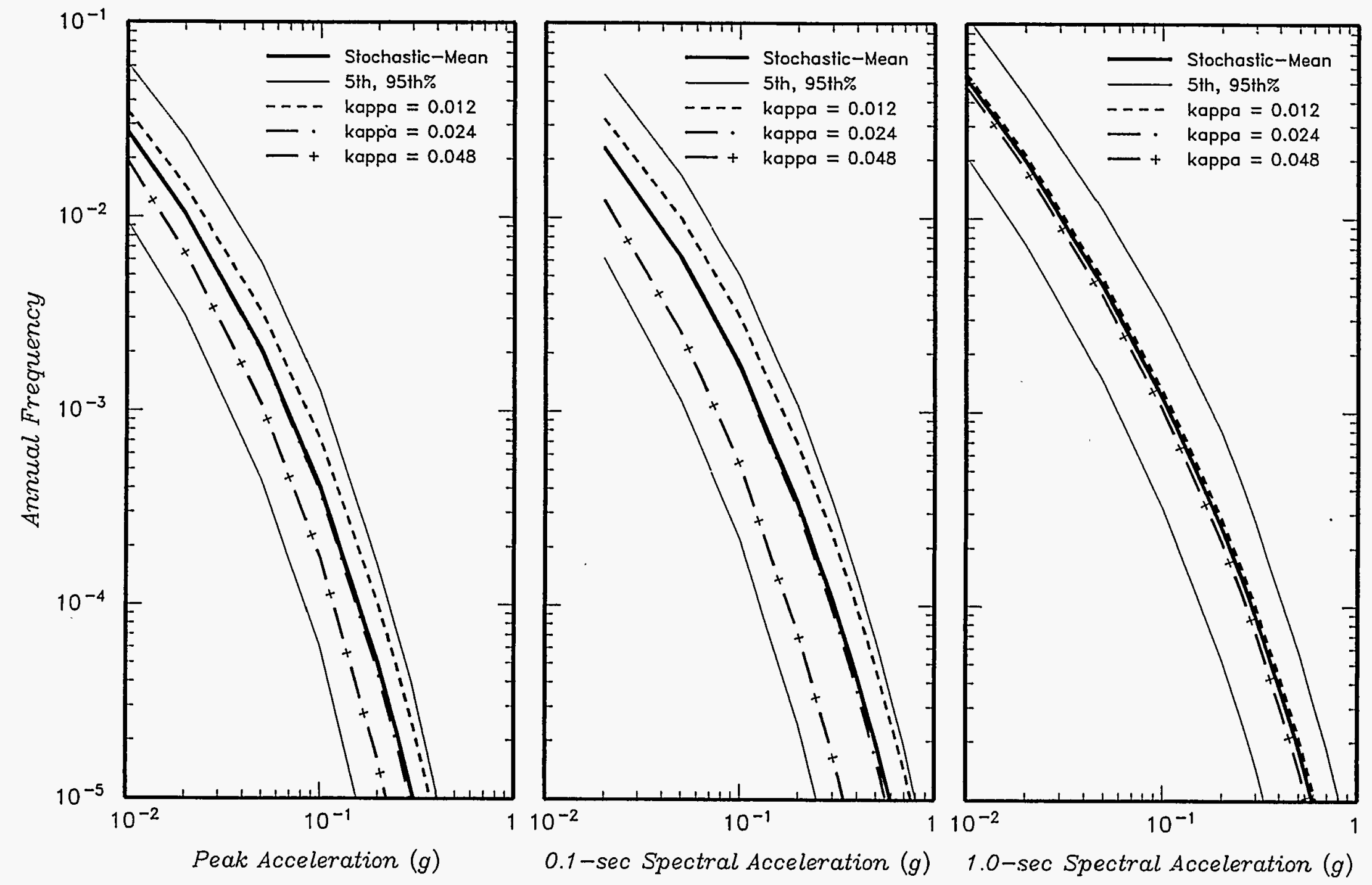

\begin{tabular}{|c|c|c|c|}
\hline $\begin{array}{c}\text { Project No. } \\
\text { SK9455 }\end{array}$ & INEL - Probabilistic Analyses & $\begin{array}{c}\text { EFFECT OF KON } \\
\text { STOCHASTIC-BASED MEAN } \\
\text { Woodward-Clyde Federal Services }\end{array}$ & $\begin{array}{c}\text { Figure } \\
6-9 d\end{array}$ \\
\hline \multicolumn{2}{|c|}{ WEISMIC HAZARD CURVE AT NRF }
\end{tabular}




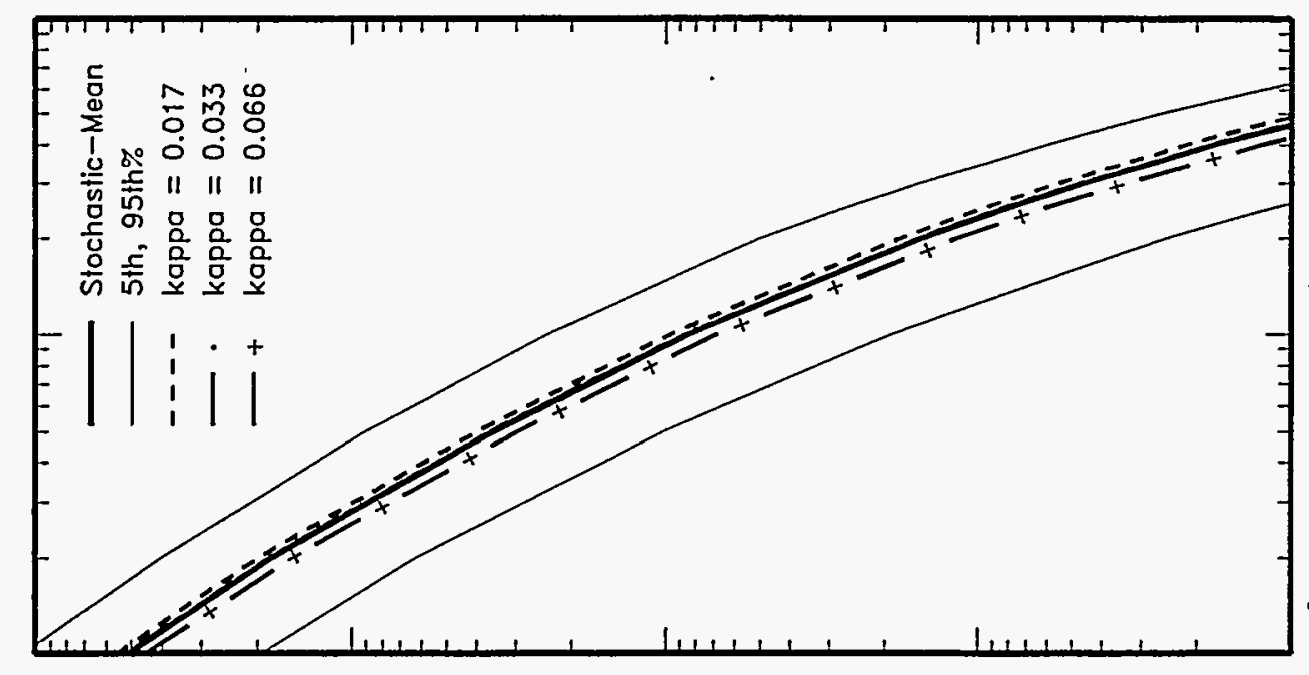

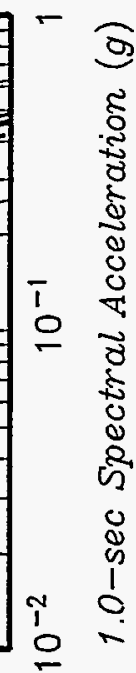

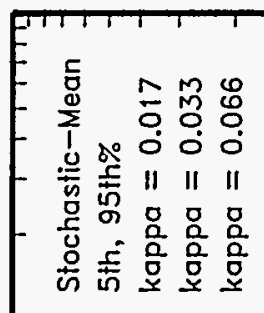

|lli i
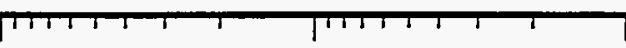

$-3$

产弯

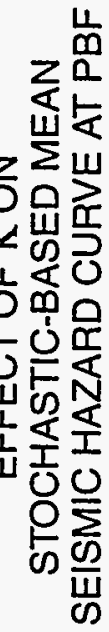

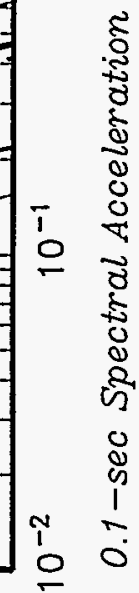

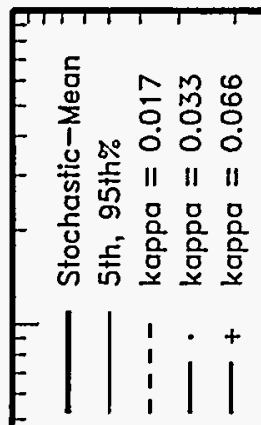

$-$

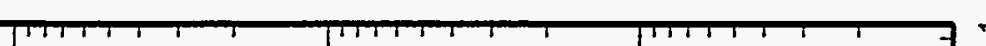

\begin{tabular}{|c|}
\hline 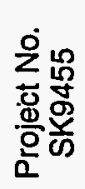 \\
\hline
\end{tabular}

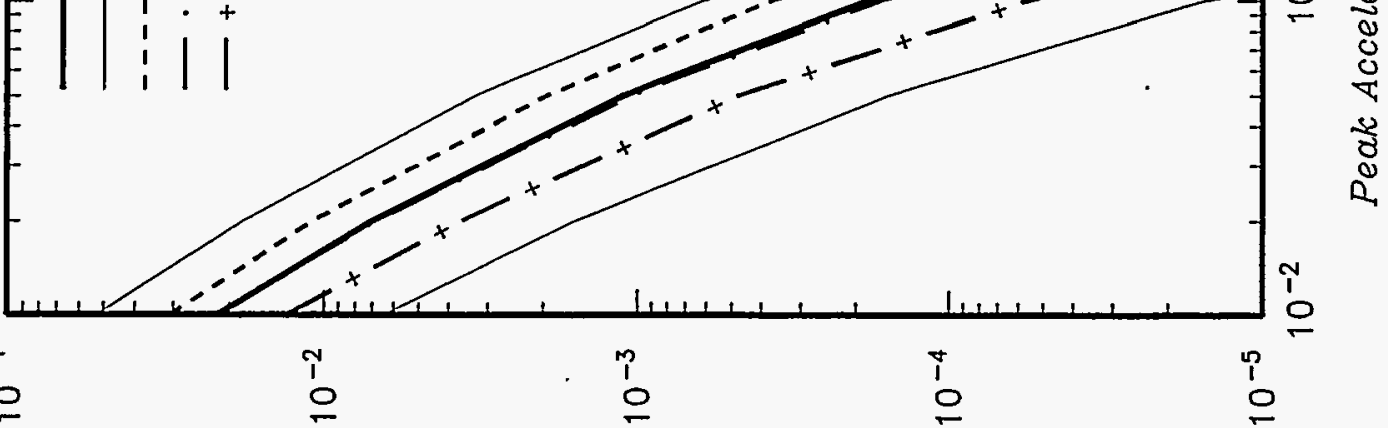

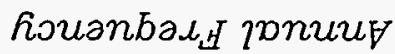



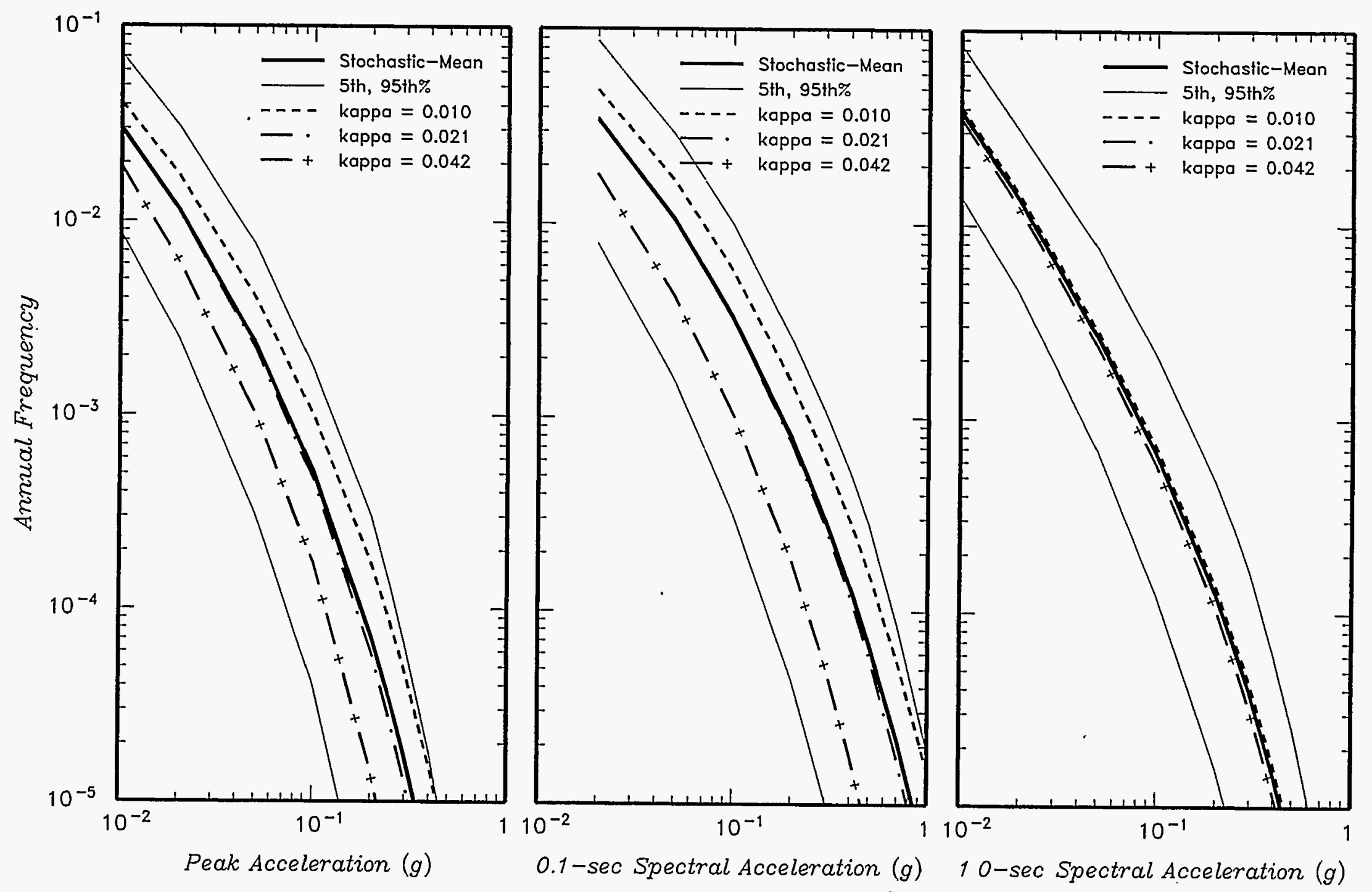

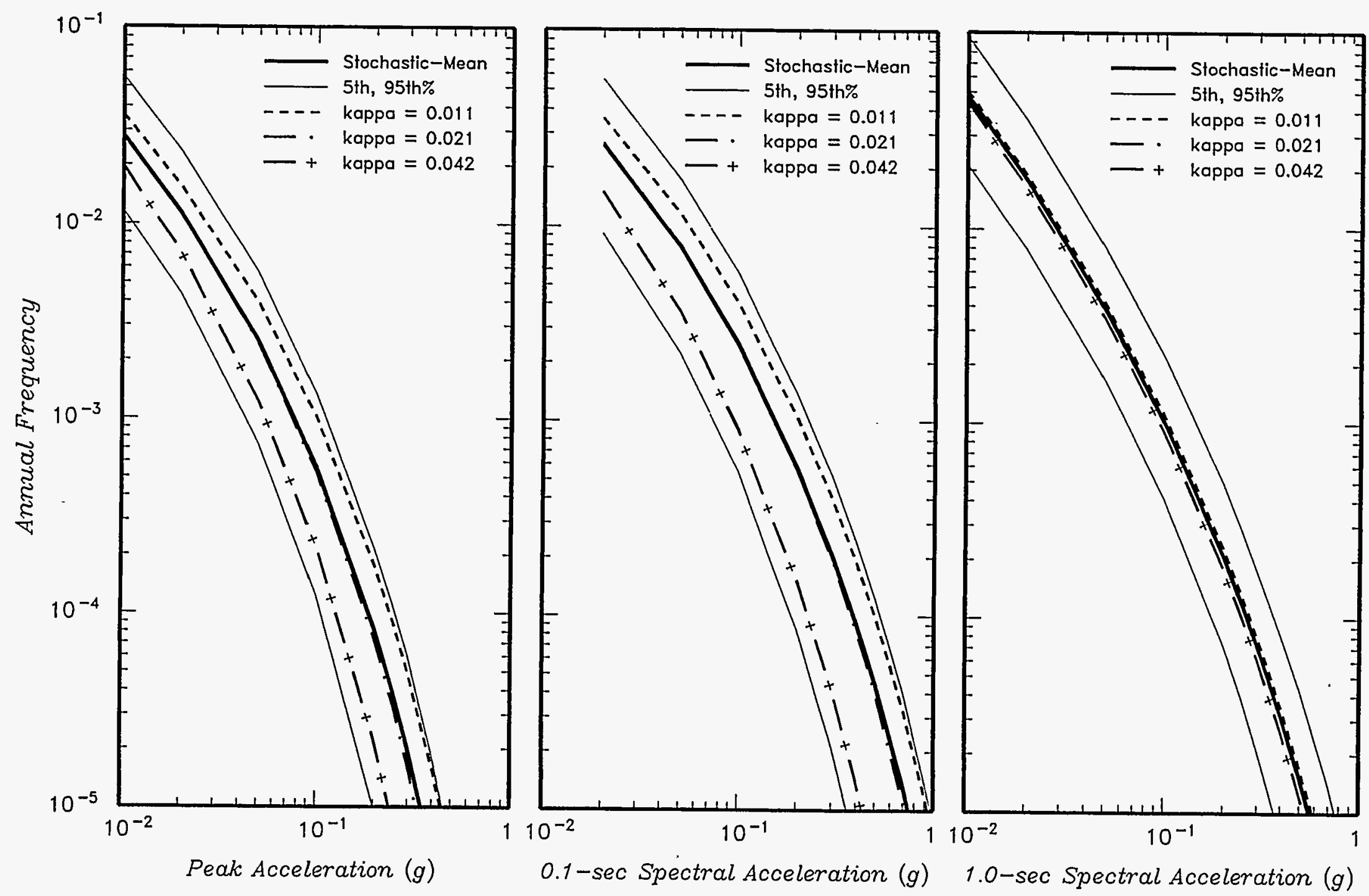

\begin{tabular}{|c|c|c|c|}
\hline $\begin{array}{l}\text { Project No. } \\
\text { SK9455 }\end{array}$ & INEL - Probabilistic Analyses & \multirow{2}{*}{$\begin{array}{c}\text { EFFECT OF KON } \\
\text { STOCHASTIC-BASED MEAN } \\
\text { SEISMIC HAZARD CURVE AT TAN }\end{array}$} & \multirow{2}{*}{$\begin{array}{c}\text { Figure } \\
6-9 g\end{array}$} \\
\hline \multicolumn{2}{|c|}{ Woodward-Clyde Federal Services } & & \\
\hline
\end{tabular}




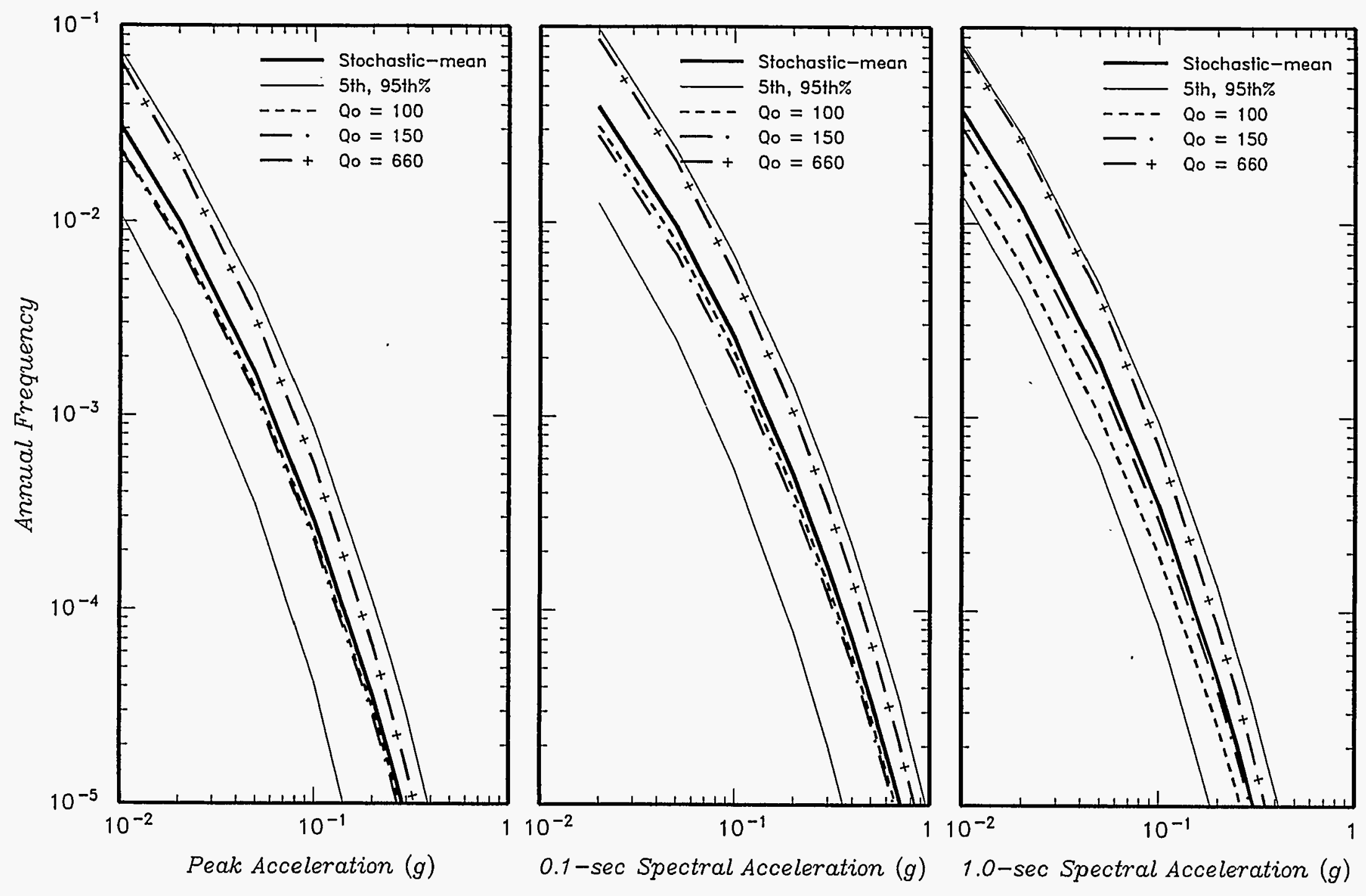

\begin{tabular}{|c|c|c|c|}
\hline $\begin{array}{l}\text { Project No. } \\
\text { SK9455 }\end{array}$ & INEL - Probabilistic Analyses & \multirow{2}{*}{$\begin{array}{c}\text { EFFECT OF } Q_{0} \text { ON } \\
\text { STOCHASTIC-BASED MEAN } \\
\text { SEISMIC HAZARD CURVE AT ANL }\end{array}$} & \multirow{2}{*}{$\begin{array}{c}\text { Figure } \\
6-10 a\end{array}$} \\
\hline \multicolumn{2}{|c|}{ Woodward-Clyde Federal Senvices } & & \\
\hline
\end{tabular}



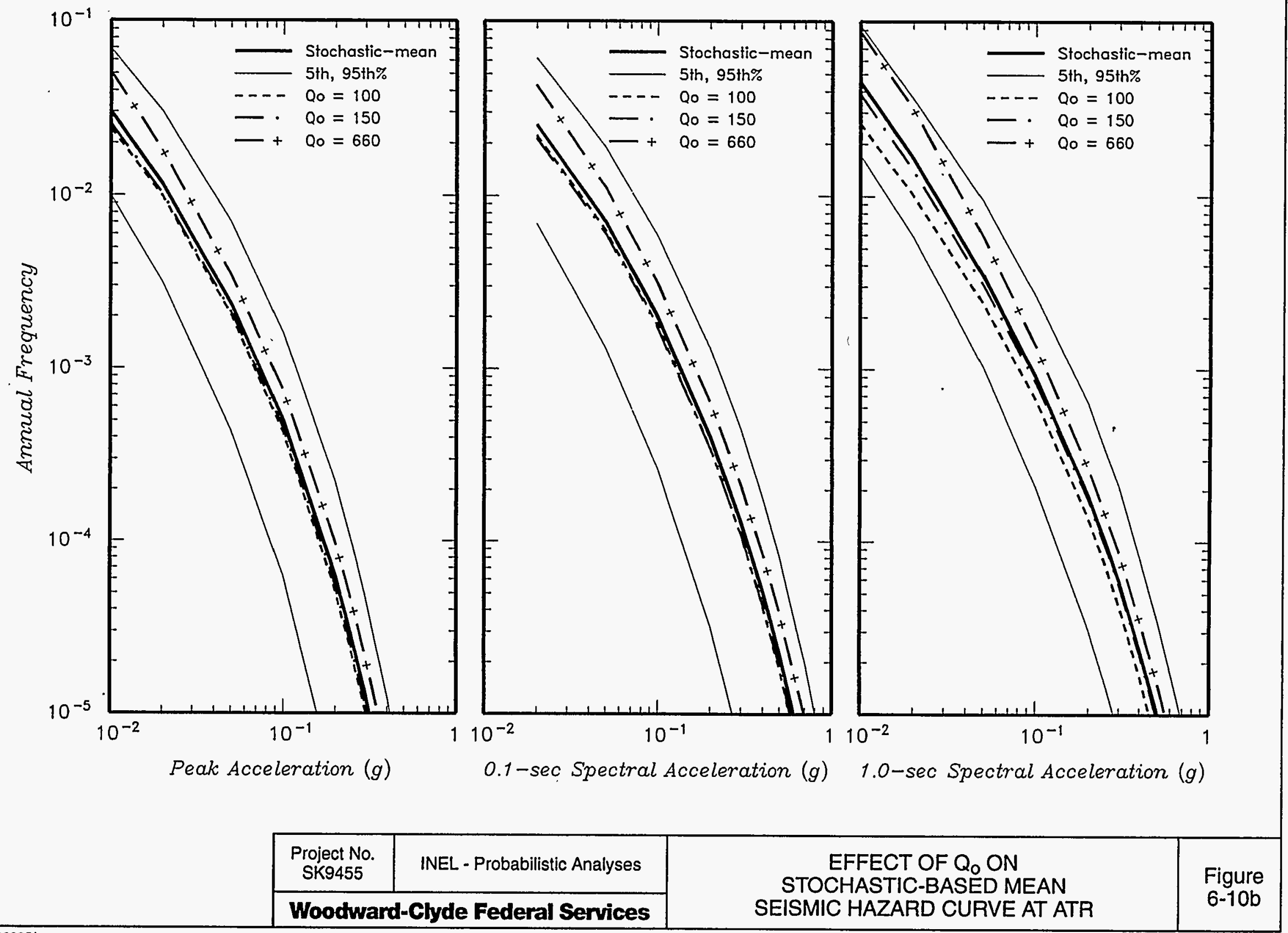

\begin{tabular}{|c|c|c|}
$\begin{array}{c}\text { Project No. } \\
\text { SK9455 }\end{array}$ & INEL - Probabilistic Analyses & $\begin{array}{c}\text { EFFECT OF Q Q ON } \\
\text { STOCHASTIC-BASED MEAN }\end{array}$ \\
\cline { 1 - 1 } Woodward-Clyde Federal Services & SEISMIC HAZARD CURVE AT ATR
\end{tabular}




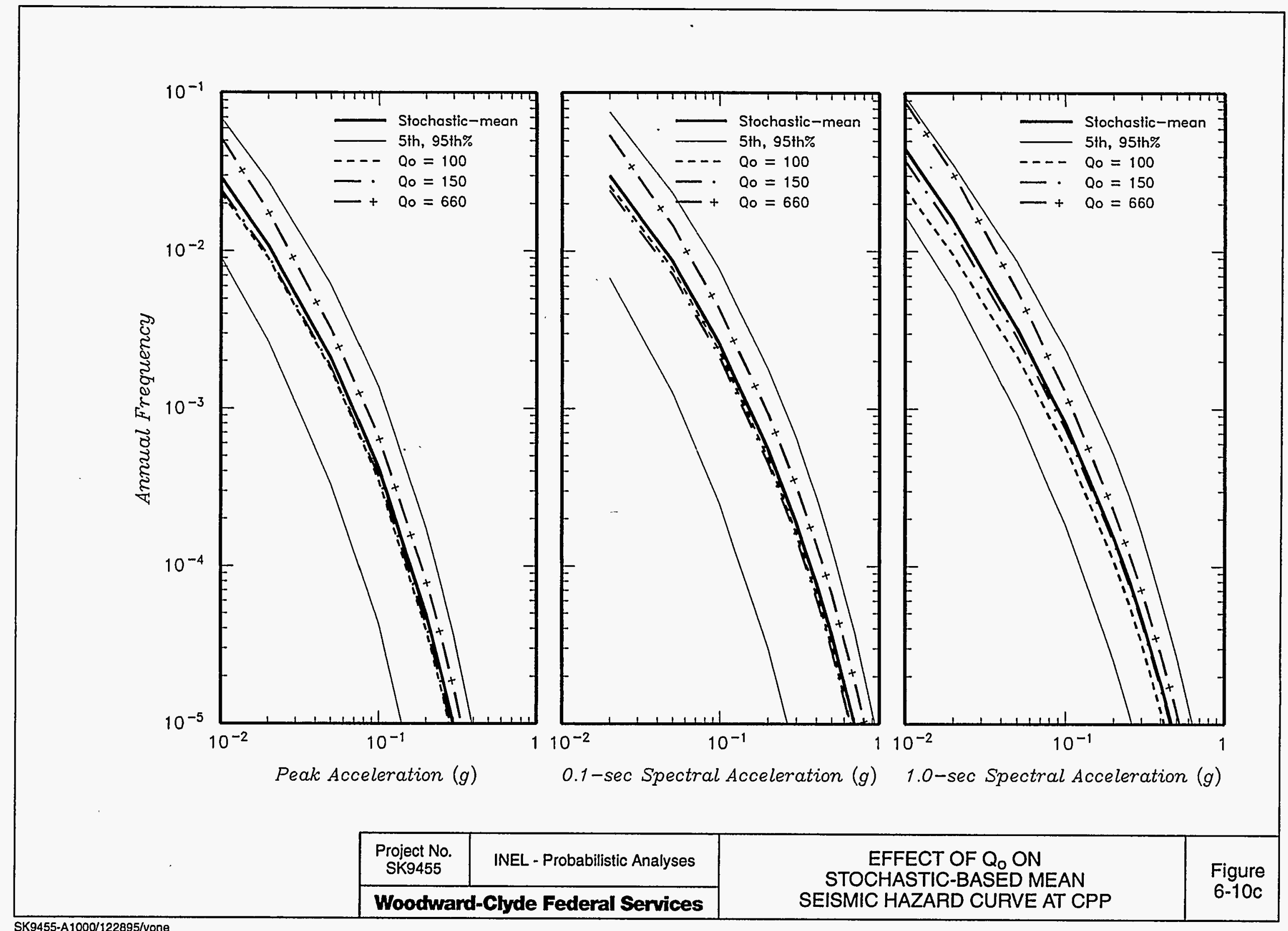



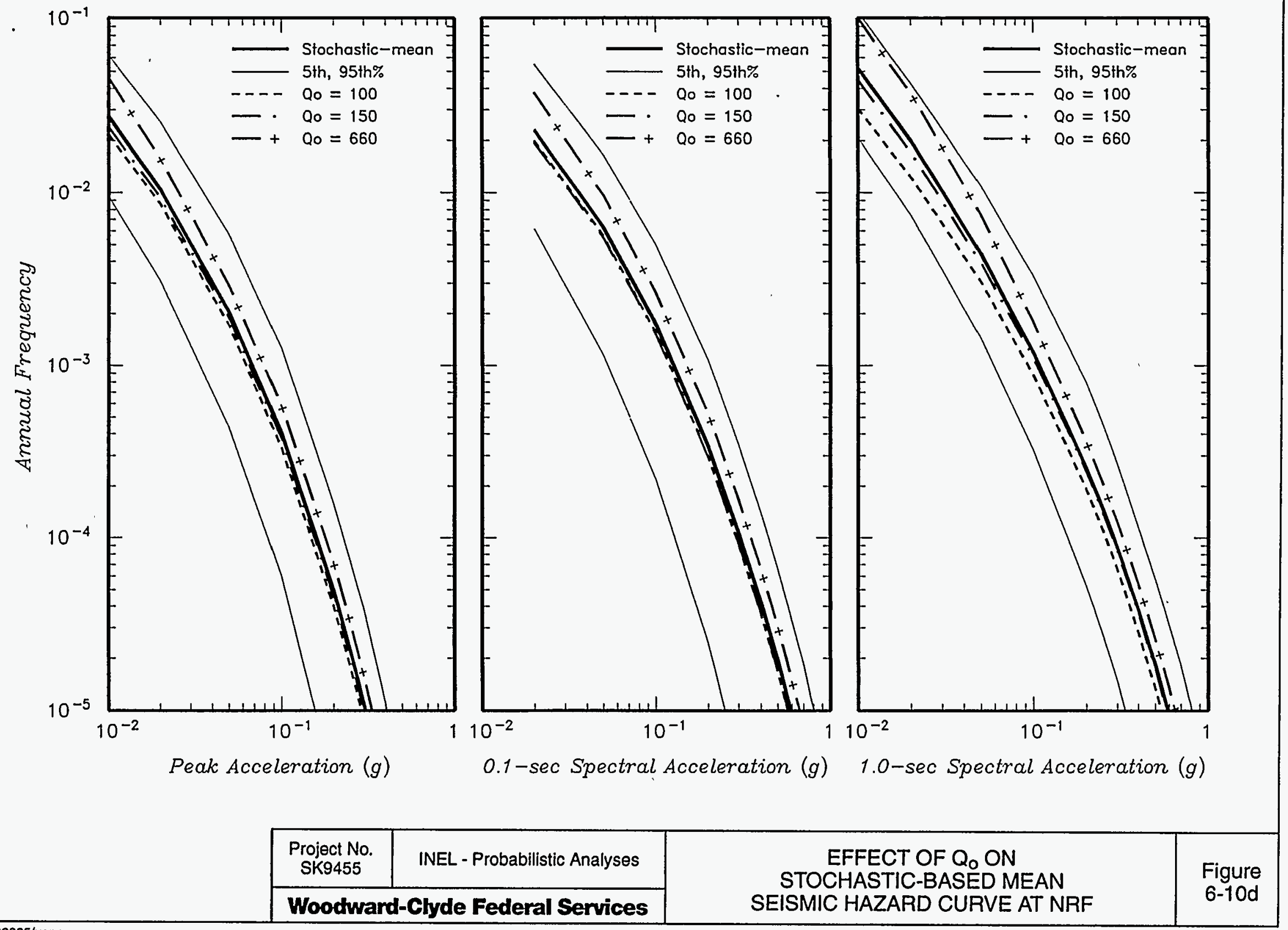

SK9455-A1000/122895/von

\begin{tabular}{|c|c|c}
\hline $\begin{array}{c}\text { Project No. } \\
\text { SK9455 }\end{array}$ & INEL - Probabilistic Analyses & $\begin{array}{c}\text { EFFECT OF Q Q ON } \\
\text { STOCHASTIC-BASED MEAN }\end{array}$ \\
\hline Woodward-Clyde Federal Services & SEISMIC HAZARD CURVE AT NRF
\end{tabular}




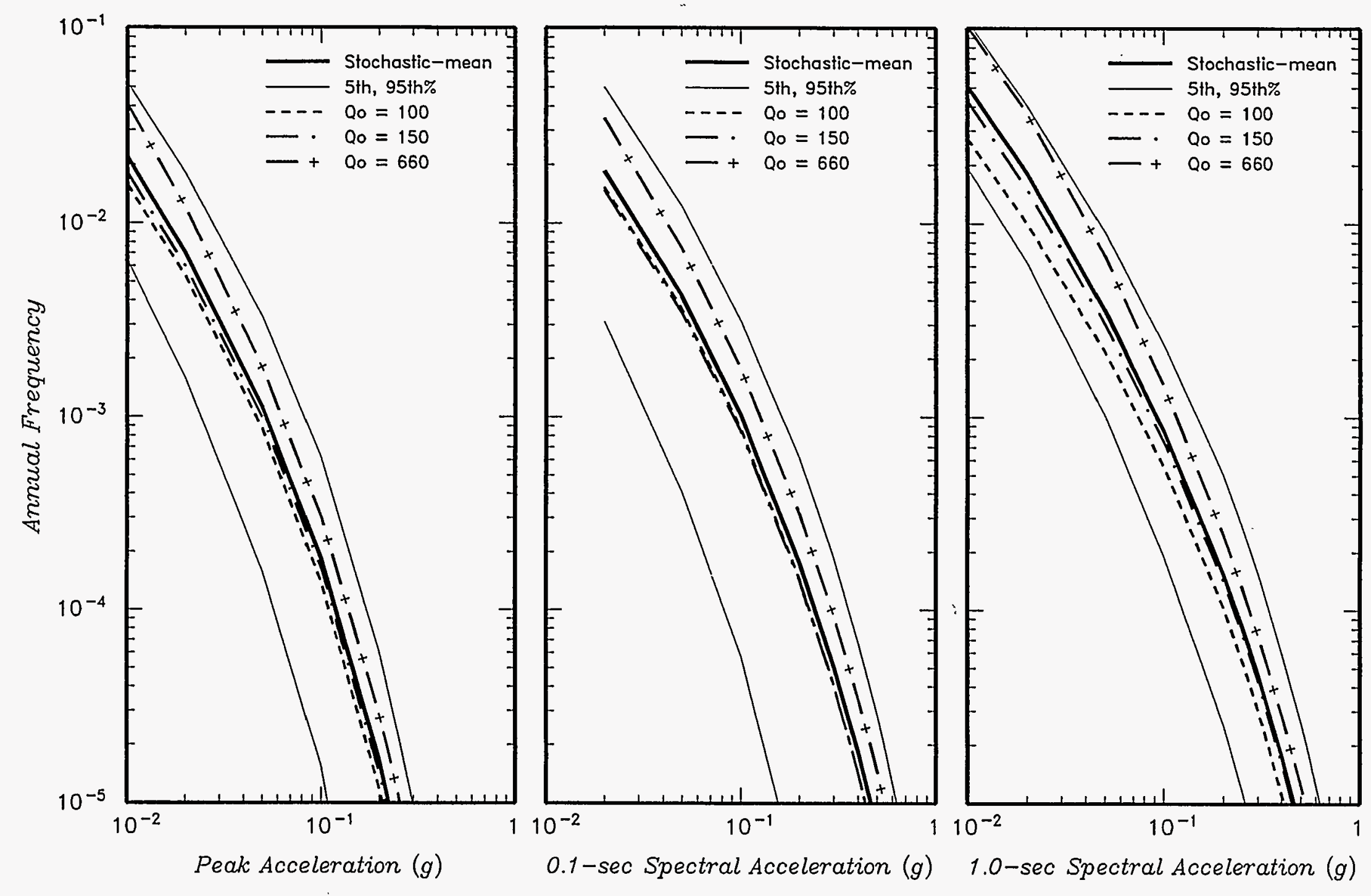

\begin{tabular}{|c|c|c|c|}
\hline $\begin{array}{c}\text { Project No. } \\
\text { SK9455 }\end{array}$ & INEL - Probabilistic Analyses & $\begin{array}{c}\text { EFFECT OF Q ON } \\
\text { STOCHASTIC-BASED MEAN } \\
\text { SEISMIC HAZARD CURVE AT PBF }\end{array}$ & $\begin{array}{c}\text { Figure } \\
6-10 \mathrm{e}\end{array}$ \\
\hline Woodward-Clyde Federal Services &
\end{tabular}



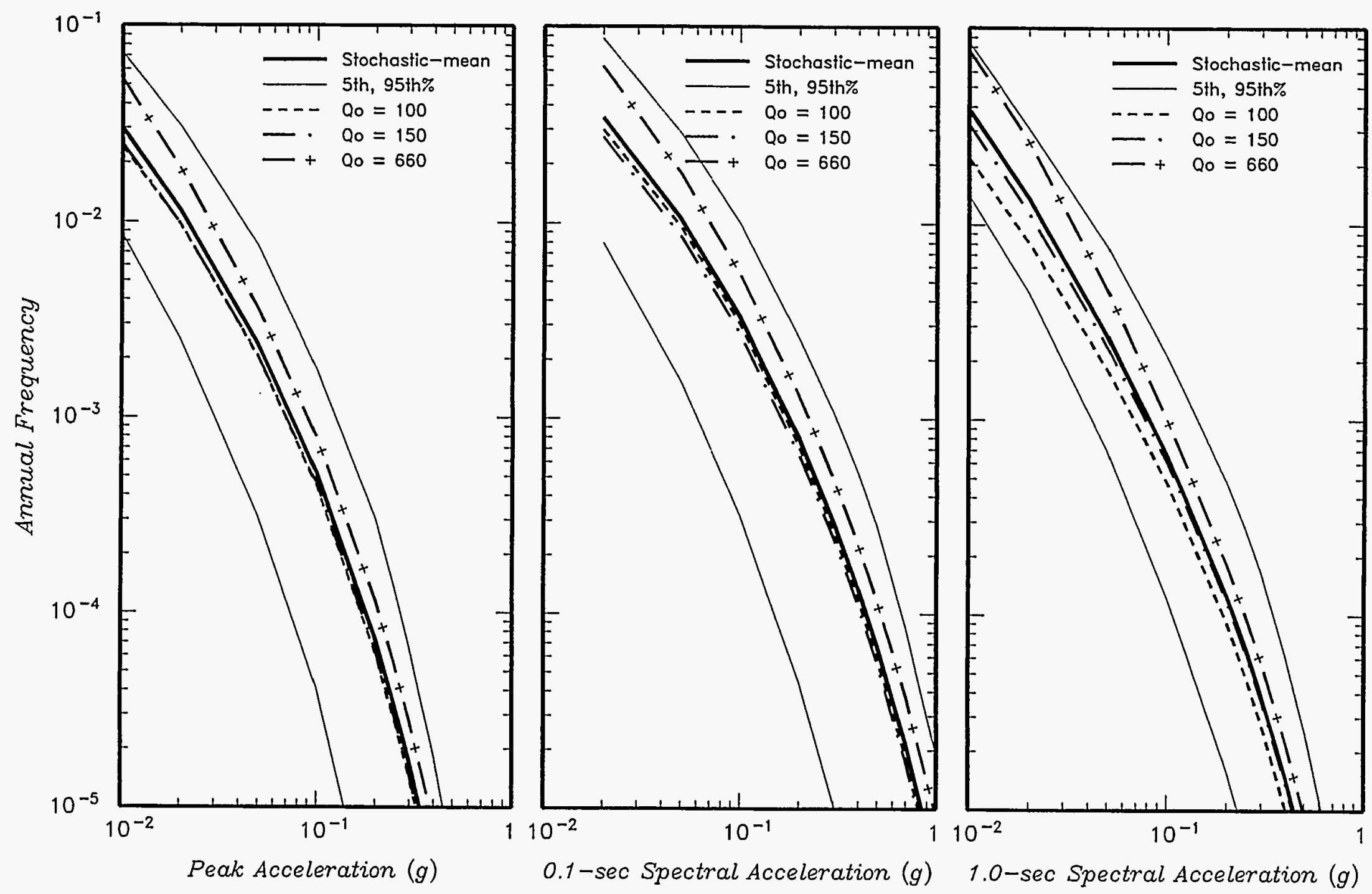

\begin{tabular}{|c|c|c|c|}
\hline $\begin{array}{c}\text { Project No. } \\
\text { SK9455 }\end{array}$ & INEL - Probabilistic Analyses & $\begin{array}{c}\text { EFFECT OF Q ON } \\
\text { STOCHASTIC-BASED MEAN } \\
\text { Woodward-Clyde Federal Services }\end{array}$ & $\begin{array}{c}\text { Figure } \\
6-10 f\end{array}$ \\
\hline
\end{tabular}



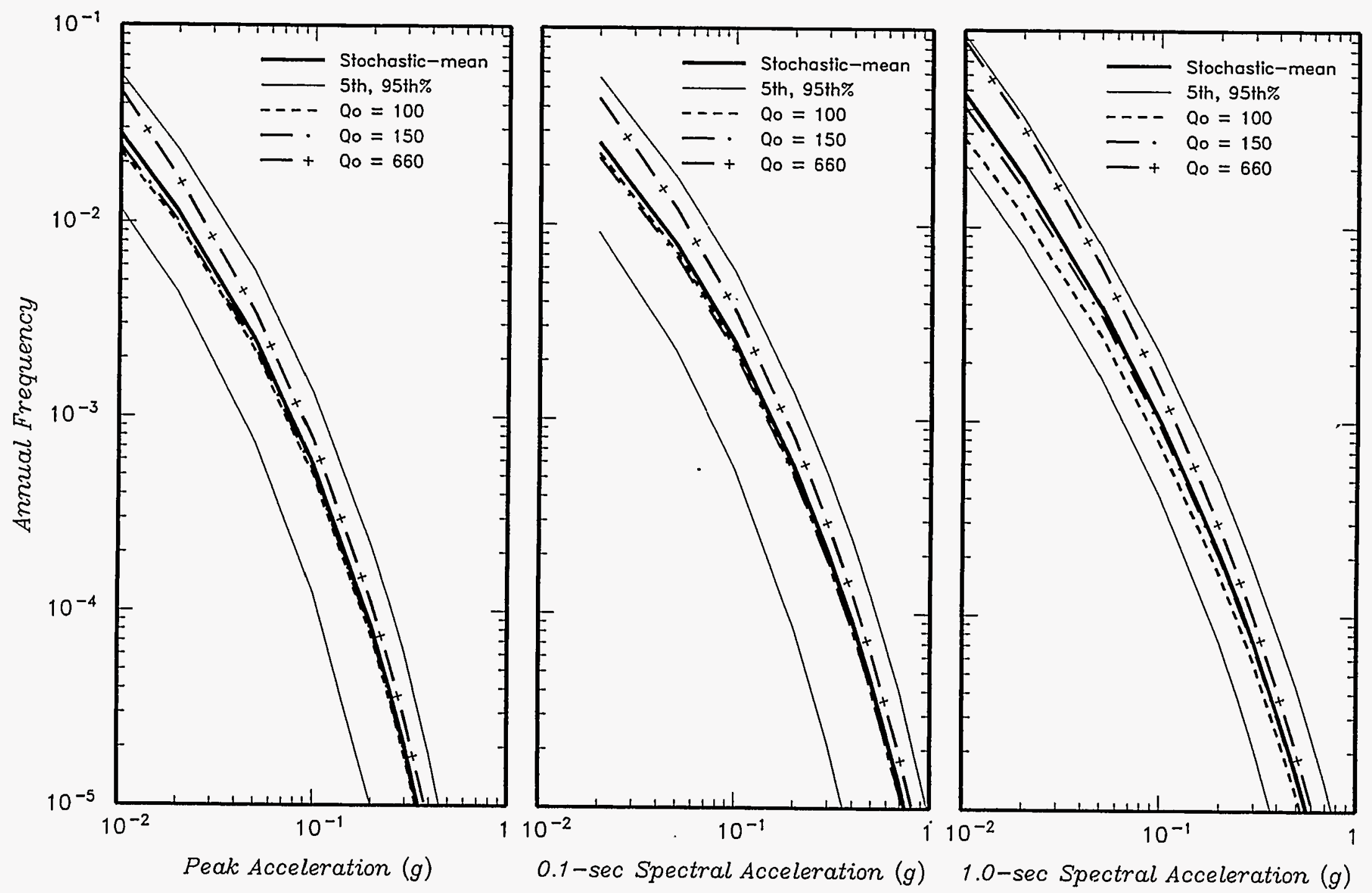

\begin{tabular}{|c|c|}
\hline $\begin{array}{c}\text { Project No. } \\
\text { SK9455 }\end{array}$ & INEL - Probabilistic Analyses \\
\hline Woodward-Clyde Federal Services \\
\hline
\end{tabular}
SEISMIC HAZARD CURVE AT TAN 


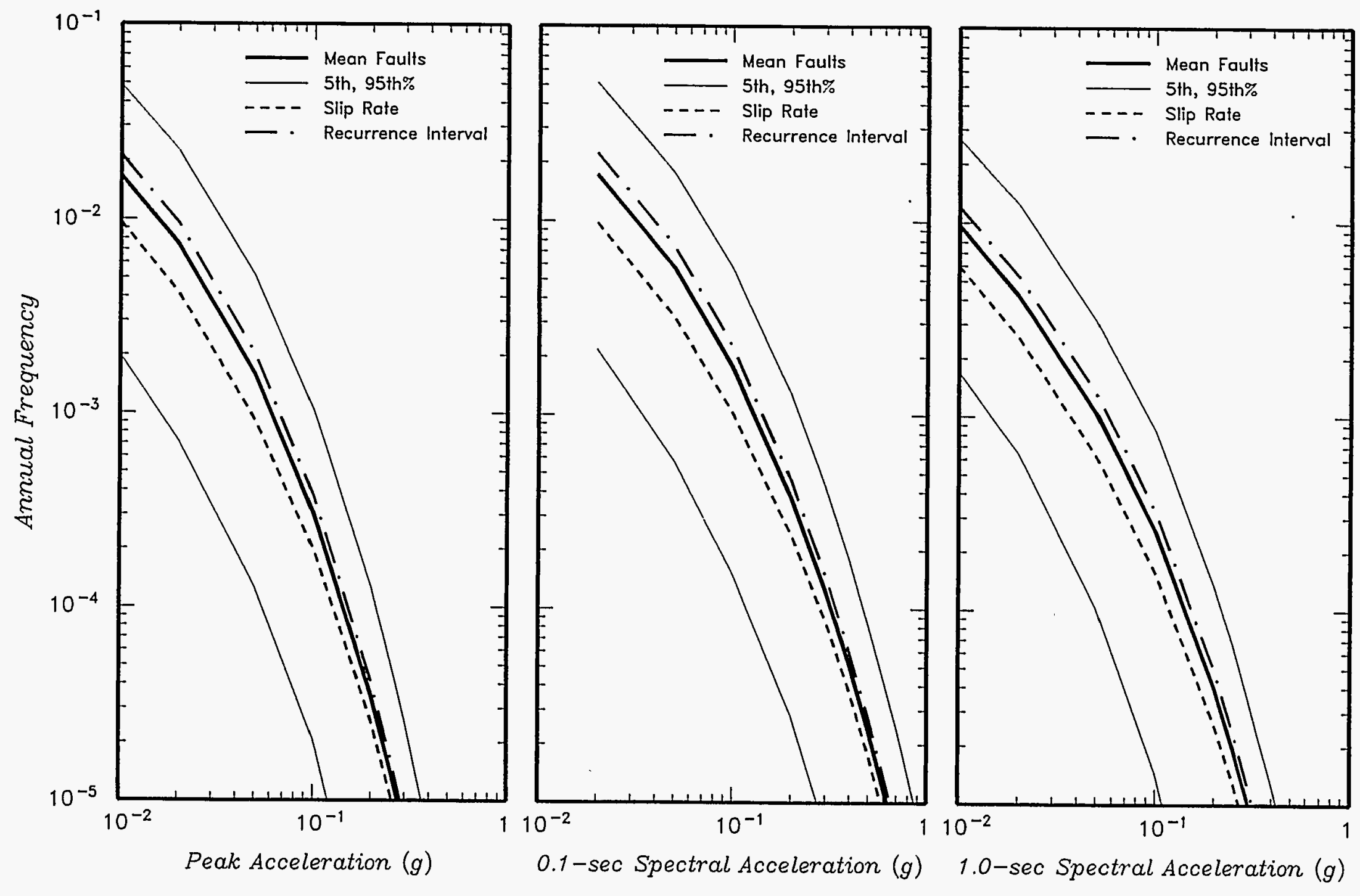
FAULT SOURCES AT ANL 

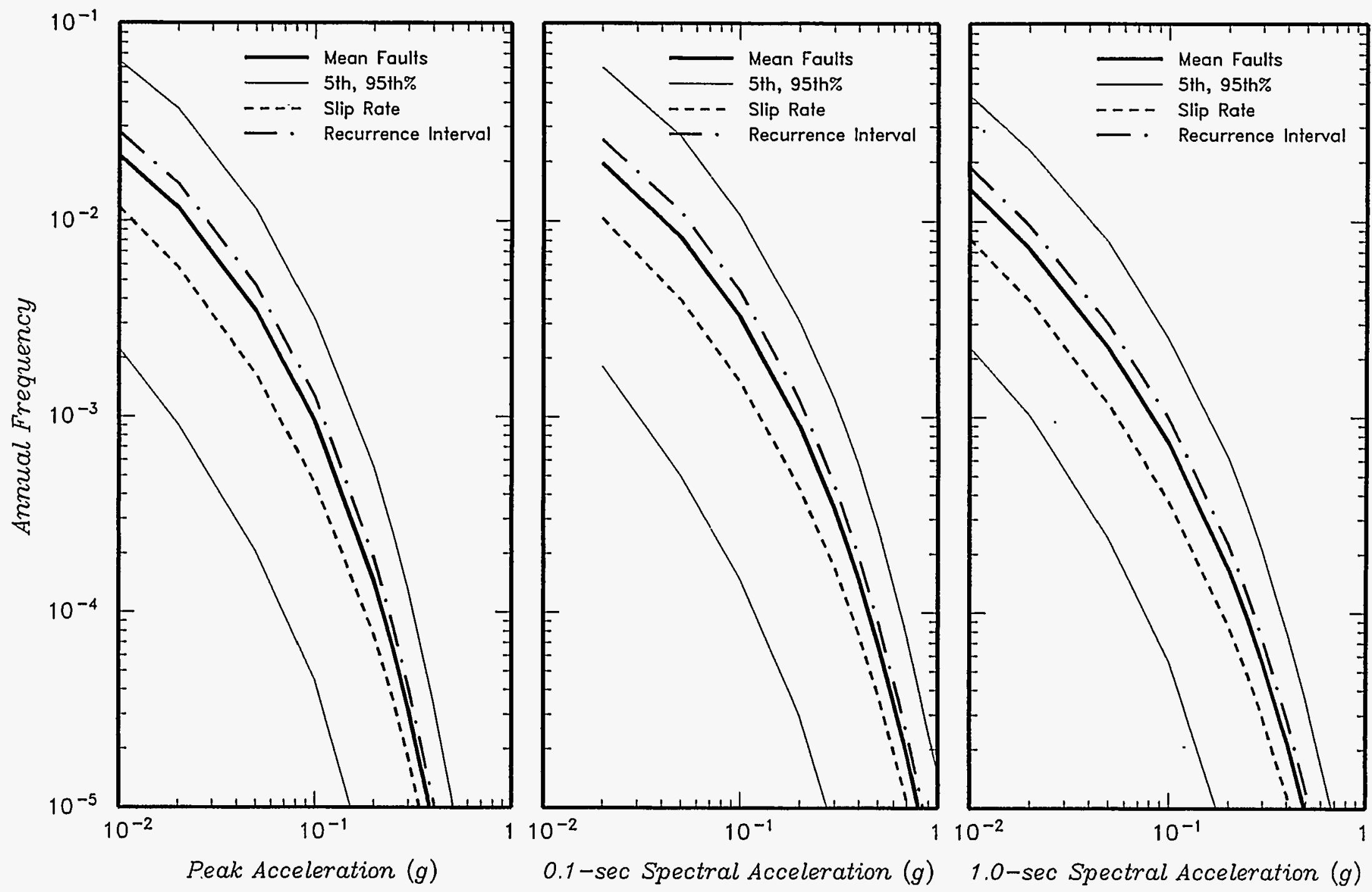

\begin{tabular}{|c|c|}
\hline $\begin{array}{c}\text { Project No. } \\
\text { SK9455 }\end{array}$ & INEL - Probabilistic Analyses \\
\hline \multicolumn{2}{|c|}{ Wooctward-Clyde Federal Services } \\
\hline
\end{tabular}
EFFECT OF RECURRENCE CALCULATION METHOD ON SEISMIC HAZARD FROM FAULT SOURCES AT ATR



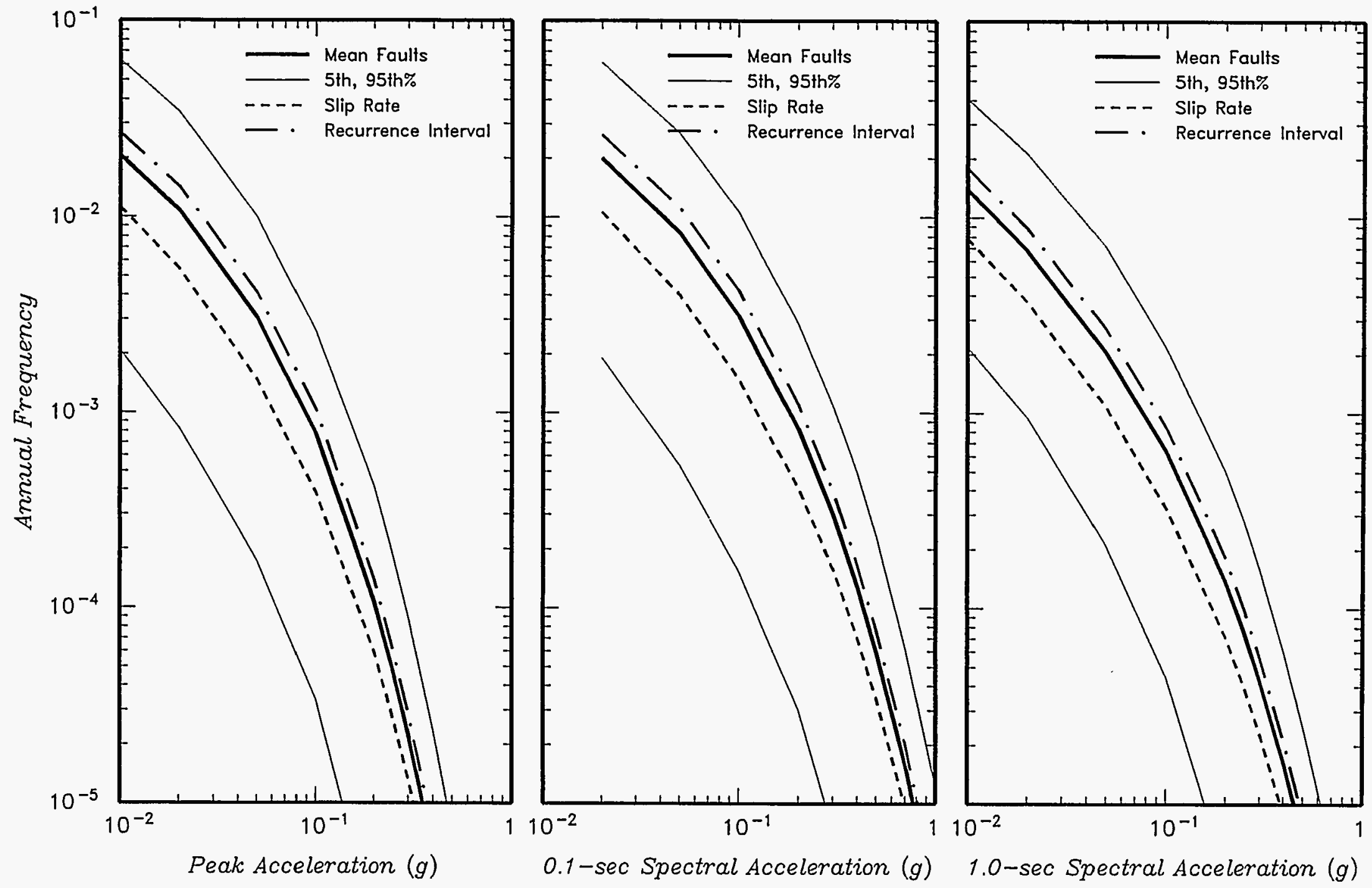

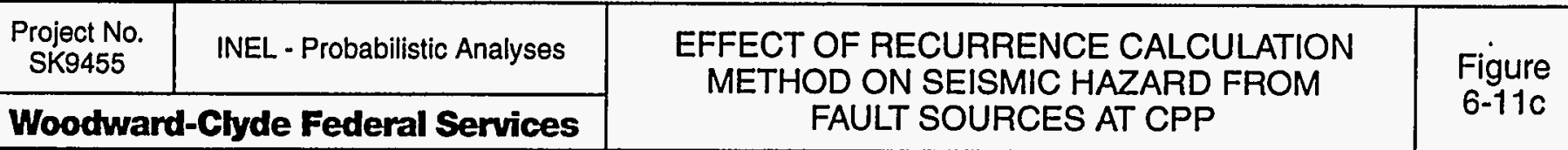



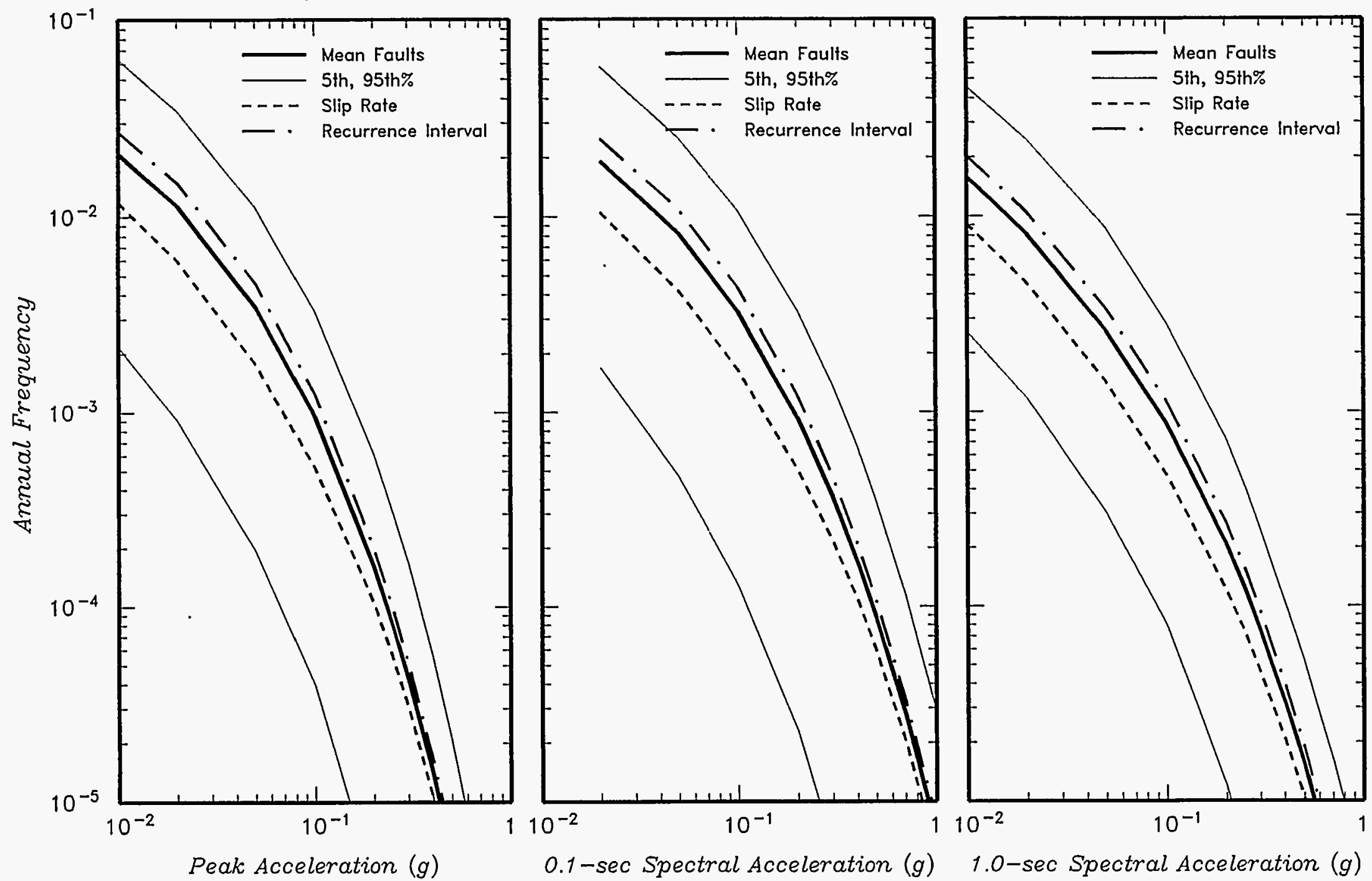

\begin{tabular}{|c|c|}
\hline $\begin{array}{c}\text { Project No. } \\
\text { SK9455 }\end{array}$ & INEL - Probabilistic Analyses \\
\hline
\end{tabular}

Woodward-Clyde Federal Services

EFFECT OF RECURRENCE CALCULATION METHOD ON SEISMIC HAZARD FROM FAULT SOURCES AT NRF 

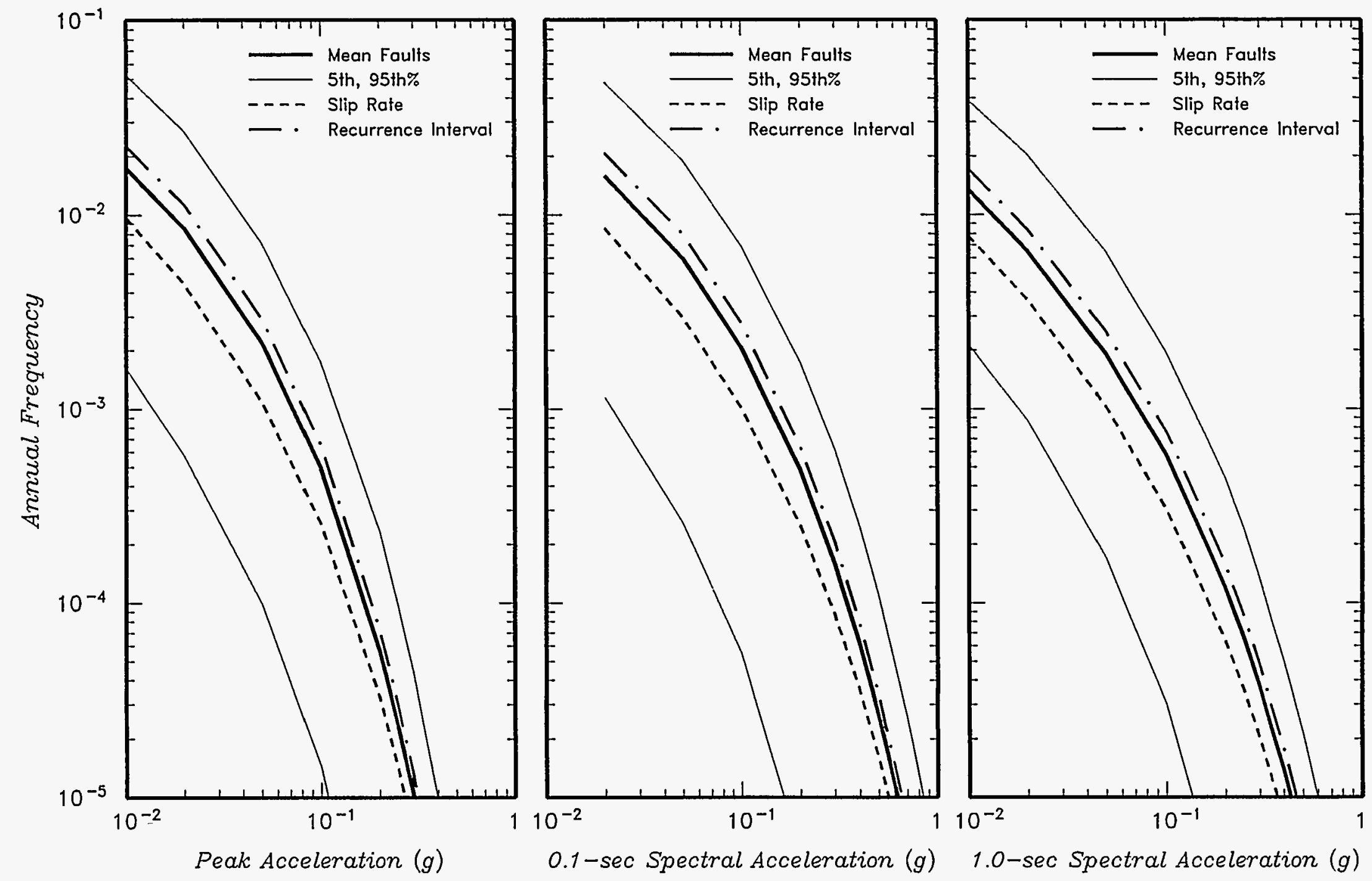

SK9455-A1000/122895/von

\begin{tabular}{|c|c|}
\hline $\begin{array}{l}\text { Project No. } \\
\text { SK9455 }\end{array}$ & robabilistic Ar \\
\hline & \\
\hline
\end{tabular}



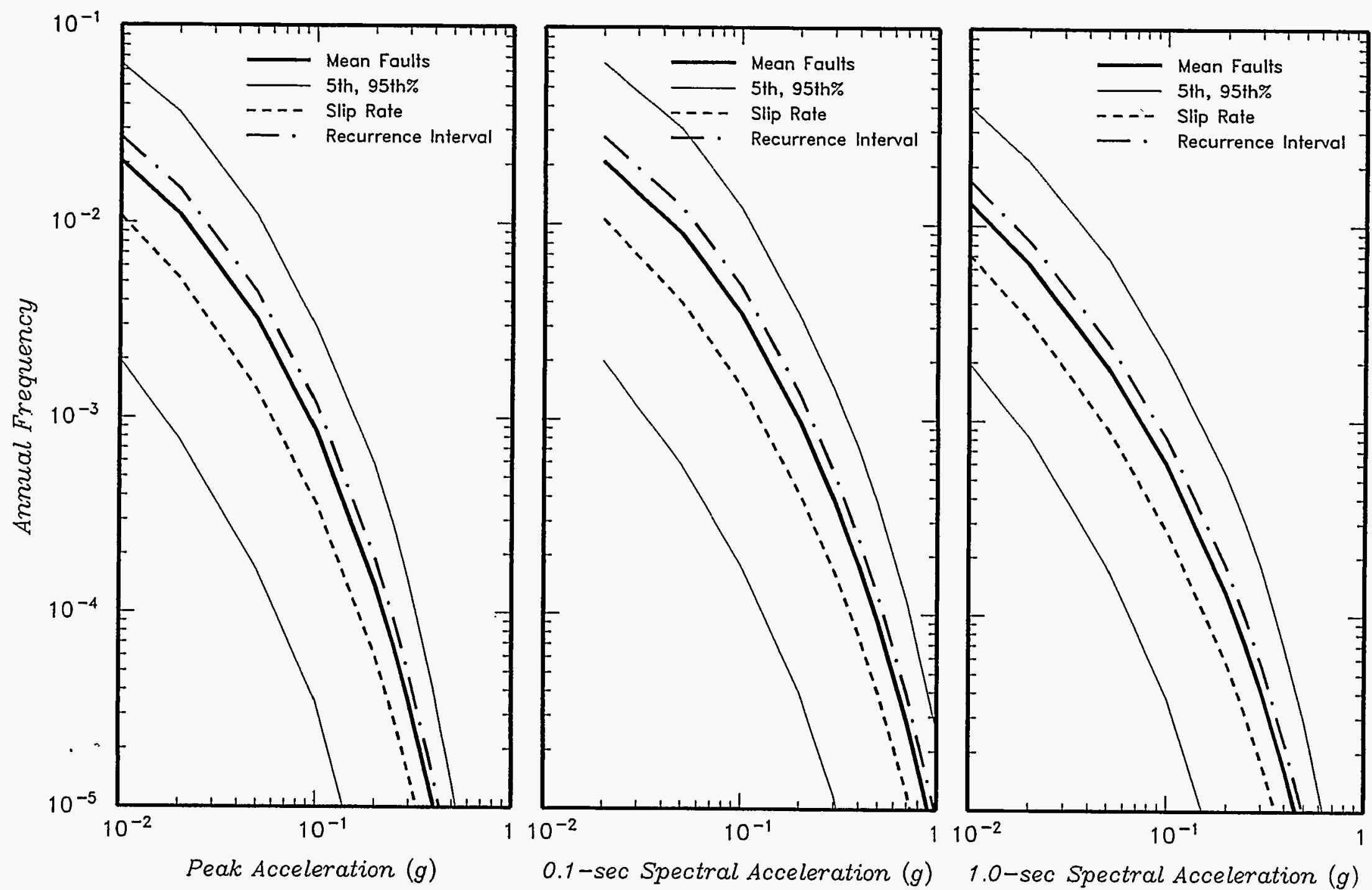

\begin{tabular}{|c|c|c|c|}
\hline $\begin{array}{c}\text { Project No. } \\
\text { SK9455 }\end{array}$ & INEL - Probabilistic Analyses & $\begin{array}{c}\text { EFFECT OF RECURRENCE CALCULATION } \\
\text { METHOD ON SEISMIC HAZARD FROM }\end{array}$ & \begin{tabular}{c} 
Figure \\
$6-11 f$ \\
\hline Woodward-Clyde Federal Services
\end{tabular} \\
\hline
\end{tabular}



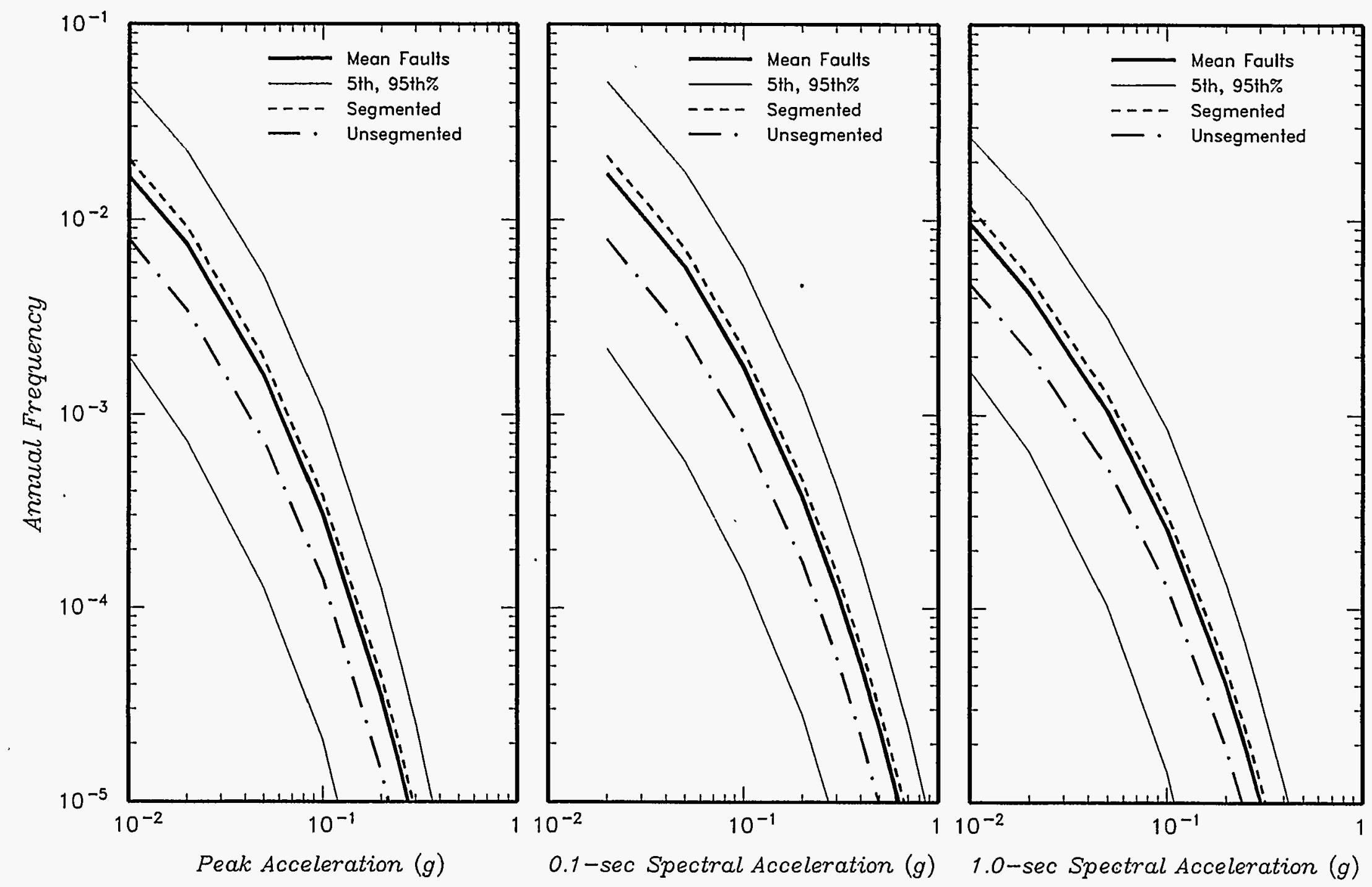

\begin{tabular}{|c|c|c|c|}
\hline $\begin{array}{l}\text { Project No. } \\
\text { SK9455 }\end{array}$ & INEL - Probabillistic Analyses & \multirow{2}{*}{$\begin{array}{l}\text { EFFECT OF FAULT SEGMENTATION } \\
\text { MODEL ON SEISMIC HAZARD AT ANL. }\end{array}$} & \multirow{2}{*}{$\begin{array}{l}\text { Figure } \\
6-12 a\end{array}$} \\
\hline \multicolumn{2}{|c|}{ Woodward-Clyde Federal Services } & & \\
\hline
\end{tabular}



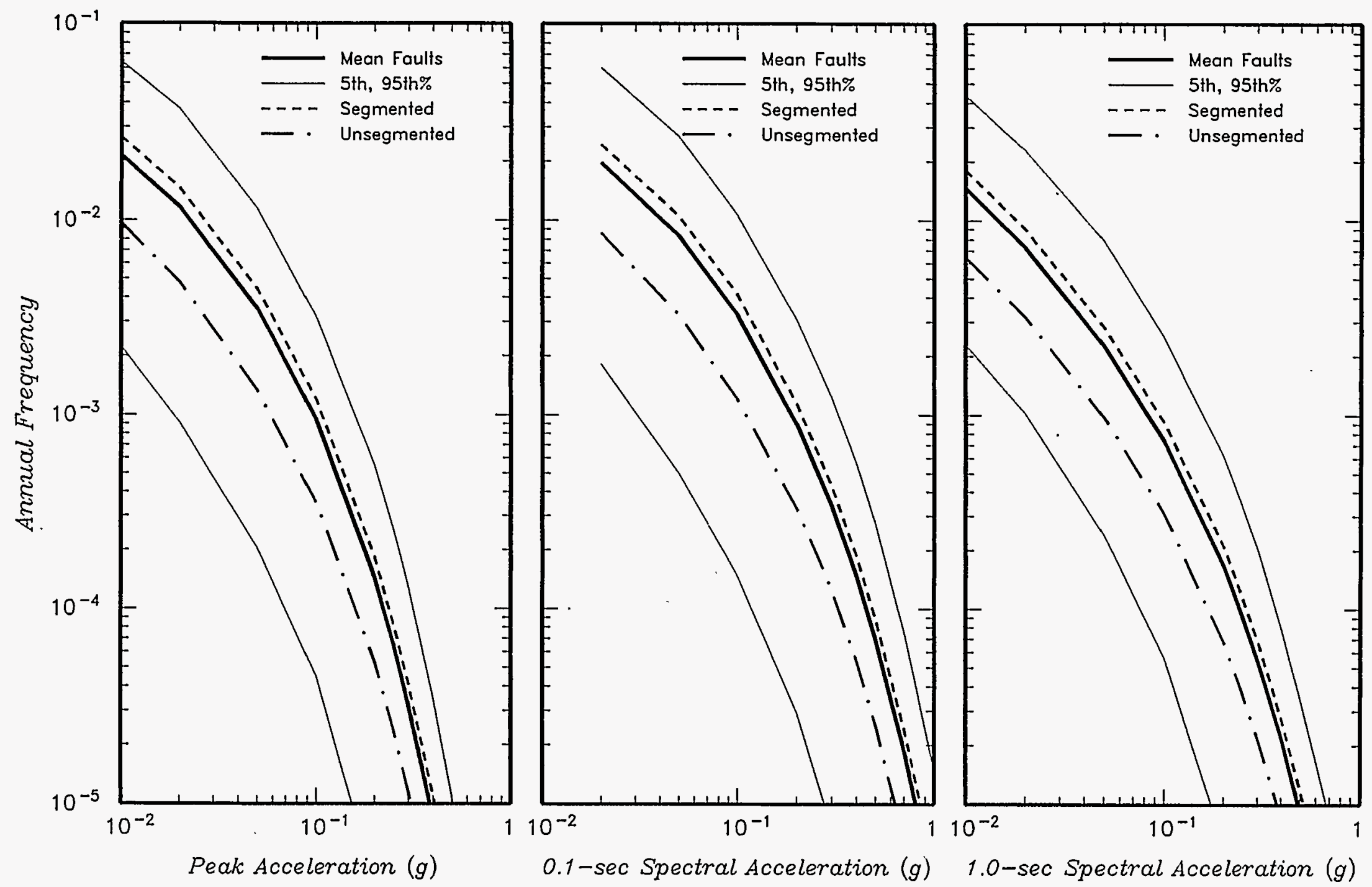


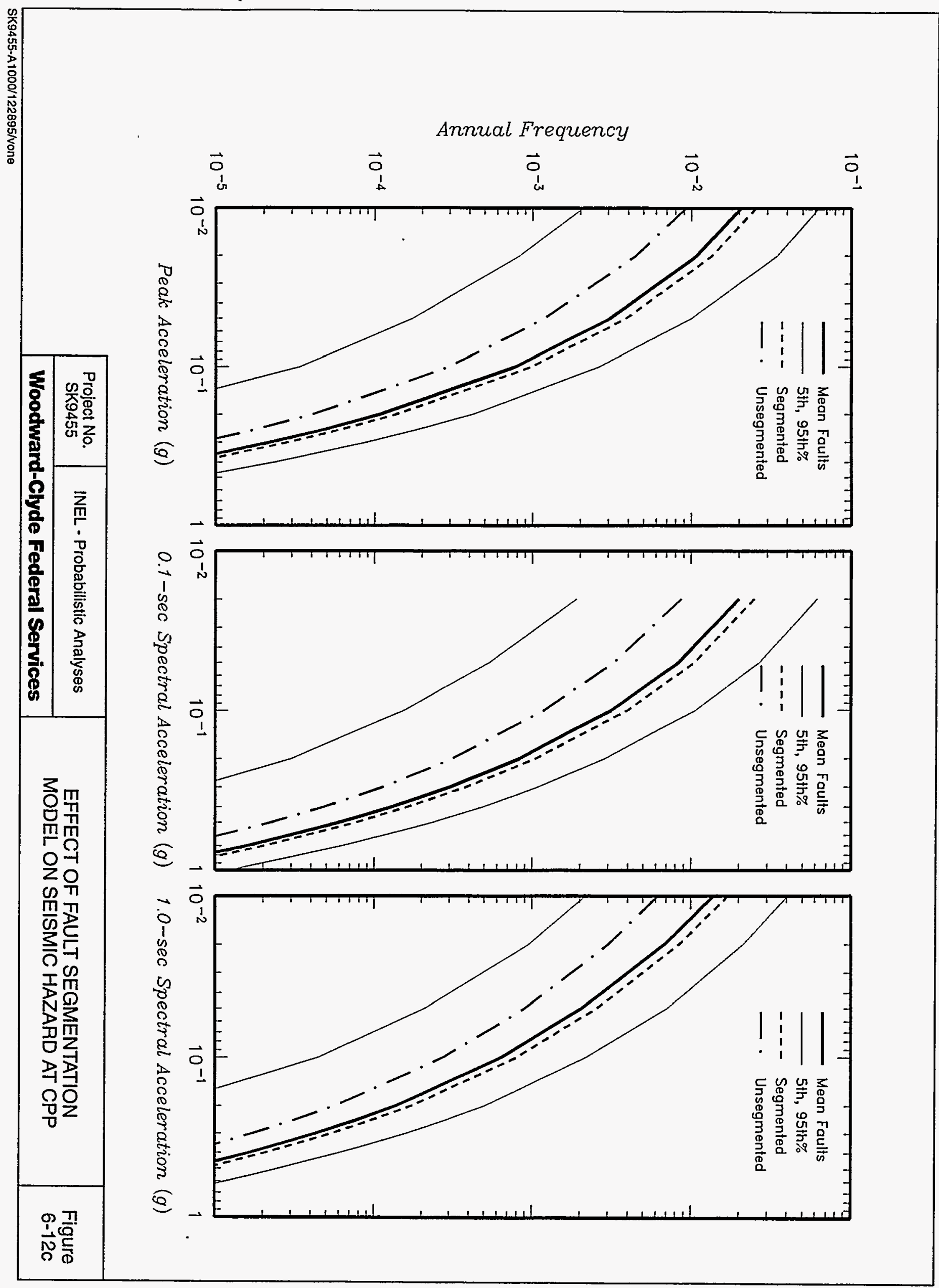



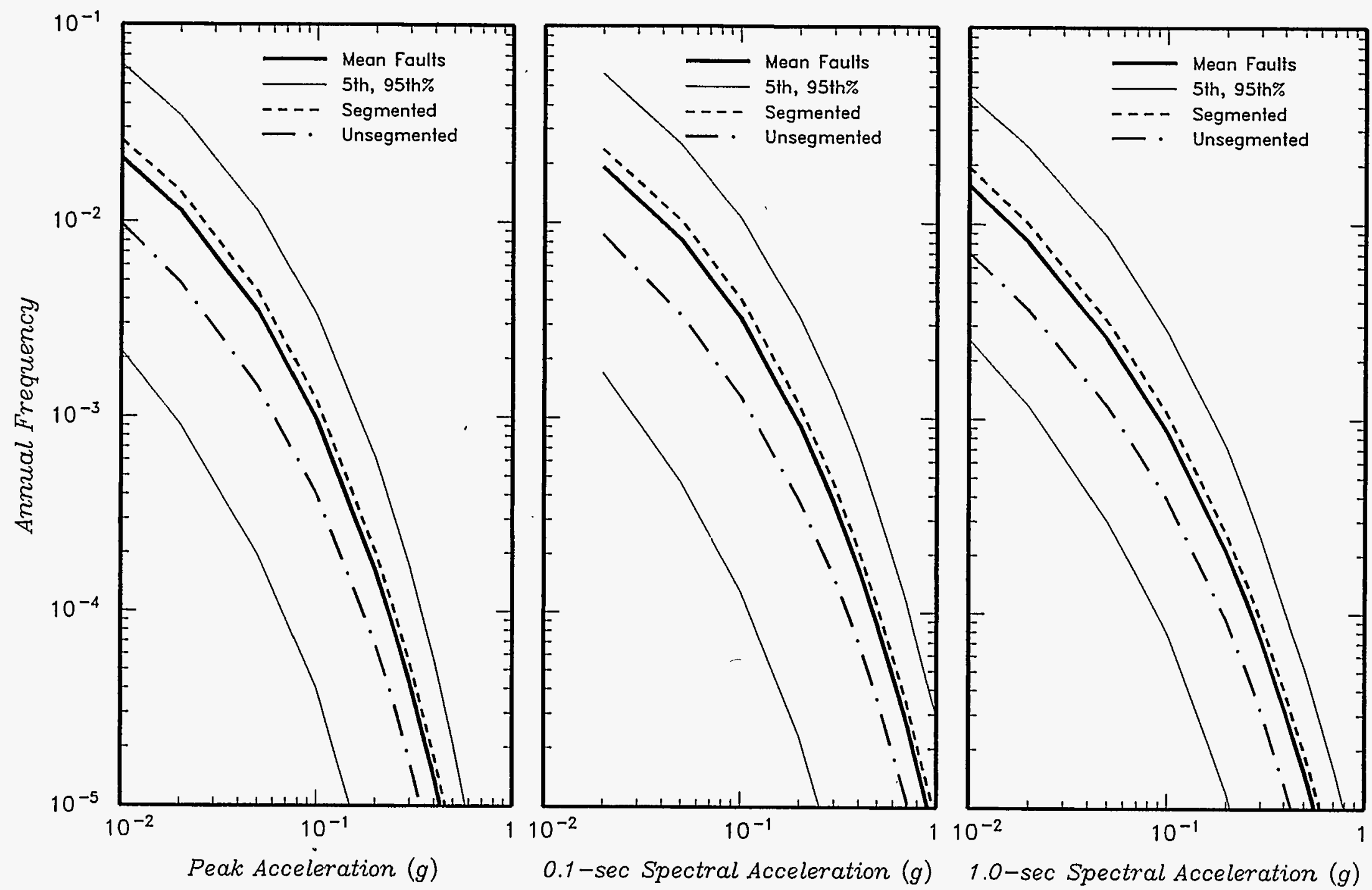

\begin{tabular}{c|c|c}
$\begin{array}{c}\text { Project No. } \\
\text { SK9455 }\end{array}$ & INEL - Probabilistic Analyses & $\begin{array}{r}\text { EFFECT OF FAULT SEGMENTATION } \\
\text { MODEL ON SEISMIC HAZARD AT NRF }\end{array}$ \\
\cline { 1 - 1 } Woodwrard-Clyde Federal Services &
\end{tabular}



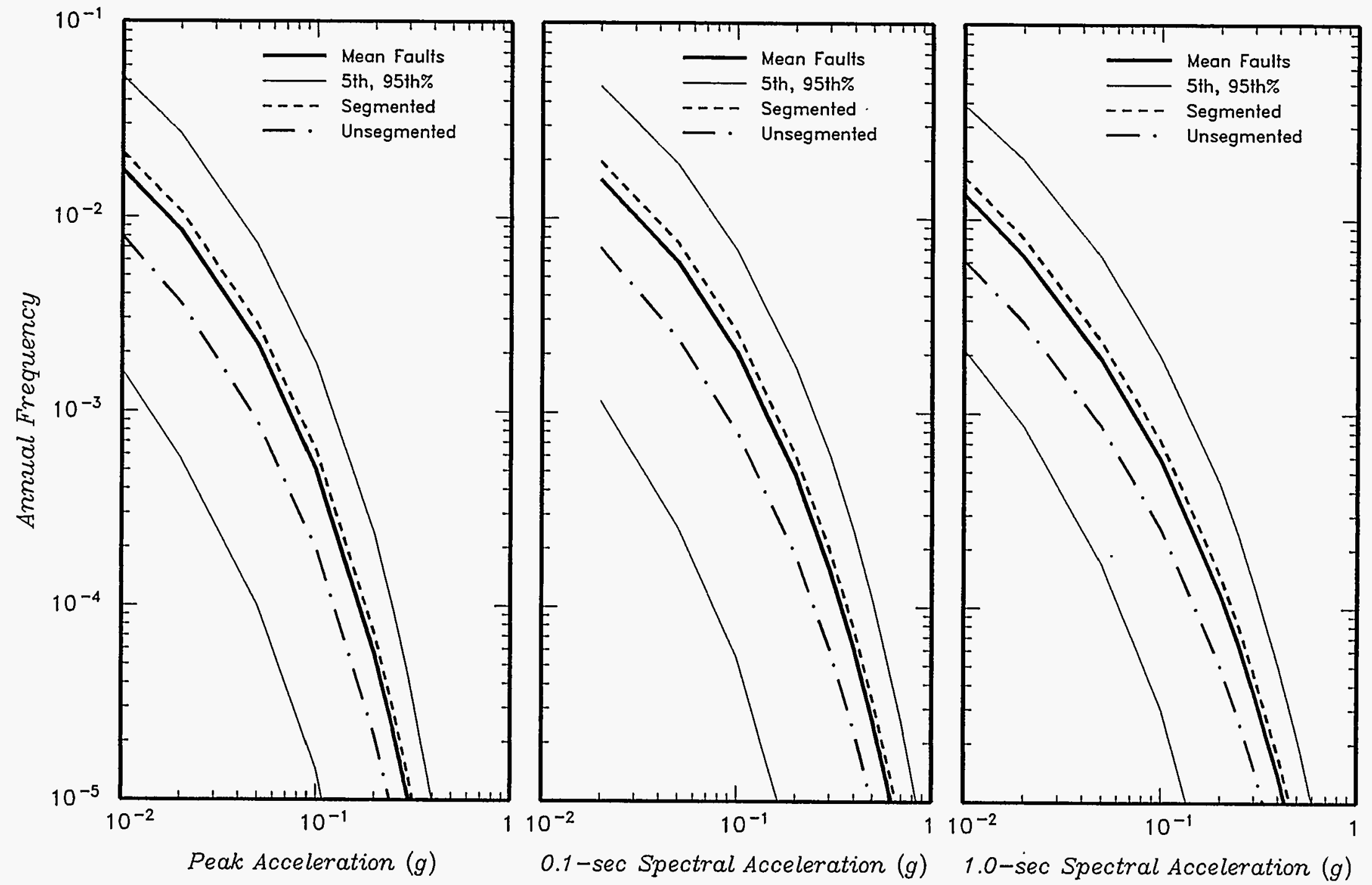

\begin{tabular}{|c|c|c|c|}
\hline $\begin{array}{l}\text { Project No. } \\
\text { SK9455 }\end{array}$ & INEL - Probabilistic Analyses & \multirow{2}{*}{$\begin{array}{l}\text { EFFECT OF FAULT SEGMENTATION } \\
\text { MODEL ON SEISMIC HAZARD AT PBF }\end{array}$} & \multirow{2}{*}{$\begin{array}{c}\text { Figure } \\
6-12 e\end{array}$} \\
\hline \multicolumn{2}{|c|}{ Woodward-Chde Federal Services } & & \\
\hline
\end{tabular}




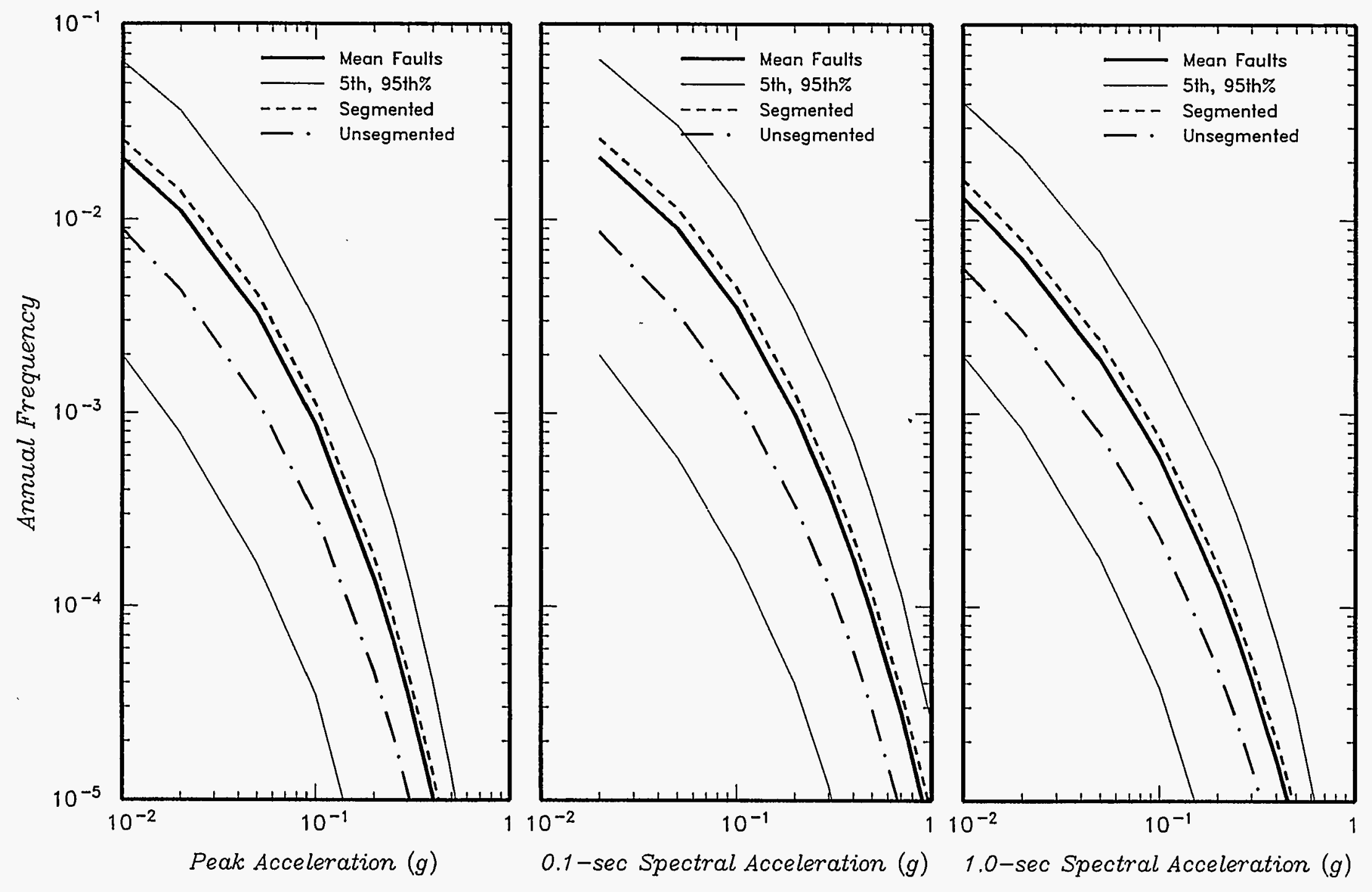



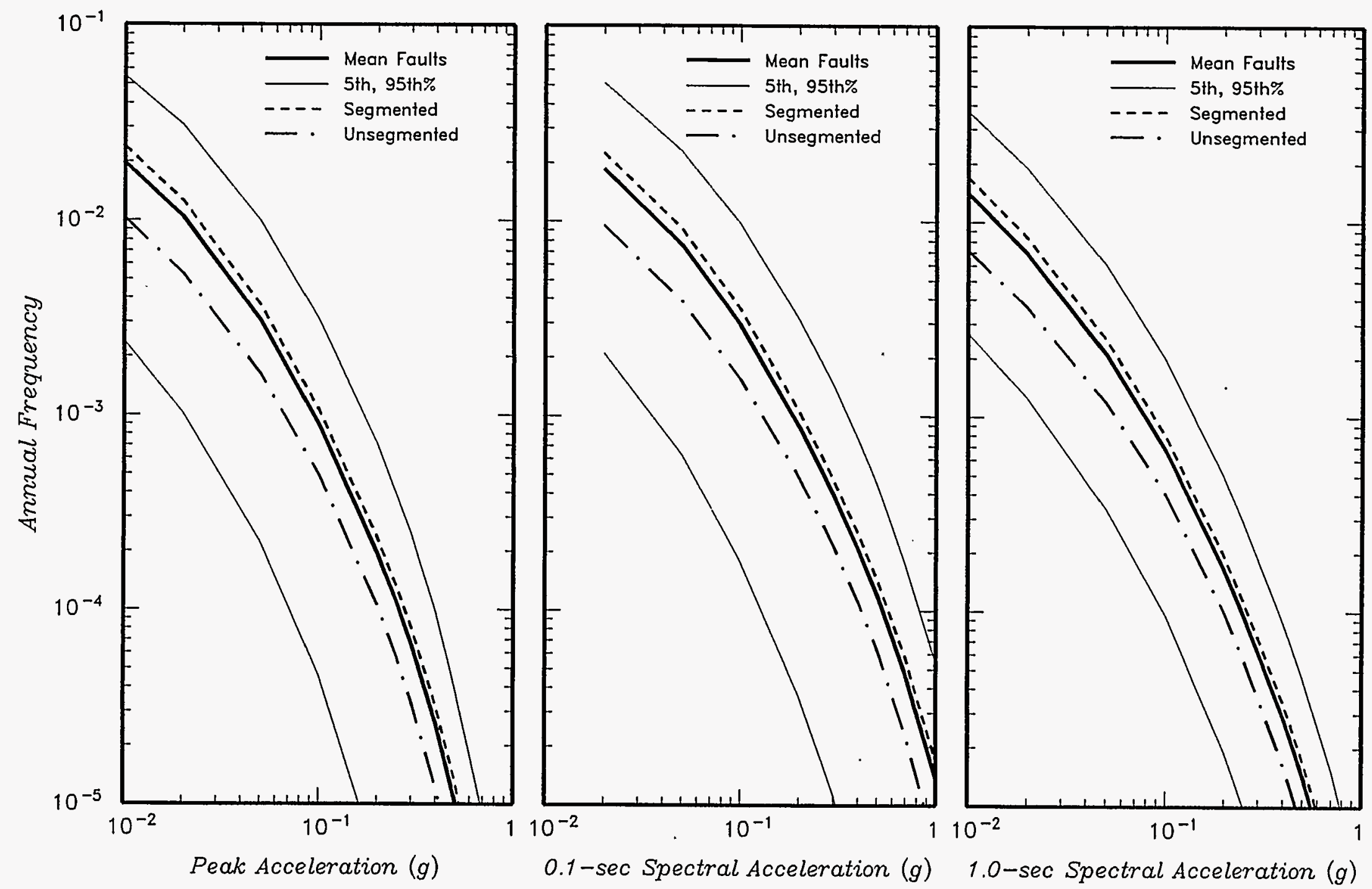

\begin{tabular}{|c|c|c|c|}
\hline $\begin{array}{c}\text { Project No. } \\
\text { SK9455 }\end{array}$ & INEL - Probabilistic Analyses & $\begin{array}{c}\text { EFFECT OF FAULT SEGMENTATION } \\
\text { MODEL ON SEISMIC HAZARD AT TAN }\end{array}$ & $\begin{array}{c}\text { Figure } \\
6-12 \mathrm{~g}\end{array}$ \\
\cline { 1 - 2 } Woodward-Clyde Federal Services & &
\end{tabular}



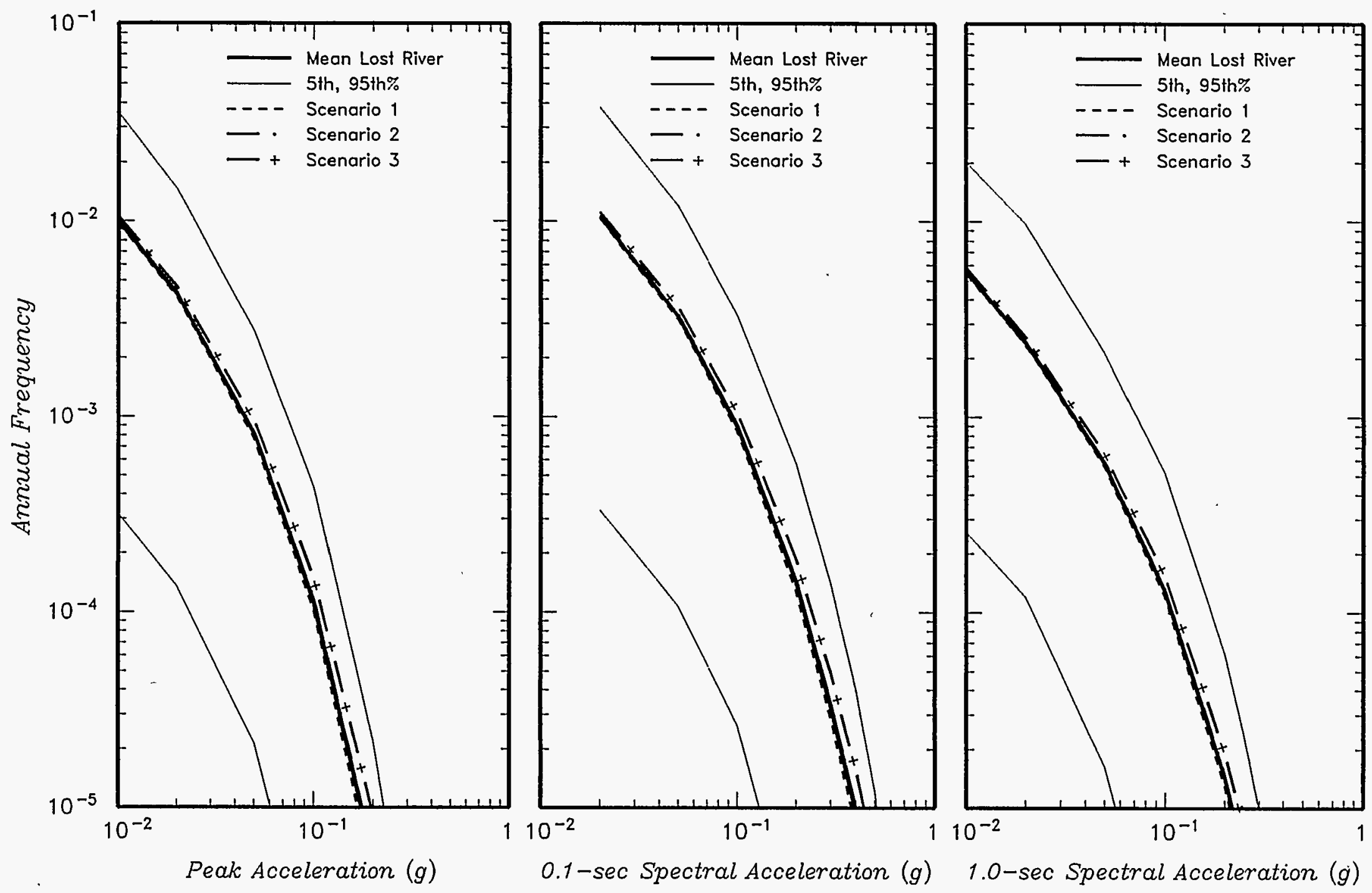

\begin{tabular}{|c|c|c|c|}
\hline $\begin{array}{c}\text { Project No. } \\
\text { SK9455 }\end{array}$ & INEL - Probabilistic Analyses & $\begin{array}{c}\text { EFFECT OF LOCATION OF SOUTHERN } \\
\text { TERMINATION OF LOST RIVER FAULT } \\
\text { ON SEISMIC HAZARD AT ANL }\end{array}$ & $\begin{array}{c}\text { Figure } \\
6-13 a\end{array}$ \\
\hline \multicolumn{2}{|c|}{ Woodward-Clyde Federal Services } & \begin{tabular}{c} 
ON SEl \\
\hline
\end{tabular}
\end{tabular}




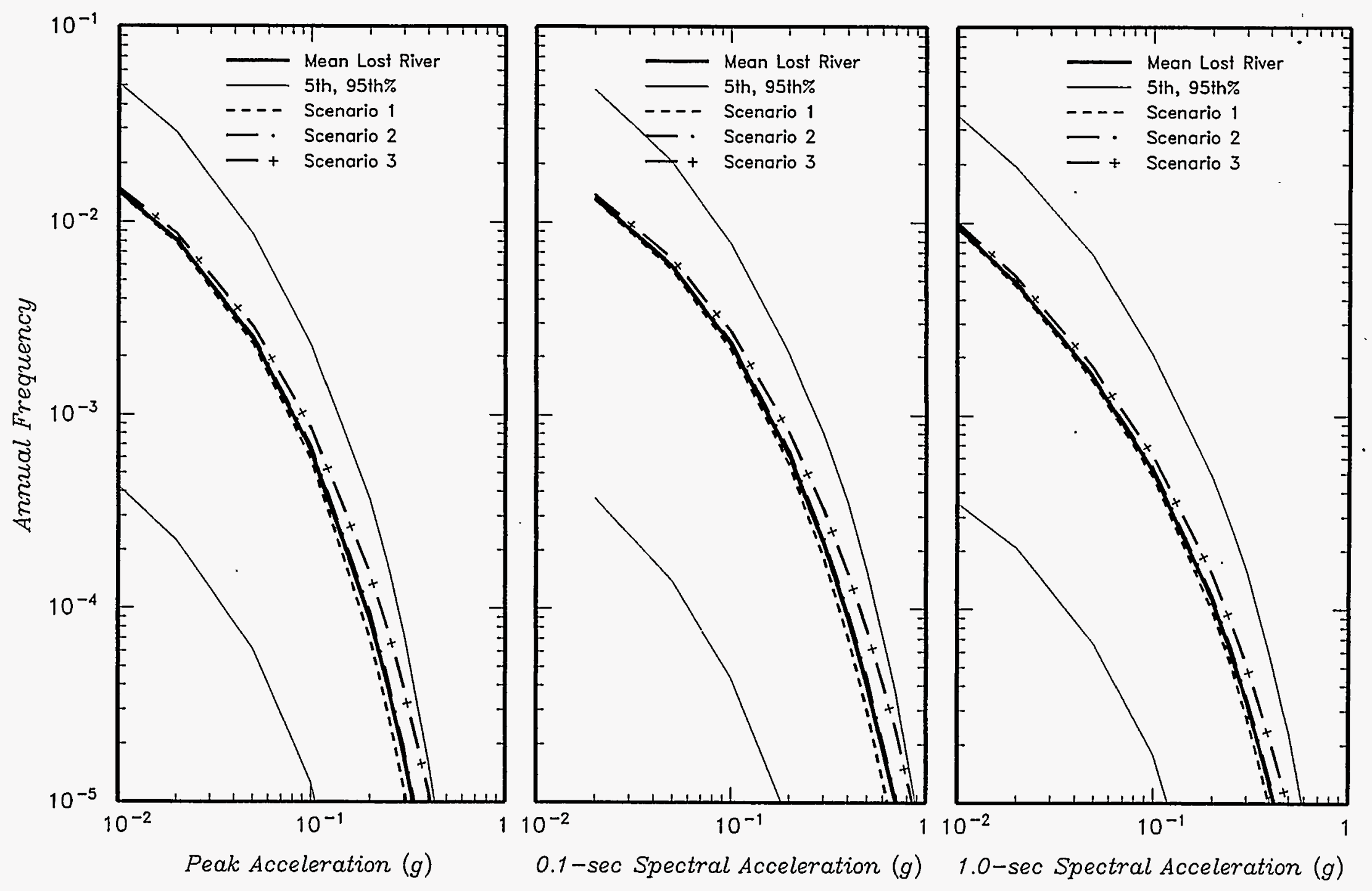

\begin{tabular}{|c|c|c|}
\hline $\begin{array}{l}\text { Project No. } \\
\text { SK9455 }\end{array}$ & INEL - Probabilistic Analyses & \multirow{2}{*}{$\begin{array}{l}\text { EFFECT OF LOCATION OF SOUTHERN } \\
\text { TERMINATION OF LOST RIVER FAULT } \\
\text { ON SEISMIC HAZARD AT ATR }\end{array}$} \\
\hline Woodw & tyde Fe & \\
\hline
\end{tabular}




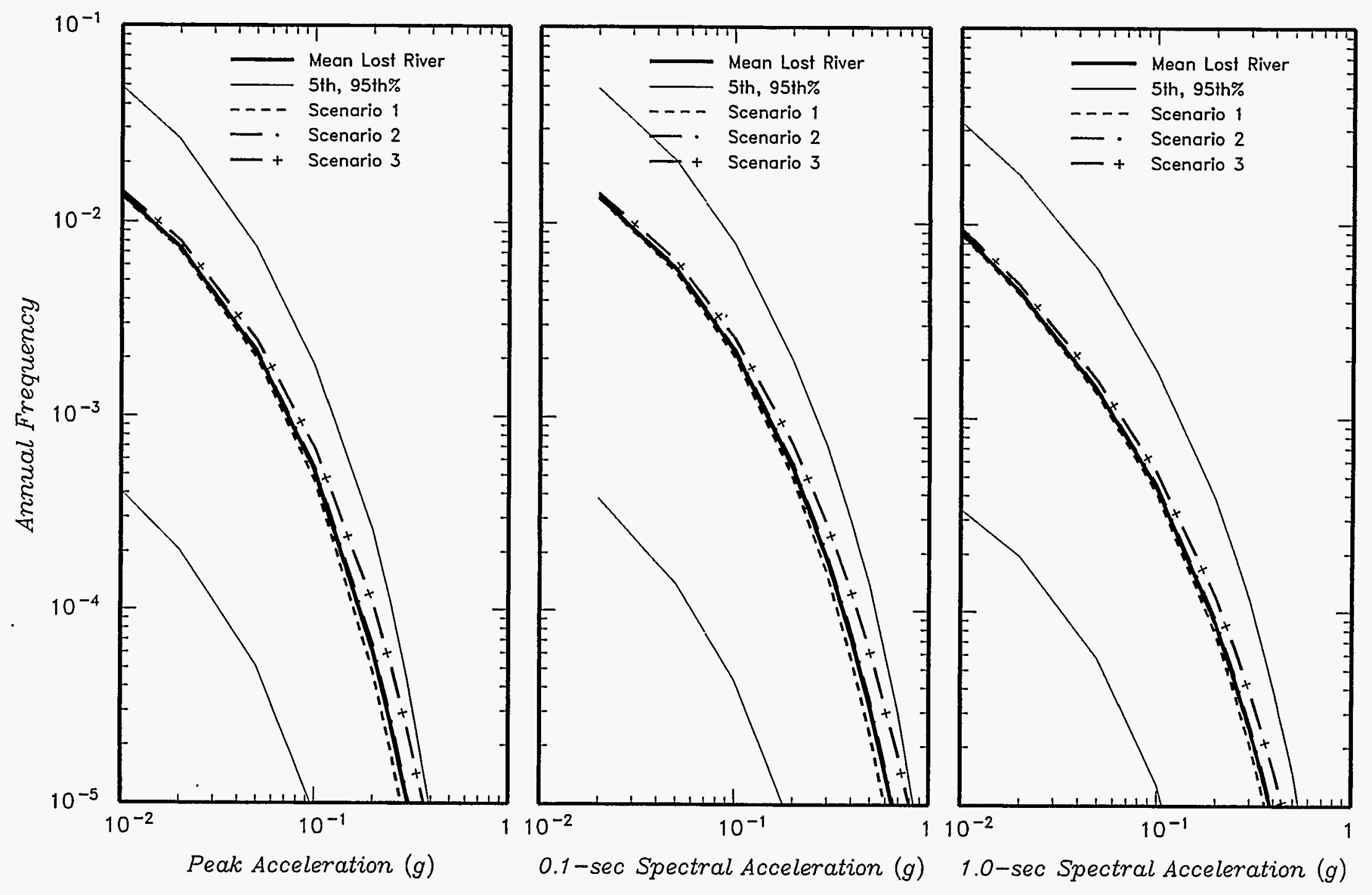

\begin{tabular}{|c|c|c|c|}
\hline $\begin{array}{c}\text { Project No. } \\
\text { SK9455 }\end{array}$ & INEL - Probabilistic Analyses & \multirow{2}{*}{$\begin{array}{c}\text { EFFECT OF LOCATION OF SOUTHERN } \\
\text { TERMINATION OF LOST RIVER FAULT } \\
\text { ON SEISMIC HAZARD AT CPP }\end{array}$} & \multirow{2}{*}{$\begin{array}{l}\text { Figure } \\
6-13 c\end{array}$} \\
\hline Woodwa & Clyde Federal Services & & \\
\hline
\end{tabular}



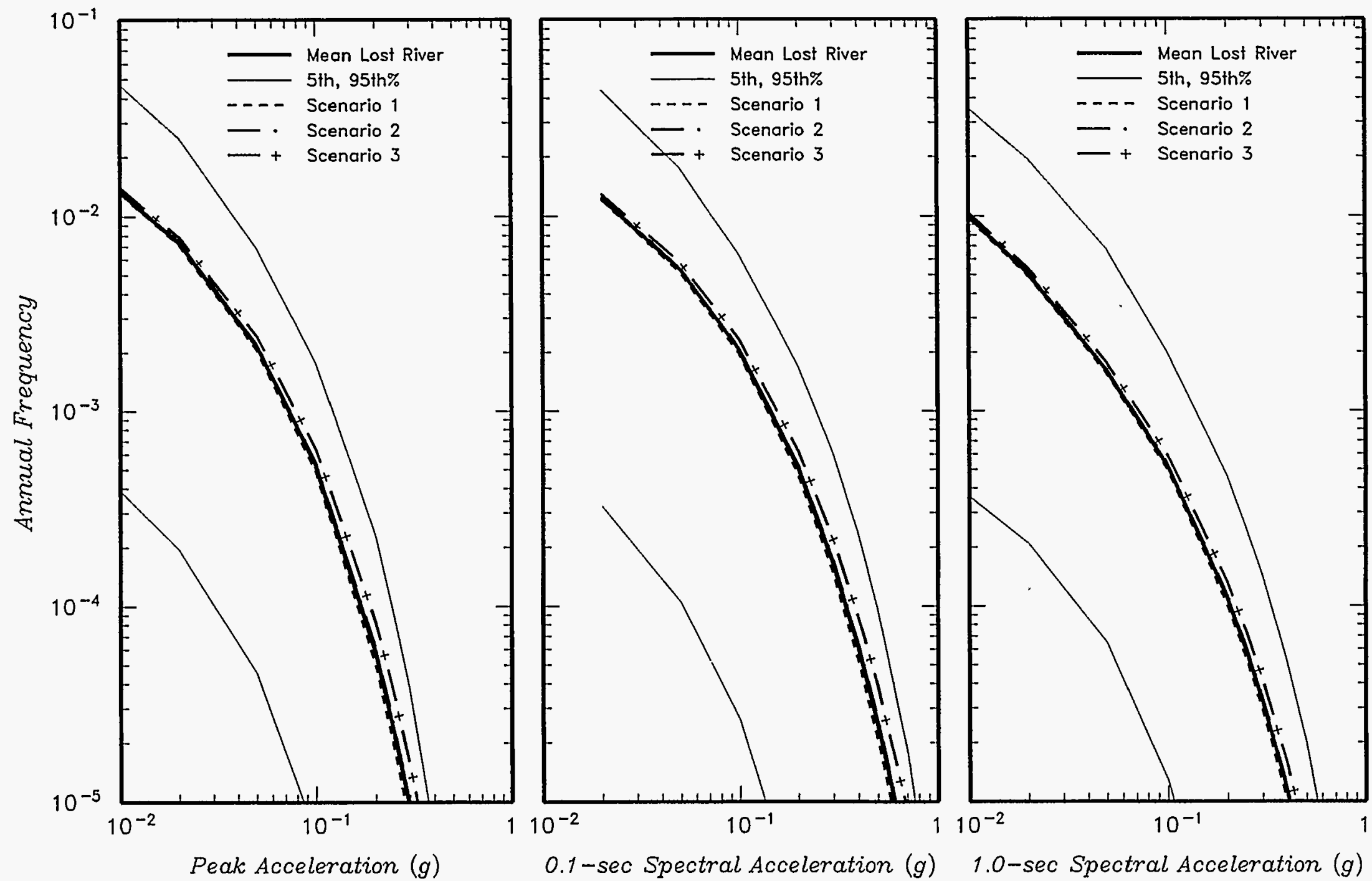

SK9455-A 1000/122895/vone

\begin{tabular}{|c|c|}
\hline $\begin{array}{l}\text { Project No. } \\
\text { SK9455 }\end{array}$ & INEL - Probabilistic Analyses \\
\hline an & $\lambda$ \\
\hline
\end{tabular}




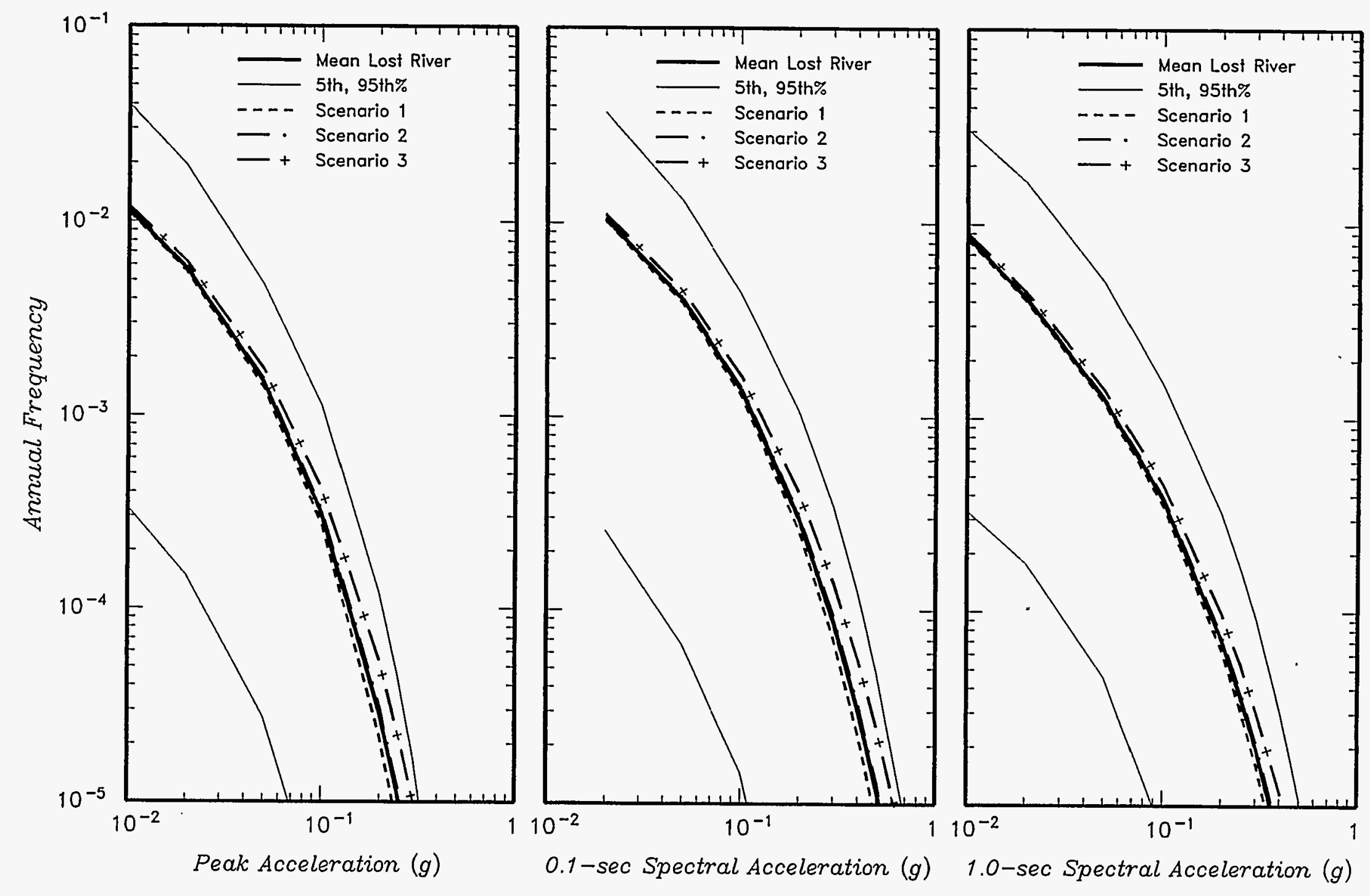

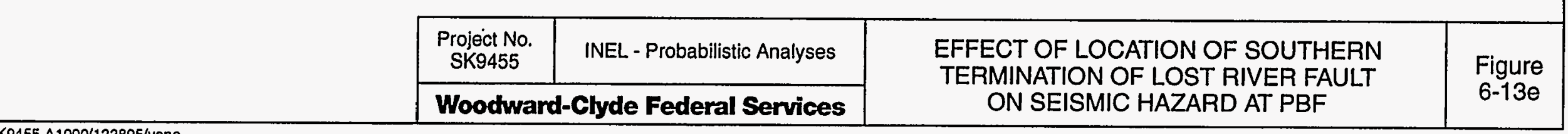



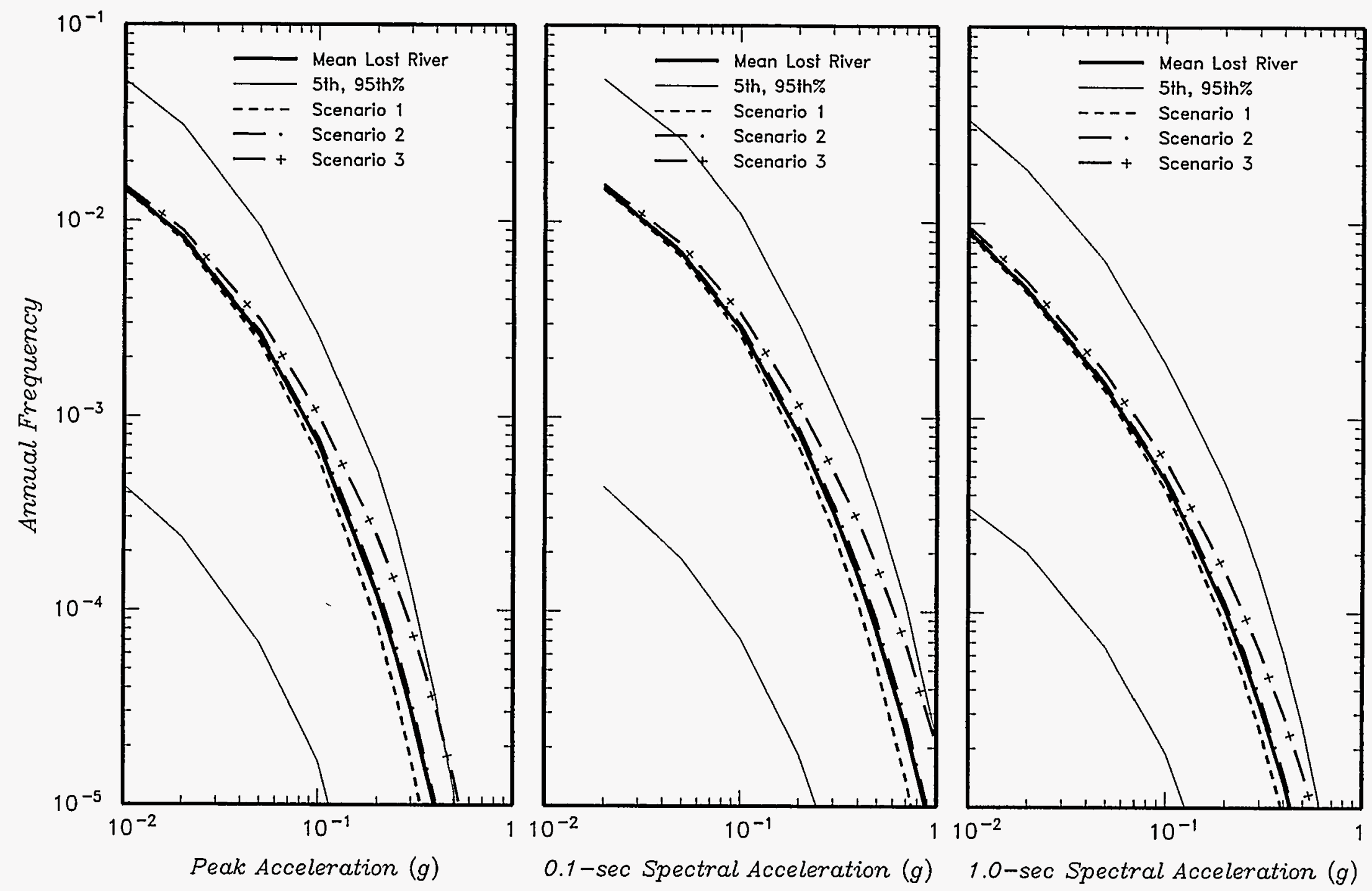

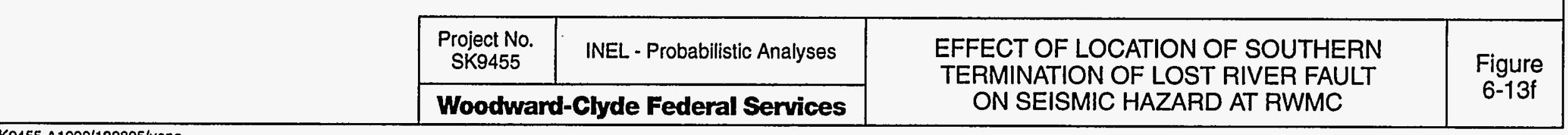



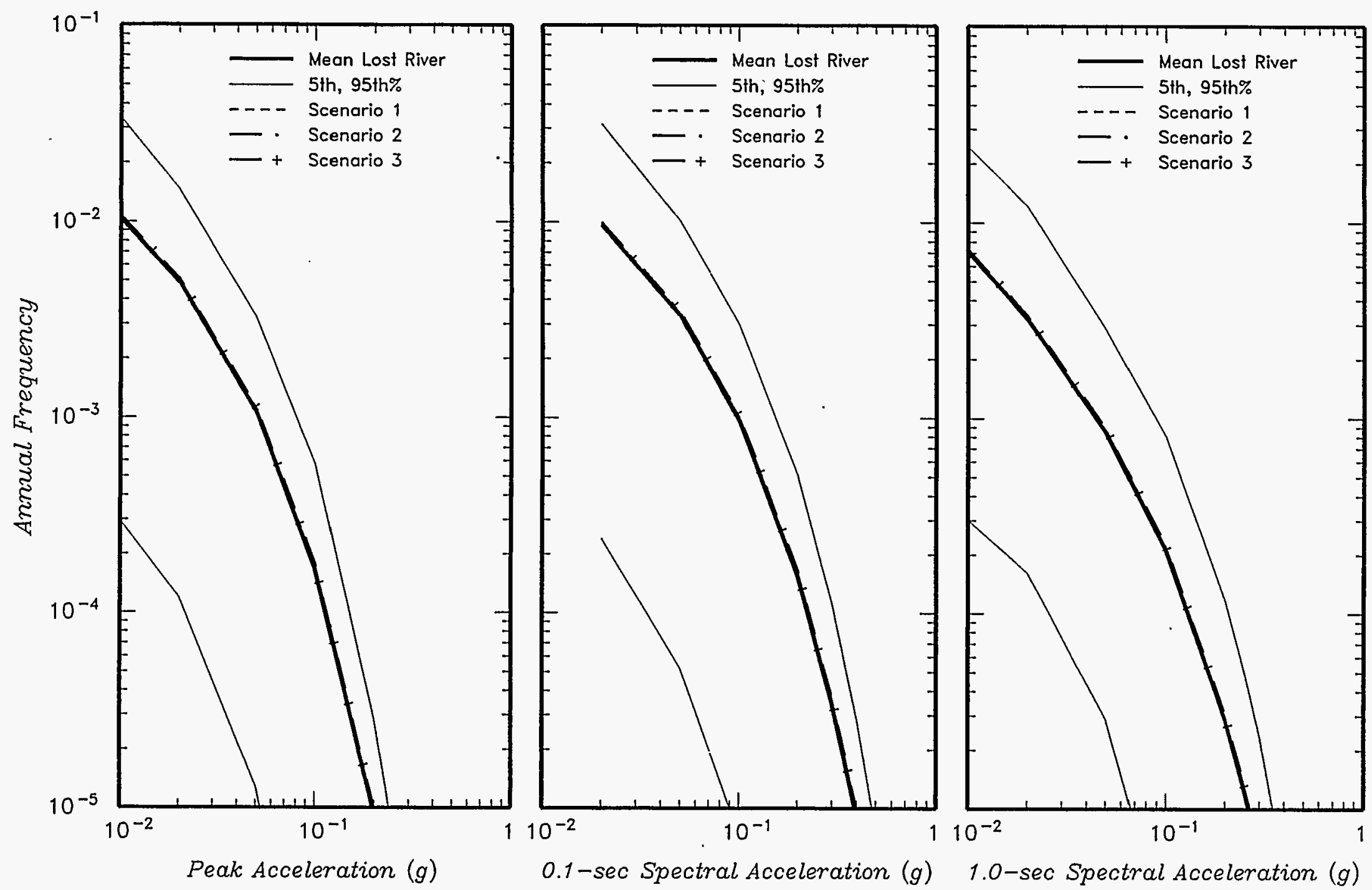

\begin{tabular}{|c|c|}
\hline $\begin{array}{c}\text { Project No. } \\
\text { SK9455 }\end{array}$ & INEL - Probabilistic Analyses \\
\hline
\end{tabular}
EFFECT OF LOCATION OF SOUTHERN TERMINATION OF LOST RIVER FAULT ON SEISMIC HAZARD AT TAN



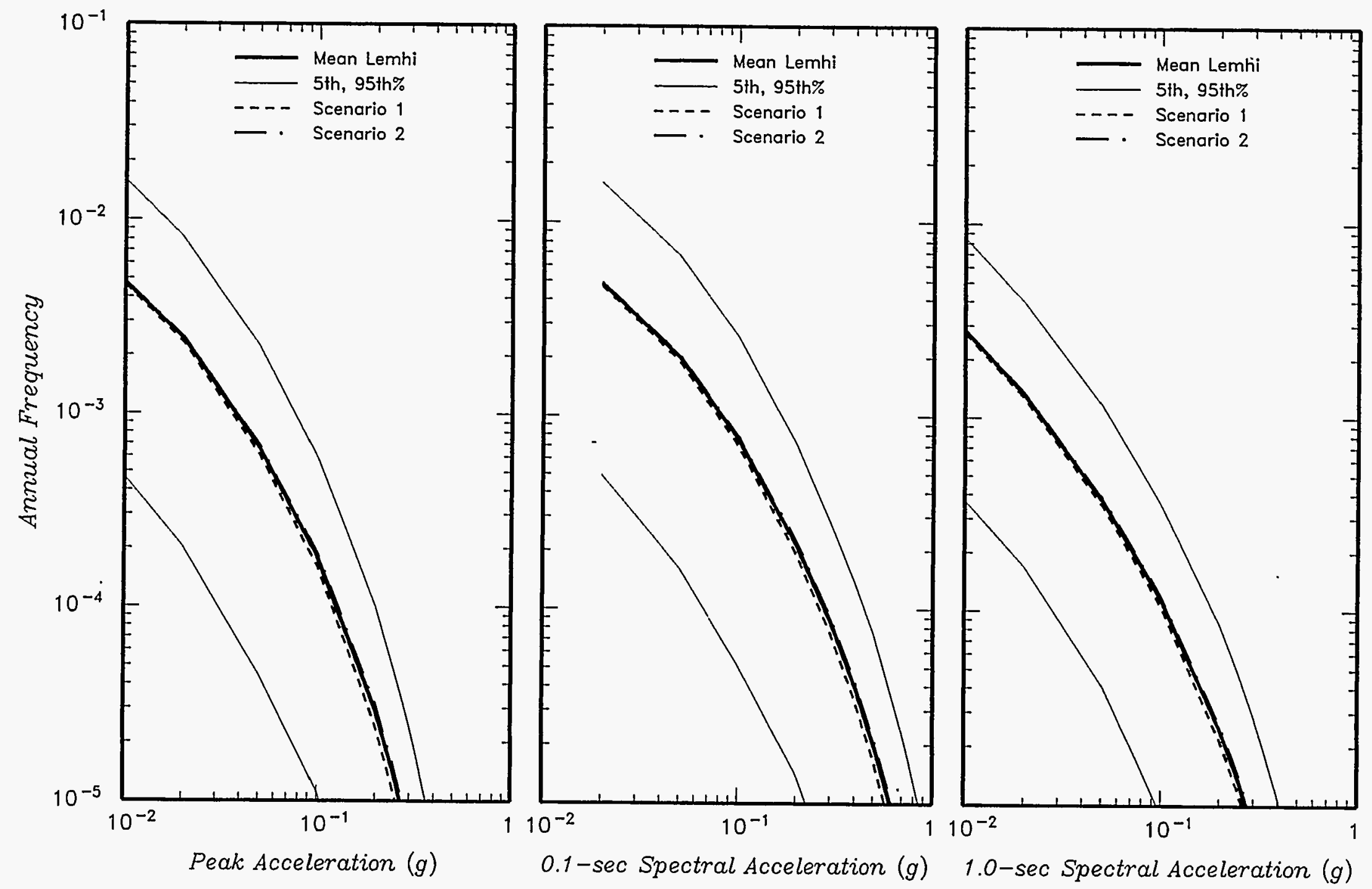

\begin{tabular}{|c|c|c|c|}
\hline $\begin{array}{l}\text { Project No. } \\
\text { SK9455 }\end{array}$ & INEL - Probabilistic Analyses & \multirow{2}{*}{$\begin{array}{c}\text { EFFECT OF LOCATION OF SOUTHERN } \\
\text { TERMINATION OF LEMHI FAULT } \\
\text { ON SEISMIC HAZARD AT ANL }\end{array}$} & \multirow{2}{*}{$\begin{array}{l}\text { Figure } \\
6-14 a\end{array}$} \\
\hline \multicolumn{2}{|r|}{ Plyde Federal Services } & & \\
\hline
\end{tabular}




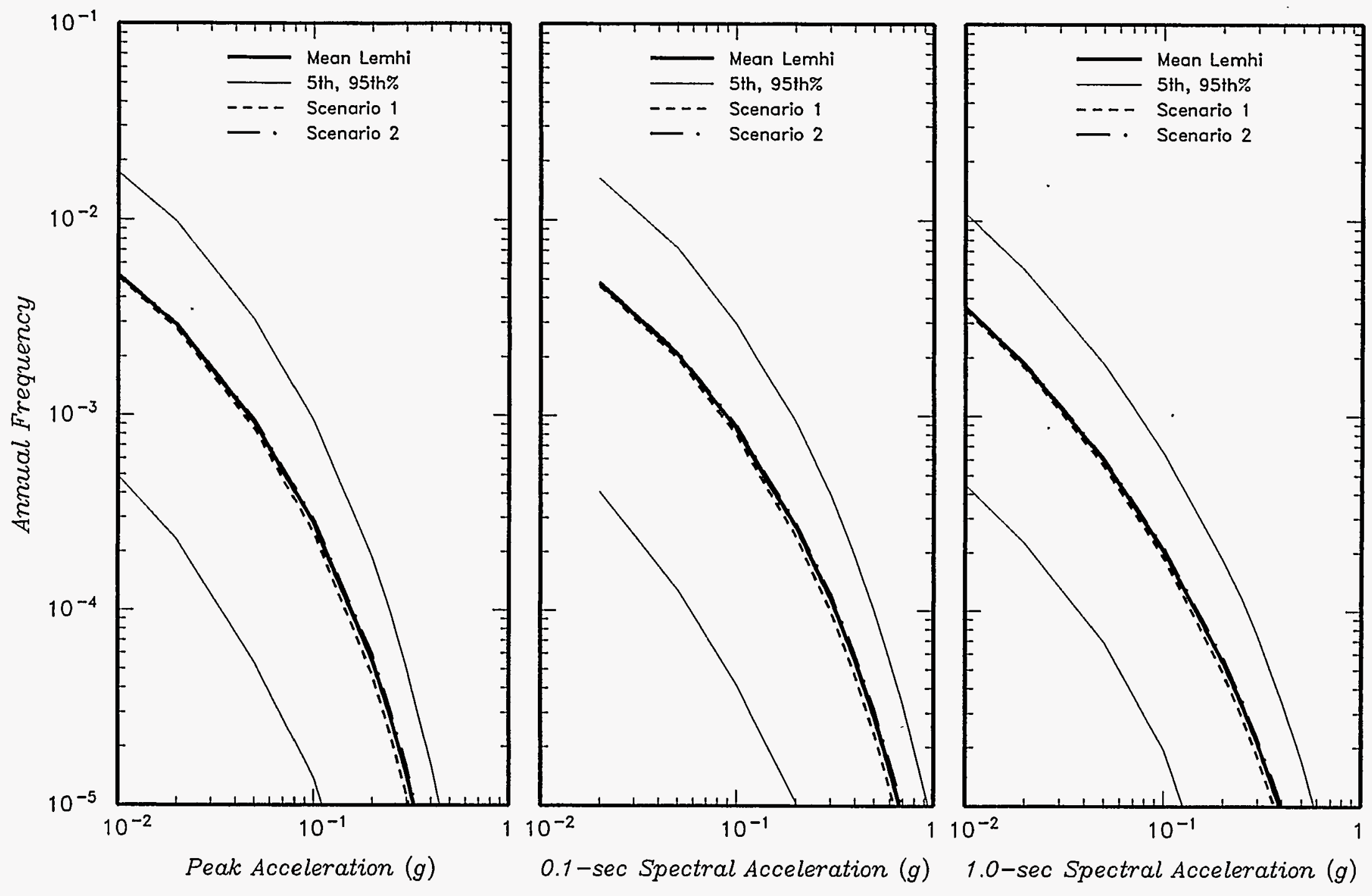

SK9455-A1000/122895/vone

\begin{tabular}{c|c}
$\begin{array}{c}\text { Project No. } \\
\text { SK9455 }\end{array}$ & INEL - Probabilistic Analyses \\
\hline
\end{tabular}

EFFECT OF LOCATION OF SOUTHERN TERMINATION OF LEMHI FAULT ON SEISMIC HAZARD AT ATR 

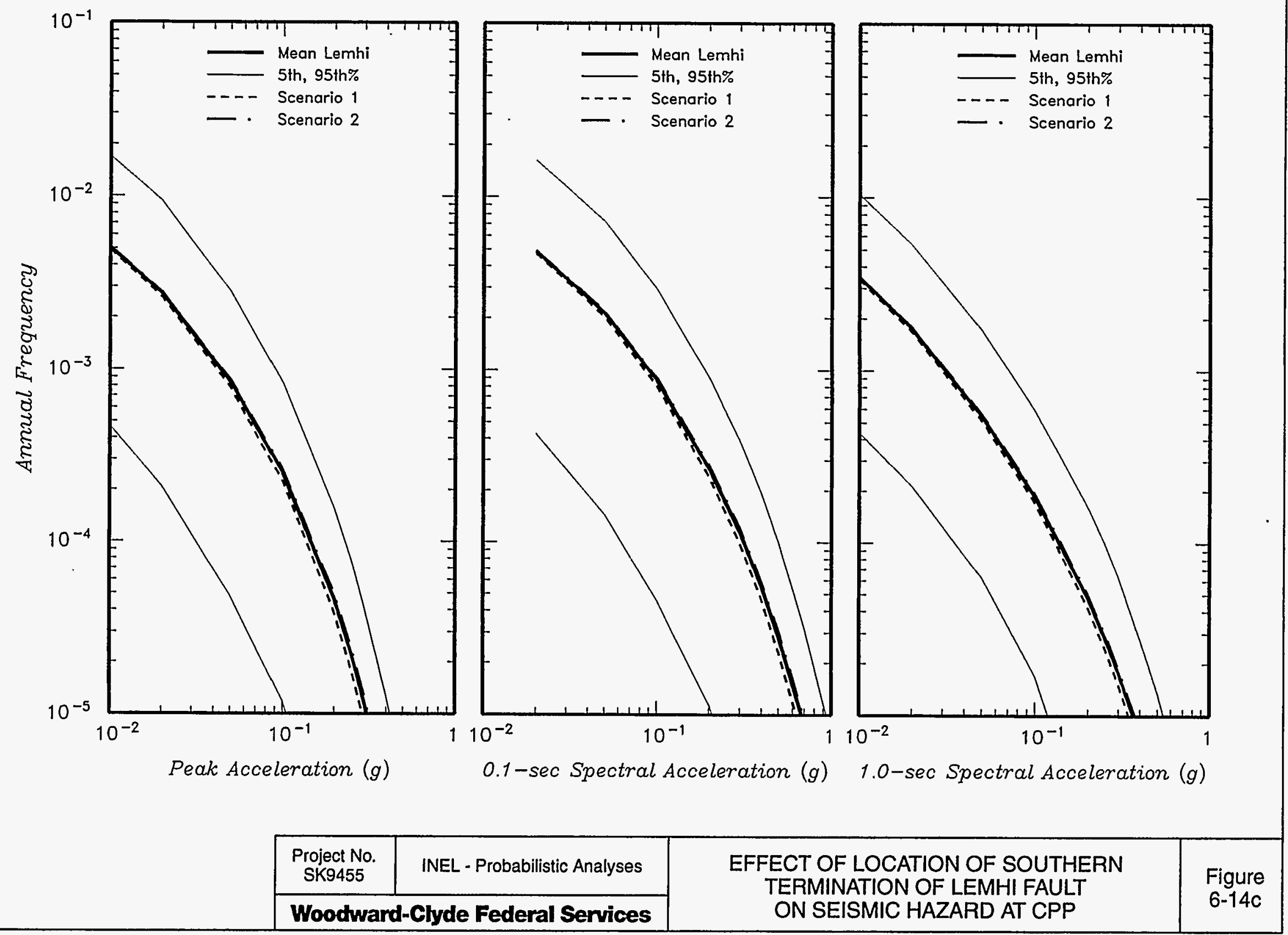

SK9455-A1000/122895/vone
TERMINATION OF LEMHI FAULT
ON SEISMIC HAZARD AT CPP



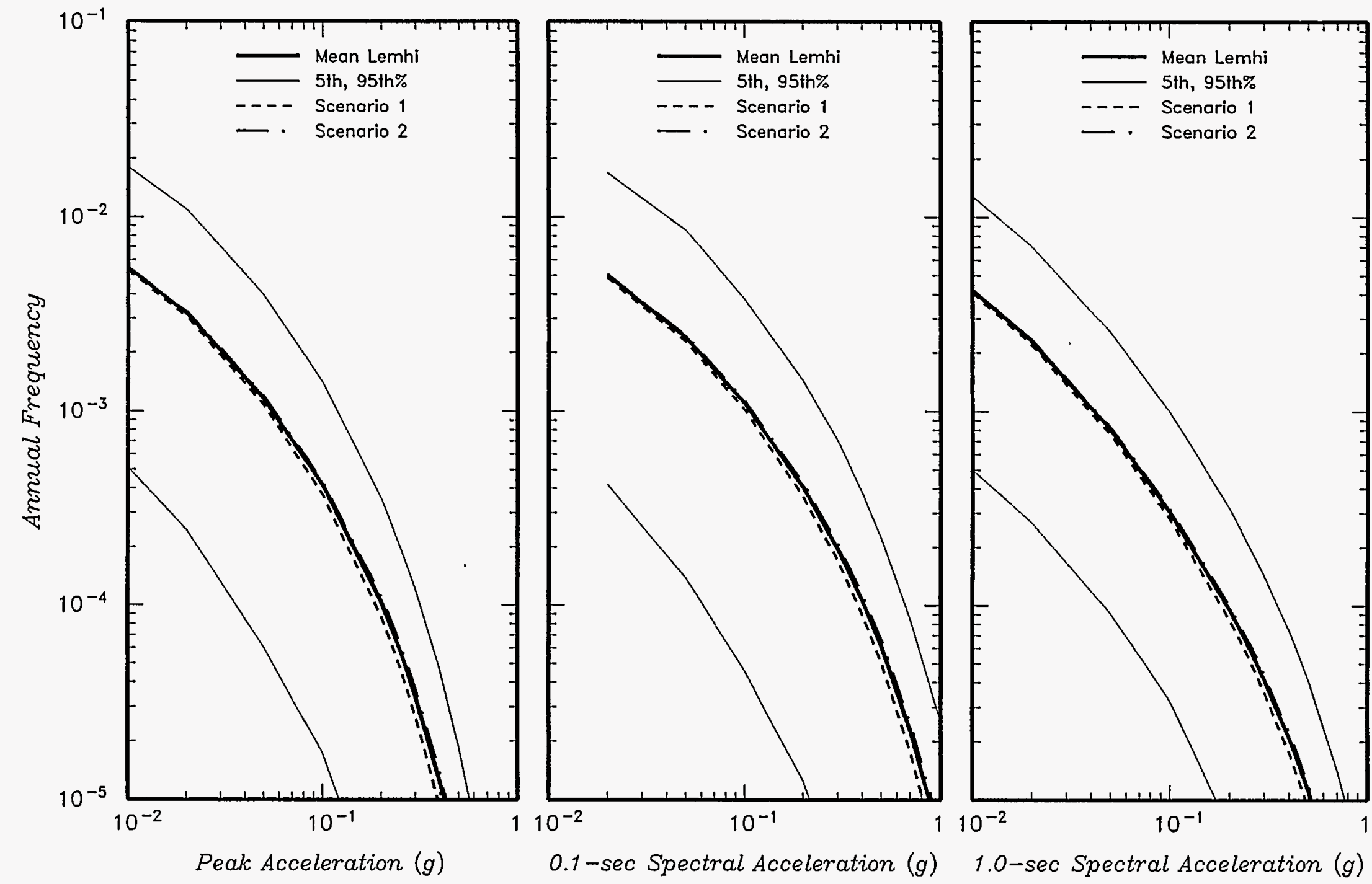

\begin{tabular}{|c|c|}
\hline $\begin{array}{c}\text { Project No. } \\
\text { SK9455 }\end{array}$ & INEL - Probabilistic Analyses \\
\hline
\end{tabular}

EFFECT OF LOCATION OF SOUTHERN TERMINATION OF LEMHI FAULT ON SEISMIC HAZARD AT NRF 


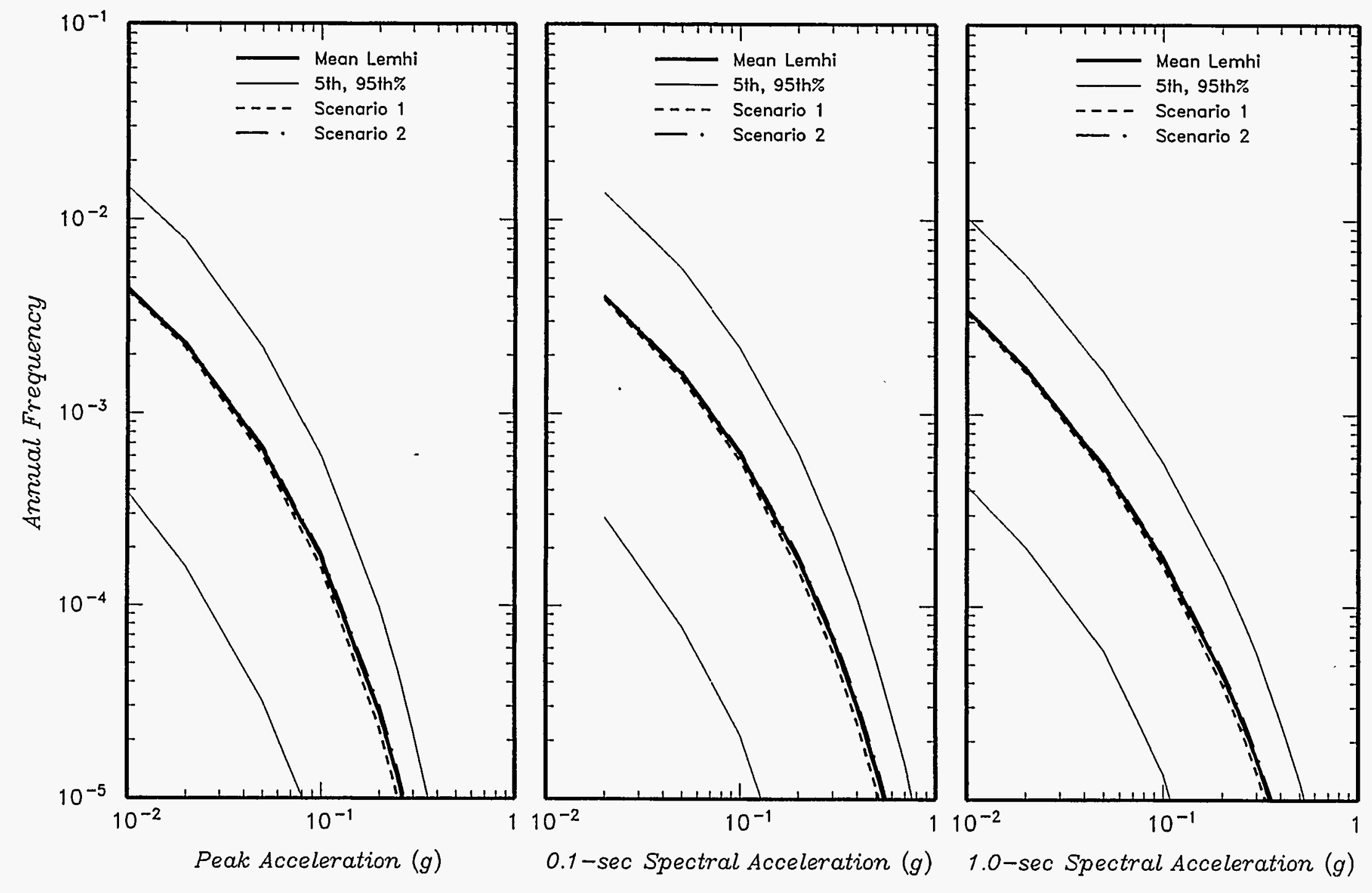



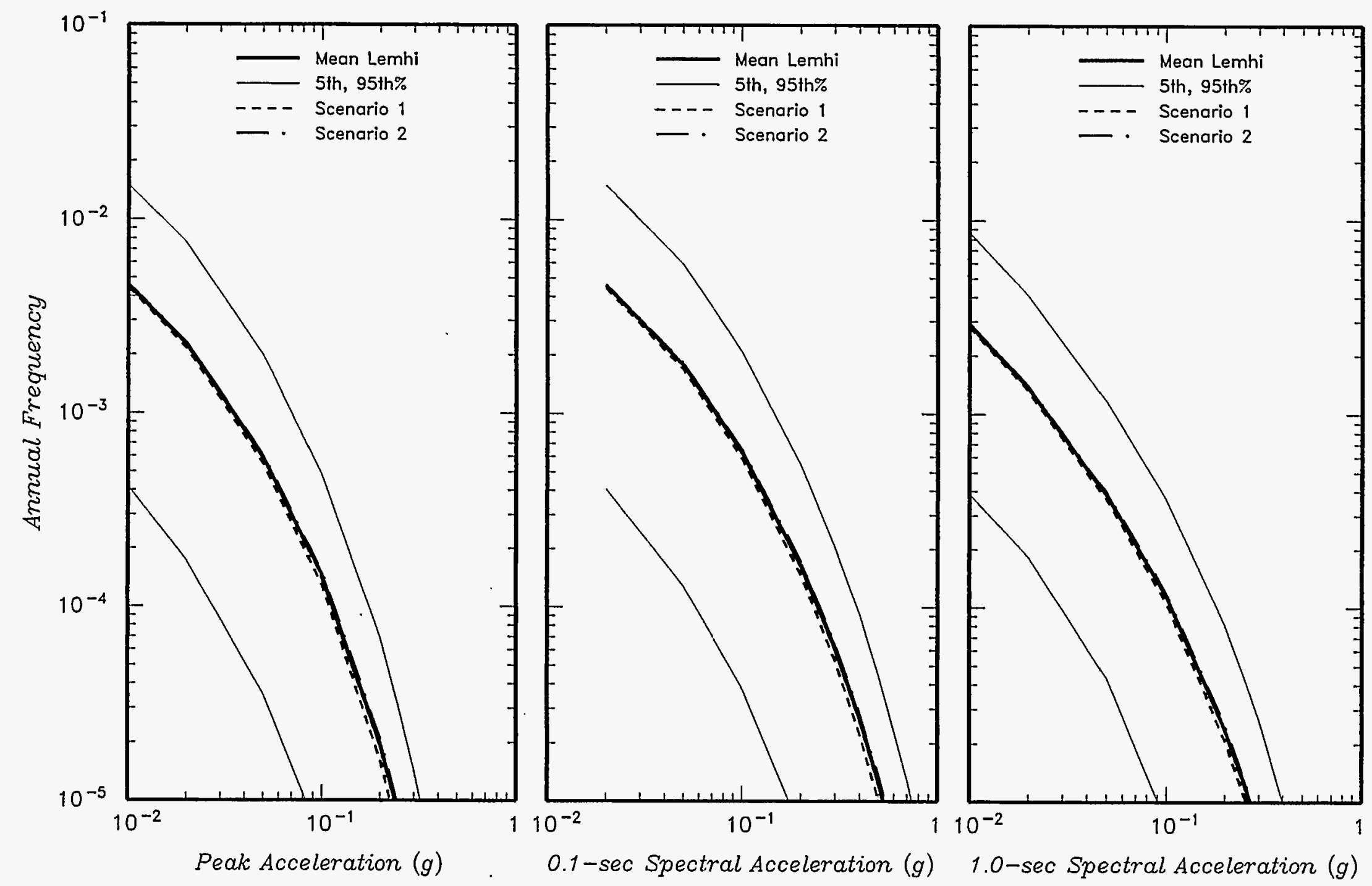

\begin{tabular}{|c|c|}
\hline $\begin{array}{c}\text { Project No. } \\
\text { SK9455 }\end{array}$ & INEL - Probabilistic Analyses \\
\hline \multicolumn{2}{|c|}{ Woodward-Chyde Federal Services } \\
\hline
\end{tabular}
EFFECT OF LOCATION OF SOUTHERN TERMINATION OF LEMHI FAULT ON SEISMIC HAZARD AT RWMC




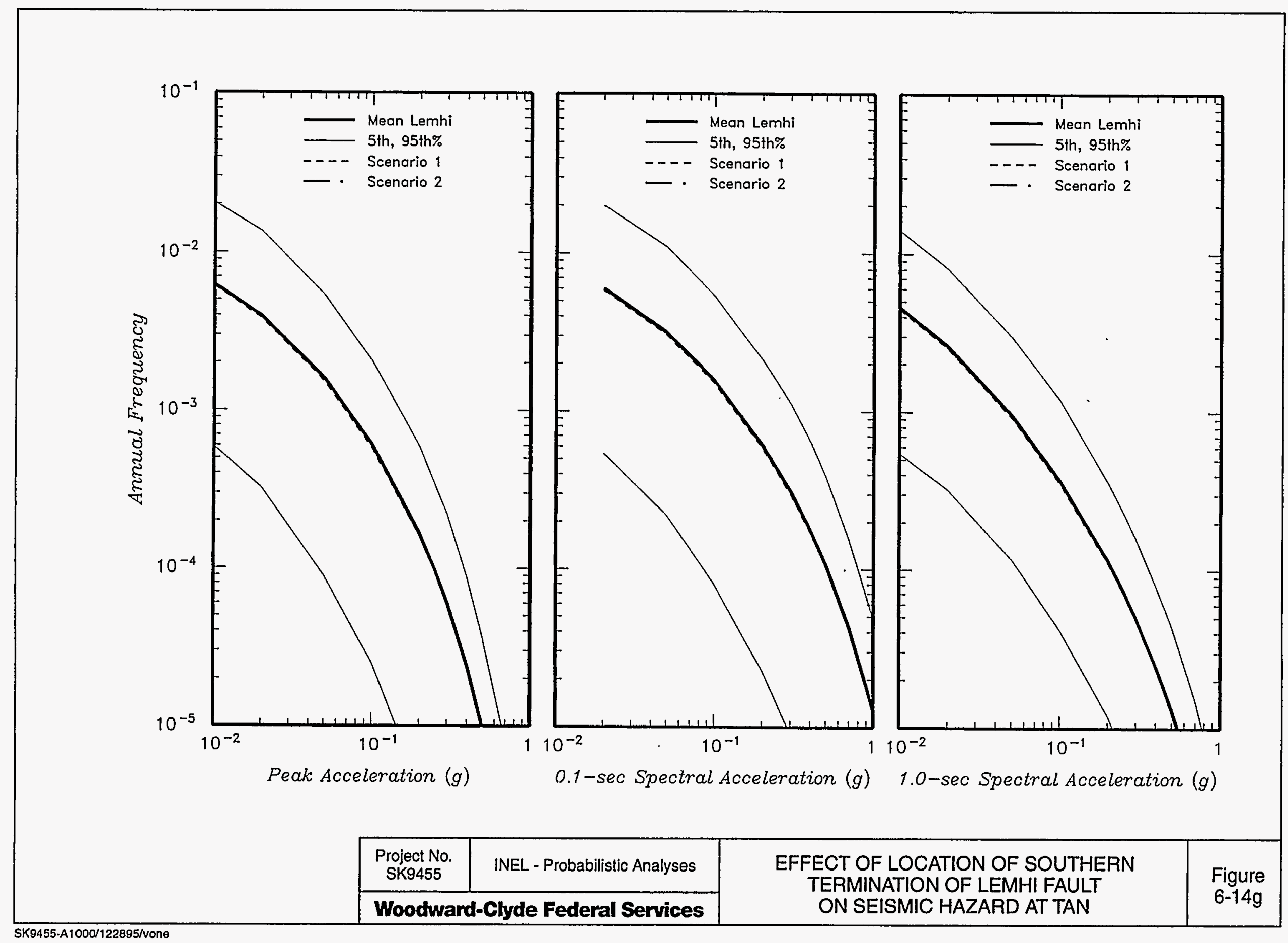




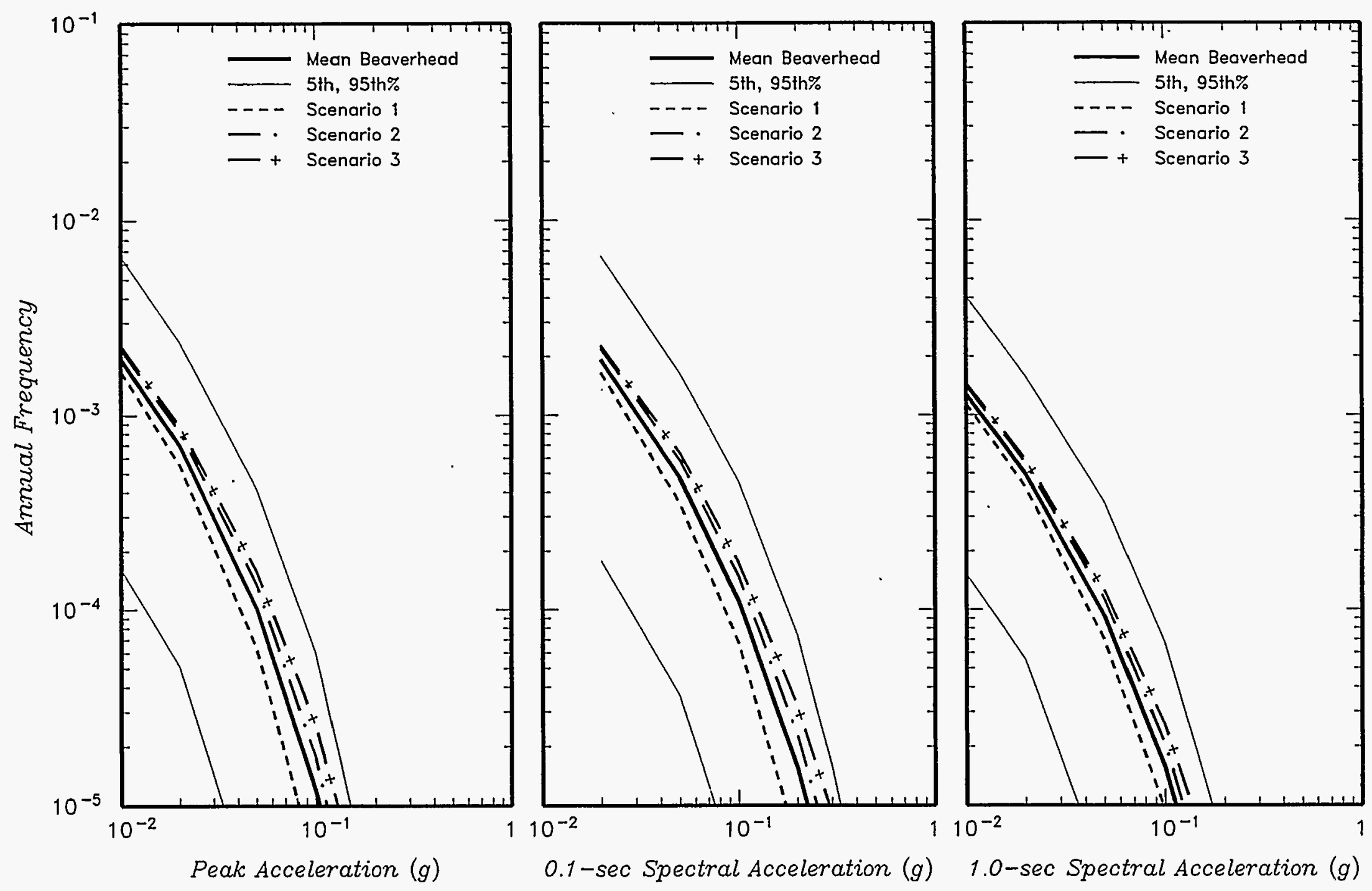

\begin{tabular}{|c|c|c|c|}
\hline $\begin{array}{l}\text { Project No. } \\
\text { SK9455 }\end{array}$ & INEL - Probabilistic Analyses & \multirow{2}{*}{$\begin{array}{c}\text { EFFECT OF LOCATION OF SOUTHERN } \\
\text { TERMINATION OF BEAVERHEAD FAULT } \\
\text { ON SEISMIC HAZARD AT ANL }\end{array}$} & \multirow{2}{*}{$\begin{array}{c}\text { Figure } \\
6-15 a\end{array}$} \\
\hline \multicolumn{2}{|c|}{ Woodward-Clyde Federal Senvices } & & \\
\hline
\end{tabular}




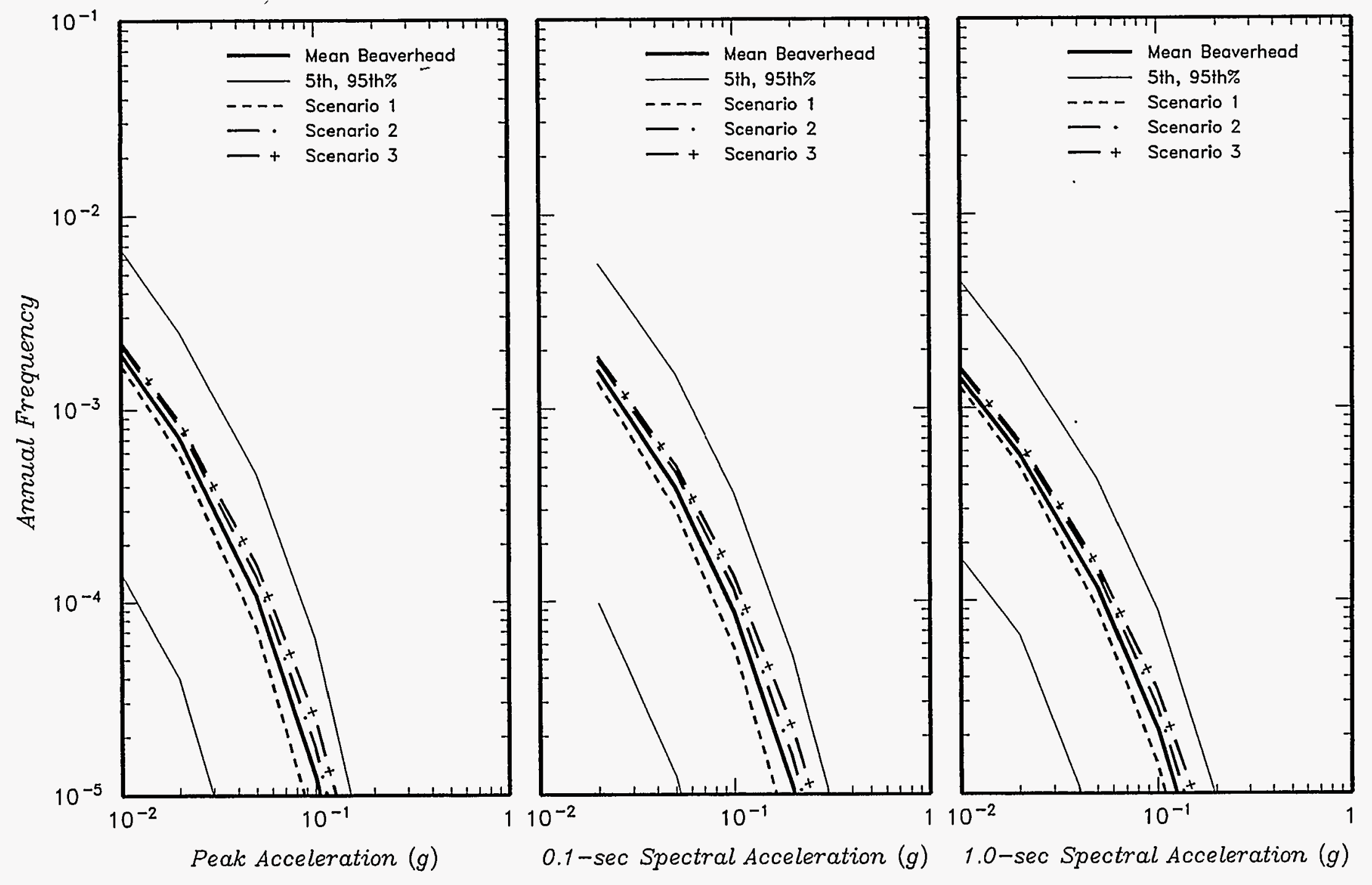

\begin{tabular}{|c|c|c|c|}
\hline $\begin{array}{l}\text { Project No. } \\
\text { SK9455 }\end{array}$ & INEL - Probabilistic Analyses & \multirow{2}{*}{$\begin{array}{c}\text { EFFECT OF LOCATION OF SOUTHERN } \\
\text { TERMINATION OF BEAVERHEAD FAULT } \\
\text { ON SEISMIC HAZARD AT ATR }\end{array}$} & \multirow{2}{*}{$\begin{array}{l}\text { Figure } \\
6-15 b\end{array}$} \\
\hline Woodwa & yde Fede & & \\
\hline
\end{tabular}



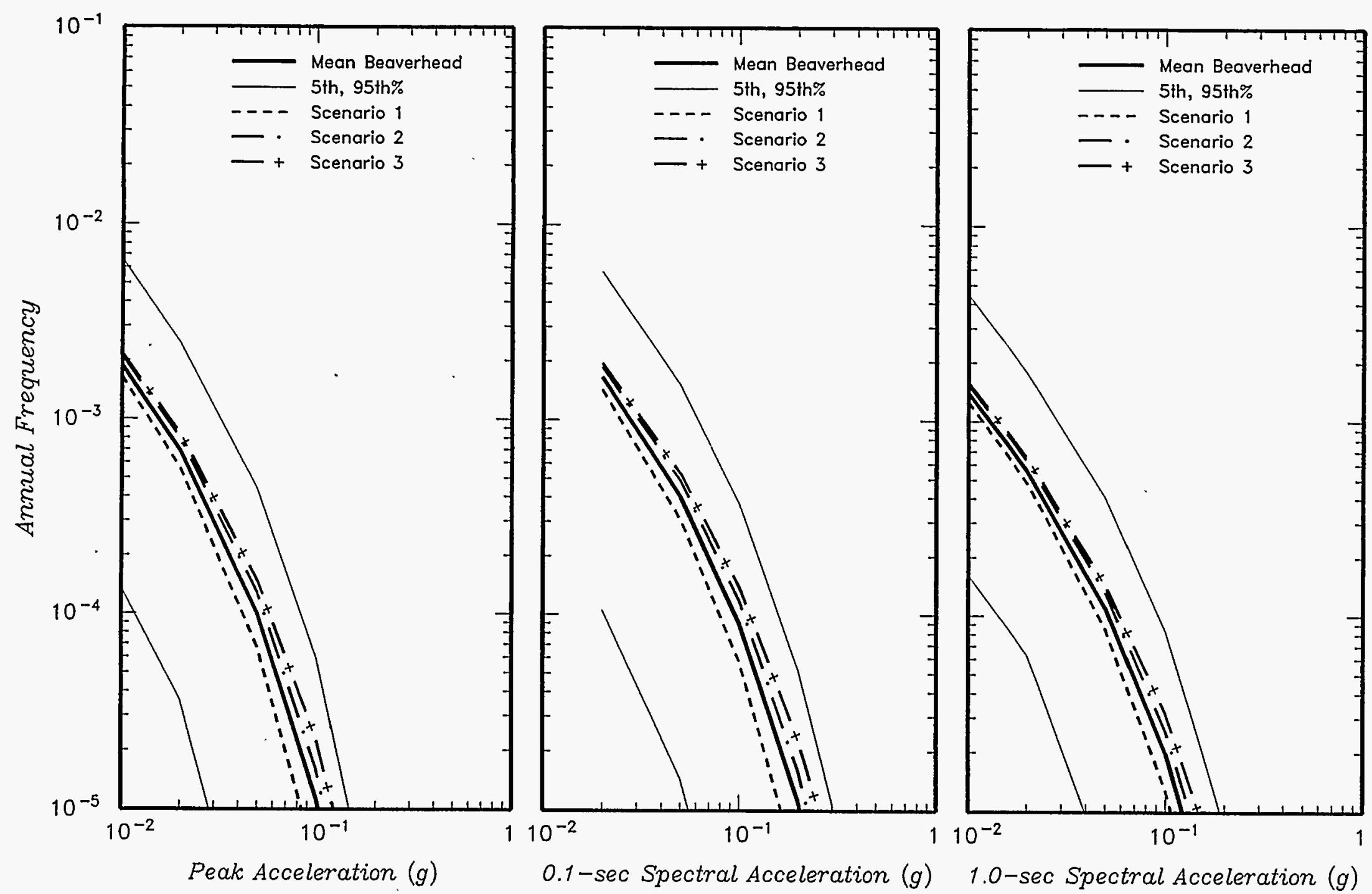

\begin{tabular}{|c|c|c|c|}
\hline $\begin{array}{l}\text { Project No. } \\
\text { SK9455 }\end{array}$ & INEL - Probabilistic Analyses & \multirow{2}{*}{$\begin{array}{c}\text { EFFECT OF LOCATION OF SOUTHERN } \\
\text { TERMINATION OF BEAVERHEAD FAULT } \\
\text { ON SEISMIC HAZARD AT CPP }\end{array}$} & \multirow{2}{*}{$\begin{array}{r}\text { Figure } \\
6-15 c\end{array}$} \\
\hline \multicolumn{2}{|c|}{ Woodward-Clyde Federal Services } & & \\
\hline
\end{tabular}




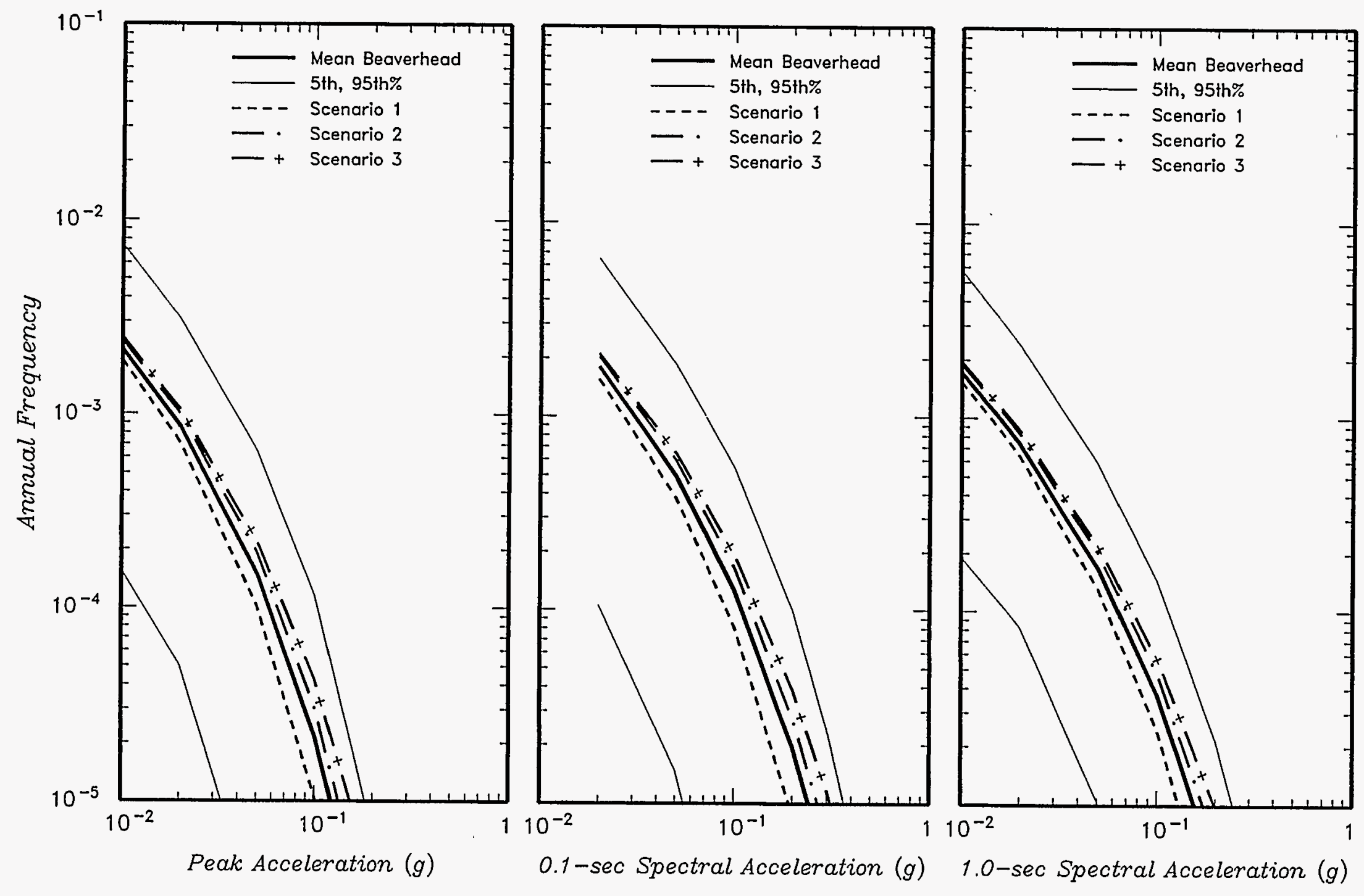

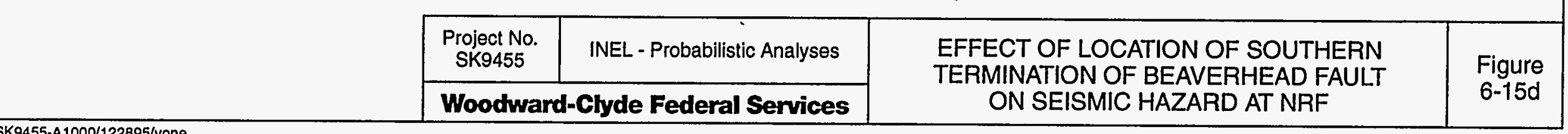



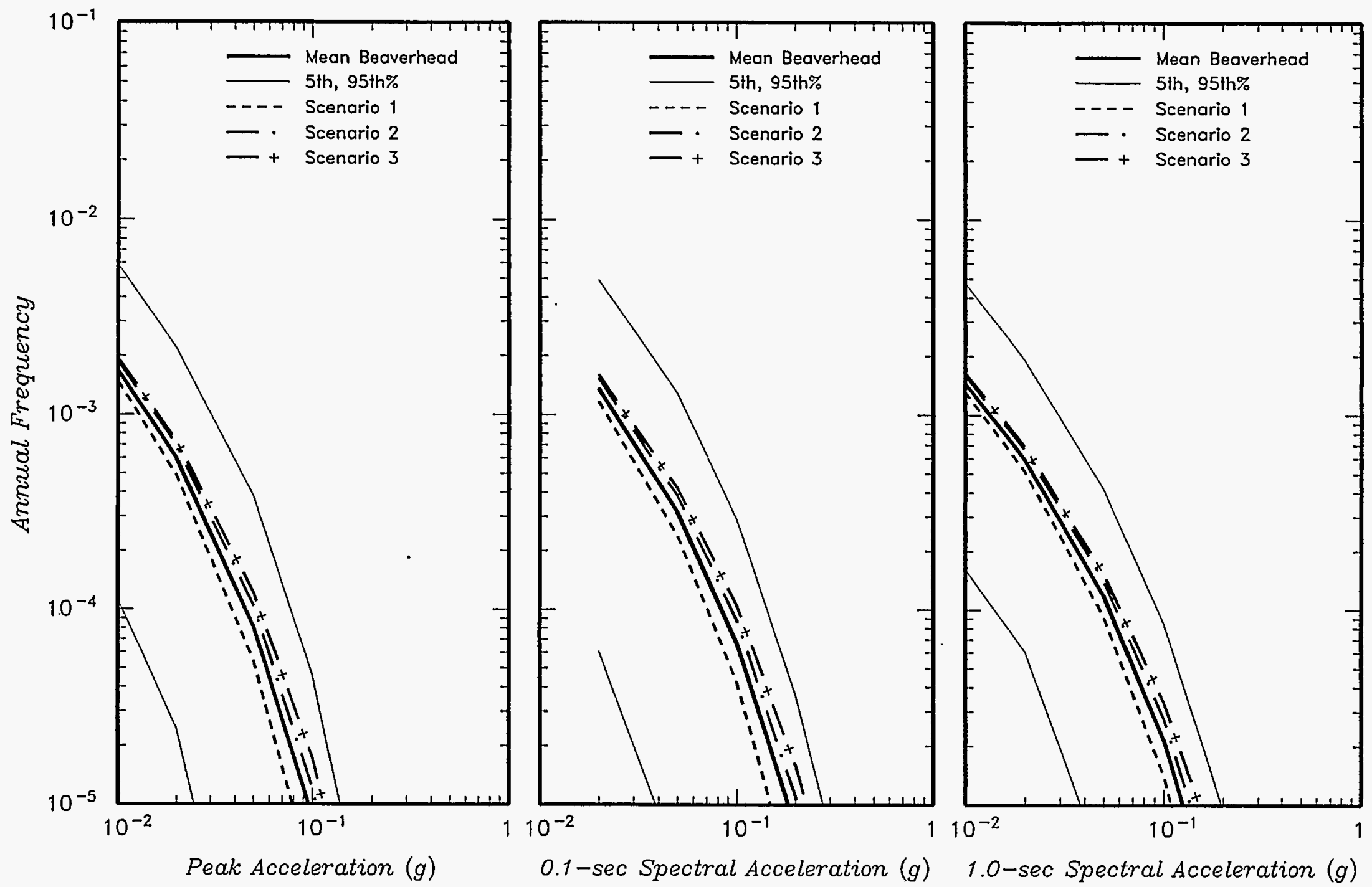

\begin{tabular}{|c|c|}
\hline $\begin{array}{l}\text { Project No. } \\
\text { SK9455 }\end{array}$ & INEL - Probabilistic Analyses \\
\hline Wos & \\
\hline
\end{tabular}




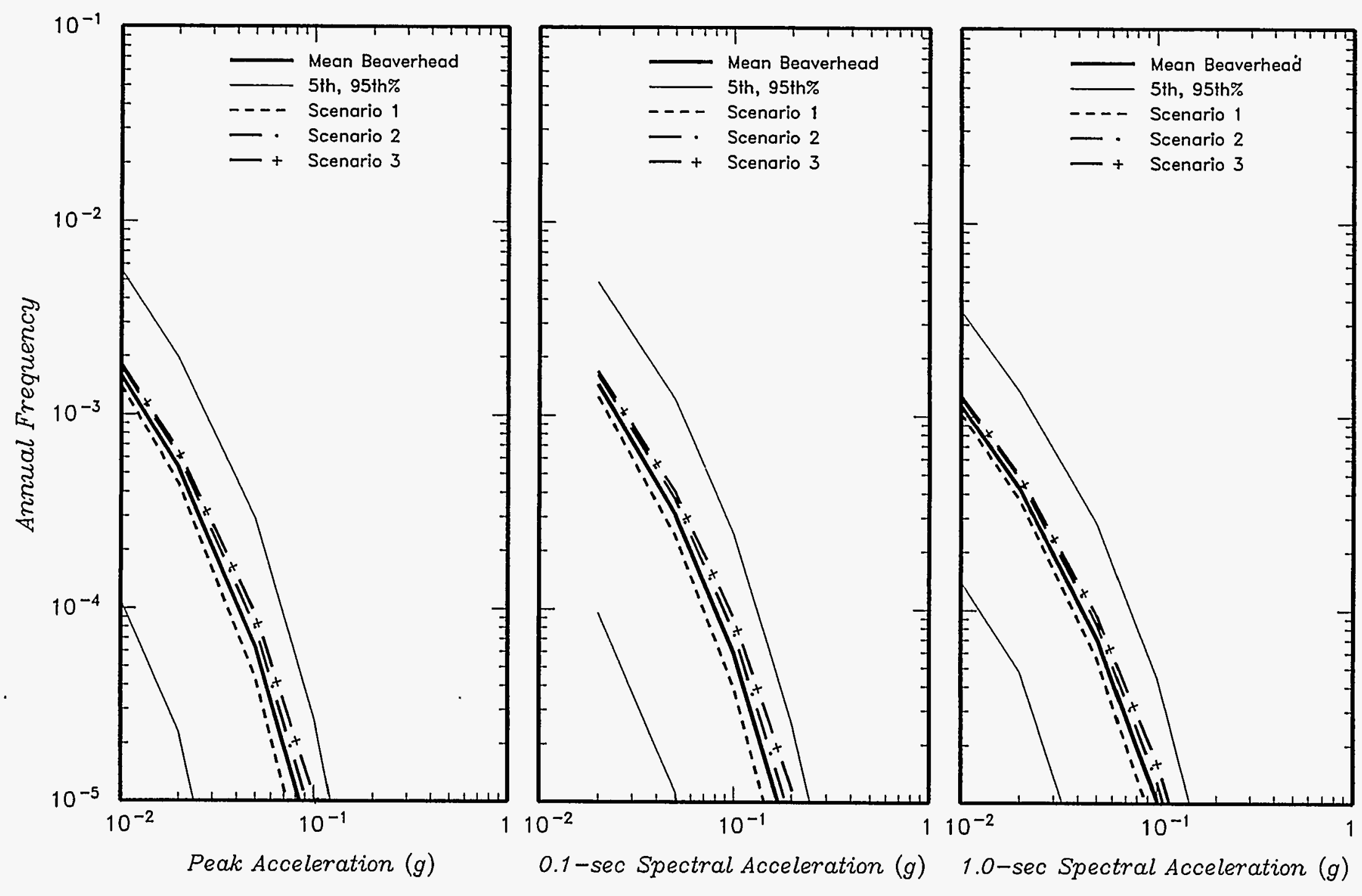

\begin{tabular}{|c|c|c|c|}
\hline $\begin{array}{c}\text { Project No. } \\
\text { SK9455 }\end{array}$ & INEL - Probabilistic Analyses & \multirow{2}{*}{$\begin{array}{l}\text { EFFECT OF LOCATION OF SOUTHERN } \\
\text { TERMINATION OF BEAVERHEAD FAULT } \\
\text { ON SEISMIC HAZARD AT RWMC }\end{array}$} & \multirow{2}{*}{$\begin{array}{c}\text { Figure } \\
6-15 f\end{array}$} \\
\hline Woodwa & Clyde Federal Services & & \\
\hline
\end{tabular}



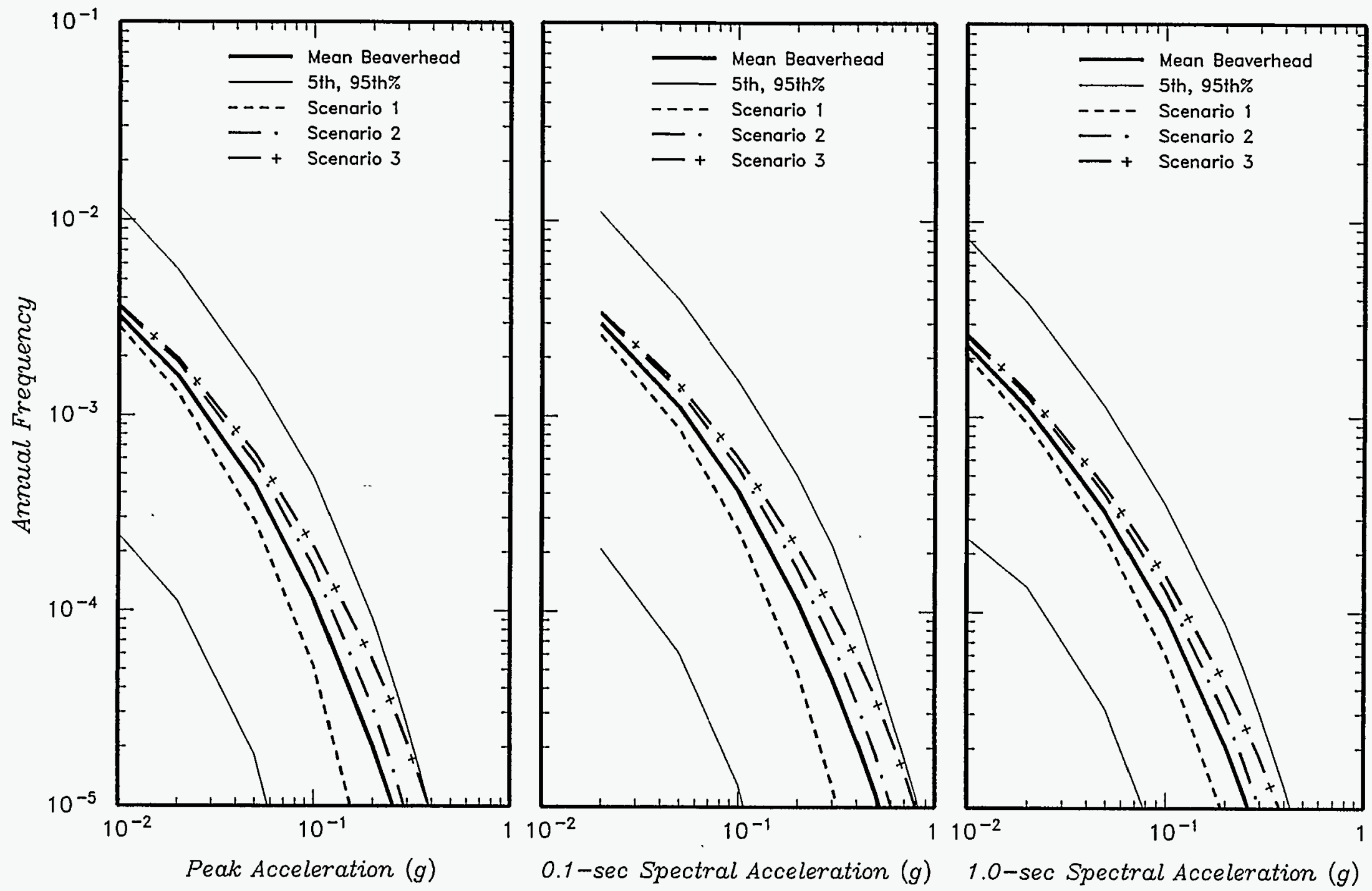

\begin{tabular}{|l|c|}
\hline $\begin{array}{c}\text { Project No. } \\
\text { SK9455 }\end{array}$ & INEL - Probabilistic Analyses \\
\hline \multicolumn{2}{|c|}{ Woodward-Clyde Federal Services } \\
\hline
\end{tabular}

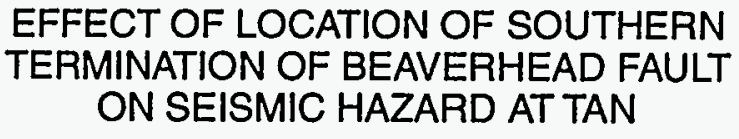



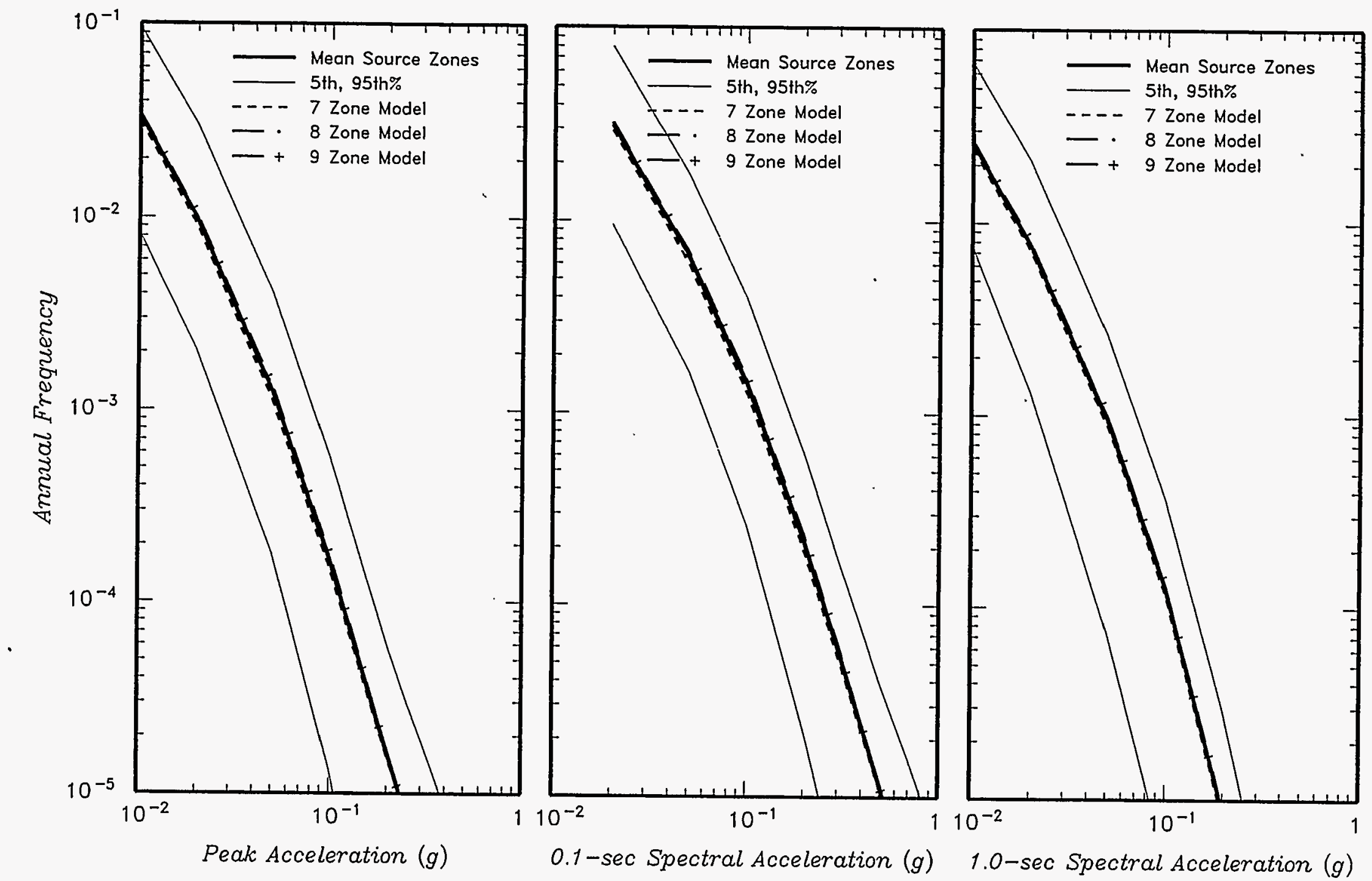

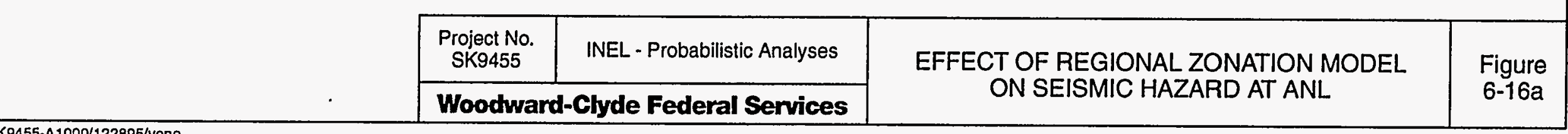



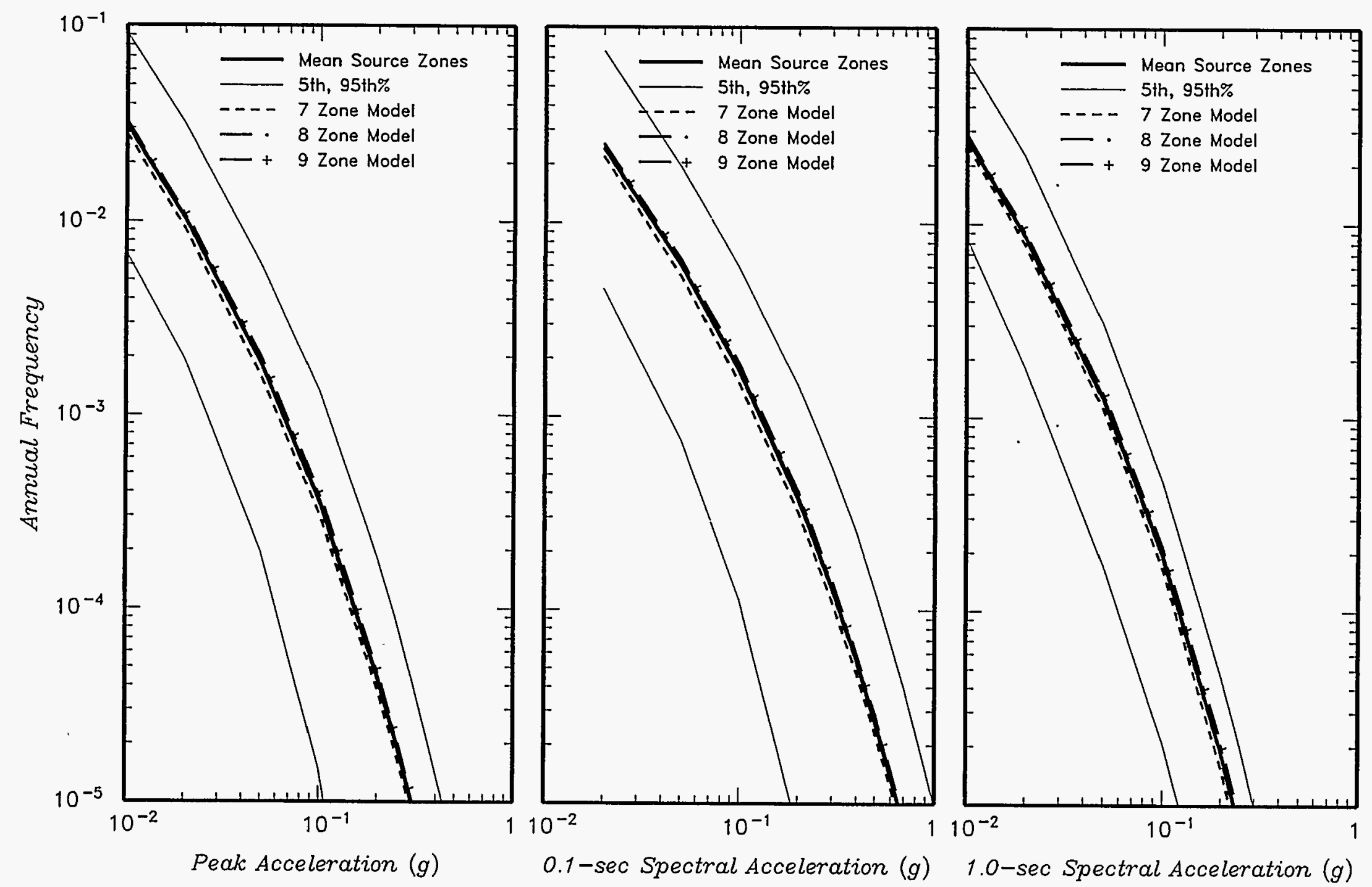

\begin{tabular}{|c|c|c|c|}
\hline $\begin{array}{l}\text { Project No. } \\
\text { SK9455 }\end{array}$ & INEL - Probábilistic Analyses & \multirow{2}{*}{$\begin{array}{c}\text { EFFECT OF REGIONAL ZONATION MODEL } \\
\text { ON SEISMIC HAZARD AT ATR }\end{array}$} & \multirow{2}{*}{$\begin{array}{l}\text { Figure } \\
6-16 b\end{array}$} \\
\hline \multicolumn{2}{|c|}{ Woodward-Clyde Federal Services } & & \\
\hline
\end{tabular}




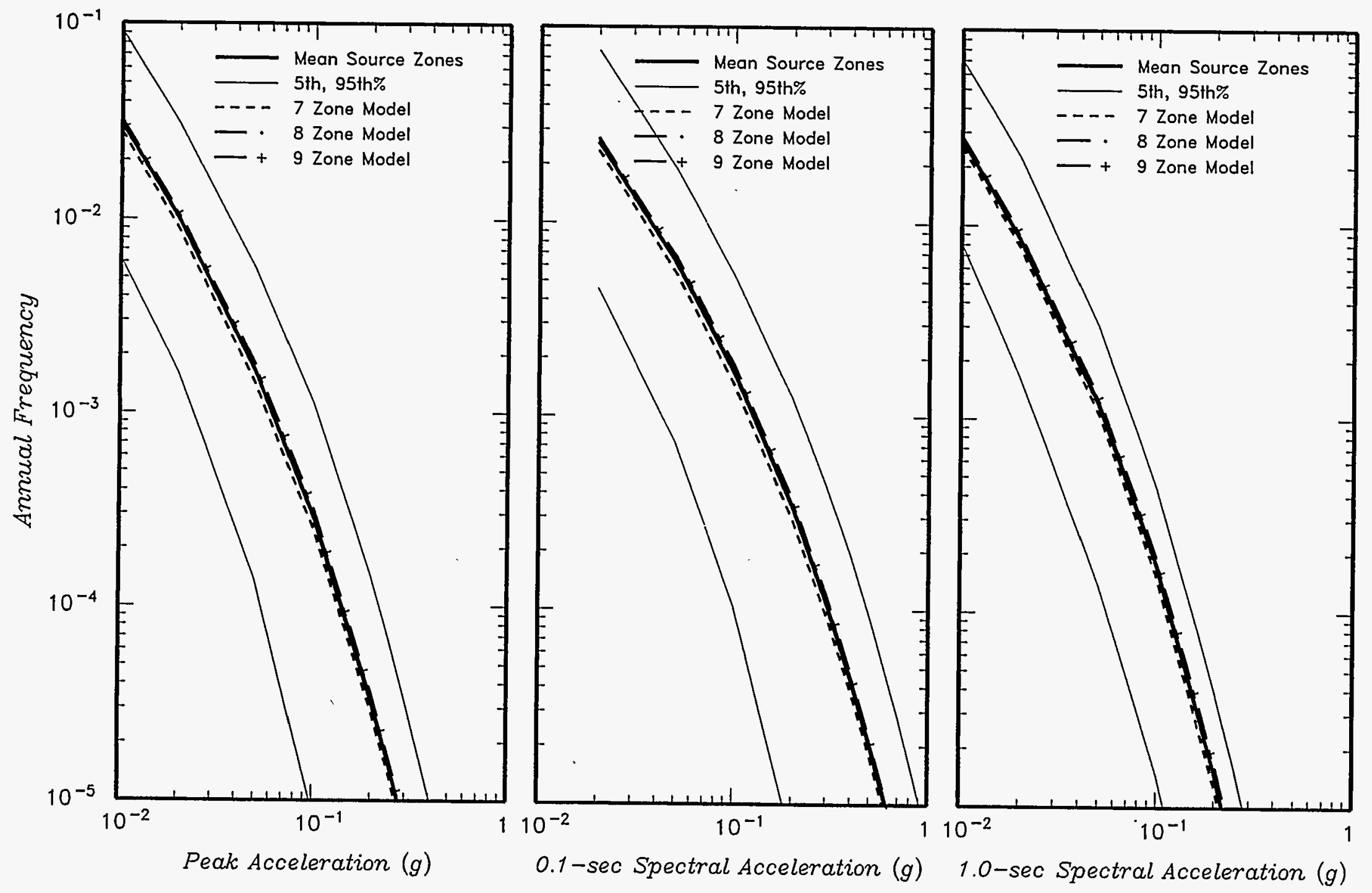

\begin{tabular}{|c|c|c|}
\hline $\begin{array}{l}\text { Project No. } \\
\text { SK9455 }\end{array}$ & INEL - Probabilistic Analyses & \multirow{2}{*}{$\begin{array}{c}\text { EFFECT OF REGIONAL ZONATION MODEL } \\
\text { ON SEISMIC HAZARD AT CPP }\end{array}$} \\
\hline \multicolumn{2}{|c|}{ Woodward-Clyde Federal Services } & \\
\hline
\end{tabular}



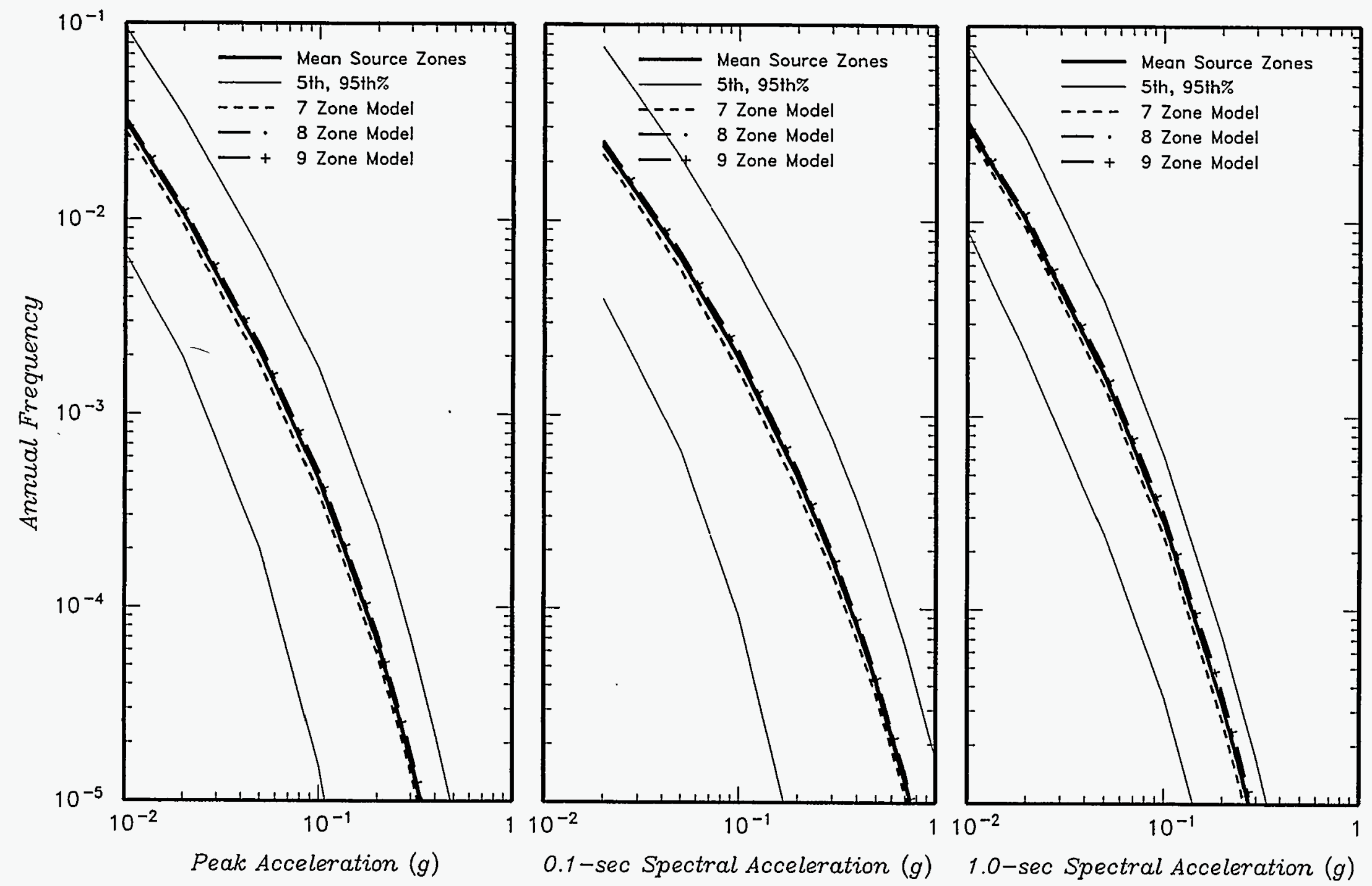

\begin{tabular}{|c|c|c|c|}
\hline $\begin{array}{l}\text { Project No. } \\
\text { SK9455 }\end{array}$ & INEL - Probabilistic Analyses & \multirow{2}{*}{$\begin{array}{l}\text { EFFECT OF REGIONAL ZONATION MODEL } \\
\text { ON SEISMIC HAZARD AT NRF }\end{array}$} & \multirow{2}{*}{$\begin{array}{c}\text { Figure } \\
6-16 d\end{array}$} \\
\hline \multicolumn{2}{|c|}{ Woodward-Clyde Federal Services } & & \\
\hline
\end{tabular}



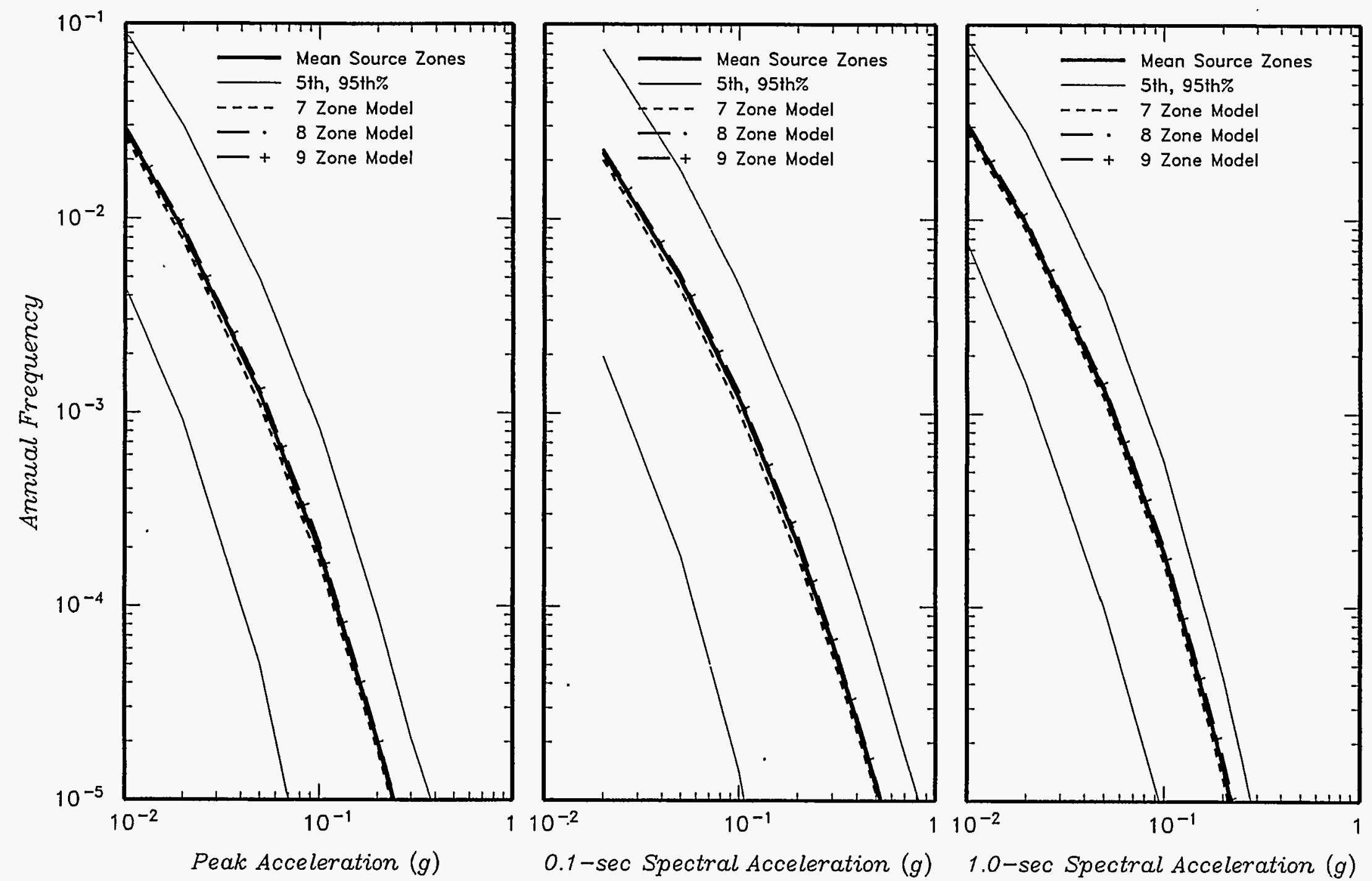


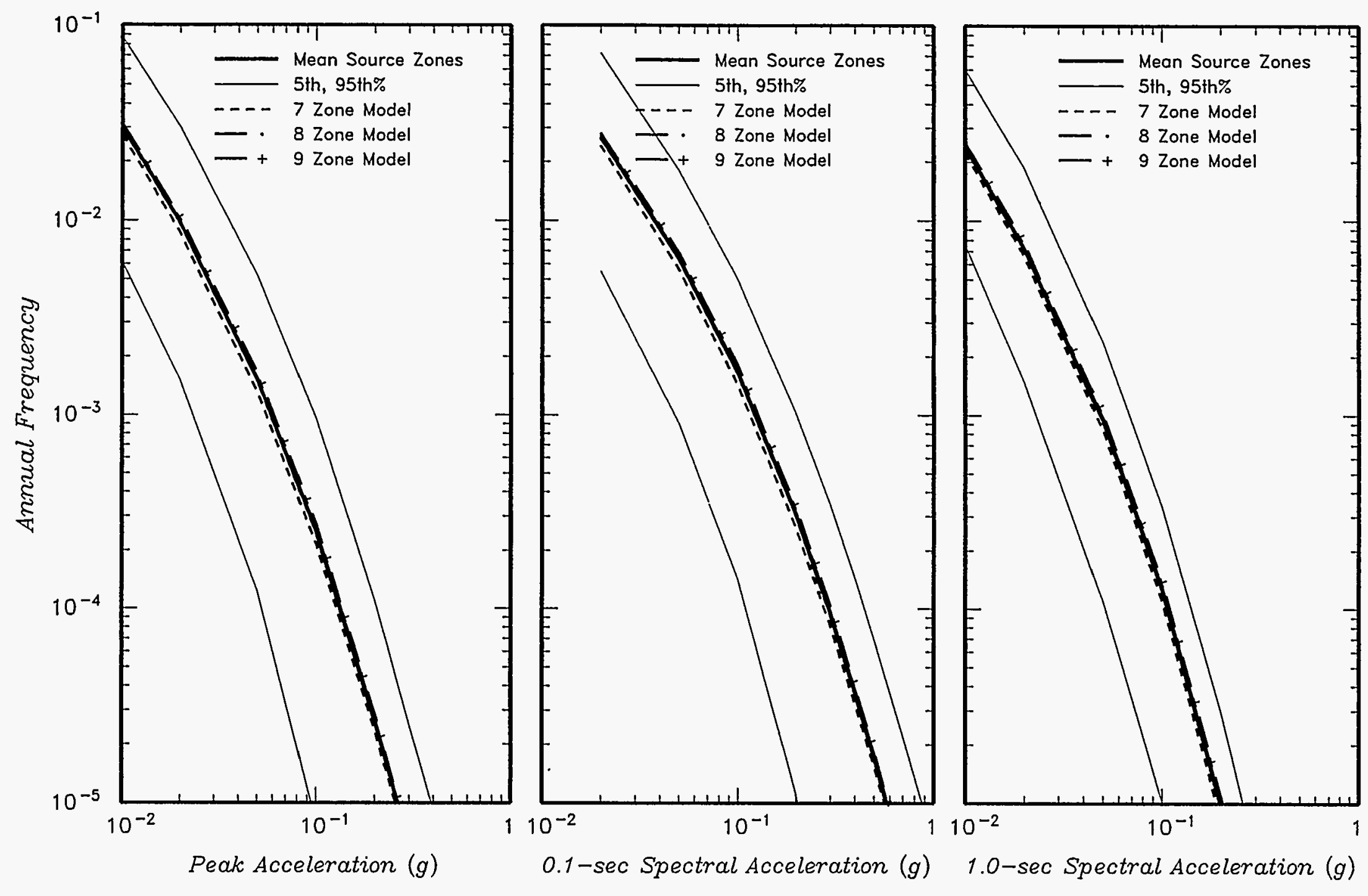
ON SEISMIC HAZARD AT RWMC 

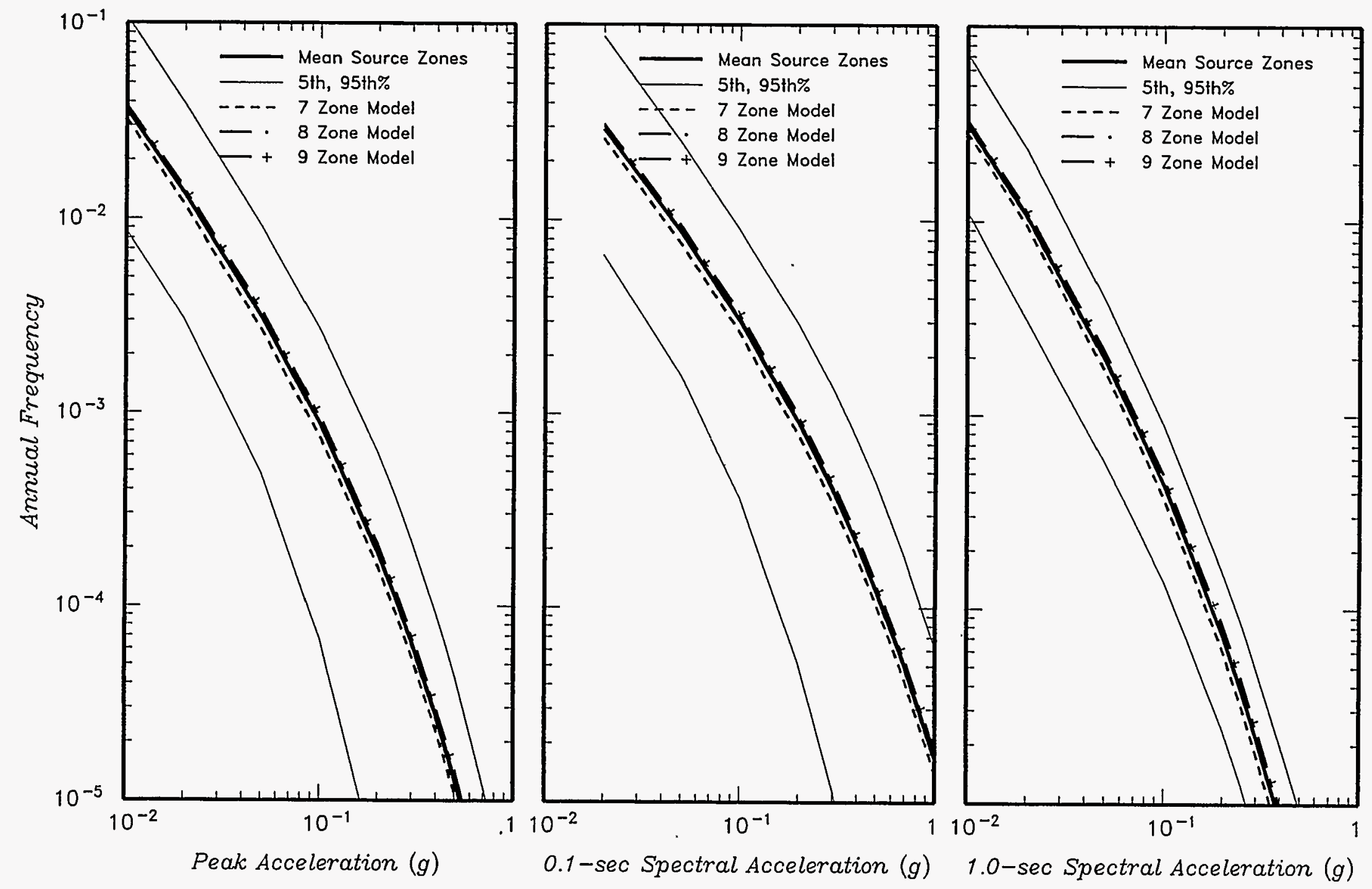

\begin{tabular}{|c|c|c|c|}
\hline $\begin{array}{c}\text { Project No. } \\
\text { SK9455 }\end{array}$ & INEL - Probabilistic Analyses & EFFECT OF REGIONAL ZONATION MODEL \\
ON SEISMIC HAZARD AT TAN & $\begin{array}{c}\text { Figure } \\
6-16 \mathrm{~g}\end{array}$ \\
\hline Woodward-Clyde Federal Services & \begin{tabular}{c} 
Wodward \\
\hline
\end{tabular}
\end{tabular}



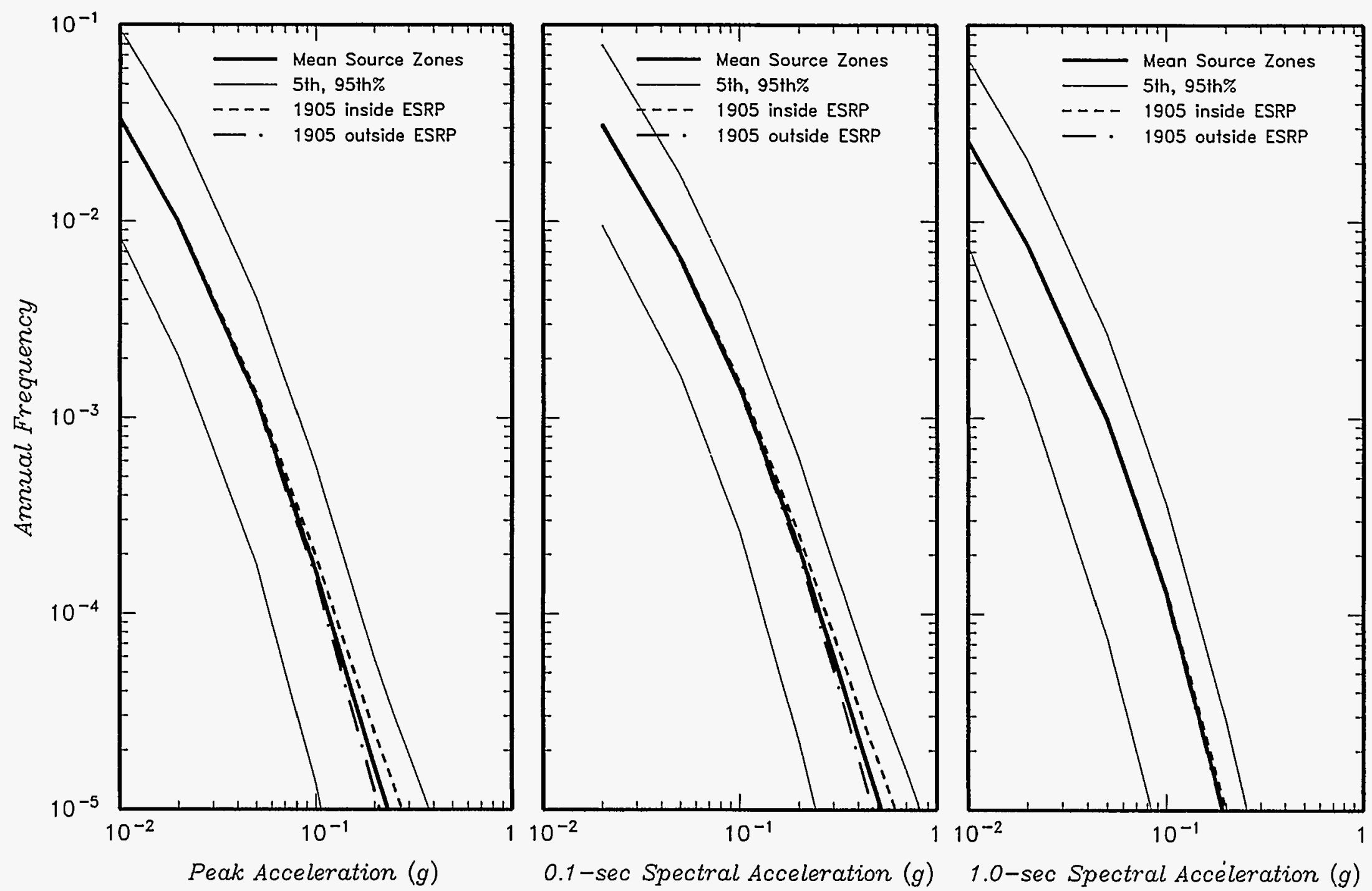

\begin{tabular}{|c|c|c|c|}
\hline $\begin{array}{c}\text { Project No. } \\
\text { SK9455 }\end{array}$ & INEL - Probabilistic Analyses & $\begin{array}{c}\text { EFFECT OF 1905 EARTHQUAKE } \\
\text { LOCATION ON SEISMIC HAZARD AT ANL }\end{array}$ & $\begin{array}{c}\text { Figure } \\
6-17 a\end{array}$ \\
\cline { 1 - 2 } Woodward-Clyde Federal Services & \\
\hline
\end{tabular}



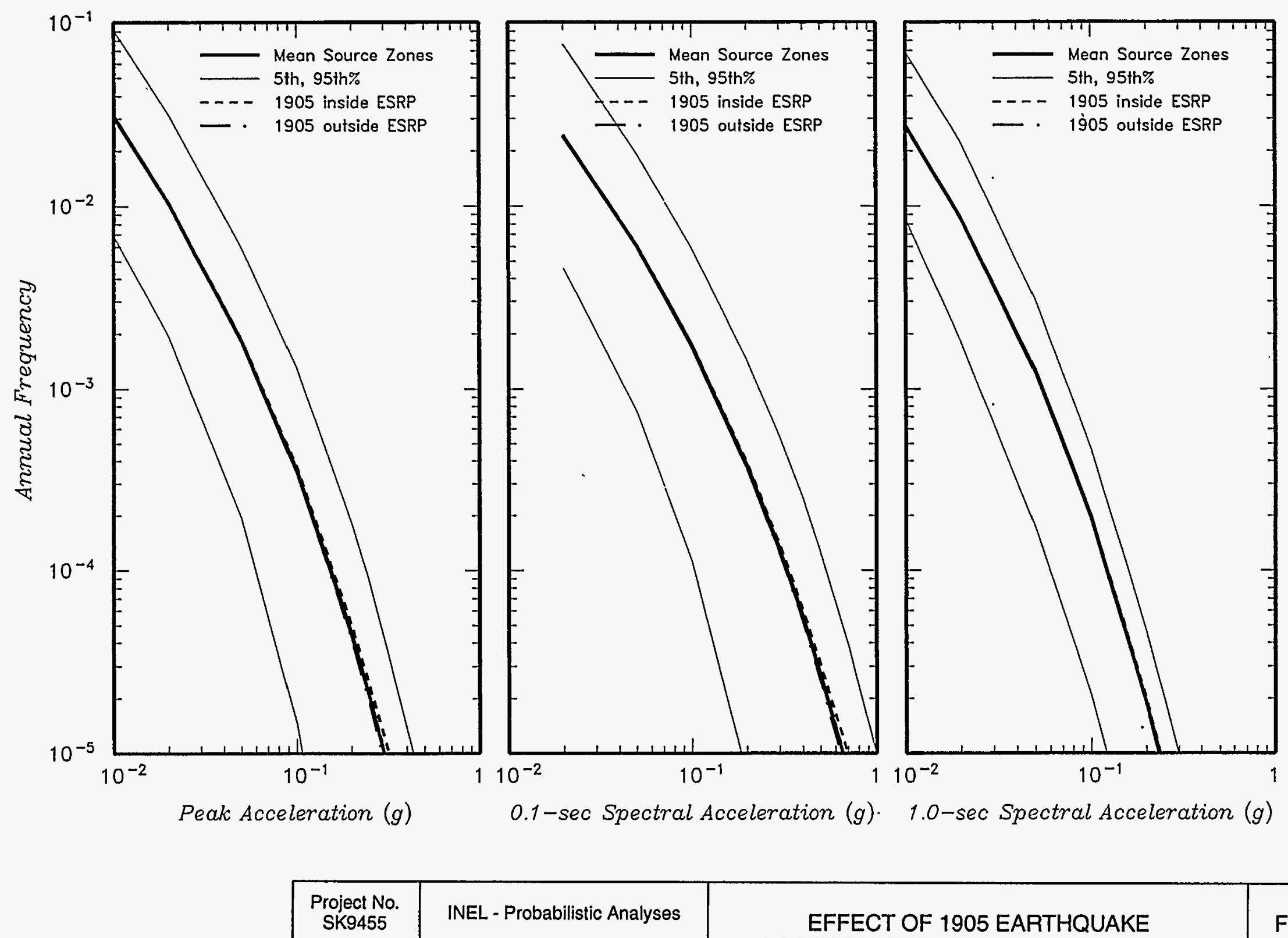

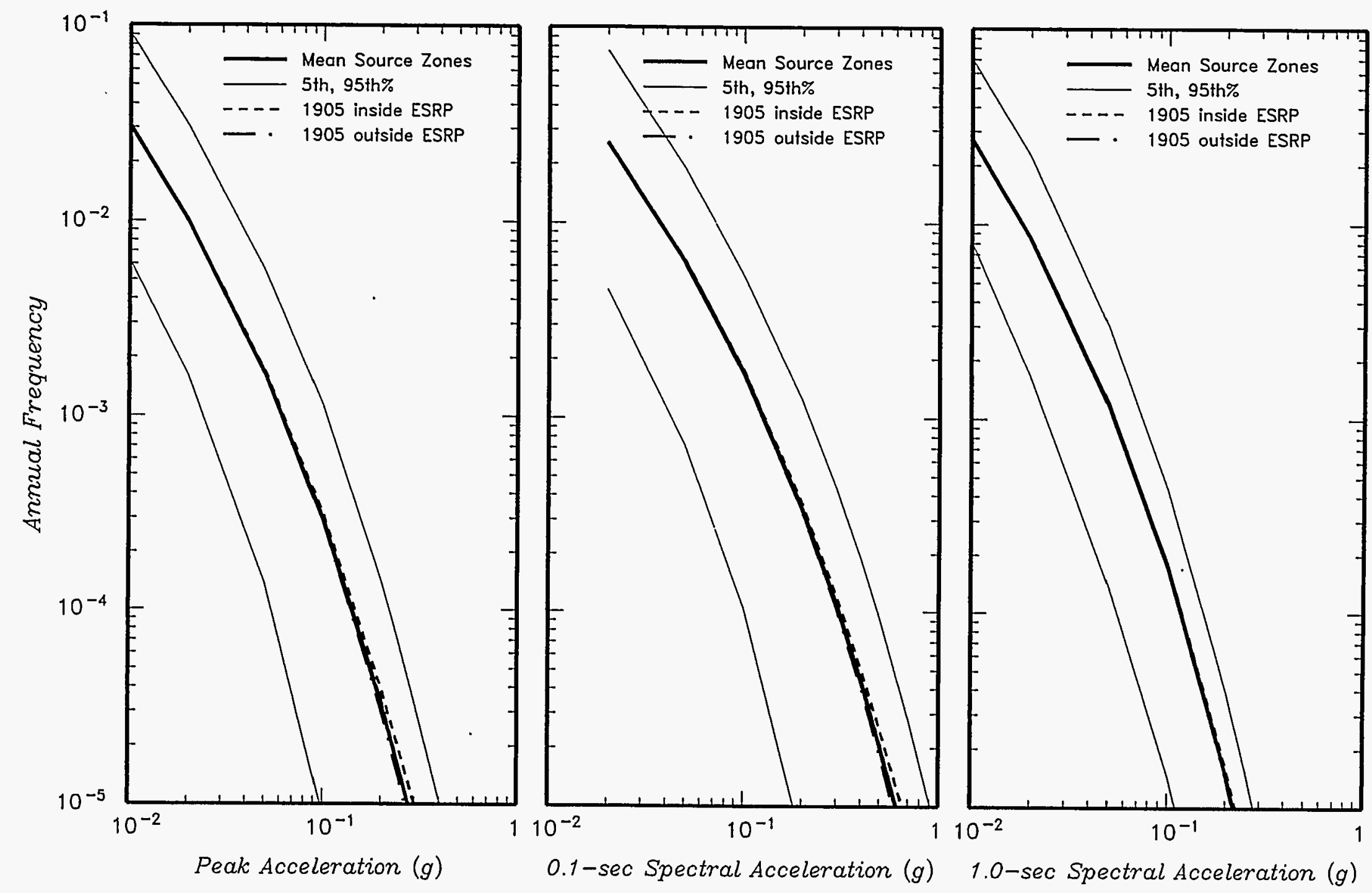

\begin{tabular}{|c|c|c|c|}
\hline $\begin{array}{c}\text { Project No. } \\
\text { SK9455 }\end{array}$ & INEL - Probabilistic Analyses & $\begin{array}{c}\text { EFFECT OF 1905 EARTHQUAKE } \\
\text { LOCATION ON SEISMIC HAZARD AT CPP }\end{array}$ & $\begin{array}{c}\text { Figure } \\
6-17 \mathrm{c}\end{array}$ \\
\cline { 1 - 1 } Woodward-Clyde Federal Services & LOdward \\
\hline
\end{tabular}




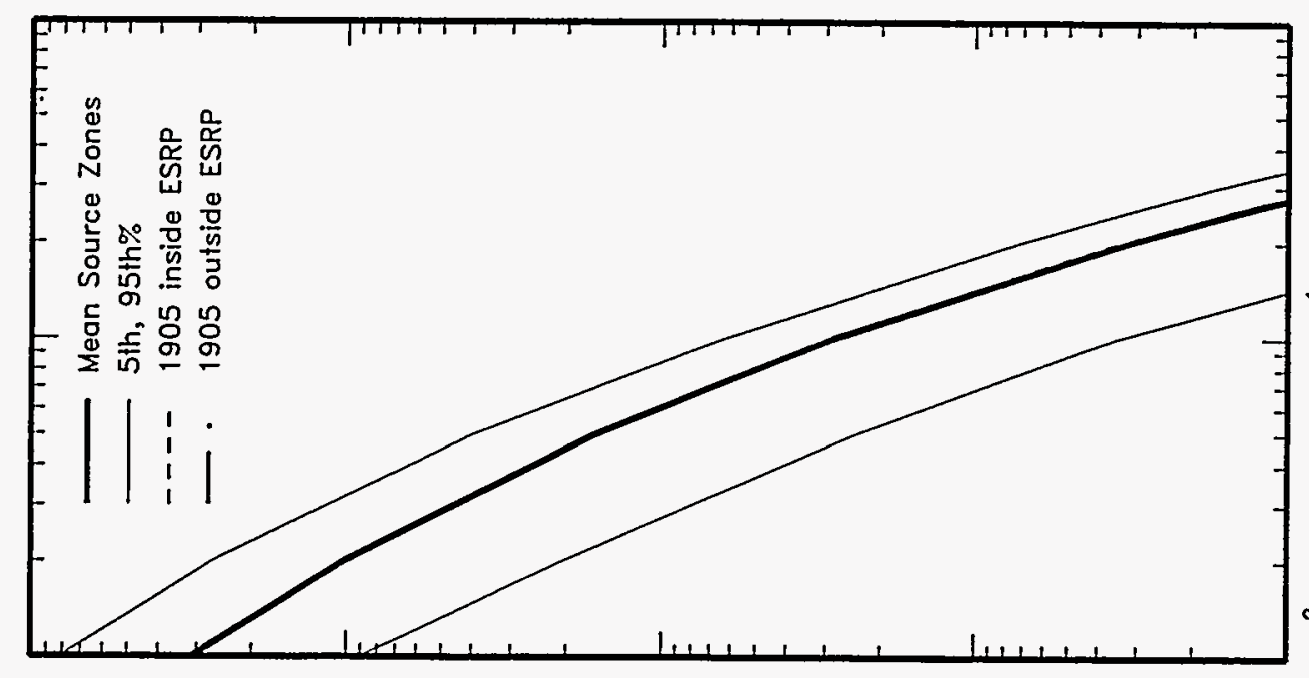

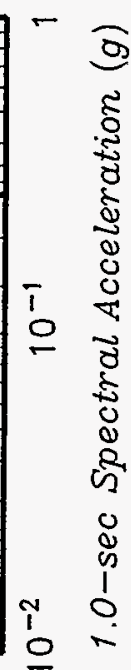

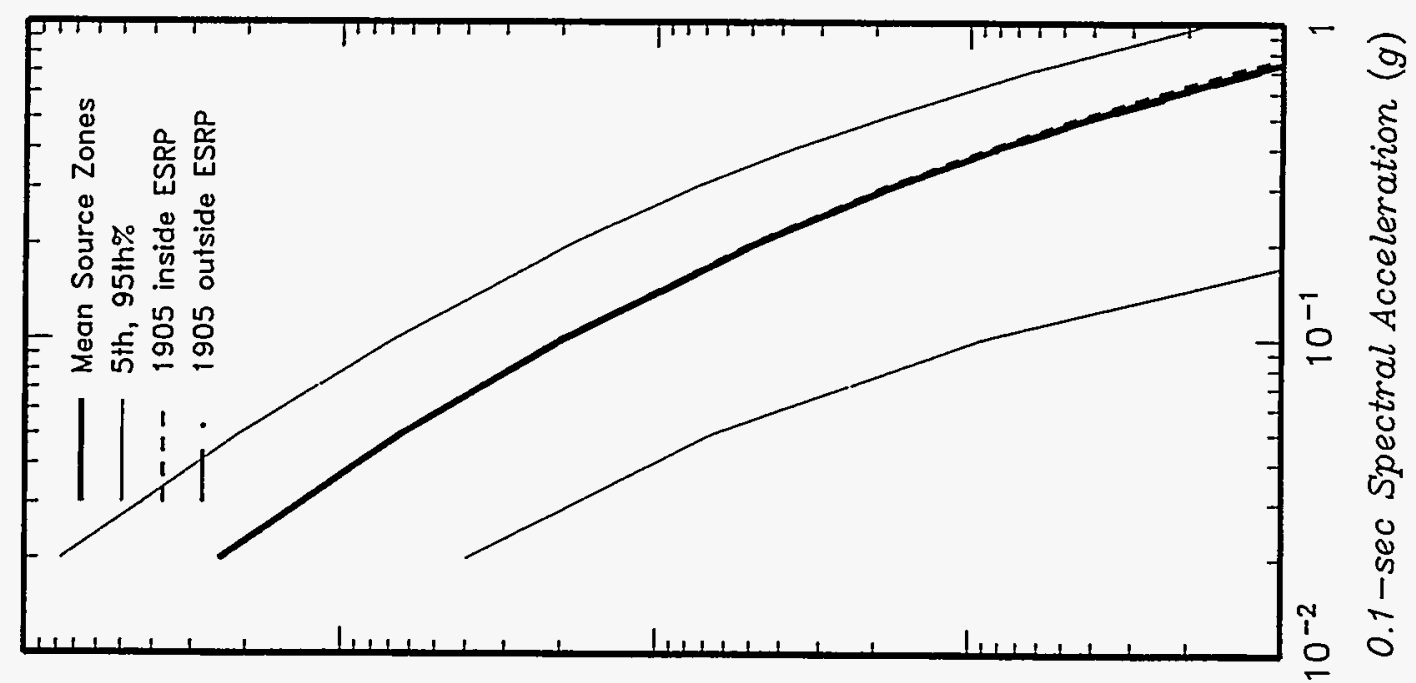

这是立

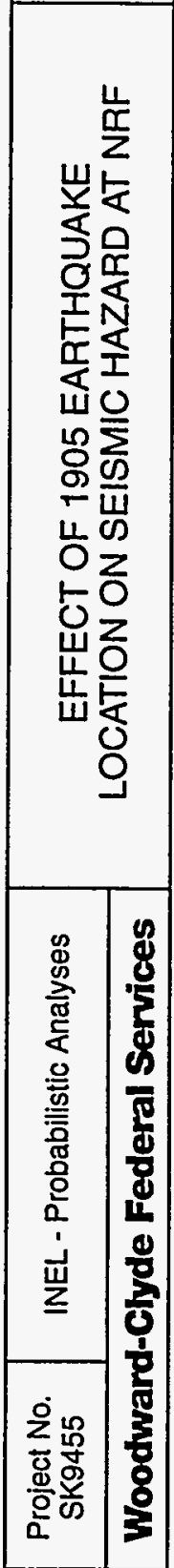

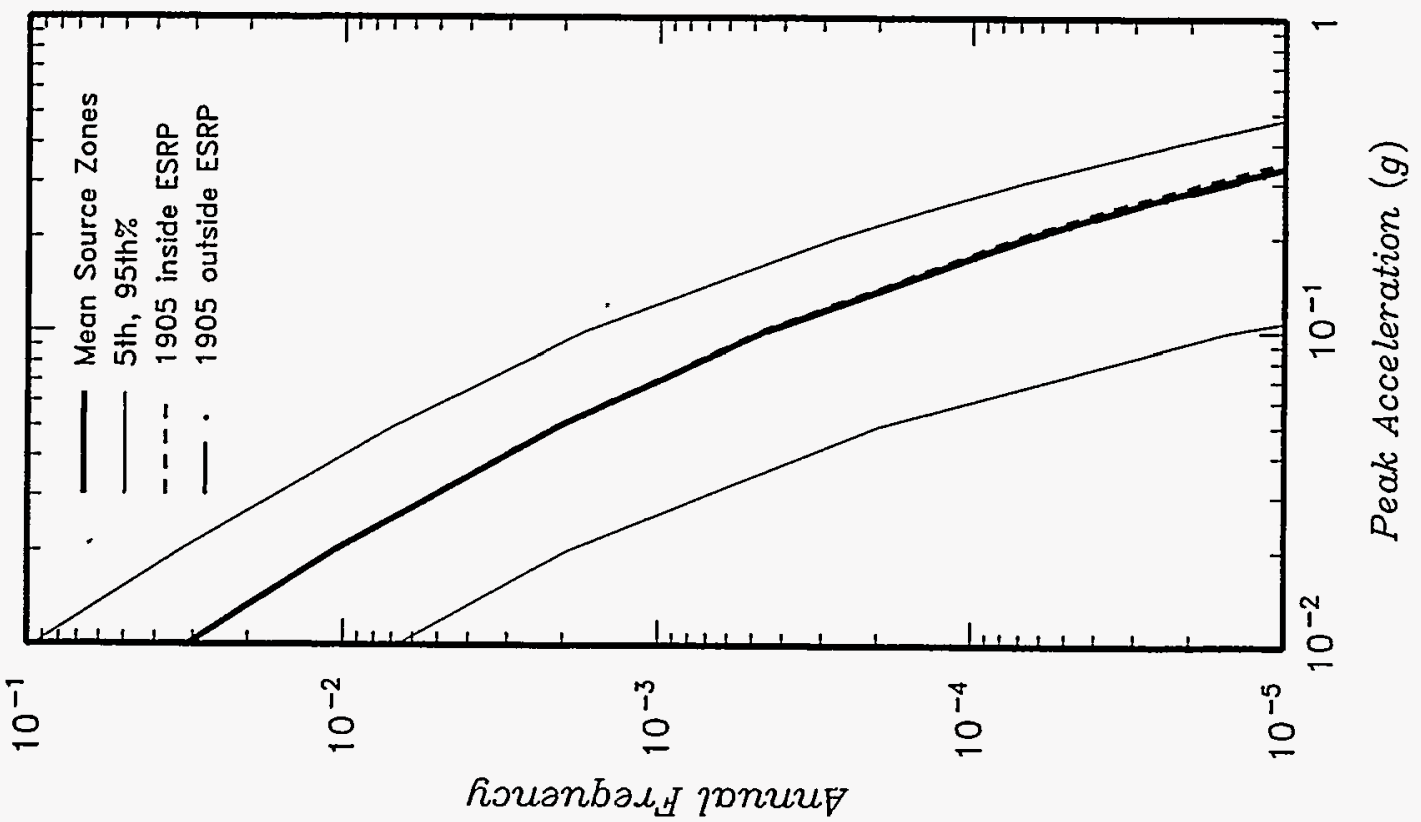



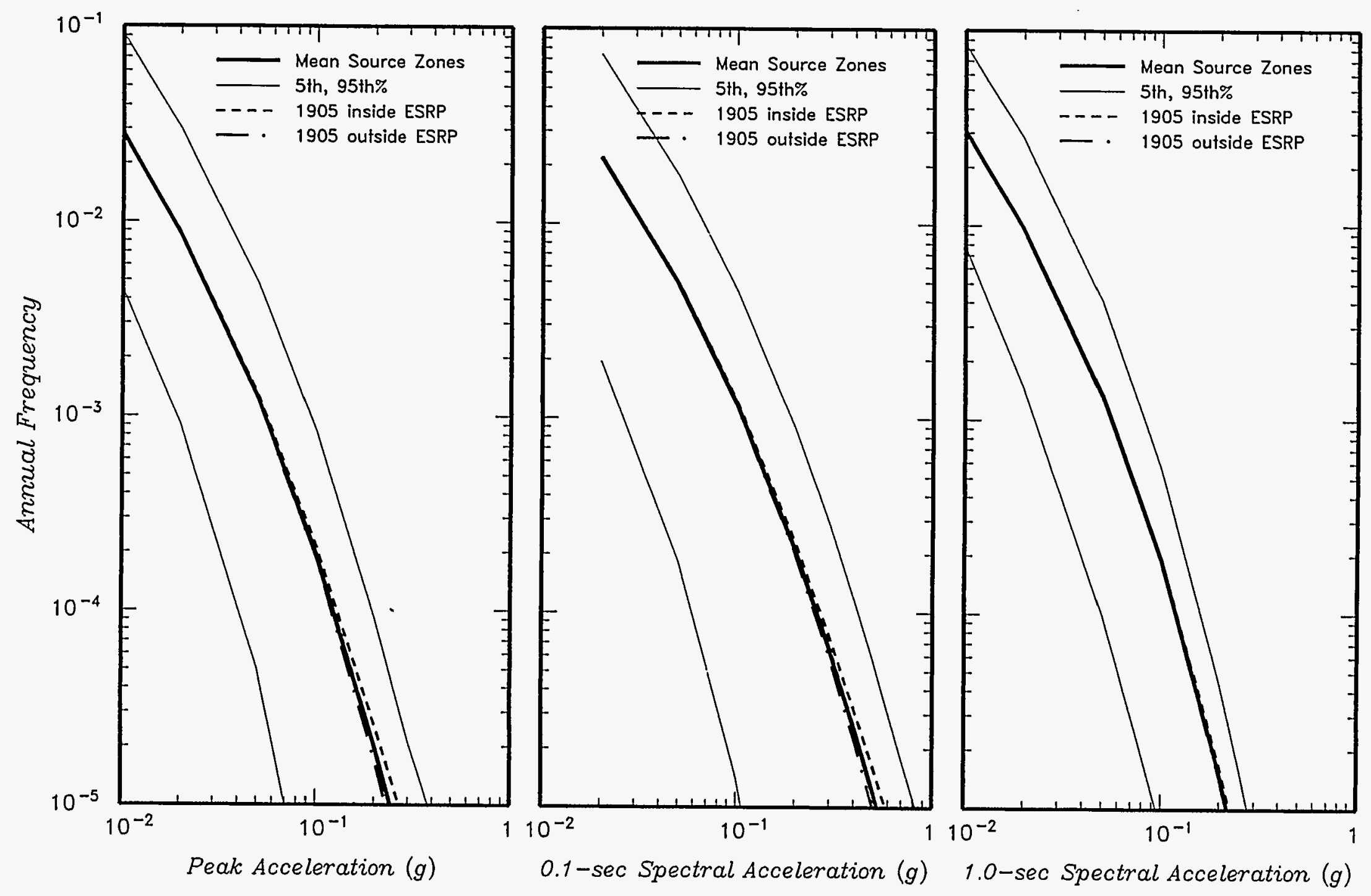

SK9455-A1000/122895/vone

\begin{tabular}{|c|c|c|}
\hline $\begin{array}{l}\text { Project No. } \\
\text { SK9455 }\end{array}$ & INEL - Probabilistic Analyses & \\
\hline Woodwar & Dlyde Federal Services & \\
\hline
\end{tabular}



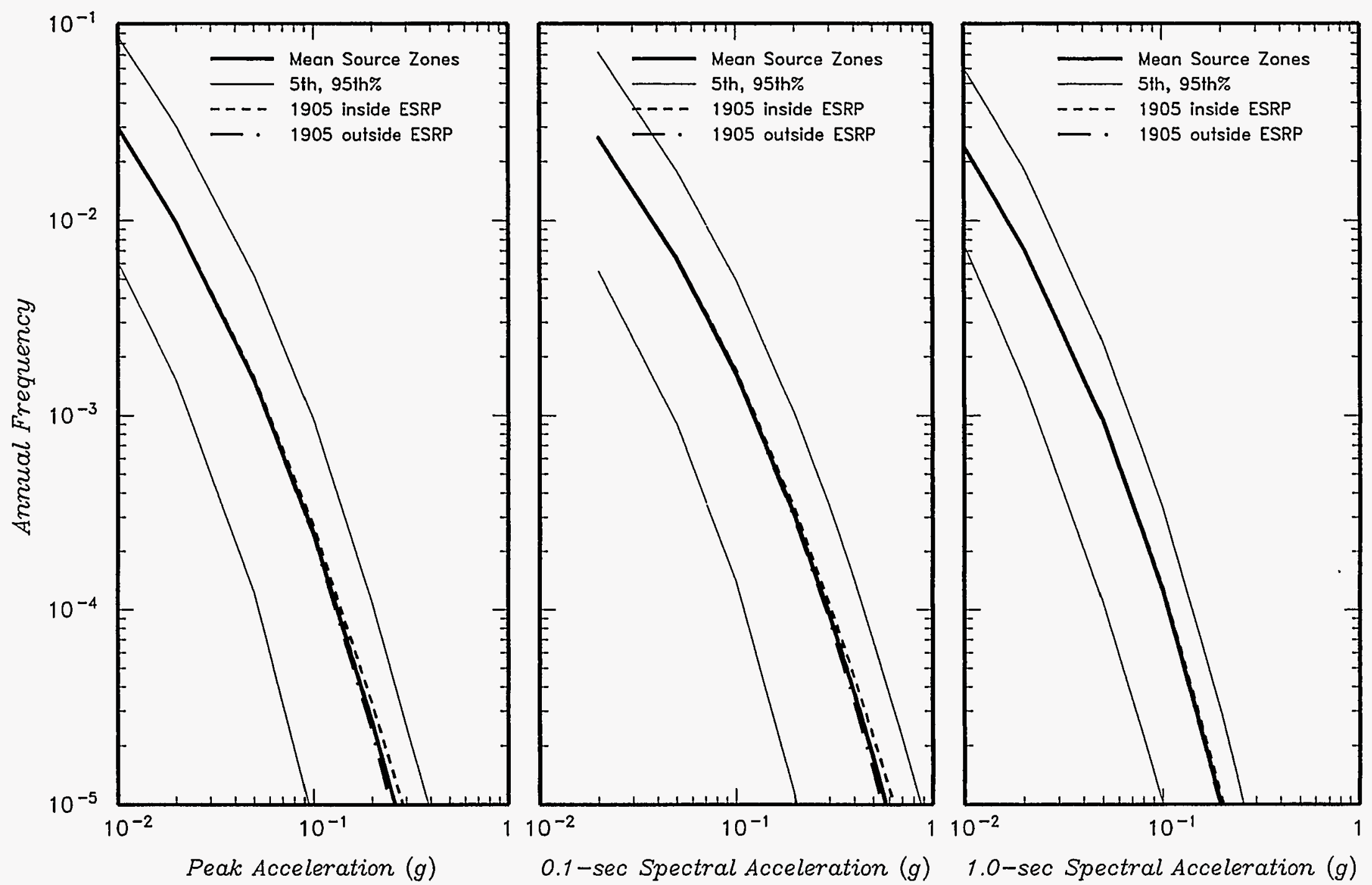

\begin{tabular}{|c|c|}
\hline $\begin{array}{c}\text { Project No. } \\
\text { SK9455 }\end{array}$ & INEL - Probabilistic Analyses \\
\hline
\end{tabular}

EFFECT OF 1905 EARTHQUAKE LOCATION ON SEISMIC HAZARD AT RWMC 


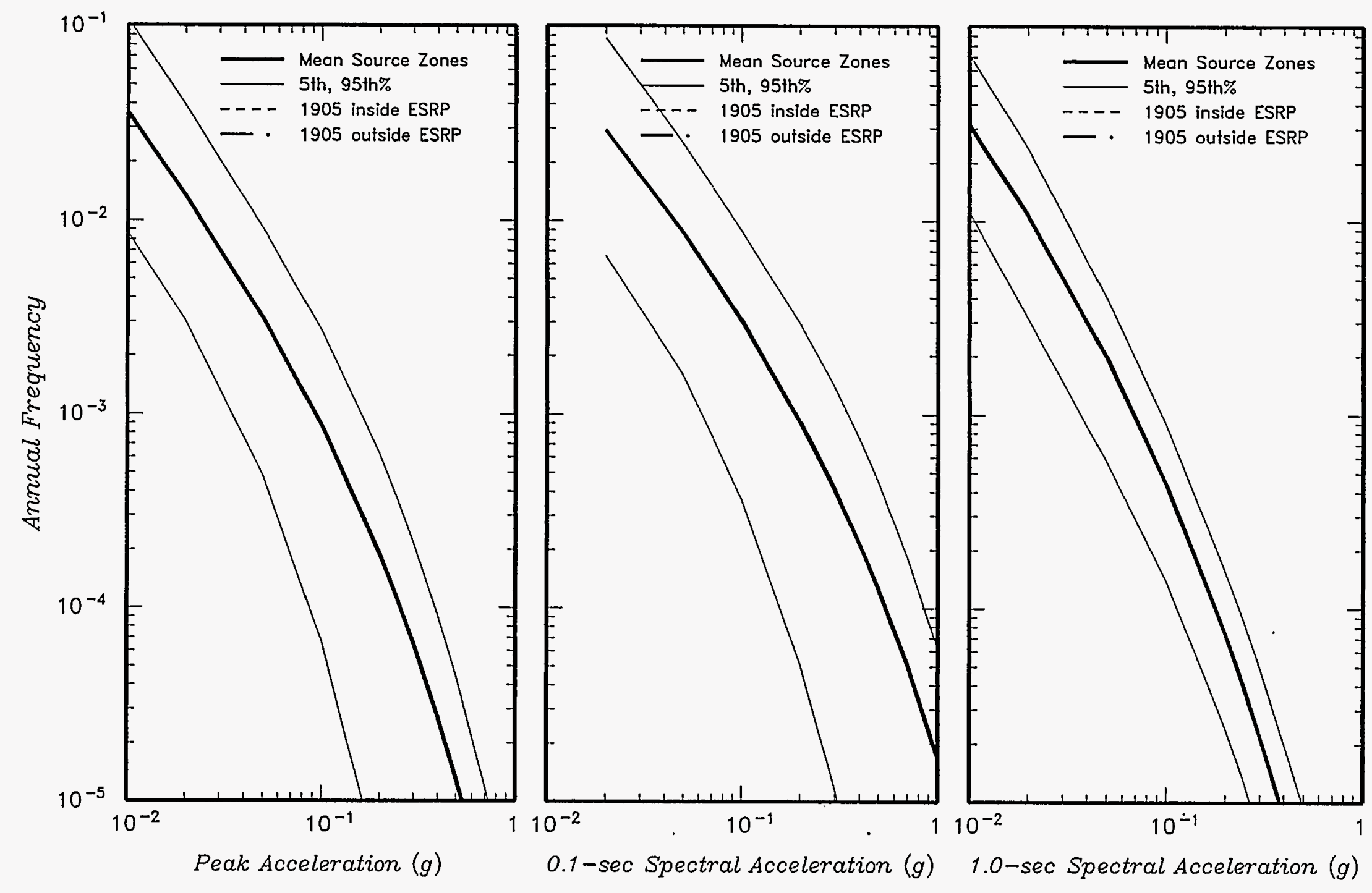




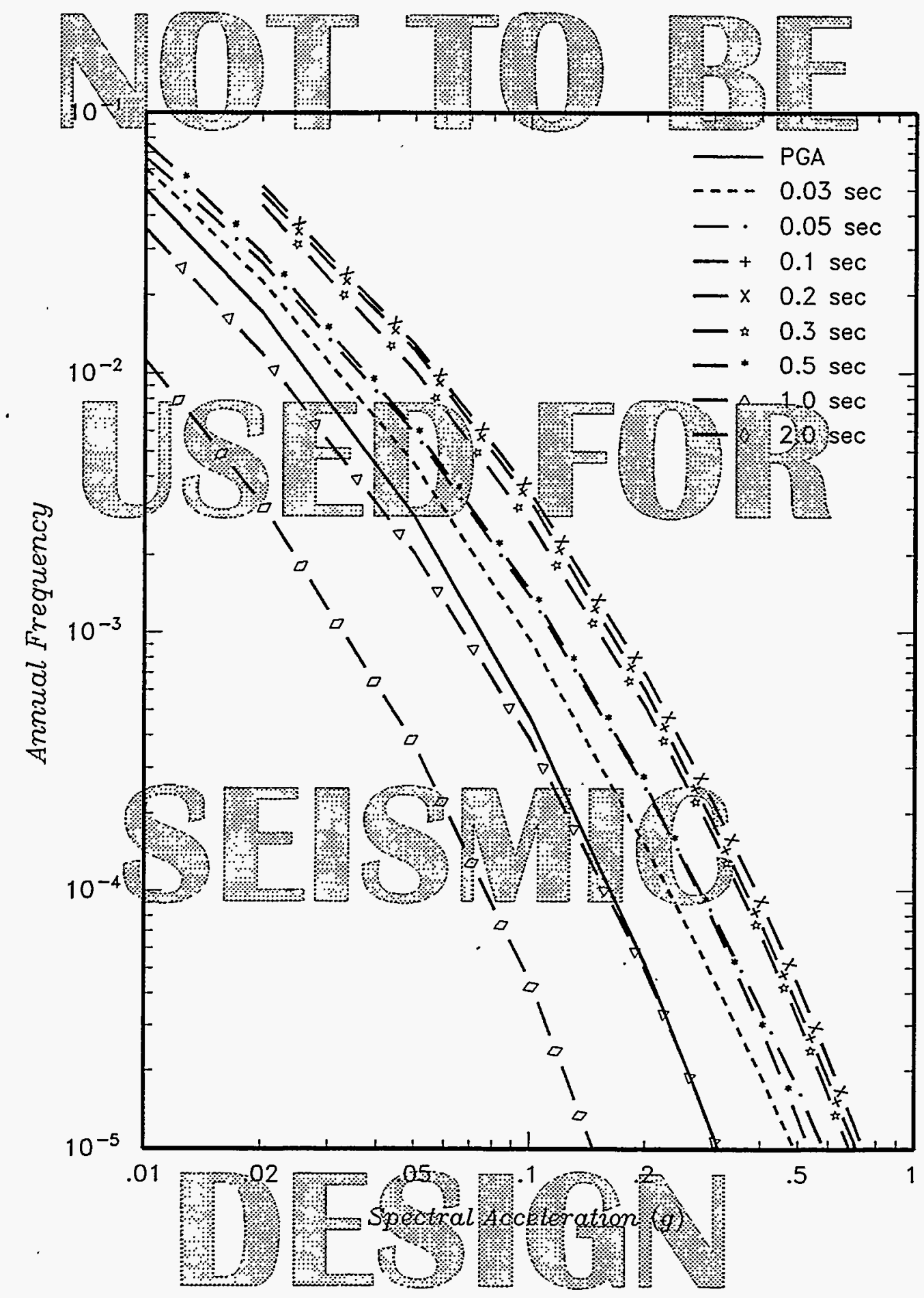

\begin{tabular}{|c|c|c|c|}
\hline $\begin{array}{c}\text { Project No. } \\
\text { SK9455 }\end{array}$ & INEL-Probabilistic Analyses & MEAN SEISMIC HAZARD CURVES & Figure \\
\cline { 1 - 1 } Woodward-Clyde Federal Services & FOR PEAK ACCELERATION AND & $6-18 \mathrm{a}$ \\
\hline SK $9455-A 1000 / 122795 /$ vene & SPCTRAL ACCELERATION AT ANL & \\
\hline
\end{tabular}




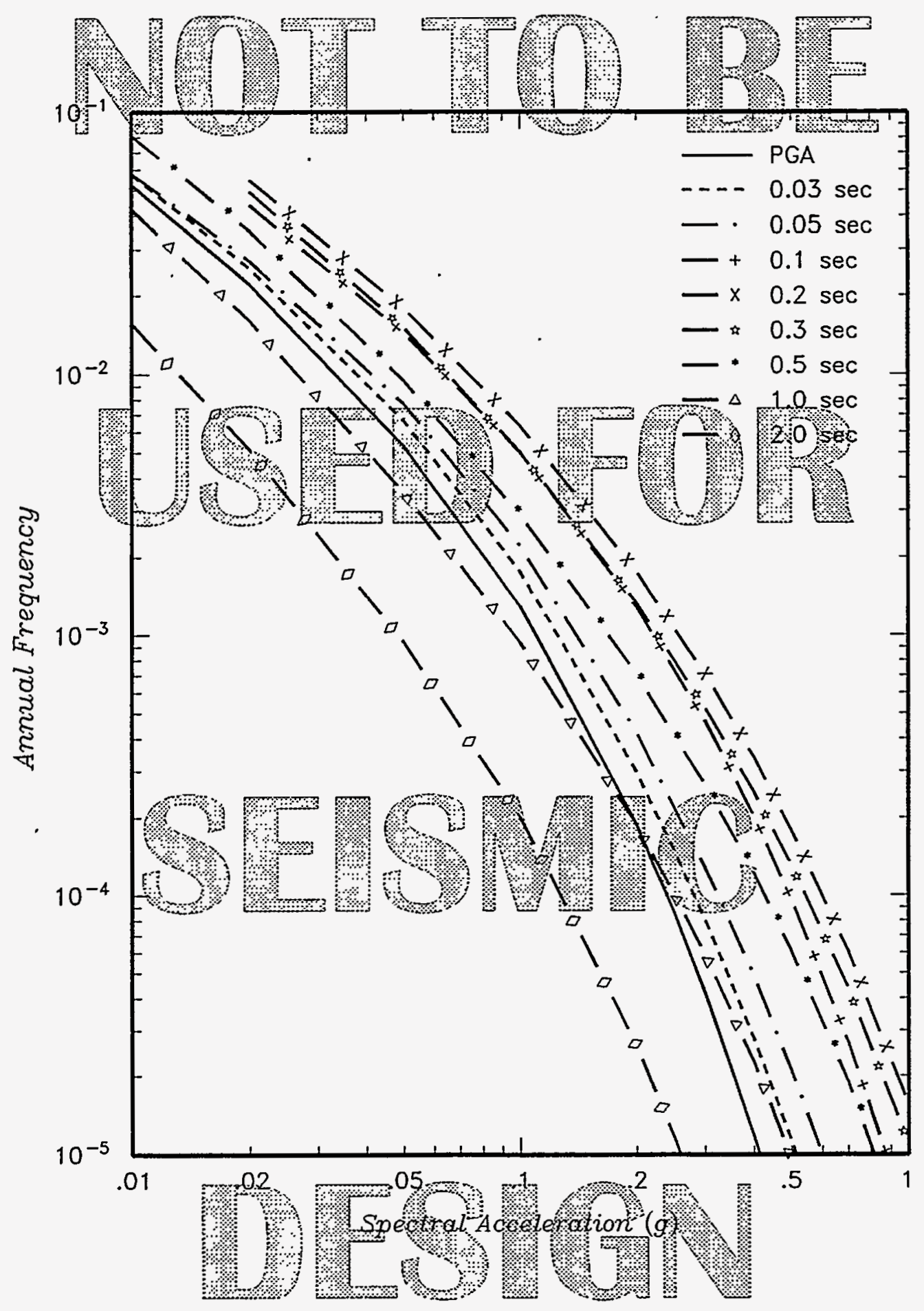

\begin{tabular}{|c|c|c|c|}
\hline $\begin{array}{c}\text { Project No. } \\
\text { SK9455 }\end{array}$ & INEL-Probabilistic Analyses & \multirow{2}{*}{$\begin{array}{l}\text { MEAN SEISMIC HAZARD CURVES } \\
\text { FOR PEAK ACCELERATION AND } \\
\text { SPECTRAL ACCELERATION AT ATR }\end{array}$} & \multirow{2}{*}{$\begin{array}{l}\text { Figure } \\
6-18 b\end{array}$} \\
\hline \multicolumn{2}{|c|}{ Woodward-Clyde Federal Services } & & \\
\hline
\end{tabular}




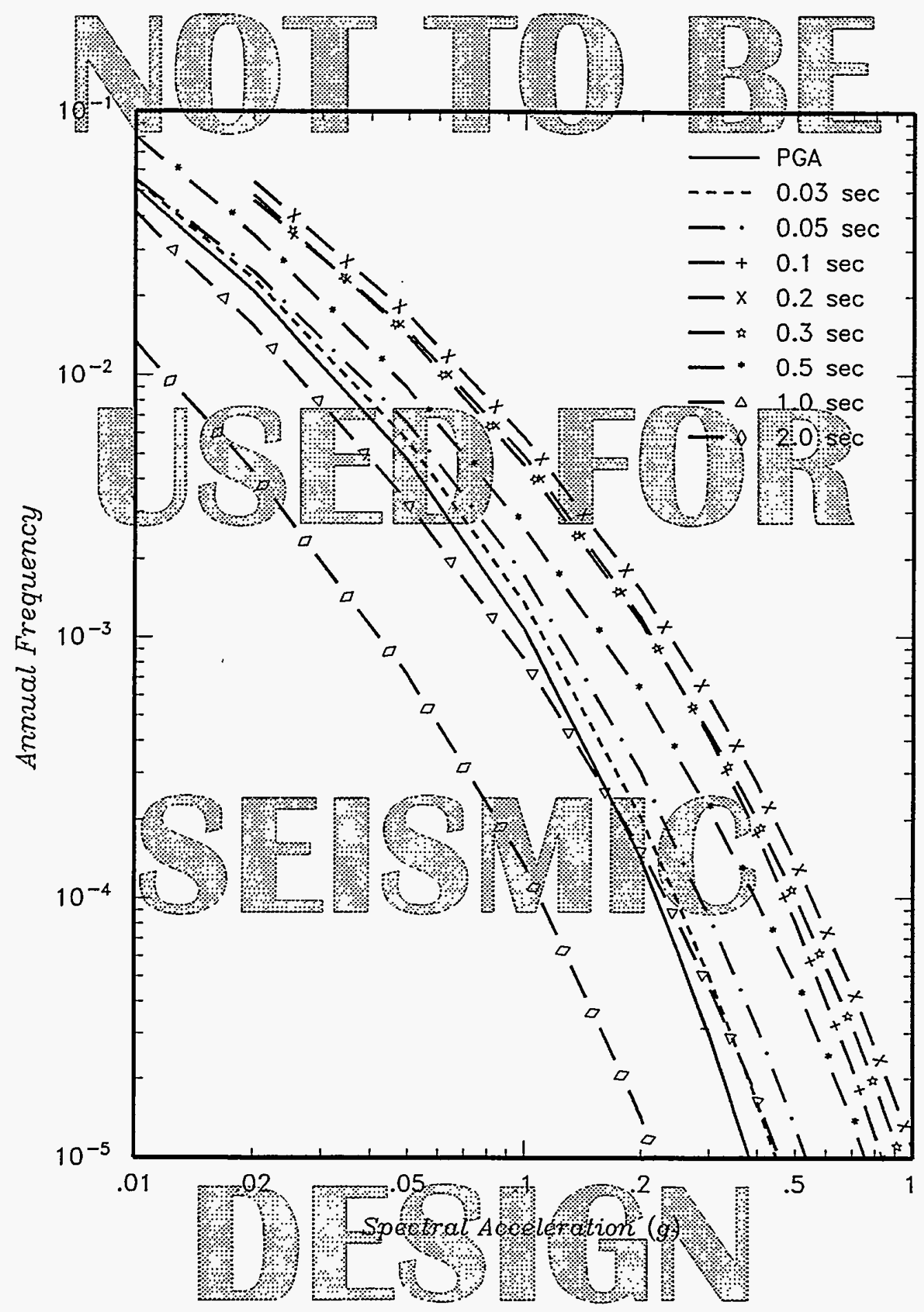

\begin{tabular}{|c|c|c|c|}
\hline $\begin{array}{c}\text { Project No. } \\
\text { SK9455 }\end{array}$ & INEL-Probabilistic Analyses & MEAN SEISMIC HAZARD CURVES & Figure \\
\cline { 1 - 2 } Woodward-Clyde Federal Services & FOR PEAK ACCELERATION AND & $6-18 \mathrm{C}$ \\
\hline
\end{tabular}




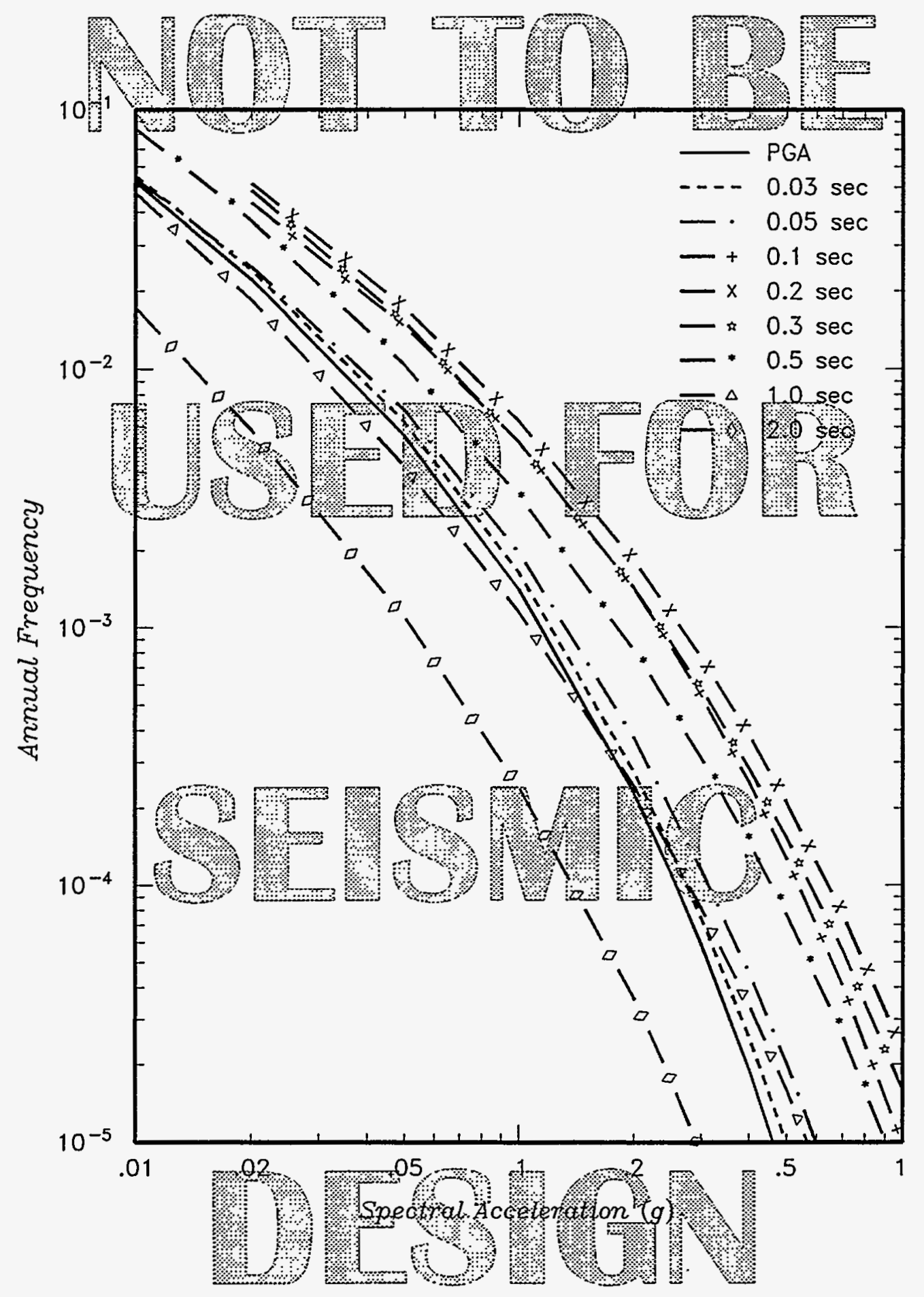

\begin{tabular}{|c|c|c|c|}
\hline $\begin{array}{c}\text { Project No. } \\
\text { SK9455 }\end{array}$ & INEL-Probabilistic Analyses & $\begin{array}{c}\text { MEAN SEISMIC HAZARD CURVES } \\
\text { FOR PEAK ACCELERATION AND } \\
\text { SPECTRAL ACCELERATION AT NRF }\end{array}$ & $\begin{array}{c}\text { Figure } \\
6-18 d\end{array}$ \\
\hline Woodward-Clyde Federal Senvices & SPETA
\end{tabular}




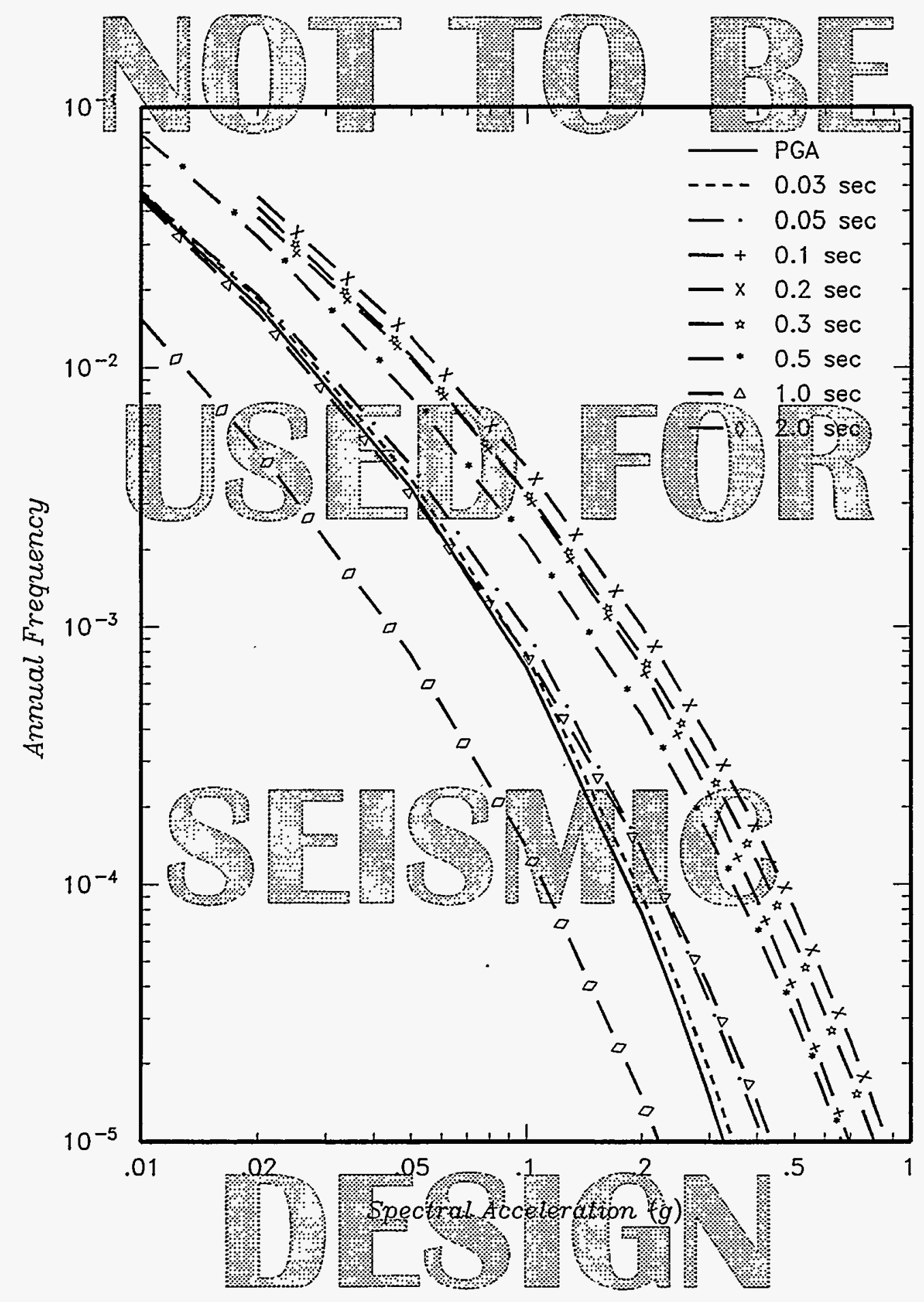

\begin{tabular}{|c|c|c|c|}
\hline $\begin{array}{c}\text { Project No. } \\
\text { SK9455 }\end{array}$ & INEL-Probabilistic Analyses & MEAN SEISMIC HAZARD CURVES & Figure \\
\hline \multicolumn{2}{|c|}{ Woodward-Clyde Federal Services } & FOR PEAK ACCELERATION AND & $6-18 \mathrm{e}$ \\
\hline
\end{tabular}




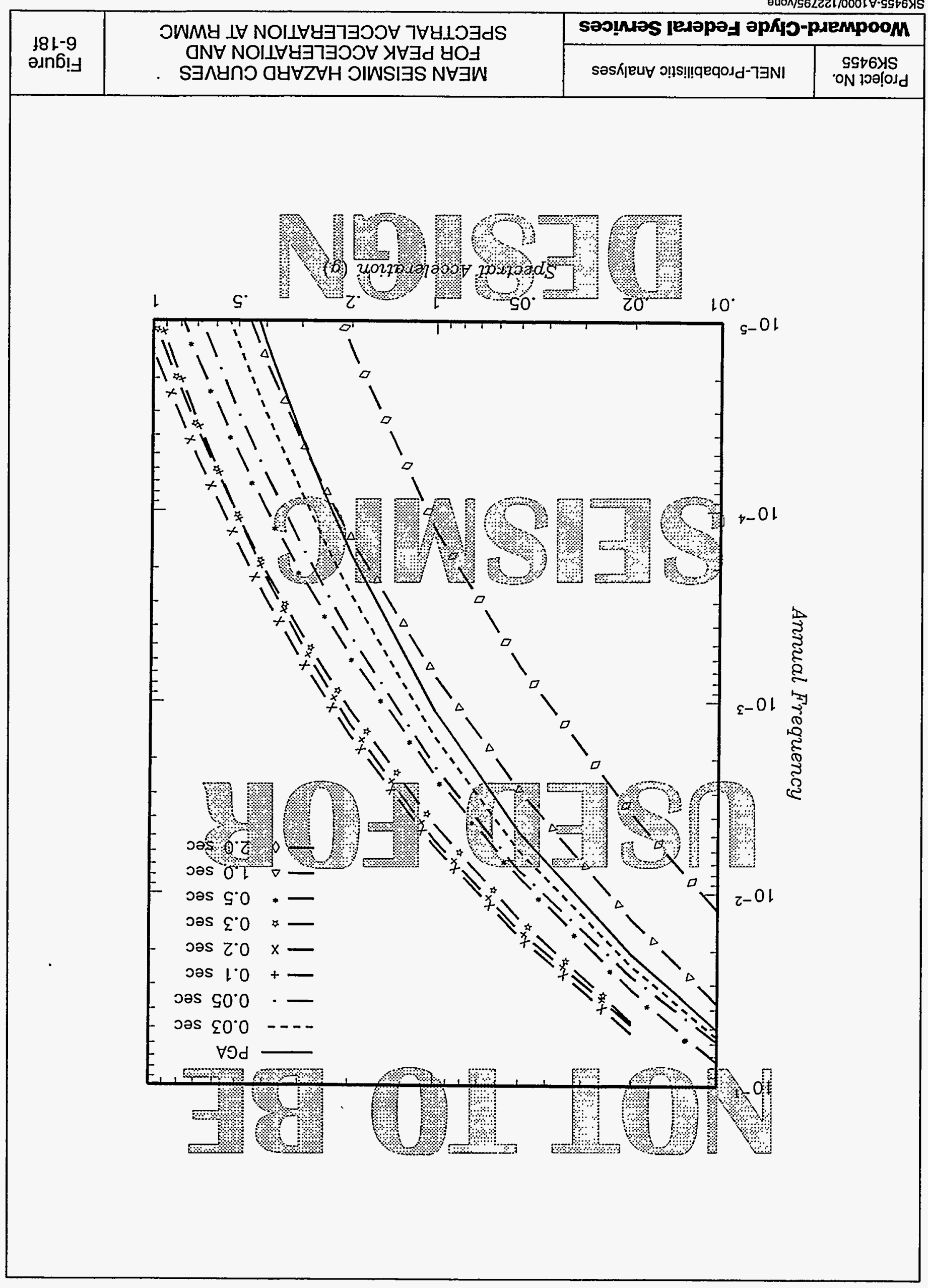




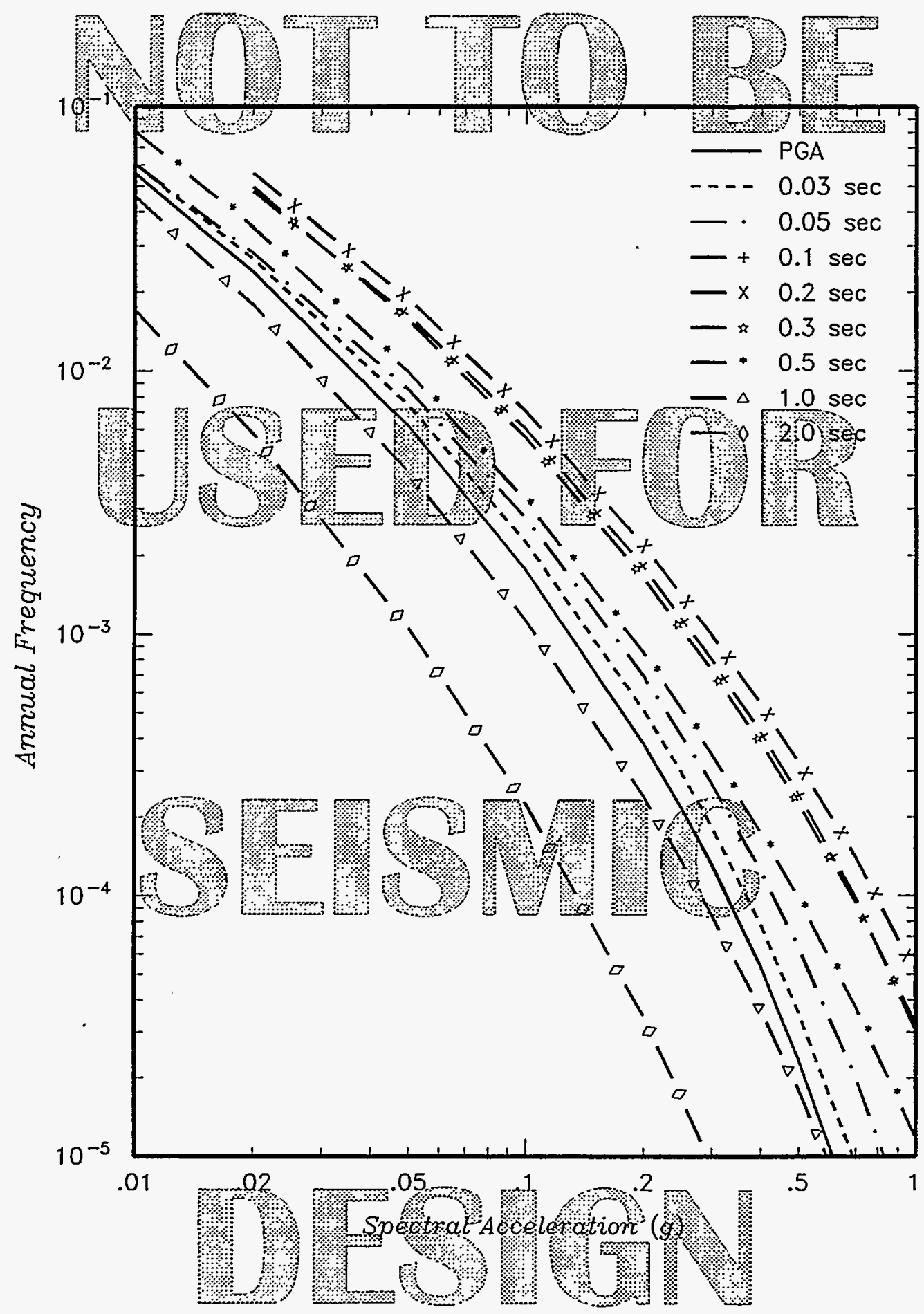

\begin{tabular}{|c|c|c|c|}
\hline $\begin{array}{c}\text { Project No. } \\
\text { SK9455 }\end{array}$ & INEL-Probabilistic Analyses & MEAN SEISMIC HAZARD CURVES & Figure \\
\cline { 1 - 1 } Woodward-Clyde Federal Services & FOR PEAK ACCELERATION AND & $6-18 g$ \\
\hline
\end{tabular}




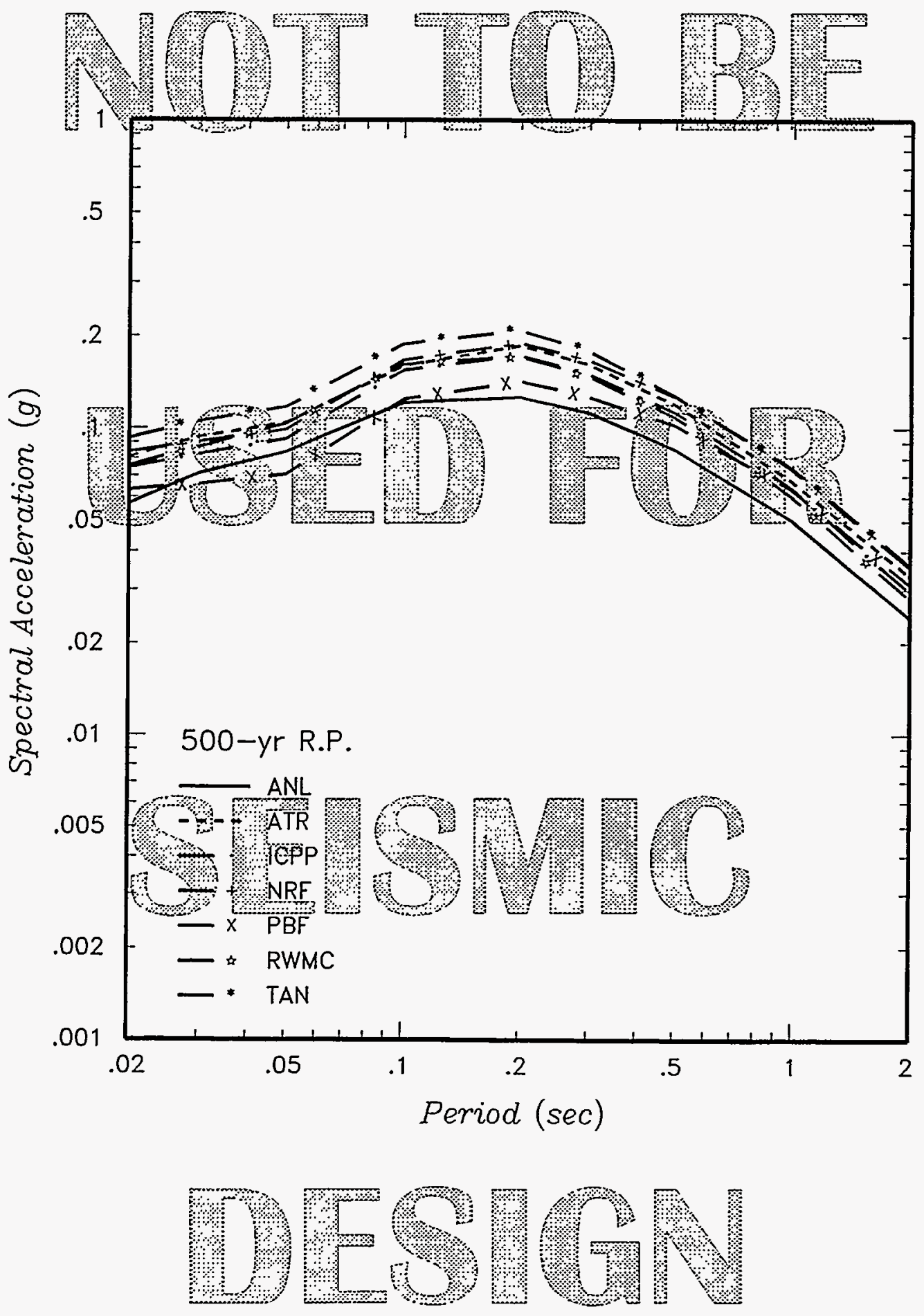

\begin{tabular}{|c|c|c|c|}
\hline $\begin{array}{c}\text { Project No. } \\
\text { SK9455 }\end{array}$ & INEL-Probabilistic Analyses & EQUAL HAZARD SPECTRA & Figure \\
& FOR ANNUAL EXCEEDANCE & $-19 a$ \\
\hline Woodwrard-Clyde Federal Senvices & PROBABILITY OF $2 \times 10^{-3}$ & \\
\hline
\end{tabular}



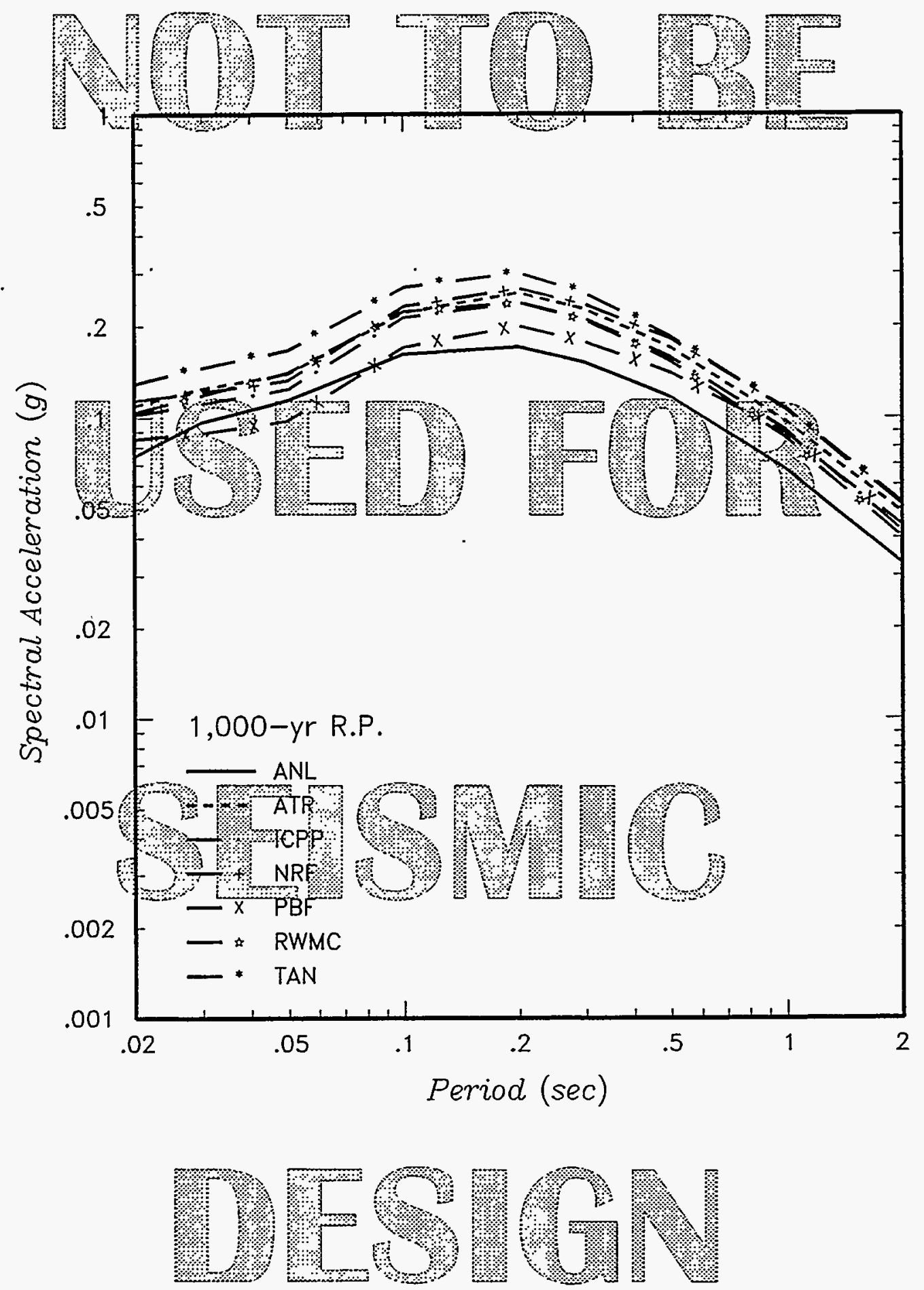

\begin{tabular}{|c|c|c|c|}
\hline $\begin{array}{c}\text { Project No. } \\
\text { SK9455 }\end{array}$ & INEL-Probabilistic Analyses & \multirow{2}{*}{$\begin{array}{c}\text { EQUAL HAZARD SPECTRA } \\
\text { FOR ANNUAL EXCEEDANCE } \\
\text { PROBABILITY OF } 10^{-3}\end{array}$} & \multirow{2}{*}{$\begin{array}{l}\text { Figure } \\
6-19 b\end{array}$} \\
\hline \multicolumn{2}{|c|}{ Woochward-Clyde Federal Services } & & \\
\hline
\end{tabular}



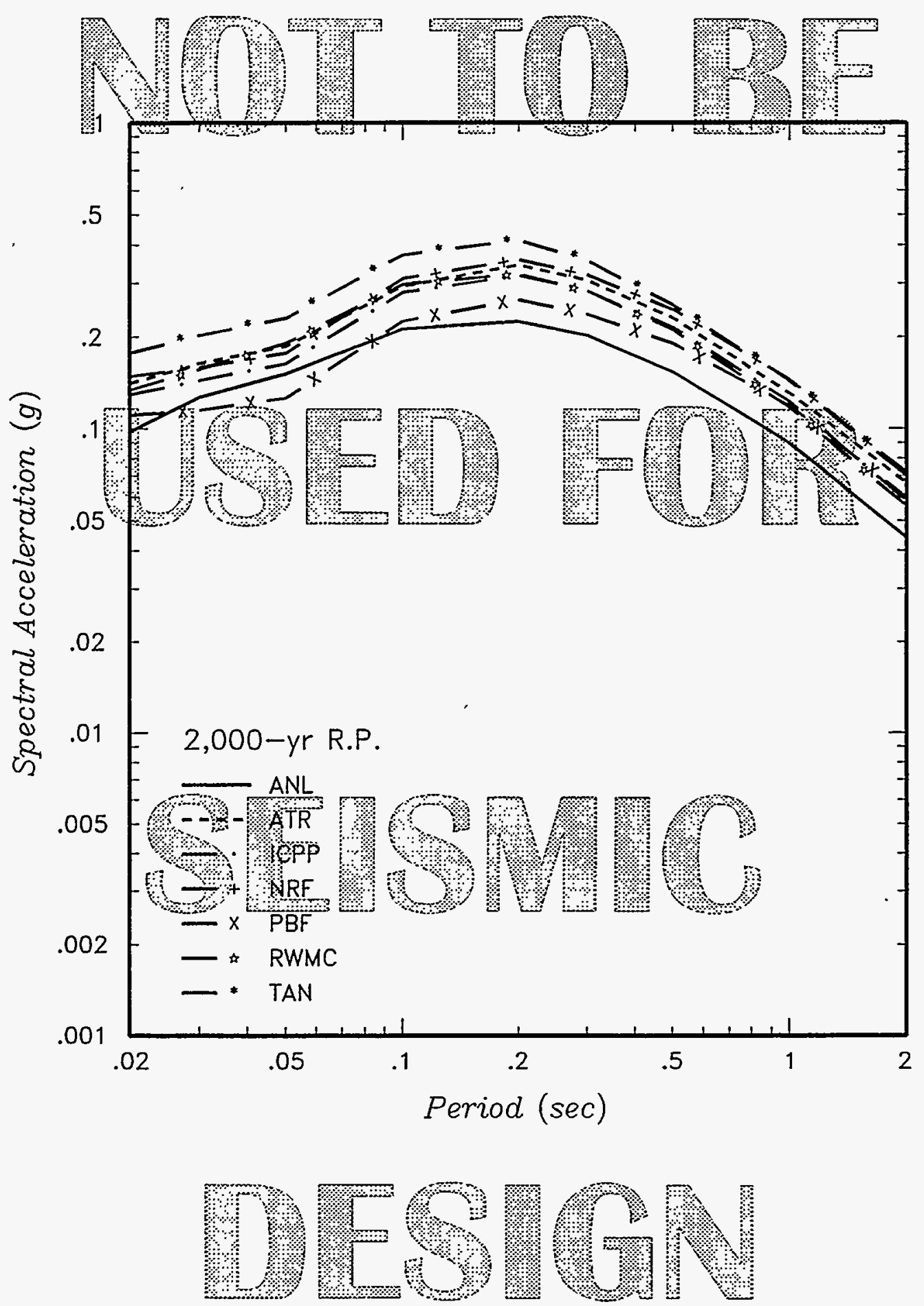

\begin{tabular}{c|c}
\hline $\begin{array}{c}\text { Project No. } \\
\text { SK9455 }\end{array}$ & INEL-Probabilistic Analyses \\
\hline
\end{tabular}



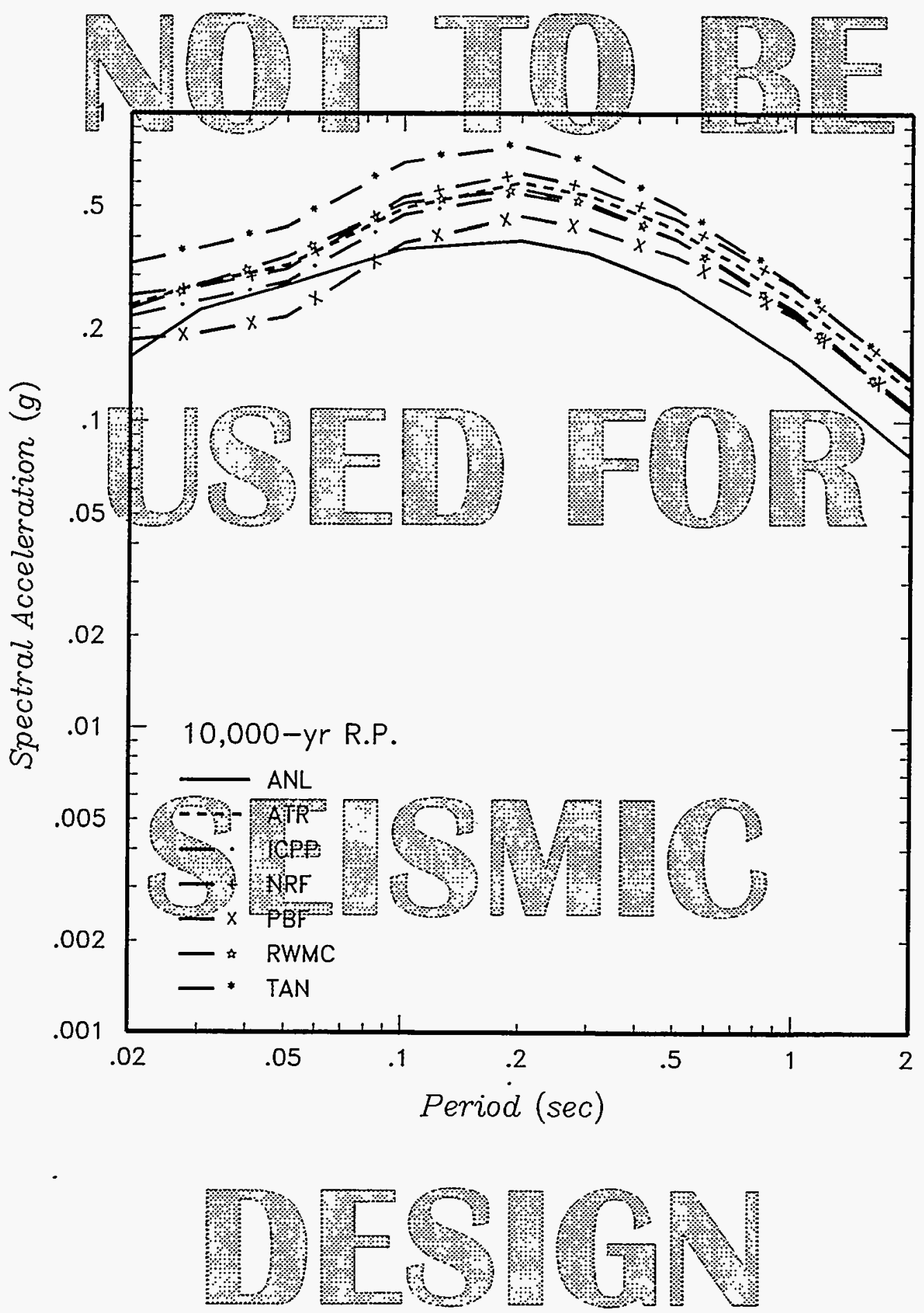

\begin{tabular}{|c|c|c|c|}
\hline $\begin{array}{c}\text { Project No. } \\
\text { SK9455 }\end{array}$ & INEL-Probabilistic Analyses & EQUAL HAZARD SPECTRA & Figure \\
\hline Woodward-Clyde Federal Services & FOR ANNUAL EXCEEDANCE & $6-19 d$ \\
\hline SK9455-A1000/122795/von & PROBABILITY OF 10-4 & \\
\hline
\end{tabular}


Abe, K., 1988, Magnitude and origin times from Milne seismographic data: Earthquakes in China and California, 1898-1912 in W.H.K. Lee, H. Meyers, and K. Shimazaki (eds.), Historical Seismograms and Earthquakes of the World, Academic Press, p. 37-50.

Anders, M.H., Geissman, J.W., Piety, L.A, and Sullivan, J.T., 1989, Parabolic distribution of circumeastern Snake River Plain seismicity and latest Quaternary faulting: Migratory pattern and association with the Yellowstone hotspot, Journal of Geophysical Research, v. 94, p. $1589-1621$.

Anderson, J.G., 1986, Implication of attenuation for studies of the earthquake source in S. Das, J. Boatwright, and C. Scholz (eds.), Earthquake Source Mechanics, American Geophysical Union Monograph 37, p. 311-318.

Anderson, J.G. and Hough, S.E., 1984, A model for the shape of the Fourier amplitude spectrum of acceleration at high frequencies, Bulletin of the Seismological Society of America, v. 74, p. 1969-1994.

Arabasz, W.J., Pechmann, J.C. and Brown, E.D., 1987a, Observational seismology and the evaluation of earthquake hazards and risk in the Wasatch Front area, Utah in W.W. Hays and P.L. Gori (eds.), Assessment of Regional Earthquake Hazards and Risk Along the Wasatch Front, Utah, U.S. Geological Survey Professional Paper (in press).

Arabasz, W.J., Pechmann, J.C., and Brown, E.D., 1987b, Evaluation of seismicity relevant to the proposed siting of a superconducting supercollider (SSC) in Tooele County, Utah, University of Utah Seismograph Stations Technical Report to the Dames and Moore Utah SSC Project Team, $107 \mathrm{p}$.

Arabasz, W.J., Richins, W.D., and Langer, C.J., 1981, The Pocatello Valley (Idaho-Utah border) earthquake sequence of March to April 1975, Bulletin of the Seismological Society of America, v. 71, p. 803-826.'

Archuleta, R.J., Cranswick, E., Mueller, C. and Spudich, P., 1982, Source parameters of the 1980 Mammoth Lakes, California, earthquake sequence, Journal of Geophysical Research, v. 87, p. 4595-4607.

Atkinson, G.M., 1984, Attenuation of strong ground motion in Canada, Bulletin of the Seismological Society of America, v. 74, p. 2629-2953. 
Atkinson, G.M, 1996, Attenuation and source parameters of earthquakes in the Cascadia region, Bulletin of the Seismological Society of America (in press).

Bache, T.C., Lambert, D.G. and Barker, T.G., 1980, A source model for the March 28, 1975 Pocatello Valley earthquake from time-domain modeling of teleseismic $P$ waves, Bulletin of the Seismological Society of America, v. 70, p. 405-418.

Bakun, W.H., 1984, Seismic moments, local magnitudes, and coda-duration magnitudes for earthquakes in central Califormia, Bulletin of the Seismological Society of America, v. 74, p. $439-458$.

Baldwin, E.W., 1951, Faulting in the Lost River Range area of Idaho, American Journal of Science, v. 89, p. 884-902.

Baltzer, E.M., 1990, Quaternary Surface Displacements and Segmentation of the Northern Lemhi Fault, Idaho, Master's of Science Thesis, State University of New York at Binghamton, $88 \mathrm{p}$.

Bankey, V., Webring, M., Mabey, D.R., Kleinkopf, M.D., and Bennett, E.H., 1985, Complete Bouguer gravity anomaly map of Idaho, U.S. Geological Survey Miscellaneous Field Studies Map MF-1733.

Barrientos, S.E., Ward, S.N., Gonzalez-Ruiz, J.R., and Stein, R.S., 1985, Inversion for moment as a function of depth from geodetic observations and long period body waves of the 1983 Borah Peak, Idaho earthquake, in R.S. Stein and R.C. Bucknam (eds.), Proceedings of Workshop XXVIII on the Borah Peak, Idaho, Earthquake, U.S. Geological Survey OpenFile Report 85-290, p. 485-518.

Bartholomay, R.C., 1990, Digitized geophysical logs for selected bore holes on or near the INEL, U.S. Geological Survey Open-File Report 90-366, 347 p.

Bender, B., 1984, Seismic hazard estimation using a finite fault rupture model, Bulletin of the Seismological Society of America, v. 74, p. 1899-1923.

Berg, J.W., Jr. and Baker, C.D., 1963, Oregon earthquakes, 1841 through 1958, Bulletin of the Seismological Society of America, v. 53, p. 95-108.

Bjarnason, I.T. and Pechmann, J.C., 1989, Contemporary tectonics of the Wasatch Front region, Utah, from earthquake focal mechanisms, Bulletin of the Seismological Society of America, v. 79, p. 731-755.

Bjornsson, A., Saemundsson, K., Einarsson, P., Tyggvason, E., and Gronvald, K., 1977, Current rifting episode in north Iceland, Nature, v. 266, p. 318-323. 
Blackwell, D.D., 1989, Regional implications of the heat flow of the Snake River Plain, northwestern United States, Tectonophysics, v. 164, p. 323-343.

Boatwright, J., 1984, Seismic estimates of stress release, Journal of Geophysical Research, v. 89, p. 6961-6968.

Boatwright, J., 1985, Characteristics of the aftershock sequence of the Borah Peak, Idaho, earthquake determined from digital recordings of the events, Bulletin of the Seismological Society of America, v. 75, p. 1265-1284.

Boatwright, J. and Choy, G.L., 1985, Teleseismic estimates of the energy radiated by shallow earthquakes, in R.S. Stein and R.C. Bucknam (eds.), Proceedings of Workshop XXXVIII on the Borah Peak, Idaho, Earthquake, U.S. Geological Survey Open-File Report 85-290, p. 408-448.

Bolt, B.A., 1984, The magnitudes of the Hebgen Lake 1959 and Idaho 1983 earthquakes (abs.), Earthquake Notes, v. 55, p. 13.

Boore, D.M., 1983, Stochastic simulation of high-frequency ground motions based on seismological models of the radiated spectra, Bulletin of the Seismological Society of America, v. 73, p. 1865-1884.

Boore, D.M., 1986, Short-period P- and S-wave radiation from large earthquakes: Implications for spectral scaling relations, Bulletin of the Seismological Society of America, v. 76, p. 4364.

Boore, D.M. and Atkinson, G.M., 1987, Prediction of ground motion and spectral response parameters at hard-rock sites in eastern North America, Bulletin of the Seismological Society of America, v. 77, p. 440-467.

Boore, D.M. and Joyner, W.B., 1984, A note on the use of random vibration theory to predict peak amplitudes of transient signals, Bulletin of the Seismological Society of America, v. 74, p. 2035-2039.

Braile, L.W., Smith, RB., Ansorge, J., Baker, MR., Sparlin, M.A., Prodehl, C., Schilly, M.M., Healy, J.H., Mueller, S., and Olsen, K.H., 1982, The Yellowstone-Snake River Plain seismic profiling experiment: Crustal structure of the eastern Snake River Plain, Journal of Geophysical Research, v. 87, p. 2597-2609.

Brott, C.A., Blackwell, D.D., and Mitchell, J.C., 1978, Tectonic implications of the heat flow of the western Snake River Plain, Idaho, Geological Society of America Bulletin, v. 89, p. 1697-1707. 
Brott, C.A, Blackwell, D.D., and Ziagos, J.P., 1981, Thermal and tectonic implications of heat flow in the eastern Snake River Plain, Idaho, Journal of Geophysical Research, v. 86, p. 11709-11734.

Brune, J.N., 1970, Tectonic stress and the spectra of seismic shear waves from earthquakes, Journal of Geophysical Research, v. 75, p. 4997-5009.

Brune, J.N., 1971, Correction, Journal of Geophysical Research, v. 76, p. 5002.

Byrd, J.O.D. and Smith, R.B., 1990, Dating recent faulting and estimates of slip rates for the southern segment of the Teton fault, Wyoming, Abstracts with Programs, Geological Society of America, v. 22, p. 4-5.

Byrd, J.O.D., Smith, RB., and Geissman, J.W., 1994, The Teton fault, Wyoming: Topographic signature, neotectonics, and mechanisms of deformation, Journal of Geophysical Research, v. 99 , p. $20,095-20,122$.

Campbell, K.W., 1993, Empirical prediction of near-source ground motion from large earthquakes: International Workshop on Earthquake Hazard and Large Dams in the Himalaya, Indian National Trust for Art and Cultural Heritage (INTACH), New Delhi, India.

Campbell, K.W. and Bozorgnia, Y., 1994, Near-source attenuation of peak horizontal acceleration from worldwide accelerograms recorded from 1957 to 1993, Fifth U.S. International Conference on Earthquake Engineering, Chicago, Mllinois.

Carver, D., Richins, W.D., and Langer, C.J., 1983, Details of the aftershock process following the 30 September 1977 Uinta Basin, Utah, earthquake, Bulletin of the Seismological Society of America, v. 73 , p. $435-448$.

Caskey, S.J., 1995, Geometric relations of dip slip to a faulted ground surface: New nomograms for estimating components of fault displacement, Journal of Structural Geology, v. 17, p. 1197-1202.

Chávez, D.E. and Priestley, K.F., 1986, Measurement of frequency-dependent Lg attenuation in the Great Basin, Geophysical Research Letters, v. 13, p. 551-554.

Coffman, J.L., von Hake, C.A., and Stover, C.W., 1982, Earthquake history of the United States, National Oceanic and Atmospheric Administration and the U.S. Geological Survey, Publication 41-1 With Supplement, 208 p. 
Cohn, S.N., Hong, T.L., and Helmberger, D.V., 1982, The Oroville earthquakes: A study of source characteristics and site effects, Journal of Geophysical Research, v. 87, p. 4585-4594.

Coppersmith, K.J. and Youngs, RR, 1986, Capturing uncertainty in probabilistic seismic hazard assessments within intraplate environments, Proceedings of the $3 \mathrm{rd}$ National Conference on Earthquake Engineering, v. I, p. 301-312.

Comell, C.A., 1968, Engineering seismic risk analysis, Bulletin of the Seismological Society of America, v. 58, p. 1583-1606.

Cornell, C.A. and Van Marke, E.H., 1969, The major influences on seismic risk, Proceedings of the Third World Conference on Earthquake Engineering, v. A-1, p. 69-93.

Crone, AJ. and Haller, K.M., 1989, Segmentation of Basin-and-Range normal faults: examples from east-central Idaho and southwestern Montana in D.P. Schwartz and R.H. Sibson (eds.), Proceedings of Conference XLV, Fault Segmentation and Controls of Rupture Initiation and Termination, U.S. Geological Survey Open-File Report 89-315, p. 110-130.

Crone, A.J. and Haller, K.M., 1991, Segmentation and the coseismic behavior of Basin and Range normal faults: Examples from east-central Idaho and southwestern Montana, U.S.A., Journal of Structural Geology, v. 13, p. 151-164.

Crone, A.J. and Machette, MN., 1984, Surface faulting associated with the Borah Peak earthquake, central Idaho, Geology, v. 12, p. 664-667.

Crone, A.J., Machette, M.N., Bonilla, M.G., Lienkaemper, J.J., Pierce, K.L., Scott, W.E., and Bucknam, R.C., 1985, Characteristics of surface faulting accompanying the Borah Peak earthquake, central Idaho, in R.S. Stein and R.C. Bucknam (eds.), Proceedings of Workshop XXXVIII on the Borah Peak, Idaho, Earthquake, U.S. Geological Survey Open-File Report 85-290, p. 43-58.

Crone, A.J., Machette, M.N., Bonilla, M.G., Lienkaemper, J.J., Pierce, K.L., Scott, W.E., and Bucknam, R.C., 1987, Surface faulting accompanying the Borah Peak earthquake and segmentation of the Lost River fault, central Idaho, Bulletin of the Seismological Society of America, v. 77, p. 739-770.

dePolo, C.M., Clark, D.G., Slemmons, D.B., and Ramelli, A.R, 1991, Historical surface faulting in the Basin and Range Province, western North America: Implications for fault segmentation, Journal of Structural Geology, v. 13, p. 123-136.

Dewey, J.W., 1987, Instrumental seismicity of central Idaho, Bulletin of the Seismological Society of America, v. 77, p. 819-836. 
Doherty, D.J., McBroome, L.A., and Kuntz, M.A., 1979, Preliminary geologic interpretation and lithologic log of the exploratory test well INEL-1, Idaho National Engineering Laboratory, eastern Snake River Plain, Idaho, U.S. Geological Survey Open-File Report 79-1248, 10 p.

Doser, D.I., 1985a, Source parameters and faulting processes of the 1959 Hebgen Lake, Montana, earthquake sequence, Journal of Geophysical Research, v. 90, p. 4537-4555.

Doser, D.I., 1985b, The 1983 Borah Peak, Idaho and 1959 Hebgen Lake, Montana earthquakes-Models for normal fault earthquakes in the Intermountain seismic belt, in R.S. Stein and RC. Bucknam (eds.), Proceedings of Workshop XXVIII on the Borah Peak, Idaho, Earthquake, U.S. Geological Survey Open-File Report 85-290, p. 368-384.

Doser, D.I., 1989a, Source parameters of Montana earthquakes (1925-1964) and tectonic deformation in the northern Intermountain Seismic Belt, Bulletin of the Seismological Society of America, v. 79, p. 31-50.

Doser, D.I., 1989b, Extensional tectonics in northern Utah-southern Idaho, U.S.A., and the 1934 Hansel Valley sequence, Physics of the Earth and Planetary Interiors, v. 54, p. 120-134.

Doser, D.I. and Smith, RB., 1982, Seismic moment rates in the Utah region, Bulletin of the Seismological Society of America, v. 72, p. 525-551.

Doser, D.I. and Smith, RB., 1985, Source parameters of the 28 October 1983 Borah Peak, Idaho earthquake from body wave analysis, Bulletin of the Seismological Society of America, v. 75 , p. 1041-1051.

Doser, D.I. and Smith, RB., 1989, An assessment of source parameters of earthquakes in the Cordillera of the western U.S., Bulletin of the Seismological Society of America, v. 79, p. 1383-1409.

$\mathrm{Du}, \mathrm{Y}$. and Aydin, A, 1992, Three-dimensional characteristics of dike intrusion along the northern Iceland rift from inversion of geodetic data, Tectonophysics, v. 204, p. 111-121.

Embree, G.F., 1989, Neogene fault activity in southern Beaverhead range adjacent to the eastern Snake River Plain and Birch Creek Valley, Idaho, unpublished report prepared for EG\&G Idaho.

Engdahl, E.R. and Rinehart, W.A, 1988, Seismicity map of North America, DNAG, Geological Society of America, Map-004, Scale 1:5,000,000. 
Engdahl, E.R. and Rinehart, W.A., 1991, Seismicity map of North America Project, in D.B. Slemmons, E.R. Engdahl, M.D. Zoback and D.D. Blackwell (eds.), Neotectonics of North America, Geological Society of America Decade Map, v. 1, p. $21-27$.

EPRI, 1989, Lower-bound magnitude for probabilistic seismic hazard assessment, unpublished report prepared for the Electric Power Research Institute by Jack Benjamin and Associates, EPRI Report NP-6496.

Fletcher, J. Boatwright, J., Haar, L., Hanks, T., and McGarr, A, 1984, Source parameters for aftershocks of the Oroville, California earthquake, Bulletin of the Seismological Society of America, v. 74, p. 1101-1123.

Geomatrix Consultants, 1995, Seismic design mapping for the State of Oregon, unpublished Final Report prepared for the Oregon Department of Transportation.

Gilbert, J.D., Ostenaa, D., and Wood, C., 1983, Seismotectonic study for Jackson Lake dam and reservoir, Minidoka Project, Idaho-Wyoming, U.S. Bureau of Reclamation, Seismotectonic Report 83-8, 123 p.

Golder Associates, 1992, New Production Reactor Site Characterization - Volcanic Zones, Geologic Mapping Report, unpublished report prepared for EG\&G Idaho, Inc.

Gorton, A.E., 1995, Late Quaternary surface displacements and segmentation along the southern Lemhi fault, east-central Idaho, unpublished Master's thesis, Binghamton University, 103 p.

Gorton, A.E. and Knuepfer, P.L.K., 1993, Late Quaternary segmentation of the southern Lemhi fault, Idaho (abs.), Abstracts with Programs, Geological Society of America, v. 25 p. 44.

Hackett, W.R., Jackson, S.M., and Smith, R.P., 1996, Paleoseismology of volcanic environments, in J.P. McCalpin (ed.), Paleoseismology, Academic Press (in press).

Hackett, W.R. and Smith, R.P., 1994, Volcanic hazards of the Idaho National Engineering Laboratory and adjacent areas, prepared for the U.S. Department of Energy, INEL94/0276, $31 \mathrm{p}$.

Hackett, W.R, Smith, R.P., and Josten, N.E., 1991, Interaction of. Quaternary volcanic and tectonic processes, eastern Snake River Plain, Idaho, Abstracts with Programs, Geological Society of America, v. 23, p. 32.

Haller, K.M., 1988, Segmentation of the Lemhi and Beaverhead faults, east-central Idaho, and Red Rock fault, southwest Montana, during the late Quaternary, M.S. Thesis, University of Colorado, $141 \mathrm{p}$. 
Hanks, T.C., 1979, b valves and $\omega^{-2}$ seismic source models: Implications for tectonic stress variations along active crustal fault zones and the estimation of high-frequency strong ground motion, Journal of Geophysical Research, v. 84, p. 2235-2242.

Hanks, T.C., 1982, fmax, Bulletin of the Seismological Society of America, v. 72, p. 1867-1879.

Hanks, T.C. and Kanamori, H., 1979, A moment magnitude scale, Journal of Geophysical Research, v. 84, p. 2348-2350.

Hanks, T.C. and McGuire, RK., 1981, The character of high-frequency strong ground motion, Bulletin of the Seismological Society of America, v. 71, p. 2071-2095.

Hanks, T.C. and Schwartz, D.P., 1987, Morphologic dating of the pre-1983 fault scarp on the Lost River fault at Doublespring Pass Road, Custer County, Idaho, Bulletin of the Seismological Society of America, v. 77, p. 837-846.

Hemphill-Haley, M.A., Sawyer, T.L., Knuepfer, P.L.K., Forman, S.L., and Wong, I.G., 1994, Late Quaternary paleoseismicity and segmentation along the Southern Lemhi fault, southeastern Idaho, in Proceedings of the Workshop on Paleoseismology, U.S. Geological Survey Open-File Report 94-568, p. 81-83.

Hill, D.P., Kissling, E., Luetgert, J.H., and Kradolfer, U., 1985, Constraints on the upper crustal structure of the Long Valley-Mono Craters volcanic complex, eastern California, from seismic refraction measurements, Journal of Geophysical Research, v. 90, p. $11,135-11,150$.

Hoblitt, R.P., Miller, C.D., and Scott, W.F., 1987, Volcanic hazards with regard to siting nuclear power plants in the Pacific Northwest, U.S. Geological Survey Open-File Report OFR 87297.

Hough, S.E. and Anderson, J.G., 1988, High-frequency spectra observed at Anza, California: Implications for Q structure, Bulletin of the Seismological Society of America, v. 78, p. 692-707.

Hough, S.E., Anderson, J.G., Brune, J., Vernon, F. III, Berger, J., Fletcher, J., Haar, L., Hanks, T. and Baker, L., 1988, Attenuation near Anza, California, Bulletin of Seismological Society of America, v. 78, p. $672-691$.

Idriss, I.M., 1991, Earthquake ground motions at soft soil sites, Second International Conference on Recent Advances in Geotechnical Earthquake Engineering and Soil Dynamics, v. 3, p. 2265-2272. 
Jackson, S.M., 1994, Magnitudes of earthquakes associated with basalt dike intrusion for use in INEL seismic hazard evaluations, prepared for the U.S. Department of Energy, INEL94/0132, $44 \mathrm{p}$.

Jackson, S.M., Carpenter, G.S., Smith, R.P., and Casper, J.L., 1995, Seismic reflection project near the southern terminations of the Lost River and Lemhi faults, eastern Snake River plain, Idaho, Idaho National Engineering Laboratory, INEL-95/0489 (in preparation).

Jackson, S.M., Wong, I.G., Carpenter, G.S., Anderson, D.M., and Martin, S.M., 1993, Contemporary seismicity of the Eastern Snake River Plain based on microearthquake monitoring, Bulletin of the Seismological Society of America, v. 83, p. 680-695.

Janecke; S.U., 1993, Structures in segment boundary zones of the Lost River and Lemhi faults, east-central Idaho, Journal of Geophysical Research, v. 98, p. 16,223-16,238.

Josten, N.E., Hackett, W.R., Smith, R.P., 1993, Attempted integration of geologic and geophysical data from the Idaho National Engineering Laboratory area, eastern Snake River Plain (abs.), Geological Society of America, Abstracts with Programs, v. 25, p. 60.

Joyner, W.B. and Boore, D.M., 1982, Prediction of earthquake response spectra, U.S. Geological Survey Open-File Report 82-977.

Karpin, T.L. and Thurber, C.H., 1987, The relationship between earthquake swarms and magma transport: Kilauea Volcano, Hawaii, Pageoph, v. 125, p. 971-991.

Keefer, D.I. and Bodily, S.E., 1983, Three-point approximations for continuous random variables, Management Science, v. 26, p. 595-609.

King, J.J., Doyle, T.E., and Jackson, S.M., 1987, Seismicity of the eastern Snake River Plain region, Idaho, prior to the Borah Peak, Idaho, earthquake: October 1972-October 1983, Bulletin of the Seismological Society of America, v. 77, p. 809-818.

Klein, F.W., Koyanagi, R.Y., Nakata, J.S., and Tanigawa, W.R., 1987, The seismicity of Kilauea's magma system, in RW. Decker, T.L. Wright, and P.H. Stauffer (eds.), Volcanism in Hawaii, U.S. Geological Survey Professional Paper 1350, p. 1019-1185.

Knuepfer, P.L.K., 1994, Implications for the nature of rupture segmentation from paleoseismic studies of normal faults, east-central Idaho, in Proceedings of the Workshop on Paleoseismology, U.S. Geological Survey Open-File Report 94-568, p. 97-99.

Knuepfer, P.L.K., Baltzer, E.M., and Turko, J.M., 1990, Late-Quaternary earthquake recurrence and seismic hazard of the Lemhi fault, Idaho, Abstracts With Programs, Geological Society of America, v. 22, p. 17. 
Kulkarni, R.B., Youngs, R.R, and Coppersmith, K.J., 1984, Assessment of confidence intervals for results of seismic hazard analysis, Proceedings of the Eight World Conference on Earthquake Engineering, v. 1, p. 263-270.

Kuntz, M.A., 1977, Extensional faulting and volcanism along the Arco Rift zone, eastern Snake River, Plain, Idaho, Abstracts with Programs, Geological Society of America, p. 740-741.

Kuntz, M.A, 1978, Geologic map of the Arco-Big Southern Butte area, Butte, Blaine, Bingham Counties, Idaho, U.S. Geological Survey Open-File Report 78-302.

Kuntz, M.A. Champion, D.E., Lefebvre, R.H., and Covington, H.R., 1988, Geologic map of the Craters of the Moon, Kings Bowl, and Wapi Lava Fields, and the Great Rift Volcanic Rift Zone, south-central Idaho, U.S. Geological Survey Miscellaneous Investigations Series Map I-1632, 1:100,000 scale.

Kuntz, M.A., Covington, H.R, and Schorr, L.J., 1992, An overview of basaltic volcanism of the eastern Snake River Plain, Idaho, in P.K. Link, M.A. Kuntz, and L.B. Platt (eds.), Regional Geology of Eastern Idaho and Western Wyoming, Geological Society of America Memoir 179, p. 227-267.

Kuntz, M.A., Skipp, B., Lamphere, M.A., Scott, W.E., Pierce, K.L., Dalrymple, G.B., Champion, D.E., Embree, G.F., Page, W.R, Morgan, L.A., Smith R.P., Hackett, W.R, and Rodgers, D.W., 1994, Geologic map of the Idaho National Engineering Laboratory and adjoining areas, eastern Idaho, U.S. Geological Survey Miscellaneous Investigation Map I-2330, scale 1:100,000.

Kuntz, M.A., Spiker, E.C., Rubin, M., Champion, D.E., and Lefebvre, R.H., 1986, Radiocarbon studies of latest Pleistocene and Holocene lava flows of the Snake River Plain, Idaho: Data, lessons, interpretations, Quaternary Research, v. 25, p. 163-176.

LaPoint, P.J.I., 1977, Preliminary photogeologic map of the eastern Snake River Plain, Idaho, U.S. Geological Survey Miscellaneous Field Studies Map.MF-850.

Mabey, D.R, 1978, Regional gravity and magnetic anomalies in the eastern Snake River Plain, Idaho, U.S. Geological Survey, Journal of Research, v. 6, p 553-562.

Machette, M.N., Personius, S.F., Nelson, A.R., Schwartz, D.P., and Lund, W.R, 1991, The Wasatch fault zone, Utah - Segmentation and history of Holocene earthquakes, in P.L. Handcock, R.S. Yeats, and D.J. Sanderson (eds.), Characteristics of Active Faults, Journal of Structural Geology, v. 13, p. 137-150. 
Malde, H.E., 1971, Geological investigation of faulting near the National Reactor Testing Station, Idaho, with a section on microearthquake studies by A.M. Pitts and J.P. Eaton, U.S. Geological Survey Open-File Report, $167 \mathrm{p}$.

Malde, H.E., 1985, Quaternary faulting near Arco and Howe, Idaho in R.S. Stein and R.C. Bucknam (eds.), Proceedings of Workshop XXVIII on the Borah Peak, Idaho Earthquake, U.S. Geological Survey Open-File Report 85-290, v. A, p. 207-235.

Malde, H.E., 1987, Quaternary faulting near Arco and Howe, Idaho, Bulletin of the Seismological Society of America, v. 77, p. 847-867.

McGarr, A., 1984, Scaling of ground motion parameters, state of stress, and focal depth, Journal of Geophysical Research, v. 89, p. 6969-6979.

Merz, H.A. and Cornell, C.A., 1973, Aftershocks in engineering seismic risk analysis, M.I.T. Department of Civil Engineering Research Report R73-25, Cambridge, Massachusetts.

Moos, D., Barton, C.A., and Smith, R.P., 1990, Results of borehole televiewer logging to $3 \mathrm{~km}$ depth in the Snake River Plain - In situ stress and fractures (abs.), EOS, v. 43, p. 1622.

Mueller, C., Spudich, P., Cranswick, E., and Archuleta, R, 1981, Preliminary analysis of digital seismograms from the Mammoth Lakes, California earthquake sequence of May-June, 1980, U.S. Geological Survey Open-File Report, p. 81-155.

Oaks, S.D., 1992, Historical seismicity investigation for the November 11, 1905, earthquake, unpublished report prepared for EG\&G Idaho, Inc., Idaho National Engineering Laboratory.

Oaks, S.D., Jackson, S.M., and Wong, I.G., 1992, An investigation of the 11 November 1905 Shoshone, Idaho, earthquake: Implications for seismic hazards within the eastern Snake River Plain (abs.), Seismological Research Letters, v. 63, p. 22.

Ou, G.B. and Herrmann, R.B., 1990, A statistical model for ground motion produced by earthquakes at local and regional distances, Bulletin of the Seismological Society of America, v. 80, p. 1397-1417.

Papageorgiou, A. S. and Aki, K., 1983, A specific barrier model for the quantitative description of inhomogeneous faulting and the prediction of strong ground motion, Part II: Applications of the model, Bulletin of the Seismological Society of America, v. 73, p. 953-978.

Pankratz, L.W. and Ackermann, H.D., 1982, Structure along the northwest edge of the Snake River Plain interpreted from seismic refraction, Journal of Geophysical Research, v. 87, p. 2676-2682. 
Parsons, T. and Thompson, G.A., 1991, The role of magma overpressure in suppressing earthquakes and topography: World-wide examples, Science, v. 253, p. 1399-1402.

Pelton, J.R, Vincent, RJ., and Anderson, N.J., 1990, Microearthquakes in the Middle Butte/East Butte area, eastern Snake River Plain, Idaho, Bulletin of the Seismological Society of America, v. 80, p. 209-212.

Pennington, W.D., Smith, RB., and Tremble, AB., 1974, A microearthquake study of parts of the Snake River Plain and central Idaho, Bulletin of the Seismological Society of America, v. 64, p. 307-312.

Pierce; K.L., 1985, Quaternary history of faulting on the Arco segment of the Lost River fault, central Idaho, in R.S. Stein and R.C. Bucknam (eds.), Proceedings of Workshop XXVIII on the Borah Peak, Idaho, Earthquake, U.S. Geological Survey Open File Report 85-290, v. A, p. 195-206.

Pierce, K.L., 1988, Field guides to the Quaternary geology of central Idaho: Part E, History of Quaternary faulting and scarp degradation studies, Southern Lost River valley in P.K. Link and W.R. Hackett (eds.), Guidebook to the Geology of Central and Southern Idaho, Idaho Geological Survey Bulletin 27, p: 233-240.

Pierce, K.L. and Morgan, L.A, 1992, The track of Yellowstone hot spot: Volcanism, faulting, and uplift, Geological Society of America Memoir 179, p. 1-53.

Piety, L.A. Wood, C.K., Gilbert, J.D., Sullivan, J.T., and Anders, M.H., 1986, Seismotectonic study for Palisades dam and reservoir, Palisades Project, U.S. Bureau of Reclamation Seismotectonic Report 86-3, 198 p.

Pitt, AM., Weaver, C.S., and Spence, W., 1979, The Yellowstone Park earthquake of June 30, 1975, Bulletin of the Seismological Society of America, v. 69, p. 187-205.

Pratt, RM., 1982, The case for lateral offset of the overthrust belt along the Snake River Plain in R.B. Powers (ed.), Geologic Studies of the Cordilleran Thrust Belt, Denver, Colorado, Rocky Mountain Association of Geologists, v. 1, p. 235-245.

Rasmussen, N., 1966, Seismology report on Washington, Idaho and Northern California and the Hanford Area, Washington, Douglas Nuclear Inc.

Reaveley, L.D., 1985, The Borah Peak, Idaho, earthquake of October 28, 1983 - Summary, Earthquake Spectra, v. 2, p. 1-9. 
Reynolds, M.W., 1979, Character and extent of Basin-Range faulting, western Montana and eastcentral Idaho, 1979 Basin and Range Symposium, Rocky Mountain Association of Geologists and Utah Geological Association, p. 185-193.

Richins, W.D., Pechmann, J.C., Smith, R.B., Langer, C.J., Goter, S.K., Zollweg, J.E., and King, J.J., 1987, The 1983 Borah Peak, Idaho, earthquake and its aftershocks, Bulletin of the Seismological Society of America, v. 77, p. 694-723.

Rodgers, D.W., Hackett, W.R, and Ore, H.T., 1990, Extension of the Yellowstone plateau, eastern Snake River Plain, and Owyhee plateau, Geology, v. 18, p. 1138-1141.

Rodgers, D.W. and Zentner, N.C., 1988, Fault geometries along the northern margin of the Eastern Snake River Plain, Idaho, Abstracts with Programs, Geological Society of America v. 20, p. $465-466$.

Ross, C.P., 1947, Geology of the Borah Peak quadrangle, Idaho, Geological Society of America Bulletin, v. 58, p. 1085-1160.

Royse, F., Warner, M.A., and Reese, D.L., 1975, Thrust belt structural geometry and related stratigraphic problems, Wyoming-Idaho-Northern Utah, in D.W. Bolyare (ed.), Deep drilling frontiers in the central Rocky Mountains, Rocky Mountain Association of Geologists, p. 41-54.

Rubin, A.M., 1992, Dike-induced faulting and graben subsidence in volcanic rift zones, Journal of Geophysical Research, v. 97, p. 1839-1858.

Rubin, A.M. and Pollard, D.D., 1988, Dike-induced faulting in rift zones of Iceland and Afar, Geology, v. 16, p. 413-417.

Ruppel, E.T., 1978, Medicine Lodge thrust system, east-central Idaho and southwest Montana, U.S. Geological Survey Professional Paper 1031, 23 p.

Ruppel, E.T., 1982, Cenozoic block uplifts in east-central Idaho and southwest Montana, U.S. Geological Survey Professional Paper 1224, 24 p.

Sadigh, K., Chang, C-Y., Abrahamson, N.A., Chiou, S.J., and Power, M.S., 1993, Specification of long-period ground motions: Updated attenuation relationships for rock site conditions and adjustment factors for near-fault effects, in Proceedings of ATC-17-1 Seminar on Seismic Isolation, Passive Energy Dissipation, and Active Controll, v. 1, p. 59-70.

Salyards, S.L., 1985, Patterns of offset associated with the 1983 Borah Peak, Idaho, earthquake and previous events, in R.S. Stein and R.C. Bucknam (eds.), Proceedings of the Workshop 
XXVIII on the Borah Peak, Idaho, Earthquake, U.S. Geological Survey Open-File Report $85-290$, v. A; p. 59-75.

Savy, J., Bernreuter, D., Chen, J.C., Davis, B.C., Ueng, J., and Short, C., 1992, Seismic hazard characterization of the DOE New Production Reactor Sites, draft report prepared for the U.S. Department of Energy by Lawrence Livermore National Laboratory, Report NPR92147JBS, Rev. A., 3 vol.

Schwartz, D.P., 1989, Paleoseismicity, persistence of segments, and temporal clustering of large earthquakes-examples from the San Andreas, Wasatch, and Lost River fault zones in D.P. Schwartz and R.H. Sibson (eds.), Proceedings of Conference XIV on Fault Segmentation and Controls of Rupture Initiation and Termination, U.S. Geological Survey Open-File Report 89-315, p. 361-375.

Schwartz, D.P. and Coppersmith, K.J., 1984, Fault behavior and characteristic earthquakes: Examples from the Wasatch and San Andreas fault zones, Journal of Geophysical Research, v. 89, p. 5681-5698.

Schwartz, D.P. and Crone, A.J., 1985, The 1983 Borah Peak earthquake: A calibration event for quantifying earthquake recurrence and fault behavior on Great Basin normal faults, in R.S. Stein and R.C. Bucknam (eds.), Proceedings of Workshop XXVIII, on the Borah Peak, Idaho, earthquake, U.S. Geological Survey Open File Report 85-290, p. 153-160.

Scott, W.E., 1982, Surficial geologic map of the eastern Snake River Plain and adjacent areas, $111^{\circ}$ and $115^{\circ}$ W., Idaho and Wyoming, U.S. Geological Survey Miscellaneous Investigations Series Map I-1372, 2 sheets, 1:250,000.

Scott, W.E., Pierce, K.L., and Hait, M.H., 1985, Quaternary tectonic setting of the 1983 Borah Peak earthquake, central Idaho, Bulletin of the Seismological Society of America, v. 75, p. 1053-1066.

Seekins, L.C. and Hanks, T.C., 1978, Strong-motion accelerograms of the Oroville aftershocks and peak acceleration data, Bulletin of the Seismological Society of America, v. 68, p. 677-689.

Seekins, L.C., Hill, D.P., and Hanks, T.C., 1978, Shear-wave velocity structure near Oroville, California, Bulletin of the Seismological Society of America, v. 68, p. 691-697.

Shannon and Wilson, Inc/Agbabian Associates, 1980, Geotechnical and strong motion earthquake data from U.S. accelerograph stations, NUREG CR-0985, v. 3.

Shemata, J.E. and Pechmann, J.C., 1993, Source parameters of aftershocks of the 1983 Borah Peak, Idaho earthquake, Journal of Geophysical Research (in press). 
Silva, W.J., 1976, Body waves in a layered anelastic solid, Bulletin of the Seismological Society of America, v. 66, p. 1539-1554.

Silva, W.J. and Darragh, RB., 1995, Engineering characterization of strong ground motion recorded at rock sites, Electric Power Research Institute, EPRI TR-102262.

Silva, W.J. and Lee, K., 1987, WES RASCAL code for synthesizing earthquake ground motions, State-of-the-Art for Assessing Earthquake Hazards in the United States, Report 24, U.S. Corps of Engineers Waterways Experiment Station, Miscellaneous Paper S-73-1, 120 p.

Singh, S. and Herrmann, R.B., 1983, Regionalization of crustal coda Q in the continental U.S., Journal of Geophysical Research, v. 88, p. 527-538.

Skipp, B. and Hait, M.H., Jr., 1977, Allochthons along the northeast margin on the Snake River Plain, Idaho, in E.L. Heisey, E.R.d Norwood, P.H. Wach, and L.A. Hall (eds.), Rocky Mountain Thrust Belt Geology and Resources, Wyoming Geological Association, 29th Annual Field Conference Guidebooks p. 499-515.

Smith, R.B., and Arabasz, W.J., 1991, Seismicity of the Intermountain seismic belt in D.B. Slemmons, E.R. Engdahl, MD. Zoback, M.L. Zoback, and D. Blackwell (eds.), Neotectonics of North America, Geological Society of North America, SMV V-1, p. 185228.

Smith, R.B., and Braile, L.W., 1993, Topographic signature, space-time evolution, and physical properties of the Yellowstone-Snake River Plain volcanic system: the Yellowstone hotspot, in A.W. Snoke, J.R. Steidtmann, and S.M. Roberts (eds.), Geology of Wyoming, Geological Survey of Wyoming Memoir No. 5, p. 694-754.

Smith, R.B. and Bruhn, R.L., 1984, Intraplate extensional tectonics of the eastern Basin-Range: Inferences on structural style from seismic reflection data, regional tectonics, and thermalmechanical models of brittle-ductile deformation, Journal of Geophysical Research 89, p. 5733-5762.

Smith, R.P., Hackett, W.R, and Roberts, D.W., 1989, Geological aspects of seismic hazards assessments at the INEL, southeastern Idaho, in Proceedings of the Second DOE Natural Hazards Mitigation Conference, p. 282-289.

Smith, R.P., Jackson, S.M., and Hackett, W.R, 1996, Paleoseismology in extensional volcanic terrains, Journal of Geophysical Research, v. 101, p. 6277-6292.

Smith, R.B., Nagy, W.C., and Doser, D.I., 1991, The 1983 Borah Peak, Idaho, earthquake: Regional seismicity, stress field inversion, fault kinematics and seismotectonics of the Snake River Plain (unpublished manuscript). 
Smith R.B., Richins, W.D., and Doser, D.I., 1985, The 1983 Borah Peak, Idaho earthquake: Regional seismicity, kinematics of faulting, and tectonic mechanism, in Proceedings of Conference XXVIII on the Borah Peak, Idaho Earthquake, U.S. Geological Survey OpenFile Report 85-290, p. 236-263.

Smith, RB. and Sbar, M., 1974, Contemporary tectonics and seismicity of the western United States with emphasis on the Intermountain seismic belt, Bulletin of the Seismological Society of America, v. 85, p. 1205-1218.

Sparlin, M.A, Braile, L.W., and Smith, R.B., 1982, Crustal structure of the eastern Snake River Plain determined from ray trace modeling of seismic refraction data, Journal of Geophysical Research, v. 87, p. 2619-2633.

Stanley, W.D., 1982, Magnetotelluric soundings on the Idaho National Engineering Laboratory Facility, Idaho, Journal of Geophysical Research, v. 87, p. 2683-2691.

Stein, R.S. and Barrientos, S.E., 1985, The 1983 Borah Peak, Idaho, earthquake: Geodetic evidence for deep rupture on a planar fault in Proceedings of Workshop XXVIII On the Borah Peak, Idaho Earthquake, U.S. Geological Survey Open-File Report 85-290, p. 459484.

Stepp, J.C., 1972, Analysis of completeness of the earthquake sample in the Puget Sound area and its effects on statistical estimates of earthquake hazard, Proceedings of the Microzonation Conference, Seattle, WA, p. 897-909.

Stickney, M.C., and Bartholomew, MJ., 1987, Seismicity and late Quaternary faulting of the northern basin and range province, Montana and Idaho, Bulletin of the Seismological Society of America, v. 77, p. 1602-1625.

Stover, C.W., 1985, The Borah Peak, Idaho earthquake of October 28, 1983 - Isoseismal map and intensity distribution, Earthquake Spectra, v. 2, p.11-16.

Tera Corporation, 1984, Seismic hazard analysis for the Idaho National Engineering Laboratory, unpublished report prepared for Lawrence Livermore National Laboratory, $55 \mathrm{p}$.

Toro, G.R. and McGuire, R.K., 1987, An investigation into earthquake ground motion characteristics in eastern North America, Bulletin of the Seismological Society of America, v. 77, p. $468-489$.

Townley, S.D. and Allen, M.W., 1939, Descriptive catalog of earthquakes of the Pacific Coast of the United States: 1769 to 1928, Bulletin of Seismological Society of America, v. 29, p. 1297. 
Turko, J.M., 1988, Quaternary segmentation history of the Lemhi fault; Idaho, Master of Science Thesis, State University of New York at Binghamton, 91 p.

Turko, J.M. and Knuepfer, P.L.K., 1991, Late Quaternary fault segmentation from analysis of scarp morphology, Geology, v. 19, p. 718-721.

U.S. Department of Energy-Idaho, 1992, DOE-ID Architectural Engineering Standards, U.S. Department of Energy, Idaho Field Office, Idaho Falls, Idaho, Revision No. 13.

Veneziano, D. and Van Dyck, J., 1985, Analysis of earthquake catalogs for incompleteness and recurrence rates, Seismic Hazard Methodology for Nuclear Facilities in the Eastern United States, EPRI Research Project N. P101-29, EPRI/SOG Draft 85-1, v. 2, Appendix A-6.

Vincent, K.R., 1985, Measurement of vertical tectonic offset using longitudinal profiles of faulted geomorphic surfaces near Borah Peak, Idaho--A Preliminary report in R.S. Stein and R.C. Bucknam (eds.), Proceedings of Workshop XXVIII on the Borah Peak, Idaho, Earthquake, U.S. Geological Survey Open-File Rep 85-290, p. 76-96.

Weichert, D.H., 1980, Estimation of the earthquake recurrence parameters for unequal observation periods for different magnitudes, Bulletin of the Seismological Society of America, v. 70, p. 1337-1346.

Wells, D. and Coppersmith, K.J., 1994, New earthquake magnitude and fault rupture parameters, Correlations among earthquake magnitude, rupture length, and fault displacement, Bulletin of the Seismological Society of America, v. 84, p. 974-1002.

West, M.W., 1992, An integrated model for seismogenesis in the Intermountain seismic belt, Bulletin of the Seismological Society of America, v. 82, p. 1350-1372.

Westaway, R. and Smith, R.B., 1989, Strong ground motion in normal-faulting earthquakes, Geophysical Joumal, v. 96, p. 529-559.

Whitehead, RL., 1986, Geologic framework of the Snake River Plain, Idaho and eastern Oregon, U.S. Geological Survey Atlas HA-681.

Wong, I.G. and Chapman, D.S., 1990, Deep intraplate earthquakes in the western U.S. and their relationship to lithospheric temperatures, Bulletin of the Seismological Society of America, v. 80, p. $589-599$.

Woodward, N.B., 1988, Primary and secondary basement controls on thrust sheet geometries; in C.J. Schmidt and W.J. Perry, Jr. (eds.), Interaction of the Rocky Mountain foreland and Cordilleran thrust belt, Geological Society of America Memoir 171, p. 353-366. 
Woodward-Clyde Consultants, 1990, Earthquake strong ground motion estimates for the Idaho National Engineering Laboratory, EG\&G Idaho, Inc., Informal Report EGG-BG-9350, 3 volumes.

Woodward-Clyde Consultants, 1992a, Earthquake ground motion evaluations for the proposed New Production Reactor at the Idaho National Engineering Laboratory, Volume I: Deterministic evaluation, EG\&G Idaho, Inc., Informal Report EGG-GEO-10304.

Woodward-Clyde Consultants, 1992b, Earthquake ground motion evaluations for the proposed New Production Reactor at the Idaho National Engineering Laboratory, Volume II: Probabilistic study, EG\&G Idaho, Inc., Informal Report EGG-GEO-10304.

Woodward-Clyde Consultants, 1992c, Paleoseismic investigations of the southern Lemhi fault, Idaho, EG\&G Idaho, Inc., Informal Report EGG-GEO-10178, 32 p.

Woodward-Clyde Federal Services, 1994, Recommendations for neotectonic investigations of the Arco rift zone and southern Lost River fault zone, Idaho, unpublished final report prepared for EG\&G Idaho, Inc., $22 \mathrm{p}$.

Woodward-Clyde Federal Services, 1995, Paleoseismic investigation of the southern Lost River fault zone, Idaho, unpublished report prepared for Lockheed Martin Idaho Technologies and the U.S. Department of Energy, INEL-95-0508.

Wu, D. and Bruhn, RL., 1994, Structural and rupture characteristics of the southern Lost River fault zone, Idaho, unpublished report prepared for Woodward-Clyde Federal Services, $33 \mathrm{p}$.

Youngs, R.R and Coppersmith, K.J., 1985, Implications of fault slip rates and earthquake recurrence models to probabilistic seismic hazard estimates, Bulletin of the Seismological Society of America, v. 75, p. 939-964.

Youngs, R.R and Coppersmith, K.J., 1990, Keeping pace with the science: Seismic hazard analysis in the western U.S., Proceedings of the Second Natural Phenomena Hazards Mitigation Conference, p. 262-270.

Youngs, R.R, Swan, III, F.H., and Power, M.S., 1988, Use of detailed geologic data in regional probabilistic seismic hazard analysis - an example from the Wasatch Front, Utah, in Earthquake Engineering and Soil Dynamics II -Recent Advances in Ground Motion Evaluation, ASCE Geotechnical Special Publication 20, p. 156-172. 
Youngs, R.R, Swan, III, F.H., Power, M.S., Schwartz, D.P., and Green, R.K., 1987, Probabilistic analysis of earthquake ground shaking hazard along the Wasatch Front, Utah, in Assessment of Regional Earthquake Hazards and Risk Along the Wasatch Front, Utah, U.S. Geological Survey Open File Report 87-585, v. II, p. M-1-110.

Zentner, N.C., 1989, Neogene normal faults related to the structural origin of the eastern Snake River Plain, Idaho, MS Thesis, Idaho State University, 48 p.

Zoback, M.L. and Zoback, M.D., 1989, Tectonic stress field of the continental United States in L.C. Pakiser and W.D. Mooney (eds.), Geophysical Framework of the Continental United States, Geological Society of America Memoir 172, p. 523-539. 
